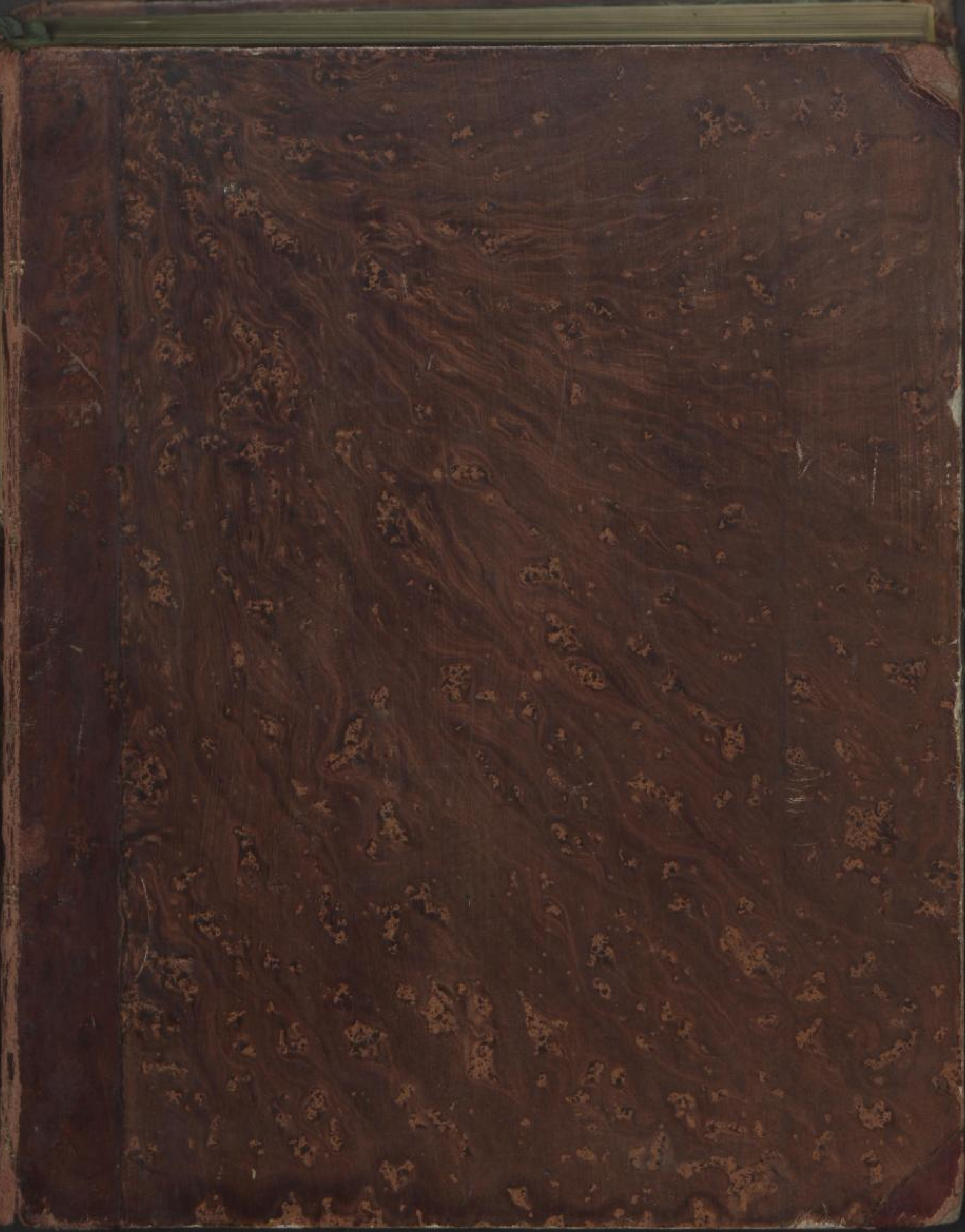




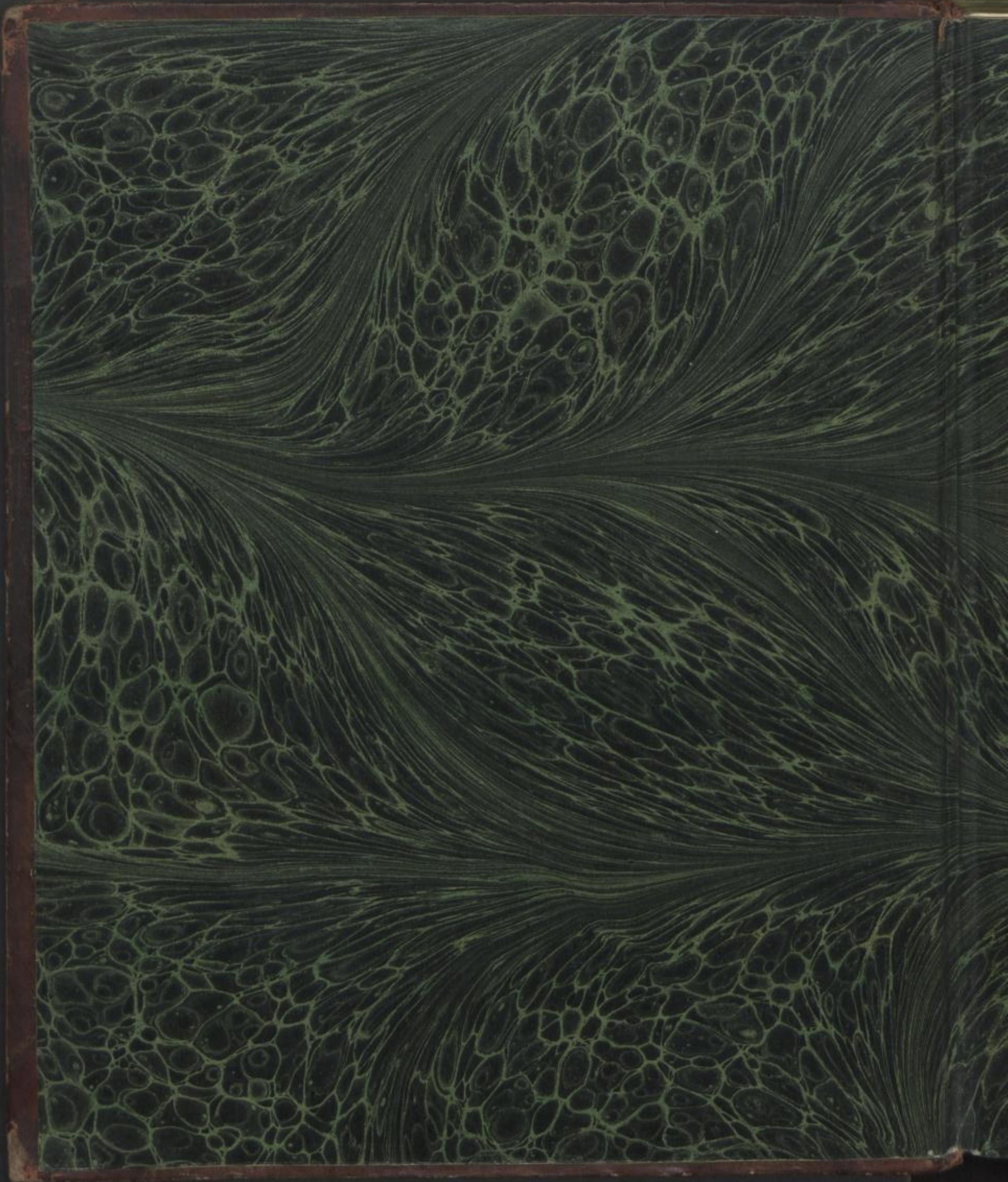




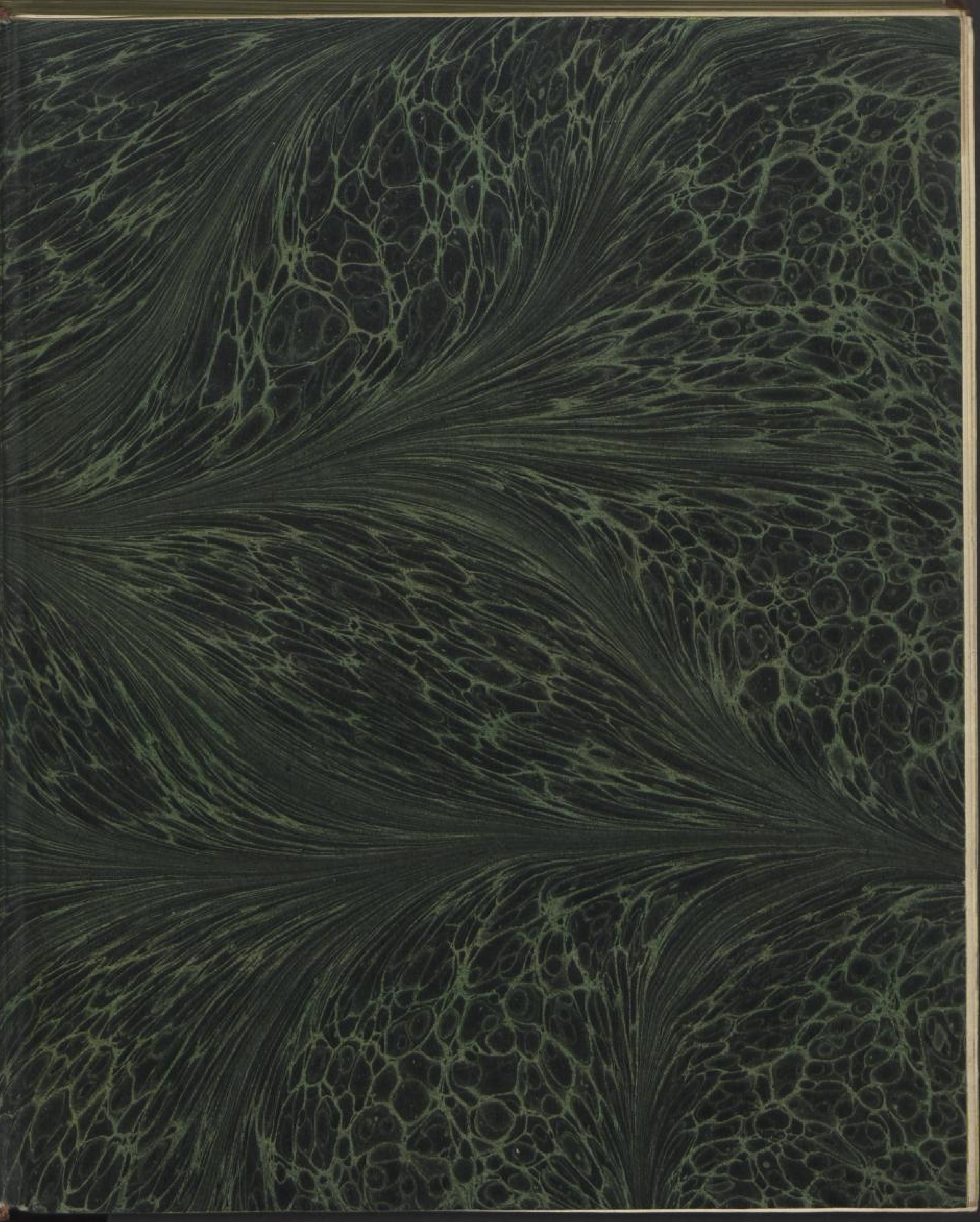




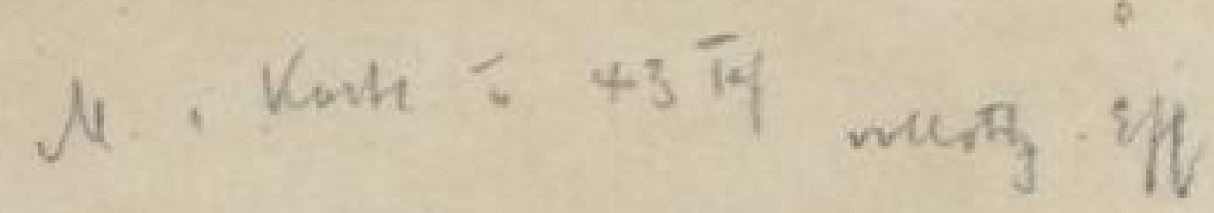



Deutj巾es mon foutu

salubenitumbe

7 SLUB 


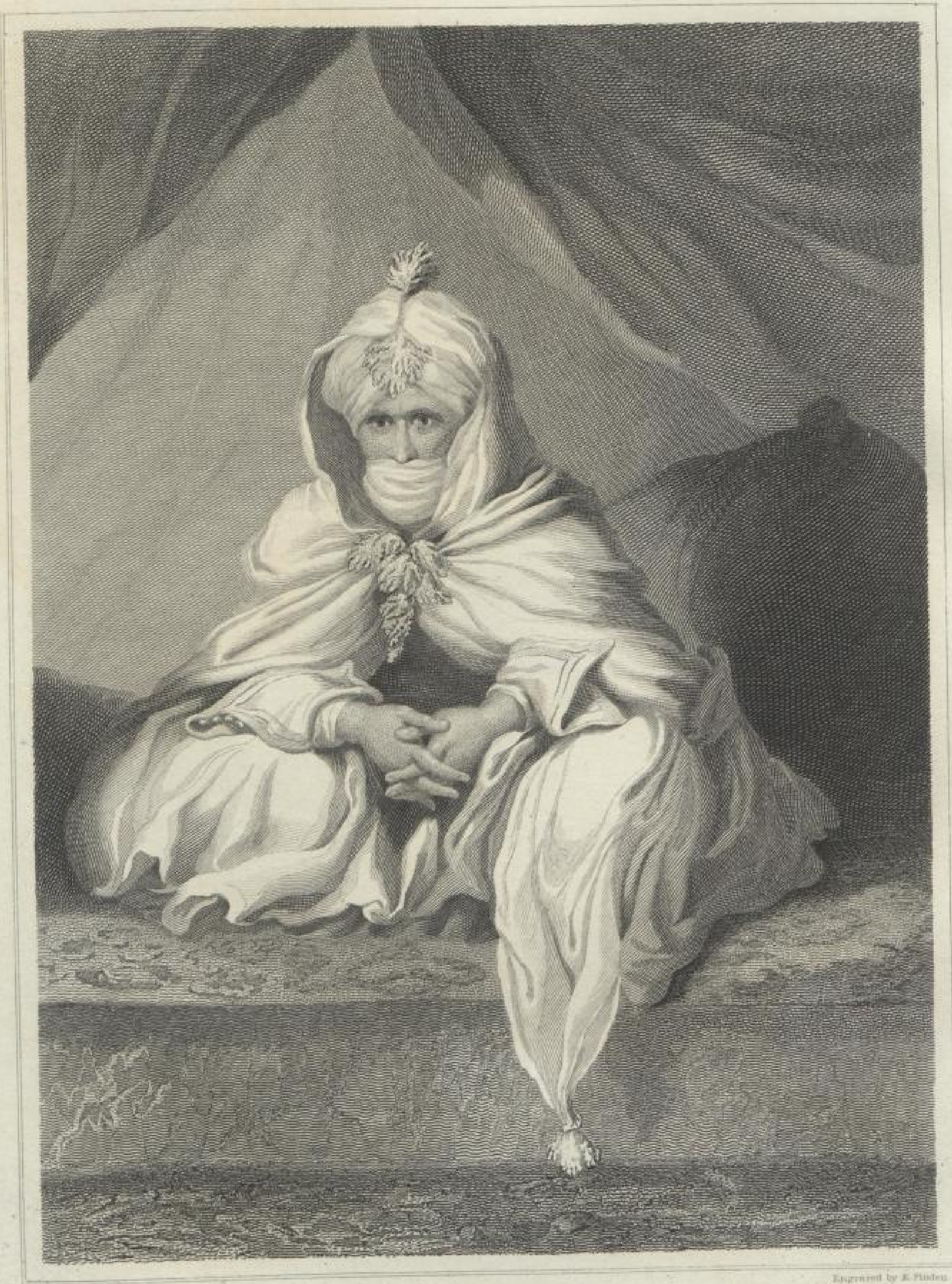

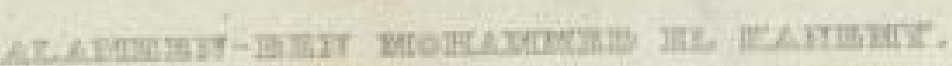

garasar of nommot

\section{$\square$ SLUB}

Wir führen Wissen.
Leibniz-Institut
für Länderkunde 


\section{NARRATIVE}

or

\section{TRAVELS AND DISCOVERIES}

iN

\section{NORTHERN AND CENTRAL AFRICA,}

IN THE YEARS 1822, 1823, AND 1824,

BY MAJOR DENHAM, CAPTAIN CLAPPERTON, AND THE

LATE DOCTOR OUDNEY,

EXTENDING ACROSS THE

GREAT DESERT TO THE TENTH DEGREE OF NORTHERN LATITUDE, AND FROM KOUKA IN BORNOU, TO SACKATOO, THE CAPITAL OF THE FELLATAH EMPIRE.

WITH

\section{AN APPENDIX,}

PUBI.ISHED BY AUTHORITY OF THE RIGHT HONOURABLE RARL BATHURST, ONE OF HIS MANESTY'S PRINCIPAL SECRETARIES OF STATE, AND DEDICATED BY PERMISSION TO HIS LORDSHIP,

\section{BY M A JOR DIXON DENHAM,} OF HIS MAJESTY'S 17TH REGIMENT OF FOOT,

AND

\section{CAPTAIN HUGH CLAPPERTON,} OP THE ROYAL NAVY,

THE SURVIVORS OF THE EXPEDITION.

LONDON :

JOHN MURRAY, ALBEMARLE-STREET.

MDCcCXXVI.

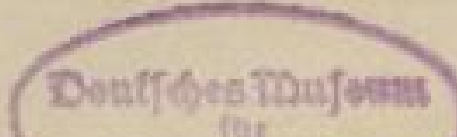

sansintranios 
LONDON :

TRINTKD BY THOMAS DAVIRON, WHTEFRIARB.

R.S..Vitheim

\section{$\neg$ SLUB}


THE RIGHT HONOURABLE

THE EARL BATHURS', K. G.

HIS MAJESTY'S PRINCIPAL SECRETARY OF STATE FOR THE COLONIES,

THIS VOLUME,

CONTAINING

AN ACCOUNT OF THEIR DISCOVERIES

MADE UNDER THE AUSPICES OF HIS LORDSHIP,

IS INSCRIBED,

WITH THE GREATEST RESPECT AND GRATITUDE,

BY HIS OBLIGED AND FAITHFUL SERVANTS,

THE AUTHORS. 


\section{P R E F A C E.}

By the death of Dr. Oudney, it has fallen to the lot of Captain Clapperton and myself to render an account to the public of our expedition into the interior and central parts of Northern Africa. The sudden departure of my surviving companion, on a second mission, has necessarily thrown the greater part of the burden on myself. I believe, however-for I have not seen any of his papers -that Captain Clapperton, during the lifetime of Dr. Oudney, made but few remarks himself beyond the construction of the chart of our route, from daily observations of the latitude, and of lunars for the longitude, whenever favourable opportunities occurred; but, subsequently to the death of his travelling companion, which happened at an early stage of their journey into Soudan, a journal of his proceedings and remarks appears to have been regularly kept; and this, together with other documents connected with that journey, were left at his departure in the hands of Mr. Barrow, with a request that he would see them through the press. 
It may naturally enough be asked, Why something more than a short excursion to the westward of Mourzuk, and a few notes, do not appear from the pen of Dr. Oudney in the present volume? I can only answer the question by the fact, that the only papers placed in my hands consist of "An Itinerary from Mourzuk to Bornou;" and "An Excursion to the Westward of Mourzuk;" neither of which have been deemed fit for publication in extenso, from their imperfect state, and containing very little beyond what will be found in my own journals. I have, however, printed in foot notes such parts of them as have been pointed out to me. Not a paper of his, to my knowledge, has been lost or destroyed; and I can only account for the unsatisfactory state in which they have been found, from the circumstance of his ill health, which became extremely precarious from the moment of our departure from Mourzuk, where he had caught a cold, which settled on his lungs, and never left him. On our arrival at Kouka, and frequently afterwards, he experienced so many attacks of fever, that there appeared little hope of his surviving to return to England, which was indeed his own opinion; and when he set out on his last journey towards Soudan, he was so exhausted, and in a state so unfit for such an undertaking, that he fell a martyr to his zeal very soon after his departure, though, had he remained at Kouka, the melancholy event would not, in all probability, have been prolonged many days.

My own expeditions in various parts of Bornou, in Mandara, and Loggun, and the two fruitless attempts I made to complete the tour of the great lake Tchad, will be found to occupy a considerable 
portion of the volume; and being made in countries, and among a people unknown to Europeans, - many of them even by name or report,-it is hoped that observations, faithfully and circumstantially minuted down at the time and spot, will not be found tedious or uninteresting to the reader.

It will, perhaps, be thought by some, that I have been more minute than necessary in the account of our journey across that tremendous desert which lies between Mourzuk and Bornou, and which, generally speaking, is made up of dark frowning hills of naked rock, or interminable plains, strewed in some places with fragments of stone and pebbles, in others of one vast level surface of sand, and, in others again, the same material rising into immense mounds, altering their form and position according to the strength and direction of the winds. But, even in the midst of this dreary waste, towns, villages, wandering tribes, and kafilas, or caravans, sometimes occur to break the solitude of this dismal belt, which seems to stretch across Northern Africa, and, on many parts of which, not a living creature, even an insect, enlivens the scene. Still, however, the halting places at the wells, and the wadeys or valleys, afford an endless source of amusement to the traveller, in witnessing the manners, and listening to the conversation, of the various tribes of natives, who, by their singing and dancing, their story telling, their quarrelling and fighting, make him forget, for a time, the ennui and fatigue of the day's journey.

As for the rest, I have to trust to its novelty, for its recom- 
viii

mendation to the public, rather than to any powers of writing, which I pretend not to possess; and it is now a source of great satisfaction to me that, under all my difficulties, and they were not few, I was able to adhere to the resolution I set out with, of recording, at the end of each day, the occurrences, however trifling, that had taken place.

To Sir Robert Ker Porter, my friend since the days of boyhood, I am indebted for having perfected several drawings, with his experienced pencil, from my hasty, but yet faithful sketches, of the people and scenery of Central Africa. His eye was nearly as familiar as my own with the picturesque objects they display ; and, indeed, all who are acquainted with the published narrative of his Researches amongst the Remains of Ancient Persia and Babylonia, might readily recognise the same hand, in these his spirited delineations of African costume and character.

\section{DIXON DENHAM.}

\footnotetext{
Albany, London,
} Jan. 1st. 1826. 


\section{O N T E N T S.}

Introductory Chapter. - From Tripoli to Mourzuk

Excursion to the Westward of Mourzuk . . . . . xliii

MAJOR DENHAM's NARRATIVE.

CHap. I.-From Mourzuk to Kouka in Bornou . . . . . . 1

CHAP. II.-Kouka

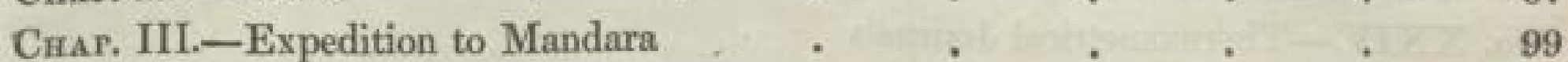

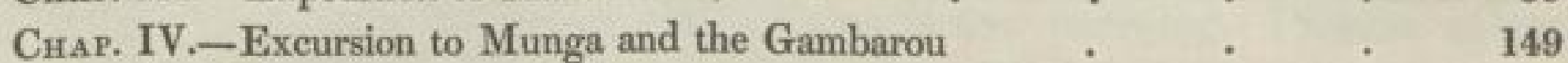

CHAP. V.-Rainy Season at Kouka . $\quad . \quad . \quad . \quad 181$

Crap. VI.-Excursion to Loggun, and Death of Mr. Toole $\quad$. . $\quad 226$

Crap. VII.-Journey to the Eastern Shores of the Lake Tchad . . 248

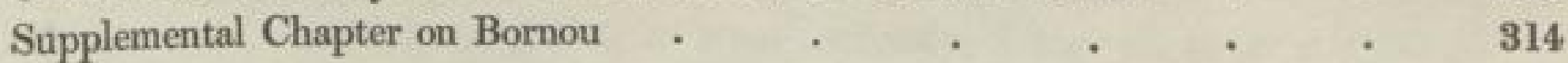

CAPTAIN CLAPPERTON'S NARRATIVE.

Secr. I.-From Kouka to Murmur, where Dr. Oudney died . . 1

Secr. II.From Murmur to Kano . $\quad$. $\quad$. $\quad$. $\quad$. 34

SEcr. III.-From Kano to Sackatoo, and Residence there . . . $\quad 67$

\section{APPENDIX.}

No. I.-Translation of a Letter from the Sheikh Mohammed El Kanemy $\quad$. 139

No. II.-Translation of a Letter from an African Chieftain . . $\quad$. 140

No. III.-A Letter from Yousuf, Pasha of Tripoli, to the Sheikh of Bornou 141

No. IV.-A Letter from the Pasha of Tripoli $\quad$. $\quad$. $\quad . \quad 143$

No. V.-A Letter from the Sheikh of Bornou to the Sultan of Kanou . 144

No. VI-A Letter from the Sheikh of Bornou to the Sultan of Hoossa . 145

No. VII-A Letter from the Chieftain Mohammed Gamsoo . . 146

No. VIII.-A Document relating to the Death of Mungo Park ․ . $\quad 147$ 
No. IX-A Letter from the Sheikh of Bornou to Captain Clapperton 148 No. X.-A Document made at the Court of Justice of Bornou _ . $\quad 149$ No. XI.-Translation of Letters and Documents received from the Sheikh of Bornou concerning Mr. Tyrwhit's Death . . . 151

No. XII.-Translation of an Arabic MS. . . . . . 158

No. XIII. A Narrative of the first Battle of Kadawee . . . $\quad$. 167

No. XIV.-The Song of Mohammed-Alameen ben Mohammed El Kanemy 171

XV.-Translation of an extempore Arab Song . $\quad 173$

No. XV.-Translation of an

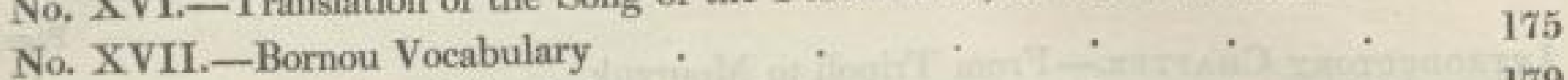

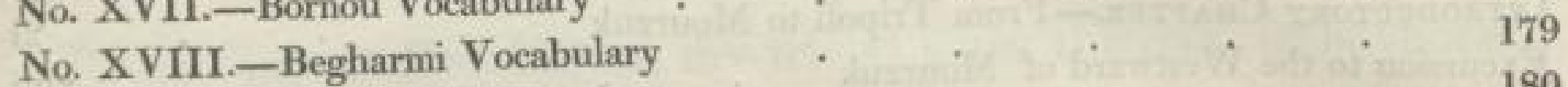

No. XIX.-Mandara Vocabulary . . . . . $\quad$. 180

No. XX.-Timbuctoo Vocabulary . . . . . . . $\quad$. 181

No. XXI.Z Zoology

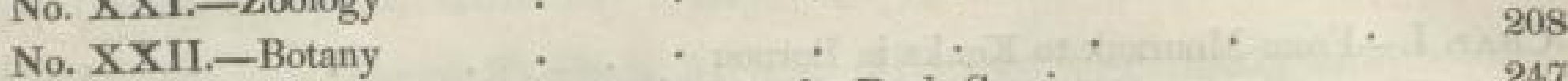

No. XXIII.-Letter to Major Denham on the Rock Specimens 247

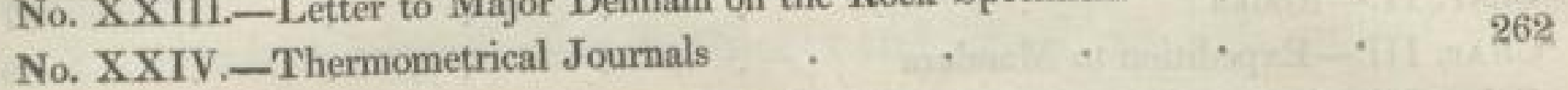




\title{
INTRODUCTORY CHAPTER.
}

\author{
BY MAJOR DENHAM.
}

FROM TRIPOLI TO MOURZUK.

Previous to any knowledge I had received of the intentions of His Majesty's government to follow up the mission of Mr. Ritchie and Captain Lyon, I had volunteered my services to Lord Bathurst to proceed to Timbuctoo, by nearly the same route which Major Laing is now pursuing. I learnt, in reply, that an expedition had been planned, and that Doctor Oudney and Lieutenant Clapperton, both of the navy, were appointed; and with these gentlemen, by the kindness of Lord Bathurst, I was, at my request, associated. My companions left London before me; but, as soon as ready, I lost no time in proceeding in the packet to Malta, where I found that they had left the island for Tripoli nearly a month before. By the kindness of Admiral Sir Graham Moore, Sir Manley Power, Sir Richard Plasket, and Captain Woolley, commissioner of the dock-yard, all my wants were amply supplied; and judging that the assistance of a shipwright or carpenter might prove of essential use, and being allowed by my instructions to engage any one, at a reasonable salary, who might choose to volunteer to accompany the mission, William Hillman, shipwright, a man of excellent character, immediately offered his services, on an agreement that he should receive $120 l$. a year so long as he should continue to be employed.

I embarked in the Express schooner, which the admiral lent me for the purpose, and, on the 18th November, after three days' sail, arrived at Tripoli, and found my two companions at the house of Mr. Consul Warrington, anxiously expecting my arrival. Of this gentleman it is not too much to say, that by his cheerful and good humoured disposition, his zeal, perseverance, and extraordinary good management, we owe, in a great degree, that influence 
which England possesses with this government far beyond that of any other of the Barbary powers. The English name, in fact, is of such importance in Tripoli, that there is scarcely a point to carry, or a dispute to settle, in which the bashaw does not request the interference of the British consul : and to him, indeed, is, in a great degree, owing the origin and success of the late mission. $\mathrm{He}$ stated broadly to the government at home, that the road from Tripoli to Bornou was as open as that from London to Edinburgh; which, with a small allowance for Oriental hyperbole, was found to be true-witness the journey of my lamented friend Lieutenant Toole, and also of Mr. Tyrwhitt, the latter laden with valuable presents.

But this is not all : the British flag has a peculiar power of protection, and the roof of the English consul always affords a sanctuary to the perpetrator of any crime, not even excepting murder; and scarcely a day passes that some persecuted Jew or unhappy slave, to escape the bastinado, does not rush into the court-yard of the British consulate for protection. A circumstance occurred in returning from one of our excursions, which shows in what high estimation the English character is held in Tripoli. A poor wretch, who, for some trifling offence, was sentenced to five hundred bastinadoes, having, while on his way to receive the sentence of the law, contrived to slip from the custody of his guards, fortunately met with the child and servant of Doctor Dickson, a most respectable and intelligent English physician practising in Tripoli : the condemned wretch, with wonderful presence of mind, snatched up the child in his arms, and halted boldly before his pursuers. The talisman was sufficiently powerful : the emblem of innocence befriended the guilty, and the culprit walked on uninterrupted, triumphantly claiming the protection of the British flag.

But the following proves still more strongly to what extent the influence of the British flag might be carried.-Since the reduction of the refractory Arabs to submission, no chief had received such repeated marks of kindness and attention from the bashaw, as sheikh Belgassam ben Khalifa, head of the powerful tribe of $\mathrm{El} \mathrm{Gibel.} \mathrm{At} \mathrm{the} \mathrm{particular} \mathrm{request} \mathrm{of} \mathrm{the} \mathrm{former,} \mathrm{sheikh}$ Khalifa had quitted his tents and flocks, resided in the city, and was high in his prince's confidence-fatal pre-eminence in Barbary states!-and had been presented, but a few months before, with one of the most beautiful gardens in the Minshea. Returning from the castle after an evening of music and dancing in the bashaw's private apartments, Belgassam kissed the hand that had signed 
his death-warrant, and took his leave. At his own door a pistol-shot wounded him in the arm, and on entering the skiffa, or passage, a second entered his body. The old sheikh, after his slave had fastened the door, staggered to his carpet, and then, in the arms of his wife, proclaimed his assassin to be his own nephew, sheikh Mahmoud Belgassam Wildé Sowdoweah. The work being, however, but half done, others rushed in, and seven stabs put an end to his sufferings, notwithstanding the screams of his wife, who received two wounds herself, in endeavouring to save her husband. The poor old man was almost instantly buried, and the three persons who had undertaken the murder fled to the British consulate for protection. Early the next morning, however, the consul despatched his dragoman to give the bashaw notice, "that the murderers of Khalifa would find no protection under the flag of England." The bashaw said, " he was shocked at the murder, and regretted the assassins having taken refuge in the consulate, as it was a sanctuary he could not violate, particularly as he understood they meant to resist, and were well armed." Our consul replied, "that the bashaw was at liberty to send any force he pleased, and use any means he thought best, to drag them from beneath a banner that never was disgraced by giving protection to assassins." The minister also came and expressed the bashaw's delicacy ; and it was evident he did not expect such would be the conduct of the consul : he was, however, peremptory, and the bashaw dared not seem to favour such an act of villany. It was sunset before he decided on taking them away, when about sixteen of the chosen people of the castle entered the consulate, and the wretches, although provided with arms, which they had loaded, tremblingly resigned themselves, and were, in less than an hour, hanging over the walls of the castle.

On a day appointed we waited on the bashaw. After passing the court-yard, crowded with guards, and several groups of Arabs in the passages and ante-rooms playing at cards or dice, we were introduced to the audience chamber, where the bashaw, sitting cross-legged on a carpet, supported by his two sons, and attended by armed negroes, received us kindly, ordered us to be served with sherbet and coffee, and expressed himself in the most favourable manner on the subject of our mission, which he promised to forward in safety into the interior of Africa. He invited us to join him in a hawking party. The cavalcade, consisting of about three hundred, altogether presented so novel an appearance, that I shall endea- 
vour to give some description of our morning's amusement. The bashaw was mounted on a milk-white Arabian, superbly caparisoned, with saddle of crimson velvet richly studded with gold nails, heavy stirrups of the same, and trappings of embroidered cloth hanging down on each side nearly to the horse's fetlock joint; he was preceded by six chaoushes, or officers, also mounted and richly caparisoned, armed with long guns, swords, and pistols, and a white silk barracan thrown loosely and gracefully round their bodies. His highness was supported on each side by a favourite black slave, whose glittering vest, light bornouse, and white turban, formed a pleasing contrast to the costume of the Arabs. We proceeded in a westerly direction; and on arriving at the desert, parties of six and eight dashed forward, with the rapidity of lightning, several hundred paces, fired, immediately halted in a most surprising manner, and with loud cries rushed back again to the main body, when instantly the same ceremony was repeated by another party. Their superior skill in the management of their horses is really beautiful; and the way they manœuvre their long musket, by repeatedly spinning it over their heads at full speed, has a most picturesque effect. Near the bashaw's person rode Sidy Ali, his third son, although second in succession, in consequence of the banishment of the eldest; he also was attended by his particular guard of Arabs, distinguished not only by their superior and determined appearance, but by their figured muslin bornouses. Sidy Ali is the bashaw's favourite son, and is particularly handsome, although what we should call too fat, and is said to resemble very much what the bashaw was at his age: he is allowed great privilege and liberty, which is indeed proved by his saying, the other day, to his father, "I shall succeed you as bashaw." "How do you mean?" "How ? why, by taking the same steps you did yourself," said the youth.

I was invited, with my colleagues, to pass a day about five miles from Tripoli, at the garden of Mahomed D'Ghies, to whom I brought letters from his son, who was residing in London, much noticed and respected. This old gentleman had been minister for foreign affairs to the bashaw, but had retired from office some time, on account of a complaint in his eyes. $\mathrm{He}$ is a most respectable man, and particularly kind to all European travellers who visit Tripoli; and so well known throughout Northern Africa, that letters of credit from him are sure to be duly honoured. Nothing could exceed the hospitality 
and attention with which we were received: having regaled ourselves with sherbet, coffee, and tobacco, several times in the course of the day, and partaken of an excellent dinner, a la Turque, in a grove of lemon and orange trees, we returned in the evening to Tripoli, well pleased with our day's excursion.

Tripoli has been so often described, that I shall pass it over in silence. Its Jews, its Arabs, its Moors, and Maraboots; the slave population, and the bashaw's family ; are all so well painted to the life in " Tully's Letters," as to require no further notice from me as a casual visitor. Neither is it my intention to enter into a minute description of the country between Tripoli and Mourzuk; the surface of which is not essentially different from that between Mourzuk and Bornou, and has already been noticed by Captain Lyon, and in the communications to the African Association.

On the 5th March, 1822, I left Tripoli for Benioleed *, to join my two

* Benioleed, a rich valley, bounded on all sides by whitish brown hills, capped in many places with green stone and amygdaloid, or vesicular lava, rugged villages, and ruinous castles, on every point, some overtopping the columnar green stone, and scarcely distinguishable from it.

The hills possess a very interesting structure. The height does not exceed 400 feet, and limestone is the prevailing rock. On the nortlr side the whole of the range, till within a mile of the western extremity, is limestone: at that point above the limestone is a thick bed of columnar greenstone, with thick layers of vesicnlar lava.

On the southern side, most of the hills have their tops covered with lava and columnar green stone, and have a structure similar to that of the one I have delineated. A little difference is here and there observable, but not so much as to be worthy of notice. The tops of the hills on this side form an oxtensive, hlack, dreary-looking plain, strewed over with loose stones, extending eastwardly as far as the eye can discern. The upper, or, as I would call it, the lavaceous erust, appears as if a layer left by a flowing fluid, and therefore of more recent formation than the rock on which it rests. This is seldom more than a few feet in thickness, and spread over the sub-
jacent rock.

The rocks dip in various directions, but generally at an angle of $18^{\circ}$.

The Jibel Gulat is one of the highest hills we have yet come to. It is about six hundred feet high : its top is tabular, and its sides exceedingly rugged, from an amazing number of detached pieces. The lowest exposed stratum is a calcareous tufa, containing, or indeed almost formed of sea-shells; the most abundant are a species of oyster and limpet, in a very entire state. Above, which is imbedded a large quantity of lang, and falling into dust on the slightest touch, and in which is imbedded a large quantity of lamellar calcareous spar. Above, and apparently extending to the summit, tolerably fine marble. The quantity of debris, and the size and appearance of the masses, might make one believe that an earthquake had been the cause of that rent state; but it appears to me more probable that the undermining, by the monldering of the soft stratum under- 
companions, who had proceeded thither with our servants, horses, camels, and baggage. They had gone on to Memoom, a very pretty valley, which, at this season of the year, was green with herbage, and adorned by flowers of various hues and colours, richly scattered in beautiful disorder;-but it was the last of the kind we were fortunate enough to meet with between this place and Bornou ; and here the consul and his son, who had accompanied us from Tripoli, took their leave, with many hearty good wishes for our success and prosperity.

neath, accounts well for the state and appearance of the side of the hill. The hill is about three miles long, and runs from east to west. It is inhabited by a solitary family; a man, his wife, and several children. We were told that he had resided in this dreary and barren place for eleven years, and it is said lives chiefly by plunder.

Near Niffud, the hills are of lime, and in structure and form not unlike those of the Tarhons range.

In the vicinity of the long range there are a number of small conical hills, of a soft whitinglike substance, appearing as if recently thrown up, although, from every thing around, that is not at all probable. The range runs parallel to that near the coast; but we had no opportunity of determining how far it extends to the eastward and westward. There are several passes, into one of which we entered. It is rugged, from the number of masses that have fallen from the sides of the hills. Several tumuli of stones are observable, marking the burial-places of unfortunate travellers, who have been murdered here, it was said, by large rocks rolled from the overhanging heights. When I was examining the rocks, in the dry bed of a river, these monuments were pointed out, to make me aware my presence there was not free from danger. This led to a valley, with some thick groves of acacias, and a plant like a mespilus, with pleasant small astringent berries : it is called by the natives butomo. From this we passed over a low hill, into the valley Niffud. This valley has been the seat of much fighting, as our condnctors informed us, among the Arabs of different tribes.

We left the valley, by a pass to the southward, and entered an extensive plain, named Ambulum : in this we travelled the whole day. The surface, in some places, a firm sand, with here and there rocky eminences, and patches of gravel : the latter was fine, and mixed with fragments of shells. Often, for a considerable extent, not the least vestige of vegetation ; and in no place was the ground completely covered, except in a few small oases, where there was a species of grass, of the genus festuca. The feniculum duter, and a beautiful genista, which extends all the way from the coast, were common. The butum occurred in abundance, and its shade was a defence to us at times. We found some beautiful fragments of striped jasper, and some small pieces of cornelian.

Bonjem.-We had no opportunity of examining any of these; but from the strewed masses they appear to be limestone. The wadey of Bonjem has characters different from any of the other valleys we have passed through. This valley is strewed over with gypsum in different states, with numerous shells, of the genus pecten, and several terebrella. There are here and 


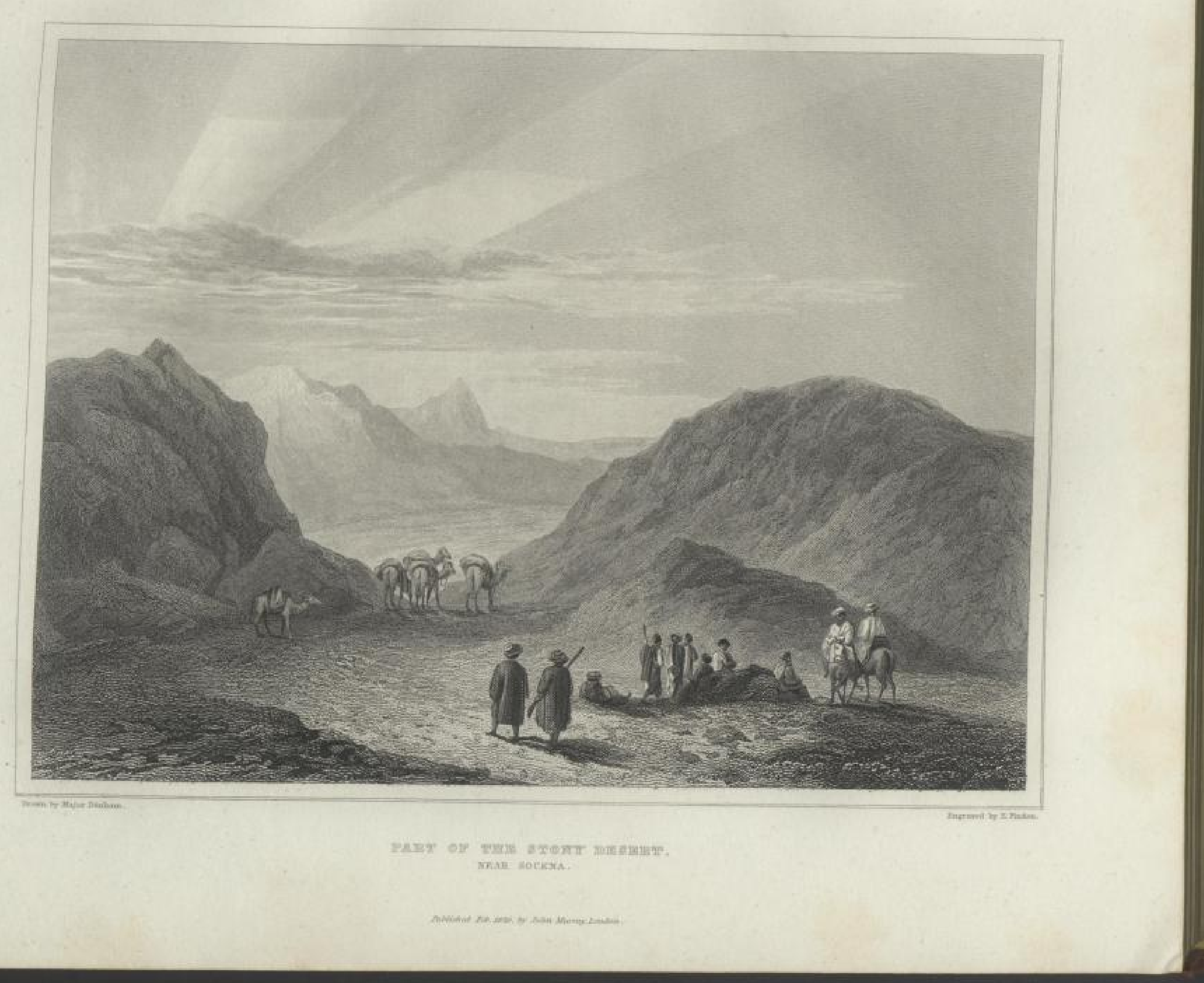

ㄱ SLUB

Wir führen Wissen.

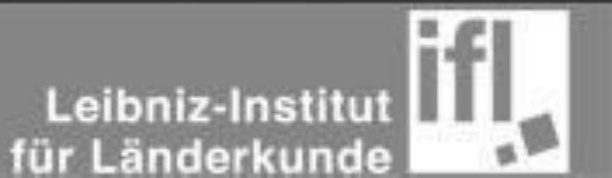



On the day previous to our approach to Sockna, a town about half way between Tripoli and Mourzuk, which we reached in fourteen days, the uniformity of the journey was somewhat enlivened, by meeting with a kafila of slaves, from Fezzan, in which were about seventy negresses, much better looking, and more healthy, than any we had seen near the sea-coast. They were marching in parties of fifteen or twenty ; and on our inquiring of one of those parties from whence they came, the poor things divided themselves with the greatest simplicity, and answered, "Soudan, Begharmi, and Kanem," pointing out the different parcels, from each country, as they spoke : those from Soudan had the most regular features, and an expression of countenance particularly pleasing.

Passing a small wadey and plantation of date trees, we had soon a view of Sockna, and were met on the plain, on which it stands, by the governor and principal inhabitants, accompanied by some hundreds of the country people, who all crowded round our horses, kissing our hands, and welcoming us with every appearance of sincerity and satisfaction; and in this way we entered

there sand, and many incrustations of the carbonate, mixed with crystals of the sulphate, of lime, that gives to the surface a shining white appearance, which, in place of being pleasing, is disagreeable, by the power of the reflected light. There are small ranges of low hills, composed of soft white chalk (whiting), covered with a crust of gypsum. In this structure we found one large pit, about forty feet deep, and nearly as much in diameter. These low hills are bounded by much higher, and of a dark brown colour: the low hills are numerous, some are separate, but in general they are in short ridges, and have, at a distance, very much the appearance of fortifications. A small senecio, a geranium, and a statice, were the principal beings of the vegetable creation. Barometer 30.020. temperature 72 .

Near the wells, the arundo phragmites grows in abundance; it has long creeping roots, the first true roots of that kind I have seen in North Africa. Plants of this kind would soon make considerable encroachments on the desert, and render habitable where it is difficult even to travel over. This quarter is poor in the grusses, for I think I have not seen above eight different kinds. Our course was among sand-hills, and over a gravelly road, strewed with masses of common opal, with small portions of botroidal iron ore, and thick layers of gypsum, with their edges appearing above ground. The low hills presented the same features as those near which we remained in the wadey : one, detached on the road, had a curious appearance, and was called, by the natives, "The Bowl of Bazeen," It is about forty feet high, and formed above of a calcareous crust, with sulphate of lime, and below of soft chalk.

The higher ridge was observable on each side of us, running south-south-east on the east side, and south-south-west on the west: some of those to the westward have detached hills, and one has the name of the "Salt Hill." W. O, 
the town: the words “ Inglesi! Inglesi !" were repeated by a hundred voices from the crowd. This, to us, was highly satisfactory, as we were the first English travellers in Africa who had resisted the persuasion that a disguise was necessary, and who had determined to travel in our real character as Britons and Christians, and to wear, on all occasions, our English dresses ; nor had we, at any future period, occasion to regret that we had done so. There was here no jealousy, nor distrust of us as Christians ; on the contrary, I am perfectly satisfied that our reception would have been less friendly had we assumed a character that could have been at best but ill supported. In trying to make ourselves appear as Mussulmans, we should have been set down as real impostors.

The dates of Sockna are excellent, and in abundance: our animals were liberally supplied with this fruit of fruits; and after the first two days appeared to eat them nearly as well as corn. The population of Sockna must be considerably more than three thousand. The town is walled, and about a mile in circumference : has eight gates; and wears altogether a clean and neat appearance that surprised us. The women are certainly very pretty, and are said to be remarkable for their love of intrigue. This may be true, or not; but we had no opportunity of ascertaining it from our own knowledge. Of their affability and good humour, however, we had many proofs; and while only two of us were walking through the town one morning, with a little army of ragged boys following us, two, of rather the better order, quickly dispersed them; and invited us to enter a house, saying that a mara zene (a beautiful woman) wished to see us. We put ourselves under their guidance, and entering a better sort of dwelling-house, were quickly surrounded by at least half-a-dozen ladies, most of them aged; but who asked us a thousand questions, and, when satisfied we were not dangerous, ealled several younger ones, who appeared to be but waiting for permission to appear. Our dresses and ourselves were then minutely examined. The yellow buttons on our waistcoats, and our watches, created the greatest astonishment; and a pair of loose white trowsers that I wore, into the pockets of which I accidentally put my hands, raised their curiosity to a wonderful degree : my hands were pulled out, and those of three or four of the ladies thrust in, in their stead: these were replaced by others, all demanding their use so loudly and violently, that I had considerable difficulty in extricating myself, and was glad to make my escape. The dress of the Sockna 
women is nearly that of the Tripoline: they wear striped shirts, of silk or linen, large silver ear-rings, with leg-lets and arm-lets of the same : the lower classes wear those of glass or horn.

The remaining half of our journey to Mourzuk was over pretty nearly the same kind of surface as that we had passed before; in some places worse. Sometimes two, and once three days, we were without finding a supply of water; which was generally muddy, bitter, or brackish : nor is this the worst that sometimes befalls the traveller. The overpowering effects of a sudden sand-wind, when nearly at the close of the desert, often destroys a whole kafila, already weakened by fatigue; and the spot was pointed out to us, strewed with bones and dried careasses, where the year before fifty sheep, two camels, and two men, perished from thirst and fatigue, when within eight hours' march of the well which we were anxiously looking out for.

Indeed the sand-storm we had the misfortune to encounter in crossing the desert gave us a pretty correct idea of the dreaded effects of these hurricanes. The wind raised the fine sand with which the extensive desert was covered, so as to fill the atmosphere, and render the immense space before us impenetrable to the eye beyond a few yards. The sun and clouds were entirely obscured, and a suffocating and oppressive weight accompanied the flakes and masses of
sand, which, I had almost sand, which, I had almost said, we had to penetrate at every step. At times we completely lost sight of the camels, though only a few yards before us. The horses hung their tongues out of their mouths, and refused to face the lorrents of sand. A sheep, that accompanied the kafila, the last of our stock, lay down on the road, and we were obliged to kill him, and throw the carcass on a camel. A parching thirst oppressed us, which nothing alleviated. We had made but little way by three o'clock in the afternoon, when the wind got round to the eastward, and refreshed us something: with this change we moved on until about five, when we halted, protected a little by three several ranges wood, our fare was confined to tea; and we hoped to find we had but little fatigues by a sound sleep. That was, and we hoped to find relief from our imprudently pitched, and was exposed to the east wind, which tent had been during the night : the tent was blown down, and the whole detach hurricane employed a full hour in getting it up again; and our bedde detachment were that was within it was, during that time, our bedding and every thing c 2 
driving of the sand. I was obliged, three times during the night, to get up for the purpose of strengthening the pegs; and when, in the morning, I awoke, two hillocks of sand were formed on each side of my head, some inches high.

On the 7th April we arrived at a village in the midst of a vast multitude of palm trees, just one day's journey short of Mourzuk. As it was to be the last day's march, we were all in good spirits at the prospect of rest; and had we made our arrangements with judgment, every thing would have gone on well. We had, however, neglected sending on to advise the sultan of our arrival - a constant practice, and consequently our reception was not what it ought to have been. We arrived at D'leem, a small plantation of date trees, at noon, and finding no water in the well, were obliged to proceed; and it was three in the afternoon before we arrived at the wells near Mourzuk. Here we were obliged to wait until the camels came up, in order that we might advance in form. We might, however, have saved ourselves the trouble :-no one came out to meet us, except some naked boys, and a mixture of Tibboos, Tuaricks, and Fezzanese, who gazed at us with astonishment, and no very pleasant aspect.

We determined on not entering the town in a manner so little flattering to those whom we represented : and retiring to a rising ground, a little distance from the gates of the town, waited the return of a chaoush, who had been despatched to announce our arrival. After half an hour's delay, the sheikh El Blad (the governor of the town) came out, and, in the sultan's name, requested we would accompany him to the house which had been prepared for us ; and he added, to our great surprise, the English consul is there already. The fact was, a very ill-looking Jew servant of mine, mounted on a white mule, with a pair of small canteens under him, had preceded the camels, and entered the town by himself : he was received with great respect by all the inhabitants - conducted through the streets to the house which was destined to receive us; and from the circumstance of the canteens being all covered with small brass shining nails, a very high idea of his consequence was formed. He very sensibly received all their attentions in silence, and drank the cool water and milk which was handed to him : and we always had the laugh against them afterwards, for having shown so much civility to an Israelite-a race they heartily despise. " We thought the English," said they, "were better looking than Jews-Death to their race! but then God made us all, though not all hand- 



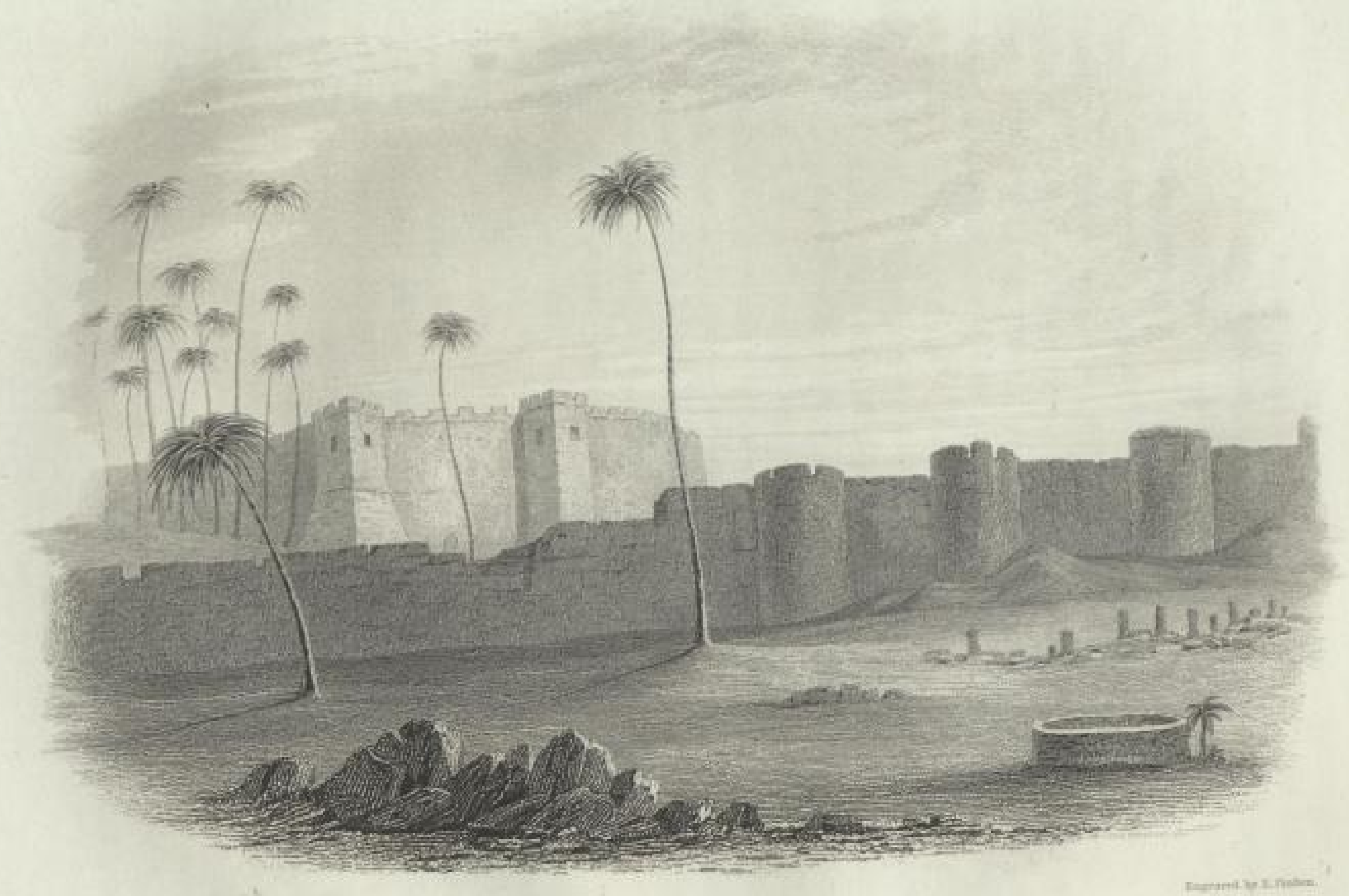

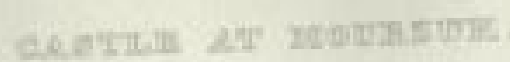

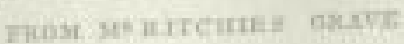


some like Mussulmans, so who could tell ?" As we were all this time exposed to a burning sun, we were well inclined to compromise a little of our dignity, and determined on entering the town, which we did by the principal gate. The walls are well built, at least twenty feet high; and the gate sufficiently wide to admit, with care, a loaded camel. You pass through the fsug, slavemarket, a wide street, with houses on each side, three hundred yards in length. It leads into an open space, in the centre of which the castle stands, surrounded by a second wall. In the inside of this inner wall, in the castle yard, are a few houses, originally built for the Mamelukes, and particular followers of the late sultan, when they were subject to the occasional attacks of the Arabs. In one of these, the house occupied by the late Mr. Ritchie and Captain Lyon, arrangements were made for our reception. Almost as soon as the camels were unloaded, we paid our respects to the sultan: he received us with a great deal of affability and good nature, and made an impression in his favour, which, however, his subsequent conduct tended but little to strengthen.

Our interview with the sultan of Mourzuk was any thing but encouraging : expedition to proceed to the southward for some time to come; that an army could only move in the spring of the year; that the arrangements for moving a body of men through a country where every necessary must be carried on camels, both for men and horses, were so numerous, that before the following spring it was scarcely possible to complete them: that two camels were required for every man and horse, and one for every two men on foot. And as to our proceeding to Bornou, it would be necessary, had the bashaw instructed him to forward us, that we should be accompanied by an escort of two hundred men. He said he would read to us the bashaw's letter, and we should see the extent to which he could forward our wishes. The letter was then handed to his fighi, or secretary ; and we found that to the protection of the and so insure our being intrusted, who was to charge himself with our safety, that we were to reside at Sebha, or Mourt and attention by all his subjects; dom of Fezzan, and to await his or Mourzuk, or where we chose in the kingended, and we returned to our habitation.

It is quite impossible to express the disheartening feelings with which we left the castle. The heat was intense ; the thermometer at $97^{\circ}$ in the coolest spot in the house, during the middle of the day; and the nights were scarcely 
less oppressive : the flies were in such myriads, that darkness was the only refuge from their annoyance. All poor Mr. Ritchie's sufferings and disappointments were brought to our recollections ; and although, from the arrangements which we had been able to make, we were better provided with necessaries than those who had gone before us,-yet did we consider our stock as a very sacred charge, applicable only to the grand objects of our expedition.

We received visits from all the principal people of Mourzuk the day after our arrival; and remarking a very tall Tuarick, with a pair of expressive, large, benevolent-looking eyes, above the black mask with which they always cover the lower part of their face, hovering about the door, I made signs to him to come near, and inquired after Hateeta, the chief Captain Lyon had spoken so highly of, and for whom, at his request, I was the bearer of a sword. To my great surprise, striking his breast, he exclaimed, "I am Hateeta! are you a countryman of Said*? - how is he? I have often longed to hear of him." I found Hateeta had been but once in Mourzuk since Captain Lyon's departure, and was now only to remain a few days. On the following morning he came to the house, and the sword was presented to him. It would be difficult to describe his delight; he drew the sword and returned it, repeatedly ; pressed it to his breast, exclaimed "Allah, Allah!" took my hand, and pressing it, said "Katar heyrick yassur yassur" (thank you very very much); nearly all the Arabic he could speak. It was shortly reported all over the whole town, that Hateeta had received a present from Said, worth one hundred dollars.

12th.-We had been several times visited, and our hopes and spirits raised, by a person called Boo-Bucker Boo-Khaloom. He said that it was in the sultan's power to send us on to Bornou if he pleased : he even hinted that a bribe for himself might induce him to do so-this, however, we found was not the case. Boo-Khaloom was represented to us, and truly, as a merchant of very considerable riches and influence in the interior. He was on the eve of starting for Tripoli, with really superb presents for the bashaw. He had five hundred slaves, the handsomest that could be procured, besides other things. He stated to us, secretly, that his principal object in going to Tripoli was to obtain the removal of the present sultan of Fezzan; and wished that we should make application to the bashaw for him to accompany us farther into the in-

* Captain Lyon's travelling name. 
terior : we were not, however, to hint that the proposition had come from him. Boo-Khaloom said that he should be instantly joined by upwards of one hundred merchants who waited but for his going, and no further escort would be necessary; that he should merely remain a few weeks in Tripoli, and, on his return, we could instantly move on. The substance of all these conversations was transmitted to Colonel Warrington.

Boo-Khaloom left Mourzuk for Tripoli, with his slaves and presents, loading upwards of thirty camels, apparently reconciled to, and upon good terms with, the sultan. It was, however, very well known that Sultan Mustapha had set every engine at work to have Boo-Khaloom's head taken off on his arrival in Tripoli; and that the other was willing to sacrifice all he was worth to displace and ruin Mustapha in the bashaw's favour.

It was not till the 18th, that the sultan, after attending the mosque, started for Tripoli; all his camels and suite had marched in divisions, for three days previous, - in slaves he had alone more than one thousand five hundred. $\mathrm{He}$ was attended by about ten horsemen, his particular favourites, and four flags were carried before him through the town. The inhabitants complained dreadfully of his avarice, and declared that he had not left a dollar, or an animal worth one, in all Fezzan.

Nothing was now to be done but to make our arrangements for a favourable start the following spring. By the sultan's departure, every necessary for our proceeding was withdrawn from the spot where we were. Not a camel was to be procured, and every dollar, that he could by any means force from his subjects, was forwarded to Tripoli. To Tripoli, therefore, were we to look for supplies of every kind; and it was decided by us all, that my departure had better follow his as soon as possible.

In pursuance of our determination to represent to the bashaw of Tripoli how necessary it was that something more than promises should be given us for our sterling money, on Monday, the 20th May, I left Mourzuk, with only my own negro servant Barca, three camels, and two Arabs; and, after a most dreary journey of twenty days, over the same uninteresting country I had arrived at Tripoli on the 12th June, where I was received by companions,-I his usual hospitality and kindness, and I was received by the consul with consulate. 
12th.-I requested an immediate audience of the bashaw, which in consequence of the Rhamadan was not granted me until the following evening. The consul, Captain Smyth of the navy, and myself, attended : I represented, in the strongest terms, how greatly we were disappointed at the unexpected and ruinous delay we had experienced in Mourzuk, and requested a specific time being fixed for our proceeding to Bornou; stating, also, that were the answer not satisfactory, I should proceed forthwith to England, and represent to the government how grievously we had been deceived. The bashaw denied having intentionally broken his word, and solemnly declared that the will of God, in visiting the sultan of Fezzan with sickness, had alone prevented our being now on the road to Bornou.

A voyage to Marseilles, on my way to England, was the consequence of our altercation with the bashaw; and the promptitude with which it was decided upon, and carried into effect, by means of a small French vessel which, at the time, most fortunately lay in the harbour, was not without its good effects. The bashaw sent three despatches after me, by three different vessels, to Leghorn, Malta, and the port I had sailed to, which I received in quarantine, informing me, that Boo-Khaloom was appointed with an escort to convey us forthwith to Bornou. This was every thing I wished for; and immediately re-embarking, a seven days' passage brought me once more to the shores of Barbary. Boo-Khaloom and part of the escort were already at the entrance to the desert; and on the 17 th of September we re-entered the pass of Melghra in the Tarhona mountains. Hope and confidence had taken possession of my mind, in the place of anxiety and disappointment; there was now an air of assurance and success in all our arrangements; and I felt my health and spirits increase with this conviction. But little beyond the casualties attendant on desert travelling occurred, previous to our arriving again at Sockna, which we did on the $2 \mathrm{~d}$ of October.

I found the great failing of my friend, Boo-Khaloom, was pomp and show; and feeling that he was, on this occasion, the bashaw's representative, he was evidently unwilling that any sultan of Fezzan should exceed him in magnificence. On entering Sockna, his six principal followers, handsomely attired in turbans and fine barracans, and mounted on his best horses, kept near his person, whilst the others, at a little distance, formed the flanks. I rode on his right hand, dressed in my British uniform, with loose Turkish trowsers, a 
red turban, red boots, with a white bornouse over all, as a shade from the sun; and this, though not strictly according to order, was by no means an unbecoming dress. Boo-Khaloom was mounted on a beautiful white Tunisian horse, a present from the bashaw, the peak and rear of the saddle covered with gold, and his housings were of scarlet cloth, with a border of gold six inches broad. His dress consisted of red boots, richly embroidered with gold, yellow silk trowsers, a crimson velvet caftan with gold buttons, a silk benise of sky blue, and a silk sidria underneath : a transparent white silk barracan was thrown lightly over this, and on his shoulders hung a scarlet bornouse with wide gold lace, a present also from the bashaw, which had cost, at least, four hundred dollars; a cashmere shawl turban crowned the whole. In this splendid array, we moved on until, as we approached the gates of the town, the dancing and singing men and women met us; and, amidst these, the shouts and firing of the men, who skirmished before us, and the "loo! loo!" of the women, we entered Sockna.

We found that houses were provided for us in the town; but the kafila bivouacked outside the gates. It had always been our intention to halt at Sockna, for three or four days ; and here we expected to be joined by a party of the Megarha Arabs, whom their sheikh, Abdi Smud ben Erhoma, had left us, for the purpose of collecting together. Hoon and Wadan were also to furnish us with another quota. My house consisted of a court-yard eighteen feet square, and a small dark room, leading out of it by two steps : the court, however, was the greater part of the day shaded; and here, on a carpet, I received my visitors. The Arabs, as they arrived, were all sent to me by Boo-Khaloom ; and their presentation has a form in it, not much in character with their accustomed rudeness: they all came armed with their long guns; and the same girdle which confines their barracan contains also two long pistols. The chief enters, and salutes, dropping on one knee, and touching the stranger's right hand with his, which he carries afterwards to his lips; he then says, "Here are my men, who are come to say health to you." On receiving permission, they approached me, one by one, saluting in the same manner as their chief, who continued to remain at my side: they then sat down, forming a sort of semicircle round me, with their guns upright between their knees; and, after a little time, on the sheikh making a signal, they all quitted
the presence. 
Boo-Khaloom, who had suffered very considerably from fever, cold, and ague, now became so seriously ill, that our departure was of necessity postponed, and he insisted upon my prescribing for him, saying, "he was quite sure that I could cure him, if it was the will of God that he should live: if not, that nobody could." His confidence in me gave me some confidence in myself : but alone, with very few medicines, and less skill, my situation was really one of great anxiety; for no one could foresee what might have been the consequence, had any thing serious happened to him while under my hands. $\mathrm{He}$ became alarmingly ill, and for two days and nights I had great doubts of his recovery ; to my great satisfaction, however, on the third morning, after a night of pain and delirium (and which $I$ had passed in watching by his side), a violent eruption appeared on his skin, with some little moisture, produced by covering him up the whole day with blankets, and suffering no one to come into the room but his favourite female slave. By the evening, he became much better.-Hajamad, or charms, are what the Arabs have most faith in, when they are ill. All the fighis (writers) and maraboots in Sockna were employed on this occasion by my friend's friends, and one night the tassels of his cap were literally loaded with them. He assured me, when alone, that he had no faith in such things, and smiled when he said his friends would think ill of him, were he to refuse; his faith, however, was stronger than he chose to acknowledge, and entering, unexpectedly, one morning, I found him with a dove that had been just killed and cut open lying on his head, which, as he assured me, was because a very great maraboot had come from Wadan on purpose to perform the operation.

During our stay at Sockna, the marriage of the son of one of the richest inhabitants, Hadgi Mohammed-el-Hair-Trigge, was celebrated in the true Arab style. There is something so rudely chivalric in their ceremonies (so very superior to the dull monotony of a Tripolitan wedding), where from one to five hundred guests, all males, assemble, covered with gold lace, and look at one another, from the evening of one day until daylight the next, that I cannot help describing them.

The morning of the marriage-day (for the ceremony is always performed in the evening, that is, the final ceremony ; for they are generally betrothed, and the fatah read, a year before) is ushered in by the music of the town or tribe, consisting of a bagpipe and two small drums, serenading the bride first, 
and then the bridegroom, who generally walks through the streets very finely dressed, with all the town at his heels; during which time, the women all assemble at the bride's house, dressed in their finest clothes, and place themselves at the different holes in the wall which serve as windows, and look into the court-yard. When they are so placed, and the bride is in front of one of the windows with her face entirely covered with her barracan, the bridal clothes, consisting of silk shifts, shawls, silk trowsers, and fine barracans, to show her riches, are hung from the top of the house, quite reaching to the ground : the young Arab chiefs are permitted to pay their respects; they are preceded from the skiffa, or entrance, by their music, and a dancing woman or two advances with great form, and with slow steps, to the centre of the court, under the bride's window : here the ladies salute their visitors, with " loo! loo! loo!" which they return by laying their right hand on their breasts, as they are conducted quite round and there are but few, is afforded them to survey the surrounding beauties; quite closed. Such an assemblage of bright be so cruel as to keep the veil white teeth, are but rarely seen in bright black eyes, large ear-rings, and having made the circuit, the largess is given, and, I should suppose. After danseuse, and, according to its amount, is the donor hes to view by the chief spectators. Previous to their departure, all visitors disched and greeted by the then again the ladies salute with the "loo! loo!" So far fre their pistols, and at my asking permission to pay my respects, they considered it as a conferred; and the bridegroom, although he could not himself be admitted, attended me to and from the house of his mistress. This ceremony being eamel is sent for her with a the bride prepares to leave her father's house: a covered with skins of animaafa *, or sedan chair of basket-work, on its back, she steps into this, and so pls, shawls from Soudan, Cairo, and Timbuctoo: yet to be entirely hid from the view of others see what is going forward, and the town, where all the hiew of others. She is now conducted outside Our escort on this occasion added footmen who have arms are assembled. by Boo-Khaloom's order, in the field, and when they all charged and fired at the foot of of sixty mounted Arabs;

* This is only called jaafa when a bride is convejed in it - at other ting a con

\section{d 2}


felt for the virgin's situation ; but it was thought a great honour, and that, I suppose, consoled her for the fright. They commenced by skirmishing by twos and fours, and charging in sections at full speed, always firing close under the bride's jaafa : in this manner they proceeded three times round the town, the scene occasionally relieved by a little interlude of the bridegroom's approaching the camel, which was surrounded by the negresses, who instantly commenced a cry, and drove him away, to the great amusement of the bystanders, exclaiming, "Burra! Burra! be off! be off! mazal shouia! a little yet!" With discharges of musketry, and the train of horsemen, \&c. she is then conveyed to the bridegroom's house; upon which it is necessary for her to appear greatly surprised, and refuse to dismount : the women scream, and the men shout, and she is at length persuaded to enter; when, after receiving a bit of sugar in her mouth from the bridegroom's hand, and placing another bit in his, with her own fair fingers, the ceremony is finished, and they are declared man and wife.

We had now to pass the Gibel Assoud, or Black Mountains : the northernmost part of this basaltic chain commences on leaving Sockna. We halted at Melaghi, or the place of meeting immediately at the foot of the mountain, the well of Agutifa; and from hence probably the most imposing view of these heights will be seen. To the south, the mountain-path of Niffdah presents its black overhanging peaks, and the deep chasm, round which the path winds, bearing a most cavern-like appearance : a little to the west, the camel path, called El Nishka, appears scarcely less difficult and precipitous; the more southern crags close in the landscape, while the foreground is occupied by the dingy and barren wadey of Agutifa, with the well immediately overhung by red ridges of limestone and clay: the whole presenting a picture of barrenness, not to be perfectly described, either by poet or painter.

Large masses of tabular basalt, and irregular precipices, common to this formation, are scattered over this range of hills, and extend over all the plains which environ them. The most lofty hills are those which present the most massive façades of tabular basalt; the sides sometimes exhibit a step-like appearance, and in many instances are overhung by pillars, curved, inclined, and perpendicular : these produce a singular effect, not devoid of grandeur. The lower stratum of all these hills is invariably limestone, mixed with a reddish clay. Hills of the same are found bordering upon, and in some cases 



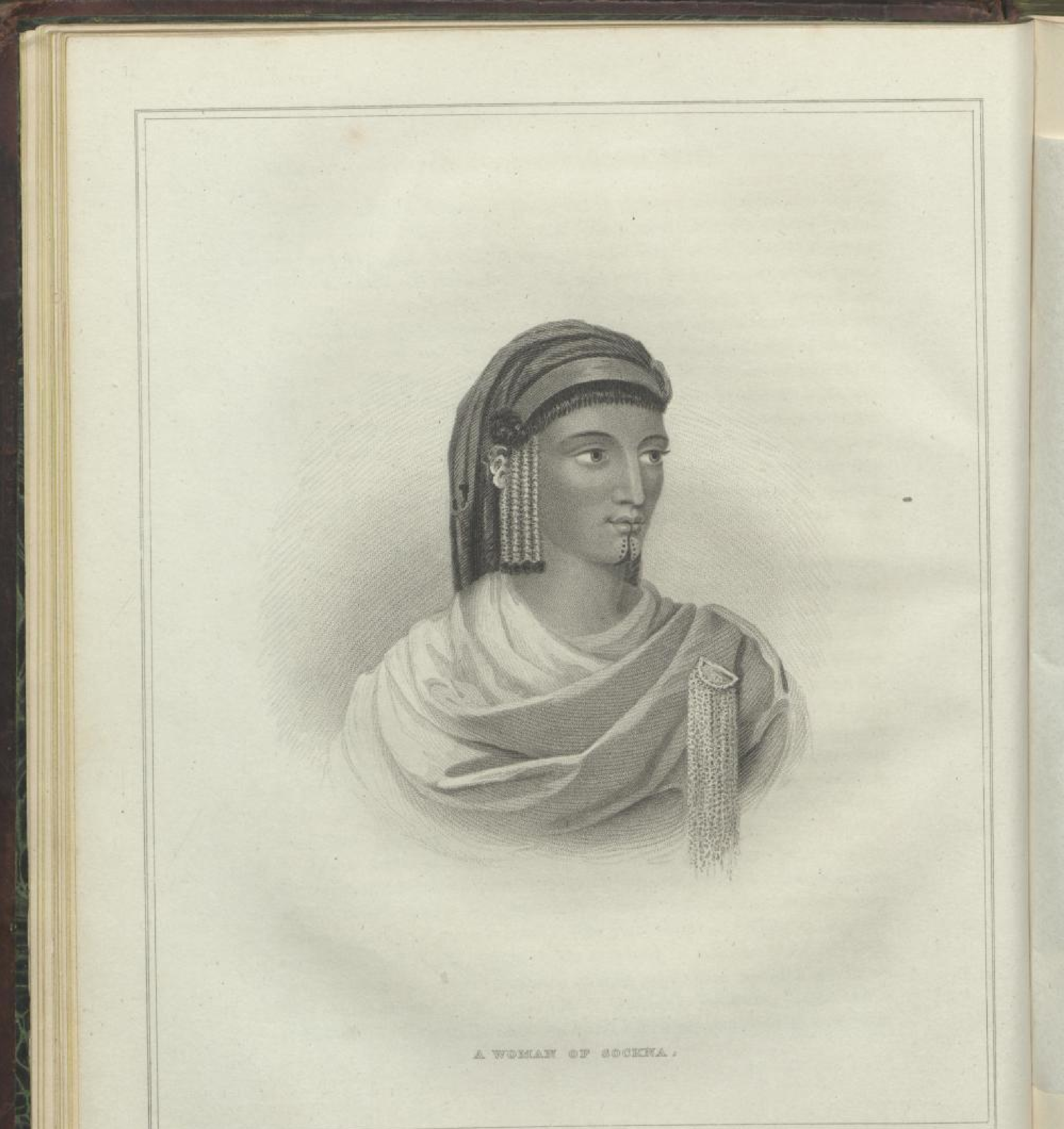

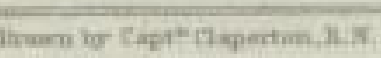

\section{$\neg$ SLUB}

Wir führen Wissen.

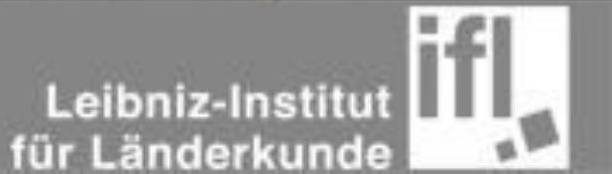


joining, the basaltic ones; some of these are strewed over with a covering of basalt stones of various sizes and forms, none of them large, from three to eighteen inches in circumference, but still showing the colour and structure of the soil on which they are spread. Other hills of limestone are also indiscriminately found without the slightest particle of basalt on them, although in the immediate vicimity of what could easily be imagined the ancient crater of a volcano, which had showered a sombre covering heaved from the very bowels of the earth, on all the then existing hills and plains which surrounded it. Some of these limestone hills have been cut through, either by the falling of masses of rock from the higher hills, or by violent watercourses; and a section of them reveals nothing but pure limestone mixed with clay.

The Souda, or Gibel Assoud *, extend from north to south, three days* journey, but in so winding a direction, as not to exceed thirty-five miles at the utmost in a straight line: to the west, as far as the well called Assela, on the road to the Shiati, where the red clay hills continue alone, and join the hills at Benioleed : to the east, they extend three days on the road to Zella, or Bengagi, to a wadey called Temelleen.

The first four days of our journey, after leaving Agutifa, were all dreariness and misery. This was the third time that I passed these deserts : but no familiarity with the scenery at all relieves the sense of wretchedness which the dread barrenness of the place inspires. We marched from dawn until dark,

* Gibel Assoud and the hills on this side have the same name. The valley is bounded on both sides by hills, from 400 to 600 feet high-tops in general tabular; but a few are irregular, and two or three end in conical peaks; the sides of all are covered with much debris. The colour of the hills gives a very peculiar character to the valley; the tops of a shining black, as if covered over with black lead, that often extends some way down the sides, which are of a light brown, mixed with a dirty yellow : this is often observable in patches in the black, which gives to the whole a very striking appearance. The lower strata are limestone, of a yellowish colour, almost entirely formed of marine remains : this, although hard, is ensily acted on by the air, and the exposed surface mouldering away leaves cavities in the rock, which, undermining the superincumbent ones, gives rise to the quantity of detached fragments. There are several thin strata of earthy gypsum: above that, limestone, with a fine fibrous-looking external surface, something like wood: this has the jingling sound of burnt lime; above is the shining basalt, of a fine texture, mixed with amygdaloid.

About six miles from where we halted, are a range of low white hills, running about west by north, of the same name as the plains. The top is a fine shining white, from thick beds of a milk-white marble, the base of porphyritic limestone. W. $O$. 
for the sake of getting over them as quickly as possible; and as scarcely sufficient fuel was to be found to boil a little water, a mess of cold tumuta was usually our supper. On leaving Tingazeer, we had the blessing of a rainy day; for such it was to all, but particularly to the poor negroes who accompanied the kafila, although Boo-Khaloom always gave them to drink from his skins once in the day (an unusual kindness), yet marching as they were for twelve and fourteen hours, once scarcely satisfied nature. In consequence of the rain, we found water fresh and pure during almost every day's march, and arrived at Zeghren * with the loss of only one camel. On the last day, previous to arriving at the well, Omhul Abeed, a skeleton of a man, with some flesh still hanging about him, lay close to the road; but it was passed by the whole kafila, with scarcely a remark.

After these dreary wastes, it was no small pleasure to rest a day at Zeghren, the native town of a considerable merchant who accompanied our kafila. When we first left Sockna for Mourzuk, Abdi Zeleel had before taken me to his house, and presented me to his mother and sister; and he now insisted on my taking up my quarters there altogether. Almost the first person that presented herself was my friend the merchant's sister, I had almost said the fair, Omhal Hennat. She had a wooden bowl of haleeb (fresh milk) in her hand, the greatest rarity she could offer, and holding out the milk with some confusion towards me with both her hands, the hood which should have concealed her beautiful features had fallen back; as my taking the milk from her would have prevented the amicable salutation we both seemed prepared for, and which consisted of four or five gentle pressures of the hand, with as many aish harlecks, and tiebs, and ham-dulillahs, she placed the bowl upon the ground, while the ceremonies of greeting, which take a much longer time in an African village than in an English drawing-room, were, by mutual consent, most cordially performed. I really could not help looking at her with astonishment,

* The hills of Zeghren opened : a low range, running nearly east and west; their appearance different from any we had yet seen, long, oval, and truncated at the top-colour black, with white streaks.

About the same time a detached rock came in view : it was about a hundred feet high, and 200 from the land from which we descended.

This is the geological structure of the neighbouring land, which has at no very distant period been joined to this. W. O.

+ The mother of peace. 
and I heartily wish that I had the power of conveying an idea of her portrait. It was the Jemma (Friday), the Sabbath, and she was covered, for I cannot call it dressed, with only a blue linen barracan, which passed under one arm, and was fastened on the top of the opposite shoulder with a silver pin, the remaining part thrown round the body behind, and brought over her head as a sort of hood, which, as I remarked, had fallen off, and my having taken her hand when she set down the milk had prevented its being replaced. This accident displayed her jet black hair in numberless plaits all round her expressive face and neck, and her large sparkling eyes and little mouth, filled with the whitest teeth imaginable. She had various figures burnt on her chin with gunpowder: her complexion was a deep brown; and round her neck were eight or ten necklaces of coral and different coloured beads. So interesting a person I had not seen in the country; and on my remaining some moments with my eyes fixed on her, she recommenced the salutation, "How is your health," \&c. and smiling, asked, with great naivete, " whether I had not learnt, during the last two months, a little more Arabic." I assured her I had. Looking round to see if any body heard her-and having brought the hood over her face-she said, "I first heard of your coming last night, and desired the slave to mention it to my brother. I have always looked for your coming, and at night, because at night I have sometimes seen you : you were the first man whose hand I ever touched-but they all said it did not signify with you, an Insara (a Christian). God turn your heart !-but my brother says you will never become Moslem—won't you, to please Abdi Zeleel's sister? My mother says God would have never allowed you to come, but for your conversion." By this time, again the hood had fallen back, and I again had taken her hand, when the unexpected appearance of Abdi Zeleel, accompanied interruption. Omhal-henna quicklo came to visit me, was a most unwelcome the line, and I saw henena quickly escaped; she had, however, overstepped

Besides ouw her no more.

number of liberated slaves who and the followers of Boo-Khaloom, we had a had given freedom to twenty-four from the castle, sixteen of Our friend, Mohammed D'Ghies, had also libe, sixteen of whom were females. under twenty, natives of Begharmi, the evening three young women, all telling them, in my presence, that his friends thevious to our leaving Tripoli, 
country, was the cause of their being set at liberty. There are circumstances attached to this act of D'Ghies beyond the mere liberation of three healthy negresses, so creditable to the feelings of this excellent old man, that they must not be omitted. Two of these girls only had fallen into his hands, and on his intimating to them his intention of giving them their liberty, they told him that another sister had been brought to Tripoli with them, and sold, like themselves, to slavery; but they knew not what was become of her. Mohammed D'Ghies, after much inquiry, succeeded in finding out who had been the purchaser, paid the price demanded for her liberation, and provided the means for enabling all the sisters to return together to their own country with BooKhaloom.

On the 20th October, in a date grove a short distance from the town of Temenhint, we found a kafila from Mourzuk, and some of the Mamelukes who had come from Darfoor and Waday. I visited them with Boo-Khaloom: their tents scarcely held together, and they gave a deplorable account of their sufferings : two of them had been beys, and one, Mohammed Bey, was still in the prime of life, and conversed with spirit; the other, Ali Bey, appeared weighed down by his misfortunes, and was between fifty and sixty years of age : they had left Cairo fifteen years, and had passed the greater part of their exile in and near Dongala. On the approach of the army of Mohammed Ali, three hundred and fifty of them mustered at Dongala, and determined on passing to Kordofan, and from thence to Darfoor. At Darfoor they refused to receive them, and they then moved on to Wara, the capital of Waday, where also they were refused permission to remain. For four months they had been in great distress, the Waday people refusing to sell them any thing for themselves, or forage for their horses, all of which they were consequently obliged to part with : taking slaves for them, which they again exchanged for ostrich feathers, and any thing they could get. At Waday, all but twenty-six determined on proceeding to the south; they, however, afterwards altered their minds, and took the direction of the army of Mohammed Ali, meaning to claim protection there. The twenty-six left Waday just before the Rhamadan (May), and followed the tracks of camels until they came to a kafila of Fezzaneers proceeding to Mourzuk : this kafila they joined; but in passing through the Tibboo Borgoo country, one of their camels strayed and tore a branch from a date tree, for which the Borgoo people beat and wounded one 
of the Mameluke slaves: this was resented by the Mamelukes, and a quarrel ensued, which the Fezzaneers in vain attempted to arrange. They also became sufferers : the Borgoo people attacked and followed the kafila for five days, during which time twenty of the Mamelukes were killed, and thirteen of the Fezzaneers; the six remaining Mamelukes were now on their way to Tripoli, in the hope of obtaining from the bashaw permission to pass the remainder of their lives in his regency: they had lost forty thousand dollars since leaving Egypt.

Mohammed Bey describes the people of Borgoo and Waday as savages of the worst description, abhorring even the sight of a white man. I told him it was my intention to proceed in the direction of Darfoor, if possible: he replied, placing my hand in Boo-Khaloom's, "Do not leave this good man, SidiRais, if you hope to return."-But rarely a kafila passes from Dongala to Darfoor ; to Bornou, never. The army of Egypt had been repulsed with considerable loss at Darfoor; the people of which country, Mohammed Bey said, could muster one hundred thousand men, armed, in the field, equipped with artillery and mortars. The beys of Egypt had sent the King of Darfoor, many years ago, eight pieces of ordnance; they had made others, and worked them, as well as the people of Egypt themselves. The army had gone south, and meant to over-run all the Kordofan, when it was thought, if they had no reinforcement, that they would return to Egypt : with their present strength, they could do nothing with Darfoor, but the people of Darfoor wished for peace with Mohammed Ali, and feared him; on this account it was that they would not receive the Mamelukes. Affecting my own plans so materially as this information appeared to do, it was listened to by me with the deepest interest.

On Thursday, the 24th of October, we halted at Sebha, and remained there until Saturday the 26th, gathering our escort and collecting our supplies.

On Wednesday, the 30th October, we made our entrée into Mourzuk with all the parade and show that we could muster. By Boo-Khaloom's presents to the bashaw, but chiefly on account of his having undertaken to conduct us to Bornou, he had not only gained the bashaw's favour, but had left Tripoli with strong proofs of his master's consideration. Boo-Khaloom, naturally liberal, had, by successful trade, been enabled early in life to gratify his charitable and benevolent inclinations. This made him so popular in Mourzuk, that nearly half the inhabitants came out to meet him, at a short distance from the town, 
although not any of the authorities, and we entered the gates amidst the shouts of the people, preceded by singing and dancing women; and the Arabs who formed our escort made such repeated charges upon their jaded and tired animals, that I really expected some of them would "fall to rise no more." No living creatures can be treated worse than an Arab's wife and his horse, and if plurality could be transferred from the marriage bed to the stable, both wives and horses would be much benefited by the change.

I could not quite resist a sensation of disappointment that no friends came out to meet me : but as the sun was insufferably powerful, and as I had received a message by Boo-Khaloom's brother, from Doctor Oudney, that he was unwell, and that Clapperton had the ague, I did not much expect it ; I was, however, by no means prepared to see either of them so much reduced as they were. Both my companions and Hillman I found had been confined to their beds with hemma (fever and ague), had been delirious, and the Doctor and Hillman only a little recovered. Clapperton was still on his bed, which for fifteen days he had not quitted. Doctor Oudney was suffering also from a severe complaint in his chest, arising from a cold caught during his excursion to Ghraat, and nothing could be more disheartening than their appearance. The opinion of every body, Arabs, Tripolines, and our predecessors, were unanimous as to the insalubrity of its air. To account physically for the sickliness of the place, was beyond the powers of wiser medical heads than mine, but facts are stubborn things. Mr. Ritchie had fatally felt the baneful influence of the climate of Mourzuk, and Captain Lyon had suffered extremely during his stay there : every one of us, some in a greater or less degree, had been seriously disordered; and amongst the inhabitants themselves, any thing like a healthy looking person was a rarity.

Notwithstanding Boo-Khaloom made every exertion in his power to get away from Mourzuk as early as possible, yet, from the numerous arrangements which it was necessary for him to make, for the provisioning so many persons during a journey through a country possessing no resources, it was the 29th November before those arrangements were complete. Doctor Oudney and Mr. Clapperton, from a most praiseworthy impatience to proceed on their journey, and at the same time, thinking their health might be benefited by the change of air, preceded him to Gatrone by ten days. I had remained behind to urge Boo-Khaloom and expedite his departure, and we thought by 
these means to obviate any wish which he might have to delay on account of his private affairs, even for a day. Our caution was, however, needless; no man could be more anxious to obey the orders he had received, and forward our views, than himself: indeed so peremptory had been the commands of the bashaw, in consequence of the representations of our consul general, when complaining of former procrastination, that Boo-Khaloom's personal safety depended on his expedition, and of this he was well aware.

It may not be unacceptable to the reader, if I here give some account of the strength of our party.

I had succeeded in engaging, on my return to Tripoli, as an attendant to accompany me to Bornou, a native of the island of St. Vincent, whose real name was Adolphus Sympkins; but who, in consequence of his having run away from home, and in a merchant vessel traversed half the world over, had acquired the name of Columbus; he had been several years in the service of the bashaw, spoke three European languages, and perfect Arabic. This person was of the greatest service to the mission, and so faithful an attendant, that His Majesty's government have since employed him to accompany my former companion and colleague, Captain Clapperton, on the arduous service he is now engaged in : we had besides three free negroes, whom we had hired in Tripoli as our private servants; Jacob, a Gibraltar Jew, who was a sort of store-keeper; four men to look after our camels; and these, with Mr. Hill. man and ourselves, made up the number of our household to thirteen persons. We were also accompanied by several merchants from Mesurata, Tripoli, Sockna, and Mourzuk, who gladly embraced the protection of our escort to proceed to the interior with their merchandize.

The Arabs in the service of the bashaw of Tripoli, by whom we were to be escorted to Bornou, and on whose good conduct our success almost wholly depended, were now nearly all assembled, and had been chosen from the most obedient tribes; they gained considerably in our good opinion, each day we became better acquainted with them : they were not only a great and most necessary protection to us, breaking the ground as we were for any Europeans who might follow our steps, but enlivened us greatly on our dreary desert way by their infinite wit and sagacity, as well as by their poetry, extempore and traditional. We had several amongst our party who shone as orators in verse, to use the idiom of their own expressive language, particularly one of the tribe 
of Boo Saiff Marabooteens, or gifted persons, who would sing for an hour together, faithfully describing the whole of our journey for the preceding fortnight, relating the most trifling occurrence that had happened, even to the name of the well, and the colour and taste of the water, with astonishing rapidity and humour, and in very tolerable poetry; while some of his traditionary ballads were beautiful. The names of the chiefs who were to accompany us were as follows :-

Of the tribe of M'Garha, Sheikh Abdi Smud ben Erhoma, from the Syrtis, with seventy men. He often said that his father's name was renowned in song, for having killed one hundred men with his own hand in battle, and please God! he should exceed him, for he was but thirty-five, and had brought forty to the ground already.

The M'Garhas are at this time in great favour with the bashaw, and entirely exempt from tribute of any sort, from having assisted him very materially in annihilating the Waled Suleyman: I must, therefore, give some account of them.

They principally inhabit the Syrtis, where a considerable body always remain ; tribes of them, with their flocks, pitch their tents for the months of pasture wherever they can find forage, and in times of peace even to within a few leagues of Tripoli. When the present bashaw determined on putting a finishing stroke to the Waled Suleyman, by the extermination of the tribe, he, like a wily politician, sent offers of peace and protection to the M'Garha, the ancient and inveterate enemies of the Seffenusser *. In their occasional skirmishes, no quarter was given; and a Waled Suleyman literally sucked the blood of a M'Garha, after giving him the finishing blow : children were even called upon to follow the parent's example, so that they might imbibe all the hatred felt by their ancestors, and vice versa. The tribe of M'Garha readily accepted the bashaw's offers ; and with their assistance, about six years back, the Waled Suleyman struggled with the power of the bashaw for the last time. It was near the borders of Fezzan, in one of those extensive upland plains called Hormut Mahulla, that the grandsons of Seffenusser, the last of the house, returned from Egypt, and headed the remaining followers of their ancestors. The Orfilly, and several other tribes, flocked to the standard: the M'Garha

\footnotetext{
* The name of their sheikh or chief; also often used when speaking of the tribe.
} 
marched from the eastward to assist the bashaw, who came from the side of Tripoli; the rebels were surrounded, and the Orfilly capitulated, promising an enormous tribute. No terms were, however, granted to the Waled Suleyman; they were followed with fire and sword to their very huts-Seffenusser's children fell into the hands of their enemies; they were, however, spared, and two of them sent to Mourzuk. Since that time, the name of Waled Suleyman is scarcely breathed; indeed the tribe has ceased to exist, with the exception of some few who escaped to Egypt. A solitary being, who thinks himself unobserved, is sometimes pointed out to you as having been one; but his misery protects him. So complete an overthrow of the most numerous tribe that inhabited the regency of Tripoli, and one whose riches and influence were so well known, has had the effect of humbling the turbulent spirit of the Arabs to a wonderful degree : the bashaw rules them literally with a rod of iron, and for the slightest cause he has the heads of their sheikhs over the gates of his palace in a few hours. He makes it his policy to keep up their feuds and ancient enmities, by which means he prevents that unanimity which might make them dangerous. The name of Seffenusser is, however, still the tocsin of revolt; it is in itself a thousand strong; and the bravery displayed by Abdi Zeleel, the eldest survivor of the name, during the late campaign in the negro country, has not a little contributed to strengthen the feeling.

Abdallah Bougeel, a chief and a warrior, from the Shiati, whose father and grandfather died because they would not fly; who never attended to flocks, but were chief in fight-twenty men.

Sheikh Sultan ben Kaid, from the Shiati, a great warrior, who had a terrible wound in his face, which had nearly demolished his nose, from the sword of a Tuarick-ten men.

Hamed el Geide, Shiati-ten men.

Hamed Bendou el Hothmani, Shiati-ten men.

Sheikh Boo Bucker Saakhi, Shiati-ten men.

Salem Asheneen Hashnuowy, Shiati-thirty men.

The Maraboot Sid Hassan ben Eran-ten men.

Il R'baiah-ten men.

Boo Ahgoom, Osfilly-twenty men.

Futhaem-ten men. 
Arabs are generally thin meagre figures, though possessing expressive and sometimes handsome features, great violence of gesture and muscular action. Irritable and fiery, they are unlike the dwellers in towns and cities : noisy and loud, their common conversational intercourse appears to be a continual strife and quarrel; they are, however, brave, eloquent, and deeply sensible of shame. I have known an Arab of the lower class refuse his food for days together, because in a skirmish his gun had missed fire : to use his own words, "Gulbi wahr," " My heart aches ;" "Bindikti kedip hashimtni gedam el naz;" " My gun lied, and shamed me before the people." Much has been said of their want of cleanliness; I should, however, without hesitation, pronounce them to be much more cleanly than the lower order of people in any European country. Circumcision, and the shaving the hair from the head, and every other part of the body; the frequent ablutions which their religion compels them to perform; all tend to enforce practices of cleanliness. Vermin, from the climate of their country, they, as well as every other person, must be annoyed with; and although the lower ranks have not the means of frequently changing their covering (for it scarcely can be called apparel), yet they endeavour to free themselves as much as possible from the persecuting vermin. Their mode of dress has undergone no change for centuries back; and the words of Fenelon will at this day apply with equal truth to their present appearance*.

The fondness of an Arab for traditional history of the most distinguished actions of their remote ancestors is proverbial : professed story-tellers are ever the appendages to a man of rank: his friends will assemble before his tent, or on the platforms with which the houses of the Moorish Arabs are roofed, and there listen, night after night, to a continued history for sixty, or sometimes one hundred nights together. It is a great exercise of genius, and a peculiar gift, held in high estimation amongst them. They have a quickness and clearness of delivery, with a perfect command of words, surprising to a European ear : they never hesitate, are never at a loss; their descriptions are highly poetical, and their relations exemplified by figure and metaphor, the

\footnotetext{
* Leurs habits sont aisés à faire, car en ce doux climat on ne porte qu'une piece d’étoffe fine et lègère, qui n'est point taillée et que chacun met à longs plis autour de son corps pour la modestie; lui donnant la forme qu'il veut.
} 
most striking and appropriate : their extempore songs are also full of fire, and possess many beautiful and happy similes. Certain tribes are celebrated for this gift of extempore speaking and singing; the chiefs cultivate the propensity in their children ; and it is often possessed, to an astonishing degree, by men who are unable either to read or write.

Arabic songs go to the heart, and excite greatly the passions : I have seen a circle of Arabs straining their eyes with a fixed attention at one moment, and bursting with loud laughter; at the next, melting inte tears, and clasping their hands in all the ecstacy of grief and sympathy.

Their attachment to pastoral life is ever favourable to love. Many of these children of the desert possess intelligence and feeling, which belong not to the mode of gaining their livelihood, except by the sword and gun. An Arab values himself chiefly on his expertness in arms and horsemanship, and on
hospitality.

Hospitality was ever habitual to them. At this day, the greatest reproach to an Arab tribe is, "that none of their men have the heart to give, nor their women to deny." Nor does this feeling of liberality alone extend to the chiefs, or Arabs of high birth: I have known the poor and wandering Bedouin to practise a degree of charity and hospitality far beyond his means, from a sense
of duty alone.

Notwithstanding all the savageness of an Arab, there are sometimes noble thoughts which seem to cross over his powerful mind; and then again to leave him choked up with weeds of too strong a growth to be rooted out.

The M'Garha sheikhs were, after the defeat of Waled Suleyman, all taken into the bashaw's service; and are now amongst his most faithful and favoured some portion of his grandsire's being ordered to repair with a extensive lands at Sebha in Fezzan; and on his accompany the Sultan of Fezzan into number of camels to Mourzuk, and to delayed obeying the order : his enemies negro country, he was reported to have and want of courage. The bashaw's judgment was reluctance to disaffection Ghreneim, the brother of my chaoush judgment was summary; and Hamet Zeleel, and orders to stab him while he read it, and wetter to Abdi 
M'Garha had five hundred miles to ride, previous to executing his bloody commission ; and, by his account to me, it was the sixteenth of the same kind that he had been intrusted with: he seldom failed either in the execution or in receiving the reward, which always follows: "they were his master's orders-with Bis milla! (in God's name) he struck, and struck home!" His victim, in this case, was of more consequence than any of his former ones, and his reward would have been greater in proportion: Hamet was withal the descendant of the old enemy of his clan; but there was still some magic in the name of the Seffenusser. They were a race of heroes-cowardice could not be a crime for any of the blood to be guilty of; and the chance of being strangled on his return appeared to him preferable to assassinating Abdi Zeleel, and he determined on hesitating before he executed the bashaw's orders. On arriving at the hut of the Arab chief, notwithstanding his fallen state, friends enough remained to warn him of his approaching fate: he met Hamet at the door, kissed the signet of the bashaw, and desired him to perform his office; adding, "You are a M'Garha, and an enemy to our house." " I am," replied the other, " and therefore not capable of assassinating a Seffenusser : if you are guilty, fly - mine be the risk."

Cowardice is ever visited in an Arab by the most disgraceful punishments; he is often bound, and led through the huts of the whole tribe, with the bowels and offal of a bullock, or some other animal, tied round his head; and amongst a people who only desire to be rich in order to increase the number of their wives, probably the greatest punishment of all is, that could even any woman be found who would receive him as a husband, which would be an extraordinary circumstance, no Arab would allow him to enter into his family with such a stain on his character as cowardice.

The amor patria discoverable in even the wildest inhabitant of the most barren rock is not felt by the wandering Arab, or the Moor. He wanders from pasture to pasture, from district to district, without any local attachment ; and his sole delight is a roving, irregular, but martial life. I have met with several, mostly Moors of Mesurata and Sockna, who have made three times the pilgrimage to Mecca ; visited severally all the ports in the Red Sea ; had been in Syria, from St. Jean d'Acre to Antioch; had traded to Smyrna and Constantinople, visiting Cyprus, Rhodes, and most of the islands in the Archi. 
pelago ; had penetrated to the west of Nyffe, in Soudan, and every other part of the black country; had been two or three times stripped and robbed of every thing in the Negro country, escaping only with life, after receiving several wounds. Some of them had not seen their families for fifteen or twenty years, yet were still planning new expeditions, with as much glee as if they were just beginning life, instead of tottering on the brink of death.

Arabs have always been commended by the ancients for the fidelity of their attachments, and they are still scrupulously exact to their words, and respectful to their kindred; they have been universally celebrated for their quickness of apprehension and penetration, and the vivacity of their wit. Their language is certainly one of the most ancient in the world; but it has many dialects. The Arabs, however, have their vices and their defects; they are naturally addicted to war, bloodshed, and cruelty; and so malicious as scarcely ever to
forget an injury.

Their frequent robberies committed on traders and travellers, have rendered the name of an Arab almost infamous in Europe. Amongst themselves, however, they are most honest, and true to the rites of hospitality ; and towards those whom they receive as friends into their camp, every thing is open, and nothing ever known to be stolen : enter but once into the tent of an Arab, and by the pressure of his hand he ensures you protection, at the hazard of his life. An Arab is ever true to his bread and salt; once eat with him, and a knot of friendship is tied which cannot easily be loosened.

Arabs have been truly described as a distinct class of mankind. In the bashaw's dominions, they have never been entirely subdued : violent attempts at subjugation have often deprived them of tracts of their vast territories; whole tribes have been annihilated ; but, as a people, they have ever remained
independent and free.

The few fertile spots of scanty verdure, called " oases," which now and then refresh the languid senses of the weary traveller, and which are desolate, beyond the wildest wastes of European land, are the tracts inhabited by the eastern Arabs. Masses of conglomerated sand obstruct the path which leads to these oases or wadeys; nothing relieves the eye, as it stretches over the wide expanse, except where the desert scene is broken by a chain of bleak and barren mountains : no cooling breezes freshen the air : the sun descends in overpower- 
ing force : the winds scorch as they pass; and bring with them billows of sand, rolling along in masses frightfully suffocating, which sometimes swallow up whole caravans and armies, burying them in their pathless depths!

"Their hapless fate unknown!"

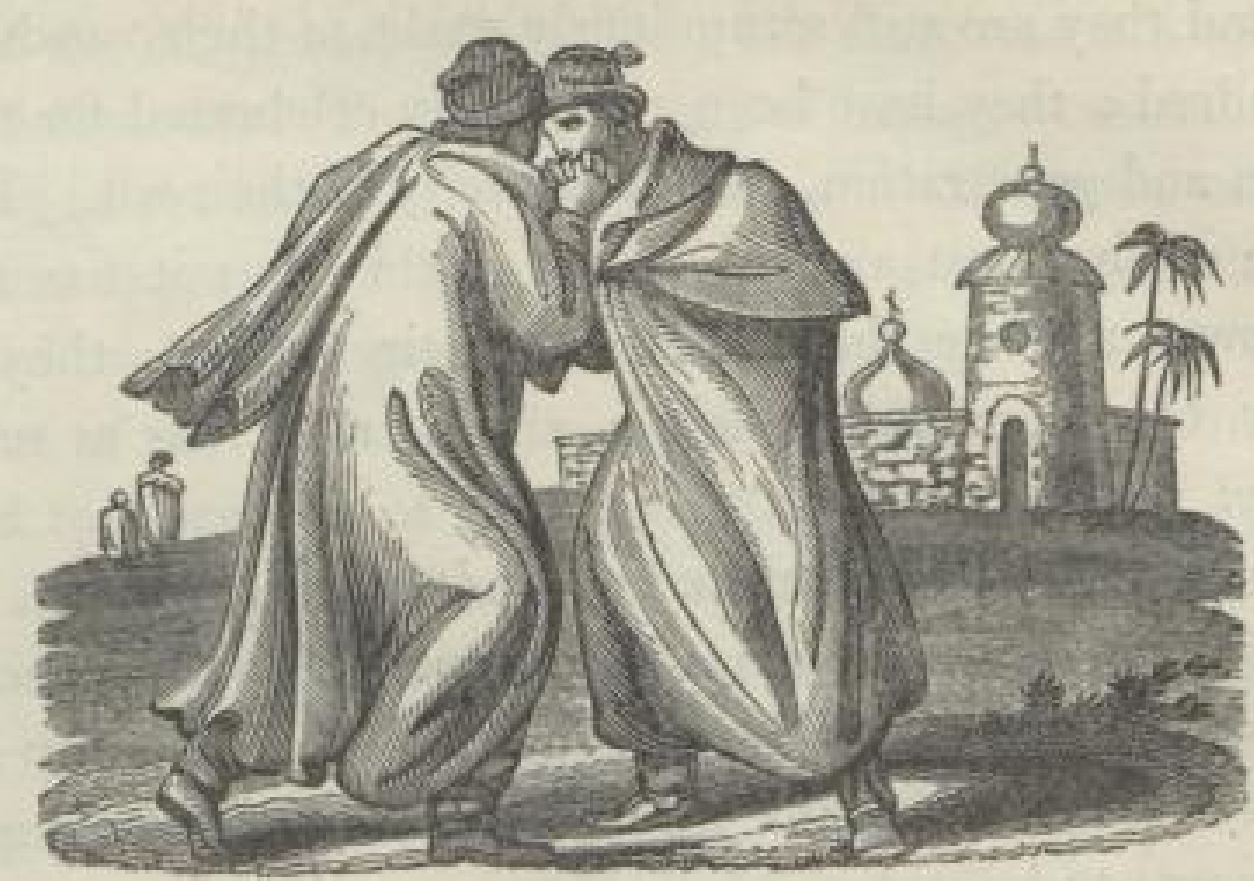




\title{
EXCURSION TO WESTWARD OF MOURZUK,
}

\author{
IN JUNE, JULY, AND AUGUST, 1822,
}

BY WALTER OUDNEY, M.D.

Saturday, June 8, 1822.-At a little after sunrise departed from Mourzuk. Lieutenant Clapperton, Mr. William Hillman and I were accompanied by Hadje Ali, brother of Ben Bucher, Ben Khullum, Mahommed Neapolitan Mamelouk, and Mahomet, son of our neighbour Hadje Mahmud. It was our intention to have proceeded direct to Ghraat, and laboured hard to accomplish our object. Obstacle after obstacle was thrown in our way, by some individuals in Mourzuk. Several came begging us not to go, as the road was dangerous, and the people not at all under the bashaw's control. We at length hired camels from a Targee, Hadje Said; but only to accompany us as far as the Wadey Ghrurby.

Our course was over sands skirted with date trees; ground strewed with fragments of calcareous crust, with a vitreous surface, from exposure to the weather. About mid-day, after an exhausting journey from oppressive heat, mostly at El Hummum, a straggling village, the houses of which are and then proceeded on our leaves. We remained till the sun was well down, At eight we arrived at Tessouwa. The country bad the same character.

The greater number of inhabitants are Tuaricks. They have a warlike

f 2 
appearance, a physiognomy and costume different from the Fezzaneers. More than a dozen muzzled up faces were seated near our tent, with every one's spear stuck in the ground before him. This struck us forcibly, from being very different from what we had been accustomed to see. The Arab is always armed, in his journey, with his long gun and pistols; but there is something more imposing in the spear, dagger, and broad straight sword.

About eight, we departed : several wadeys in our course, with numerous small acacias, a few gravelly and sandy plains, and two or three low white alluvial hills. About three, halted at a well of good water.

Our course lay over an extensive high plain, with a long range of hills, running nearly east and west. Distance, about fourteen miles. We entered them by a pass which runs north and south, in which are numerous recesses, evidently leading to more extensive wadeys. Before reaching the hills, we found some people digging a well. It was about a hundred feet deep.

The hills are at about a hundred yards' distance. Their form is that of a table top, with a peak here and there. The structure sandstone, finely stratified with beds of blue and white pipeclay, and alum slate.

The pass led to another, the finest we have seen, and the only part approaching to the sublime we have beheld in Fezzan. It is rugged and narrow; its sides high, and overhanging in some places. The whole exposed rock is a slaty sandstone, with thin strata of alum slate. The path has several trunks of petrified trees, with branches going out from them; the stem very similar to the acacia. They appear as if precipitated from the top. Near the end of the pass, the Wadey Ghrurby opens, with groves of date .palms, and high sand hills. The change is sudden and striking; and instead of taking away, added to the effect of the pass we were descending. The hills from the wadey have rugged, irregular, peaked tops, as if produced by some powerful cause ; although it appeared, on examination, that all was produced by the mouldering away of the lower strata.

The hills are composed of thick beds of blue clay, alternating with sandstone, beds of alum slate, and thick strata of porphyritic clay stone, and all the tops of finely stratified sandstone.

Wednesday, June 12. Moved up the valley for about four miles, and halted at a small town, Kharaik, having passed two in our course. Valley, fine 
groves of palm trees, with cultivated patches; water good, depth of the wells as about Mourzuk; hills bound the valley on the south side, and sand hills on the north. The number of date trees in the eastern and western division of the valley is said to be 340,000 . The first division, or Wadey Shirgi, extends from near Seba to within a few miles of Thirtiba; the other, from the termination of Shirgi to Aubari.

In the evening saw some of the preparatory steps for a marriage. The woman belonged to this, and the man to the next town. A band of musicians, accompanied by all the women of the village, dancing and singing, with every now and then a volley of musketry. One woman carried a basket on her head, for the purpose of collecting gomah, to form a feast and pay the musicians. They came from the village of the bridegroom, which was about a mile distant. The marriage was not to take place till the feast after Rhamadan.

There are very few plants here. A species of asclepias, with milky juice; the agoul, apparently a species of ulex, has a fine red papilionaceous flower; species, with small obovate leaves, pod small and obtuse at the apex. A species of sweet-smelling rue, and two other plants in fruit, one like a veronica, and the other I have not seen a similar one before.

Friday, June 14. Rain sometimes falls in the valley, sufficient to overflow the surface, and form mountain torrents. But it has no regular periods; five, eight, and nine years frequently intervening between each time. Thus no trust can be placed in the occurrence of rain, and no application made in agricultural concerns. The sheikh of this town is Ali, a good natured Tiboo, exceedingly poor, but very attentive, and always in good humour. The place is so poor, that we had sometimes to wait half a day before we could get a couple of fowls, or a feed of dates or barley for our horses. We are in hourly expectation of camels from friends of Hateeta, for the purpose of conveying us to Ghraat.

There are a number of ants, of a species different from any $I$ have seen in North Africa. Colour, a light shining brown, speckled with a silvery white, a strong pair of nippers, like the large claws of a crab. They run with great swiftness.

Saturday, June 15. No camels have arrived, and we are obliged to remain ; much against our inclination. Hateeta was conversing yesterday on the diffi- 
culty we experienced in getting away from Mourzuk, from obstacles thrown in our way by the people. He said that the dread they had of the Tuaricks was unfounded, and we would soon be convinced of it. He further added, that he could, by his influence alone, conduct us in perfect safety to Timbuctoo, and would answer with his head. He was indignant at the feelings the people of Mourzuk had against the Tuaricks, who, he said, pride themselves in having but one word, and performing what they promise.

Sunday, June 16. Our camels have not yet arrived; but we were able to hire two from one Mahomet El Buin, and with these we proceeded on to Germa. Our course lay along the wadey, which grew finer and finer as we advanced, the number of gummah and gussub fields and date groves increasing. The hills formed some small recesses; the tops of most were level, and all of the same height. Passed several villages built all in the same manner. Notwithstanding the nearness and fitness of the stone, the salt mould is preferred; perhaps from the want of lime, and the ease with which the house is erected. Another thing: so very little rain falls, that there is no danger of the fabric falling. Near Break passed some imperfect inscriptions, apparently Arabic.

About eleven arrived at Germa, a larger town than any in the wadey, but both walls and houses have the marks of time. We waited in the house of the kaid till our camels came up. The sheikh, Mustapha ben Ussuf, soon visited us. $\mathrm{He}$ is an old man, a Fezzaneer, dark complexion, arch of nose small, tip depressed, and alæ expanded, lips a little thick, but mouth not large, hair black, and from the appearance of the beard, woolly. His ancestors are natives of this place; and his features may be considered as characteristic of the natives of Fezzan.

Monday, June 17. We had many accounts of inscriptions being here, which the people could not read. We were conducted to-day by Sheikh Mustapha to examine a building, different, as he stated, from any in the country. When we arrived, we found, to our satisfaction, it was a structure which had been erected by the Romans.

There were no inscriptions to be found, although we carefully turned up a number of the stones strewed about, but a few figures and letters rudely hewn out, and evidently of recent date. We imagined we could trace some resemblance 
to the letters of Europe, and conjectured that they had been hewn out by some European traveller at no very distant period. Our thoughts naturally went back to Hornemann; but again we had no intelligence of his having been here. In short, to confess the truth, we did not know what to make of them, till we afterwards made the discovery of the Targee writing. This building is about twelve feet high, and eight broad. It is built of sandstone, well finished, and dug from the neighbouring hills. Its interior is solid, and of small stones, cemented by mortar. It stands about three miles from Germa, and a quarter of a mile from the foot of the mountain. It is either a tomb or an altar: those well acquainted with Roman architecture, will easily determine which. The finding a structure of these people proves, without doubt, their intercourse here. It is probable they had no extensive establishment ; otherwise we should see more remains. As we went along we passed by, and saw to the westward, the remains of ancient Germa. It appeared to occupy a space more extensive than the present town. We were not able to learn from the old sheikh whether any old coins were ever found, or any building similar to this, in the vicinity. Was this the track merely of the Romans into the interior, or did they come to the valley for dates?

Tuesday, June 18. Hateeta arrived during the night; but our departure was delayed on account of his being sick. He has a severe fever, and it is likely it may be of some continuance. The ague is very prevalent in the wadey; and, if we can believe the natives, the water is a very powerful agent in inducing bilious affection. The town is surrounded by a ditch, now nearly dry, and its site covered with a thick crust of the muriate of soda, evidently containing a large quantity of the muriate and sulphate of magnesia. This crust extends to a considerable distance from the town, and is five or six inches thick in several places. There are several wells, not two feet deep, containing excellent water. The date trees are close to the vicinity of the town, and most are heavily loaded with fruit. It is lamentable to see the number of houses in ruin, and the marks of poverty in the dress of the inhabitants. We could scarcely get a fowl to buy ; and a sheep was out of the question.

Wednesday, June 19. Struck our tents at daylight, and commenced our journey about seven. We now sent our horses home, under charge of my servant Adam, and set out on foot. We intended mounting the camels; but 
the loads were so ill arranged, that we could not venture as yet. Our course lay through groves of date trees growing on the salt plain. These extended for about four miles; and two miles farther west was a small Arab town. We saw several of the Arabs as we passed along; but merely gave the usual compliments. The country for several miles was a loose sand, and heavy travelling for those on foot. The hills of the same shape, forming several large bays, with projecting headlands ; the sides, to within fifty or sixty feet of the top, having gentle but rugged ascents; but above almost perpendicular. We passed three wells, one about fifty feet deep, temp. 22. 6. at which two women were watering goats belonging to Tuaricks. The other two were holes in the ground; the water of all good. We halted about an hour under the shades of date trees, waiting for the camels. I then mounted, and about three, entered the date groves of Oubari, where we halted. Hateeta joined us in the evening, with considerable fever. We had numerous Tuarick visitors, some residents of the town, and others belonging to a kafila about to depart for the Tuarick country. They are an independent-looking race. They examine with care every thing they see, and are not scrupulous in asking for different articles, such as tobacco, powder, and flints. The sheikh, and a number of the other inhabitants of the town, soon came out; and he procured what we wished.

Thursday, June 20.--Intended starting this morning; but the camel-men did not come forward with their camels. Hateeta still very ill. Took advantage of our detention to visit the neighbouring hills. One part appeared at a distance as an artificial exeavation, which disappeared as we approached; and we found it to be a smooth surface, with a portion so removed, as to give rise to the delusion.

In ascending this by the tract of a mountain torrent, we fell in with numerous inscriptions, in characters similar to those on the Roman building. Some were evidently done centuries ago, others very recently.

The hill is of fine sandstone, which has not been used for building. There are also several thick strata of a fine blue clay, containing embedded masses of iron ore. The summit is formed of a dark bluish red clay stone, which gives a dreary cast to the hills. We ascended with difficulty, as it is one of the highest and steepest hills of the range. It commands an extensive view of the 
whole neighbouring wadey. The sand hills are much lower than to the eastward ; and, from this position, all to the northward appears an extensive sandy plain.

The palms of Oubari are like paltry shrubs; and from viewing them here, one would not believe them to be half 7000 , the estimated number. To the southward, another portion of the same range. When we got to the top, we were perspiring copiously, and had to take care that the perspiration was not checked too suddenly, as a strong cool breeze was blowing on the top. Many spaces were cleared away for prayer, in the same manner as we have observed in places on all the roads we have travelled along. The form in general is an oblong square, with a small recess in one of the longer sides looking to the rising sun, or it is semicircular, with a similar recess. On the top of a steep precipice, the King's Anthem was sung with great energy and taste by Hillman.

The new moon was seen this evening, to the great joy of all the followers of Mahomet. Muskets and pistols were discharged, and all the musicians began their labours. This sport was continued all night. A party of musicians came out to visit us; but several were so drunk that they could scarcely walk. The fast is kept by all with a bad grace ; and scarcely one is to be seen who has not a long visage. It is even laughable to see some young men going about the streets with long walking sticks, leaning forward like a man bent with age. As soon as the maraboot calls, not a person is to be seen in the streets; all commence, as soon as he pronounces "Allah Akbar;" all pretend to keep it; and if they do not, they take care no one shall know : but from the wry faces and great pharasaical shows, the rigidity may be called in question. None of our party kept it, except for a day now and then; for all travellers after the first day are allowed exemption; but they have to make up at some other time.

For the first time, we found out the writings on the rocks were Tuarick; and we met one man that knew a few of the letters; but could not find one that knew all. The information was satisfactory to us, and put our minds to rest on the subject of the writing.

We were amused with stories of the great powers of eating of the Tuaricks. We were told that two men have consumed three sheep at one meal; another 
eating a kail of bruised dates, with a corresponding quantity of milk, and another eating about a hundred loaves, of about the size of our penny loaves. We had many inquiries respecting our females. A notion prevailed, that they always bore more than one child at a time, and that they went longer than nine calendar months. On being told that they were the same in that respect as other women, they appeared pleased. We were also asked how they were kept; if locked up as the Moorish woman, or allowed to go freely abroad. The Tuarick women are allowed great liberties that way, and are not a little pleased at having such an advantage.

The greater number of Tuaricks follow the nomade life, moving from place to place as they find pasturage. They appear to delight in solitary abodes; and the different mountain recesses in the vicinity appear to have been often the residences of these people. The houses are of the skin of the camel, and have something of the form of the Arab.

I had a great many female Tuarick patients to-day. They are free and lively; and there is no more restraint before men than in the females of our own country; and they are greatly noticed by the men. They have a copper complexion; eyes large, black, and rolling; nose plain; but two or three had fine ancient Egyptian shaped noses; hair long and shedded, not plaited like the Arab women; neither did there appear to be any oil.

Tuesday, June 25.-There are several roads to Ghraat; and the upper one, where we had to enter the hills, was last night fixed on for us. There is plenty of water, but more rough than the lower, which is said to be a sandy plain, as level as the hand, but no water for five days.

It is not necessary among the Tuaricks that the woman should bring a portion to the husband, although she generally brings something: but it is almost always requisite that the man pay so much to the father for permission to marry his daughter. The price, when the parties are rich, is generally six camels.

The customs and manners of our country, which we related to our friends, were so similar to some of theirs, that an old Targee exclaimed in a forcible manner, "That he was sure they had the same origin as us." We are getting on amazingly well with them, and would, no doubt, soon be great friends. The women here have full round faces, black curling hair, and, from a Negro 
mixture, inclined to be crispy; eyebrows a little arched, eyes black and large, nose plain and well-formed. The dress a barracan neatly wrapped round, with a cover of dark blue cloth for the head; sometimes that comes over the lower part of the face as in the men. They are not very fond of beads, but often have shells suspended to the ears as ear-drops.

Thursday, June 27. Hateeta is really so unwell, that he is not able to go; we in consequence have put off our departure for ten days, and have determined during that time to visit wadey Shiati, \&c.; and Mr. Hillman goes up to Mourzuk to send down supplies and take charge of our property. It would have been unkind to Hateeta to have proceeded on; for he is so anxious, that, rather than be left behind, he would have ordered himself to have been bound to a camel. We arranged about the fare for our camels, and prepared ourselves to depart to-morrow morning. We left our spare baggage, which our Tuaricks deposited in one of their mountain recesses.

Friday, June 28.-Before we could set out, a guide for the sands was necessary. For that purpose we engaged an old Targee, who professed to know every part of our tract. When all things were ready, it was near eight in the evening; but we were determined to start. Now Mr. Hillman left us for Mourzuk, I felt glad and satisfied, as I had always since our departure been uneasy respecting our property ; but with Hillman every thing would be taken care of, and as safe as if we were all present. The interest he took in the mission, and the important duty in taking care of all our concerns, deserve the highest praise from every one.

We travelled by moonlight over a sandy soil, with numerous tufts of grass and mound hillocks, covered with shrubs, the surface in many places hard and crusty, from saline incrustation. The old man told us that the mounds of earth were formed by water, as the wadey, at the times of great rain, was covered with water. He further added, that in former times a large quantity of rain used to fall, information agreeing with what we had before received.

Saturday, June 29.-At daylight resumed our journey ; and a little after sunrise entered among the sand hills, which are here two or three hundred feet high. The ascending and descending of these proved very fatiguing to both our camels and ourselves. The precipitous sides obliged us often to make a circuitous course, and rendered it necessary to form with the hands a tract by which the camels might ascend. Beyond this boundary of the sand 
hills of the wadey Ghrurbi, there is an extensive sandy plain, with here and there tufts of grass. We observed, for the first time, a plant with leaves like those of an equisetum, and a triginious grass.

In the afternoon our tract was on the same plain. There were observable several furrows with strips of grass in tufts. Near sunset began ascending high sand hills; they were as if one heaped upon another. Our guide ran before to endeavour to find out the easiest tract with all the agility of a boy. The presence of nothing but deep sandy valleys and high sand hills strikes the mind forcibly. There is something of the sublime mixed with the melancholy. Who can contemplate without admiration masses of loose sand, fully four hundred feet high, ready to be tossed about by every breeze, and not shudder with horror at the idea of the unfortunate traveller being entombed in a moment by one of those fatal blasts, which sometimes occur. On the top of one of these hills we halted for the night. It was near full moon. Her silvery rays, contrasted with the golden hue of the sand, and the general stillness, gave rise to a diversity of reflections.

Sunday, June 30.-At sunrise began our journey through valleys of sand, bounded on each side, and every where intersected by high sand hills. We had to pass over several of these, to our great annoyance. Our water was low, half a gerba only was left, and we began to be a little uneasy at the chance of losing our way, or the well being filled up. Our fears were soon removed. We saw the well at a distance, and found it full of good water on our arrival. The name of the valley is Tigidafa. Much of the equisetum-leaved plant grows here, and four or five date trees overshadow the well.

We halted during the heat of the day. The Mamelouk very unwell with ague and affection of the liver, probably arising from the want of his usual quantity of sour lackbi. In Mourzuk we were told he used to drink all he could procure.

About four we moved along the summits of several of the highest ridges, and descended some of the most difficult passes. About sunset arrived at a large plain, with a little feeding for the camels. Here we halted. The grasses have long tapering roots, but not finely divided into fibres; each fibre descends perpendicularly, and does not creep along the surface. It is covered with a fine velvety epidermis, and that again with fine particles of sand, so as to give it the appearance and elasticity of twine finely coiled up. None of the 
plants I saw had creeping roots, but all long and tapering; thus forming but a weak barrier to the fixing of the sand.

Tuesday, July 2.- Our course over and among the sand hills, and sandy walls, or barriers, like falls in a river, every here and there running across the valleys. Our guide, whom we now styled Mahomet ben Kaml, or son of the sand, was almost always on before, endeavouring to find out the best way. We could detect in the sand numerous foot-marks of the jackal and fox, and here and there a solitary antelope. In some of the wadeys there were a great many fragments of the ostrich egg. Clapperton and Mahomet ben Hadje went a long way out of the tract. They followed the footsteps of some camels, and went on ahead of us. Our road lay in a different direction from theirs : we were therefore separated a considerable distance from each other. When we saw no appearance of them we halted, and sent the servants in search. The moment was trying : they were in the midst of sand hills, without provisions or water; but, luckily, it was not long ; our searchers soon detected them from the heights. About mid-day halted in a valley, and remained under the shade of some date trees for a few hours. Set out again in the afternoon. The heat was oppressive, and our travelling was difficult. We next came to an extensive level plain, which was some refreshment; for we were completely tired of ascending and descending sand hills. Our servants strayed; they went on a tract which was pointed out to them as the right one, and, before we were aware of the error, they went so far that we were not able to send after them. They, as well as ourselves, thought the town was near, and they went with the intention of getting in before us. We felt exceedingly uneasy respecting them, as they might so easily lose themselves in such intricate travelling. We halted in low spirits, and, after a little refreshment, went to sleep with heavy hearts.

Wednesday, July 3.- Strong breeze in the night. Our trunks and bedclothes were all covered with sand in the morning. We heard nothing of our servants, and consoled ourselves that they had found some place before now. We commenced our journey early. The hills of wadey Shiati were seen stretching east and west, and the date palms in several groves; but between us and them some high sand hills were seen. We wished our old guide to take us a more direct course, as we conceived; but, notwithstanding our desire and even threats, he persevered in having his way; and, to do the old man 
justice, we afterwards found it would have been almost impossible for the camels to have gone the way we wished. After passing the base of some high sand hills, we came to a stony pass, of gentle descent, covered with loose fragments of quartz rock, a yellowish feltspar, and iron ore, very similar to the rocks in the Sebah district. From this place the town opened to our view. It is erected on a hill about three hundred feet high. This stands in the middle of the valley nearly, and has the appearance, at a distance, of a hill studded. over with basaltic columns. I had no idea the town was built on the hill, and, consequently, that the deception was produced by it. The approach from this side is over large plains of salt, and through fields of gomah and date groves. The different divisions of the fields did not appear to us so neat as near other towns; but that may be owing to the grain having mostly been cut and all in. There is no necessity here for wells, as there are a number of springs near the surface that open into large basins, from which channels are cut to the different fields. Temperature of the water 30 cent.; but the basins are so exposed, and so large, that the temperature of the water is influenced by the soil and sun's rays.

The soil is dark, and mixed with a large quantity of salt. In the salt plain here there are a number of small conical hills, the base composed of pipeclay, above that of a fine grained yellow sandstone, and the top a conglomerate, the principal ingredient of which is ironstone.

The most of the inhabitants soon visited us, and all appeared pleased at our arrival. The kadi of the two neighbouring towns paid us many compliments, and pressed us hard to spend a few days in his towns. We could not take advantage of his offer, which was no doubt of a selfish nature; for I had not conversed long with him before he began to beg a shirt. I told him mine could be of no use to him, as it was very different from those of the country. On that he asked for a dollar to buy one, which I took care to refuse ; and said to him, that I only gave presents of money to the poor. The people made numerous urgent demands for medicines; and, in a very short time, our large tent was surrounded with sick: the female part formed the majority. Some beautiful faces and forms were clothed in rags: the plaited hair and necks of these even were loaded with ornaments. The physiognomy of the women, as well as of the men, is of two kinds, - that of the Bedouin Arab and Fezzaneer, with mixtures also which it would puzzle a 
physiognomist to discover and describe. The females are rather under the middle stature, stoutly built, and possess considerable vivacity and liveliness : complexion of those not much exposed to the sun of a dirty white.

Thursday, July 4.-Numbers of patients greatly augmented, and several of the applicants brought small presents for medicines, such as a bowl of libau. I was also applied to in a new capacity - that of a charm writer. A man came and offered me two fowls if I would give him a charm for a disease of the belly ; but I was obliged to decline the office of charm writer, and confine myself to cure diseases by medicine. A buxom widow applied for medicine to get her a husband. It is not good to pretend ignorance: I therefore told her I had no such medicine along with me. The same worthy personage took my friend Clapperton for an old man-from his light coloured beard and mustachiosto my great amusement, and his chagrin. He had prided himself on the strength and bushiness of his beard, and was not a little hurt that light colour should be taken as a mark of old age. None of them had ever seen a light coloured beard before, and all the old men dye their grey beards with henna, which gives them a colour approaching that of my friend.

We went a little before sunset to visit the town. The houses are of mud, and built on the sides of the hill. They appear as if one was pulled on another. The passages or streets between them are narrow, and, in two or three instances, exeavations through the rock. The exposed rocks denote the same composition as the insulated hills on the salt plain. The ascent was steep in some places, and we had to pass through the mosque before we arrived at the highest portion. From this we had a fine view of wadey Shiati in every direction. The wadey runs nearly east and west : in the former direction it is well inhabited as far as Oml'abeed : this is the westernmost town; and although, from this position, the soil appears favourable, there are no inhabitants between this and Ghadamis. A range of hills forms the northern boundary : these run as far as Ghadamis, and end easterly, in the hills about Oml'abeed. A low range forms the southern boundary; and between them and the wadey Ghrurbi all is sand. Many houses are in ruins, and many more are approaching to that state. Still it is called the new town, although its appearance little entitles it to that appellation; but the ancient inhabitants lived in excavations in the rocks, the remains of which are very distinct. We saw numerous recesses, but thought they were produced by the present race digging for pipe-clay, and the natural 
mouldering away of the soft rock. When we had finished our visit, we were told the former people lived in these holes. At the bottom of the hill we entered several, not much decayed by time. Most of them are oblong spaces, about ten or twelve feet long, and seven feet high. The entrances of all these had mouldered away very much. At a hundred yards, however, from the base of the hill, and now used as burying ground, there is a subterranean house of large dimensions, and probably the residence of the great personage. The entrance was more than half filled up with sand and small stones that had been thrown in. Clapperton and I entered, and found three extensive galleries, which communicated only by small openings, in passing through which we had to stoop considerably. But the galleries were high (nearly seven feet), and of considerable length (about 150 feet), and each had several small recesses, like sleeping rooms. The whole had neatness about it, and showed a taste in the excavators. There are no traces of similar abodes in Fezzan. The present race are entirely ignorant of the ancient occupiers. The people are so afraid, and so superstitious, that scarcely one of the town had ever entered it. They were astonished when we entered without ceremony; and two, encouraged by our example, brought us a light, by which we were enabled to look into the different recesses.

Saturday, July 6.-At 2.40. started with a beautiful moonlight, over a sandy plain, with a great many small hillocks. We stopped at Dalhoon, a well nearly filled up with sand, and containing water so brackish that we were unable to drink it. We started again, and got in among the sand hills. Our new guide proved neither such an active man nor experienced pilot as our old Tuarick, as we had several times to retrace our steps.

Monday, July 8.-We entered the wadey Trona early this morning, on the north-east side. Near where we entered there are a cluster of date palms, and a small lake, from which impure trona is obtained. On the western side the trona lake is surrounded with date trees, and its marshy borders are covered on almost all sides by grass, and a tall juncus. It is about half a mile long, and nearly two hundred yards wide. At present it is of inconsiderable depth, from the evaporation of the water ; for many places are dry now, which are covered in the winter and spring. The trona crystallizes at the bottom of the lake, when the water is sufficiently saturated; for when the water is in large quantities it eats the trona, as the people say. The cakes vary in thick- 
ness, from a fine film to several inches (two or three). The thickest at present is not more than three-fourths of an inch; but in the winter, when the water begins to increase, it is of the thickness I have mentioned. The surface next the ground is not unequal from crystallization, but rough to the feel, from numerous small rounded asperities. That next the water is generally found studded with numerous small, beautiful vertical crystals of muriate of soda ; the line of junction is always distinct, and the one is easily removed from the other. When not covered with muriate of soda, the upper surface shows a congeries of small tabular pieces joined in every position. When the mass is broken there is a fine display of reticular crystals, often finely radiated. The surface of the water is covered in many places with large thin sheets of salt, giving the whole the appearance of a lake partially frozen over: film after film forms, till the whole becomes of great thickness. Thus may be observed, on the same space, trona and cubical crystals of muriate of soda, and, on the surface of the water, films accumulating, till the whole amounts to a considerable thickness. The soil of the lake is a dark brown sand, approaching to black, of a viscid consistence, and slimy feel; and, on the lately uncovered surface of the banks, a black substance, something like mineral tar, is seen oozing out. The water begins to increase in the winter, and is at its height in the spring. In the beginning of the winter the trona is thickest and best, but in the spring it disappears entirely. The size of the lake has diminished considerably within the last nine years; and, if care be not taken, the diminution will soon be much more considerable; for plants are making rapid encroachments, and very shallow banks are observable in many places. On making inquiry, I found the quantity of trona has not sensibly diminished for the last ten years. Perhaps it may appear so from there always being sufficient to answer every demand. The quantity annually carried away amounts to between 400 and 500 camel loads, each amounting to about 4 cwt.,- - large quantity, when the size of the lake is taken into account. It is only removed from the lake when a demand comes. A man goes in, breaks it off' in large pieces, and those on the banks remove the extraneous matter, and pack it in large square bundles, and bind it up with the retecious substance observable on the roots of the leaves of the date tree, and, bound up in that way, it is taken to the different places, - the greatest to Tripoli, but a considerable quantity is consumed in Fezzan. The price of each load here is two dollars. The water in the valley is good, and 
very free from saline impregnation. The whole is taken care of by an old black Fezzaneer, Hadje Ali, an unassuming but sensible man. He treated us with every kindness, and showed the greatest readiness to give us every information. He resides here the whole year, and only comes up to Mourzuk occasionally to settle money affairs. When we asked him if he felt his residence solitary, he answered, he was now an old man, and he gained a comfortable livelihood by it, which he could not elsewhere. He possesses great energy ; and in his younger years few could cope with him. Since his charge of this place, which is about nine years, it happened Mukni wished more money. $\mathrm{He}$ told him decidedly he would give him no more, on which Mukni began to bluster in his usual manner. The old man quietly took up his staff and walked off. The matter was soon settled in the Hadje's favour; for he is, as our relators informed us, of only one speech; and Mukni, although he speaks harshly, has a good heart. The worms, so much used in Fezzan, are found in this lake in the spring. About twenty camels of the Waled Busafe were waiting for their loads.

Clapperton was sitting on the top of a high sand hill, and so pleased with the view, that he called out several times for me to dismount from my camel to enjoy the treat. The appearance was beautiful. A deep sandy valley, without vegetation, and containing only two large groves of date trees; within each a fine lake was enclosed. The contrast between the bare lofty sand hills, and the two insulated spots, was the great cause of the sensation of beauty. There is something pretty in a lake surrounded with date palms; but when every other object within the sphere of vision is dreary, the scene becomes doubly so.

The worms so celebrated in this kingdom are found in these lakes. They are small animals, almost invisible to the naked eye, and surrounded with a large quantity of gelatinous matter. They are of a reddish-brown colour, and have a strong slimy smell. When seen through a microscope, the head appears small and depressed, the eyes two large black spots, supported on two long peduncles; the body a row of rays on each side, like the fins of fishes, but probably perform the action of legs; they have a continual motion like the tail of fish.

These animalculæ abound in the spring; they are to be found at all times, but in particularly large quantities in high winds. They are caught in a long 


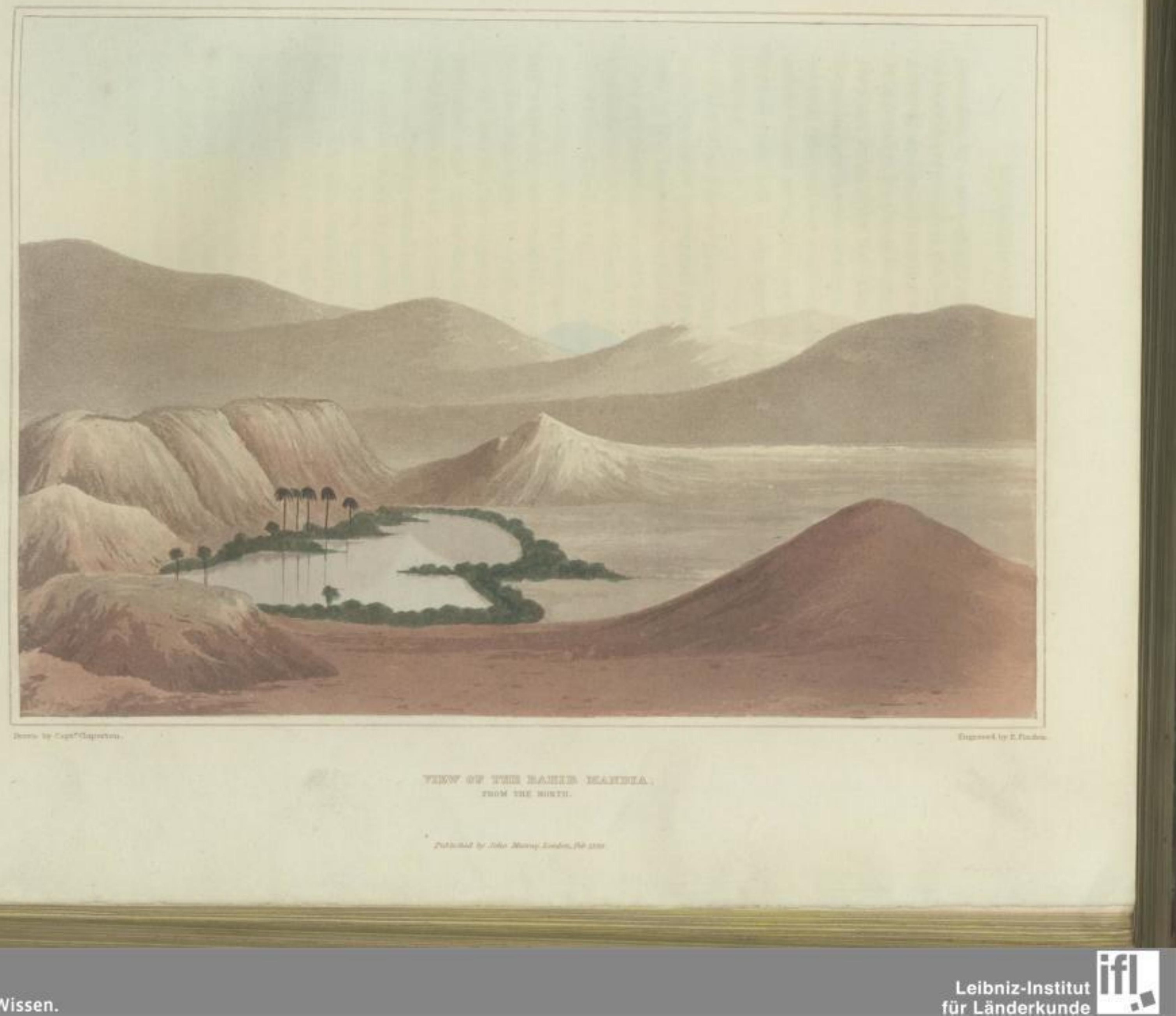


hand net, by a man going some way into the lake, and after allowing the net to remain some time at the bottom, it is taken up, or drawn a little along the ground; and in this manner several pints are sometimes caught at one time. It is found to be almost impossible to preserve them alive for a few hours after they are taken from the lake. An animal that evidently preys on them is found in considerable numbers. It is about an inch long, annulose, has six feet on each side, and two small corniform processes at the tail. It was past sunset before we saw any of the people of the town; but by the promise of a dollar, a small basin full of the insects was procured for us before daylight in the morning.

The other lakes of these worms are at two days' journey from this, situated in valleys almost inaccessible from the highness of the sand hills, and frequented only by the Dowedee, or men that fish for the insects only, at the riper season. They are placed in the sun's rays for a few hours to dry, and in that state sell at a high rate in the different towns in Fezzan.

Wednesday, July 10. We departed at sunrise, and had a much more pleasant journey. The tract was much more free from sand hills, although some of a great height were observable on each side.

The sheikh was very civil, and all our wants were speedily supplied.

We had two marriages to-night. The brides were brought out on a camel, decorated with gaudy dresses, and concealed from public view by awnings. Both brides were on one camel, for the purpose, we were told, of saving expense. Another camel went behind, for receiving the presents of the people, as wheat or barley, by which a feast is made. They went a considerable distance from the town, surrounded by almost all the inhabitants, both male and female. The men, dressed in their best, amused themselves firing muskets and pistols, while the women were singing. The musicians preceded the procession, and exhibited signs of having paid their devotions to Bacchus. They were nearly two hours amusing themselves, before the brides were carried home to their husbands' houses. The ceremony was announced by the yelling of the women, and the discharge of musketry.

Friday, July 12. We departed early in the morning, and arrived about mid-day at Oubari, where we were obliged to remain a day, for the camel men to arrange their affairs, and rest their camels, 
Tuesday, July 16 . We had directed the camels to be brought before daylight; but it was after sunrise when they made their appearance. After six we departed. Our course was over a level gravelly valley, with the mountains to the south, and sand hills to the north. The tulloh trees in abundance; some large patches of calcareous crust. We were accompanied by Mahomet, a black Tuarick, that resides in the vicinity of Biar Hadje Ahmut. Halted at Biar.

Wednesday, July 17. Early in the forenoon, a kafila of Tuaricks, most of them Hadjes, arrived from Ghraat. Hateeta rose to salute them, and paid them great respect. One was a maraboot, much respected by the Tuaricks. $\mathrm{He}$ is an oldish man, of pleasing countenance and free manner. They were muffled up to near the eyes; but they talked freely with us, and appeared a little prepossessed in our favour; no doubt from the account Hateeta had given them. One was able to give some account of the Targee letters; but no information on the ancient history of his nation. They were anxious we should profess Islamism; but it was only the lips, not the heart they wished to make any impression on. It is sufficient if a man says, "There is no God but one, and Mahomet is his prophet," and goes through a few forms of prayers. There is some pleasure in beholding a number at one and the same time at their devotions; but when reason is called into action, when the whole is considered as outward show, the beauty and the loveliness lose themselves.

Thursdoy, July 18. Started, an hour before sunrise. Our course the same as yesterday, over a wide level valley, bounded by the same mountain range, which all along forms shallow bays with bluff extremities. Tops of the hills level. Almost the whole range, from Biar Hadje Ahmut, as free from inequality as the valley. Scattered acacias mostly in flower, and large drops of fine gum arabic hanging from the branches. Notwithstanding the strong prickles, the camels browse on this tree with great avidity and rapidity, and apparently little inconvenience.

Friday, July 19. Form of hills becoming a little different; in place of the regulartable tops, peaks and rugged inequalities are making their appearance. At an hour after sunset halted in Wadey Elfoo, or Valley of Cool Breezes. This was a long and fatiguing day for us. We travelled from sunrise till near eight o'clock, and advanced twenty-nine miles without halting. The mid-day heat 
was oppressive; but would have been doubly so, had it not been for fine cool breezes. The heat, since we left Mourzuk, has generally been moderated by a fine breeze springing up about eight or nine in the morning, and following the sun's course. It came at times in strong puffs; and according to the state of the skin, appeared cold or hot. When perspiring, cold; when dry, hot. The idea of the want of water made us perhaps more desirous of it. The distance from the one well to the other is four days, which at this season is not small.

Saturday, July 20. Tract, almost entirely destitute of vegetation, till mid-day. Our course among low hills of sandstone and claystone. Here we arrived at a beautiful small wadey, winding among the hills; the last, we are told, we come to, till we arrive at Ludinat. The hills are taking a more southerly direction. We were told they run a considerable distance in the Soudan road, take a bend to the eastward, and pass into the Tibboo country, and down to near Bornou. It is along these hills the Tuaricks make their ghrassies into the Tibboo country. These two nations are almost always at war, and reciprocally annoy each other by a predatory warfare, stealing camels, slaves, \&c. killing only when resistance is made, and never making prisoners.

Monday, July 21. About half an hour before sunrise, resumed our journey. We came to alum slate hills, and early in the morning passed a small conical hill called Boukra, or Father of the Foot, where the people of kafilas passing amuse themselves by hopping overit ; and he who does that best, is considered least exhausted by the journey. Near this there are a few hills, among which a serpent as large as a camel is said to reside. The Targee is superstitious and credulous in the extreme; every hill and cave has something fabulous connected with it. About mid-day entered the boundaries of the Tuarick country. It is by a small narrow pass over alum slate hills into a sterile sandy valley. At a distance the Tuarick hills, running north and south, not table-topped like those we have left, but rising in numerous peaks and cones. There are here in the vicinity a number of sand hills; and all the valleys are bounded by low alum slate hills, and recently formed fixed sand hills. Sulphate of barytes in several places. About eight, arrived at Ludinat.

The name of the wadey is Sardalis. On a small eminence near us is an old ruinous building, foolishly thought by the people here to be of Jewish origin; although from its structure, it is evidently Arabian. A large spring issues from the middle, and pours out water sufficient to irrigate a large space 
of ground. It opens into a large basin; the temperature of the water is consequently influenced by the soil and the sun's rays. Abundant crops of grain might be reared by an industrious people; but the Tuaricks are no agriculturists, and the small cultivated spots are wrought by Fezzaneers. The Tuaricks of the country have a sovereign contempt for inhabitants of cities and cultivators of ground. They look upon them all as degenerated beings. A wide-spreading tree grows near this castle, under which gold is said to be deposited. The accounts are, that the father of the present maraboot, a man renowned for his sanctity, destroyed the writings that pointed out the place. The grave of this Mahometan saint is near, and so revered, that people passing deposit what they consider superfluous; and always find it safe on their return. Thus there is not to be found a Tuarick or Arab so courageous as to violate this sanctuary. The inhabitants are thinly scattered; and we could only observe here and there a few grass houses. The water of the spring is excellent. A few sheep are in the valley, and we were able to buy a tolerably good one from the maraboot.

Thursday, July 24. Camel men long in starting; it was near seven before we were on our journey. Passed near several springs, and on the bank of one found some beautiful bog iron ore. The west side of the wadey had the appearance of a rugged sea coast, and the exposed ledges of rock, that of the beach washed by the waves. The rock is a fine grained sandstone, lying on aluminous slate, which mouldering into dust by exposure to the weather, undermines the sandstone, and gives rise to the rugged appearance. It is rendered more dreary and awful by the black colour of the external surface. At a distance we took the whole to be a basaltic formation, and were not a little deceived on our examination. We entered a narrow pass with lofty rugged hills on each side ; some were peaked. The black colour of almost all with white streaks, gave them a sombre appearance. The external surface of this sandstone soon acquires a shining black like basalt: so much so, that $\mathrm{I}$-have several times been deceived, till I took up the specimen. The white part is from a shining white aluminous schistus, that separates into minute flakes like snow. The ground had in many places the appearance of being covered with snow. It blew a strong gale as we passed through the different windings; sand was tossed in every direction; the sky was sometimes obscured for several minutes. These, conjoined with the white of the ground and hills, brought forcibly to 
our minds a snow storm; but the hot wind as speedily convinced us of our error. The pass led to a valley, with a few tulloh trees; this we traversed, and soon entered on a large sandy plain, with the hills of Tadrart on the east, and the high sand hills on the west. This range has a most singular appearance; there is more of the picturesque in this, than in any hills we have ever seen. Let any one imagine ruinous cathedrals and castles; these we had in every position and of every form. It will not be astonishing, that an ignorant and superstitious people should associate these with something supernatural. That is the fact; some particular demon inhabits each. The cause of the appearance is the geological structure. In the distance, there is a hill more picturesque and higher than the others, called Gassur Janoun, or Devil's Castle. Between it and the range, there is a pass through which our course lies. Hateeta dreads this hill, and has told us many strange stories of wonderful sights having been seen : these he firmly believes; and is struck with horror, when we tell him we will visit it.

Friday, July 25. Kept the range of hills in the same direction. We were much amused by the great diversity of forms. One is called the Devil's House; and when Clapperton thought he perceived the smell of smoke last night, Hateeta immediately said that it was from the Devil's House. Another is called the Chest, and under it a large sum of money is supposed to have been deposited by the ancient people, who are said to have been giants of extraordinary stature. At a considerable distance to the southward, a part of the same range is seen taking to the westward, and is continued, we are told, as far as Tuat. Another branch is said to take a bend to the southward and eastward, and join the mountain range of Fezzan. About mid-day halted in the pass between the range and Devil's Castle.

Made an excursion to Janoun. Our servant Abdullah accompanied me. He kept at a respectable distance behind. When near the hill, he said in a pitiful tone, there is no road up. I told him we would endeavour to find one. The ascent was exceedingly difficult, and so strewed with stones, that we were only able to ascend one of the eminences : there we halted, and found it would be impossible to go higher, as beyond where we were was precipice. Abdullah got more bold, when he found there was nothing more than what is to be seen in any other mountain. The geological structure the same as the range that is near. When Hateeta found I was gone, he got amazingly alarmed; and 
Clapperton was not able to allay his fears: he was only soothed, when I returned. He was quite astonished I had seen nothing, and began relating what had happened to others.

On the 26th, about half an hour after sunset, arrived at Ghraat; and were soon visited by a number of Hateeta's relations, one of whom was his sister. Some were much affected, and wept at the sufferings that had detained him so long from them. A number of his male relations soon came, and many of the inhabitants of the town. The ladies were a free and lively set. They were not a little pleased with the grave manner we uttered the various complimentary expressions. Hateeta was not well pleased with something that he had heard. He told us not to be afraid; for he had numerous relations. We said that fear never entered our breasts, and begged him not to be uneasy on our account.

Saturday, July 27. Early in the morning numerous visitors paid their respects to Hateeta, and were introduced in due form to us. We felt the length of time spent in salutations quite fatiguing, and so absurd in our eyes, that we could scarcely at times retain our gravity. Our visitors were mostly residents of the city, and all were decorated in their best. There was a sedateness and gravity in the appearance of all, which the dress tended greatly to augment. There were three natives of Gadames, one of whom knew us through our worthy friend Mahomet D'Ghies; another we had seen in the house of Dr. Dickson; and the third was well acquainted with European manners, having been over at Leghorn.

In the afternoon we visited the sultan. Mats had been spread in the castle, in a small ante-chamber. The old man was seated, but rose up to receive us and welcome us to his city. He apologized for not waiting on us ; but said he was sick, and had been very little out for some time. He had guinea-worm, and a cataract was forming in his eyes. He was dressed in a nearly worn out tobe, and trowsers of the same colour; and round his head was wrapped an old piece of yellow coarse cloth for a turban. Notwithstanding the meanness of the dress, there was something pleasing and prepossessing in his countenance, and such a freeness as made us soon quite as much at home as if in our tents. We presented him with a sword, with which he was highly pleased. Hateeta wished it had been a bornouse; but we had none with us we considered sufficiently good. We were led away by the title, sultan. We had no idea the Tuaricks were so vain; 
for they used to be filling us with high notions of the wealth and greatness of the people here.

Our interview was highly interesting; and every one seemed much pleased with us. The old sultan showed us every kindness; and we had every reason to believe him sincere in his good wishes. After our visit we called at the house of Lameens, son of the kadi. He is a young man of excellent character, and universally respected. His father is now in Ghadames, arranging with some of the other principal inhabitants the affairs of the community. He had left directions with his son to show us every attention. His house was neatly fitted up, and carpets spread on a high bed, on which we seated ourselves. Several of the people who were in the castle came along with us, and by the assistance of those that could speak Arabic, we were able to keep up a tolerably good conversation. On inquiring about the Tuarick letters, we found the same sounds given them as we had before heard from others. We were here at the fountain head, but were disappointed in not being able to find a book in the Tuarick language ; they told us there was not one. Some only of the Tuaricks speak the Arabic. We were the more astonished to find this, when we considered the great intercourse between them and nations that speak Arabic only.

It was near sunset before we returned to our tents, which were now tolerably clear of visitors. All had retired to pray and eat. Stewed meat, bread, and soup, were again sent us by the sultan.

In the evening Hateeta's kinswomen returned. They were greatly amused, and laughed heartily at our blundering out a few Tuarick words. It may be well supposed we were very unfit companions for the ladies, as they could speak no other language than their own, and we knew very little of it. Still, however, we got on well, and were mutually pleased. I could scarcely refrain laughing several times at the grave manner Clapperton assumed. $\mathrm{He}$ had been tutored by Hateeta, and fully acted up to his instructions; no Tuarick could have done better. Our friend Hateeta was anxious we should shine, and read a number of lectures to Clapperton. He is naturally lively, and full of humour. He was directed not to laugh or sing, but look as grave as possible, which Hateeta said would be sure to please the grave Tuaricks. As for myself, I had a natural sedateness, which Hateeta thought would do. The liveliness of the women, their freeness with the men, and the marked attention 
the latter paid them, formed a striking contrast with other Mahommedan states. Thus the day passed over well, and we had every reason to be pleased with the demeanour of the people, and the attention they paid us.

Violent gale from the northward, which almost smothered us with sand.

About four we went to visit the spring we had heard so much about, and to make a circuit round the town. The water is contained in a large reservoir, surrounded with palm trees; and the banks are covered with rushes, except when the people go to draw water. There is not that bubbling up we saw in the spring of Shiati and Ludinat, but apparently an oozing from a large surface, as in those of Traghan. The water is clear, well tasted, and in abundance : a large extent of soil is supplied by it, through channels cut in the ground; and all the town is supplied from this place. Good water and plenty of it is a great blessing in every quarter of the globe, but much more in a hot climate. The people are sensible of it ; for you hear this place and that praised for the abundance of this water, and the healthiness of its quality; and you often hear them say that it does not engender bile, as the waters of such a place. Some small spots here are really beautiful, from the diversity of seenery in a small compass. Here and there patches of grass and beds of water melons, in the edge of the water channels, fine palms loaded with ripe fruit, small squares of gufolly and cassoub, and beautiful vines clinging tô the trees; in the brakes, the town and black tinted low hills. We observed platforms, of palm leaves, raised about five feet from the ground, for the purpose of sleeping, and defending the person from scorpions, which are very common.

We now came in sight of the town, and were well pleased with the appearance. The houses neat and clean; and the mosque, finer than any thing of the kind in Fezzan. All was neat and simple. It is built at the foot of a low hill, on the summit of which the former town stood; but it, as we were told, was destroyed, and the greater part of the inhabitants, by the giving way of the portion of hill on which it was erected. The hills, composed as those about here, are very apt to fall down in large masses. Indeed, none of the hills appear of their original height. It was not long since a large portion of a neighbouring mountain gave way, and the noise of its fall was heard at a great distance. When the melancholy event of the destruction of the town took place, we could not learn.

The town is surrounded with walls, in good repair, formed of sand and 
whitish clay, that gives a clean and lively appearance to the whole. There is only one gate opening to the east; formerly there were more, that are now blocked up. The houses are built of the same substance as the walls, and the external form and internal arrangement the same as those of Mourzuk and other Mahommedan towns. The town appears to be about the size of Oubari, and perhaps contains about 1000 inhabitants. The burying-ground is outside the town; it is divided into two departments, one for those arrived at maturity, the other for children, - a distinction not observable in Fezzan.

In our walk we fell in with a number of females, who had come out to see us. All were free and lively, and not at all deterred by the presence of the men. Several had fine features; but only one or two could be called beautiful. Many of the natives came out of their houses as we passed/along, and cordially welcomed us to their town. It was done in such a manner, that we could not but feel pleased and highly flattered.

In the evening we heard a numerous band of females singing at a distance, which was continued till near midnight. The women were principally those of the country. This custom is very common among the people, and is one of the principal amusements in the mountain recesses. Hateeta said they go out when their work is finished in the evening, and remain till near midnight in singing and telling stories, return home, take supper, and go to bed.

The language of the Tuaricks is harsh and guttural; but it has great strength, and is evidently expressive. That at least is the opinion we were led to form, with our imperfect knowledge. The want of books, and the little attention paid to cultivating a language, must tend to keep it in a very imperfect state. The sedate character of the Tuarick seems to be a firm barrier against the muses. The males seldom sing; it is considered an amusement fit only for females. Their songs were described to us as sweet. We never heard one repeating any poetical lines. The people have good sound sense, and give more distinct accounts of what they have seen than $I$ have received from the Moorish merchants. They would be a shining people, were they placed in more favourable situations. On almost every stone in places they frequent, the Tuarick characters are hewn out. It matters nothing whether the letters are written from the right to the left, or vice versa, or written horizontally. 
LETTERS,

+ Yet.
$\vdots$ Yuk.
$\because$ Yugh.
: Yow
A.
0 Yib.
0 Yes.
J Yim.
Э Yish.
/) Yill.

\# Yuz.

X Iz.

H

W Yew.

$\Lambda$ Yid.

$\boldsymbol{D}$ Yir.

$S$ Yei.

$\because$ Yigh.

/ Yin.

These characters will be sufficient to enable the learned to trace the connexion of the language with others that are now extinct. Here we have no opportunity of making inquiries into this important subject.

Note. The rest of the Journal, describing their return to Mourzuk, is wholly uninteresting, and is therefore omitted. 


\title{
RECENT DISCOVERIES
}

\author{
IN

\section{A F R I C A.}

\section{CHAPTER I.}

FROM MOURZUK TO KOUKA IN BORNOU.

ON the evening of the 29th of November we left Mourzuk, accompanied by nearly all those of the town, who could muster a horse : the camels had moved early in the day, and at Zezow we found the tents pitched-there are here merely a few huts. From Zezow to Traghan there is a good high road, with frequent incrustations of salt, and we arrived there before noon. It is a clean walled town, one of the best of one hundred and nine, of which Fezzan is said to boast. Traghan was formerly as rich as Mourzuk, and was the capital and residence of a sultan, who governed the eastern part of Fezzan, whose castle, in ruins, may still be seen.

A maraboot, of great sanctity, is the principal person in Traghan, as his father was before him. During the reign of the present bashaw's father, when the Arab troops appeared before the town, the then maraboot and chief went out to meet them; and, from his own stores, paid sixty thousand dollars to prevent the property of his townspeople from being plundered. They make carpets here 
equal to those of Constantinople. There are some springs of good water in the gardens near the town, the only ones in Fezzan, it is said, except the tepid one at Hammam, near Sockna.

After being crammed, as it were, by the hospitality of the maraboot, we left Traghan for Maefen, an assemblage of date huts, with but one house. The road to this place lies over a mixture of sand and salt, having a curious and uncommon appearance: the surface is full of cracks, and in many places it has the effect of a new ploughed field: the clods are so hard, that it is with great difficulty they can be broken. The path by which all the animals move for some miles is a narrow space, or stripe, worn smooth, bearing a resemblance, both in hardness and appearance, to ice : near Maefen, it assumes a new and more beautiful shape, the cracks are larger, and from the sides of cavities several feet deep hang beautiful crystals, from beds of frost of the purest white*. I broke off a large mass, but the interior was as brittle as the exterior' was difficult to break; the frost work was fine salt, and fell away in flakes on being lightly shaken. It extends more than twenty miles, east and west. The water of Maefen, though strongly tinctured with soda, is not disagreeable to the taste, or unwholesome.

Quitting Maefen, we quickly entered on a desert plain; and, after a dreary fourteen hours march for camels, we arrived at Mes-

* The surface is of a dark colour, with here and there patches and streaks of a snowy white. It is uneven from the heaping, as it were, of large flat clods on each other: these are all hollow underneath, and have a very uneven surface, from the number of projections. What $I$ have remarked was observed in all the salt fields we have seen. The heaping of the salty clods, and the circulation of air underneath, are phenonema attending this formation which it is difficult to explain-Are they the production of art, or of nature alone? In the numerous gardens at Traghan, and other places left fallow, we observe, on the small scale, an appearance like this, and the earthy clods soon became strongly impregnated with salt: the degree is not comparable to what is seen in the large salt plain. The salt is of two kinds; one a white snowy-looking efflorescence, that is often several inches thick, the other with an earthy-coloured shining surface, $-W$. O. 
toola, a maten, or resting place, where the camels find some little grazing from a plant called Ahgul. Starting at sun-rise, we had another fatiguing day over the same kind of desert, without, I think, seeing one living thing that did not belong to our kafila-not a bird, or even an insect : the sand is beautifully fine, round, and red. We now arrived at Gatrone. The Arabs watch for a sight of the high date trees, which surround this town, as sailors look for land; and after discovering these landmarks, they shape their course accordingly.

I here joined my companions, whom I found in a state of health but ill calculated for undertaking a long and tedious journey. During my stay at Mourzuk, I had suffered from a severe attack of fever, which had kept me for ten days in my bed; and although considerably debilitated, yet was I strong in comparison with my associates. Doctor Oudney was suffering much from his cough, and still complaining of his chest. Mr. Clapperton's ague had not left him, and Hillman had been twice attacked so violently as to be given over by the doctor. We all, however, looked forward anxiously to proceeding, and fancied that change of scene and warmer weather would bring us all round. Gatrone is not unpleasingly situated: it is surrounded by sandhills, and mounds of earth covered with a small tree, called athali. Huts are built all round the town for the Tibboos.

Though encamped on the south side of the town, we had cold north and north-east winds, and the thermometer in the tent was from 43 to 45 in the mornings. The person of the greatest importance at Gatrone is one Hagi-el-Raschid, a large proprietor and a maraboot. He is a man of very clear understanding and amiable manners, and as he uses the superstition of the people as the means of making them happy and turning them from vicious pursuits, one becomes almost reconciled to an impostor.

Much necessary arrangement had been made here by laying in в 2 
a stock of dates, \&c. for our long journey : and at eleven A. M. we left Gatrone. The maraboot accompanied Boo-Khaloom outside the town, and having drawn, not a magic circle, but a parallelogram, on the sand, with his wand he wrote in it certain words of great import from the Koran; the crowd looking on in silent astonishment, while he assumed a manner both graceful and imposing, so as to make it impossible for any one to feel at all inclined to ridieule his motions. When he had finished repeating the fatah aloud, he invited us singly to ride through the spot he had consecrated, and, having obeyed him, we silently proceeded on our journey, without even repeating an adieu.

We passed a small nest of huts on the road, prettily situated, called El-Bahhi, from whence the women of the place followed us with songs for several miles. Having halted at Medroosa, we moved on the next morning, and leaving an Arab castle to the south-east, and some table-top hills, bearing south and by east, we arrived at Kasrowa by three in the afternoon.

Kasrowa has tumuli of some height all round the town, covered with the plant athali, and there is a well of good water : a road from hence branches off to the south-east, which goes to Kanem and Waday. It is also said to be the shortest road to Bornou, but there is a great searcity of water.

On the 9 th, we were to arrive at Tegerhy; and the Arabs commenced skirmishing as soon as we came within sight of it, and kept it up in front of the town for half an hour after our arrival.

We were here to halt for a day or two, for the purpose of taking in the remainder of our dates and provisions, and never was halt more acceptable. Hillman, our carpenter, and two of our servants, were really too ill to be moved; two of them had fevers, and one the ague. Hillman had been so weakened by previous attacks, as to be lifted on and off his mule: indeed we were all sickly. Doctor Oudney's complaint in his chest, and his cough, had gradually become worse; 


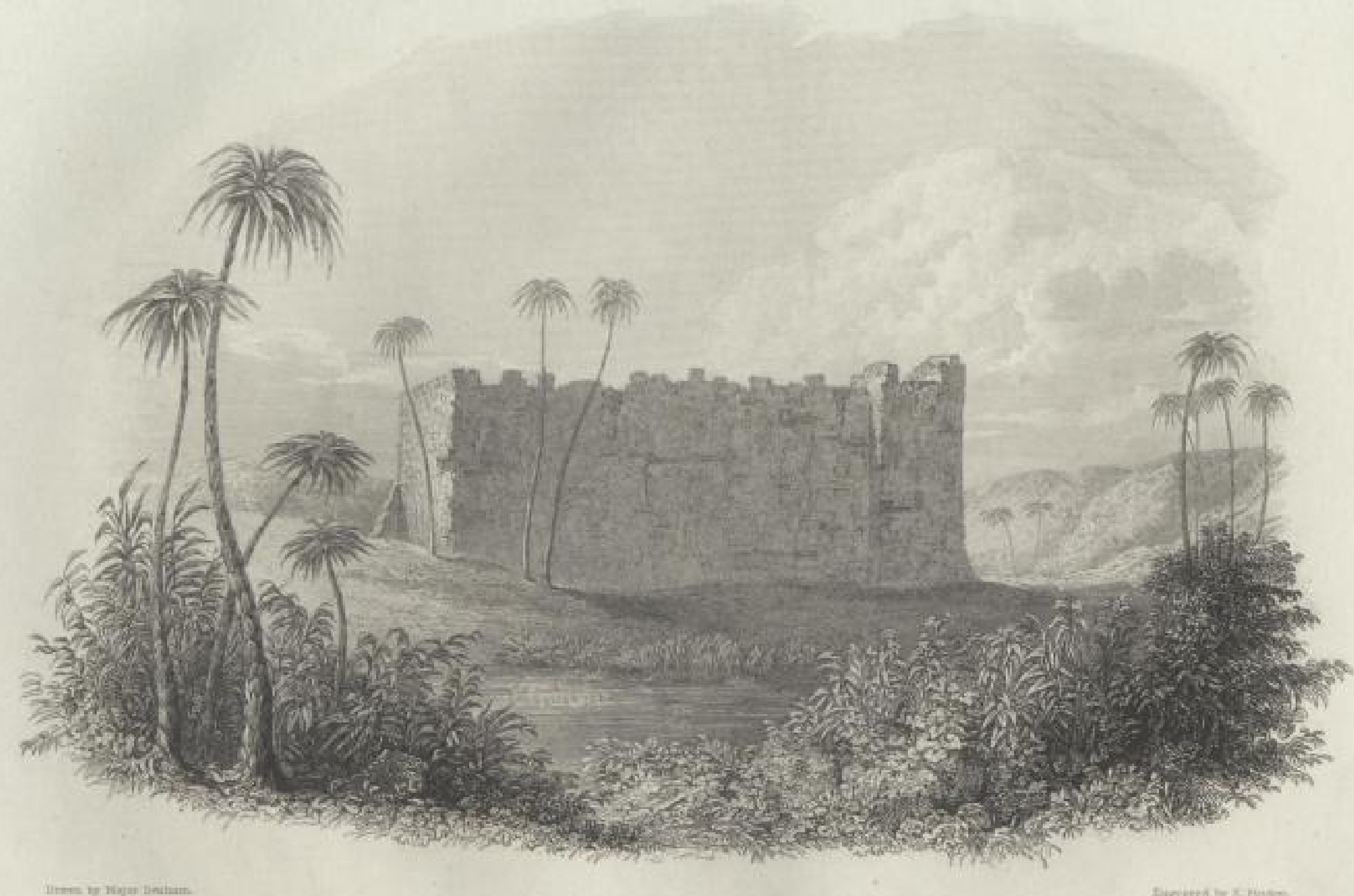

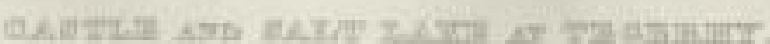

7 SLUB

Wir führen Wissen.

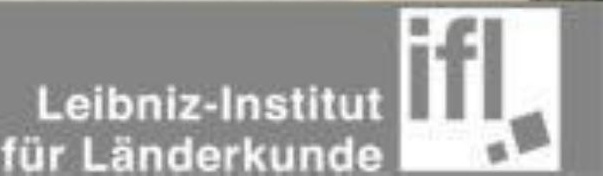


and going only a few hundred yards to see a dome date tree so fatigued him that, after lying down, he was obliged to return, supported by Mr. Clapperton. As our servants were all ill, one of the negro women made us a mess of kouscasou, with some preserved fat, which had been prepared in Mourzuk : it was a sorry meal, for the fat was rancid; and although tired, and not very strong, I could not refuse an invitation, about nine at night, after I had lain down to sleep, to eat camel's heart with Boo-Khaloom : it was wofully hard and tough, and I suffered the next morning from indulging too much at the feast.

The Tibboos and Arabs kept us awake half the night with their singing and dancing, in consequence of the bousafer, or feast, on entering the Tibboo country. Boo-Khaloom gave two camels, and we gave one. Our sick seemed to gain a little strength; and as we had succeeded in purchasing a sheep, a little soup seemed to revive them much; but we feared that Hillman and one of the servants must be left behind. However distressing would such an event have been, it was impossible for men who could not sit upright on a mule to commence a journey of fifteen days over a desert, during which travellers are obliged to march from sunrise until dark.

The 12th December was a beautifully mild morning, the thermometer at eight being at 56 . After breakfast, all seemed revived; but it was with pain I observed the exceeding weakness of Doctor Oudney and Hillman. I managed to get a sketch of the castle of Tegerhy from the south side of a salt pool close to the town; the entrance to which is small, low, and arched, something resembling a sally-port : within a second wall and gateway, there are loop-holes which would render the entrance by the narrow passage before mentioned extremely difficult : above the second gateway, there is also an opening from whence missiles and firebrands, of which the Arabs formerly made great use, might be poured on the assailants. Wells of water are within the walls, and tolerably good; and with supplies, 
when in a state of repair, I have no doubt Tegerhy might make a very good defence.

The sultans of Fezzan probably think that the only means of keeping these people in order is by keeping them poor. Their only produce is dates, but thoșe are of excellent quality. No vegetables are raised here, and we could not even procure an onion. Almost every town in Africa has its charm or wonder, and Tegerhy is not without one. There is a well just outside the castle gates, the water of which, we were told most gravely, "always rose when a kafila was coming near the town! that the inhabitants always prepared what they had to sell on seeing this water increase in bulk, for it never deceived them !"-In proof of this assertion, they pointed out to me how much higher the water had been previous to our arrival than it was at the moment we were standing on the brink. This I could have explained by the number of camels that had drank at it, but I saw it was better policy to believe what every body allowed to be true: even Boo-Khaloom exclaimed, "Allah! God is great, powerful, and wise! How wonderful! Oh!" Over the inner gate of the castle there is a large hole through to the gateway underneath, and they tell a story of a woman dropping from thence a stone on the head of some leader who had gained the outer wall, giving him, by that means, the death of Abimelech in sacred history.

The situation of Tegerhy is rather pleasing than otherwise: it is surrounded by date trees, and the water is excellent; a range of low hills extends to the eastward ; and snipes, wild-ducks, and geese, frequent the salt-pools, which are near the town. The natives are quite black, but have not the negro face: the men are slim, very plain, with high cheek bones, the negro nose, large mouth, teeth much stained by the quantity of tobaceo and trona (or muriate of soda) which they eat; and even snuff, when given to them, goes directly into their mouths.

The young girls are most of them pretty, but less so than those 
of Gatrone. The men always carry two daggers, one about eighteen inches, and the other six inches, the latter of which is attached to a ring and worn on the arm or wrist. A Tibboo once told me, pointing to the long one, "this is my gun; and this," showing the smaller of the two, " is my pistol." The women make baskets and drinkingbowls of palm leaves with great neatness.

On the 13th, we left Tegerhy, and proceeded on the desert: it was scattered with mounds of earth and sand, covered with athila (a plant the camels eat with avidity), and other shrubs. After travelling six miles we arrived at a well called Omah, where our tents were pitched, and here we halted three days. On the 16th, after clearing the palm trees, by which Omah is surrounded, we proceeded on the desert. About nine we had a slight shower of rain. At three in the afternoon, we came to a halt at Ghad, after travelling ten miles. Near the wells of Omah, numbers of human skeletons, or parts of skeletons, lay scattered on the sands. Hillman, who had suffered dreadfully since leaving Tegerhy, was greatly shocked at these whitened skulls, and unhallowed remains; so much so, as to want all the encouragement I could administer to him.

Dec. 17.-We continued our course over a stony plain, without the least appearance of vegetation. Coarse opal and sand-stone* strewed the path. We saw Alowere-Seghrir, a ridge of hills, bearing east by south; Alowere-El-Kebir, a still higher ridge, lies more

* The sand of a fine cream colour: yesterday it had many particles of a black substance mixed with it.

Exposed rocks, sandstone of different kinds, mostly red, and a black kind like basalt from iron; fine specimens of petrified wood; the centre, sap, vessels and knots filled with a calcareous matter, the woody fibre changed into a siliceous substance; beautiful conical layers, and lines running like rays, from the centre to the circumference. Many columnar mounds of clay in the first basin, about ten feet high-the clay as if semi-baked : many are round, and the one we went to about thirty feet in circumference; these were probably the original height of the surface : the present form arises from the other part being washed away. 


\section{to the east, but was not visible. These, by the accounts of the natives, are the highest mountains in the Tibboo country, with the}

The depth of the well at Meshroo is from sixteen to twenty feet : the water good, and free from saline impregnations: the ground around is strewed with human skeletons, the slaves who have arrived exhausted with thirst and fatigue. The horrid consequences of the slave trade were strongly brought to our mind; and, although its horrors are not equal to those of the European trade, still they are sufficient to call up every sympathy, and rouse up every spark of humanity. They are dragged over deserts, water often fails, and provisions scarcely provided for the long and dreary journey. The Moors ascribe the numbers to the cruelty of the Tibboo traders : there is, perhaps, too much truth in the accusation. Every few miles a skeleton was seen through the whole day ; some were partially covered with sand, others with only a small mound, formed by the wind: one hand often lay under the head, and frequently both, as if in the act of compressing the head. The skin and membranous substance all shrivel up, and dry from the state of the air: the thick muscular and internal parts only decay.

Course through basins, having low, rugged, conical hills to the eastward. The hills have a great similarity of geological structure to those of western Fezzan and Ghraat.

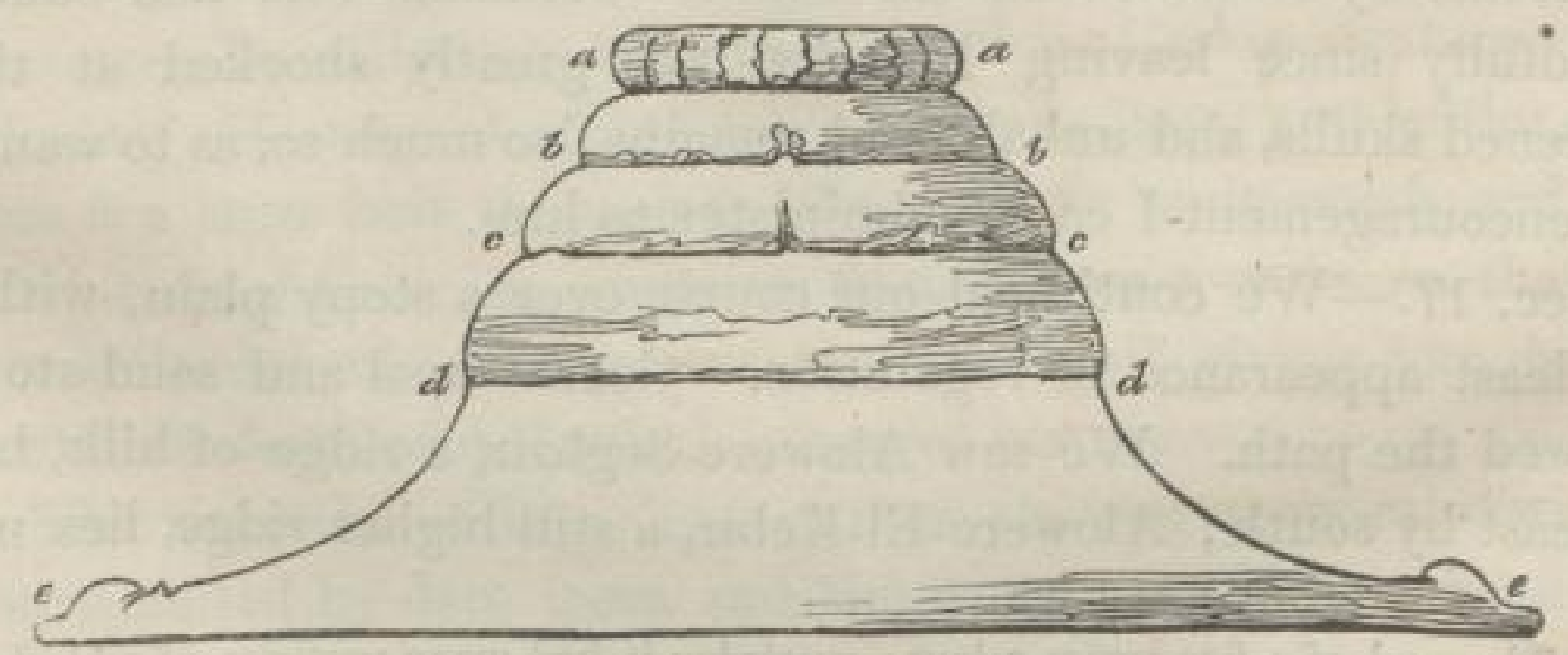

$a b$ Sandstone of fine texture, of a black colour, giving it the appearance of basalt.

c Aluminous shistus.

d Clay iron stone, with here and there strata of bluish clay.

e Fine white sandstone, mixed with a large quantity of lime.

There is a fine blue, very hard stone, with slender white lime streaks, forming the surface of many of the lower grounds, evidently of recent formation. A similar formation is seen in the large sterile plain between the hills of Fezzan to the westward, and the Tuarick range: the fine white sandstone is found deep in the same hills; the aluminous slate in 
exception of Ercherdat Erner. More to the south, the inhabitants are called Tibboo-Irchad (the Tibboos of the rocks). Through passes in both these mountains, the road lies to Kanem. About sunset, we halted near a well, within a half mile of Meshroo. Round this spot were lying more than one hundred skeletons, some of them with the skin still remaining attached to the bones-not even a little sand thrown over them. The Arabs laughed heartily at my expression of horror, and said, "they were only blacks, nam boo ?" (damn their fathers!) and began knocking about the limbs with the butt end of their firelocks, saying, "This was a woman! This was a

abundance. The kind of sandstone, the other rocks and similarity of appearance, show a sameness of geological structure as far as we have gone.

From a fine pass between two of the hills, the view from above had something of the grand. A rocky and sandy space, about two hundred yards broad, bounded on each side by a high rugged black hill, below a fine level plain, with low hills in the distance. The descent of the camels fine, and accomplished without an accident.

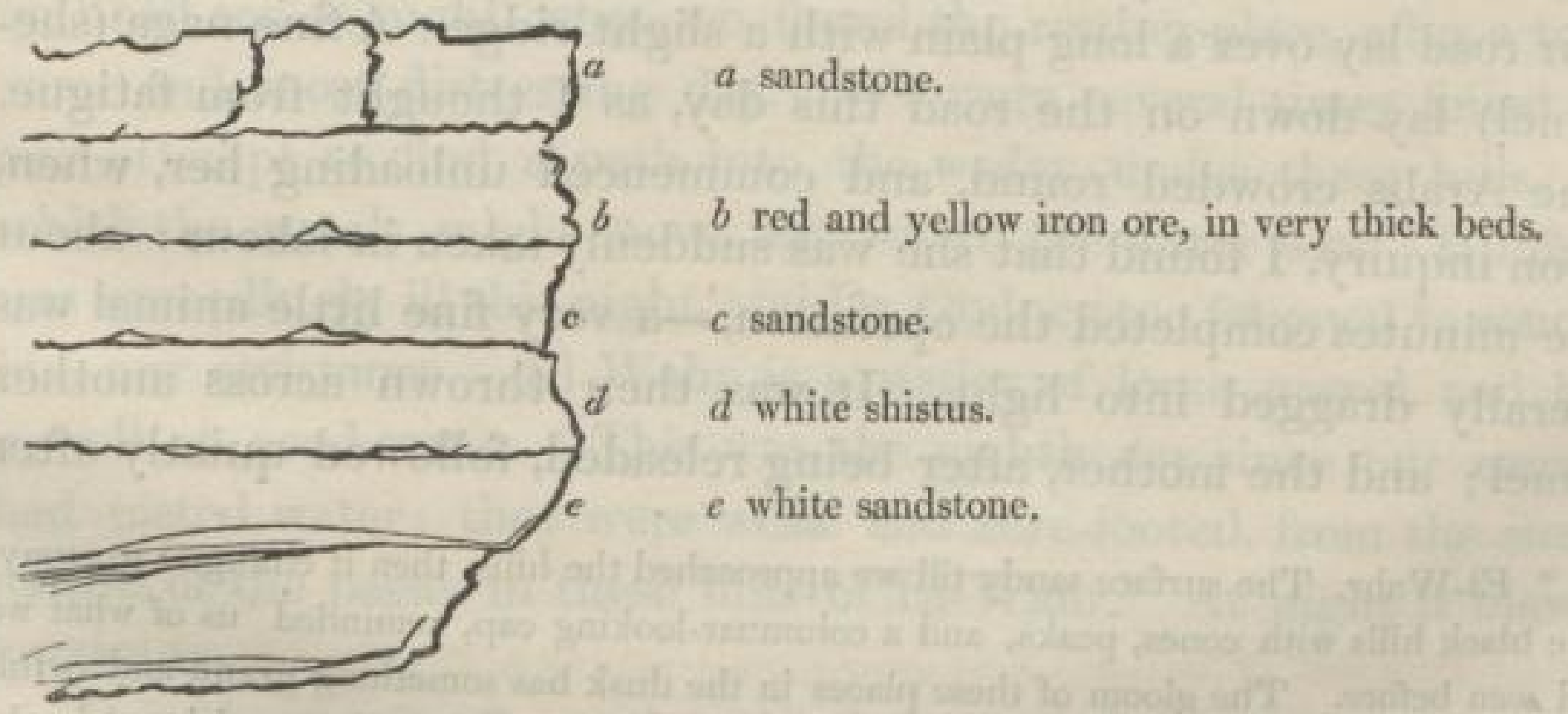

The surface of the plain has -strata of a slatiform blue stone; frequently, however, massive, and so hard as not to be scratched by iron; imbedded in it is a large quantity of periform iron ore. After traversing this plain, we ascended a low hilly range, and passed across its stony surface. From here we saw El-Wahr, or Difficult: it is between two high hills. We passed many skeletons, both of human beings and camels, which always kept us in mind of the dangers we were exposed to.-W. O. 
youngster!" and such like unfeeling expressions. The greater part of the unhappy people, of whom these were the remains, had formed the spoils of the sultan of Fezzan the year before. I was assured that they had left Bornou with not above a quarter's allowance for each; and that more died from want than fatigue : they were marched off with chains round their necks and legs : the most robust only arrived in Fezzan in a very debilitated state, and were there fattened for the Tripoli slave market.

Our camels did not come up until it was quite dark, and we bivouacked in the midst of these unearthed remains of the victims of persecution and avarice, after a long day's journey of twenty-six miles, in the course of which, one of our party counted 107 of these skeletons.

Dec. 19*.-Moved round a winding pass to the west, and after an ascent of three hundred feet descended a sandy steep to the east. This was rather a picturesque spot, looking back upon Thenea Our road lay over a long plain with a slight ridge. A fine naga (shecamel) lay down on the road this day, as I thought from fatigue. The Arabs crowded round, and commenced unloading her, when, upon inquiry, I found that she was suddenly taken in labour: about five minutes completed the operation,- a very fine little animal was literally dragged into light. It was then thrown across another camel; and the mother, after being reloaded, followed quietly after

* El-Wahr. The surface sandy till we approached the hills, then it changed to stony. The black hills with cones, peaks, and a columnar-looking cap, reminded us of what we had seen before. The gloom of these places in the dusk has something grand and awful. We winded up, with the light of a moon not a quarter old, and that lessened by a cloudy sky. Some sandy and pebbly beds, as of a stream, and in one place high clayey banks, with iron ore underneath. Skeletons lay about, mangled in a shocking manner; here a leg, there an arm, fixed with their ligaments, at considerable distances from the trunk. What could have done this? Man forced by hunger, or the camels? The latter are very fond of chewing dried bones, but whether they ever do so to those with dried flesh on them, I cannot say.-W. $\mathbf{O}$. 
her offspring. One of the skeletons we passed to-day had a very fresh appearance; the beard was still hanging to the skin of the face, and the features were still discernible. A merchant, travelling with the kafila, suddenly exclaimed, "That was my slave! I left him behind four months ago, near this spot."-" Make haste! take him to the fsug" (market), said an Arab wag, "for fear any body else should claim him." We had no water, and a most fatiguing day.

Dec. 20 was also a dreary day of most uninteresting country; and it was 5. 30, when we arrived at the Hormut-el-Wahr. These were the highest hills we had seen since leaving Fezzan : the highest peak might be five or six hundred feet. They had a bold black appearance, and were a relief to the eye, after the long level we had quitted. We entered the pass, which is nearly two miles in width, and wound round some high hills to the south: the path was rugged and irregular in the extreme, and bordered by bold conical and table-topped detached hills. We blundered and stumbled on until ten at night, when we found the resting-place, after a toilsome and most distressing day. We were several times foiled in our attempt to find a path into the wadey, under these hills, by which the camels might move, and where the water was. Hillman was exceedingly ill this night, and Dr. Oudney too fatigued to render him any assistance. El-Wahr is a wadey of loose gravel, and has a well of good water. This was the eighth day since our camels had tasted water: they were weak and sore-footed, from the stony nature of the passes in these hills of El-Wahr. At night it blew a hurricane.

It is three miles from where we halted to the end of the wadey; where, to the west, there is a high hill called El-Baab. These hills extend away to the east, and form part of the range which are found near Tibesty, where they become higher and bolder. We had now a stony plain, with low hills of sand and gravel, till we

c 2 
reached El-Garha, which is a detached conical hill to the west, close to our road; and here we halted for the night*.

Dec. 22.-We moved before daylight, passing some rough sand hills, mixed with red stone, to the west, over a plain of fine gravel, and halted at the maten, called El-Hammar, close under a bluff head, which had been in view since quitting our encampment in the morning. Strict orders had been given this day for the camels to keep close up, and for the Arabs not to straggle-the Tibboo Arabs having been seen on the look out. During the last two days, we had passed on an average from sixty to eighty or ninety skeletons each day; but the numbers that lay about the wells at El-Hammar were countless : those of two women, whose perfect and regular teeth bespoke them young, were particularly shocking; their arms still remained clasped round each other as they had expired; although the flesh had long since perished by being exposed to the burning rays of the sun, and the blackened bones only left : the nails of the fingers, and some of the sinews of the hand, also remained; and part of the tongue of one of them still appeared through the teeth. We had now passed six days of desert without the slightest appearance of vegetation, and a little branch of the souak was brought me here as a comfort and curiosity. On the following day we had alternately plains of sand and loose gravel, and had a distant view of some hills to the west. While I was dozing on my horse about noon, overcome by the heat of the sun, which at that time of the day always shone with great power, I was suddenly awakened by a crashing under his feet, which startled me excessively. I found that my steed had, without any sensation of shame or alarm, stepped upon

* Several of our camels are drunk to-day: their eyes are heavy, and want animation; gait staggering, and every now and then, falling as a man in a state of intoxication. It arose from eating dates after drinking water; these probably pass into the spirituous fermentation in the stomach.-W. O. 
the perfect skeletons of two human beings, cracking their brittle bones under his feet, and, by one trip of his foot, separating a skull from the trunk, which rolled on like a ball before him This event gave me a sensation which it took some time to remove. My horse was for many days not looked upon with the same regard as formerly.

Dec. 24.-When the rains fall, which they do here in torrents in the season, a sort of grass quickly springs up many feet high. In passing the desert, a few remaining roots of this dried grass, which had been blown by the winds from Bodemam, were eagerly seized on by the Arabs, with eries of joy, for their hungry camels. The plain was this day covered with slight irregularities, and strewed with various coloured stones - thick beds of gypsum, stones resembling topazes, and pieces of calcareous spar, which, reflecting the rays of the setting-sun, displayed a most beautiful variety of tints. An incrustation of fine whiting lay in patches, at no great distance from the well : and soon after the sun had retired behind the hills to the west, we descended into a wadey, where about a dozen stunted bushes (not trees) of palm marked the spot where the water was to be found. Even these miserable bushes were a great relief to the eye, after the dreary sameness of the preceding days ; and at daybreak in the morning, I could not help smiling at seeing Hillman gazing at them with pleasure in his look, while he declared they reminded him of a valley near his own home in the West of England. The wells are situated under a ridge of low white hills of sandstone, called Mafrasben-Kasarettsa, where there are also beds and hills of limestone. The wells were so choked up with sand, that several cart-loads of it were removed previous to finding sufficient water; and even then the animals could not drink until near ten at night.

One of our nagas had this day her accouchement on the road; and we all looked forward to the milk which the Arabs assured us 
she had in abundance, and envied us not a little our morning draughts, which we were already quaffing in imagination. However, one of the "many slips between the cup and the lip" was to befall us. The poor thing suddenly fell, and as suddenly died: the exclamations of the Arabs were dreadful._." The evil eye ! the evil eye !" they all exclaimed-" She was sure to die, I knew it.""Well! if she had been mine, I would rather have lost a child, or three slaves!"- "God be praised! God is gxeat, powerful, and wise! those looks of the people are always fatal."

Dec. 25.-This was a beautiful mild morning : the thermometer 54. at 6. 30. Our skins were here filled with water which was not disagreeable, although strongly impregnated with sulphur. The camels moved at eight. The head of a range of high hills bore westsouth-west, called Tiggerindumma: they resemble in shape and structure those we had passed nearer : they extend to the west, as far as the Arooda, five days hence, where there is a well; and ten days beyond which is Ghraat. At the distance of four miles from Mafras, we came to a small wadey, where we saw the first dome date trees: they were full of fruit, though green. We continued winding amongst a nest of hills,--crossed two water-courses, in which were tulloh and dry grass (ashub), until seven. These hills are bold and picturesque, composed of black and coloured sandstone. No water.

Dec. 26*. -We emerged from the hills, and broke into a plain, 'extending to the east as far as the eye could reach; to the west, Tiggerindumma sweeps off, and forming nearly a semi-circle, appears again to the south, a very handsome range, though not exceeding

* Our road by the side of detached hills, and several small chains, having rocky and sandy windings among them. The detached hills were mostly conical, with fine columnar tops, as if capped with basalt,- all, however, was of sandstone. The sombre appearance and solitariness of the situations, the form of the hills, and the dreariness of nature around, gave a gloomy cast to every object, which the beauty and life of a large kafila could not eradicate. - W. $\mathbf{O}$. 
six hundred feet at any part in height. After passing between two low ridges of dark hills, we opened on a plain bounded with flattopped and conical hills, called La Gaba. We found pieces of iron ore this day, kidney-shaped, and of various other forms. We travelled till nine at night, when some of us were nearly falling from our horses with fatigue. After a narrow stony pass, we came to a halt in a wadey called Izhya.

Here we had a gale of wind from the north-east for three days. Our tents were nearly buried in sand, and we were obliged to roll ourselves up in blankets nearly the whole time.

Dec. 30.-Izhya is called by the Tibboos Yaat. There are here four wells, which resemble troughs cut in the sand, two or three feet deep ; and it is said, that by thus digging, water may be found in any part of the wadey. We were encamped nearly west of the wells, about one hundred yards between them and a raas, or head, which had been in sight for some time. This head is a land-mark to kafilas, coming in all directions, who wish to make the wadey. We passed Ametradumma about four hours; from which, to the north-west, is a wadey of palms, called Seggedem, with sweet water: here is generally a tribe of plundering Tibboos, who are always on the look out for small kafilas. No water.

Dec. 31.-A cold shivering morning. At 7. 30. thermometer 49., and we had a long day's march over a plain, varying but little from Izhya. The Arabs had no knowledge of the road; and the Tibboo guide was all we had to rely on. We kept on until late, when the Tibboo acknowledged he had lost the road, that the well was not far off, but where he knew not; we therefore halted under some low brown sandstone hills, and determined on waiting for the daylight. We lost a camel this day from fatigue. 
1823.

On the 1st January, after six miles' travelling, we came to the wadey Ikbar, and rested on the $2 \mathrm{~d}$. The Arabs here caught an hyæna (dhubba), and brought it to us: we, however, had no wish beyond looking at it. They then tied it to a tree, and shot at it until the poor animal was literally knocked to pieces. This was the most refreshing spot we had seen for many days; there were dome trees loaded with fruit, though not ripe, which lay in clusters, and grass in abundance; and I could have stayed here a week with pleasure, so reviving is the least appearance of cultivation, or rather a sprinkling of Nature's beauty, after the parching wilds of the long dreary desert we had passed.

Jan. 3.-Looking back with regret at leaving the few green branches in Ikbar, with nothing before us but the dark hills and sandy desert, we ascended slightly from the wadey, and leaving the hills of Ikbar, proceeded towards a prominent head in a low range to the east of our course, called Tummeraskumma, meaning " you'll soon drink water ;" and about two miles in advance, we halted just under a ridge of the same hills, after making twenty-four miles. Four camels knocked up during this day's march: on such oceasions the Arabs wait, in savage impatience, in the rear, with their knives in their hands, ready, on the signal of the owner, to plunge them into the poor animal, and tear off a portion of the flesh for their evening meal. We were obliged to kill two of them on the spot; the other two, it was hoped, would come up in the night. I attended the slaughter of one; and despatch being the order of the day, a knife is struck in the camel's heart while his head is turned to the east, and he dies almost in an instant; but before that instant expires, a dozen knives are thrust into different parts of the carcass, in order to carry off the choicest part of the flesh. The heart, considered as the greatest delicacy, is torn out, the skin stripped from the breast 


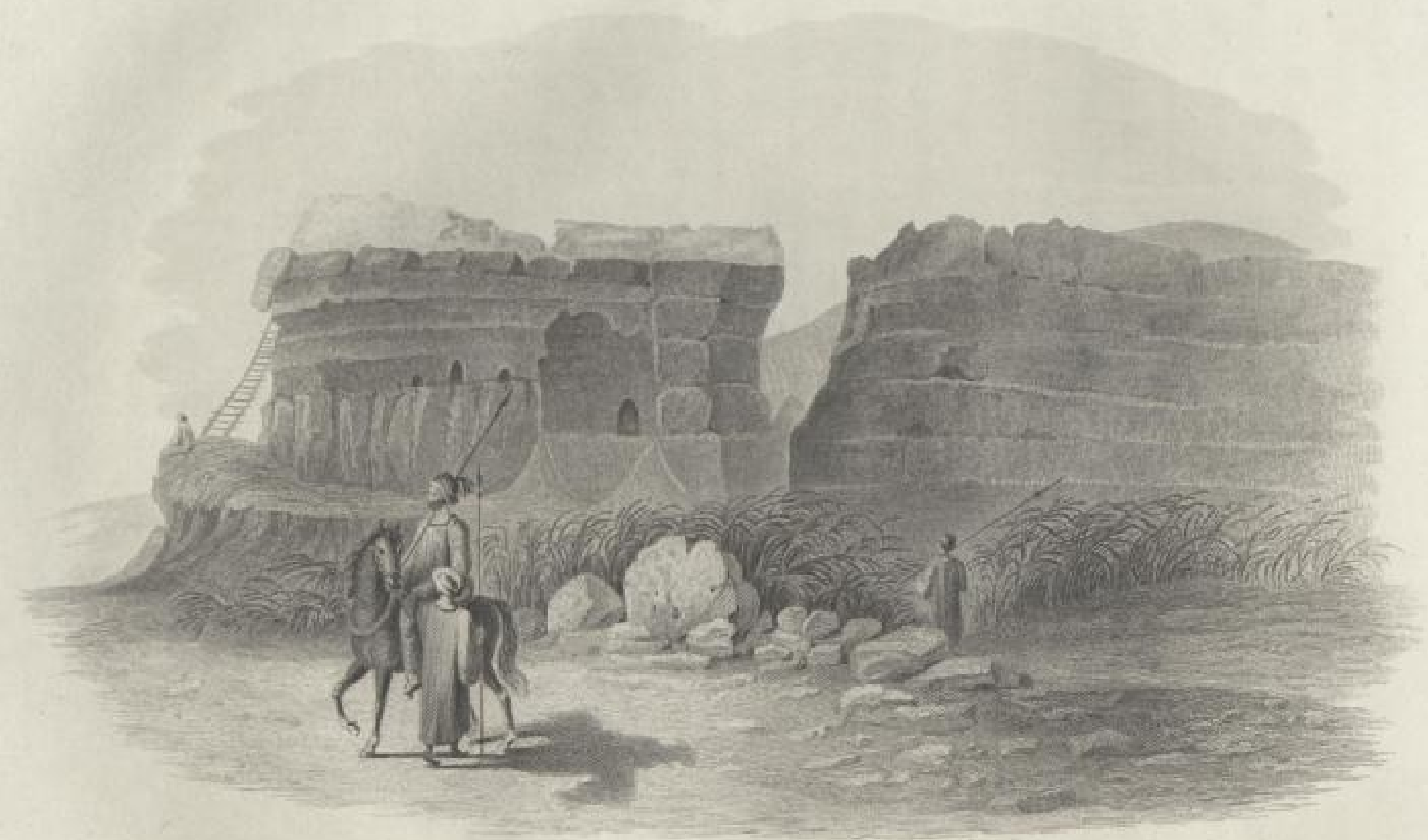

\section{SLUB}

Wir führen Wissen.

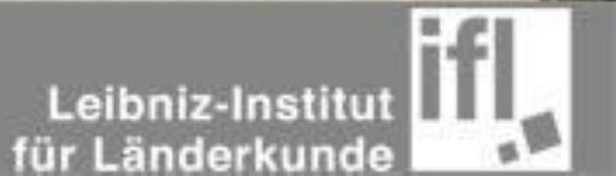


and haunches, part of the meat cut, or rather torn, from the bones, and thrust into bags, which they carry for the purpose; and the remainder of the carcass is left for the crows, vultures, and hyænas, while the Arabs quickly follow the kafila.

Jan. 4.-We crossed the ridge before us by eight this morning, and proceeded between a conical hill to the east and one to the west, called Gummaganumma. We had a fine open space of a mile in width between these hills, and about noon we came to a large mass of dark, soft sandstone, one hundred feet in height; about twenty yards from this stone is a rising well of water, only a few inches deep, and a sprinkling of coarse grass. Arabs call the spot "Irchat," Tibboos, "Anay." The sultan's army halted here two days, on its return from Begharmi.

The town of Anay consists of a few huts built on the top of a similar mass of stone to the one we had just left; round the base of the rock are also habitations, but their riches are always kept aloft. The Tuaricks annually, and sometimes oftener, pay them a most destructive visit, carrying off cattle and every thing they can lay their hands on. The people on these occasions take refuge at the top of the rock; they ascend by a rude ladder, which is drawn up after them; and as the sides of their citadel are always precipitous, they defend themselves with their missiles, and by rolling down stones on the assailants. The people who came out to meet us had each four short spears and one long one.

Jan. 5.-The Sultan Tibboo, whose territory extends from this place to Bilma, was visiting a town to the south-west of A nay, called Kisbee, and he requested Boo-Khaloom to halt there one day, promising to proceed with him to Bilma; we accordingly made Kisbee this day, distant five miles. Our animals got some pickings of dry grass.

Kisbee is a great place of rendezvous for all kafilas and merchants; and it is here that the sultan always takes his tribute for 
permission to pass through his country. It is eight days distant from Aghadis, twenty-four from Kashna, and, by good travelling by the nearest road, twenty-seven from Bornou*. The sultan had neither much majesty nor cleanliness of appearance : he came to BooKhaloom's tent accompanied by six or seven Tibboos, some of them really hideous. They take a quantity of snuff both in their mouths and noses; their teeth were of a deep yellow; the nose resembles nothing so much as a round lump of flesh stuck on the face; and the nostrils are so large, that their fingers go up as far as they will reach, in order to ensure the snuff an admission into the head. My watch, compass, and musical snuff-box, created but little astonishment; they looked at their own faces in the bright covers, and were most stupidly inattentive to what would have excited the wonder of almost any imagination, however savage : here was the " os sublime," but the "spiritus intus," the "mens divinior," was scarcely discoverable. Boo-Khaloom gave the sultan a fine scarlet bornouse, which seemed a little to animate his stupid features. We had a dance by Tibboo-men performed in front of our tents, in the evening: it is graceful and slow, but not so well adapted to the male as the female; it was succeeded by one performed by some free slaves from Soudan, who were living with the Tibboos, enjoying their liberty, as they said. It appears most violent exertion : one man is placed in the middle of a circle, which he endeavours to break, and each one whom he approaches throws him off, while he adds to the impetus by a leap, and ascends several feet from the ground:-when one has completed the round, another takes his place.

An Arab returned this evening, whom I had sent the night before for the purpose of finding a poodle dog which had accompanied me from Malta, and had remained behind from fatigue, the day we

* The Tibboos were positive as to this distance, which we could scarcely credit; they must mean, however, Tuarick days, or a maherhy, equal to forty miles at least. 
left Ikbar: he was unsuccessful, and said that some of the wandering Tibboos must have eaten him; he had found marks in the sand of the footsteps of these people, and the remains of the two camels we had left on the road were carried off: he traced their steps to the east, but was afraid to follow them. It is from these wanderers that small kafilas, or single merchants, have to dread attack. Generally speaking, the regular sheikhs are satisfied by levying a tax, while these are contented with nothing short of the whole.

Jan. 6.-At seven the thermometer was $42^{\circ}$ in the tent.-About five miles from Kisbee we left a wadey called Kilboo, by the Tibboos Trona to our left, and coming close under the ridge of hills at a point called Ametrigamma, we proceeded to Ashenumma, which is about four miles beyond, with the high hills to the east, and a very pleasing wadey to the west, producing palm and other trees. A violent disturbance arose this morning on the road among our Arabs ; one of them having shot a ball through the shirt of another of the Magarha tribe: the sheikh of the Magarha took up the quarrel, and the man saved himself from being punished, by hanging to the stirrup leather of my saddle. The Arab sheikh made use of some expressions in defending his man, which displeased Boo-Khaloom, who instantly knocked him off his horse, and his slaves soundly bastinadoed him.

Tiggema, near which we halted, is one of the highest points in the range, and hangs over the mud houses of the town : this point stands at the south extremity of the recess, which the hills here form, and is about four hundred feet high ; the sides are nearly perpendicular, and it is detached from the other hills by a chasm. On the approach of the Tuarieks the whole population flock to the top of these heights, with all their property, and make the best defence they can. The insides of some of the houses are neat and tidy; the men are generally travelling merchants, or rather pedlers, and probably do not pass more than four months in the year with their 
families, for the Tibboos rarely go beyond Bornou to the south, or Mourzuk to the north; they appeared light-hearted, and happy as people constantly in dread of such visitors as the Tuaricks can be, who spare neither age nor sex. A wadey, comparatively fertile, extends several miles parallel to the heights under which the village stands, producing dates and grass in abundance, and a salt water or trona lake is within two miles of them, in which are wild fowl. Mr. Clapperton shot two of the plover species, with spurs on their wings. A general caution was given for no person to go out of the circle after sunset.

Jan. $8^{*}$.- Our course was still under the range of hills, and at five miles distance we came to another town called Alighi, and two miles beyond that another called Tukumani: these towns were built to the south of, and sheltered by slight projections from, the hills under which they were placed. The people always came out to meet us, and when within about fifty paces of the horses, fell on their knees singing and beating a sort of drum, which always accompanies their rejoicing. To the west of both these towns is a salt lake resembling the one near Ashenumma, but rather smaller. We proceeded from hence nearly south-west, leaving the hills, and while resting under the shade of some gourd trees, which are here abundant, we had the agreeable, and to us very novel, sight of a drove of oxen : the bare idea of once more being in a country that afforded beef and pasture was consoling in the extreme, and the luxurious thought of fresh milk, wholesome food, and plenty, was most exhilarating to us all. At two we came to a halt at Dirkee. A good deal of powder was

* We passed two salt water lakes at a short distance on the west, which add much to the beauty of the scenery. There is something to-day quite cheering: large groves of palm trees, many beautiful acacias both in flower and fruit, and two fine, small salt lakes. The lakes are about two miles in circumference, have salt islands, and marshy borders: no salt, I believe, is taken from them. They are the abodes of a beautiful bird of the plover species.-W. $\mathbf{O}$. 
here expended in honour of the sultan, who again met us on our approach : his new scarlet bornouse was thrown over a filthy checked shirt, and his turban and cap, though once white, were rapidly approaching to the colour of the head they covered; when, however, the next morning his majesty condescended to ask me for a small piece of soap, these little negligences in his outward appearance were more easily accounted for.

We had rather a numerous assembly of females, who danced for some hours before the tents: some of their movements were not inelegant, and not unlike the Greek dances as they are represented. The sultan regaled us with cheese, and ground nuts from Soudan, the former of a pleasant flavour, but so hard that we were obliged to moisten it with water previous to eating. Dirkee is of a different description from the Tibboo towns we had seen: it stands in a wadey, is a mile in circumference, and it has two trona lakes, one to the east, and the other to the west. Of this saline substance an account will be found in the Appendix.-It is generally supposed that these lakes were originally caused by taking from the spot they now occupy the earth which was required for building the town, and its surrounding walls. Water, as we have before observed, is found in many parts of this country, at the depth of from six inches to six feet, and the soil near the surface, particularly in the neighbourhood of these Tibboo towns, is very powerfully impregnated by saline substances; so much so, that incrustations of pure, or nearly pure, trona are found sometimes extending several miles. The borders of these lakes have the same appearance : they are composed of a black mud, which almost as soon as exposed to the sun and air becomes crisp like fresh dug earth in a frosty morning. In the centre of each of these lakes is a solid body or island of trona, which the inhabitants say increases in size annually: the one in the lake to the east is probably fourteen or fifteen feet in height, and one hundred in circumference: the edges quite close to the water are 
solid, nor is there any appearance of mud or slime; it breaks off in firm pieces, but is easily reduced to powder*. There are several wells in the town of tolerably good water very slightly impregnated with the trona taste.

Dirkee, from its situation in the wadey, is more exposed to the attacks of the Tuaricks than the towns nearer the hills, and on this account, they say, it is so thinly peopled. The houses have literally nothing within them, not even a mat; and a few women and old men are the only inhabitants : the men, they said, were all on journeys, or at Kisbee, Ashenumma, or Bilma, where they go themselves after the date season. During the time we halted here, the women brought us dates fancifully strung on rushes in the shape of hearts with much ingenuity, and a few pots of honey and fat.

We halted two days. So many of Boo-Khaloom's camels had fallen on the road, that notwithstanding all their peaceable professions, a marauding party was sent out to plunder some maherhies, and bring them in; an excursion that was sanctioned by the sultan, who gave them instructions as to the route they were to take. The former deeds of the Arabs are, however, still in the memory of the Tibboos, and they had increased the distance between their huts and the high road by a timely striking of their tents. But nine camels of the maherhy species were brought in, yet not without a skirmish : a fresh party was despatched, and did not return at night. We were all ordered to remain loaded, and no one was allowed to quit the circle in which the tents were pitched.

On the 11th we proceeded along the wadey. The thickly seattered mimosa trees afforded some very delightful varieties of shade. Our

- The lakes have marshy borders, and high salt islands, as if formed by man, which however are natural, and, the people say, have existed since their remembrance. The saline materials are a carbonate and muriate of soda : we saw no incrustations on the bottom or surface: at this season, the same is the case in the Bahr-Trona, in Fezzan. Each lake is not more than half or three-fourths of a mile in circumferenee-W. $\mathbf{O}$. 
course was nearly two miles distant from the hills*, which are all here called Tiggema. After our march, while waiting for the coming up of the camels, the Tibboos tried their skill with the spear, and were far more expert than I expected to see them; the arm is bent, and the hand not higher than the right shoulder, when they discharge the spear: as it leaves the hand, they give it a strong twist with the fingers, and as it flies it spins in the air. An old man of sixty struck a tree twice at twenty yards; and another, a powerful young man, threw the spear full eighty yards : when it strikes the ground, it sometimes bends nearly double: all who travel on foot carry two. Another weapon, which a Tibboo carries, is a sword of a very peculiar form, called hungamunga; of these they sometimes carry three or four. The Arabs, who had been out foraging, returned with thirteen camels, which they had much difficulty in bringing: the Tibboos had followed them several miles. We had patroles the whole night, who, to awaken us for the purpose of assuring us they were awake themselves, were constantly exclaiming Balek-ho, the watchword of the Arabs. We had near us a well of very good water amidst high grass and agoul. On the surface was a saline incrustation of several inches in thickness; below, a sandstone rock, and at a depth of two feet, water clear and good. We had also this day a dish of venison, one of the Arabs having succeeded in shooting two gazelles; many of which had crossed our path for the last three days. On finding a young one, only a few days old, the tawny, wily rogue instantly lay down in the grass, imitated the cry of the young one, and as

* The hills run nearly north and south, edging a little to the westward; they have numerous small bays or recesses, which produce a fine echo; many places with saline incrustations, and some of the large black patches like the frozen surface of a recently ploughed field. Almost all the salt formations are in low, protected situations; the water is near; and, often in the very centre, you have fine fresh springs.-From whence is this salt derived? I have already suggested that the air has a powerful effect, and is a principal agent. There is no reason to believe there are large subterranean salt beds; if these existed to any great extent, we should not have the fresh springs so prevalent.-W. 0 . 
the mother came bounding towards the spot, he shot her in the throat.

On the 12th we reached Bilma*, the capital of the Tibboos, and the residence of their sultan, who, having always managed to get before and receive us, advanced a mile from the town attended by some fifty of his men at arms, and double the number of the sex we call fair. The men had most of them bows and arrows, and all

- We had a fine wadey the greater part of the way, and many patches of saline incrustations; some exposed beds of red sandstone, containing numerous nodules of iron ore. Hills of much blacker colour; and a few have the appearance as of ruins of towns and castles, on their summits. Passed three springs, like the oozings at Traghen. A large tract of black surface, as if the situation of an extensive salt bed, from which the salt had only been removed a few years; it extends more than four or five miles to the eastward, and was more than a mile across, on our road. It is black and crispy, but has none of the irregular heapings taken notice of in other salt plains.

a There is another small town about two miles to the westward, of the same name. Round it are a number of mud elevations, which appear as if produced by mud volcanoes; but these are artificial, and made for the preparation of salt. I had long wished to see the extensive salt plain that afforded such copious supplies : originally, no doubt, the large spaces I have several times noticed afforded abundance, but the re-production could not keep up with the quantity taken away. Art was employed to obtain Nature; shallow pits were dug, which soon filled with water, and its evaporation left thick layers of salt: high embankments were raised round these, evidently to prevent currents of air. These places have much the look of our tanyards, with small pits partitioned from each other. The water is now strongly impregnated; in summer a thick crust is formed, which is the salt in use. One of these works apparently yields a large quantity of salt every year. When removed, the sordes are heaped up on the embankments. In the recesses there are many stalactites, of a beautiful white colour, which consist of muriate and carbonate of soda.

The great mystery is, the origin of the salt in all situations in which the water is near the surface, and the inclemency of the sater prevented by shelter. It is highly probable all this vast country was once a salt ocean; its height is nothing, considering its distance inland. What effect has the want, or almost want of rain,-for, as far as I can learn, no salt formations exist within the boundaries of the rains? There are many fine fresh springs issuing from the soil, and none of the wells are brackish; when the water, however, remains some time stagnant, it gets impregnated with saline matter.-W. 0 . 
carried spears : they approached Boo Khaloom, shaking them in the air over their heads; and after this salutation we all moved on towards the town, the females dancing, and throwing themselves about with screams and songs in a manner to us quite original. They were of a superior class to those of the minor towns; some having extremely pleasing features, while the pearly white of their regular teeth was beautifully contrasted with the glossy black of their skin, and the triangular flaps of plaited hair, which hung down on each side of their faces, streaming with oil, with the addition of the coral in the nose, and large amber necklaces, gave them a very seducing appearance. Some of them carried a sheish, a fan made of soft grass, or hair, for the purpose of keeping off the flies; others a branch of a tree, and some fans of ostrich feathers, or a bunch of keys: all had something in their hands, which they wave over their heads as they advance. One wrapper of Soudan tied on the top of the left shoulder, leaving the right breast bare, formed their covering, while a smaller one was thrown over the head, which hung down to their shoulders, or was thrown back at pleasure : notwithstanding the apparent scantiness of their habiliments, nothing could be farther from indelicate than was their appearance or deportment.

On arriving at Bilma, we halted under the shade of a large tulloh tree while the tents were pitching; and the women danced with great taste, and, as I was assured by the sultan's nephew, with skill also. As they approach each other, accompanied by the slow beat of an instrument formed out of a gourd, covered with goat's skin, for a long time their movements are confined to the head, hands, and body, which they throw from one side to the other, flourish in the air, and bend without moving the feet; suddenly, however, the music becomes quicker and louder, when they start into the most violent gestures, rolling their heads round, gnashing their teeth, and shaking their hands at each other, leaping up, and 
on each side, until one or both are so exhausted that they fall to the ground: another pair then take their place.

I now, for the first time, produced Captain Lyon's book in Boo Khaloom's tent, and on turning over the prints of the natives he swore, and exclaimed, and insisted upon it, that he knew every face:- " This was such a one's slave-that was his own-he was right-he knew it. Praised be God for the talents he gave the English! they were shater, clever; wolla shater, very clever !" Of a landscape, however, I found that he had not the least idea; nor could I make him at all understand the intention of the print of the sand-wind in the desert, which is really so well described by Captain Lyon's drawing; he would look at it upside down; and when I twice reversed it for him, he exclaimed, "Why! why! it is all the same." A camel or a human figure was all I could make him understand, and at these he was all agitation and delight"Gieb! gieb! Wonderful! wonderful!" The eyes first took his attention, then the other features: at the sight of the sword, he exclaimed, "Allah! Allah!" and on discovering the guns instantly exclaimed, "Where is the powder?" This want of perception, as I imagined, in so intelligent a man, excited at first my surprise; but perhaps just the same would an European have felt under similar circumstances. Were an European to attain manhood without ever casting his eye upon the representation of a landscape on paper, would he immediately feel the particular beauties of the picture, the perspective and the distant objects? Certainly not: it is from our opportunities of contemplating works of art, even in the common walks of life, as well as to cultivation of mind, and associations of the finer feelings by an intercourse with the enlightened and accomplished, that we owe our quick perception in matters of this kind, rather than from nature.

To the south of Bilma are marshes with pools of stagnant water, which our horses could scarcely drink. The town stands in a hollow, 
and is surrounded by low mud walls, which, with the houses within, are mean and miserable. About two miles north of the town are a few huts, and near them several lakes, in which are great quantities of very pure crystallized salt: some was brought to us for sale in baskets, beautifully white, and of an excellent flavour. On visiting the two most productive lakes, which lay between low sand hills, I expressed my surprise at the difference between that which the Tibboos were carrying away from the heaps by the side of the water, and that which I had seen the day before: I however found that their time for gathering the salt was at the end of the dry season, when it was taken, in large masses, from the borders of the lake. This transparent kind they put into bags, and send to Bornou and Soudan; a coarser sort is also formed into hard pillars, and for which a ready market is found. In Soudan, a single pillar weighing eleven pounds brings four or five dollars. The Tuaricks supply themselves with salt entirely from the wadeys of the Tibboos. Twenty thousand bags of salt were said to have been carried off during the last year by the Tuaricks alone. The Tibboos say, "It is hard to rob us, not only for their own consumption, but for the purposes of commerce too; and in consequence of paying nothing for the commodity, undersell us likewise in the Soudan market." But the Tibboos must be another people before they can keep the Tuaricks from plundering their country: a people who neither plant nor sow ; whose education consists in managing a maherhy, and the use of the spear; and who live by plundering those around them, as well as those whom necessity or chance may lead to pass through their own country.

About a mile from Bilma is a spring of beautiful clear water, which rises to the surface of the earth, and waters a space of two or three hundred yards in circimference, which is covered with fresh grass : but passing this, the traveller must bid adieu to every appearance of vegetable production, and enter on a desert which 
requires thirteen days to cross. Near the first hill of sand I succeeded, with the assistance of two Arabs, in catching a small beautiful animal, nearly white, much resembling a fox in make and shape, although not larger than a moderate-sized cat. It was of the species called fitchet: the belly was white, and the back and rest of the body of a light brown colour; the tail was bushy like that of the fox, nearly white, and the end of the hair tipped with black.

Jan. 16.-Our road lay over loose hills of fine sand, in which the camels sank nearly knee-deep. In passing these desert wilds, where hills disappear in a single night by the drifting of the sand, and where all traces of the passage, even of a large kafila, sometimes vanish in a few hours, the Tibboos have certain points in the dark sandstone ridges, which from time to time raise their heads in the midst of this dry ocean of sand, and form the only variety, and by them they steer their course. From one of these landmarks we waded through sand formed into hills from twenty to sixty feet in height, with nearly perpendicular sides, the camels blundering and falling with their heavy loads. The greatest care is taken by the drivers in descending these banks: the Arabs hang with all their weight on the animal's tail, by which means they steady him in his descent. Without this precaution the camel generally falls forward, and, of course, all he carries goes over his head. We halted at Kaflorum (where the kafila stops), which is a nest of hills of coarse, dark sandstone: an irregular peak to the east is called Gusser, or the castle. At the end of these hills, about two miles from the road, lies a wadey called Zow Seghrir, in which grows the suag tree, and also grass. Our course was south; but we were obliged to wind round the different sand hills in order to avoid the rapid descents, which were so distressing to the camels. We bivouacked under a head called Zow (the Difficult), to the east, where we found several wells.

Jan. 18.-The sand hills were less high to-day, but the 
animals sank so deep, that it was a tedious day for all. Four camels of Boo Khaloom's gave in ; two were killed by the Arabs, and two were left to the chance of coming up before morning. Tremendously dreary are these marches: as far as the eye can reach, billows of sand bound the prospect. On seeing the solitary foot passenger of the kafila, with his water-flask in his hand, and bag of zumeeta on his head, sink at a distance beneath the slope of one of these, as he plods his way alone, hoping to gain a few paces in his long day's work, by not following the track of the camels, one trembles for his safety:-the obstacle passed which concealed him from the view, the eye is strained towards the spot in order to be assured that he has not been buried quick in the treacherous overwhelming sand.

An unfortunate merchant of Tripoli, Mohamed N'diff, who had suffered much on the road from an enlarged spleen, was here advised to undergo the operation of burning with a red-hot iron, the sovereign Arab remedy for almost every disorder : he consented; and, previous to our move this morning, he was laid down on his back, and, while five or six Arabs held him on the sand, the rude operators burnt him on the left side, under the ribs, in three places, nearly the size of a sixpence each. The iron was again placed in the fire, and while heating, the thumbs of about a dozen Arabs were thrust in different parts of the poor man's side, to know if the pressure pained him, until his flesh was so bruised, that he declared all gave him pain : four more marks with the iron were now made near the former ones, upon which he was turned on his face, and three larger made within two inches of the back bone. One would have thought the operation was now at an end; but an old Arab, who had been feeling his throat for some time, declared a hot iron, and a large burn, absolutely necessary just above the collarbone, on the same side. The poor man submitted with wonderful patience to all this mangling, and after drinking a draught of water, 
moved on with the camels. We made this day twenty-one miles, and halted at Chukœma, which means half way. We lost more than twenty of our camels this day, by their straying out of the path.

Jan. 20.-We were promised to find water early; and as the animals had not drank the night before, we pushed on with our horses : we were told the wells were near ; but it was a long twenty miles, over loose rolling sand hills. At less than half way, we passed two hills of dark sandstone, called Geisgae (Dhubba - the hyena), which had been in sight great part of yesterday; and at 1.30. arrived at a wadey called Dibla (Inchat tegeel-heavy stone). In the wadey near is a little sprinkling of rusty grass, which the animals devoured with an avidity that would have done credit to better fare. The water was extremely brackish, and strongly impregnated with trona; but it was fresh and cool, and therefore a delightful beverage to us.

In the wadey Dibla stands a detached conical table-topped hill: the summit had a black rugged appearance from below, and was formed of a sort of bituminous earth, dry and crumbling to the touch. Under this were layers or strata of thin plates, almost resembling foil, of brittle schistose clay, of black, yellow, and green: these also crumbled on receiving the pressure of the hand*. About

* Some curious tubular, hollow, coralliform productions were picked up in the sand: they appear of very recent formation, and evidently produced by rain and wind acting on the sand. The particles are most minute; when broken, the substance has a shining glassy appearance: some lie horizontally, but the general position is perpendicular. The external surface is rough : the size varies, both in length and circumference, from a few lines to an inch and $a$ half in the latter, and from an inch to a foot in the former direction.

The wells are holes, about eighteen inches deep : the water has a slight taste of carbonate of soda, that was strong at first, but diminished greatly after some water had been drawn. The holes fill very fast. The saline impregnation arises, very probably, from the earth around falling, and being blown into the holes. Dibla is bounded on the north by black sandstone and quartz hills, which extend some way to the eastward; on the south by sand hills, and by a winding wadey on the east. In the middle there are several small 
ten miles from Dibla we came to Chegarub, and four miles further to Kersherma, where we rested for the night. No wood or water.

Jan. 22.-A tedious day over sandy deserts, without even the relief of a dark hill to look forward to. About sun-set we came to a spot with some little sprinkling of a grass called sbeet, and some fine grass, with a flower called nisse. Made twenty-four miles, and halted at Kasama-foma-hamse, or the five trees. No wood nor water. Alarm of Tibboos,- all mounted and turned out.

Jan. 23.-Desert as yesterday. High sand hills*. Burmenmadua (all sand). - At three in the afternoon, we arrived at an extensive wadey, called Aghadem. Here are several wells of excellent water, forage, and numbers of the tree called suag, the red berries of which are nearly as good as cranberries. We broke in on the retreats of about a hundred gazelles, who were enjoying the fertility of the valley. It was, however, with great difficulty, from their extreme shyness, that we shot one, which afforded us an ample meal. A road

conical hillocks with table-tops: the lower part is formed of a fine schistus, of different colours, that next the base light and white; over that, green, exactly resembling large well-dried leaves of plants, which separate into the finest layers; the top is a black bituminous matter, which crumbles into small pieces by the slightest touch: these hillocks are from thirty to forty feet high, the probable height of the valley in former days; and it is not unlikely that the bituminous matter is a vegetable deposit. There are a few acacias, but so few, that we could procure no firewood, and the camels very little food.

A number of round semi-vitrified small stones were found on the sands, which the people collected to use as bullets. The mode of formation appears the same as the corallifor msubstances $I$ have mentioned. These substances, in great quantities, are said to be formed after the rains that every now and then occur in this quarter.

* There is grass in abundance, and small mounds covered with a tetrandrous plant, called suag : its fruit a small drupa, which is in great request in Bornou and Soudan, for removing sterility in females. Boo Khaloom related one instance of a female, who had been in that state eighteen years, but was cured by the fruit. It is sweetish and hot to the taste, approaching to the Sisymbrium nasturtium. In passing the plant, a heavy narcotic smell is always perceived.-W. $\mathbf{O}$. 
here branched off to the westward, leading to the Tuarick country, and Soudan, but not frequented by kafilas. Aghadem is a great rendezvous, and the dread of all small kafilas and travellers. It is frequented by freebooters of all descriptions.

Jan. 24, we halted. The thermometer, in the shade of my tent, was $101^{\circ}$. at half-past two. The animals were all enjoying the blessings of plenty in the ravines, which ran through the range of low black hills, extending nearly north and south, quite across the valley. The camels, in particular, feasted on the small branches of the suag, of which they are fond to excess. The tracks of the hyæna had been numerous for the last three days; and last night they approached in droves quite close to our encampment.

My telescope this evening afforded great delight to Boo-Khaloom, the brother of the kadi at Mourzuk, Mohamed Abeedeen, and several others, for more than an hour. I usually passed some time every evening in Boo-Khaloom's tent, and had promised them a sight of the moon grib (near), for some time. One old hadje, who obtained a sight by my assistance, for he could not fix the glass on the object, after an exclamation of wonder, looked me fully in the face, spoke not a word, but walked off as fast as he could, repeating words from the Koran. This conduct, I was pleased to see, brought down the ridicule of the others, who were gratified beyond measure, and asked a hundred questions. The night was beautifully serene and clear, and the three splendid constellations of Orion, Canis Major, and Taurus, presented a coup d'œil truly impressive and sublime.

Jan. 25.-The camels moved off soon after eight; and we took shelter from the sun under the shade of some clumps, covered with high grass, near the wells, in order that the horses might drink at the moment of our departure. We had three or four long days to the next water; and the camels were too fatigued to carry more than one day's food for the horses. While we were in this situation, two 
Arabs, who had gone on with the camels, came galloping back, to say that they had encountered two Tibboo couriers, on their way from Bornou to Mourzuk. They soon made their appearance, mounted on maherhies, only nine days from Kouka. They brought news that the Sheikh Kanemy had just returned from a successful expedition against the sultan of Begharmi; that he had attacked and routed a powerful tribe of Arabs, called la Sala; and that the sultan, on hearing this, had fled as before to the south side of the Great River, amongst the Kirdies.

We proceeded on our route, which was along a continued desert; and at sun-set halted on the sand, without either wood or water, after twenty-four miles. The courier from Bornou to Mourzuk assured us, that he should not be more than thirty days on the road from where we left him. Since Sheikh Kanemy's residence at Kouka, couriers have occasionally passed between Bornou and Mourzuk,-a circumstance before that event unknown. One of Kanemy's wives and three children were in Mourzuk; and the Bashaw, in order to secure his perfect submission, refused to allow them to leave that place. The Tibboos are the only people who will undertake this most arduous service; and the chances are so much against both returning in safety, that one is never sent alone. The two men we had encountered were mounted on two superb maherhies, and proceeding at the rate of about six miles an hour. A bag of zumeeta (some parched corn), and one or two skins for water, with a small brass basin, with a wooden bowl, out of which they ate and drank, were all their comforts. A little meat, cut in strips and dried in the sun, called gedeed, is sometimes added to the store, which they eat raw; for they rarely light a fire for the purpose of cooking, although the want of this comfort during the nights, on approaching Fezzan, where the cold winds are sometimes biting after the day's heat, is often fatal to such travellers. A bag is suspended under the tail of the maherhy, by which means the 
dung is preserved, and serves as fuel on halting in the night. Without a kafila, and a sufficient number of camels to carry such indispensables as wood and water, it is indeed a perilous journey.

On the 27th we appeared gradually approaching something resembling vegetation : we had rising sands and clumps of fine grass the whole way; and the country was not unlike some of our heaths in England. Towards evening the trees increased greatly in number; and where we halted, the animals found abundance of food. The tulloh trees, the kossom (a very beautiful parasitical plant), and the herbage, were most refreshing to our parched feelings, although in reality they were of the most dingy green and stunted appearance. A herd of more than a hundred gazelles crossed us towards the evening; and the foot-marks of the ostrich, and some of its feathers, were discovered by the Arabs. The spot where we halted is called Geogo Balwy.

Jan. 28. - We met two Tibboos this day, who informed us that the Tuaricks had been to Kanem, eight hundred strong, and had carried off every thing from two towns. The Arabs were all anxiety to fall in with them, and rob the true rogues. The route resembled that of yesterday. Early in the day we made Beere-Kashifery. The well here was of great depth; Arabs were obliged to descend into it, and throw out several loads of sand, before any water could be drawn, and which occupied them the greater part of the night. By daylight the next morning, Mina Tahr, or the black bird, the sheikh of the Gunda Tibboos, attended by three of his followers, approached the camp. Beere-Kashifery lay within his territories, and no kafilas pass without paying tribute, which, as he is absolute, sometimes amounts to half what they possess. In our case, his was a visit of respect: Boo-Khaloom received him in his tent, and elothed him in a scarlet bornouse of coarse cloth, and a tawdry silk caftan, which was considered as a superb present. The Tibboos are smart active fellows, mounted on small horses, of great 
swiftness : their saddles are of wood, small and light, open along the bone of the back; the pieces of wood of which it is composed are lashed together with thongs of hide; the stuffing is camel's hair, wound and plaited, so as to be a perfect guard; the girth and stirrup leathers are also of plaited thongs, and the stirrups themselves of iron, very small and light; into these four toes only are thrust, the great toe being left to take its chance. They mount quickly, in half the time an Arab does, by the assistance of a spear, which they place in the ground, at the same time the left foot is planted in the stirrup; and thus they spring into their saddle. The bridle is light, but severe; the reins and head-stall of strips of hide, fancifully twisted and plaited.

Our camels had not finished drinking until the sun was full six fathom high, as the Arabs say; and as we were in want of fresh meat, and, indeed, every thing, Mina Tahr proposed that we should go to a well nearer his people-a well, he assured us, which was never yet shown to an Arab. At eleven, therefore, on the 29th of January, we moved on, accompanied by the Tibboos, nine miles nearly south; where, about half a mile west of the road, we came to the well Duggesheinga : here were the marks of immense herds, which had been drinking in the morning. This was a retired spot, undiscoverable from the ordinary route of travellers, from which it was completely hid by rising sand hills. Here the Tibboos left us, promising to return early the day after with sheep, an ox, honey, and fat. This was joyful news to persons who had not tasted fresh animal food for fourteen or fifteen days, with the exception of a little camel's flesh. We were terribly annoyed the whole of the day by a strong easterly wind, and such volumes of sand, as quite obscured the face of nature.

Jan. 30.-The wind and drifting sand were so violent, that we were obliged to keep our tents the whole day; besides this, I was more disordered than I had been since leaving Mourzuk. I found 
a loose shirt only the most convenient covering, as the sand could be shaken off as soon as it made a lodgment, which, with other articles of dress, could not be done, and the irritation it caused produced a soreness almost intolerable : a little oil or fat from the hand of a negress (all of whom are early taught the art of shampooing to perfection), rubbed well round the neck, loins, and back, is the best cure, and the greatest comfort, in cases of this kind; and although, from my Christian belief, I. was deprived of the luxury of possessing half a dozen of these shampooing beauties, yet, by marrying my negro Barca to one of the bashaw's freed women slaves, as I had done at Sockna, I became, to a certain degree, also the master of Zerega, whose education in the castle had been of a superior kind; and she was of the greatest use to me on these occasions of fatigue or sickness. It is an undoubted fact, and in no case probably better exemplified than in my own, that man naturally longs for attentions and support from female hands, of whatever colour or country, so soon as debility or sickness comes upon him.

Towards the evening, when the wind became hushed and the sky re-assumed its bright and truly celestial blue, the Tibboo Sheikh, and about thirty of his people, male and female, returned, but their supplies were scanty for a kafila of three hundred persons. The sweet milk turned out nothing but sour camel's milk, full of dirt and sand, and the fat was in small quantities and very rancid. We, however, purchased a lean sheep for two dollars, which was indeed a treat. Great precaution must always be taken on procuring meat, after long abstaining from animal food: eating more than a very moderate quantity ever disorders the stomach, which is often succeeded by fever, ague, and all its attendant evils : although not gormandizers, some of us suffered from too great an indulgence in the luxuries of boiled mutton. Illness here should be the more avoided, from its being altogether of a nature different from illness elsewhere : the attacks are sudden, and render a person incapable 
of any exertion, leaving him in a state of weakness and debility scarcely credible to those who have not been eye-witnesses of the fact.

Some of the girls who brought the milk, \&c. were really pretty as contrasted with the extreme ugliness of the men: they were different from those of Bilma; were more of a copper colour, with high foreheads and a sinking between the eyes: they have fine teeth, and are smaller and more delicately formed than the Tibboos who inhabit the towns. The men brought, as a present to BooKhaloom, two beautiful maherhies; one of them was a most superb animal, and measured nine feet and a half from the ground to the middle of the back : they also brought a horse or two for sale. Their animals are their only riches; and Mina Tahr told me, that their tribe had more than five thousand camels : on the milk of these animals they entirely live for six months in the year, and for the remaining half year they manage to raise from their barren soil sufficient gussub (a species of millet) to satisfy their wants. Formerly, when they had little or no communication with Fezzan and Bornou, they were nearly naked, as their crops of cotton were scarcely sufficient, from the dryness and poverty of the soil, to afford them covering. Now the Kafilas bring them indigo, cotton, and readyspun linen in strips, with which they make tobes and wrappers: for these, when they are not given as tribute, the Tibboos exchange the skins and feathers of the ostrich, with dried meat of gazelles and bullocks.

Two of the horses were very handsome, though small ; and on remarking their extreme fatness, I was not a little surprised at learning that they were fed entirely on camels' milk, corn being too scarce and valuable an article for the Tibboos to spare them: they drink it both sweet and sour; and animals in higher health and condition I scarcely ever saw. It is quite surprising with what terror these children of the desert view the Arabs, and the idea 
they have of their invincibility ; while they are smart active fellows themselves, and both ride and move better and quicker: but the guns! the guns! are their dread; and five or six of them will go round and round a tree, where an Arab has laid down his gun for a minute, stepping on tiptoe, as if afraid of disturbing it, talking to each other in a whisper, as if the gun could understand their exclamations; and I dare say, praying to it not to do them an injury, as fervently as ever man Friday did to Robinson Crusoe's musket.

None of the Gunda Tibboos were above the middle size, slim, well made, with sharp, intelligent, copper-coloured faces, large prominent eyes, flat noses, large mouth and teeth, regular, but stained a deep red, from the immoderate use of tobacco; the forehead is high; and the turban, which is a deep indigo colour, is worn high on the head, and brought under the chin and across the face, so as to cover all the lower part from the nose downwards: they have sometimes fifteen or twenty charms, in red, green, and black leather cases, attached to the folds of their turbans.

Most of them have scars on different parts of their faces : these generally denote their rank, and are considered as an ornament. Our sheikh had one under each eye, with one more on each side of his forehead, in shape resembling a half moon. Like the Arabs of the north, their chieftainships are hereditary, provided the heir is worthy; any act of cowardice disqualifies, and the command devolves upon the next in succession. Our Gunda sheikh, Mina Tahr-ben-Soogo-Lammo, was the seventh in regular succession. This tribe is called Nafra Gunda, and are always near BeereKashifery.

My watch pleased him wonderfully at first; but after a little time, I found that looking at himself in the bright part of the inside of the case gave him the greatest satisfaction : they are vainer than the vainest. Mina Tahr had the finest clothes on that had ever been brought to Beere-Kashifery; and what to him could be so 
agreeable as contemplating the reflection of his own person so decked out? I could not help giving him a small looking-glass; and he took his station in one corner of my tent for hours, surveying himself with a satisfaction that burst from his lips in frequent exclamations of joy, and which he also occasionally testified by sundry high jumps and springs into the air.

Jan. 31.-After regaining the road, we moved until noon, when our horses were watered at a well called Kanimani (or the sheep's well), where some really sweet milk was brought us in immensely large basket bottles, some holding two gallons and more. We had drank, and acknowledged its goodness, and how grateful it was to our weak stomachs, before finding out that it was camels' milk.

No traveller in Africa should imagine that this he could not bear, or that could not be endured. It is wonderful how a man's taste conforms itself to his necessities. Six months ago, camels' milk would have acted upon us as an emetic; now we thought it a most refreshing and grateful cordial. The face of the country improved in appearance every mile. We passed along today what seemed to us a most joyous valley, smiling in flowery grasses, tulloh trees, and kossom. About mid-day, we halted in a luxurious shade, the ground covered with creeping vines of the colycinth in full blossom, which, with the red flower of the kossom which drooped over our heads, made our resting-place a little Areadia. Towards the evening, we saw two very large black vultures (aglou, in Bornou), but were not near enough to shoot them; and at sun-set we pitched the tents, surrounded by forage for our horses, while the half-famished camels fed on the young branches of the tulloh. The place was called Auoul Mull (before Mull).

Feb. 1.-By three in the morning our people commenced packing, and by daylight we moved off. The herbage, almost resembling wild corn, was often up to our horses' knees. We killed to-day one 
of the largest serpents we had seen : it is called liffa by the Arabs, and its bite is said to be mortal, unless the part is instantly cut out. It is a mistaken idea, that all the serpent tribe are called liffa; this species alone bears the name: it has two horns, and is of a light brown colour. My old Choush Ghreneim had a distorted foot, which was of but little use to him except on horseback, from the bite of one of these poisonous reptiles, notwithstanding the part infected was cut out: he was for thirteen months confined to his hut, and never expected to recover.

Arabs are always on the look out for plunder: " 'Tis my vocation, Hal !"-none are ashamed to acknowledge it; but they were on this occasion to act as an escort to oppose banditti, not play the part of one. Nevertheless, greatly dissatisfied were they, at having come so far, and done so little : they formed small parties for reconnoitring on each side of the road, and were open-mouthed for any thing that would offer. One fellow on foot had traced the marks of a flock of sheep to a small village of tents to the east of our course, and now gave notice of the discovery he had made, but that they had seen him, and he believed struck their tents. I felt that I should be a check upon them in the plunderings. Boo-Khaloom, myself, and about a dozen horsemen (who had each a footman behind him), instantly started for their retreat, which lay over the hills to the east. On arriving at the spot, in a valley of considerable beauty, where these flocks and tents had been observed, we found the place quite deserted. The poor frighted shepherds had moved off with their all, knowing too well what would be their treatment from the Naz Abiad (white people), as they call the Arabs. Their caution, however, was made the excuse for plundering them, and a pursuit was instantly determined on. "What! not stay to sell their sheep, the rogues! We'll take them now without payment." We scoured two valleys without diseovering the fugitives, and I began to hope that the Tibboos had eluded their pursuers, when, after crossing a 
deep ravine, and ascending the succeeding ridge, we came directly on about two hundred head of cattle, and about twenty persons, men, women, and children, with ten camels laden with their tents and other necessaries, all moving off. The extra Arabs instantly slipped from behind their leaders, and with a shout rushed down the hill; part headed the cattle to prevent their escape, and the most rapid plunder I could have conceived quickly commenced. The camels were instantly brought to the ground, and every part of their load rifled: the poor women and girls lifted up their hands to me, stripped as they were to the skin, but I could do nothing for them beyond saving their lives. A sheikh and a maraboot assured me it was quite lawful (hallal) to plunder those who left their tents instead of supplying travellers. Boo-Khaloom now came up, and was petitioned. I saw he was ashamed of the paltry booty his followers had obtained, as well as moved by the tears of the sufferers. I seized the favourable moment, and advised that the Arabs should .give every thing back, and have a few sheep and an ox for a bousafer (feast): he gave the order, and the Arabs from under their barracans threw down the wrappers they had torn off the bodies of the Tibboo women; and I was glad in my heart, when, taking ten sheep and a fat bullock, we left these poor creatures to their fate, as, had more Arabs arrived, they would most certainly have stripped them of every thing. We halted, after dark, at a place called Mull.

Feb. 2.-Our road, as yesterday, was an extensive valley, bounded to the right and left by low hills; about noon we descended slightly, and found ourselves in a productive plain of great extent, thickly planted with trees and underwood, not unlike a preserve in England. About an hour before sun-set, we came to what had the appearance of the bed of a lake, and here was the wished-for well of water. The horses had not drank since noon on the 31 st, and although ready to 
drop on the road from faintness, were, on reaching the well, quite unmanageable. The name of the well was Kofei.

On the 31st, Boo-Khaloom had thought it right to send on a Tibboo with the news of our approach to the sheikh El-Kanemy, who, we understood, resided at Kouka, and one was despatched with a camel and a man of Mina Tahr: the Gundowy accompanied him on the arrival at Kofei of the Arabs, who preceded us for the purpose of clearing the well. The Tibboo who had been despatched was found alone and naked; some Tibboo Arabs, of a tribe called Wandela, had met them near the well on the preceding evening and robbing him even to his cap, and taking from him the letters, saying, they cared not for the sheikh or Boo-Khaloom, tied him to a tree, and then left him. In this state was he found by our people; and Mr. Clapperton coming up soon after, gave him, from his biscuitbag, wherewithal to break his fast, after being twenty-four hours without eating. Eighteen men had stripped him, he said, and taken off the camel and Mina Tahr's man, who, they also said, should be ransomed, or have his throat eut. Mina Tahr represented these people as the worst on the road in every sense of the word: "They have no flocks," said he, " and have not more than three hundred camels, although their numbers are one thousand or more; they live by plunder, and have no connexion with any other people. No considerable body of men can follow them; their tents are in the heart of the desert, and there are no wells for four days in the line of their retreat. Giddy-ben-Agah is their chief, and I alone would give fifty camels for his head : these are the people who often attack and murder travellers, and small kafilas, and the Gundowy, who respect strangers, have the credit of it."

The men of Traita, with their chief, Eskou-ben-Coglu, came in the evening to welcome us : the well Kofei belongs to them; and greatly enraged they appeared to be at the conduct of the Wandelas. 
This chief returned to Boo-Khaloom his letters, which, he said, " the chief of the Wandelas had sent him that morning, begging that he would meet the kafila at the well, and deliver them to BooKhaloom: had he known then what had taken place, the slave," he said, "should have been stabbed at his father's grave before he would have delivered them." Boo-Khaloom was greatly enraged; and I was almost apprehensive that he would have revenged himself on the Traita chiefs. However, the Tibboo courier was again clothed and mounted, and once more started for Bornou. The Traita Tibboos are more important-looking fellows than the Gunda, but they want their quickness and activity : they are said not to be more than eight hundred strong in males.

Feb. 3.- Our course, during the early part of the day, was due south, and through a country more thickly planted by the all-tasteful hand of bounteous Nature. We disturbed a flock of what we at first thought were deer, but they were only a large species of antelope; they are of a deeper fawn colour, and have black and white stripes under the belly. The Guinea fowl were in great numbers, but extremely shy. The whole day our route lay through most pleasing forest scenery. It was near sunset when we arrived at Mittimee, which, in the Bornou language, means warm, tepid: the wells exceed fifty in number, and lie in a woody hollow, where there are clumps of the tulloh and other species of the mimosa tribe, encircled by kossom and various parasitical and twining shrubs, which, embracing their stems, wind to the extremities of their branches, and climb to the very tops, when, falling over, they form weeping bowers of a most beautiful kind : it was indeed a lovely and a fair retreat.

Boo-Khaloom, myself, and about six Arabs, had ridden on in front: it was said we had lost the track, and should miss the well: the day had been oppressively hot, my companions were sick and fatigued, and we dreaded the want of water. A fine dust, arising G 2 
from a light clayey and sandy soil, had also increased our sufferings : the exclamations of the Arab who first discovered the wells were indeed music to our ears; and after satisfying my own thirst, with that of my weary animals, I laid me down by one of the distant wells, far from my companions; and these moments of tranquillity, the freshness of the air, with the melody of the hundred songsters that were perched amongst the creeping plants, whose flowers threw an aromatic odour all around, were a relief scarcely to be described. Ere long, however, the noisy kafila, and the clouds of dust which accompanied it, disturbed me from the delightful reverie into which I had fallen.

Feb. 4.-Previously to arriving at Lari, we came upon two encampments of the Traita Tibboos, calling themselves the sheikh's people: their huts were not numerous, but very regularly built in a square, with a space left in the north and south faces of the quadrangle, for the use of the cattle. The huts were entirely of mats, which, excluding the sun, yet admitted both the light and the air: these habitations, for fine weather, are preferable to the bete shars, or tents, of the Arabs of the north. The interior was singularly neat: clean wooden bowls, with each a cover of basket-work, for holding their milk, were hung against the wall. In the centre of the inclosure were about one hundred and fifty head of cattle feeding from cradles : these were chiefly milch cows, with calves and sheep. The Tibboos received us kindly at first, but presumed rather too much on sheikh Kanemy's protection, which they claim or throw off, it is said, as it suits their purpose. The modest request of a man, with two hundred armed Arabs, for a little milk, was refused; and ready as the Arabs are to throw down the gauntlet, a slight expression of displeasure from their leader was followed by such a rapid attack on the Tibboos, that before I could mount, half the stock was driven off, and the sheikh well bastinadoed. Boo-Khaloom was, however, too kind to injure them; and after driving their cattle 
for about a mile, he allowed them to return, with a caution to be more accommodating for the future. Accustomed as these people are to plunder one another, they expect no better usage from any one who visits them, provided they are strong enough, and vice versa; they are perfect Spartans in the art of thieving, both male and female.

An old woman, who was sitting at the door of one of the huts, sent a very pretty girl to me, as I was standing by my horse, whose massy amber necklace, greased head, and coral nose studs and earrings, announced a person of no common order, to see what she could pick up; and after gaining possession of my handkerchief and some needles, while I turned my head, in an instant thrust her hand into the pocket of my saddle-cloth, as she said, " to find some beads, for she knew I had plenty."

Another and much larger nest of the Traitas lay to the east of our route, a little further on, with numerous flocks and herds. About two in the afternoon we arrived at Lari, ten miles distant from Mittimee. On ascending the rising ground on which the town stands, the distressing sight presented itself of all the female, and most of the male inhabitants, with their families, flying across the plain in all directions, alarmed at the strength of our kafila. Beyond, however, was an object full of interest to us, and the sight of which conveyed to my mind a sensation so gratifying and inspiring, that it would be difficult in language to convey an idea of its force or pleasure. The great lake Tchad, glowing with the golden rays of the sun in its strength, appeared to be within a mile of the spot on which we stood. My heart bounded within me at this prospect, for I believed this lake to be the key to the great object of our search, and I could not refrain from silently imploring Heaven's continued protection, which had enabled us to proceed so far in health and strength, even to the accomplishment of our task.

It was long before Boo-Khaloom's best endeavours could restore 
confidence: the inhabitants had been plundered by the Tuaricks only the year before, and four hundred of their people butchered; and but a few days before, a party of the same nation had again pillaged them, though partially. When, at length, these people were satisfied that no harm was intended them, the women came in numbers with baskets of gussub, gafooly, fowls, and honey, which were purchased by small pieces of coral and amber of the coarsest kind, and coloured beads. One merchant bought a fine lamb for two bits of amber, worth, I should think, about twopence each in Europe; two needles purchased a fowl; and a handful of salt four or five good sized fish from the lake.

Lari is inhabited by the people of Kanem, who are known by the name of Kanemboo: the women are good-looking, laughing negresses, and all but naked; but this we were now used to, and it excited no emotions of surprise. Most of them had a square or triangular piece of silver or tin hanging at the back of the head, suspended from the hair, which was brought down, in narrow plaits, quite round the neck.

Feb. 5.-By sun-rise I was on the borders of the lake, armed for the destruction of the multitude of birds, who, all unconscious of my purpose, seemed as it were to welcome our arrival. Flocks of geese and wild ducks, of a most beautiful plumage, were quietly feeding at within half pistol shot of where I stood; and not being a very keen or inhuman sportsman, for the terms appear to me to be synonymous, my purpose of deadly warfare was almost shaken. As I moved towards them they only changed their places a little to the right or left, and appeared to have no idea of the hostility of my intentions. All this was really so new, that I hesitated to abuse the confidence with which they regarded me, and very quietly sat down to contemplate the scene before me. Pelicans, cranes, four and five feet in height, grey, variegated, and white, were scarcely so many yards from my side, and a bird, between a snipe and a wood- 


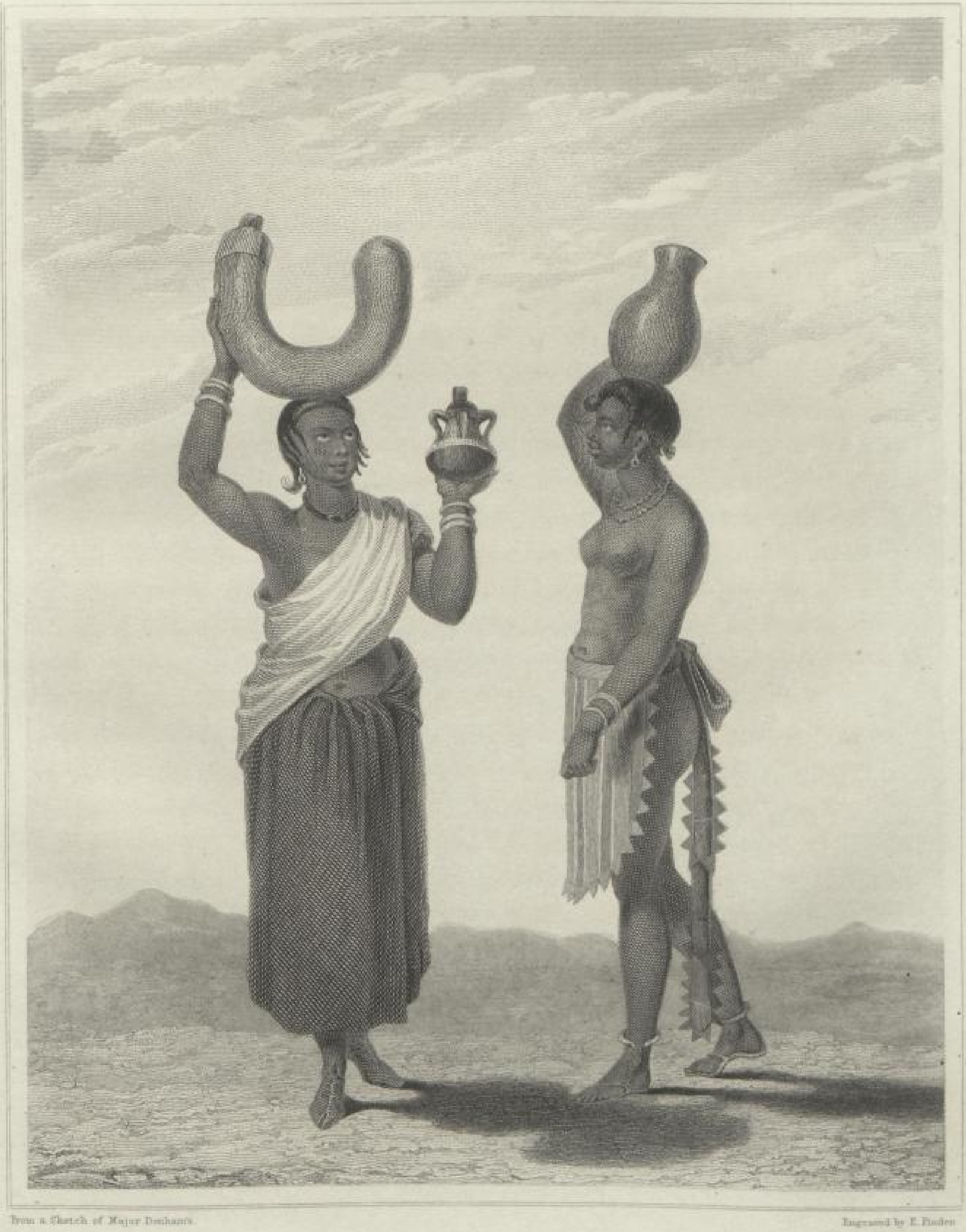

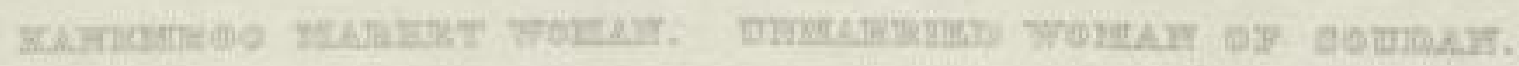

\section{SLUB}

Leibniz-Institut
für Länderkunde 
cock, resembling both, and larger than either; immense spoonbills of a snowy whiteness, widgeon, teal, yellow-legged plover, and a hundred species of (to me at least) unknown water fowl, were sporting before me; and it was long before I could disturb the tranquillity of the dwellers on these waters by firing a gun.

The soil near the edges of the lake was a firm dark mud; and, in proof of the great overflowings and recedings of the waters, even in this advanced dry season, the stalks of the gussub, of the preceding year, were' standing in the lake, more than forty yards from the shore. The water is sweet and pleasant, and abounds with fish; which the natives have a curious way of catching. Some thirty or forty women go into the lake, with their wrappers brought up between their legs, and tied round their middles, as I should say, by single files, and forming a line at some distance in the water, fronting the land, for it is very shallow near the edges, and absolutely charge the fish before them so close, that they are caught by the hand, or leap upon the shore. We purchased some, and the best flavoured was a sort of bream.

A circumstance happened whilst I was on the margin of the lake, which was a further proof that the little kindnesses I had shown the Arabs were not lost upon them; and which supported my favourite position, that no people on earth are so savage, but that gentle kind treatment, with a frank and liberal manner, will gain their confidence and regard. A lamb, the most harmless thing that breathes, alarms a child who for the first time sees such an animal. I had suffered my horse to go loose, in order to approach close to the flights of birds around me, and he probably thinking the tents might afford him better fare than where I left him, first rubbed off his bridle, and then quietly returned to the encampment. About the same time one of the freed women found my bornouse, which had fallen from the saddle, and brought it to Boo Khaloom. All this created an alarm, and it was then found out, that two boats or canoes had been 
seen coming from the south-east, in which direction are islands inhabited by the Biddoomah, a people who live by plundering on the main land, and carry off any thing they can pick up. This was quite enough to make Boo Khaloom think I was already gone, or in great danger; and not only several Arab chiefs armed themselves, and mounted, to seek me, but some of the merchants also. They found me, after a long search, on the lake among the gussub stalks, loaded with more birds than I could carry, and would scarcely believe that I had seen neither enemies nor boats. The dread which the natives appear to have of these koorie, or islanders, is almost equal to their fear of the Tuaricks; but the former are less rapacious and bloody in their visits. Their habitations are three or four days distant to the southward of east, towards the centre of the lake.

In the evening I visited the town of Lari : it stands on an eminence, and may probably contain two thousand inhabitants. The huts are built of the rush which grows by the sides of the lake, have conical tops, and look very like well thatched stacks of corn in England. They have neat inclosures round them, made with fences of the same reed, and passages leading to them like labyrinths. In the inclosure is a goat or two, poultry, and sometimes a cow. The women were almost all spinning cotton, which grows well, though not abundantly, near the town and lake. The interior of the huts is neat: they are completely circular, with no admission for air or light, except at the door, which has a mat, by way of safeguard. I entered one of the best appearance, although the owner gave me no smiles of encouragement, and followed close at my heels, with his spear and dagger in his hand. In one corner stood the bed, a sofa of rushes lashed together, and supported by six poles, fixed strongly in the ground. This was covered by the skins of the tiger-cat and wild bull; round the sides were hung the wooden bowls, used for water and milk: his tall shield rested against the wall. The hut had a division of mat-work, one half being allotted to the female part of 
the family. My host, however, continued to look at me with so much suspicion, and seemed so little pleased with my visit, notwithstanding all my endeavours to assure him I was a friend, that I hurried from the inhospitable door, and resumed my walk through the town.

Feb. 6.-A gratifying scene took place this morning, in the departure of nearly thirty freed slaves, natives of Kanem, who here left us for their homes, three days' journey to the eastward. I had been applied to, the night before, to intercede with Boo Khaloom for this indulgence; for as he had heard that the sheikh was at war with some of the chiefs of Kanem, he had determined on first taking them to Bornou, for fear of their being plundered on the road of the little they had saved in slavery. These poor creatures had, however, found one or two of their countrymen at the market of Lari, who assured them of their safety on the road between that place and their homes. The good man complied with evident reluctance on their own account, and they took leave, kissing his hand, with tears and blessings. They had most of them been in the service of the bashaw, some for a term of years, and were returning to die at home at last. One poor deaf and dumb woman, whom the rapacity of Mukni, the former sultan of Fezzan, who spared neither age, sex, nor infirmity, had induced him to march to Tripoli, had shed torrents of tears ever since she had been made acquainted, by signs, that she was to go to Bornou. She had left two children behind her; and the third, which was in her arms when she was taken by the Arabs, had been torn from her breast after the first ten days of her journey across the desert, in order that she might keep up with the camels. Her expressive motions in describing the manner in which the child was forced from her, and thrown on the sand, where it was left to perish, while whips were applied to her, lame and worn out as she was, to quicken her tottering steps, were highly eloquent and interesting. They had all been my friends for more than five 
months, and to some I had rendered little services by carrying their bag of zumeeta, or salt. They were not ungrateful, and our parting had something in it affecting, which, considering negroes in the degraded light they do, seemed greatly to astonish the Arabs.

On quitting Lari, we immediately plunged into a thickly-planted forest of acacias, with high underwood; and at the distance of only a few hundred yards from the town, we came upon large heaps of the elephants' dung, forming hillocks three and four feet in height, and marks of their footsteps : the tracks of these animals increased as we proceeded. Part of the day our road lay along the banks of the Tchad, and the elephants' footmarks, of an immense size, and only a few hours old, were in abundance. Whole trees were broken down, where they had fed; and where they had reposed their ponderous bodies, young trees, shrubs, and underwood, had been crushed beneath their weight. We also killed this day an enormous snake, a species of coluber; it was a most disgusting, horrible animal, but not however venomous. It measured eighteen feet from the mouth to the tail; it was shot by five balls, and was still moving off; when two Arabs, with each a sword, nearly severed the head from the body. On opening the belly, several pounds of fat were found, and carefully taken off by the two native guides who accompanied us. This they pronounced a sovereign remedy for sick and diseased cattle, and much prized amongst them. Scarcely a mile further, a drove of wild red cattle, which I at first took for deer, were seen bounding to the west. I had no gun, but got extremely close to them, and found they were what the Arabs call " bugra-hammar-wahash" (red cow wild). They appeared to partake of the bullock and buffalo, with a tuft or lump on the shoulder.

We bivouacked near a small parcel of huts, called Nyagami, in a beautiful spot, so thick of wood, that we could scarcely find a clear place for our encampment. While the tents were fixing, an alarm was given of wild boars : one of our party followed the scent, and, 
on his return, said he had seen a lion, and near him seven gazelles. I could not, however, find from the natives, that lions were ever seen here: numerous other animals appeared to abound, and that confirmed the opinion.

Feb. 7.-We moved for Woodie about eight, accompanied by two Arabs of Boo-Saif. I left the kafila, and proceeded a little to the westward, making a parallel movement with the camels. Birds of the most beautiful plumage were perched on every tree. Guinea fowls were in flocks of eighty or one hundred; and several monkeys chattered at us so impudently, that, separating one from the rest, we chased him for nearly half an hour : he did not run very fast, or straight forward, but was constantly doubling and turning, with his head over his shoulder, to see who was close to him. He was a handsome fellow, of a light brown colour, and black about the muzzle. About noon we came on a village of huts, called Barrah; and although only three in number, the natives flew in all directions. On our approaching the town, we beckoned to them, and got off our horses, for the purpose of giving them confidence, and sat down under the shade of a large tamarind tree. An old negro, who spoke a little Arabic, was the first who ventured to approach : seeing that he was not ill-treated, the others soon followed his example. I begged a little leban (sour milk), a most refreshing beverage after a hot ride, but none was to be found, until they were assured that I should pay for it; and at the sight of the dollar they all jumped and skipped like so many monkeys. Some biscuit, which I carried in my saddle-cloth pocket, and now began to eat, created much astonishment, and the first to whom I gave some, refused to eat it. One, rather bolder than the rest, put a small piece into his mouth, and pronounced it good, with such extravagant gestures, that my visitors all became so clamorous, that my stock was speedily demolished. I refused for a long time the man who had been sus-

H 2 
picious at first, to the great amusement of the rest, who seemed to like the joke amazingly.

I had promised the Arabs to share with them a sheep, provided they did not help themselves, and now made signs of my wish to purchase one. Two men went off to bring, as they said, a fat one. After a short time had elapsed, during which they had been delighted with the opening and shutting of my pocket-knife, a very miserable sheep was brought to me, which they seriously endeavoured to make me understand was a very fine one. The Arabs declared it to be good for nothing; and, therefore, though unwilling to be displeased, I quickly returned my dollar to my pocket, and made a motion towards my horse. The whole tribe, to my great astonishment, shouted out, and began to push about the vender of the sheep, and dance round me. Another very fine fat sheep was now brought forward from behind the crowd: offering the other first seemed a trick, in order to try whether I should find out the lean from the fat one; and although much sagacity was not required for this, it appeared to have raised me very much in their estimation.

The little nest of thatched huts in which they lived was most beautifully situated on a rising spot, in the midst of a rich and luxuriant, though not thick forest, about three miles to the north-east of Woodie; and the wells, which stand in a dell, thickly planted with palms (the first we had seen on this side of the desert), had troughs for more than a hundred and fifty cattle to drink at. One of the old men accompanied us, while his son carried the carcass of the sheep to Woodie, for which service he was rewarded by two coral beads, and a little snuff.

Close to the town we found the tents. Our party had made about fourteen miles, without leaving the banks of the lake at any great distance. Two elephants were seen swimming in the lake this day; and one, belonging to a drove at a distance, absolutely remained just 
before the kafila. Hillman had gone on in front on his mule, suffering sadly from weakness and fatigue, and had laid himself down in what appeared a delightful shade, to await the arrival of the camels, not expecting to see an elephant. He was absolutely reposing within a dozen yards of a very large one, without being aware of it; and on an Arab's striking the animal with a spear, he roared out and moved off. Poor Hillman's alarm was extreme.

Feb. 8. - On walking to the shores of the lake this morning, soon after sunrise, I was surprised to see how the water had encroached since the day before. More than two miles of the wood was entirely overflowed-the cotton plantations were covered with water. Were the lands cleared of wood, which would not be a laborious task, as the trees are mostly tulloh, and not large, almost any thing might be produced.

Feb. 9.-The courier had been sent off a second time, after being re-clothed and re-mounted, to receive the sheikh's orders, and we were not to proceed beyond Woodie until his pleasure was known. So jealous and so suspicious are these negro princes of the encroachment of the Arabs, that divers were the speculations as to whether the sheikh would, or would not, allow them to proceed with us nearer his capital.

A weekly fsug, or market, was held about a mile from the town; and the women flocking from the neighbouring negro villages, mounted on bullocks, who have a thong of hide passed through the cartilage of the nose when young, and are managed with great ease, had a curious appearance : a skin is spread on the animal's back, upon which, after hanging the different articles they take for sale, they mount themselves; milk, sour and sweet, a little honey, fowls, gussub, gafooly, are amongst their wares, fat and meloheea (ochra), a green herb, which, with bazeen, all negroes eat voraciously, and indeed Christians too, as I afterwards found out. The men brought 
oxen, sheep, goats, and slaves : the latter were few in number, and in miserable condition.

Woodie is a capital, or as they say, Blad Kebir, and is governed by a sheikh, who is a eunuch, and a man of considerable importance: they appear to have all the necessaries of life in abundance, and are the most indolent people I ever met with. The women spin a little cotton, and weave it into a coarse cloth of about six inches' width; the men either lie idling in their huts all day, or in the shade of a building, formed by four supporters and a thatched roof, which stands in an open space amongst the huts : this is also the court of justice and place of prayers. The men are considerably above the common stature, and of an athletic make; but have an expression of features particularly dull and heavy. The town stands about one mile west of the Tchad, four short days' march from Bornou. Game of all descriptions comes to within a stone's-throw of their doors, and the lake abounds with fish and water-fowl; yet have they so little exertion, that a few fish was almost the only produce of their labour which was offered for sale.

The women, like the Tibboo, have a square piece of blue or white cloth, tied over one shoulder, which forms their whole covering: their hair is however curiously and laboriously trained, and I observed that no one of tender years had any thing like a perfect head of hair. From childhood the head is shaved, leaving only the top covered; the hair from hence falls down quite round from the forehead to the pole of the neck, and is then formed into one solid plait, which in front lying quite flat just over the eyes, and behind being turned up with a little curl, has just the appearance of an old-fashioned coachman's wig in England: some of them are, however, very pretty.

Feb. 10.-I this morning went to the eastward, in order to see the extent of the forest, and also, if possible, to get a sight 
of the herd, of upwards of one hundred and fifty elephants, which some of the Arabs had seen the day before while their camels were feeding. I was not disappointed. I found them about six miles from the town, in the grounds annually overflowed by the waters of the lake, where the coarse grass is twice the height of a man : they seemed to cover the face of the country, and, I should think, exceeded the number I had expected to see. When the waters flow over these their pasturages, they are forced by hunger to approach the towns, and spread devastation throughout their march; whole plantations, the hopes of the inhabitants for the next year, are sometimes destroyed in a single night. Nothing, however, more ferocious than large antelopes, with a fox and wild hog or two, was to be seen, besides elephants, although I beat every thicket. We had followed about half a dozen of these antelopes for more than three hours, who merely changed their place without ever getting out of sight, but never allowed us to get near enough to hazard a shot. When quite fatigued, I determined on making for some distant huts, and begging a little milk, sweet or sour. No knowing landlady of a country inn ever scanned the character of her customer more than did this untaught, though cunning negro, whom we found there. He first denied that he had any, notwithstanding the bowls were full scarcely ten paces behind him; and then asked, what I had got to pay for it? I had really nothing; and after offering my pocket-handkerchief, which was returned to me as not worth any thing, I was about to depart, though ten long miles from the tents, thirsty as I was, when the Arab pointed to a needle, which was sticking in my jacket : for this and a white bead which the Arab produced, we had a bowl of fine milk and a basket of nuts, which refreshed us much; and we returned home by the lake, where I shot two birds-one a very fine crane, and the other of the woodpecker species, and saw a flock of at least five hundred pelicans, but could not get near enough to fire at them. 
The whole surface of the country for the last eighteen days had been covered with a grass which produced a calyx so full of prickles as to annoy us almost to misery : these prickles were of the finest and most penetrating sharpness that can be imagined; they attached to every part of our dress; and so small were the points, that it was impossible to extract them without their breaking and leaving a part behind: if we walked, at every step we were obliged to clear them from our feet-mats, blankets, trowsers, were filled with these irritating annoyances, so that there was no getting rid of them, by day or night; in short, no part of the body was free from them. The seed from this grass is called kashcia, and is eaten *.

Feb. 11. Two of the sheikh's officers arrived last night, with letters, and a present of goroo nuts of Soudan : they have a pleasant bitter taste, and are much esteemed by all the Tripoli people. After eating these nuts, water has a grateful flavour, be it ever so bad: the Arabs call them the coffee of the black country. /These letters pressed Boo Khaloom to continue his march towards Kouka, with all his people-a very great proof of his confidence in the peaceable disposition of our chief. The men were clothed with a bornouse each, a turban, and a red cap ; and after giving us fifteen bullocks, six sheep, and seventeen kail of gussub, returned home, promising that fresh supplies should be prepared for his people at Yeou, two days' march nearer Bornou. It was nearly dark when we reached a town called Burwha. We had travelled at a considerable distance from the lake after the first four miles of our journey, which here sweeps off greatly to the east.

* There is a very common grass which is grievously annoying from the prickles on its husk: it adheres to the dress and penetrates the skin. There is not one prickle, but the calyx is studded round, and they fasten themselves like grappling irons. These prickles may be considered one of the pests of the country : there is scarcely a place free from them, Our dog Niger is unable to walk, for they have got between his toes, and are adhering to every part of his long silken hair. 
Burwha is a walled town, and the first negro one we had seen: it may be called in this country a place of some strength; in proof of which the inhabitants have always defied the Tuarick marauders, who never entered the town: the walls may be about thirteen or fourteen feet high, and have a dry ditch, which runs quite round them. The town probably covers an extent equal to three square miles, and contains five or six thousand inhabitants. There is a covered-way, from which the defenders lance their spears at the besiegers, and instantly conceal themselves: there are but two gates, which are nearly east and west; and these being the most vulnerable parts for an enemy to attack, are defended by mounds of earth thrown up on each side, and carried out at least twenty yards in front of the gate, and have nearly perpendicular faces. These advanced posts are always thickly manned, and they conceive them to be a great defence to their walls : they cannot, however, calculate upon their being abandoned, as an enemy once in possession of them would so completely command the town, that from thence every part of it may be seen. Nevertheless, Burwha is a strong place, considering the means of attack which the Arabs have; and we were much struck with its appearance.

Feb. 12.-I rode through the town early this morning, previous to our move. All the principal huts had their little inclosure, with a cow or two, some goats and fowls ; and I saw a very fine fish, apparently roasted, or broiled, carried into one of them, on which I could have breakfasted with great pleasure. Gussub, in large baskets, and in the straw, was every where to be seen, and the women were spinning at the doors of most of the huts.

I rode nearly the whole of this day with Min Ali Tahar, the Gundowy Tibboo sheikh, who was accompanying us to Bornou: he had some little difference with the sheikh, of whom he was perfectly independent, and Boo Khaloom, ever politic, undertook to make up the misunderstanding; thereby not only showing his influence, but 
securing, in a manner, the future friendship of Tahar, whose district was always considered as the most dangerous part of the Tibboo country on the road to Mourzuk. Tahar was a sharp, intelligent fellow, spoke a little Arabic, and had often asked me many questions about my country, and my sultan; but to-day he was more inquisitive than usual._- Rais Khaleel," said he, " what would your sultan do to Min Ali, if he was to go to England? Would he kill me, or keep me there a prisoner? I should like to be there for about a month." I answered, "Certainly neither one nor the other : he would be much more inclined to make you a handsome present, and send you back again." Min Ali. "Oh! I should take him something; but what could I give him ? nothing but the skins of a dozen ostriches, some elephants' teeth, and a lion's skin." Ans. "The value of the present could be of no importance to my sultan; he would look at the intention : befriend his people-remember the Inglezi that you have seen; and should any more ever find their way to your tents, give them milk and sheep, and put them in the road they are going: promise me to do this, and I can almost promise you, that my sultan shall send you a sword, such a one as Hateeta had on my return, without your going to England, or giving him any thing." Min Ali. "Is he such a man? Barak Allah! What's his name?" "George." "George! Health to George; much of it! Salam Ali: George Yassur. Tell him, Min Ali Tahar wishes him all health and happiness; that he is a Tibboo who can command a thousand spears, and fears no man. Is he liberal? Is his heart large? Gulba Kebir. Does he give presents to his people?" "Very much so, indeed; some of his people think him too generous." Min Ali. "By the head of my father! Raas el Booe! they are wrong; the sultan of a great people should have a large heart, or he is unworthy of them. Who will succed him when he dies?" "His brother." "What is his name?" "Frederick." " Barak Allah! I hope he will be like George, matlook, liberal. Salem Ali ! 
Frederick. Health to Frederick! How many wives have they ?" "No Englishman has more than one," said I. " A gieb! a gieb! Wonderful! wonderful! why they should have a hundred." "No! no! we think that a sin," replied I. "Wallah! really (literally, by G- !) why I have four now ; and I have had more than sixty. Her I like best, however, always says, one would be more lawful: she may be right. You say she is. You are a great people. I see you are a great people, and know every thing. I, a Tibboo, am little better than a gazelle."

The road to-day was thickly scattered with trees-saw flocks of red cattle, and killed a wild hog. The hyænas came so close to the tents last night, that a camel, which lay about a hundred yards from the enclosure, was found nearly half-eaten. A lion first made a meal on the poor animal; when the hyænas came down upon what he had left. We had fires the whole night; and notwithstanding the continued howlings which these animals kept up until daylight, our rest was but little disturbed.-Halted near a water, called Chugelarem. We had now about eleven miles to make, previous to arriving at Yeou.

13th.-Chugelarem, though said to be a branch of the Tchad, was merely a still water, increased considerably by the overflowings of that lake in the wet season: the bottom was muddy, and nowhere deeper than two feet. The camels, horses, and followers of the kafila, waded through it without being much above their knees: it takes a zigzag direction, going first to the east, then to the north, and then to the east again.

We proceeded south, passing several very neat negro villages; and after about eleven miles, came to a very considerable stream, called the Yeou, in some parts more than fifty yards wide, with a fine hard sandy bottom, and banks nearly perpendicular, and with a strong current running three miles and a half in an hour to the eastward. As I expected, every one of the Arabs said this was the 
Nile, and that it ran into the great water the Tchad. A town of the same name stands on the south side of the river, which the inhabitants were unanimous in saying came from Soudan. It is at times double the width, and considerably deeper, and two canoes now lay upon the sand, in which the goods and passengers of kafilas passing in the wet season are conveyed across. The camels and horses swim with their heads made fast to the canoes./These canoes were of the rudest manufacture, and were formed of planks, rudely shaped by a small hatchet, and strongly fastened together by cords passed through holes bored in them, and a wisp of straw between, which they say effectually keeps out the water: they have high poops like the Grecian boats, and would hold twenty or thirty persons. The air from a running stream of clear water, and the freshness it imparted to all around, was such a relief after a march through sandy deserts, that both man and beast were in a manner renovated by its effects. The men, and even the women, bathed and washed, and the negroes swam all the horses. We here received ten bullocks by the sheikh's order, to make up the fifteen which he had directed to be given to Boo Khaloom, and the remainder of the seventeen kail (loads) of gussub which was to accompany them.

Feb. 14.-Visited Yeou, which is a neat town of huts, walled, but not above half the size of Burwha, and proceeded fourteen miles, when we came to a well. Here we should have remained with our tired camels and horses; but the numerous negro parties, with from two to twelve laden oxen, all said another well was grieb (near). Boo Khaloom, therefore, determined on proceeding to the next maten, or halting-place: some of the group were picturesque in the extreme; the women all laden with some purchase at the market, and the naked black children mounted on the tops of the loaded bullocks; and after twelve additional miles, an hour and a half after sunset, we came to a halt, but without arriving at the well. The branches of the trees hung so much over the road, and 
impeded the movements of the camels so greatly, that it was past ten o'clock at night before some of them came up.

Feb. 15.-We found the well, kalielwa, just off the road, nearly four miles nearer Bornou, and we were to push the camels on as far as possible, in order that the day after we might enter Kouka, the residence of the sheikh, in Arab form, and at an early hour. The road branched off in two directions: the one to the west led towards Kouka. Soon after this we came to a well and small town, and after sunset another; near the latter of which a Fezzaneer in the service of the sheikh met us, with a request that we would pitch our tents near a dead water called Dowergoo, a few miles further on, and remain the next day, as the huts that had been preparing were not ready. About eight we came to this piece of still water, abounding with wild fowl, having a village near it, called Gurdawa.

Feb. 16.-Halted. Our visitors here were not very numerous, although we were not above one hour's journey from the sheikh's residence, Kouka. Various were the reports as to the opinion the sheikh formed of the force which accompanied Boo-Khaloom: all agreed, however, that we were to be received at some distance from the town, by a considerable body of troops; both as a compliment to the bashaw, and to show his representative how well prepared he was against any attempt of those who chose to be his enemies.

One of the Arabs brought to me this day a Balearic crane; it measured thirteen feet from wing to wing.

Feb. 17.-This was to us a momentous day, and it seemed to be equally so to our conductors. Notwithstanding all the difficulties that had presented themselves at the various stages of our journey, we were at last within a few short miles of our destination; were about to become acquainted with a people who had never seen, or scarcely heard of, a European; and to tread on ground, the knowledge and true situation of which had hitherto been wholly unknown, 
These ideas of course excited no common sensations; and could scarcely be unaccompanied by strong hopes of our labours being beneficial to the race amongst whom we were shortly to mix; of our laying the first stone of a work which might lead to their civilization, if not their emancipation from all their prejudices and ignorance, and probably, at the same time, open a field of commerce to our own country, which might increase its wealth and prosperity. Our accounts had been so contradictory of the state of this country, that no opinion could be formed as to the real condition or the numbers of its inhabitants. We had been told that the sheikh's soldiers were a few ragged negroes armed with spears, who lived upon the plunder of the Black Kaffir countries, by which he was surrounded, and which he was enabled to subdue by the assistance of a few Arabs who were in his service; and, again, we had been assured that his forces were not only numerous, but to a certain degree well trained. The degree of eredit which might be attached to these reports was nearly balanced in the scales of probability; and we advanced towards the town of Kouka in a most interesting state of uncertainty, whether we should find its chief at the head of thousands, or be received by him under a tree, surrounded by a few naked slaves.

These doubts, however, were quickly removed. I had ridden on a short distance in front of Boo-Khaloom, with his train of Arabs, all mounted, and dressed out in their best apparel; and, from the thickness of the trees, soon lost sight of them, fancying that the road could not be mistaken. I rode still onwards, and on approaching a spot less thickly planted, was not a little surprised to see in front of me a body of several thousand cavalry drawn up in line, and extending right and left quite as far as I could see; and, checking my horse, I awaited the arrival of my party, under the shade of a wide-spreading acacia. The Bornou troops remained quite steady, 
without noise or confusion; and a few horsemen, who were moving about in front giving directions, were the only persons out of the ranks. On the Arabs appearing in sight, a shout, or yell, was given by the sheikh's people, which rent the air : a blast was blown from their rude instruments of music equally loud, and they moved on to meet Boo-Khaloom and his Arabs. There was an appearance of tact and management in their movements which astonished me: three separate small bodies, from the centre and each flank, kept charging rapidly towards us, to within a few feet of our horses' heads, without checking the speed of their own until the moment of their halt, while the whole body moved onwards. These parties were mounted on small but very perfect horses, who stopped, and wheeled from their utmost speed with great precision and expertness, shaking their spears over their heads, exclaiming, "Barca! barca! Alla hiakkum cha, alla cheraga!-Blessing! blessing! Sons of your country! Sons of your country!" and returning quickly to the front of the body, in order to repeat the charge. While all this was going on, they closed in their right and left flanks, and surrounded the little body of Arab warriors so completely, as to give the compliment of welcoming them very much the appearance of a declaration of their contempt for their weakness. I am quite sure this was premeditated; we were all so closely pressed as to be nearly smothered, and in some danger from the crowding of the horses and clashing of the spears. Moving on was impossible; and we therefore came to a full stop: our chief was much enraged, but it was all to no purpose, he was only answered by shrieks of "Welcome !" and spears most unpleasantly rattled over our heads expressive of the same feeling. This annoyance was not however of long duration; Barca Gana, the sheikh's first general, a negro of a noble aspect, clothed in a figured silk tobe, and mounted on a beautiful Mandara horse, made his appearance; and, after a little delay, the rear was 
cleared of those who had pressed in upon us, and we moved on, although but very slowly, from the frequent impediment thrown in our way by these wild equestrians.

The sheikh's negroes, as they were called, meaning the black chiefs and favourites, all raised to that rank by some deed of bravery, were habited in coats of mail composed of iron chain, which covered them from the throat to the knees, dividing behind, and coming on each side of the horse : some of them had helmets, or rather skullcaps, of the same metal, with chin-pieces, all sufficiently strong to ward off the shock of a spear. Their horses' heads were also defended by plates of iron, brass, and silver, just leaving sufficient room for the eyes of the animal.

At length, on arriving at the gate of the town, ourselves, BooKhaloom, and about a dozen of his followers, were alone allowed to enter the gates; and we proceeded along a wide street completely lined with spearmen on foot, with cavalry in front of them, to the door of the sheikh's residence. Here the horsemen were formed up three deep, and we came to a stand : some of the chief attendants came out, and after a great many "Barca's! Barca's !" retired, when others performed the same ceremony. We were now again left sitting on our horses in the sun: Boo-Khaloom began to lose all patience, and swore by the bashaw's head, that he would return to the tents if he was not immediately admitted: he got, however, no satisfaction but a motion of the hand from one of the chiefs, meaning " wait patiently ;" and I whispered to him the necessity of obeying, as we were hemmed in on all sides, and to retire without permission would have been as difficult as to advance. Barca Gana now appeared, and made a sign that Boo-Khaloom should dismount: we were about to follow his example, when an intimation that BooKhaloom was alone to be admitted again fixed us to our saddles. Another half hour at least passed without any news from the interior 


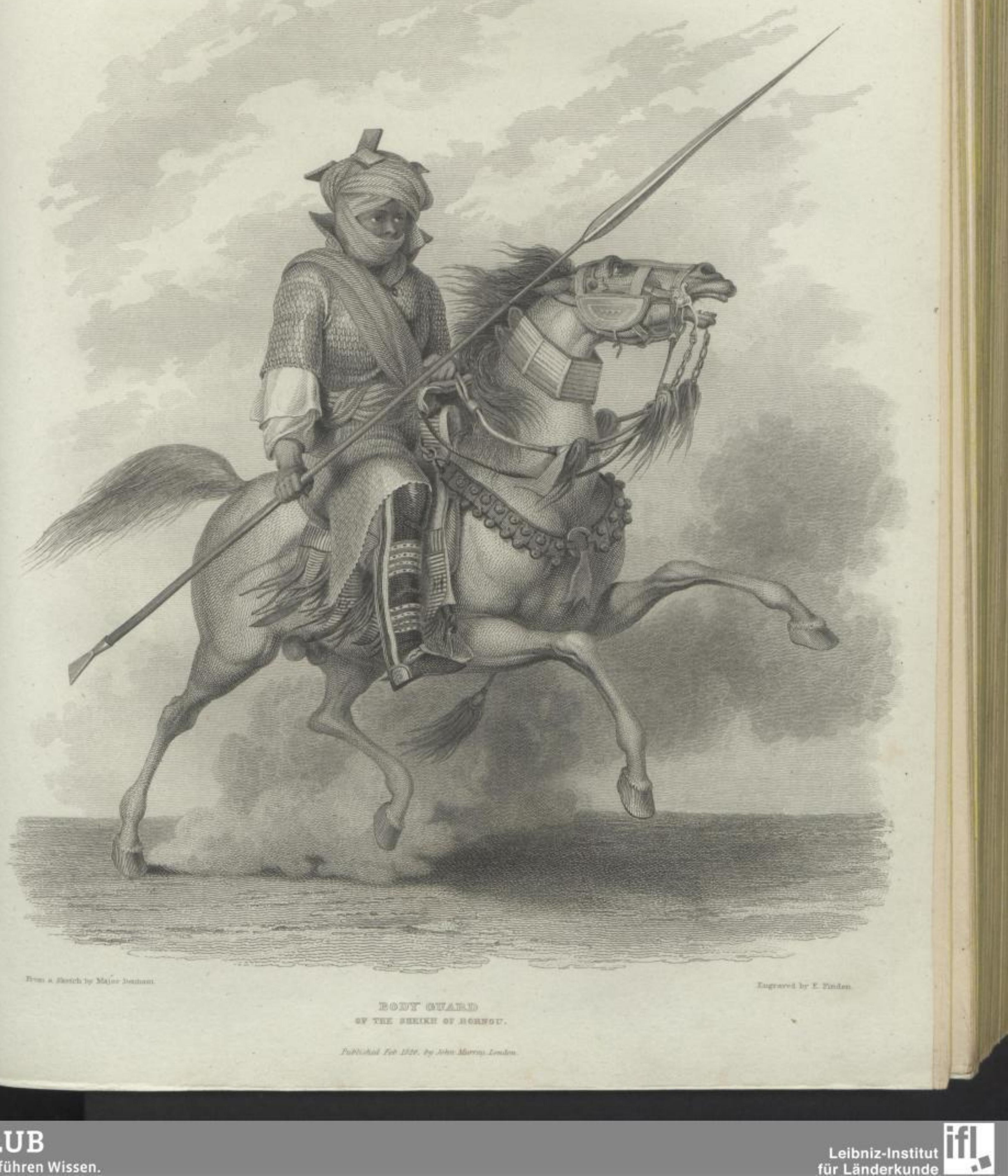

\section{ᄀ SLUB}

Wir führen Wissen. 

of the building; when the gates opened, and the four Englishmen only were called for, and we advanced to the skiffa (entrance). Here we were stopped most unceremoniously by the black guards in waiting, and were allowed, one by one only, to ascend a staircase; at the top of which we were again brought to a stand by crossed spears, and the open flat hand of a negro laid upon our breast. Boo-Khaloom came from the inner chamber, and asked "If we were prepared to salute the sheikh as we did the bashaw ?" We replied "Certainly :" which was merely an inclination of the head, and laying the right hand on the heart. He advised our laying our hands also on our heads, but we replied, " the thing was impossible! we had but one manner of salutation for any body, except our own sovereign."

Another parley now took place, but in a minute or two he returned, and we were ushered into the presence of this Sheikh of Spears. We found him in a small dark room, sitting on a carpet, plainly dressed in a blue tobe of Soudan and a shawl turban. Two negroes were on each side of him, armed with pistols, and on his carpet lay a brace of these instruments. Fire-arms were hanging in different parts of the room, presents from the bashaw and Mustapha L'Achmar, the sultan of Fezzan, which are here considered as invaluable. His personal appearance was prepossessing, apparently not more than forty-five or forty-six, with an expressive countenance, and a benevolent smile. We delivered our letter from the bashaw; and after he had read it, he inquired " what was our object in coming ?" We answered, " to see the country merely, and to give an account of its inhabitants, produce, and appearance; as our sultan was desirous of knowing every part of the globe." His reply was, " that we were welcome! and whatever he could show us would give him pleasure: that he had ordered huts to be built for us in the town; and that we might then go, accompanied by one of his people, to see them; and that when we were recovered from the fatigue of our long 
journey, he would be happy to see us." With this we took our leave.

Our huts were little round mud buildings, placed within a wall, at no great distance from the residence of the sheikh : the inclosure was quadrangular, and had several divisions formed by partitions of straw mats, where nests of huts were built, and occupied by the stranger merchants who accompanied the kafila: one of these divisions was assigned to us, and we crept into the shade of our earthy dwellings, not a little fatigued with our entré and presentation. 


\section{CHAPTER II.}

KOUKA.

Our huts were immediately so crowded with visitors, that we had not a moment's peace, and the heat was insufferable. BooKhaloom had delivered his presents from the bashaw, and brought us a message of compliment, together with an intimation that our own would be received on the following day. About noon we received a summons to attend the sheikh; and we proceeded to the palace, preceded by our negroes, bearing the articles destined for the sheikh by our government; consisting of a double-barrelled gun, by Wilkinson, with a box, and all the apparatus complete, a pair of excellent pistols in a case, two pieces of superfine broad cloth, red and blue, to which we added a set of china, and two bundles of spices.

The ceremony of getting into the presence was ridiculous enough, although nothing could be more plain and devoid of pretension than the appearance of the sheikh himself. We passed through passages lined with attendants, the front men sitting on their hams; and when we advanced too quickly, we were suddenly arrested by these fellows, who caught forcibly hold of us by the legs, and had not the crowd prevented our falling, we should most infallibly have become prostrate before arriving in the presence. Previous to entering into the open court, in which we were received, our papouches, or slippers, were whipped off by these active though sedentary gentlemen of the chamber; and we were seated on some clean sand on each side of a raised bench of earth, covered with a carpet, on which the

к 2 
sheikh was reclining. We laid the gun and the pistols together before him, and explained to him the locks, turnscrews, and steel shot-cases holding two charges each, with all of which he seemed exceedingly well pleased: the powder-flask, and the manner in which the charge is divided from the body of powder, did not escape his observation; the other articles were taken off by the slaves, almost as soon as they were laid before him. Again we were questioned as to the object of our visit. The sheikh, however, showed evident satisfaction at our assurance that the king of England had heard of Bornou and himself; and, immediately turning to his kaganawha (counsellor), said, "This is in consequence of our defeating the Begharmis." Upon which, the chief who had most distinguished himself in these memorable battles, Bagah Furby (the gatherer of horses) seating himself in front of us, demanded, "Did he ever hear of me?" The immediate reply of "Certainly" did wonders for our cause. Exclamations were general; and, "Ah ! then, your king must be a great man !' was re-echoed from every side. We had nothing offered us by way of refreshment, and took our leave.

I may here observe, that besides occasional presents of bullocks, camel-loads of wheat and rice, leathern skins of butter, jars of honey, and honey in the comb, five or six wooden bowls were sent us, morning and evening, containing rice, with meat, paste made of barley flour, savoury but very greasy; and on our first arrival, as many had been sent of sweets, mostly composed of curd and honey.

In England a brace of trout might be considered as a handsome present to a traveller sojourning in the neighbourhood of a stream, but at Bornou things are done differently. A camel-load of bream, and a sort of mullet, was thrown before our huts on the second morning after our arrival; and for fear that should not be sufficient, in the evening another was sent.

We had a fsug, or market, in front of one of the principal gates of the town. Slaves, sheep, and bullocks, the latter in great num- 
bers, were the principal live stock for sale. There were at least fifteen thousand persons gathered together, some of them coming from places two and three days distant. Wheat, rice, and gussub, were abundant: tamarinds in the pod, ground nuts, ban beans, ochroes, and indigo; the latter is very good, and in great use amongst the natives, to dye their tobes (shirts) and linen, stripes of deep indigo colour, or stripes of it alternately with white, being highly esteemed by most of the Bornou women: the leaves are moistened, and pounded up altogether when they are formed into lumps, and so brought to market. Of vegetables there was a great scarcity -onions, bastard tomatoes, alone were offered for sale; and of fruits not any : a few limes, which the sheikh had sent us from his garden, being the only fruit we had seen in Bornou. Leather was in great quantities; and the skins of the large snake, and pieces of the skin of the crocodile, used as an ornament for the scabbards of their daggers, were also brought to me for sale; and butter, leban (sour milk), honey, and wooden bowls, from Soudan. The costumes of the women, who for the most part were the vendors, were various : those of Kanem and Bornou were most numerous, and the former was as becoming as the latter had a contrary appearance. The variety in costume amongst the ladies consists entirely in the head ornaments; the only difference, in the scanty covering which is bestowed on the other parts of the person, lies in the choice of the wearer, who either ties the piece of linen, blue or white, under the arms, and across the breasts, or fastens it rather fantastically on one shoulder, leaving one breast naked. The Kanemboo women have small plaits of hair hanging down all around the head, quite to the poll of the neck, with a roll of leather or string of little brass beads in front, hanging down from the centre on each side of the face, which has by no means an unbecoming appearance: they have sometimes strings of silver rings instead of the brass, and a large round silver ornament in front of their foreheads. The female slaves from 
Musgow, a large kingdom to the south-east of Mandara, are particularly disagreeable in their appearance, although considered as very trustworthy, and capable of great labour : their hair is rolled up in three large plaits, which extend from the forehead to the back of the neck, like the Bornowy ; one larger in the centre, and two smaller on each side: they have silver studs in their nose, and one large one just under the lower lip of the size of a shilling, which goes quite through into the mouth; to make room for this ornament, a tooth or two is sometimes displaced.

The prineipal slaves are generally intrusted with the sale of such produce as the owner of them may have to dispose of; and if they come from any distance, the whole is brought on bullocks, which are harnessed after the fashion of the country, by a string or iron run through the cartilage of the nose, and a saddle of mat. The masters not unfrequently attend the fsug with their spears, and loiter about without interfering; purchases are mostly made by exchange of one commodity for another, or paid for by small beads, pieces of coral and amber, or the coarse linen manufactured by all the people, and sold at forty gubka* for a dollar. Amongst other articles offered to me for sale by the people (who, if I stood still for an instant, crowded round me) was a young lion and a monkey; the latter appeared really the more dangerous of the two, and from being a degree or two lighter in complexion than his master, he seemed to have taken a decided aversion to me.

The lion walked about with great unconcern, confined merely by a small rope round his neck held by the negro, who had caught him when he was not two months old, and having had him for a period of three months, now wished to part with him : he was about the size of a donkey colt, with very large limbs, and the people seemed to go very close to him without much alarm, notwithstanding

* Gubka, about a yard English. 
he struck with his foot the leg of one man who stood in his way, and made the blood flow copiously: they opened the ring which was formed round this noble animal as I approached; and, coming within two or three yards of him, he fixed his eye upon me in a way that excited sensations I cannot describe, from which I was awakened by the fellow calling to me to come nearer, at the same time laying his hand on the animal's back; a moment's recollection convinced me that there could be no more danger nearer than where I was, and I stepped boldly up beside the negro, and I believe should have laid my hand on the lion the next moment; but after looking carelessly at me, he brushed past my legs, broke the ring, and pulled his conductor away with him, overturning several who stood before him, and bounded off to another part where there were fewer people.

Feb. 22.-Boo-Khaloom came to us this morning, after seeing the sheikh, and said, "that he had explained to him our anxiety to see every thing, and take home the skins of birds, and gather the plants that appeared most interesting to us, and to take notes of what we saw." The sheikh's reply was, that "we, or any of our countrymen, whom the bashaw thought proper to send, should be welcome to see any part of his dominions, but that out of them he could not suffer us at present to go." Boo-Khaloom, who was fully aware of the ulterior objects we had in view, and whose advice $I$ always found dictated by an anxious desire to serve us, was of the greatest use, from his intimate acquaintance with the dispositions of the people; and he was of opinion that we should, in the first instance, be satisfied with this offer of the sheikh, and not alarm him, by declaring too abruptly all our intentions. Accustomed as they are to plunder, and to be plundered, at the sight of strangers, apparently possessing superior powers, and superior weapons to themselves, their alarm is not to be wondered at; and when these strangers were represented to them as having come from a distance 
KOUKA.

almost beyond their belief, for purposes they could not in the least comprehend the importance of, it required extreme delicacy and great management to tranquillize their minds, and obtain their confidence.

A report had gone abroad, that one of our purposes was to build ships, in which we should embark on the lake, return to our own country, and then that the white people would come and destroy them all. For these reports we had, I have no doubt, to thank some of the Mourzuk merchants who had preceded us; and whose frequent visits were as injurious to our stores as their advice would have been to our interests, had not circumstances prevented the latter from being acted upon.

Boo-Khaloom assured us " these reports had gained considerable ground, but that he had explained to the sheikh how unfounded they were; and what we proposed doing here was what had been done during the last year by the bashaw's permission, in many parts of the regency of Tripoli."

All the Arabs, who had formed our escort, were in great glee by the report of the approach of the sultan of Begharmi, with a large force, to within four short days of Kouka. The sheikh-el-Kanemy had, in former expeditions, laid waste his whole country, each time driving the sultan from Kermuk, or the capital. On the last occasion he had destroyed, by fire, the towns which the natives had deserted, and had remained nearly three months in the country. The sultan, with all his family and slaves, had, as before, retired to the other side of a large river, to the south of his dominions, inhabited by Kaffirs or savages; but who, nevertheless, always afforded him shelter and protection. This people were described as resembling the sands of the desert in number; and they had now accompanied him to revenge himself on the sheikh of Bornou. The prospect of plunder, and making slaves, which these reports held out to the Arabs, raised their spirits to such a degree, that they passed 
half the night in debating how their booty was to be conveyed across the desert : without remembering that their enemies were first to be conquered. A gun being merely presented, they all declared sufficient to drive away a thousand negroes. Could these poor creatures but once be made to understand the real state of an Arab's pouch, with seldom more than one or two loads of bad powder, and the little dependence to be placed in his firelock, a miserable French piece, of the original value of about twelve shillings, that misses fire at least every other time, how much more justly would they estimate the Arabs' strength!

Feb. 24.-We heard this day that the Begharmis had halted at a place called Gulphi, on hearing that Boo-Khaloom was here with a party of Arab warriors; but it was strongly reported that the sheikh would immediately send a force into their country, in order to punish the sultan for even thinking of revenge.

Feb. 26.-Boo-Khaloom was to have seen the sheikh, in order to convince him that all, and more than the presents destined for him by our government, had been delivered to him; and we were afterwards to see him ourselves, and request permission to visit some of the neighbouring towns. After this interview, Boo-Khaloom came to our huts, and explained to us that the sheikh had mentioned merely to his chief attendant, that he had heard of a watch being intended for him as well as the powder, and that as he had not seen it, he was disappointed-he, however, desired us to visit him the next day. The sheikh had given all Boo-Khaloom's people a blue tobe, and himself two very handsome female slaves from Soudan, of a deep copper colour, under twenty years of age, with two others, negresses, to attend on them. We had news this day that the people of Begharmi had left Gulphi on their return home, and were about to rebuild their capital.

Feb. 2\%.-We attended the sheikh, about three hours before noon. He received us with considerable affability, and appeared 
satisfied that his presents were all delivered to him: when the explanation was given, he said nothing was necessary to secure his good will; but they told him the articles he mentioned were brought, and therefore he asked for them. Indeed, if the things had been properly delivered at first, no question, I am sure, would have arisen on the subject. He again inquired what were our wishes ; no mention was however made of the orders of our government, that any one should remain for any time near him. He made numberless inquiries, wished that the nature of a map should be described to him, and begged that Ali (as Hillman the carpenter was called) should make some boxes for him.

We asked to see the Tchad and the Shary, both of which waters, with the old town of Bornou, he promised us we should visit in a few days. He asked many questions about our manner of attacking a walled town; and on our explaining to him that we had guns which carried ball of twenty-four and thirty-two pounds weight, with which we breached the wall, and then carried the place by assault, his large dark eyes sparkled again, as he exclaimed, "Wonderful! wonderful!" He inquired if we had any thing with us like wild-fire, which could be thrown into a place and burn it; and was greatly disappointed on our answering in the negative. I could not help however consoling him by an assurance that what we had brought him was that which we considered as likely to be most acceptable; that before our coming he was a stranger; that now we should see what he was most in need of; and that two camel-loads of gunpowder were easier for us to send him than the like quantity of dates from Fezzan. We promised at night to show him two rockets; and we had scarcely eaten our dinner when Karawash, one of his chiefs, came to say the sheikh was impatient, and very fortunately there were in the town several of the hostile Shouas-a dangerous race of Arab origin, who occupy the frontier of his kingdom, and he was anxious they should see the effect of these terrible fire-engines. 
Mr. Clapperton fixed them on a rest of three spears in front of the sheikh's residence, before a crowd of persons; and the shrieks of the people, both there assembled and in their huts, were heard for some seconds after the rockets had ascended.

Feb. 28.-There was a disturbance in the camp this morning that nearly approached to direct mutiny, amongst Boo-Khaloom's Arabs. $\mathrm{He}$ had brought with him a very large assortment of valuable merchandize, for which there was but little sale at either Kouka or Angornou, and he was anxious to proceed to Soudan. The tghrees, or infantry, refused to accompany him : they said the bashaw had ordered them to come thus far with the English, and that Soudan was bhaid (distant), and go they would not. Some one had hinted to them that the sheikh wished to send a ghrazzie (marauding expedition) to Begharmi, and that Boo-Khaloom opposed such wish, as not consistent with his orders; and their profit being greater by an expedition of plunder and cruelty, than by one of peace and commerce, they preferred the east to the west. Boo-Khaloom certainly had refused to proceed on one of these marauding expeditions, much to the credit of his humanity, and highly complimentary to the English nation; whose servant, he often assured me, he felt himself to be on this mission. The Arabs, however, knew the sheikh's wishes, and things remained in a very unsettled state.

I paid a visit this evening to Sooloo, one of the sheikh's principal Shouaas, to whom I had given a silk handkerchief in the morning: his habitation consisted of two inclosures, besides one for his two horses, cow, and goats, and may be taken as a sample of the best residences in Kouka. In the first of these divisions was a circular hut, with a cupola top, well thatched with gussub straw, something resembling that of the Indian corn: the walls were of the same materials; a mud wall, of about two feet high, separated one part from the rest, and here his corn was kept; and a bench of like simple composition, at the opposite side, was his resting-place : this

L 2 
KOUKA.

was covered with mats; and his spears, and wooden bowls for water and milk, hung on pegs, completed the furniture: here was his own apartment. In the second division there were two huts, rather smaller, about ten paces from each other, in which dwelt his two wives: they were called to the door, and desired to salute me; but on looking up, uttered a scream, and hiding their faces with their hands, crept back again so quickly, as to make me almost ashamed of my complexion.

March 1.-A few yams were sent us by the sheikh, the only ones we had seen, and a great treat they proved to us, for it was the only vegetable we had tasted for many months. A meeting took place this morning at day-break, under a large tree in front of the sheikh's residence, and in his presence, between the Arab sheikhs and Boo-Khaloom. The Arabs had appealed to him as their umpire; and although he appeared not to take any part in their disputes, yet $I$ thought a disposition was very apparent in him to increase the feud : he offered to mount one hundred of the Arabs, and send one of his chiefs, under Boo-Khaloom's orders, to Begharmi, with fifteen hundred or two thousand horsemen; and great part of the produce of this expedition was to be sent as a present to the bashaw. Nothing could be more distressing than Boo-Khaloom's situation; he knew the disposition of his master too well not to feel what his fate would be, if he refused such an opportunity of taking him at least two thousand slaves, - his own inclinations led him to proceed to Soudan ; but he was still anxious to avoid becoming the scourge of one people, to gratify the revenge of another. The Arabs were also divided. The people of Begharmi had, on the last expedition, nearly foiled their invaders by abandoning their towns, driving off their flocks and cattle, and obliging the sheikh's people to subsist entirely, for twenty-five days, on a little prepared paste made of flour and curd, which they always take with them to the field. This the mounted Arabs dreaded a repetition of, while the more adventurous infantry, 
who had nothing to trade with but their gun, and consequently nothing to lose but their lives, exclaimed loudly for the ghrazzie.

March 2.-Boo-Khaloom went this day to Birnie, for the purpose of paying his respects to the sultan, who resides there, and we accompanied him. Angornou, a very large and populous town, where the sheikh resided previous to his building Kouka, is about sixteen miles from that place, and two miles from Birnie. BooKhaloom took with him presents to the amount of about one hundred and twenty dollars, but by some strange mistake we went empty-handed.

On our arrival at Birnie, which is a walled town, with huts of the same description as those in Kouka, and probably contains ten thousand inhabitants, we were first conducted to the gate of the sultan's mud edifice, where a few of the court were assembled to receive us; and one, a sort of chamberlain, habited in eight or ten tobes, or shirts, of different colours, the outside one of fine white tufted silk of the manufacture of Soudan. In his hand he carried an immense staff, like a drum-major's baton, and on his head he bore a turban exceeding in size any thing of the kind we had before seen; this was however but a trifling one to those we were destined to behold at the audience on the following morning. After salutations, Barca l'affia el hamdalilla! (Blessing!-Are you well? Thank God!) which lasted for some minutes, we were conducted to some huts destined for our resting-place for the night: they were not, however, of a tempting description; and Boo-Khaloom proposed that a large tent should be pitched any where, which would be preferable. These wishes were quickly complied with; a large marquee was in a very short time ready for our reception, with a screen of linen running all round it, which, although it kept out the crowds of people who were assembled round the place, admitted the air, and formed a most inviting retreat from the burning sun that shone above us. The sultan shortly after sent word, that by sunrise the 
next morning he would receive us. In the evening a most plentiful, if not delicate, repast was brought to us, consisting of seventy dishes, each of which would have dined half-a-dozen persons with moderate appetites. The sultan himself sent ten, his wives thirty, and his mother thirty; and for fear the English should not eat like the Bornowy, a slave or two was loaded with live fowls for our dinner. The meats consisted of mutton and poultry, and were baked, boiled, and stewed.

March 3.-Soon after daylight we were summoned to attend the Sultan of Bornou. He received us in an open space in front of the royal residence: we were kept at a considerable distance while his people approached to within about 100 yards, passing first on horseback; and after dismounting and prostrating themselves before him, they took their places on the ground in front, but with their backs to the royal person, which is the custom of the country. He was seated in a sort of cage of cane or wood, near the door of his garden, on a seat which at the distance appeared to be covered with silk or satin, and through the railing looked upon the assembly before him, who formed a sort of semicircle extending from his seat to nearly where we were waiting. Nothing could be more absurd and grotesque than some, nay all, of the figures who formed this court. Here was all the outward show of pomp and grandeur, without one particle of the staple commodity, power, to plead its excuse; he reigns and governs by the sufferance of the sheikh: and the better to answer his views, by making him more popular with all parties, the sultan is amused by indulging in all the folly and bigotry of the ancient negro sovereigns. Large bellies and large heads are indispensable for those who serve the court of Bornou; and those who unfortunately possess not the former by nature, or on whom lustiness will not be forced by cramming, make up the deficiency of protuberance by a wadding, which, as they sit on the horse, gives the belly the curious appearance of hanging over the pummel of the 


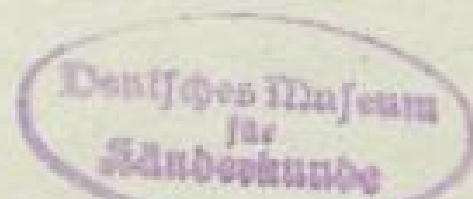

\section{ㄱ SLUB}




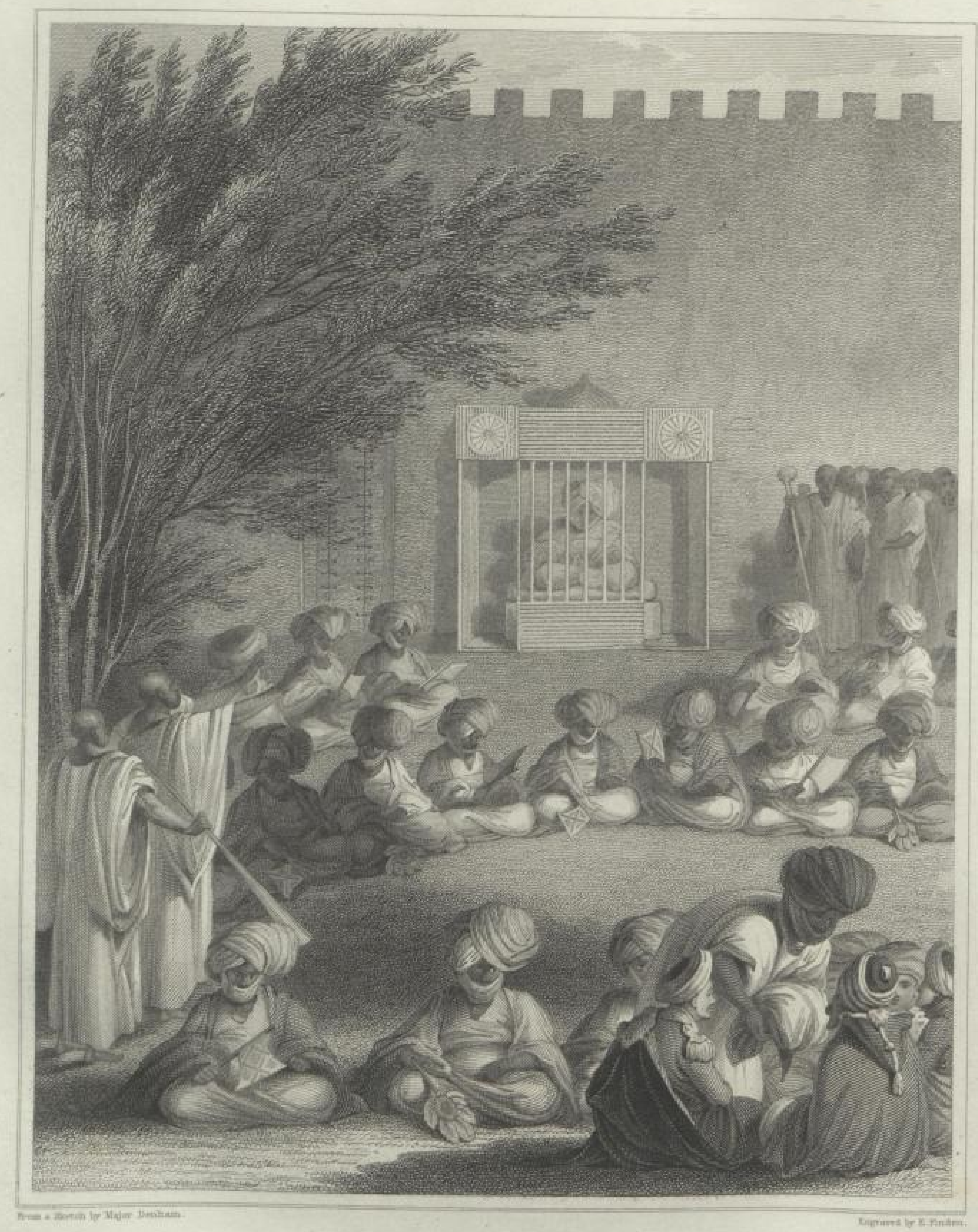

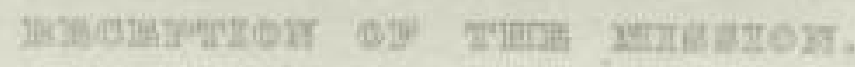

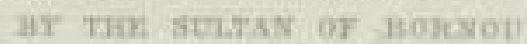

\section{$\square$ SLUB}


saddle. The eight, ten, and twelve shirts, of different colours, that they wear one over the other, help a little to increase this greatness of person: the head is enveloped in folds of muslin or linen of various colours, though mostly white, so as to deform it as much as possible; and those whose turban seemed to be the most studied had the effect of making the head appear completely on one side. Besides this they are hung all over with charms, inclosed in little red leather parcels, strung together; the horse, also, has them round his neck, in front of his head, and about the saddle.

When these courtiers, to the number of about two hundred and sixty or three hundred, had taken their seats in front of the sultan, we were allowed to approach to within about pistol-shot of the spot where he was sitting, and desired to sit down ourselves, when the ugliest black that can be imagined, his chief eunuch, the only person who approached the sultan's seat, asked for the presents. BooKhaloom's were produced, inclosed in a large shawl, and were carried unopened to the presence. Our glimpse was but a faint one of the sultan, through the lattice-work of his pavilion, sufficient however to see that his turban was larger than any of his subjects', and that his face, from the nose downwards, was completely covered. A little to our left, and nearly in front of the sultan, was an extempore declaimer shouting forth praises of his master, with his pedigree; and near him one who bore the long wooden frumfrum, on which he ever and anon blew a blast, loud and unmusical. Nothing could be more ridiculous than the appearance of these people squatting down in their places, tottering under the weight and magnitude of their turbans and their bellies, while the thin legs that appeared underneath but ill accorded with the bulk of the other parts.

Immediately after this ceremony we took our departure for Angornou. Angornou is the largest and most populous town of Bornou, and is situated a few miles from the Tchad. This town contains at least thirty thousand inhabitants: it is large and straggling, 
KOUKA.

but not walled. The huts are also larger and more commodious than those of Kouka; some of them having four mud walls, and two chambers. All our friends the merchants, who had accompanied the kafila from Tripoli and Mourzuk, had removed here, after paying their respects to the sheikh at Kouka, this being the fsug, or market town : they visited us immediately on our arrival. The only traders to Soudan are Moors. I found here a native of Loggun, who had just returned from Sennaar; he had been, however, two years on the journey. This man I was extremely anxious to see, but he was purposely moved away; and when, on the following day, I followed him to Kouka, he sent me word, that until he had seen the sheikh he dared not come to the hut.

The public market day is on a Wednesday, and attended sometimes by eighty or a hundred thousand persons, as the natives say, in peaceable times; but there was a very good market this day in an open space in the centre of the town, which is held every evening. Fish, flesh, and fowls, were in abundance, dressed and undressed, and tomatas, and onions, but no other vegetables.-Again my excessive whiteness became a cause of both pity and astonishment, if not disgust: a crowd followed me through the market, others fled at my approach; some of the women oversetting their merchandize, by their over anxiety to get out of my way; and although two of them were so struck with astonishment as to remain fixed to the spot, unconscious of the escape of their companions, they no sooner perceived me quite close to them, than they too ran off irresistibly affrighted. The day had been insufferably hot, and the night was little less so : indeed I think Kouka the better air of the two. I preferred this night sleeping in the open air.

March 4.-Linen is so cheap that most of the males in Angornow indulge in the luxury of a shirt and a pair of trowsers : several beggars stood near the fsug, and holding the remains of an old pair of the latter in their hand, while they held up their shirt, in proof 
of their assertion, kept exclaiming, " But breeches, there are none! But breeches, there are none!" This novel mode of drawing the attention of the passers-by so amused me, that I could not help laughing outright.

The principal demand at Angornou was for amber and coral; a large round piece of the former brought four dollars in money, and a string, eighty or one hundred. Pieces of brass and copper were also much sought after: all other kinds of merchandize were paid for in slaves or tobes; but these brought money, and were readily sold. The inhabitants are mostly Bornowy. The strangers, however, are numerous ; and many Tibboos and Kanemboos reside here for certain months in the year. The men are well grown, but not so well-looking as the people of Kanem : the large mouth, and thick lips, are strikingly ugly features; the men's heads are, in general, closely shaved, and those of the lower orders uncovered. The only persons armed near the sultan's person were some hundreds of negroes, in blue tobes, who were outside the court circle. These bore immense clubs, with a large round head: bows and arrows were slung at their backs, and a short dagger placed along the inside of the right arm. A footman, in attendance on a chief mounted, ran behind him, carrying four spears.

March 5.-I had proposed making an excursion, for a few days, to a large river to the southward of Kouka, called the Shary, as the only way to gain authentic information about it; and Dr. Oudney wished to accompany me. We were, however, obliged to put off our journey, first, in consequence of his illness, and, secondly, from the unsettled state of Boo-Khaloom's affairs with the Arabs. BooKhaloom paid us a visit after seeing the sheikh; and from what I could gather, although nothing was freely communicated, the probability of the ghrazzie's going was increased. Hillman had made two wooden boxes for the sheikh, the workmanship of which surprised him exceedingly, and, during our absence, he had sent for him, and 
requested he would commence making a sort of litter, to go between two camels, or mules, such as he had heard were used by the sultans of Fezzan : our carpenter very frankly said, that any thing he could do should be done with pleasure, but he could not work in the sun, and that a shed must be built for him, and wood must be found for him, as he had seen none in the country that would make the keel of a jolly-boat. As much as was necessary of this reply was interpreted to the sheikh, who promised him that negroes should make mats directly for his shed, and that others should go into the wood and bring the largest trees they could find; and in the evening a present came for the carpenter of wheat, rice, honey, and butter.

March 6.-The sheikh sent this morning to say, that he wished for some of our rockets, in order that the Shouaas, his enemies, might see what the English had brought him. On Monday, the day of the fsug or market, when they would be in the town, we promised him six; but reminded him, at the same time, that we had but few, and that here we could make no more. He also sent a very fine young lion, about three months old, not above half the size of that I had seen before : this was a very tame good-natured fellow, and I could not help regretting the necessity we were under of refusing him a corner of our huts, as he was ordered to be immediately killed in consequence of our declining to accept him.

March 7.-Doctor Oudney's illness increased, and he had daily fits of the ague, which, in his weak state, became alarming. I had made it my business, as I thought it my duty, to cultivate the friendship and good-will of Boo-Khaloom, and by his means I hoped to be made acquainted with the sheikh's real intentions towards us. The man of Loggun, who had returned from Senaar, I used every means to get a sight of, but I found it impossible, and he sent me word privately that he dared not come.

March 8 and 9.-Both these days the numbers of persons who crowded my hut, from morning to night, were greater, and con- 
sequently their visits more pestering than common. Every little thing, from the compass to the pen and ink, from the watch to the tin cup out of which I drank, excited their curiosity; and as they now became bolder, they seized hold of every thing which they formerly only eyed at a distance. It was not, however, their curiosity alone that was excited-the possession was coveted, either for themselves or the sheikh, of every article: a looking-glass, and a small lantern, I rescued out of the hands of at least a dozen, a dozen times. A copy of Captain Lyon's book, the fame of which had preceded us, in consequence of Doctor Oudney's having shown it to some merchants at Mourzuk, was demanded twenty times a day, and it required all my patience to go over and explain the pictures as often as they required. It produced very different effects, but in all astonishment and in most suspicion. The sheikh had heard of it, and one of his slaves borrowed it for him of my servant, by stealth, as he did not wish it to be known that he had a desire to see it. For three days after this I was again and again applied to by all his chief people to see what I had drawn, or written, as they express it, of Bornou. I repeatedly assured them, that those in the book were not mine, that the person who wrote them was far away. It would not do; they shook their heads, and said I was eunning, and would not show them. They then changed their tone, and very seriously begged that I would not write them, that is, draw their portraits ; that they did not like it, that the sheikh did not like it, that it was a sin; and I am quite sure, from the impression, that we had much better never have produced the book at all.

The sheikh expressed a wish that two rockets might be started, on a signal being made from the top of his house. I gave Karowash a blue light, with instructions how to make the signal: his heart, however, failed him when he got to the spot, and the signal was made by a wisp of straw. The first rocket 'went off nearly 
perpendicular, and with beautiful effect. I lessened very much the elevation of the second, and it flew over the town not more than a hundred yards higher than the tops of the huts; and bursting in its course, occasioned a universal scream, that lasted for some seconds. Its consequences I believe were not so serious as the first display of fire-works was at Mourzuk: there several ladies lost all present hopes of blessing their husbands with little pledges of love; and in one house the favourite slave of a particular friend of ours was put instantly to bed of a seven months'. child.

March 10.-We had now been in Kouka nearly a month-had seen the sheikh but three times; and we discovered, that people coming from the east and from the south, of which there were but few, were carefully prohibited from visiting us. I found out also that a conversation had taken place between Boo-Khaloom and the sheikh, in which the latter had mentioned, that he had heard the Doctor wished, or rather intended, to proceed to Soudan, but that he could not allow of such a proceeding, for that the bashaw's despatch had not mentioned such being the wish of the English king.

This day I had a little respite, my visiting list being much reduced in consequence of its being market-day; there was, as usual, an abundance of all necessaries, though but few luxuries; and as the people got more accustomed to my appearance, they became more familiar: and one young lady, whose numerous bracelets of elephants' teeth, heavy silver rings on each side of her face, coral in her nose, and amber necklace, proclaimed her a person of wealth, nimbly jumped off her bullock, and tore the corner from my pockethandkerchief, as she said, for a souvenir. I could do no less than request her to accept the remainder of so useful an appendage, and I was happy to see that this piece of gallantry was not lost even upon savages. They all clapped their hands, and cried, " Barca! barea!" 
and the lady herself, whose hands and face were really running down with grease, so regardless was she of expense, generously poured into the sleeve of my shirt nearly a quart of ground nuts.

March 11.-Doctor Oudney was still confined to his bed, and I received a summons from the sheikh, to whom a report had been made of a musical box of mine, which played or stopped merely by my holding up my finger. The messenger declared he was dying to see it, and I must make haste. The wild exclamations of wonder and screams of pleasure that this piece of mechanism drew from the generality of my visitors were curiously contrasted in the person of the intelligent sheikh : he at first was greatly astonished, and asked several questions, exclaiming " $A$ gieb! gieb!" "Wonderful! wonderful!" but the sweetness of the Swiss Ranz-des-Vaches which it played, at last overcame every other feeling: he covered his face with his hand and listened in silence; and on one man near him breaking the charm by a loud exclamation, he struck him a blow which made all his followers tremble. He instantly asked, " if one twice as large would not be better?" I said "Yes; but it would be twice as dear." " By G-!" said he, " if one thousand dollars would purchase it, it would be cheap." Who will deny that nature has given us all a taste for luxuries?

During this short conversation we became better friends than we had ever been before, during our three former visits. To his surprise, he now found that I spoke intelligible Arabic, and he begged to see me whenever I chose : these were just the terms upon which I wished to be with him; and thinking this a favourable moment for adding strength to his present impressions, I could not help begging he would keep the box. He was the more delighted as I had refused it before to Karouash, when he had requested it in the sheikh's name.

March 12.-I had another interview this day with the sheikh, in his garden, about four in the afternoon: we were only three per- 
sons, Barca Gana, his first general, Karouash, and myself. We had the musical box playing until he understood its stops as well as myself; and after really a pleasant interview of an hour's duration, we separated, improved considerably in each other's good opinion. I asked to visit the Tchad next day, and he gave immediate orders to Barca Gana, that some one should attend me who knew the roads, and that a hut and food might be in readiness for me at night. I lost no time in availing myself of this permission; and soon after daylight on the next day my guides were at the door,-Fajah, a Kanemboo, high in the sheikh's favour, and Maramy, a sort of halfcast Felatah, who was sent merely because he could speak a little Arabic. We proceeded about ten miles, to a town called Bree; where the kaid (governor), after hearing the orders, came to my horse's side, and said he should be ready in an instant to accompany me: he also proposed that we should return that night to the town, where a supper and hut, with dancing-girls, should be ready for me. I, however, refused this, and said I was prepared with my blanket, and that we would sleep near the lake. We now went eastward for about five miles, when we came to the banks of the Tchad. I had seen no part of the lake so unencumbered by trees as this, and there were evident proofs of its overflowings and recedings near the shores; but beyond was an uninterrupted expanse of waters, as far as the eye could reach east and south-east. A fine grass grew abundantly along the marshy shores, and thousands of cattle belonging to the sheikh, the produce of his last expedition to Begharmi, were grazing, and in beautiful condition. The sun was now at its greatest power, and, spreading my mat under the shade of a clump of tulloh trees, I was just preparing a repast of some bread and honey, when two or three black boys who had accompanied us from Bree, and whom I had seen rushing about in the water, brought me five or six fine fish resembling a mullet, and which they had driven into the shallow water almost in as many minutes: a fire 
was quickly made, and they roasted them so well and expeditiously, that their manner of cooking deserves to be noticed :-A stick is run through the mouth of the fish, and quite along the belly to the tail; this stick is then stuck in the ground, with the head of the fish downwards, and inclined towards the fire: our negroes had quickly a circle of these fish round a clear flame, and by turning them constantly by the tail, they were most excellently dressed. These fish are called by the Kanemboo, kerwha; in Arabic, turfaw ;- the name of fish in general in the Bornou language is boonie.

I told my satellites that here would be my quarters for the night : they assured me that the musquitoes were both so numerous and so large, that I should find it impossible to remain, and that the horses would be miserable. They advised our retiring with the cattle to a short distance from the water, and sleeping near them; by which means the attention of these insects would be taken off by the quadrupeds. Englishman-like, I was obstinate; and very soon falling asleep, although daylight, I was so bitten by musquitoes, in size equalling a large fly, that I was glad, on awaking, to take the advice of my more experienced guides. Towards the evening we mounted our horses and chased some very beautiful antelopes, and saw a herd of elephants at a distance, exceeding forty in number; two buffaloes also stood boldly grazing, nearly up to their bodies in water; on our approaching them they quickly took to the lake: one of them was a monstrous animal, at least fourteen feet in length from the tail to the head. The antelopes are particularly beautiful, of a light brown colour, with some stripes of black and white about their bellies; they are not very swift, and are only to be found in the neighbourhood of the Tchad, and other large waters.

The tamarind and locust-trees were here abundant, and loaded with fruit; the former of a rich and fine flavour. The horses now became so irritated by the shoals of insects that attacked them, the 
white one of Fajah being literally covered with blood, that we determined on seeking the cattle herd, and taking up our quarters for the night with them. A vacant square was left in the centre, and ourselves and horses were admitted: mats were spread, and about thirty basket jars of sweet milk were set before me, with another of honey; this, in addition to some rice which $I$ had brought with me, made a sumptuous repast ; and although, previous to leaving the lake, my face, hands, and back of the neck, resembled those of a child with the small-pox, from the insects, yet here I slept most comfortably, without being annoyed by a single musquito.

March 14.-A very heavy dew had fallen this night, a thing we had not felt since leaving Gatrone, and then but very slightly: in the morning my bornouse, which lay over me, was completely wet through ; and on the mat, after daylight, crystalline drops were lying like icicles. On arriving at the lake, Maramy left us, as he said, to look for the elephants, as the sheikh had desired him to take me close to them; and I commenced shooting and examining the beautiful variety of waterfowl that were in thousands sporting on the water, and on its shores. I succeeded in shooting a most beautiful white bird of the crane kind, with black neck and long black bill; and some snipes, which were as numerous as swarms of bees : and in three shots killed four couple of ducks, and one couple of wild geese - these were very handsomely marked, and fine specimens. While I was thus employed, Maramy came galloping up, saying that he had found three very large elephants grazing, to the south-east, close to the water: when we came within a few hundred yards of them, all the persons on foot, and my servant on a mule, were ordered to halt, while four of us, who were mounted, rode up to these stupendous animals.

The sheikh's people began screeching violently : and although at first they appeared to treat our approach with great contempt, 
yet after a little they moved off, erecting their ears, which had until then hung flat on their shoulders, and giving a roar that shook the ground under us. One was an immense fellow, I should suppose sixteen feet high; the other two were females, and moved away rather quickly, while the male kept in the rear, as if to guard their retreat. We wheeled swiftly round him; and Maramy casting a spear at him, which struck him just under the tail, and seemed to give him about as much pain as when we prick our finger with a pin, the huge beast threw up his proboscis in the air with a loud roar, and from it cast such a volume of sand, that, unprepared as I was for such an event, nearly blinded me. The elephant rarely, if ever, attacks; and it is only when irritated that he is dangerous: but he will sometimes rush upon a man and horse, after choking them with dust, and destroy them in an instant.

As we had cut him off from following his companions, he took the direction leading to where we had left the mule and the footmen : they quickly fled in all directions; and my man Columbus (the mule not being inclined to increase its pace) was so alarmed, that he did not get the better of it for the whole day. We pressed the elephant now very close, riding before, behind, and on each side of him; and his look sometimes, as he turned his head, had the effect of checking instantly the speed of my horse-his pace never exceeded a clumsy rolling walk, but was sufficient to keep our horses at a short gallop. I gave him a ball from each barrel of my gun, at about fifty yards' distance; and the second, which struck his ear, seemed to give him a moment's uneasiness only; but the first, which struck him on the body, failed in making the least impression. After giving him another spear, which flew off his tough hide without exciting the least sensation, we left him to his fate.

News was soon brought us that eight elephants were at no great distance, and coming towards us : it was thought prudent to chase them away, and we all mounted for that purpose. They appeared 
unwilling to go, and did not even turn their backs until we were quite close, and had thrown several spears at them; the flashes from the pan of the gun, however, appeared to alarm them more than any thing : they retreated very majestically, first throwing out, as before, a quantity of sand. A number of the birds here called tuda were perched on the backs of the elephants; these resemble a thrush in shape and note, and were represented to me as being extremely useful to the elephant, in picking off the vermin from those parts which it is not in his power to reach.

When the heat of the sun was a little diminished, we followed the course of the water; and had it not been for the torment which the mosquitoes and flies occasioned, there were spots in which I could have pitched my tent for a week. I saw several Balearic cranes, but I was too far off to get a shot at them. Having proceeded nearly eight miles along the shores of the Tchad, in which there is no sort of variety either in appearance or vegetable production, a coarse grass, and a small bell-flower, being the only plants that I could discover, about an hour before sunset we left these banks, and arrived at Koua, a small village to the north; where, the kaid of the town being absent, we were glad to take up our quarters within the fence of rushes that went round his hut, and after making some coffee, I laid myself down for the night: about midnight he returned, and we then got corn for our horses, and fowls and milk for ourselves. Both this town and Bree were quite new, and peopled by the Kanemboos, who had emigrated with the sheikh from their own country; and I never saw handsomer or better formed people.

When I appeared in the town, the curiosity and alarm which my hands and face excited almost inclined me to doubt whether they had not been changed in the night. One little girl was in such agonies of tears and fright at the sight of me, that nothing could console her, not even a string of beads which $I$ offered her--nor 
would she put out her hand to take them. I must, however, do the sex the justice to say, that those more advanced in years were not afflicted with such exceeding diffidence-at the sight of the beads they quickly made up to me; and seeing me take from the pocket of a very loose pair of Turkish trowsers a few strings, which were soon distributed, some one exclaimed, "Oh! those trowsers are full of beads, only he won't give them to us." This piece of news was followed by a shout, and they all approached, so fully determined to ascertain the fact, that although I did not until afterwards understand what had been said, Fajah, my guide, thought it right to keep the ladies at a distance, by what $I$ thought rather ungentle means. Had I been aware of all the circumstances, I do not think that I should have consented to their being so harshly treated, as I have no doubt they would, like their sisterhood, those beautiful specimens of red and white womankind in our own country, have been reasoned into conviction, without absolutely demanding ocular demonstration.

March 15.-A little after noon, we arrived again at Kouka. Although much fatigued by the excessive heats, yet I was greatly gratified by the excursion: no information was, however, on this occasion to be obtained, as to the inhabitants of those islands which are said to be far away to the eastward, up the lake $/$ These Kerdies, as they are called, come, at certain times, to the spot where $I$ had been, and even close to Angornou ; plunder sometimes a village, and carry off the cattle in their canoes. These plunderers continue their depredations, without any means being taken to oppose them. I was not at all prepared for the news which was to reach me on returning to our inclosure. The horse that had carried me from Tripoli to Mourzuk and back again, and on which I had ridden the whole journey from Tripoli to Bornou, had died, a very few hours after my departure for the lake. There are situations in a man's life in which losses of this nature are felt most keenly; and this was one of them. It was not grief, but it was something very nearly

N 2 
approaching to it; and though I felt ashamed of the degree of derangement which I suffered from it, yet it was several days before I could get over the loss. Let it be however remembered, that the poor animal had been my support and comfort-may I not say companion? - through many a dreary day and night; had endured both hunger and thirst in my service with the utmost patience; was so docile, though an Arab, that he would stand still for hours in the desert, while I slept between his legs, his body affording me the only shelter that could be obtained from the powerful influence of a noon-day sun : he was yet the fleetest of the fleet, and ever foremost in the race. My negro lad opened his head, and found a considerable quantity of matter formed on the brain. Three horses at the Arab tents had died with similar appearances; and there can be little doubt but that it was the effect of climate, the scarcity and badness of the water, and the severe exposure to the sun which we had all undergone. The thermometer was this day in the hut $105^{\circ}$; the hottest day we had yet felt in Bornou.

I made it a rule to show myself among the people and merchants at some part of each market-day, in order to make myself familiar to the strangers who attended from the neighbouring towns, and to-day I was eminently successful-the young and the old came near me without much apparent alarm; but stretching out my hand, a smile, or any accidental turn of the head, always started them from my side : there seemed to be, however, a reciprocal feeling of better acquaintance between us, and I was rather surprised at the complacency, nay, even satisfaction, with which I began to survey the negro beauties - frequently exclaiming to Boo-Khaloom's brother, who was with me, " What a very fine girl! what pretty features!" without even remarking that "toujours noir" which had previously accompanied any contemplation of what might otherwise have struck me as a pleasing countenance.

March 18.-Doctor Oudney thinking himself a little improved 
in health, he determined on seeing the sheikh the next day, on the subject of his departure for Soudan ; for myself, I was but too happy for the present in having received no refusal from the sheikh to my proposition of accompanying the ghrazzie. I had previously determined, whether I should succeed in this object or not, that I would as yet ask no other favour; as I felt assured that only by slow degrees and a patient cultivation of the friendship of El Kanemy, our ultimate objects could be accomplished. I was not, therefore, greatly surprised to find that the sheikh gave this morning a decided refusal to Doctor Oudney's request of accompanying the kafila to Soudan.

A Shouaa chief, Dreess-aboo Raas-ben-aboo-Deleel, whose people had their tents close to the Shary, visited me to-day. I found him a very intelligent cunning fellow : he put a hundred questions, and, strange to say, asked for nothing as a gift. I, however, gave him a looking-glass, with which he was much pleased. He and his people had passed over from the service of the sultan of Waday to that of our sheikh, three years ago : he told me that the Sultan of Begharmi was preparing to rebuild his capital, Kernuck; and from this man I obtained a route and plan of the branches of the Shary, close to Begharmi.

March 26.-I had another visit from my new ally this morning, who came alone, and assured me the sheikh was not willing that we should see any of the country to the south of the Shary; that my liberality to him yesterday had made him take an oath to be my friend; and that if I would lay my hand on that book, pointing to my own journal, that holy book, he said he would tell me what order the sheikh had given him with respect to his conduct on our arriving in his district,--which was, that we were not to cross the river. He, however, added, that if I chose to pass the Shary and come to his tents, which were at a place called Kerga, he would find means of sending me still farther south. "If you leave the Shary," 
said he, "when the sun is three fathoms high, you will be with me by sunset." I questioned him as to the danger of incurring the sheikh's displeasure; but he did not prevaricate, and his reply was " there were three brothers of them, and the sheikh wanted to bring them all over to his service, and that it was not his interest to quarrel with them."

March 28.-Doctor Oudney was getting worse and worse : he had applied a blister to his chest in consequence of the violence of his cough; but he was so weak as not to be able to move from one hut to another. His principal food was a little flour and water paste, and sometimes a little soup at night. Boo-Khaloom saw us after prayers; he said that he had determined on dismissing about thirty of the most rebellious Arabs, and they were about to return to Mourzuk.

March 29 to April 8.-Tuesday. Drees paid me a third visit previous to his leaving Kouka, and pressed me to come over the Shary, and at least stay some time at his tents. It was night when he came; and he either affected, or really had great fear, of any one's noticing him. "Do not mention my coming to you," said he; " every body who visits your hut is a spy on your actions. Every thing you say is repeated to the sheikh." "-And yourself," said $I$. "Very good," said he; " you have no reason to trust me. Say nothing; I have made you the offer. Come, if you think proper; but do not commit yourself. I have spoken to you as I would to my own bowels."

The Shouaas Arabs are a very extraordinary race, and have scarcely any resemblance to the Arabs of the north : they have fine open countenances, with aquiline noses and large eyes; their complexion is a light copper colour: they possess great cunning with their courage, and resemble in appearance some of our best favoured gypsies in England, particularly the women, and their Arabic is nearly pure Egyptian. 




\section{SLUB}

Wir führen Wissen.
Leibniz-Institut
für Länderkunde 
The disputes between the Arabs had arrived at such a height, that all idea of an amicable arrangement between them seemed at an end. Abdallah Bougiel had obtained the support of most of the sheikh's people, and was therefore favoured by the sheikh himself: he succeeded in getting away nearly half of the Arabs from BooKhaloom; and they pitched their tents at a few miles' distance from the town. The chiefs, however, were in Kouka every day, always with loaded pistols under their barracans, fearing assassination from the intrigues of each other. Abdallah Bougiel charged Boo-Khaloom with wasting his time in Kouka, for the purpose of disposing of his merchandize; while the Arabs were starving, and might have been employed in a marauding expedition for the benefit of the bashaw. Boo-Khaloom very boldly, and with great truth, accused Abdallah of mutinous and disorderly conduct, in opposing him on all occasions, -taking the part of those refractory Arabs whom he had thought it right to punish on the road for robbery, and seducing them from under his command, where the bashaw had placed both them and himself: he most properly declared, that they came as an escort to the English, and he as a merchant - that if a ghrazzie was advisable, he was to judge when the proper time would be for undertaking it.

The sheikh, however, without lessening his attentions to BooKhaloom, whom he now promised to send with his own people to the country beyond Mandara, encouraged Abdallah to pursue his plan of quitting Boo-Khaloom. The oceupation of making up our despatches, as well as the continued weakness of Doetor Oudney, had prevented our attempting any movement during the last ten days: I say attempting, for we were upon such ticklish ground, that success seemed more than doubtful. Doctor Oudney was, however, a little better, though not fit to accompany an expedition of this nature ; and I declared my intention of proceeding with Boo-Khaloom, begging him to make known my wish to the sheikh.

Thus were we situated on the 8th of April, after ten days of 
repeated disappointment, great anxiety, and excessive heat, the thermometer being some days at $106^{\circ}$. Mr. Clapperton's horse had died on the 5th, of the same complaint as my own. Both the Arab expeditions were on the eve of departing, but without our having any knowledge of their destination. Bougiel had been repeatedly to my hut, and endeavoured to convince me of the uprightness of his conduct, and his great love for the English : "Only say, sidi reis, (my lord captain) where you will go, and I will bring you a hundred men, who will accompany you, and die by your side." I told him, "I had no occasion for such an escort, and no money to reward them; that he had better return to the tents, be reconciled to Boo-Khaloom, and, as he had left Tripoli with him, return with him, and then make his complaint to the bashaw." He said, "No: Boo-Khaloom had once d- $\mathrm{d}$ his father and his faith! that it was deep in his heart; Ikmish fi gulbi, and he could never forgive him. But would I write to the bashaw, and the consul at Tripoli, and say that he had always been my friend?" I replied, "Certainly not! That, if I wrote at all, it would be to say that he was decidedly wrong in every thing that he had done."

Boo-Khaloom left Kouka this afternoon on an expedition, without coming to take leave of us: this was a sufficient proof to me that our application to accompany the ghrazzie had been met by a denial on the part of the sheikh. The disappointment this occasioned me was very great indeed, for I had always reckoned on being at least left to my own arrangements for this expedition; and I felt confident that by such means only could we get to the southward-which conclusion subsequent events proved to be a just one.

April 10.-Soon after daylight we were summoned to appear before the sheikh, and our request of visiting the Shary complied with.

The sheikh produced some uncouth ornaments for the front of 
the head and breast, of gold and silver, with a number of paste and glass imitations of ruby and other precious stones. He thought these real, and asked their value; and, showing him the little bit of yellow metal which gave the glass bead the colour of the topaz, amazed him greatly: the person who gave him these as real will meet with but a sorry reception on his next visit, as what he had thought worth one hundred dollars were probably dear at as many pence.

April 11 and 12.-The ghrazzie, under Boo-Khaloom, remained these two days at Angornou with Barca Gana, the sheikh's kashella (or general), to collect people for the expedition. Abdallah Bougiel had left Kouka the day before, in the direction of Kanem. This day five of his horsemen, and twenty of his men on foot, redeserted, and passed through Kouka in their way to rejoin Boo-Khaloom. One of the sheikh's eunuchs, of whom he had six, the only males who were allowed to enter that division of his house where the women resided, came to me on the part of his favourite wife begging for a bead, as she called it, similar to the one she sent for me to look at, adding, that his mistress would give any price for it, for the like was never seen in Bornou. On this curiosity being taken out of a beautiful silk handkerchief, to my surprise I saw one of the glass drops of a chandelier, diamond-shaped, which I suppose had been brought by some of the freed female slaves from Tripoli. "He was not at all astonished," he said, " at my not having any thing like it: $\mathrm{Ah}$ ! he was afraid not; it was wonderfully beautiful! His mistress would be very unhappy at the news he would take back." No glass beads, or such as are brittle, and likely to break, can be sold for any thing: strength in these articles is looked for even more than beauty, and the sterling weight of this crystal drop, added to its clearness, made it invaluable in the eyes of the sultana.

April 13.- I had thought it prudent to send as a present to the sheikh my remaining horse. I had mounted him but once for two 
months; a sore on his back, from a small size became inflamed, with a deep hole in the middle, surrounded with proud flesh: his blood was in a sad state, and he got thinner and thinner. I hinted, at the same time, that a horse of the country would be very acceptable to me in exchange. The sheikh very handsomely sent me word that I should have as good a one as the country afforded-and a very active powerful little iron-grey was sent me.

Boo-Khaloom, we heard, was to quit Angornou on his expedition on the 14th: the losing this opportunity of both seeing the country and in what manner these people could lead $\$ 000$ men into action, for his ghrazzie was to consist of that number, vexed me more than I can express. It was an opportunity, I felt, that was not to be lost: the sheikh's promised expedition might never take place; it would certainly be in a different direction; and at any rate $I$ knew that with Boo-Khaloom I could follow my own plans, which most likely with the sheikh I could not. In this state of dilemma I determined on applying to the sheikh's chief karouash, who professed himself greatly my friend, and to offer him fifty dollars if he could obtain the sheikh's permission. The request instantly opened my eyes as to which quarter the wind of the court blew from. "Could not you make the sheikh," said he "some pretty present? At the same time he is only afraid of your getting into danger: egal rais khaleel rajal meliah yassur (he says the rais is an excellent person)." I replied, " that was impossible; that we had already given many handsome presents, and had written to England for others; for himself he should have fifty dollars if he succeeded."-Karouash left me with, I am sure, every wish to succeed in my behalf. 
Ir was late in the evening of the 15 th April before my mind was made up as to the practicability of accompanying the ghrazzie. I had an interview with the sheikh, when he said, "I must refuse, because I know not how to ensure your safety: still I wish that I could comply with your request. The application by Boo-Khaloom for all your party to go was out of the question; your king could not wish that a mission sent out so far should run such risks-it was an imprudent request, and the bashaw would never have forgiven me if I had complied with it. You are differently situated; your sultan expressly orders you to accompany any military expeditions: but although you are a soldier, you will scarcely know how to take care of yourself, in an expedition of this nature, should BooKhaloom meet with a repulse; and on this account alone I cannot sanction your departure." I replied, " that I could not be otherwise than sensible of the anxiety he evinced for our safety, but that the orders of my sultan must be obeyed if possible: that although he refused his approbation, I trusted he would not prevent my accompanying Boo-Khaloom. Indeed," added I, smiling, " if that is your intention, I give you notice that the silsel * had better be put on-I shall certainly go, for I dare not lose such an opportunity of seeing the country."

Here ended our conference; and some time after midnight, the

* Silsel: irons placed round the necks of refractory slaves. 
negro who was to accompany me to Angornou, where I had previously intended awaiting the arrival of Doctor Oudney, roused me to commence my journey, adding, "We shall scarcely reach Angornou before daylight." My baggage and necessaries were easily carried by one camel. My sole companion was my own negro Barca, whom I mounted on a mule, with my small canteens under him, containing a scanty supply of coffee : this, and a bag of rice, were all my provisions-and I trusted to Providence for the rest. To join the ghrazzie I was determined; but in what way it was to be accomplished, I was not yet decided. Boo-Khaloom had left Angornou the day before; and it was reported that he would halt one day about thirty-five miles south of that place : the destination of the expedition still remained a secret. Maraymy ben Soudanee, the negro whom the sheikh had appointed to accompany me, was the same that had attended me before in my excursion to the Tehad: he was born a slave in Mohamed el Soudanee's family, the sheikh's first cousin, who was now on his way to Mecea. As he took with him but a small retinue, Maraymy and many others were left behind, and served as an askar, or soldier, to the sheikh. His character amongst the sheikh's people was one of great bravery; his daring manner of approaching the elephants, in our former trip, had not been unobserved by me; and during our present excursion he gave such proofs of gallantry and goodness of heart, at the same time laying me under obligations to him of the most serious kind, - no less, eventually, than the preservation of my life-that he merits every praise that it is in my power to bestow. Maraymy spoke broken Arabic, of which he was not a little proud: I had discovered that taciturnity was not among the number of his failings, and we had not proceeded many miles before he began to gratify his natural propensity with great volubility. For myself I was unusually disinclined to conversation; many circumstances combined to render me dissatisfied with the situation of our affairs. I felt, at the moment, 
more than ever the want of a companion and friend, in whose head and heart I could place some confidence; and Maraymy's account of his battles, and hair-breadth escapes from the Kerdies, was almost unnoticed by me.

I was at length, however, roused by his question of "Does the rais go with the ghrazzie ?" " How can I," said I, " when the sheikh objects to it ?" " But will you go, or not?" said he. " Whether I do or do not accompany it, at present is uncertain," replied I: " you will proceed with me as far as Angornou, and leave me at Abde Nibbee's hut. I should have thought much better of the sheikh's conduct if he had desired you to be my companion, and sent me on to join Boo-Khaloom." "If the rais will tell me whether he is determined, at all events, to proceed with the ghrazzie or not, I will then tell him what the sheikh's orders are to me," added Maraymy. "No, no!" rejoined I, " you know me well enough to be satisfied that no service done, or information given, ever goes unrewarded.Tell me, if you choose, your directions; I cannot make you acquainted with my determination."

Maraymy held out no longer; and it was to me most gratifying to learn, that the sheikh desired him not on any account to leave me; that if he found I was obstinate in persisting to join the expedition, he was to conduct me to their camp as quick as possible, and give me in charge to Barca Gana, the sheikh's black Mameluke, who commanded the whole, with every possible charge to take care of me. I was not long now in making Maraymy acquainted with my intentions. I was lavish in my praises of the sheikh, whom my companion thought nearer a god than any other mortal; and we entered Angornou while twilight still spread its grey tint around, planning our departure from thence, as soon as daylight should return.

April 16. - The whole of this day Angornou was filling fast with strangers, in consequence of the great fsug the day following - and it had the appearance of a bustling town of business. Abde Nibbe, 
at whose hut I passed the day, was a merchant we had known at Mourzuk, and here made good his professions of service, which had never before been put to the test. On a clean mat, placed in a shady corner of his hut, I slept away the heat of the day; and besides a supper of giddeed (meat dried in the sun) and rice, he regaled me with a very pleasant drink, composed of milk, red pepper, and honey. The evening was so sultry, that I determined on waiting until after midnight; and about an hour before sunrise we mounted our horses.

A pril 17.-Our course was south, near a number of gardens; but the only vegetable produced in them appeared to be onions. For many miles our road was over one continued plain, covered with wheat and gussub stubble; and a little before noon we arrived at Yeddie, twenty-one miles from Angornou, a considerable town, walled, and governed by a kaid. A hut was pointed out to us, after some altercation, where we were to pass the heat of the day. $\mathrm{I}$, however, took my place in the skiffa or entrance, the coolest place I could find.

The kaid soon after paid me a visit, who it seemed was asleep when $I$ arrived. He was extremely desirous that I should come to his habitation, and was greatly distressed at not having better provided for my convenience; moving was, however, quite out of the question. The heat was excessive; and I merely begged a little sweet milk, and that the crowd round the door, which I was obliged to keep open, might, if practicable, be in part dispersed; and I added, "They are all men - pray are there no women in your town?" The kaid, who evidently wished to make up for his former inattention, immediately answered, "Yes, yes! plenty; and they also would like to come and look at you, if you will give them leave." This I was not disposed to refuse; and the kaid, sitting by me, and Maraymy keeping the door, so that not more than three or four came in at a time, I received upwards of one hundred of the softer sex. 
Some of them were beautiful unaffected children of nature. I had nothing to show them but a looking-glass, and probably nothing could have pleased them more. One insisted upon bringing her mother, another her sister, in order to see the face she loved best reflected by the side of her own, which appeared to give them exquisite pleasure; as on seeing the reflection they repeatedly kissed the object of their affection. One very young and intelligent girl asked if she might bring her child, and on gaining permission quickly returned with an infant in her arms: she absolutely screamed with joy; and the tears ran down her cheeks when she saw the child's face in the glass, who shook its hand in token of pleasure on perceiving its own reflected image.

By four in the afternoon we were again on the road, and Maraymy had raised my spirits by saying, " that if they had not moved on, we should reach the camp of the Arabs, and the sheikh's troops, soon after sunset." Fortunately they had not moved; and after fourteen miles we made Merty, and to the west of the town we saw the tents of the Arabs. Maraymy now told me, "that the sheikh wished I should put myself under the protection of Barca Gana; that Boo-Khaloom's responsibility ceased on arriving at Bornou; that he was now bound to provide for my safety, and that with his people he wished me to remain." I should have been better pleased to have pitched my tent close to that of my tried friend, and amongst my old companions the Arabs; but as Maraymy assured me the sheikh would be highly displeased, I instantly gave up the idea.

Barca Gana received me with a great deal of civility in his tent, although he kept me several minutes waiting outside, until he had summoned his fighi, or charm-writer-an indispensable person-and one or two of his chiefs, to attend him. "If it was the will of God," he said, "I should come to no harm, and that he would do all in his power for my convenience." A spot was appointed for my tent near his own; and I took my leave in order to visit the Arabs. The 
cheers they all gave me, and the hearty shake of the hand of BooKhaloom, made me regret that I was not to be amongst them, in spite of all their bad qualities. Boo-Khaloom repeatedly exclaimed, "I knew you would come; I said you would by some means or other join us." One of Barca Gana's people now brought word that we should move on by daybreak. I retired to my tent after making Boo-Khaloom acquainted with the sheikh's arrangements, first to write to Doctor Oudney of my proceedings, and then to sleep off my fatigue. Sleep, however, was my only refreshment: I was as it were between two stools; one of my friends did not think it necessary, and the other never intended, to send me any supper.

April 18.-Before sunrise the tents were struck, and we were all in motion. Barca Gana, who commanded the sheikh's people, about two thousand strong, was a native of a town called Sankara, in Soudan, and had fallen into the sheikh's hands about seventeen years before, when only nine years of age. The sheikh had always been extremely attached to him, and had raised him with his fortunes, to the rank he now held, as kaid, or governor, of Angala, part of Loggun, and all the towns on the Shary, besides making him kashella, or commander-in-chief of his troops: he was a powerful negro, of uncommon bravery, possessing a charm which he imagined rendered him invulnerable to either balls or arrows. He was keen, possessed great quickness of observation, and from being so long in the sheikh's confidence, had acquired his manner, which was gentle, and particularly pleasing : added to this, he was a bigoted Musselman.

As I have before said, the morning of the 18th saw me riding by the side of Barca Gana, in full march for Mandara. Two hours before noon we made Alla, a town fourteen miles from Merty: here our tents were pitched until the afternoon, when we again moved, and after five hours' march arrived at Deegoa, twenty miles from Alla. Deegoa is a large walled town, governed by a sultan subject to the sheikh, and may boast a population of thirty thousand. With 
the exception of the immediate neighbourhood of the town, the country has been less cleared of wood than the neighbourhood of Angornou, and consequently is less productive. There is a very large wadey, or water-course, full a quarter of a mile in breadth : to the south of Deegoa we found it perfectly dry; but a large canoe, which was laid up by the side, to be used by travellers proceeding to Mandara in the wet season.

We had here a violent thunder-storm, accompanied by heavy rain during the night, which made its way plentifully into my Egyptian tent. Before daylight on the 19th, we broke up our encampment, and passing the wadey, continued our course through a very close country; the road consisted of several narrow paths, passable only for one horse at a time, and these greatly obstructed by the branches of tulloh, and other prickly trees, which hang over them. We made Affagay, another very large and populous town, early in the day : this is also subject to the sheikh, and governed by a kaid. Affagay, with the towns around it, Sogama, Kindacha, Masseram, and Kingoa, may be said to possess upwards of twenty thousand inhabitants. To the westward of Kingoa are the ruins of a very large town called Dagwamba : the country for many miles round formerly bore that name, and was governed by a sultan. The people were then all Kerdies, and, being conquered by the former sultans of Bornou, became Musselmans. Previous to arriving at Deegoa, we came upon a nest of Shouaas of the tribe of Waled Salamat: this race extends to the east quite as far as the Tchad.

Chiefs in this part of Africa are accompanied by as many personal followers as they think proper to maintain, both as horse and footmen : some of them form the band, if I may so call it. Barca Gana had five mounted, who kept close behind him, three of whom carried a sort of drum, which hung round ther necks, and beat time while they sang extempore songs; one carried a small pipe made of a reed, 
and the other blew, on a buffalo's horn, loud and deep-toned blasts, as we moved through the wood: but by far the most entertaining and useful were the running footmen, who preceded the kashella, and acted as pioneers ; they were twelve in number, and carried long forked poles, with which they, with great dexterity, kept back the branches, as they moved on at a quick pace, constantly keeping open a path, which would without them really have been scarcely passable; they, besides this, were constantly crying aloud something about the road, or the expedition, as they went on. For example: "Take care of the holes! - avoid the branches!-Here is the road!-take care of the tulloh!-its branches are like spears-worse than spears! Keep off the branches!" "For whom ?" " Barca Gana."-" Who in battle is like rolling of thunder?” “ Barça Gana!”-“Now for Mandara!now for the Kerdies!-now for the battle of spears!-Who is our leader ?" " Barca Gana."- " Here is the wadey, but no water.""God be praised!"- " In battle, who spreads terror around him like a buffalo in his rage?" "Barca Gana*".

* The band also sang some extempore verses on my joining them, of which the following is nearly a literal translation, and delighted their chief excessively.

Christian man he come,

Friend of us and sheikhobe;

White man, when he hear my song,

Fine new tobe give me.

Christian man all white, And dollars white have he;

Kanourie like him come, Black man's friend to be.

See Felatah, how he run;

Barca Gana shake his spear:

White man carry two-mouthed gun, That's what make Felatah fear. 
This sort of question and answer, at once useful and exhilarating, is constantly kept up until the time of halting. We did not move from Affagay until the next morning, when the whole army were supplied with bullocks and sheep. This was the first meal I had made since leaving Angornou, and the following is their method of roasting the meat : the sheep were killed, cut in half, and laid upon a frame-work of wood made of strong stakes, and having four supporters; under it was a strong fire, and by this means the meat was roasted better than I ever saw it done in any part of Europe except my own country. Towards the evening I received a summons from Barca Gana, and in his tent found five or six of the chiefs assembled: half of a roasted sheep was laid on green boughs placed on the sand before us ; the black chiefs then stripped off the dark blue shirt, their only covering; the sharpest dagger in the party was searched for, and being given to one who acted as carver, large slices of the flesh were cut, distributed about, and quickly devoured without either bread or salt : when we arrived at the bones, another side shared the same fate, and our repast closed by huge draughts from a large wooden bowl of rice water, honey, tamarinds, and red pepper, which nobody was allowed to drink of but myself and the kashella.-I expressed my satisfaction at this plentiful feast. Barca Gana said, "What the country afforded he always lived on; that he never carried any thing with him in these expeditions but a kind of paste, made of rice, flour, and honey, which, mixed with water, he took, morning and evening, when no better fare was to be had."

On the 20th at noon we reached Delahay, our road lying through a thick wood. Delahay is a spot surrounded by large wide-spreading acacias, affording a delightful shade; and here there are between thirty and forty wells of very sweet water: the huts of a numerous tribe of Shouaas, called Hajainy, are near this place. It was a cloudy day, sultry and oppressive; the thermometer in my tent, in the afternoon, was at $109^{\circ}$. In the evening we made another halting- 
place, called Hasbery, where we found no water; having come a distance of thirty-four miles.

The whole of this country is covered with alluvial soil; has a dark clayey appearance. Cracks, several inches in width, make the roads difficult, and, in the wet season, the water which falls remains on the ground for several months after. This evening, Boo-Khaloom's camels, unable to keep pace with the light-footed maherhies of the Bornou people, were so long in coming up, that he came to Barca Gana's tent, and a few unfortunate questions put to him, on the subject of my religion, sank me wofully in the opinion of my Bornou friends. Boo-Khaloom had been a great traveller, and was extremely liberal in his religious opinions for a Musselman; more so than he dared to acknowledge to these bigoted followers of the Prophet. The kashella's fighi, Malem Chadily, had always eyed me with a look of suspicion, and had once said, when the whole army halted, at dawn, "Do you wash and pray?" "Yes," said I. "Where?" rejoined the fighi. " In my tent," I replied. This fighi, who continued throughout my mortal enemy and annoyance, now asked Boo-Khaloom " what these English were? were they Hanafy or Maleki ?" still believing, that as we appeared a little better than the Kerdies, or savages, that we must be Moslem in some way or other. Boo-Khaloom answered, with some hesitation, "No: that we were mesquine (unfortunate); that we believed not in 'the book,' the title always given to the Koran; that we did not sully, or pray, as they did, five times a day; that we were not circumcised; that we had a book of our own, which did not mention Saidna Mohamed, and that, blind as we were, we believed in it : but In sh' allah," added he, " they will see their error, and die Musselmans, for they are naz zein zein Yassur (good people, very good)." This account was followed by a general groan; and the fighi clasped his hands, looked thoughtful, and then said, "Why does not the great bashaw of Tripoli make them all Musselmans?" This question made Boo-Khaloom smile: "Why !" replied Boo- 
Khaloom, " that he could not very well do, great as he is; these people are powerful, very powerful, and an affront to even one of these might cost the bashaw his kingdom :-they are also rich, very rich." "May it please the Lord quickly to send all their riches into the hands of true Musselmans," said the fighi; to which the whole assembly echoed "Amen." "However," continued Boo-Khaloom, " there are insara Yassur $f i$ denier (a great many Christians in the world), but the English are the best of any; they worship no images; they believe in one God, and are almost Moslem." This was as much as he could say, although it raised me but little in the fighi's estimation; and as he decided, so every body was obliged to think.

Our rice water, and honey, was always brought in a brass basin tinned on the inside, such as are only used by sultans and people of the highest rank, wooden bowls being always drunk out of by the people; and out of this basin Barca Gana and myself only were allowed to drink. To-night, while I was drinking, the fighi made some remark; what I left in the bowl was instantly thrown away, and soon after a separate vessel was assigned me.

We continued our course to Ally Mabur, where there is a large lake of still water. The horses, who had not drunk the night before, rushed into the lake by hundreds, and, in consequence, the water we got to drink was nearly as thick as pease-soup. The day was dreadfully sultry. My camel not coming up, I could not pitch my tent, and I became nearly exhausted by the intolerable heat. The thermometer was at $113^{\circ}$ in the best shade I could find, and covered completely with a cloth, besides a thick woollen bornouse, I kept up some little moisture by excluding entirely all external air; still it was almost insupportable.

Ally Mabur, in the afternoon, and at night, halted at an open spot in the wood called Emcheday. The trees we had seen within the last two days were of a much larger kind, and the underwood 
less. We had no water but the muddy beverage we had brought with us. Through an open space, or break in the wood, I had this day seen part of the Mandara hills, and had passed an extensive line of huts belonging to the Beni-hassan Shouaas. We were now but a few miles from the capital of Mandara, and several persons had arrived from the sultan, within the last two days, to welcome Barca Gana; but this evening one of his chiefs came, attended by about twenty horsemen, saying, "that the sultan would himself meet us the next day, on the road to Mora, his residence." Our force had been increased, during the march, by several Shouaa sheikhs joining us, with their followers, both from the banks of the Tchad and from the west. We always found them drawn up on a certain spot on the road; and their salutation was by charging rapidly up, and shaking the spear at the kashella, wishing he might "crush his enemies as an elephant tramples on his victim," and such like expressions.

By these accessions we were now upwards of three thousand strong, all cavalry, with the exception of about eighty Arabs on foot. We continued to approach a noble chain of hills, which were now full in our view, of considerable height and extent, with numerous trees growing on their steep and rugged sides. Delow, the first town we arrived at in Mandara, formerly the residence of the sultan, containing at least 10,000 inhabitants, has springs of beautiful fresh water; and in the valleys fig-trees; and trees, which bore a white flower resembling the zeringa, possessing a grateful odour, were plentiful.

At about a mile from this town, we saw before us the sultan of Mandara, surrounded by about five hundred horsemen, posted on a rising ground ready to receive us, when Barca Gana instantly commanded a halt. Different parties now charged up to the front of our line, and wheeling suddenly round, charged back again to the sultan. These people were finely dressed in Soudan tobes of different 


\section{ㄱ SLUB}




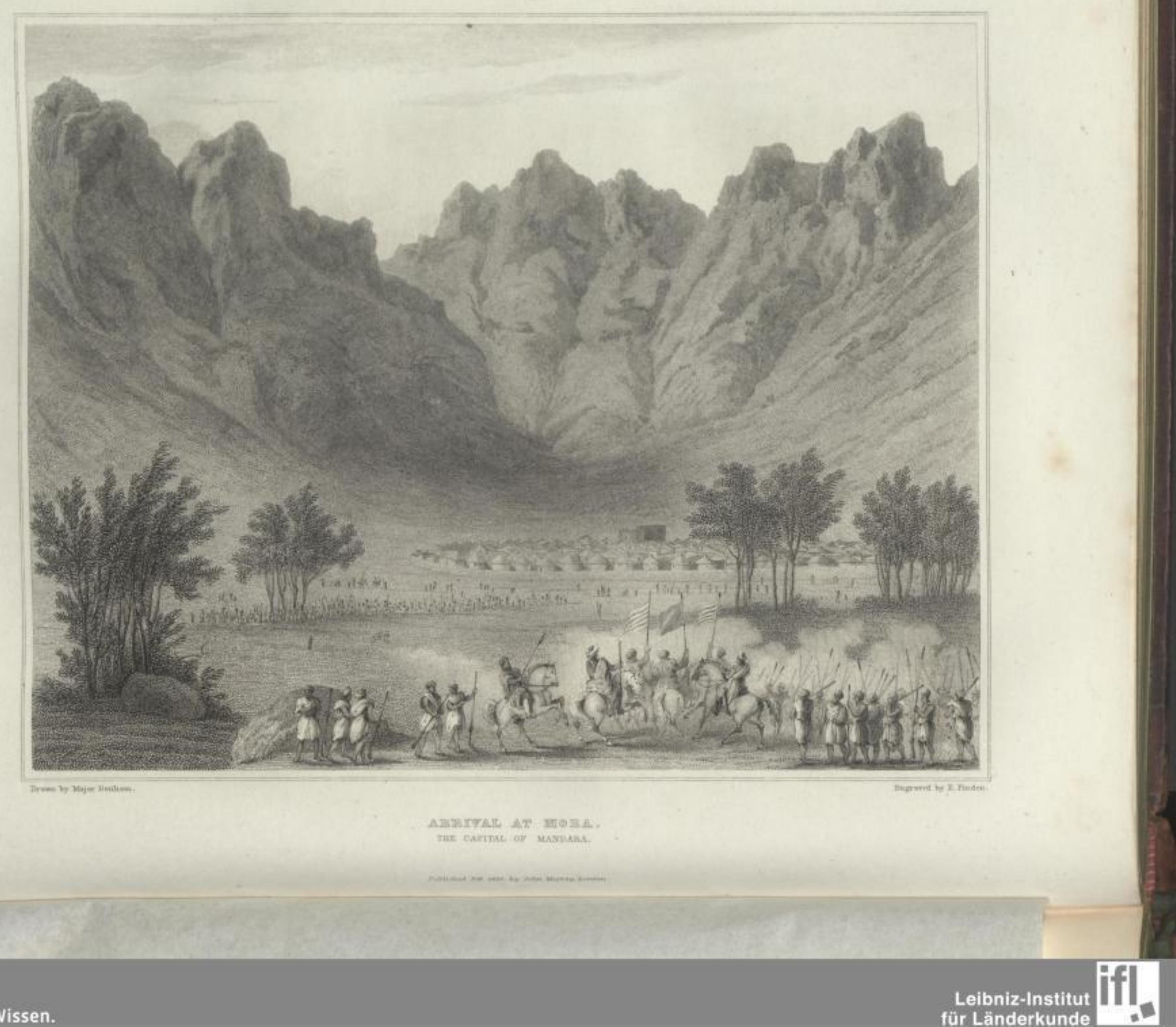


colours; dark blue, and striped with yellow and red; bornouses of coarse scarlet cloth; with large turbans of white or dark coloured cotton. Their horses were really beautiful, larger and more powerful than any thing found in Bornou, and they managed them with great skill. The sultan's guard was composed of thirty of his sons, all mounted on very superior horses, clothed in striped silk tobes; and the skin of the tiger-cat and leopard forming their shabracks, which hung fully over their horses' haunches. After these had returned to their station in front of the sultan, we approached at full speed in our turn, halting with the guard between us and the royal presence. The parley then commenced, and the object of Boo-Khaloom's visit having been explained, we retired again to the place we had left; while the sultan returned to the town, preceded by several men blowing long pipes, not unlike clarionets, ornamented with shells, and two immense trumpets from twelve to fourteen feet long, borne by men on horseback, made of pieces of hollow wood, with a brass mouth-piece, the sounds of which were not unpleasing.

The parley was carried on in the Mandara language, by means of an interpreter; and I understood that we were to visit the sultan in the course of the day, and hear his determination.

Boo-Khaloom was, as usual, very sanguine: he said " he should make the sultan handsome presents, and that he was quite sure a Kirdy * town full of people would be given him to plunder." The Arabs were all eagerness; they eyed the Kirdy huts, which were now visible on the sides of mountains before us, with longing eyes ; and contrasting their own ragged and almost naked state with the appearance of the sultan of Mandara's people in their silk tobes, not only thought, but said, " if Boo-Khaloom pleased, they would go no further ; this would do." Boo-Khaloom and the Arab sheikhs had

\section{* A general term for unbelievers.}


repeatedly exclaimed, when urging El Kanemy to send them to some country for slaves, "Never mind their numbers! arrows are nothing! and ten thousand spears are of no importance. We have guns! guns !" exclaiming, with their favourite imprecations, " Nakalou-ekelab fesaa," (We'll eat them, the dogs, quickly)—“ eich nu, abeed occul," (what! why, they are negroes all!) I fancied I could see the keen features of El Kanemy curl at these contemptuous expressions, which equally applied to his own people; and certainly nothing could be more galling than for him to hear them from such a handful of Arabs : his own people were abeed occul, and their only arms spears and arrows, and this he could not but feel and remember.

Towards the evening Barca Gana sent to desire me to mount, for the purpose of visiting the sultan. We entered the town, BooKhaloom and myself riding on his right and left; and at the farther end of a large square was the sultan's palace. As is usual on approaching or visiting a great man, we galloped up to the skiffa at full speed, almost entering the gates. This is a perilous sort of salutation, but nothing must stop you; and it is seldom made except at the expense of one or more lives. On this occasion, a man and horse, which stood in our way, were ridden over in an instant, the horse's leg broke, and the man killed on the spot. The trumpets sounded as we dismounted at the palace gate; our papouches, or outward slippers, were quickly pulled off; and we proceeded through a wide skiffa, or entrance, into a large court, where, under a dark blue tent of Soudan, sat the sultan, on a mud bench, covered however with a handsome carpet and silk pillows: he was surrounded by about two hundred persons, all handsomely dressed in tobes of silk and coloured cotton, with his five eunuchs; the principal men of the country sitting in front, but all with their backs turned towards him. The manner of saluting is curious: Barca Gana, as the sheikh's representative, approached to a space in front of the eunuchs, his eyes fixed on the ground; he then sat down, 
with his eyes still fixed on the earth, with his back to the sultan, and, clapping his hands together, exclaimed, "Engouborou dagah! (May you live for ever!)-Allah kiaro! (God send you a happy old age !-La, lai, barca, barca. (How is it with you? blessing! blessing!)" These words were repeated nearly by the sultan, and then sung out by all the court. The fatah was then said, and they proceeded to business. Boo-Khaloom produced some presents, which were carried off by the eunuchs unopened; the sultan then expressed his wish to serve him; said he would consider his request, and in a day or two give him his decision.

The sultan, whose name was Mohamed Bucker, was an intelligent little man of about fifty, with a beard dyed of a most beautiful skyblue; he had been eyeing me for some time, as I sat between BooKhaloom and Barea Gana, and first asking Boo-Khaloom his name, inquired who I was? The answer that I was a native of a very distant and powerful nation, friends of the bashaw of Tripoli and the sheikh, who came to see the country, did not appear much to surprise him; and he looked gracious as he said, "But what does he want to see ?" A fatal question however followed, and the answer appeared to petrify the whole assembly:- "Are they Moslem?" "La! la! (No! no!)" Every eye, which had before been turned towards me, was now hastily withdrawn, and, looking round, I really felt myself in a critical situation. "Has the great bashaw Kaffir friends?" said the sultan. The explanation which followed was of little use : they knew no distinctions; Christians they had merely heard of as the worst people in the world, and, probably, until they saw us, scarcely believed them to be human. We shortly after returned to our camp, and I never afterwards was invited to enter the sultan of Mandara's presence.

Our tents had been pitched but a short distance from the town of Mora, and on our return upwards of forty slaves, preceded by one of the sultan's eunuchs, came to the camp, bearing wooden bowls 
filled with paste of the gussub flour, with hot fat and pepper poured over it, mixed with a proportionate seasoning of onions. This was considered as the very acmè of Mandara cooking; it was savoury, and not very unpleasant ; but a few sides of mutton roasted, which came for the chiefs, was the better part of our fare. Malem Chadily betook himself to another bowl, because on Barca Gana's putting the mess towards me, I had, as usual, plunged my right hand in without any ceremony. Barca Gana saw that I observed it, and his dread of the sheikh's displeasure induced him to make some observation in Bornouese, which drove the fighi out of the tent : this distressed me, and I determined on adopting some measures for preventing the repetition of these disagreeables.

On the $2 S d$ we halted; but I was so dreadfully bitten by the ants and other insects, which beset us in myriads, that my hands and eyes were so swelled that I could scarcely hold a pen, or see to use one: added to this, the heat was again insufferable; for several hours in the middle of the day, the thermometer was as high as $113^{\circ}$. Covering myself up with all the blankets I could find afforded me the greatest relief - these defending me as well from the flies as the power of the sun : occasionally making my negro pour cold water on my head was another undescribable comfort. I passed the greater part of the evening with Boo-Khaloom, who had seen the sultan of Mandara in the day. He complained of being delayed; but was, nevertheless, still sanguine, and believed the sultan was endeavouring to find him a Kerdy country, which he was to attack; it, however, never was the intention of the sultan of Mandara to take any such steps, or the sheikh's wish that he should. It was against people who would create in the Arabs a little more respect for spears and arrows, that the sheikh wished them to be sent; and this he thought could not better be accomplished than by consigning them to the sultan of Mandara, whose natural enemies, as well as his own, were the Felatahs, the most warlike people in the whole country. 
Mandara had been several times conquered by these Felatah tribes, which extend over an immense space of country : they are found through the whole of Soudan, quite to Timbuctoo, and at D'jennie on the Quolla they form the greatest part of the population. A very populous town, Conally, to the west of D'jennie, is inhabited wholly by Felatahs*. They are a very handsome race of people, of a deep copper colour, who seldom mix their blood with that of the negroes, have a peculiar language of their own, and are Moslem. They bear some resemblance to the Shouaas, although they are quite a distinct race. South-west of Mandara is a country called Karowa; and these two countries were formerly governed by one sultan (Kerdy), until Mandara was wrested from them by the Felatahs of Musfeia and Kora. The son of the sultan of Karowa, the present sultan, succeeded in recovering Mandara out of their hands, and has since been able to keep possession, as they aver, from his having become Moslem-be that as it may, he is now a Musselman, and an intelligent one for his situation : his resources are great, and his country by nature easy to defend. About ten years ago, he found so little defence from the walls of his then residence Delow, against the attacks of the Felatahs, that he built the new town Mora, nearly facing the north, and situated under a semicircular ridge of very picturesque mountains. These natural barriers form a strong rampart on every side but one, and he has hitherto withstood the attempts of his enemies. It is rather a curious circumstance that no Shouaas are to be found in the Mandara dominions, nor any where to the south of them.

The Sheikh El Kanemy, very shortly after his successes and eleva-

* Abdul Kassum-ben-Maliki came from this town, and speaks of his people as having great influence with the sultan of Timbuctoo: their language is alike; and he conversed as freely with a Felatah slave from Musfeia, as if she had been his countrywoman. although they were born probably fifteen hundred miles distant from each other.

Q 2 
tion, saw the advantage of a powerful ally, such as the sultan of Mandara, against the Felatahs, who were equally the dread of both these potentates; the vicinity of Mandara to the Kerdy nations, as well as the ease with which slaves are obtained from thence, was also another consideration. The tribes of Shouaas, bordering on the Mandara frontier to the north and north-east, had always been in the habit of sending marauding parties into that part of the country nearest to them, which the sultan had never been able to prevent; and the sheikh no sooner saw the necessity of bringing these dwellers in tents into subjection to the sultan of Bornou than he determined also on making a stipulation for the discontinuance of their inroads into the Mandara country, the peace of which they had so long disturbed. This treaty of alliance was confirmed by the sheikh's receiving in marriage the daughter of the sultan of Mandara, and the marriage portion was to be the produce of an immediate expedition into the Kerdy country, called Musgow, to the south-east of Mandara, by the united forces of the sheikh and the sultan. The results were as favourable as the most savage confederacy could have anticipated-three thousand unfortunate wretches were dragged from their native wilds and sold to perpetual slavery; while, probably, double that number were sacrificed to obtain them. These nuptials are said to have been celebrated with great rejoicing, and much barbarian splendour: the blood, however, which had been shed in the path to the altar, one would almost think, was sufficient to have extinguished the hymeneal torch, and annihilated the bearers.

This treaty of alliance left the sultan of Mandara no other enemies than the Felatahs to contend with; and his power had increased too much for him to fear any offensive measures on their part: on the contrary, he had been at the time of our expedition for some months seeking for an opportunity to commence hostilities 
himself*. The Mandara force consists principally of cavalry, which, as their horses are of a superior breed, have a very imposing appearance. Some of the Kerdy towns occasionally furnish a few bowmen; but as their only object is plunder in the event of a victory, on the least appearance of a contrary result they quickly betake themselves to their mountain habitations. The principal Mandara towns are eight in number, and all stand in the valley: these, and the smaller ones by which they are surrounded, all profess Islamism. The Kerdies are far more numerous; and their dwellings are seen every where in clusters on the sides, and even at the top, of the very hills which immediately overlook the Mandara capital. The fires which were visible in the different nests of these unfortunates threw a glare upon the bold peaks and bluff promontories of granite rock by which they were surrounded, and produced a picturesque and somewhat awful appearance. The dread in which they hold the sultan has been considerably increased by his close alliance with the sheikh; and the appearance of such a force as that which accompanied Barca Gana, bivouacked in the valley, was a most appalling sight to those who occupied the overhanging heights : they were fully aware, that for one purpose alone would such a force visit their country; and which of them were to be the victims, must have been the cause of most anxious inquietude and alarm to the whole. By the assistance of a good telescope, I could discover those who, from the terms on which they were with Mandara, had the greatest dread stealing off into the very heart of the mountains; while others came towards Mora, bearing leopard skins, honey, and slaves, plundered from a neighbouring town, as peace-offerings; also asses

* A deputation of twenty-seven from Musfeia and Zouay had but a short time before arrived at Mora, for the purpose of arranging some detention of property belonging to them, which had been seized by the Mandara people. They were admitted to a parley; but had no sooner quitted the presence of the sultan, than the throats of all of them were instantly cut by the eunuchs and their slaves. 
and goats, with which their mountains abound: these were not, however, on this occasion destined to suffer. The people of Musgow, whose country it was at first reported (although without foundation) that the Arabs were to plunder, sent two hundred head of their fellow-creatures, besides other presents, to the sultan, with more than fifty horses. Between twenty and thirty horsemen, mounted on small, fiery, and very well formed steeds of about fourteen hands high, with a numerous train, were the bearers of these gifts-and a most extraordinary appearance they made. I saw them on their leaving the sultan's palace; and both then, and on their entrance, they threw themselves on the ground, pouring sand on their heads, and uttering the most piteous cries. The horsemen, who were chiefs, were covered only by the skin of a goat or leopard, so contrived as to hang over the left shoulder, with the head of the animal on the breast; and being confined round the middle, was made to reach nearly half way down the thigh, the skin of the tail and legs being also preserved. On their heads, which were covered with long woolly, or rather bristly, hair, coming quite over their eyes, they wore a cap of the skin of the goat, or some fox-like animal; round their arms, and in their ears, were rings of what to me appeared to be bone; and round the necks of each were from one to six strings of what I was assured were the teeth of the enemies they had slain in battle: teeth and pieces of bone were also pendant from the clotted locks of their hair, and with the red patches with which their body was marked in different places, and of which colour also their own teeth were stained, they really had a most strikingly wild, and truly savage, appearance. What very much increased the interest I felt in gazing upon these beings, who, to appearance, were the most savage of their race, was the positive assertion of Boo-Khaloom that they were Christians. I had certainly no other argument at the moment to use, in refutation of his position, but their most unchristian-like appearance and 
deportment; in this he agreed, but added, "Wolla Insara, they are Christians!" Some of them, however, begging permission to regale themselves on the remains of a horse, which had died during the night in our camp, gave me, as I thought, an unanswerable argument against him. I can scarcely, however, at this moment forget how disconcerted I felt when he replied, " That is nothing: I certainly never heard of Christians eating dead horse-flesh, but I know they eat the flesh of swine, and God knows that is worse!" "Grant me patience!" exclaimed I to myself; " this is almost too much to bear, and to be silent."

I endeavoured, by means of one of the Mandara people, to ask some questions of some of these reputed Christians, but my attempts were fruitless; they would hold no intercourse with any one; and, on gaining permission, carried off the carcass of the horse to the mountains, where, by the fires which blazed during the night, and the yells that reached our ears, they no doubt held their savage and brutal feast.

April 24.-The sultan of Mandara had given no intimation whatever of his intentions with regard to Boo-Khaloom's destination, and in consequence the impatience and discontent of the latter were extreme. Offerings poured in, from all the Kerdy nations; and the sultan excused himself to Boo-Khaloom for the delay, on account of the extreme tractability of the people around him, who, he said, were becoming Musselmans without force. Again Musgow was mentioned; adding, that the warlike arm of the Arabs, bearing the sword of the Prophet, might turn their hearts. This hypocrisy, however, Boo-Khaloom inveighed against most loudly to me, declaring that the conversion of the Kerdy people would lose him (the sultan) thousands of slaves, as their constant wars with each other afford them the means of supplying him abundantly.

My own patience, also, this morning underwent a severe trial. I applied to Barca Gana, by dawn of day, for one of his men to accom- 
pany me to the mountains; and after some conversation a chief was sent with me to the house of the suggamah (chief of the town), who sent me to another, and he begged I might be taken to a third. They all asked me a hundred questions, which was natural enough; begged powder-looked at my gun-snapped the lock so often, that I feared they would break it, exclaiming, "Y-e-0-0-o! wonderful! wonderful!" when the fire came. At last, however, when I once got it in my hand, I loaded both the barrels, and after that I could not induce one of them to put their hands within five yards of it. The last great man whose house I was taken to cunningly begged me to fire, calling his slaves to stand round him while I complied with his request : immediately after he asked for the gun, and carried it into an inner court. I was kept full half an hour waiting; when about ten slaves rushed out, gave me the gun, and told the guide to carry me to the palace. I complained that they had stolen both my flints. Every body came to look-crowded round me, exclaiming, "Y-e-o-o-o ?" and this was all the redress I could obtain. I soon after found out that the flints were not my only loss; my pocket handkerchief also, which several had petitioned for without success, had been stolen.

Arrived at the palace, I was desired to wait in the skiffa. I began to walk about, but was told that was not allowed, that I must sit down on the ground : after waiting nearly an hour, during which time I was desirous more than once to return, but was told by my guide that it was impossible until the sultan gave orders, I was conducted into the presence of the chief eunuch; he desired me to stop within about twelve yards of him, and then said, "The sultan could not imagine what I wanted at the hills? Did I wish to catch the Kerdies alone?-that I had better buy them,- -he would sell me as many as I pleased." He then made some remark, which was not interpreted, and which created a loud laugh in all the bystanders: the joke was evidently at my expense, although I was not aware of 
its point. I assured him, " that I did not wish to go at all to the hills if the sultan had the slightest objection, that it was purely curiosity, and that as to catching Kerdies, I would not take them if given to me." This put us all to rights ; I gave him some powder, and he was as civil as he could be to such a kafir as myself.

Six men, armed with large clubs and short daggers, were now desired to go with me. The sultan's anxiety for my safety, the eunuch assured me, was the only reason I had found any difficulty. What directions these, my satellites, had received, I know not, but they watched me so closely, appeared so jealous of every stone I picked up, that I did not venture to sketch the shape of a single hill. It was now nearly mid-day, and we proceeded about three quarters of a mile along the valley, which is on the south-west side of the town, and advanced a little into two of the chasms, which appear in the southernmost ridge of the chain. In one of these we found a beautiful stream of water, bubbling from a bed of glittering sand, under two immense blocks of granite, which seemed to form a rude arch over the spot. Several naked people, chiefly women and girls, ran from the place as we approached, and scrambled up the side of the mountain with the most monkey-like agility. I was abundantly assured that this chain of mountains, the highest parts of which, in the neighbourhood of Mandara, do not exceed two thousand five hundred feet, extends nearly south for more than two months' journey-how much beyond that they know not. The only communication, in this direction, is by means of a few venturesome freed slaves, who penetrate into these countries with beads and tobes, which are eagerly bought up, as well as turkadies from Soudan, and slaves and skins are given in exchange. The nations are very numerous; generally paint, and stain their bodies of different colours, and live in common, without any regard to relationship. Large lakes are frequently met with, plentifully supplied with fish. 
Mangoes, wild figs, and ground nuts, are found in the valleys. It does not appear that any other metal besides iron, which is abundant, has been diseovered in these hills : near Karowa, to the south-west of Mandara, it is most plentiful.

The sound of the sultan's trumpets, now heard at a distance, created a strong sensation amongst my attendants; they all declared we must return instantly; and when I very gently attempted to remonstrate a little, one of them took hold of the reins of my horse without any ceremony, turned him round, and led him on, while all the rest followed towards the town; of course I very quietly submitted, wondering what was the cause of alarm: it was, however, nothing but that the sultan was giving audience, and these gentlemen of the chamber did not choose to be absent. They left me as soon as we approached the houses, and I was then instantly surrounded by at least a hundred others, who were so anxious to put their hands into, and examine, every thing about me, that I put spurs to my horse, and made the best of my way to the camp. I was exceedingly fatigued with my morning's work, and crept into my tent, where I endured three hours of misery from a degree of excessive heat, surpassing all I could have supposed mankind were born to suffer here below.

Barea Gana sent to me soon after, and I found him preparing to receive one of the chief eunuchs of the sultan in his outward tent; his people all sitting round him on the sand, with their backs towards their chief, and eyes inclined downwards. Nothing can be more solemn than these interviews; not an eye is raised, or a smile seen, or a word spoken, beyond "Long life to you! A happy old age! Blessing! Blessing! May you trample on your enemies! Please God! Please God!" then the fatah, which is seldom or never omitted. The great man first inquired, " why I went to the hills ; and what I wanted with the stones I had picked up, and put in a bag which I carried near 

my saddle?" Barca Gana applied to me for information, and the bag was sent for. My specimens were not more than fifteen in number, and the eunuch, laying his hand on two pieces of fine grained granite, and some quartz, asked, " how many dollars they would bring in my country ?" I smiled, and told him, " Not one : that I had no object in taking them beyond curiosity-that we had as much in England as would cover his whole country, and that I was pleased to find similar natural productions here. Assure the sultan," added I, to Barca Gana, " that to take any thing from any of the inhabitants of these countries is not the wish of the English king: the sheikh knows our intentions, which are rather to make them acquainted with European produce; and if useful to them, send more into their country." " True, true!" said Barca Gana : " what have you brought for the sultan?"- and here I was again in a dilemma. I had only one small looking-glass of my own; neither knives, scissors, nor beads, although we had cases of them at Bornou. Something, however, was necessary to be given; I therefore sent for my trunk, and gave the sultan two French red imitation shawls, which I had bought for my own use, my own razor, and a pair of scissors; while for himself the eunuch took my two remaining pockethandkerchiefs, and a coloured muslin one, with which he appeared to be highly delighted.

April 25.-The news of the presents I had produced brought early this morning fifteen of the sultan's sons, with double the number of followers, to my tent : they all wanted gunpowder, knives, and scissors; I had however neither one nor the other to give them. Two or three of the oldest of the princes got a French silk handkerchief each, and one a pair of cotton socks, and, of course, the others went away sadly discontented. I this morning ventured to make two attempts at sketching, but my apparatus and myself were earried off without ceremony to the sultan. My pencils marking

R 2 
without ink, created great astonishment, and the facility with which its traces were effaced by India rubber seemed still more astonishing. My old antagonist, Malem Chadily, was there, and affected to treat me with great complaisance: he talked a great deal about me and my country, which made his hearers repeatedly cry out, "Y-e-o-o-o !" but what the purport of his observations were I could not make out. I endeavoured, however, to forget all his former rudeness, took every thing in good part, and appeared quite upon as good terms with him as he evidently wished to appear to be with me. Several words were written both by him and the others, which the rubber left no remains of; at length the fighi wrote Bismillah arachmani aracheme (in the name of the great and most merciful God), in large Koran characters; he made so deep an impression on the paper, that, after using the Indian rubber, the words still appeared legible : "This will not quite disappear," said I. "No, no!" exclaimed the fighi, exulting; "they are the words of God, delivered to our Prophet! I defy you to erase them !" “Probably so," said I; " then it will be in vain to try." He showed the paper to the sultan, and then around him, with great satisfaction; they all exclaimed, "Y-e-o-o-o! La illah el Allah! Mohammed rassoul Allah !"-cast looks at me expressive of mingled pity and contempt, and I was well pleased when allowed to take my departure.

The whole of this scene was repeated to Barca Gana in his tent in the evening, and they all exclaimed "Wonderful! Wonderful!" and as I did not contradict any part of his account, the fighi thus addressed me: "Rais, you have seen a miracle! I will show you hundreds, performed alone by the words of the wonderful book! You have a book also, you say, but it must be false.-Why? Because it says nothing of Saidna Mohammed, that is enough.-Shed! Shed! turn! turn! say ' God is God, and Mohammed is his prophet.' Sully (wash), and become clean, and paradise is open to you : with- 
out this, what can save you from eternal fire? Nothing!-Oh! I shall see you while sitting in the third heaven, in the midst of the flames, erying out to your friend Barca Gana and myself, Malem, saherbi! (friend), give me a drink or a drop of water!' but the gulf will be between us, and then it will be too late." The Malem's tears flowed in abundance during this harangue, and every body appeared affected by his eloquence.

I felt myself, at this period, extremely uncomfortable; and Barca Gana, who saw my distress, called me into the inner tent, where nobody accompanied him, except by invitation. "The fighi," said he, " is a rajal alem (clever man)." "Very likely," said I; " but he surely might leave me to my own belief, as I leave him to his." "Staffer Allah !" (God forbid!) said he. "Do not compare them." "I do not," said I, " God knows; but you, Kashella, should protect me from such repeated annoyances." " No," replied Barca, " in this I cannot interfere. Malem is a holy man. Please God! you will be enlightened, and I know the sheikh wishes it; he likes you, and would you stay amongst us, he would give you fifty slaves of great beauty, build you a house like his son's, and give you wives from the families of any of his subjects you choose!" "Were you to return to England with me, Kashella, as you sometimes talk about, with the sheikh's permission, would it not be disgraceful for you to turn Christian, and remain? Were I to do as you would have me, how should I answer to my sultan who sent me ?" " God forbid !" said he; "you are comparing our faiths again. I propose to you eternal paradise, while you would bring me to __." "Not a word more," said I. - "Good night!" "Peace be with you! I hope we shall always be friends," said he. "Please God !" returned I. "Amen !" said the kashella.

This night we had a more dreadful storm than I ever remember being out in. The top of my Egyptian tent, which I had preferred bringing on account of its portability, was carried completely off, and 
the pole broken. The brightness of the lightning rendered it more like noon than midnight: a tamarind-tree was torn up by its roots in the valley near us; huge masses of stone rolled down the sides of the mountain; and I crept into a corner of Barca Gana's outer tent, where slept his guard; and, although every rag about me was drenched with water, I was in a short time insensible to the storm which raged around me.

In the morning, however, I suffered considerably from pains in all my limbs and head. The Arabs, also, were full of complaints, and extremely dissatisfied with their situation; they loudly exclaimed against their delay. They had, for days, eaten nothing but a little flour and water, without fat: the sultan of Mandara would grant them no supply, and they demanded of Boo-Khaloom to go on, or turn back. The rain again fell in torrents, which is an Arab's greatest dread, and they assembled round Boo-Khaloom's tent, almost in a state of mutiny. Boo-Khaloom himself was excessively ill, more, I believe, from vexation than sickness. He had a long interview with the sultan, and returned very much irritated : he merely told me, as he passed, " that we should move in the evening;" and when I asked, "if every thing went well ?" he merely answered, "In shallah I" (please God). The Arabs, from whom he kept his destination a secret, received him with cheers. Whom they were going against they cared but little, so long as there was a prospect of plunder, and the whole camp became a busy scene of preparation.

Two hours after noon we commenced our march through a beautiful valley to the east of Mora, winding round the hills which overhang the town, and penetrating into the heart of the mass of mountains nearly to the south of it. About sunset we halted in a very picturesque spot, called Hairey, surrounded by a superb amphitheatre of hills. Barca Gana's tent was pitched under the shade of one side of an immense tree, called gubberah, much resembling a fig-tree, although wanting its delicious fruit; and the remnants of 



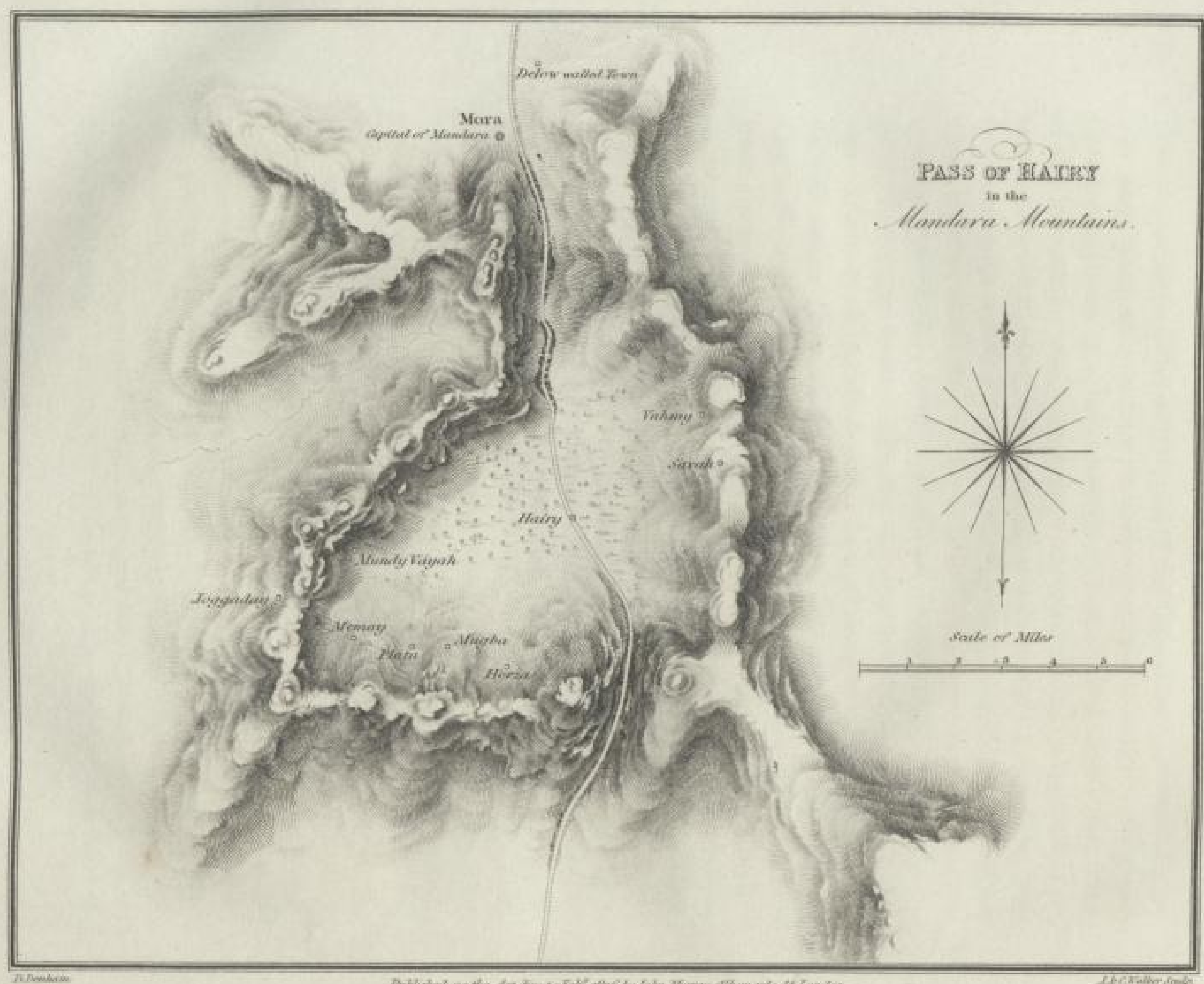

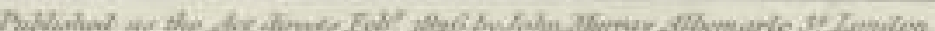

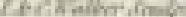

ㄱ SLUB

Wir führen Wissen.
Leibniz-Institut für Länderkunde 
my tent, which had been mended by his people, and now stood about three feet from the ground, were placed on the opposite side. The trunks of these trees commonly measure ten and twelve yards in circumference near the root, and I have seen them covering more than half an acre of ground with their wide-spreading branches.

Soon after our arrival, the sultan's trumpets announced his approach, and he took up his station, at no great distance, under a tree of the same kind: he never used a tent, but slept in an open space, surrounded by his eunuchs. At Hairey are the remains of a Mandara town, long since destroyed by the Felatahs; parts of the mud walls were still standing, and under shelter of these the troops bivouacked. The scorpions, however, made their appearance in the course of the night in great numbers, and several men were stung by them: on hearing the disturbance, and learning the cause, I called my negro, and, striking a light, we killed three in my tent; one of them was full six inches in length, of the black kind, exactly resembling those I had seen in Tripoli.

In consequence of Boo-Khaloom's illness, it was after daylight when we broke up from our encampment, and probably the mountain scenery, by which we were surrounded, could scarcely be exceeded in beauty and richness. On all sides the apparently interminable chain of hills closed upon our view : in rugged magnificence, and gigantic grandeur, though not to be compared with the Higher Alps, the Apennines, the Jura, or even the Sierra Morena, in magnitude, yet by none of these were they surpassed in picturesque interest. The lofty peaks of Vahmy, Savah, Joggiday, Munday, Vayah, Moyung, and Memay, with clustering villages on their stony sides, appeared to the east and west of us; while Horza, exceeding any of her sister hills in height, as well as in beauty, appeared before us to the south, with its chasm or break through which we were to pass; and the 
winding rugged path we were about to tread was discernible in the distance. The valley in which I stood had an elevation superior to that of any part of the kingdom of Bornou, for we had gradually ascended ever since quitting Kouka; it was in shape resembling a large pentagon, and conveyed strongly the idea of its having been the bed or basin of some ancient lake, for the disappearance of which all hypothesis would be vain and useless. There were the marks of many outlets, some long and narrow fissures, through which the waters might have broken; the channel by which we had entered appearing most likely to have carried off its contents.

On proceeding through the pass of Horza, where the ascent continued, its perpendicular sides exceeding two thousand five hundred feet in height, hung over our heads with a projection almost frightful; the width of the valley did not exceed five hundred yards, and the salient and re-entering angles so perfectly corresponded, that one could almost imagine, if a similar convulsion of nature to that which separated were to bring its sides again together, they would unite, and leave no traces of their ever having been disjoined.

It was long after mid-day when we came to the mountain stream called Mikwa, and it afforded an indescribable relief to our almost famished horses and ourselves: the road, after quitting the Horza pass, had been through an extensive and thickly-planted valley, where the tree gubberah, the tamarind, a gigantic wild fig, and the mangoe (called by the Mandaras ungerengera, and comonah by the Bornouese), flourished in great numbers and beauty. This was the first spot $I$ had seen in Africa where Nature seemed at all to have revelled in giving life to the vegetable kingdom; the leaves presented a bright luxuriant verdure, and flowers, from a profusion of climbing parasitical plants, winding round the trunks of the trees, left the imagination in doubt as to which of them the fair aromatic blossoms that perfumed the air were indebted for their nourishment. 
The ground had frequent irregularities; and broken masses of granite, ten and twelve feet in height, were lying in several places, but nearly obscured by the thick underwood growing round them, and by the trees, which had sprung up out of their crevices. The nearest part of the hills, to which these blocks could have originally belonged, was distant nearly two miles.

When the animals had drunk we again moved on, and after eighteen miles of equally verdant country, more thickly wooded, we came, after sunset, to another stream, near some low hills, called Makkeray, where we were to halt for a few hours to refresh, and then move again, so as to commence an attack on the Felatahs, who were said to be only about sixteen miles distant, with the morning sun.

Our supper, this night, which indeed was also our breakfast, consisted of a little parched corn pounded and mixed with water, the only food we had seen since leaving Mora. Nothing could look more like fighting than the preparations of these Bornou warriors, although nothing could well be more unlike it than the proof they gave on the morrow. The closely-linked iron jackets of the chiefs. were all put on, and the sound of their clumsy and ill-shapen hammers, heard at intervals during the night, told the employment of the greater part of their followers.

About midnight the signal was given to advance. The moon, which was in her third quarter, afforded us a clear and beautiful light, while we moved on silently, and in good order, the sultan of Mandara's force marching in parallel columns to our own, and on our right. At dawn, the whole army halted to sully : my own faith also taught me a morning prayer, as well as that of a Musselman, though but too often neglected.

As the day broke on the morning of the 28th of April, a most interesting scene presented itself. The sultan of Mandara was close 
on our flank, mounted on a very beautiful cream-coloured horse, with several large red marks about him, and followed by his six favourite eunuchs, and thirty of his sons, all being finely dressed, and mounted on really superb horses; besides which, they had each from five to six others, led by as many negroes: the sultan had at least twelve. Barca Gana's people all wore their red scarfs, or bornouses, over their steel jackets, and the whole had a very fine effect. I took my position at his right hand, and at a spot ealled Duggur we entered a very thick wood, in two columns, at the end of which it was said we were to find the enemy.

During the latter part of the night, while riding on in front with Maramy, the sheikh's negro, who had accompanied me from Kouka, and who appeared to attach himself more closely to me as we approached danger, we had started several animals of the leopard species, who ran from us so swiftly, twisting their long tails in the air, as to prevent our getting near them. We, however, now started one of a larger kind, which Maramy assured me was so satiated with the blood of a negro, whose carcass we found lying in the wood, that he would be easily killed. I rode up to the spot just as a Shouaa had planted the first spear in him, which passed through the neck, a little above the shoulder, and came down between the animal's legs; he rolled over, broke the spear, and bounded off with the lower half in his body. Another Shouaa galloped up within two arms' length, and thrust a second through his loins; and the savage animal, with a woful howl, was in the act of springing on his pursuer, when an Arab shot him through the head with a ball, which killed him on the spot. It was a male panther (zazerma) of a very large size, and measured, from the point of the tail to the nose, eight feet two inches; the skin was yellow, and beautifully marked with orbicular spots on the upper part of the body, while underneath, and at the throat, the spots were oblong and irregular, intermixed with white. 
These animals are found in great numbers in the woods bordering on Mandara: there are also leopards, the skins of which I saw, but not in great numbers. The panthers are as insidious as they are cruel; they will not attack any thing that is likely to make resistance, but have been known to watch a child for hours, while near the protection of huts or people. It will often spring on a grown person, male or female, while carrying a burthen, but always from behind: the flesh of a child or of a young kid it will sometimes devour, but when any full-grown animal falls a prey to its ferocity, it sucks the blood alone.

A range of minor hills, of more recent formation than the granite chain from which they emanate (which I cannot but suppose to form a part of El Gibel Gumhr, or Mountains of the Moon), approaches quite to the skirts of the extensive wood through which we were passing; and numerous deep ravines, and dry water-courses, rendered the passage tedious and difficult. On emerging from the wood, the large Felatah town of Dirkulla was perceivable, and the Arabs were formed in front, headed by Boo-Khaloom : they were flanked on each side by a large body of cavalry; and, as they moved on, shouting the Arab war-cry, which is very inspiring, I thought I could perceive a smile pass between Barca Gana and his chiefs, at Boo-Khaloom's expense. Dirkulla was quickly burnt, and another smaller town near it; and the few inhabitants that were found in them, who were chiefly infants, and aged persons unable to escape, were put to death without mercy, or thrown into the flames.

We now came to a third town, in a situation capable of being defended against assailants ten times as numerous as the besieged: this town was called Musfeia. It was built on a rising ground between two low hills at the base of others, forming part of the mass of the Mandara mountains : a dry wadey extended along the front ; beyond the wadey a swamp; between this and the wood the road was crossed by a deep ravine, which was not passable for more than two or three horses at a time. The Felatahs had carried a very 
strong fence of palisades, well pointed, and fastened together with thongs of raw hide, six feet in height, from one hill to the other, and had placed their bowmen behind the palisades, and on the rising ground, with the wadey before them; their horse were all under cover of the hills and the town :- this was a strong position. The Arabs, however, moved on with great gallantry, without any support or co-operation from the Bornou or Mandara troops, and notwithstanding the showers of arrows, some poisoned, which were poured on them from behind the palisades, Boo-Khaloom, with his handful of Arabs, carried them in about half an hour, and dashed on, driving the Felatahs up the sides of the hills. The women were every where seen supplying their protectors with fresh arrows during this struggle; and when they retreated to the hills, still shooting on their pursuers, the women assisted by rolling down huge masses of the rock, previously undermined for the purpose, which killed several of the Arabs, and wounded others. Barca Gana, and about one hundred of the Bornou spearmen, now supported Boo-Khaloom, and pierced through and through some fifty unfortunates who were left wounded near the stakes. I rode by his side as he pushed on quite into the town, and a very desperate skirmish took place between Barca Gana's people and a small body of the Felatahs. These warriors throw the spear with great dexterity; and three times I saw the man transfixed to the earth who was dismounted for the purpose of firing the town, and as often were those who rushed forward for that purpose sacrificed for their temerity, by the Felatahs. Barca Gana, whose muscular arm was almost gigantic, threw eight spears, which all told, some of them at a distance of thirty or thirtyfive yards, and one particularly on a Felatah chief, who with his own hand had brought four to the ground. 



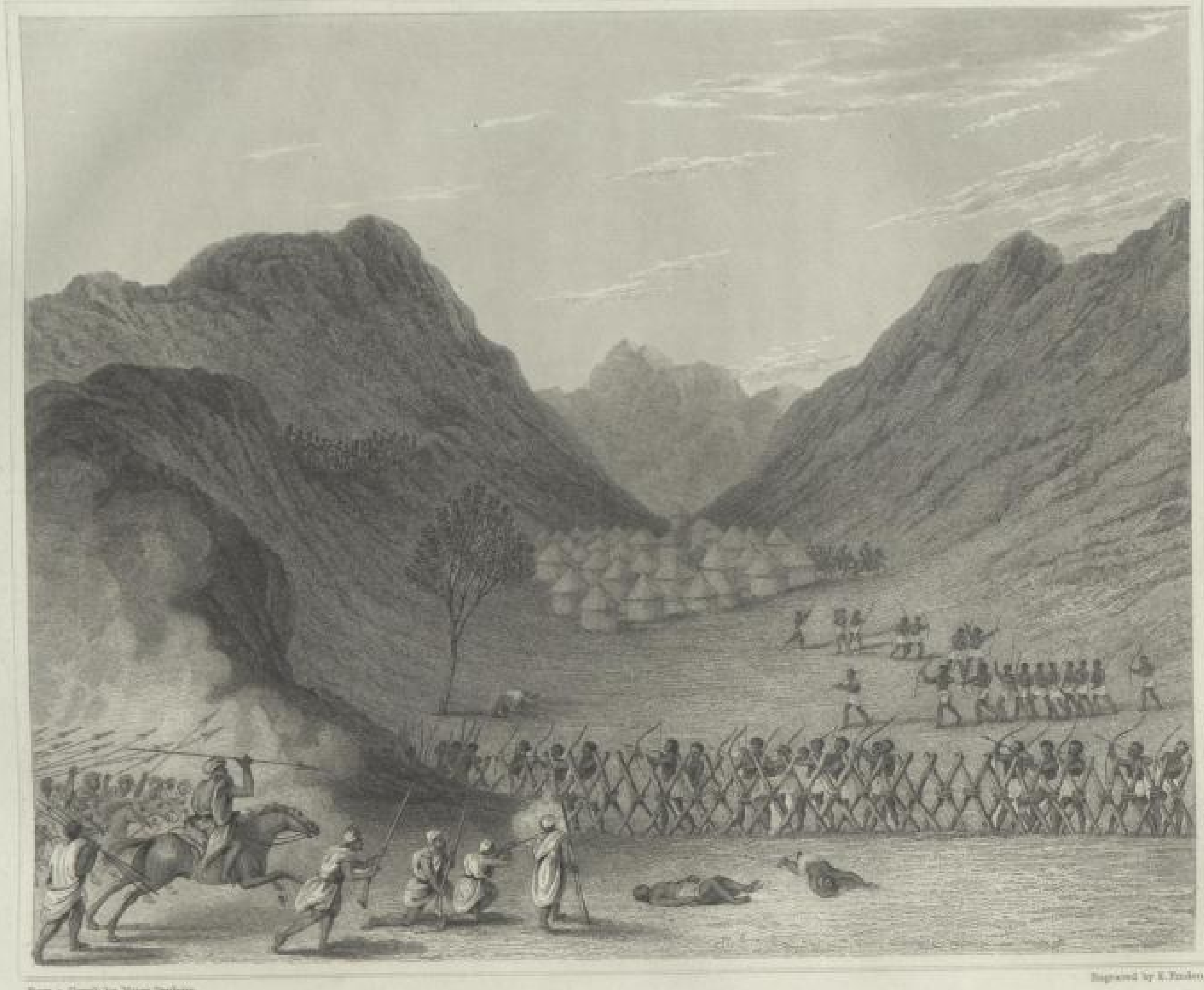

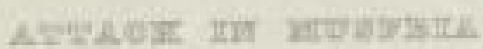

\section{SLUB}

Wir führen Wissen.

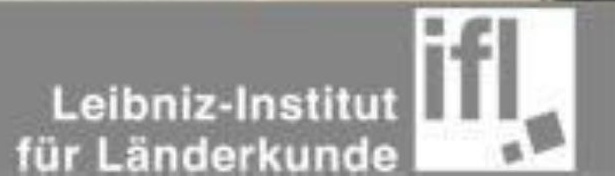


Had either the Mandara or the sheikh's troops now moved up boldly, notwithstanding the defence these people made, and the reinforcements which showed themselves to the south-west, they must have carried the town with the heights overlooking it, along which the Arabs were driving the Felatahs by the terror their miserable guns excited; but, instead of this, they still kept on the other side of the wadey, out of reach of the arrows.

The Felatahs seeing their backwardness, now made an attack in their turn : the arrows fell so thick that there was no standing against them, and the Arabs gave way. The Felatah horse now came on; and had not the little band round Barea Gana, and BooKhaloom, with a few of his mounted Arabs, given them a very spirited check, not one of us would probably have lived to see the following day: as it was, Barca Gana had three horses hit under him, two of which died almost immediately, the arrows being poisoned, and poor Boo-Khaloom's horse and himself received their death-wounds by arrows of the same description. My horse was badly wounded in the neck, just above the shoulder, and in the near hind leg: an arrow had struck me in the face as it passed, merely drawing the blood, and I had two sticking in my bornouse. The Arabs had suffered terribly; most of them had two or three wounds, and one dropped near me with five sticking in his head alone: two of Boo-Khaloom's slaves were killed also, near his person.

No sooner did the Mandara and Bornou troops see the defeat of the Arabs, than they, one and all, took to flight in the most dastardly manner, without having once been exposed to the arrows of the enemy, and in the utmost confusion. The sultan of Mandara led the way, who was prepared to take advantage of whatever plunder the success of the Arabs might throw in his way, but no less determined to leave the field the moment the fortune of the day appeared to be against them. 
I now for the first time, as I saw Barca Gana on a fresh horse, lamented my own folly in so exposing myself, badly prepared as I was for accidents. If either of my horse's wounds were from poisoned arrows, I felt that nothing could save me: however there was not much time for reflection; we instantly became a flying mass, and plunged, in the greatest disorder, into that wood we had but a few hours before moved through with order, and very different feelings. I had got a little to the westward of Barca Gana, in the confusion which took place on our passing the ravine which had been left just in our rear, and where upwards of one hundred of the Bornowy were speared by the Felatahs, and was following at a round gallop the steps of one of the Mandara eunuchs, who, I observed, kept a good look out, his head being constantly turned over his left shoulder, with a face expressive of the greatest dismay - when the cries behind, of the Felatah horse pursuing, made us both quicken our paces. The spur, however, had the effect of incapacitating my beast altogether, as the arrow, I found afterwards, had reached the shoulder-bone, and in passing over some rough ground, he stumbled and fell. Almost before I was on my legs, the Felatahs were upon me; I had, however, kept hold of the bridle, and seizing a pistol from the holsters, I presented it at two of these ferocious savages, who were pressing me with their spears: they instantly went off; but another who came on me more boldly, just as I was endeavouring to mount, received the contents somewhere in his left shoulder, and again I was enabled to place my foot in the stirrup. Remounted, I again pushed my retreat; I had not, however, proceeded many hundred yards, when my horse again came down, with such violence as to throw me against a tree at a considerable distance; and alarmed at the horses behind him, he quickly got up and escaped, leaving me on foot and unarmed.

The eunuch and his four followers were here butchered, after a very slight resistance, and stripped within a few yards of me : their 
cries were dreadful; and even now the feelings of that moment are fresh in my memory: my hopes of life were too faint to deserve the name. I was almost instantly surrounded, and incapable of making the least resistance, as I was unarmed-was as speedily stripped, and whilst attempting first to save my shirt and then my trowsers, I was thrown on the ground. My pursuers made several thrusts at me with their spears, that badly wounded my hands in two places, and slightly my body, just under my ribs on the right side: indeed, I saw nothing before me but the same cruel death $I$ had seen unmercifully inflicted on the few who had fallen into the power of those who now had possession of me; and they were alone prevented from murdering me, in the first instance, I am persuaded, by the fear of injuring the value of my clothes, which appeared to them a rich booty-but it was otherwise ordained.

My shirt was now absolutely torn off my back, and I was left perfectly naked. When my plunderers began to quarrel for the spoil, the idea of escape came like lightning across my mind, and without a moment's hesitation or reflection I crept under the belly of the horse nearest me, and started as fast as my legs could carry me for the thickest part of the wood: two of the Felatahs followed, and I ran on to the eastward, knowing that our stragglers would be in that direction, but still almost as much afraid of friends as foes. My pursuers gained on me, for the prickly underwood not only obstructed my passage, but tore my flesh miserably; and the delight with which I saw a mountain-stream gliding along at the bottom of a deep ravine cannot be imagined. My strength had almost left me, and I seized the young branches issuing from the stump of a large tree which overhung the ravine, for the purpose of letting myself down into the water, as the sides were precipitous, when, under my hand, as the branch yielded to the weight of my body, a large 
liffa, the worst kind of serpent this country produces, rose from its coil, as if in the very act of striking. I was horror-struck, and deprived for a moment of all recollection - the branch slipped from my hand, and I tumbled headlong into the water beneath; this shock, however, revived me, and with three strokes of my arms I reached the opposite bank, which, with difficulty, I crawled up; and then, for the first time, felt myself safe from my pursuers.

Scarcely had I audibly congratulated myself on my escape, when the forlorn and wretched situation in which I was, without even a rag to cover me, flashed with all its force upon my imagination. I was perfectly collected, though fully alive to all the danger to which my state exposed me, and had already begun to plan my night's rest, in the top of one of the tamarind-trees, in order to escape the panthers which, as I had seen, abounded in these woods, when the idea of the liffas, almost as numerous, and equally to be dreaded, excited a shudder of despair.

I now saw horsemen through the trees, still farther to the east, and determined on reaching them, if possible, whether friends or enemies; and the feelings of gratitude and joy with which I recognised Barca Gana and Boo-Khaloom, with about six Arabs, although they also were pressed closely by a party of the Felatahs, was beyond description. The guns and pistols of the Arab sheikhs kept the Felatahs in check, and assisted in some measure the retreat of the footmen. I hailed them with all my might; but the noise and confusion which prevailed, from the cries of those who were falling under the Felatah spears, the cheers of the Arabs rallying and their enemies pursuing, would have drowned all attempts to make myself heard, had not Maramy, the sheikh's negro, seen and known me at a distance. To this man I was indebted for my second escape; riding up to me, he assisted me to mount behind him, while the arrows whistled over our heads, and we then galloped off to the 
rear as fast as his wounded horse could carry us : after we had gone a mile or two, and the pursuit had something cooled, in consequence of all the baggage having been abandoned to the enemy, Boo-Khaloom rode up to me, and desired one of the Arabs to cover me with a bornouse. This was a most welcome relief, for the burning sun had already begun to blister my neck and back, and gave me the greatest pain. Shortly after, the effects of the poisoned wound in his foot caused our excellent friend to breathe his last: Maramy exclaimed, "Look, look! Boo-Khaloom is dead!" I turned my head, almost as great an exertion as I was capable of, and saw him drop from the horse into the arms of his favourite Arab-he never spoke after. They said he had only swooned; there was no water, however, to revive him; and about an hour after, when we came to Makkeray, he was past the reach of restoratives.

About the time Boo-Khaloom dropped, Barca Gana ordered a slave to bring me a horse, from which he had just dismounted, being the third that had been wounded under him in the course of the day; his wound was in the chest. Maramy cried, "Sidi rais! do not mount him; he will die !" In a moment, for only a moment was given me, I decided on remaining with Maramy. 'Two Arabs, panting with fatigue, then seized the bridle, mounted, and pressed their retreat: in less than half an hour he fell to rise no more, and both the Arabs were butchered before they could recover themselves. Had we not now arrived at the water as we did, I do not think it possible that I could have supported the thirst by which I was consuming. I tried several times to speak in reply to Maramy's directions to hold tight, when we came to breaks or inequalities in the ground; but it was impossible; and a painful straining at the stomach and throat was the only effect produced by the effort.

On coming to the stream, the horses, with blood gushing from their nostrils, rushed into the shallow water, and, letting myself down from behind Maramy, I knelt down amongst them, and seemed 
to imbibe new life by the copious draughts of the muddy beverage which I swallowed. Of what followed I have no recollection: Maramy told me afterwards that I staggered across the stream, which was not above my hips, and fell down at the foot of a tree on the other side. About a quarter of an hour's halt took place here for the benefit of stragglers, and to tie poor Boo-Khaloom's body on a horse's back, at the end of which Maramy awoke me from a deep sleep, and I found my strength wonderfully increased : not so, however, our horse, for he had become stiff, and could scarcely move. As I learnt afterwards, a conversation had taken place about me, while I slept, which rendered my obligations to Maramy still greater : he had reported to Barea Gana the state of his horse, and the impossibility of carrying me on, when the chief, irritated by his losses and defeat, as well as at my having refused his horse, by which means, he said, it had come by its death, replied, "Then leave him behind. By the head of the Prophet! believers enough have breathed their last to-day. What is there extraordinary in a Christian's death?" " Raas il Nibbe-Salaam Yassarat il le mated el Yeom ash min gieb l'can e mut Nesserani Wahad." My old antagonist Malem Chadily replied, "No, God has preserved him; let us not forsake him !" Maramy returned to the tree, and said " his heart told him what to do." He awoke me, assisted me to mount, and we moved on as before, but with tottering steps and less speed. The effect produced on the horses that were wounded by poisoned arrows was extraordinary : immediately after drinking they dropped, and instantly died, the blood gushing from their nose, mouth, and ears. More than thirty horses were lost at this spot from the effects of the poison.

In this way we continued our retreat, and it was after midnight when we halted in the sultan of Mandara's territory. Riding more than forty-five miles, in such an unprovided state, on the bare back of a lean horse, the powerful consequences may be imagined. I was 
in a deplorable state the whole night; and notwithstanding the irritation of the flesh wounds was augmented by the woollen covering the Arab had thrown over me, teeming as it was with vermin, it was evening the next day before I could get a shirt, when one man who had two, both of which he had worn eight or ten days at least, gave me one, on a promise of getting a new one at Kouka. Barca Gana, who had no tent but the one he had left behind him with his women at Mora, on our advance, could offer me no shelter; and he was besides so ill, or chagrined, as to remain invisible the whole day. I could scarcely turn from one side to the other, but still, except at intervals when my friend Maramy supplied me with a drink made from parched corn, bruised, and steeped in water, a grateful beverage, I slept under a tree nearly the whole night and day, of the 29th. Towards the evening I was exceedingly disordered and ill, and had a pleasing proof of the kind-heartedness of a Bornouese.

Mai Meegamy, the dethroned sultan of a country to the southwest of Angornou, and now subject to the sheikh, took me by the hand as I had crawled out of my nest for a few minutes, and with many exclamations of sorrow, and a countenance full of commiseration, led me to his leather tent, and, sitting down quickly, disrobed himself of his trowsers, insisting I should put them on. Really, no act of charity could exceed this! I was exceedingly affected at so unexpected a friend, for I had scarcely seen, or spoken three words to him; but not so much 'so as himself, when I refused to accept of them:- he shed tears in abundance; and thinking, which was the fact, that I conceived he had offered the only ones he had, immediately called a slave, whom he stripped of those necessary appendages to a man's dress, according to our ideas, and putting them on himself, insisted again on my taking those he had first offered me. I accepted this offer, and thanked him with a full heart; and Meegamy was my great friend from that moment until I quitted the sheikh's dominions. 
We found that forty-five of the Arabs were killed, and nearly all wounded; their camels, and every thing they possessed, lost. Some of them had been unable to keep up on the retreat, but had huddled together in threes and fours during the night, and by showing resistance, and pointing their guns, had driven the Felatahs off. Their wounds were some of them exceedingly severe, and several died during the day and night of the 29th; their bodies, as well as poor Boo-Khaloom's, becoming instantly swollen and black; and sometimes, immediately after death, blood issuing from the nose and mouth, which the Bornou people declared to be in consequence of the arrows having been poisoned. The surviving Arabs, who had now lost all their former arrogance and boasting, humbly entreated Barca Gana to supply them with a little corn to save them from starving. The sultan of Mandara behaved to them unkindly, though not worse than they deserved, refused all manner of supplies, and kept Boo-Khaloom's saddle, horse-trappings, and the clothes in which he died. He also began making preparations for defending himself against the Felatahs, who, he feared, might pay him a visit; and on the morning of the 30th April we left Mora, heartily wishing them success, should they make the attempt.

Boo-Khaloom's imprudence in having suffered himself to be persuaded to attack the Felatahs became now apparent, as although, in case of his overcoming them, he might have appropriated to himself all the slaves, both male and female, that he found amongst them; yet the Felatahs themselves were Moslem, and he could not have made them slaves. He was, however, most likely deceived by promises of a Kerdy country to plunder, in the event of his success against these powerful people, alike the dreaded enemies of the sheikh and the sultan of Mandara.

My wounded horse, which had been caught towards the evening of the fight by the Shouaas, and brought to me, was in too bad a state for me to mount, and Barca Gana procured me another. My 
pistols had been stolen from the holsters; but, fortunately, my saddle and bridle, though broken, remained. Thus ended our most unsuccessful expedition ; it had, however, injustice and oppression for its basis, and who can regret its failure?

We returned with great expedition, considering the wretched state we were in. On the sixth day after our departure from Mora, we arrived in Kouka, a distance of one hundred and eighty miles: the wounded Arabs remained behind, being unable to keep up with the chief, and did not arrive until four days after us. I suffered much, both in mind and body, but complained not; indeed all complaint would have been ill-timed, where few were enduring less than myself. My black servant had lost mule, canteens, and every thing, principally from keeping too near me in the action; and, by his obeying implicitly the strict orders I had given him not to fire on the Felatahs, he had narrowly escaped with his life. Bruised and lame, he could render me no assistance, and usually came in some hours after we had halted on our resting-ground. In the mid-day halts I usually crept under Mai Meegamy's tent; but at night I laid me down on the ground, close to that of Barca Gana, in order that my horse might get a feed of corn. I always fell into a sound sleep at night, as soon as I lay down, after drinking Maramy's beverage, who had supplied me with a little bag of parched corn, which he had procured at Mora; and about midnight a slave of the chief, whose name was, most singularly like my own, Denhamah, always awoke me, to eat some gussub, paste, and fat, mixed with a green herb called meloheia in Arabic. This was thrust out from under Barca Gana's tent, and consisted generally of his leavings : pride was sometimes nearly choking me, but hunger was the paramount feeling: I smothered the former, ate, and was thankful. It was in reality a great kindness; for besides myself and the chief, not one, I believe, in the remnant of our army, tasted any thing but engagy, parched 
corn and cold water, during the whole six days of our march. On the night of the 4th of May we arrived at Angornou.

The extreme kindness of the sheikh, however, was some consolation to me, after all my sufferings. He said, in a letter to Barca Gana, " that he should have grieved had any thing serious happened to me; that my escape was providential, and a proof of God's protection; and that my head was saved for good purposes." He also sent me some linen he had procured from our huts at Kouka, and a dress of the country; and the interest taken by their governor in the fate of such a kaffir, as they thought me, increased exceedingly the respect of his servants towards me. The next morning we arrived at the capital.

I presented Barca Gana with a brace of French ornamented pistols, and with pink taffeta sufficient for a tobe, which he received with great delight. The sheikh sent me a horse in lieu of the wounded one which I had left at Merty, with but small hopes of his recovery; and my bruises and wounds, which were at first but trifling, got well so surprisingly quick, from the extreme low diet I had from necessity been kept to, that I was not in so bad a condition as might have been expected. My losses, however, were severe; my trunk with nearly all my linen, my canteens, a mule, my azimuth compass, my drawing-case, with a sketch of the hills, were also lost, although I obtained another sketch the morning of our quitting Mora. Such events, however, must sometimes be the consequence of exploring countries like these. The places I had risited were full of interest, and could never have been seen, except by means of a military expedition, without still greater risk. The dominions of the sheikh, in consequence of his being so extraordinarily enlightened for an inhabitant of central Africa, appear to be open to us; but on looking around, when one sees dethroned sultans nearly as common as bankrupts in England; where the strong arm for the 
time being has hitherto changed the destiny of kings and kingdoms; no discoveries can be accomplished beyond this, without the greatest hazard both of life and property.

The sheikh laid all the blame of the defeat upon the Mandara troops, and assured me that $I$ should see how his people fought when he was with them, in an expedition which he contemplated against Munga, a country to the west. I told him that I was quite ready to accompany him; and this assurance seemed to give him particular satisfaction.

Of the Mandara chain, and its surrounding and incumbent hills, though full of interest, I regret my inability to give a more perfect account. Such few observations, however, as struck me on my visiting them, I shall lay before the reader. It is on occasions like this, that a traveller laments the want of extensive scientific knowledge. I must therefore request those under whose eye these remarks may come to regard them in the light they are offered, not as pretensions to knowledge, but merely very humble endeavours at communicating information to the best of my ability.

The elevation gradually increases in advancing towards the equator; and the soil, on approaching Delow, where the northernmost point of the Mandara chain commences, is covered with a glittering micaceous sand, principally decomposed granite, which forms a productive earth. The hills extend in apparently interminable ridges east-south-east, south-west, and west; while to the south several masses or systems of hills, if I may so express myself, spread themselves out in almost every picturesque form and direction that can be imagined. Those nearest the eye apparently do not exceed 2500 feet in height; but the towering peaks which appear in the distance are several thousand feet higher. They are composed of enormous blocks of granite, both detached and reclining on each other, presenting the most rugged faces and sides. The interstices and fissures appeared to be filled with a yellow quartzose earth, in 
which were growing mosses and lichens: trees of considerable size also grow from between them. On almost all the hills that I approached, clusters of huts were seen in several places towards the centre, and sometimes quite at the summit; generally on the flats of the ridges. At the base of these mountains, and also at a considerable elevation on their sides, are incumbent masses of what appeared to be the decomposed fragments of primitive rocks recompounded, and united anew by a species of natural cement. At some distance from the base of those which I ascended from the valley of Mora, were collections of quartzose rocks, of great variety and colour; fragments of hornblende, and several large abutments of porphyroidal rocks. About one hundred yards above the spring which $I$ have before mentioned, in a space between two projecting masses of rock, were numerous shells, some petrified and finely preserved, while others were perforated by insects, worm-eaten, and destroyed: they were confusedly mixed with fragments of granite, quartz, sand and clay; and in some cases adhered to pieces of the composition rocks: the greater part were of the oyster kind. Various specimens of these, with pieces of every variety of the structure of the hills, I had collected, but they were all lost in the general confusion of the battle; and on the return of the army I was unable to do more than procure a few specimens of the northernmost part of the mountains; and the half of these were lost by my negro.

Of the extent of this chain, or rather these groups of mountains, I can form no idea, except from the information of the Mandara people. I have met with a man who (by the way) wanted to persuade me that he was a son of Hornemann by his slave, although, from his appearance, he must have been born ten years before that unfortunate traveller entered this country. He said he had been twenty days south of Mandara, to a country called Adamowa, which he described as being situated in the centre of a plain sur- 
rounded by mountains ten times higher than any we could see; that he went first to Mona or Monana, which was five days, and then to Bogo, which was seven more; and here, for one Soudan tobe, the sultan gave him four slaves. After eight days' travelling from this latter country, he arrived at Adamowa. These people, he says (that is, the Kerdies on the hills; for Adamowa itself is occupied by Felatahs), eat the flesh of horses, mules, and asses, or of any wild animal that they kill : nobody but the sultans and their children are clothed; all the rest of the nation go naked; the men sometimes wear a skin round the loins, but the women nothing. This man, who was called Kaid-Moussa-ben-Yusuf (Hornemann's name), spoke to me of several exfensive lakes which he had seen in this journey, and also described with great clearness a river running between two very high ridges of the mountains, which he crossed previous to arriving at Adamowa. This river he declared to run from the west, and to be the same as the Quolla or Quana at Nyffe, Kora, and at Raka, but not the same as the river at Kano, which had nothing to do with the Shary, and which ran into the Tchad; but the main body of the water ran on to the south of Begharmi, was then called the D'Ago, and went eastward to the Nile. Kaid-Moussa was a very intelligent fellow, had visited Nyffe, Raka, Waday, and Darfur; by which latter place also, he said this river passed. He was most particularly clear in all his accounts, and his statement agreed in some points with the information a Shouaa named Dreess-boo-Raas-ben-aboo-Deleel had given me; therefore I was the more inclined to pay attention to it. To the south of this river, the population is entirely Kerdy, until the Great Desert. This desert is passed several times in the year by kafilas with white people, not Christians, who bring goods from the great sea: some of these reach Adamowa. He himself saw white loaf sugar, such as the merchants brought here from Tripoli to the sheikh, and a gun or two, with metal pots and pans, and arrack (rum). The inhabitants 
were unanimous in declaring these mountains to extend southward for two months' journey; and in describing them, Yusuf called them "kou kora, kora, kantaga,"-mountains large, large, moon mountains. And from the increased love of enterprise apparent in our rising generation, we may one day hope to be as well acquainted with the true character of these stupendous mountains as with the lofty peaks of the Andes.

The extreme southern peak which I could discern was that called Mendify, which rose into the air with singular boldness. It was said to be a distance from Musfeia of two long days' journey,say thirty-five miles. At that distance, it had all the character of an alpine peak, of a most patriarchal height. I could perceive with a glass other mountains extending from its sides, the forms of which bore a tranquil character, compared with the arid and steep peaks which overlooked them. It resembled very much in appearance "Les Arguilles," as they appear looking at them from the Mer-deGlace. The following outline may serve to show their shape and character.

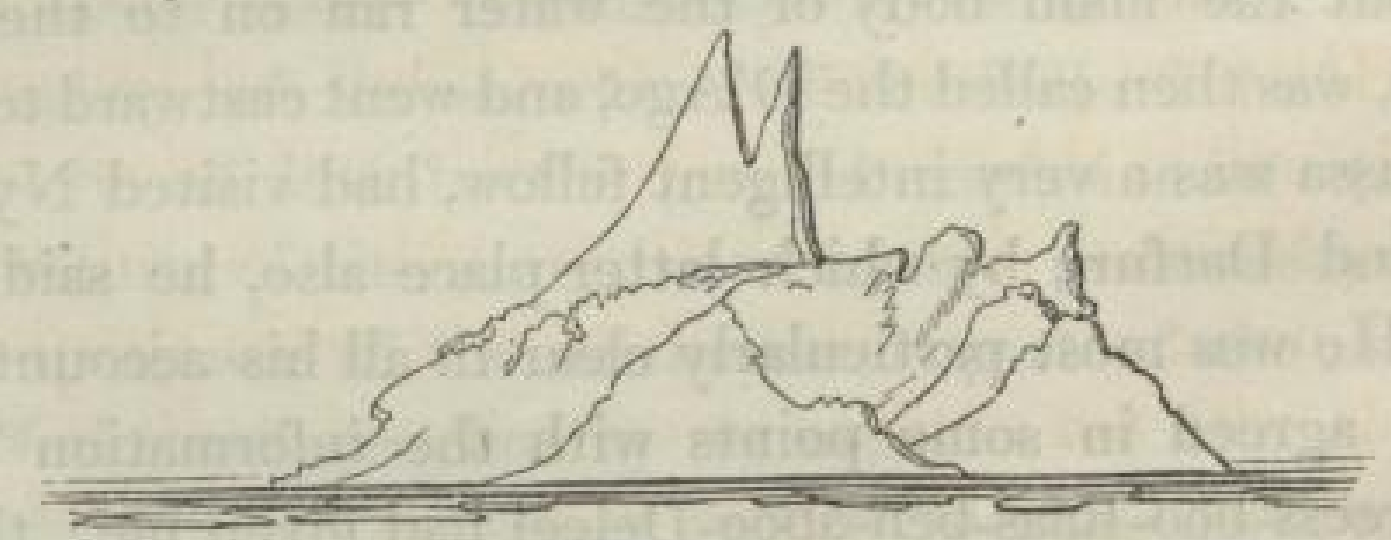

Iron is found in abundance in all the Mandara hills; but no other metal, that I was informed of. All the houses or huts at Mandara have outer doors to the court, which are made of pieces of wood, hasped together with iron. They make hinges, small bars, and a sort of hoe used to weed the corn, and send them for sale to the Bornou towns. The iron they use is mostly brought from the west near Karowa. I went to the house of a blacksmith, for the 
purpose of seeing some of the metal in its natural state, and found four men with a very rude forge, formed by a hole in the sand : the bellows were two kid skins, with an iron tube fixed in each, which tubes were conveyed underneath the fire. The wind was produced by a man blowing these skins, which were open at the top to let in the air. Their hammers were two pieces of iron, weighing about two pounds each, and a coarse piece of the same metal for an anvil; and considering their implements, they worked with some tact. I regretted much that I had not an English hammer to give them. Large masses of the iron, as nature produces it, were lying about; and they appeared to me as so many rusty earthy masses.

In appearance, the people of Mandara differ from the Bornouese, or Kanoury (as they call themselves); and the difference is all in favour of the former. The men are intelligent and lively, with high though flat foreheads, large sparkling eyes, wiry curled hair, noses inclining to the aquiline, and features altogether less flattened than the Bornouese. The women are proverbial for their good looks, -I cannot say beauty. I must allow them, however, all their acknowledged celebrity of form : they are certainly singularly gifted with the Hottentot protuberance; their hands and feet are delightfully small; and as these are all esteemed qualifications in the eye of a Turk, Mandara slaves will always obtain an advanced price. Certainly I never saw so much of them as when sporting in their native wilds, with not so much covering on as one of Eve's fig-leaves. A man who took me to be a Moorish merchant led me to his house, in order to show me the best looking slaves in Mandara. He had three, all under sixteen, yet quite women; for these are precocious climes; and certainly, for negresses, they were the most pleasing and perfectly formed I had ever seen. They had simply a piece of blue striped linen round their loins, yet they knew not their nakedness. Many of these beauties are to be seen at Kouka and Angornou : they are never, however, exposed in the fsug, but sold in the houses of

u 2 
the merchants. So much depends on the magnitude of those attractions for which their southern sisters are so celebrated, that $I$ have known a man about to make a purchase of one out of three, regardless of the charms of feature, turn their faces from him, and looking at them behind, just above the hips, as we dress a line of soldiers, make choice of her whose person most projected beyond that of her companions.

The day before the Rhamadan, which commenced on the 13th instant (May), I had an interview with the sheikh, who mentioned his intended departure for Munga; and after some conversation, it was agreed that I should proceed to Old Bornou or Birnie; and after seeing that part of the country, the ruins of the town of Gambarou, and the river of that name, which is said to come from Soudan; that I should follow its course, and join him at a place called Kabshary on the same river, to which he was about to proceed by a different route. The whole population was in confusion at the departure of this ghrazzie, and nearly all the people of Kouka, with the exception of the kadi, were to accompany the sheikh. Previously, however, to his departure, he had determined on sending off a courier to Tripoli, with an account of Boo Khaloom's death, and we availed ourselves of the opportunity by writing to England. On the 17th of May the courier departed; and on the 18th the sheikh began his march, and bivouacked at Dowergoo

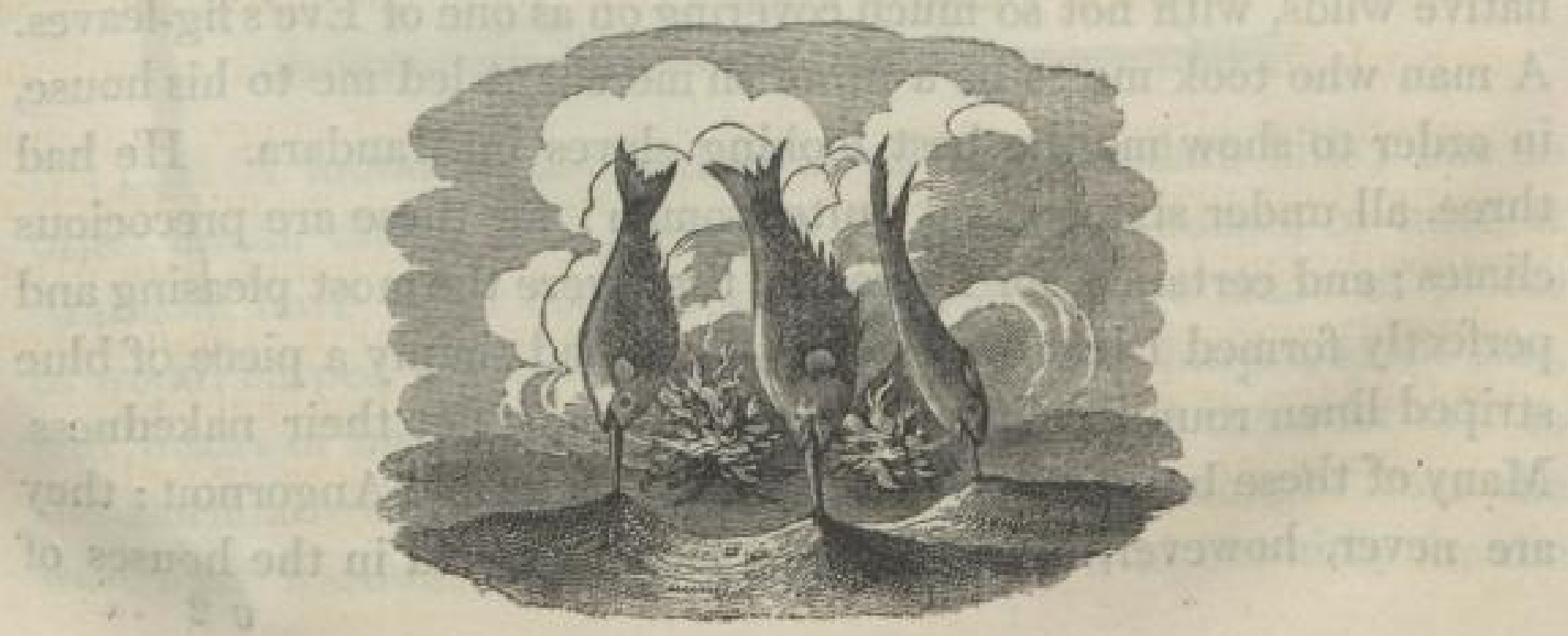




\section{CHAPTER IV.}

EXCURSION TO MUNGA AND THE GAMBAROU.

May 21.-Ever since my return from Mandara, an expedition, to be commanded by the sheikh in person, had been in agitation against a numerous people to the west called Munga. These people had never thoroughly acknowledged the sheikh's supremacy, and the collecting of their tribute had always been attended with difficulty and bloodshed. They had, however, now thrown off all restraint, and put to death about one hundred and twenty of the sheikh's Shouaas, and declared they would be no longer under his control, as the sultan of Bornou was their king; and headed by a fighi of great power, had begun to plunder and burn all the sheikh's towns near them. It was reported, and with some truth, that they could bring 12,000 bowmen into the field; by far the most efficient force to be found in the black country. To oppose these, the sheikh assembled his Kanemboo spearmen (who had accompanied him from their own country, and assisted him in wresting Bornou from the hands of the Felatahs), to the amount of between eight and nine thousand. These, with about five thousand Shouaas and Bornou men, composed the force with which he meant to subdue these rebels. Another complaint against the Mungowy was, "That they were kaffering", and not saying their prayers! the dogs." This is, however, a fault which is generally laid to the charge of any nation against whom a true Musselman wages war, as it gives him the power of making them slaves. By the laws of Mohammed, one believer must not bind another.

Rhamadan, the period generally chosen for these expeditions,

- Gaadeen, kafir. 
had commenced, since the 15th May; and on the 8th, meaning to take the town of Yeou, with the many others on the banks of the river of that name in his way, both for the purpose of collecting forces and tribute*, the sheikh left Kouka for Dowergoo, a lake about six miles distant, his women, tents, \&c. having preceded him in the morning.

Dr. Oudney and myself accompanied him outside the gates; and at our request, he left Omar Gana, one of his chief slaves, to be our guide to the old city of Bornou, which we were anxious to see; and from whence we were to proceed to Kabshary, still farther to the west, on the Gambarou, or Yeou, and there await his arrival.

May 22.-We left Kouka with five camels and four servants for Birnie, halting in the middle of the day, and making two marches, of from ten to fourteen miles, morning and evening. The country all round Kouka is uninteresting and flat, the soil alluvial, and not a stone of any kind to be seen, but thickly scattered with trees, mostly acacias. We sometimes came to a few huts, and a well or two of indifferent water; and a mess of rice from our stores was our usual supper.

On the 24th, about noon, we arrived at the river Yeou, and halted at a rather large nest of huts called Lada. We were now seventy miles from Kouka. The river here makes a bend resembling the letter $\mathrm{S}$, the water extremely shallow, and a dry path over the bed of the river appeared close to our haltingplace, although the banks were high, and capable of containing a very large stream. I walked out, following the easterly course of the stream in search of game; but within four hundred yards of the banks, the ground was so choked with high grass and prickly underwood, that I was obliged to take a path more inland, where a

- The feudal law exists here in full force; and a man unwilling to serve, provides one or more substitutes according to his means. 
partial clearance had been made for the sake of some scanty cotton plantations. Pursuing some Guinea fowl across one of these, I was assailed by the cries of several women and children, who having thrown down their water-jugs, were flying from me in the greatest alarm. I however went on, but had not proceeded above a quarter of a mile, when my negro pointed out several men peeping from behind some thick bushes, and evidently watching our motions. I desired him to be on his guard, as he carried a carbine loaded with slugs; and we called repeatedly to them without any effect. They had been alarmed by the women, who had represented us to be Tuaricks, of whom they are constantly in dread, as their country is not more than seven days distant from where these marauders are often seen; and the extreme points of the Bornou dominions they visit without fear. The inhabitants of these wilds cannot be induced to quit their present homes ; and they patiently submit to have their flocks and children taken from them, and their huts burnt, rather than seek a more secure residence in the larger towns./They have, however, a manner of defending themselves against these cruel invaders, which often enables them to gratify their revenge : the ground is covered by the high grass and jungle close to the banks of the rivers, and they dig very deep circular holes, at the bottom of which are placed six or eight sharp stakes, hardened by the fire, over the top of which they most artfully lay the grass, so as to render it impossible to discover the deception. An animal with its rider stepping on one of these traps is quickly precipitated to the bottom, and not unfrequently both are killed on the spot./

In returning to the tents with the people whom I had alarmed, and who cautioned me not to proceed farther in that direction, I quite trembled at the recollection of the various escapes I had had, as some of these blaqua, as they are called, were not a yard distant from the marks of my former footsteps.

The country near the banks of the river to the west is orna- 
mented by many very large tamarind and other trees, bearing a fruit resembling a medlar, green and pleasant to the taste, and many of the Mimosa tribe flourished in uncontrolled luxuriance. 'The Googooroo, or Jujube, abounded; and these varieties of green gave a life to the landscape that was quite new to us. The wild fruits even were palatable ; and selecting those on which the monkeys were feeding, we devoured them fearlessly and eagerly, - their freshness supplying the want of either flavour or sweetness. The monkeys, or as the Arabs say, "men enchanted,"- " Ben Adam meshood," were so numerous, that I saw upwards of one hundred and fifty assembled in one place in the evening. They did not at all appear inclined to give up their ground, but, perched on the top of the bank some twenty feet high, made a terrible noise/; and rather gently than otherwise, pelted us when we approached to within a certain distance. My negro was extremely anxious to fire at them; but they were not, I thought, considering their numbers, sufficiently presuming to deserve such a punishment.

May 25.-About two miles from Lada, we left the river, and halted at noon near a small still water. Here were several flocks of geese, and some of the species of bird called adjutant. These mid-day halts, with only partial shade, were dreadfully sultry and oppressive. We moved on in the afternoon, and passing another lake of the same description, by nine in the evening came to one much larger, called Engataranaram. Nothing could be more wild than the country we had passed through this day; and compared with the sterile plains I had lately been accustomed to, seemed rich and picturesque : it was one continued wood, with narrow winding paths, to avoid the overhanging branches of the prickly tulloh. The frequent foot-marks of lions, the jackal, and hyena, gave us a pretty good idea of the nature of the inhabitants; and their roarings at night convinced us that they were at no great distance.

We had this morning met a kafila from Soudan, consisting of 


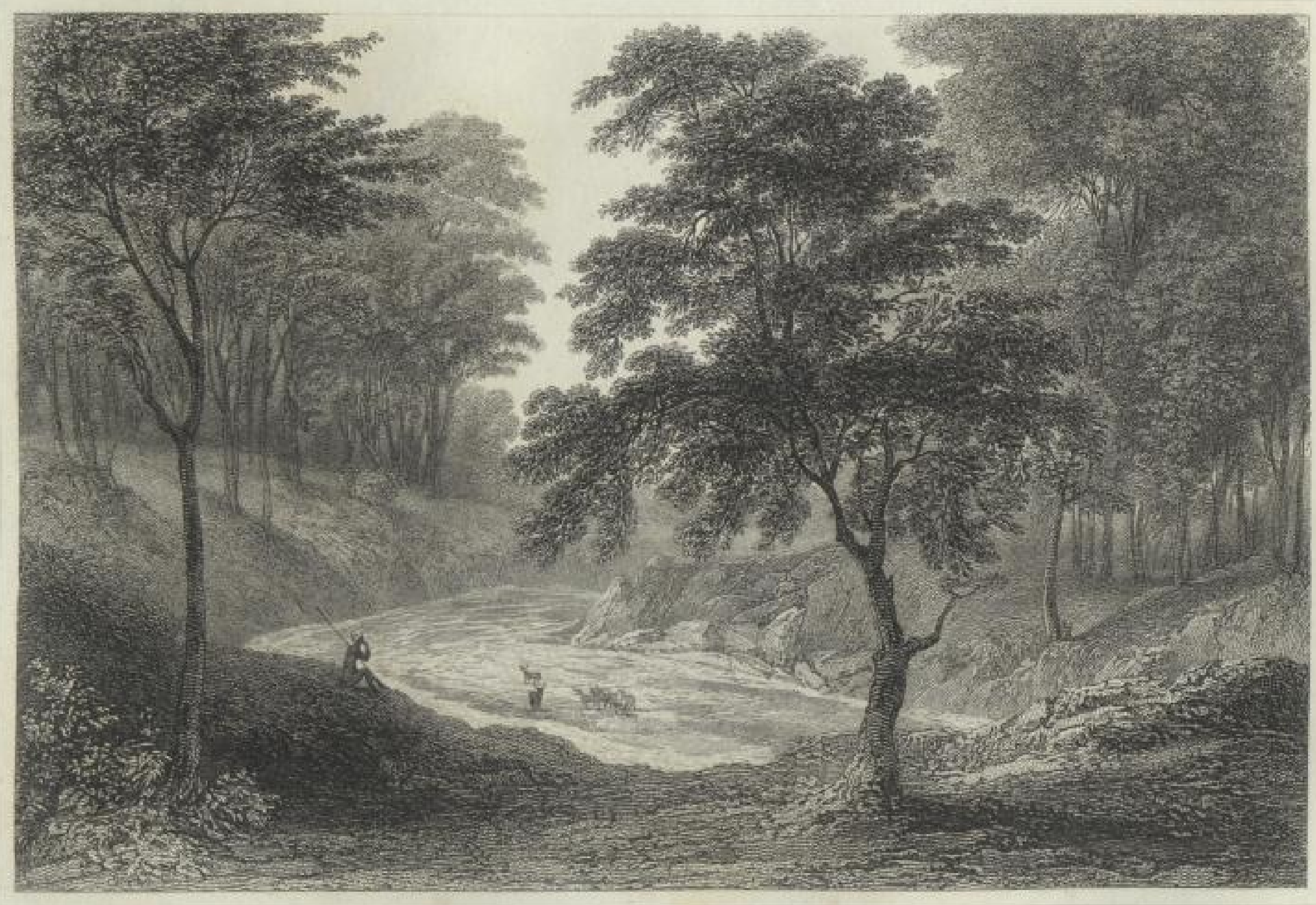

\section{SLUB}

Wir führen Wissen.

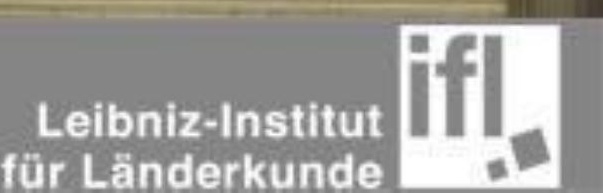


about twenty persons, and bringing one hundred and twenty slaves ; and some hours after we saw the place where they had passed the preceding night. They had lit their fires in the very centre of the path, and made a good fence all round them of large branches of trees and dry wood. This fence is sometimes set fire to, when their four-footed visitors are numerous, and approach too near. Camels and animals of every description are placed in the centre, and should one stray in the night, he is seldom again recovered. Kafilas never travel after dusk, particularly those on foot; and our negroes had such a fright during the latter part of this day's march, that they declared on coming up with the camels, that their lives were in danger from such late marches, an immense lion having crossed the road before them only a few miles from where we halted. There can be little doubt, that by their singing and number they had disturbed the lion from his lair, as we must have passed within ten paces of the foot of the tree from which he broke forth on their approach : they said that he had stopped, and looked back at them, and if they had not had presence of mind sufficient to pass on without at all noticing him, or appearing alarmed, some one of the party would have suffered.

Previous to pitching our tents at night, the sheikh's negro examined the ground, and, after dismounting and listening attentively for an instant, he declared some people to be near. We fired a gun, which, after a little time, was answered by a shout, and at no great distance we found about half a dozen Kabsharians, who said they were on their way to Kouka, and near them we fixed ourselves for the night. In these woods kafilas from Soudan are often robbed, and the runaway negroes, who are good bowmen, pick off the leaders from behind the trees, and then plunder the baggage: ten men from one kafila had, we were informed, been so murdered during the last year. 
May 26.-We pursued a westerly course for eight miles to a lake called Gumzaigee, about a mile in length, between which and another called Gumzaigee-gana, the road lies; seven miles beyond which is still another lake of considerable extent, called Muggaby, or the lake of the sultan of Bornou: this is nearly three miles long, and full half a mile broad; its banks are beautifully green, and its depth is very great; it contains hippopotami in great numbers, and every now and then their black heads appeared above the surface of the water.

A few straggling parties of Kanemboo infantry had occasionally crossed our path, for several days, on their way to join the sheikh, but here we found about a hundred and fifty Shouaas, or Arabs of Beni Wah'l. After our tents were pitched, and we had refreshed ourselves by a mess of ducks and rice, we determined on riding to visit the remains of Old Birnie*, which extended nearly to this lake. We proceeded by the high road to Soudan, and after about two miles came to the spot on which once stood the capital of Bornou, and the ruins of the city certainly tended more strongly to convince us of the power of its former sultans than any of the tales we had heard of their magnificence: we had seen upwards of thirty large towns which the Felatahs had completely razed to the ground at the time they destroyed the capital, and we were now arrived at the ruins of that capital itself $\uparrow$. Old Birnie covered a space of five or six square miles, and is said to have had a population of two hundred thousand souls: the remains of the walls were in many places still standing, in large masses of hard red brick-work, and were from three to four feet in thickness, and sixteen to eighteen

\footnotetext{
- Birnie means Medina, the capital, in the Bornou language.

+ From these ruins the sheikh procures the greater part of the nitre used in preparing his gunpowder.
} 
feet in height. From the top of one of these we obtained a sight of the river Gambarou, running nearly east, notwithstanding its windings, and only a few miles distant. At sunset we returned to our huts.

Crossing the head of the lake Muggaby, we took a north-westerly direction, for the purpose of seeing the remaining ruins of this once populous district, and particularly those of a favourite residence of the former sultan, called Gambarou, situated on the banks of the river, four miles distant, which comes from Soudan : this district gave its name to the waters during their passage through it. After wading through low grounds, occasionally overflowed, where the wild grass was above our horses' heads, and disturbing a herd of fourteen elephants, whose retired haunts were seldom so broken in upon, we came to the river, which is here a very noble stream, nearly a quarter of a mile in breadth, and situated between two high banks thickly overgrown with jungle, bushes, and bamboo*: we endeavoured to ascertain if there was any current, but the water appeared perfectly stationary. Omar Gana, however, and the Shouaas who had accompanied us, were unanimous in declaring that after the rains a very strong current from west to east constantly flowed.

We determined on remaining here the next day, and ordered the tents to be pitched under the shade of an immense tamarind tree, about two hundred and fifty yards from the bank of the river. The water was sweet and palatable, and very gratifying to us after the lake water we had been drinking for the last few days, though that was nectar in comparison with the well-water near Kouka. The shoals of fish that rushed quite close to, and sometimes on, the shore, exceeded any thing I ever could have supposed, both as to size and numbers : we waded, nearly up to our knees, to a little

- There are two species of the bamboo, one called Kayay, and the other Gummary. 
island or sand-bank âbout ten yards from the land, and found the marks of two good-sized crocodiles quite fresh.

Close to the bank, and just at the hollow of a slight curve in the river's course, fourteen years ago stood the town of Gambarou, the chosen place of residence of the late and former sultans of Bornou ; and the ruins now standing give a proof of the buildings having been, for this country, of a princely kind: the walls of a mosque, which were more than twenty yards square, are still visible, and those of the sultan's house, with gates opening to the river, still remain; a private mosque appears also to have been attached to the sultan's residence: the buildings were all of brick, and must have had a superior appearance to any town we had seen in Africa: the situation was beautiful, and although labyrinths of thickets and brambles now overspread the banks of the river, while wild plants and useless grass were in the meadows, yet I was assured that the whole neighbourhood of Gambarou was once in a superior state of cultivation; and that in the old sultan's time, boats were constantly - moving to and from Kabshary and other towns to the west. Kouka was at that time not in being, and Angornou but a small parcel of huts.

May 28.-Dr. Oudney and myself mounted our horses this morning, and followed the course of the river to the eastward, nearly three miles: there being no pathway, we were obliged to break through the high grass, trees, and thickly scattered bamboo, which made it a fatiguing excursion, and after all, we could only now and then get a sight of the water by following the track of the elephants and other animals, whose ponderous bodies beat down every thing before them. Our negro, Omar Gana, was alarmed, and would willingly have turned back more than once; we, however, urged him on, and at length came to an open, dry shoal of sand, the bed of the river extending more than two hundred yards; here was the fresh impression of the 
foot of a very large lion, and we found that the stream was here again called the Yeou. To Omar Gana's great satisfaction, we now returned by a more direct path through the wood to our tents: these wilds, from their not leading to any high road or inhabited spot, are perhaps never visited, the whole country having been abandoned ever since the Felatahs commenced their inroads. Wild animals of all descriptions here abound therefore in greater numbers than in any other part of the kingdom of Bornou : several parcels of wood tied up with oziers, and large trees stripped of their bark and afterwards deserted, showed how the wood-cutter had been disturbed at his work by the ferocious inhabitants; and some whitened bones, and the remains of a hatchet in one place, made us shudder and conclude, that some one still less fortunate had here met a miserable death. Straggling bands of Tuaricks also sometimes scour the country about the banks of the river, and carry off whatever suits their purpose.

On our return to the tents, we found that our situation was by no means so comfortable as we could have wished. Kabshary, to which place we intended proceeding, and there awaiting the arrival of the sheikh, had been attacked and partly burnt by the Munga people since our leaving Kouka, and deserted by the inhabitants; and while we were debating on what steps we should take in consequence of this intelligence, two Kanemboo spearmen came to us in great consternation, with news that the Munga horse had been reconnoitring all around us, had even visited the part of the river we had been exploring in the morning, and after murdering several Kanemboos, who were proceeding to join the sheikh, had carried off the bullocks and whatever they had with them. The sheikh's delay in coming up had made them bold, and their approach had caused all the Shouaas we had left at Muggaby to beat a retreat; we were therefore left quite alone, and, as it seemed, might expect every minute to be surrounded, taken prisoners, and with an iron round our necks, 
with which slaves are coupled like greyhounds in slips, marched off to Munga. Omar Gana was greatly alarmed, and dressing himself in his steel jacket, with red giboon (waistcoat) over it, and black turban, calmed our fears but little, by leaving us for a full hour to see if the Shouaas had really left Muggaby; notwithstanding he at the same time assured us, that the sight of his red jacket would frighten a hundred Mungowy. On his return, which we looked for with much anxiety, we found the alarming reports in part confirmed; no Shouaas were near the lake, and he was quite sure the enemy had been there. He proposed going to Kabshary, along the banks of the river to the west; but acknowledged that the sheikh was not there, and that the people had moved off towards Angornou : we considered this bad advice, and determined on returning at least to the Kouka road: that was, however, no easy task; and after some consideration it was determined that we were to keep close to the bank of the river, and creep through the woods as well as we could, avoiding all beaten paths. We moved at three in the afternoon, and crossed about two miles distant to the north bank of the river, our road being extremely intricate, and overgrown with trees and underwood.

Just before sunset we came upon a herd of elephants, fourteen or fifteen in number; these the negroes made to dance and frisk like so many goats, by beating violently a brass basin with a stick; and as night now began to cast over us its gloomy veil, we determined on fixing ourselves until morning in a small open space, where a large tree, destroyed by the attacks of the white ant, had fallen, and afforded us fire-wood to prepare our supper: to seek it at any distance would have been dangerous at that time in the evening, on account of the lions, and the little grass which was gathered for our horses was furnished by the space within sight of our tents. Our animals were brought as close to us as possible, and we kept up 
fires the greater part of the night; a few roaring salutations, and those principally from the elephant and jackal, were the only disturbance that we met with.

We proceeded on our course on the following day, winding with the river; in several places we had the bank clear of trees and covered with verdure for some hundreds of yards, and the stream nearly as broad as the Thames at Richmond. Towards noon the wood became much thicker, no pathway was to be discovered, and our guide declared, that where we were he had not the least idea. A little further on, we came to a complete stoppage; brambles were wound round the before thickly-clustered branches of tulloh and prickly acacias; and on removing, with great difficulty, some of those, we found the treacherous grass underneath merely covering blaquas, large, deep, and well staked, capable of receiving and destroying a Tuarick with his maherhy. In endeavouring to find a passage at a short distance, Dr. Oudney was very nearly precipitated,
horse and all, into one of these graves for the quick. We were absolutely afraid to move; and Omar Gana, who declared these fortifications indicated our being near to some town, which was thus prepared against the Mungowy, desired me to fire a gun, in order to bring some of the inhabitants to serve as our guide : accordingly two sturdy negroes came to our assistance, who, after eying us through the trees and ascertaining who we were, conducted us to the village, which, although at no great distance, would have foiled all our efforts to discover: the avenues were completely barricadoed on every side, the paths cut up, and these blaquas so scattered in all directions, that even with a guide, and going one by one, it was with the greatest difficulty we avoided them.

Arrived at the village, which was called Wallad, of so miserable a description that it could not even furnish a jar of milk, notwithstanding we produced both needles and beads, - a new difficulty arose; 
for although the camels were sought after and brought in safe by the people, yet my servant Columbus, who was behind on a mule, did not make his appearance: we were in considerable anxiety, both on account of the wild beasts and these pits, which were almost equally frightful. Our alarm was a good deal increased when, after having sent people in every direction, giving them pistols, and desiring them to fire signals, and not return without him, the people of the village came running to the jujube tree under which we were resting, to tell us that Columbus and the mule had fallen into one of these blaquas, and that they believed the mule was dead. We hastened to the spot, and found the poor mule indeed very near it: she was sticking on four stakes, one in her flank, and two in her hind quarter, with her knees dreadfully torn by struggling. Had she been a larger and heavier animal, nothing could have saved her: the man had, by a violent exertion, thrown himself out, how he knew not, almost as soon as he fell in, and had escaped with his leg only bruised. $\mathrm{He}$ said he had lost his way hours before, and had climbed to the top of several tamarind-trees, in order to discover traces of our route, without success : once he thought he heard a gun, but having only two charges of powder with him, he kept them as a defence against the wild animals at night, and was afraid to answer the signal.

- After all our difficulties, it was some comfort at length to find that the sheikh was within only a few hours' march of us, on the south side of the river ; and in the evening we determined on joining him. Again, therefore, crossing the Yeou at a dry spot, we came to the outskirts of the Bornou camp, on the banks of a large water called Dummasak, about five miles distant from the ford: at the river we again saw the footmarks of a very large lion, and also those of a hippopotamus. It was after sunset when we arrived, and passing through numerous groups of the Kanemboo spearmen, who were lying about without any tents or covering, we came to the open 
space where the sheikh's tent and the huts of his principal-people were fixed. On learning that we had arrived, he desired our tents might be placed near Mady Gana, the manager of his household, who brought us his congratulations, and at the same time a very good supper of Guinea fowl, and a kind of paste, made of wheat flour, called ftat, which is considered a great delicacy. Our 'joy can with difficulty be imagined at learning here the arrival of a package from England, by a kafila of merchants from Fezzan. The pleasure of hearing of our country and friends, the greatest enjoyment our situation allowed us, we had been for a length of time deprived of; and this, added to our being entirely destitute of provisions of every kind, determined us to return to Kouka on the following morning. This our decision we desired might be made known to the sheikh, but, from some cause or other, the information was not communicated to him; and, to our great surprise, by daylight he moved off, and we found ourselves again alone without a guide, and without even knowing what the sheikh's wishes were with respect to our proceedings. This was a fresh dilemma; and upon the whole we were worse off than the day before, for the sheikh's negro was always a protection, and we were now at the tail of an undisciplined army, at least demi-savage, without any knowledge of the road. After three hours' deliberation, and no intelligence arriving from the sheikh, we decided on making our way to Kouka alone; and having picked up a straggler, who assured us he knew the country, and left our wounded mule in the care of some people in the neighbouring village of huts, we loaded our fire-arms afresh, and commenced our route. We had proceeded, however, but a few hundred yards on our road, when Omar Gana, mounted on a miserable horse and in great distress, came up to us, entreating that we would follow the sheikh as quickly as possible; that on inquiring of him where we were, and finding that he had quitted us, he, the 
sheikh, had been in a violent passion; had struck him from his horse, which he desired might be taken from him; had directed him to return and bring us up to the army without delay.

We had now nothing to do but to obey; and, therefore, turning round our camels, after a four hours' march in the heat of the day, we arrived a second time at the lake Muggaby, which we had left only three days before./Some spots on the road were extremely picturesque, by nature; and this beauty of the scene was increased by the groups of naked warriors, with their shields, resting in different places on the borders of the lake; while hundreds of others were in the water, spearing the fish, which they struck, and brought to shore with very surprising dexterity: some of the fish were as large as good-sized salmon, but shaped like a bream. Fires were lighted by their companions on the shore, and rows of from fifty to one hundred were staked, or strung on a line made of grass, extended from two sticks, and most excellently and expeditiously roasted.

Muggaby, with its still dark-blue surface, had, at the time we came on it, an appearance highly interesting: the margin, and the shallow waters, were crowded with horses feeding, and men bathing. In the centre, the hippopotami were constantly throwing up their black muzzles, spouting with water; and the wood, which at the south-west end had caught fire, and blazed to the very clouds, gave a glare to all around which made the scene almost terrific.

We now commenced our march with the Bornou army, in which but little order is preserved previous to coming near the enemy: every one appears to know, that at a certain point the assembly is to take place; and the general instructions seem to be to every one to make the best of his own way. The sheikh takes the lead, and close after him comes the sultan of Bornou, who always attends him on these occasions, although he never fights. The former is preceded by five flags, two green, two striped, and one red, with extracts from 



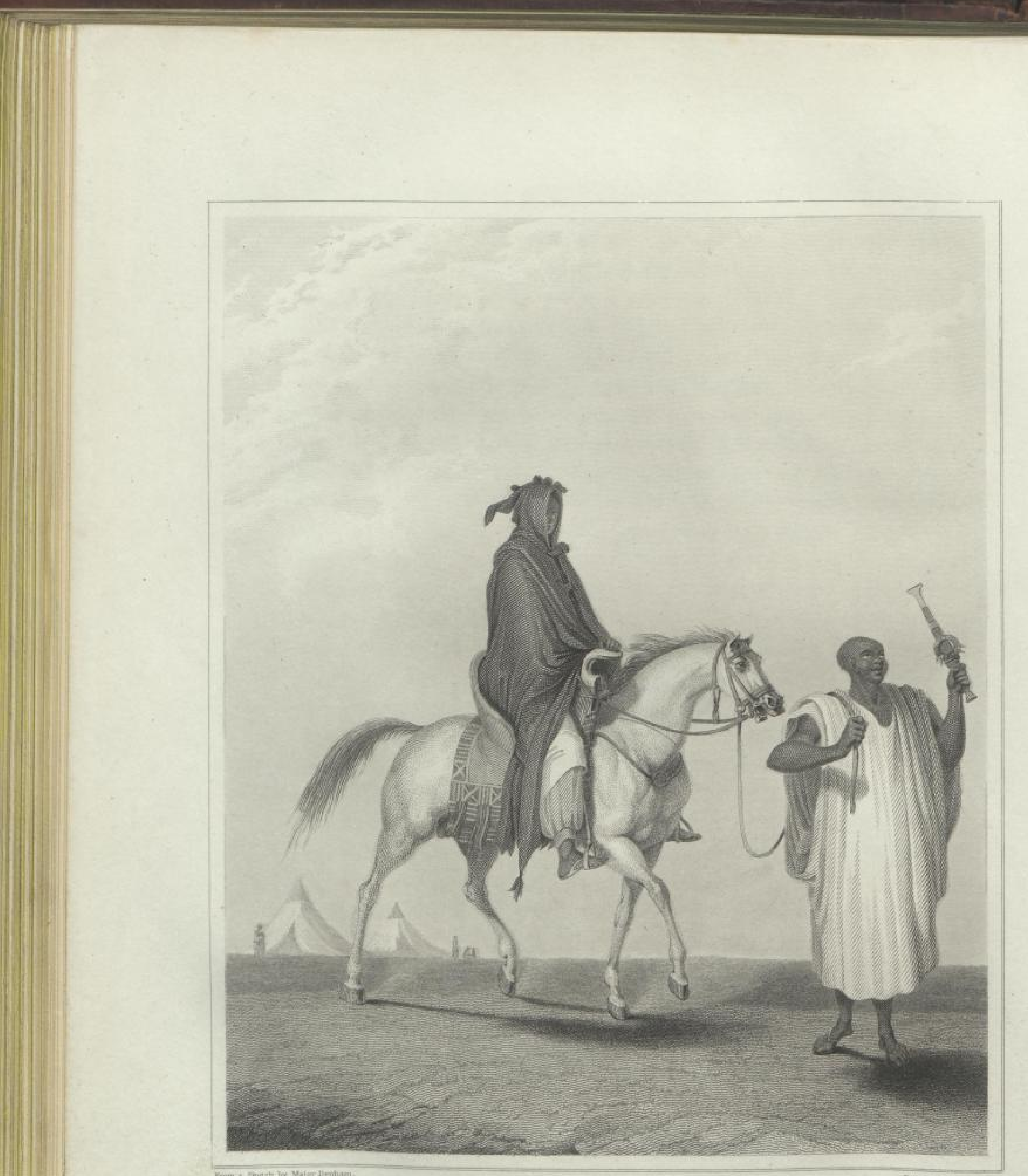


the Koran written on them in letters of gold, and attended by about a hundred of his chiefs and favourite slaves. A negro, high in confidence, rides close behind him, bearing his shield, jacket of mail, and wearing his skull-cap of steel; he also bears his arms. Another, mounted on a swift maherhy, and fantastically dressed with a straw hat and ostrich feathers, carries his timbrel or drum, which it is the greatest misfortune and disgrace to lose in action. On the expedition which cost the sultan Denhamah, the late sultan of Bornou, his life, the timbrel and the sheikh were supposed to have fallen in a sudden rush of Begharmis; almost every one near him suffered. 'The people, however, firmly believe that he was saved by a miracle; they say, " he became invisible; that the Begharmi chiefs scoured the field, calling out for the sheikh; that his drum sounded at intervals, but could not be seen, any more than their leader.' Close in the rear of the maherhies follow the eunuchs and the harem; the sheikh takes but three wives, who are mounted, astride, on small trained horses, each led by a boy-slave, or eunuch,--their heads and figures completely enveloped in brown silk bornouses, and a eunuch riding by the side of each.

The sultan of Bornou has five times as many attendants, and his harem is three times as numerous: he is attended, also, by men bearing trumpets (frumfrum), of hollow wood, ten and twelve feet long; with these a kind of music is constantly kept up. As this instrument is considered an appendage of royalty alone, the sheikh has no frumfrums ; the keigomha, or standard-bearer, rides in front of him, carrying a very long pole, hung round, at the top, with strips of leather and silk of various colours, in imitation, probably, of the bashaw's tigue, or tails; and two ride on each side of him called Meestrumha Dundelmah, carrying immense spears, with which they are supposed to defend their sultan in action, whose dignity would be infringed upon by defending himself; but the spears are so hung round with charms, and the bearers so abomina- 
bly unwieldy, that the idea of such weapons being of any use in the hands of such warriors is absurd. Indeed the grotesque appearance of the whole of this prince's train, with heads hung round with charms, and resembling the size and shape of a hogshead; their protruding stomachs, and wadded doublets, are ridiculous in the extreme.

The town of Kabshary, where we halted, had been nearly destroyed by the Mungowy. On attacking a place, it is the custom of the country instantly to fire it ; and as they are all composed of straw huts only, the whole is shortly devoured by the flames. The unfortunate inhabitants fly quickly from the destructive element, and fall immediately into the hands of their no less merciless enemies, who surround the place: the men are quickly massacred, and the women and children lashed together, and made slaves. Rhamadan, one of the sheikh's chiefs, a slave from Soudan, had been stationed here for the last fifteen days, and under his protection the survivors of the attack had returned, and were already rebuilding their dwellings. The huts are convenient, and, from the abundance of long straw which the overflowed grounds near the river furnished them, are better built, and withstand the rain better, than those of Kouka : they are divided on the inside by mats, which the women make with great neatness; they have all of them a door of plaited straw in a frame of wood; and some of the habitations of the principals have a wall of mats round them, leaving an inclosure, in which is sometimes a second hut for the female slaves, and the cow or goats which supply them with milk. These unfortunate people seldom think of defending their habitations, but rather give them up, and by that means gain time to escape themselves, should the attack not be made in the night, and the whole set fire to, before they have time to fly. The Kabsharians had long been in dread of a visit from the people of Munga, and, on their approach, the greater part of them had retreated to the banks of the 
river, to the north-west of the town, which are there extremely high; and they had made a strong post, by digging blaquas, and placing pointed crossed stakes in trenches, which rendered their retreat nearly inaccessible.

June 1.-The sun had scarcely risen this morning, when the sheikh was on horseback inspecting his favourite troops, the Kanemboo infantry: a hollow space under some sandhills, called Cornamaree, was chosen, about a quarter of a mile from the camp, and the whole was conducted with a good deal of order and system. $\mathrm{He}$ was attended to the ground by the four sultans who accompanied the expedition under his orders, and a circle was formed by the Arabs and the Bornou horse. The sheikh's principal slaves and commanders were dispersed in different parts, habited in their scarlet bornouses with gold lace, and surrounded also by their followers. His own dress was, as usual, neat and simple : two white figured muslin tobes, very large, with a bornouse of the same colour, and a Cashemere shawl for a turban, composed his dress; over the whole, across his shoulders, hung the sword which, as he repeatedly said, " the sultan Inglese had sent him." He was mounted on a very beautiful bright bay horse from Mandara, and took his station on the north side of the circle; while the Kanemboos were drawn up on the opposite extremity in close column, to the number of nine thousand. On the signal being made for them to advance, they uttered a yell, or shriek, exceeding any thing in shrillness I ever heard; then advanced, by tribes of from eight hundred to one thousand each. They were perfectly naked, with the exception of a rather fantastical belt of the goat or sheep's skin, with the hair outwards, round their middles, and a few gubkas (narrow strips of cloth, the money of the eountry), round their heads, and brought under the nose; their arms are a spear and shield, with a dagger on the left arm reversed, secured by a ring which goes on the wrist, the point running up the arm, and the handle downwards. The shields 
are made of the wood of the fogo, a tree which grows in the shallow waters of the great lake, and are so extremely light, as to weigh only a few pounds; the pieces of wood of which it is formed are bound together by thongs of the hide of bullocks with the hair on, which is also carried along the edge of the outside of the shield in vandykes and forms an ornament; they are something the shape of a gothic window, and most of them slightly convex. Under cover of these, the Kanemboo attack the bowmen with great order, and at a slow pace. Their leaders are mounted, and are distinguished merely by a tobe of dark blue, and a turban of the same colour.

On nearing the spot where the sheikh had placed himself they quickened their pace, and, after striking their spears against their shields for some seconds, which had an extremely grand and stunning effect, they filed off to the outside of the circle, where they again formed, and awaited their companions, who succeeded them in the same order. There appeared to be a great deal of affection between these troops and the sheikh; he spurred his horse onwards into the midst of some of the tribes as they came up, and spoke to them, while the men crowded round him, kissing his feet, and the stirrups of his saddle. It was a most pleasing sight; he seemed to feel how much his present elevation was owing to their exertions, while they displayed a devotion and attachment deserving and denoting the greatest confidence. I confess I was considerably disappointed at not seeing these troops engage, although more than compensated by the reflection of the slaughter that had been prevented by that disappointment.

On seeing the sheikh after this inspection, he asked me what I thought of his Kanemboos: I could not help expressing my pleasure at their orderly and regular appearance, and he smiled when I assured him that I thought with such troops as these he need fear but little the attempts of the Arabs and Fezzaneers. Rhamadan, who had been stationed at Kabshary since the burning 


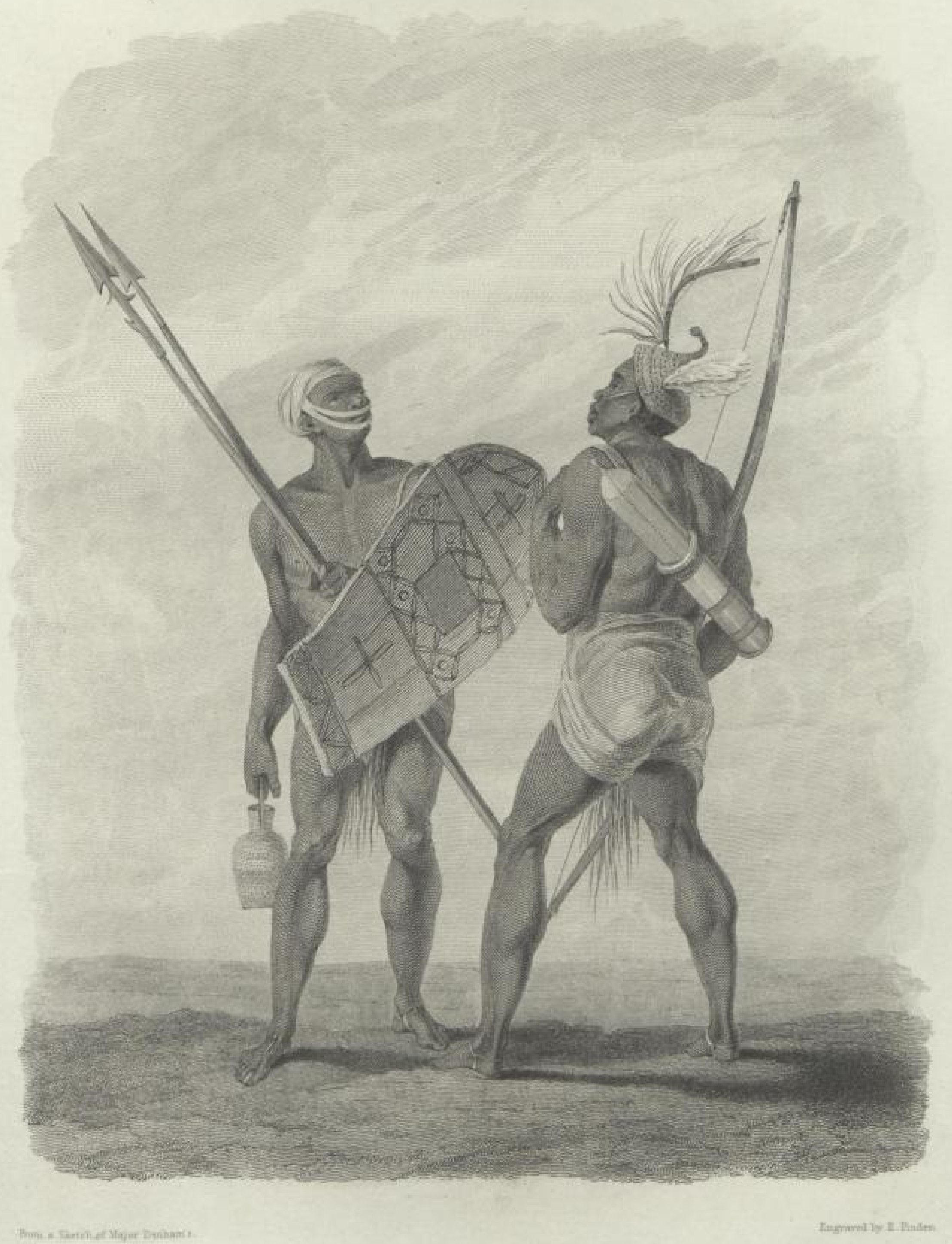

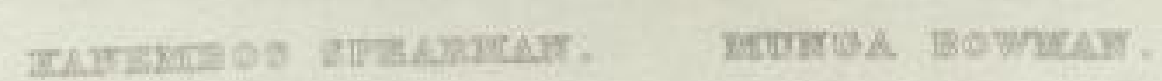

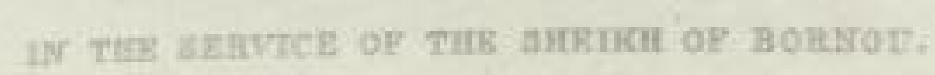

\section{ㄱ SLUB}

Wir führen Wissen.
Leibniz-Institut
für Länderkunde 


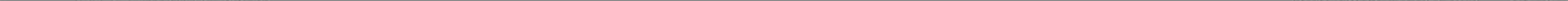


of the town, gave me an account of a second attack made by the Mungowy since his arrival. He had about two hundred and fifty people with him, amongst whom were about a dozen Arabs in the sheikh's service, who had guns. Eight or nine hundred of Munga people made their appearance by daylight one morning, principally to try the strength of their enemies, which it was, of course, Rhamadan's business to prevent their ascertaining. He succeeded in driving them back, although not without some loss, quite to the inclosed country, where they had greatly the advantage of him, and killed nearly thirty of his men with their arrows. Rhamadan now practised a ruse de guerre, by which means he destroyed nearly half the force of his enemies:- $\mathrm{He}$ appeared to give up the chase, and retired with his party ; towards evening, however, he moved round by the river to a watering-place, where he expected the Mungowy would go to drink and refresh themselves, and rushing upon them unperceived, slaughtered upwards of four hundred.

June 3.-A reconnoitring party of cavalry went out soon after daylight with Rhamadan and Dauood (David) at their head. About three in the afternoon they began to return, bringing with them women and children of both sexes, to the amount of eight hundred: one Shouaa, a friend of mine, brought a poor woman with four children, two in her arms, and two on the father's horse, who had been stabbed for defending those he held most dear upon earth. They also brought a number of very fine horses, and several hundred bullocks and sheep. The poor wretches, on being brought to the sheikh's tents, uttered the most piteous cries, and, after looking at them, he desired that they might all be released : saying,-- "God forbid that $I$ should make slaves of the wives and children of any Musselman! Go back; tell the wicked and powerful chiefs, who urge your husbands to rebel and to kafir, that I shall quickly be with them; and it is them I will punish, not the innocent and the helpless." 
June 4.-We found to the south a very pretty lake, embosomed in a thick wood, and the town Bassecour, with from fifteen hundred to two thousand inhabitants; and, on crossing it, saw two other populous towns, called Caroom and Batily; and again, nearer the river, which was about four miles from Bassecour, several others. I did not return until after sunset, when the positions of the Kanemboo, who always are on duty on the side nearest the enemy, afforded some very picturesque groups. They have a regular chain of posts, or pickets, consisting of five or six men each, extending from the main body to some one of the tribes, who always act as an advance, about two miles in front, and cover the whole front of the army. They lie very snugly under the shelter of their shields, which protect them both from wind and rain, as well as the arrows of their foes. One or two of each party are always on the look out, and their peculiar watch-cry is passed from one sentry to the other, at every half hour or oftener, the whole night through. On the least disturbance taking place in the camp, or horses breaking loose, after a sudden storm, the whole body strike their shields, and set up a yell, to show that they are awake to the circumstance: this also is their tattoo, may be heard for miles, and answers the blowing of the sheikh's horn for the last prayers at Ashè.

June 5.-Many hundreds of the Munga people now came in, bowing to the ground, and throwing sand upon their heads, in token of submission. At night every thing was prepared for our marching to the capital, leaving the women, camels, and baggage, at this place; but the people sent word, that if the sheikh remained where he was, they would come to him, and surrender themselves.

June 6.-Several towns sent their chiefs, and submitted in this manner,-bringing peace-offerings, on the sheikh's swearing solemnly not to molest them farther; but Malem Fanaamy, a fighi of great talent, the cause of the rebellion of these people, refused to come, because he feared to lose his head, and offering, at the same time, 
two thousand slaves, one thousand bullocks, and three hundred horses, to the sheikh, as the price for peace *. The offer was refused: the sheikh's object being the subjection of this rebellious chief, and not his death or plunder.

We had, the night before, attempted to send off two rockets, but which, to my great disappointment, as well as the sheikh's, had failed: they had been carelessly carried, and the composition had fallen out of them. This evening he sent " to beg that I would try two more, and, please God, make them go better." I replied, " that I would do my best;" and, most fortunately, they succeeded to my wish. They were, indeed, a beautiful sight, as the night was extremely dark, and created exceeding wonder. Some of the messengers, who had come from the towns to the west, fell on their faces, and began to pray most fearfully when the rockets burst in their descent. This evening, also, Malem Fanaamy had sent his son, a man of about thirty, handsomely attended, who also witnessed this wonderful exhibition.

The following day, Malem Fanaamy himself made his appearance. His people had become clamorous, and, having no alternative, he came superbly mounted on a white horse, with full one thousand followers, and, dismounting at the door of the sheikh's tent, humbled himself to the dust, and would have poured sand on his head, but this was by the sheikh's order prevented, and the fighi brought into his presence. As is the custom on these occasions, he came in poor habiliments, and with an uncovered head. The sheikh received

* This fighi was a most extraordinary person, and his fame for knowledge and charmwriting was by some thought to exceed that of the sheikh himself, of whom he was jealous to a degree. He had passed years amongst the Kerdies to the south, and knew

$$
\text { "To taint with deadly drugs the barbed dart." }
$$

He was now, however, about to be humbled. 
his submission, and, when he really expected to hear the order for his throat to be cut, he was clothed with eight handsome tobes, and his head made as big as six with turbans from Egypt.

June 11.-The feast of the Aide having arrived, and the Rhamadan finished, the new moon was ushered in by loud shouts, and by the firing of guns, and our last rocket was sent up in honour of the feast. It was preceded by a volley fired by my negroes with two carabines, and two brace of pistols, with my own gun, which gave great pleasure; for certainly never were people so enamoured of gunpowder and smoke. By sunrise all the troops were under arms, and the sheikh and all the chiefs mounted, and dressed in their finest bornouses, rode round the camp, and prayed at a short distance. The chiefs of two Munga towns came in to-day, but brought no tribute. We visited the sheikh in the evening, to congratulate him on the Rhamadan being over. He asked a great many questions, particularly about printing; and, addressing me, said :- " Why did you not bring plenty of rockets? They are the most wonderful things I ever saw." At night we had a dreadful storm, and we were witnesses of a curious custom which the natives have, of digging an immense hole immediately after rain, and, when they come to the dry sand, getting into the hole, and lying down to avoid the damp earth.

June 15.-To avoid the excessive heat of the tents, as we were still to be stationary, we rode to the town Gomsee, before the sun had gained sufficient power to be oppressive, and passed nearly the whole of the forenoon in the corner of the hut of a woman, who had come to the tents the day before for medicine. She had been troubled with ringworms for ten years: she recognised me on my entering the town, which I merely intended passing through, in order to gain the shade of some large tamarind-trees and mangoes that grow close to the lake; but she was so anxious that I should come to her house, that I could not refuse. Her husband was one 
of the principal persons, and their huts rather superior to the rest. In an inclosure of mats were three huts, one for the man, and the two others for his wife and slaves. I took possession of the former; when, after a repast of milk, and a kind of thick drink, made of a paste from the gussub flour, with honey and pepper, I had visits from at least one hundred of the inhabitants, male and female. This is nearly the last of the Bornou towns westwards. Although the men of Bornou are not warriors, nor the women favoured by nature, they are certainly a kind, inoffensive race; and in one hour were as intimate with me, as if I had been amongst them for years. It was decreed, however, that we were not to part quite such good friends. At noon my host brought in a very beautiful wild bull-skin, with water, on which he begged I would " sully" (pray), and, on my refusal, the usual investigation took place, which ended in my attendant explaining to them, " that I did not sully ;" that is, " that I was not Mislem :" upon which, " Kerdie, Kerdie," was whispered about. The women held up their hands, and the men retired to a distance, and I found my popularity rapidly decrease.

No kafila is permitted to enter Kouka during the sheikh's absence, nor dare the merchants offer any goods for sale till they have his permission. On this account, one consisting of ten merchants from Soudan was ordered to encamp at a short distance from us, and await the movements of the army. They had nearly a hundred slaves, the greater part female, and girls of from twelve to eighteen years of age, some of them from Nyffee, and still further to the west, of a deep copper colour, and beautifully formed; but few of these were ironed. The males, who were mostly young, were linked together in couples, by iron rings round their legs; yet they laughed, and seemed in good condition.

It is a common practice with the merchants to induce one slave to persuade his companions, that on arriving at Tripoli they will be free, and clothed in red, a colour all negroes are passionately fond

$z 2$ 
of; by which promises they are induced to submit quietly, until they are too far from their homes to render escape possible but at the risk of starvation. If the hundreds, nay thousands, of skeletons that whiten in the blast between this place and Mourzuk, did not, of themselves, tell a tale replete with woe, the difference of appearance in all slaves here (where they are fed tolerably), and the state in which they usually arrive in Fezzan, would but too clearly prove the acuteness of the sufferings which commence on their leaving the negro country.

A circumstance happened during the last two days, which created a great sensation amongst the chiefs ; and while it proved that absolute power in the person of the sheikh was not unaccompanied by a heart overflowing with feelings of mercy and moderation, it also displayed many amiable qualities in his untutored and unenlightened subjects. Barca Gana, his general, and his favourite, a governor of six large distriets, the man whom he delighted to honour, who had more than fifty female slaves, and twice the number of male, was taught a lesson of humility that made me feel exceedingly for him. In giving presents to the chiefs, the sheikh had inadvertently sent him a horse which he had previously promised to some one else, and on Barca Gana being requested to give it up, he took such great offence, that he sent back all the horses which the sheikh had previously given him, saying that he would in future walk or ride his own. On this the sheikh immediately sent for him, had him stripped in his presence, and the leather girdle put round his loins; and, after reproaching him with his ingratitude, ordered that he should be forthwith sold to the Tibboo merchants, for he was still a slave. The favourite, thus humbled and disgraced, fell on his knees, and acknowledged the justness of his punishment. He begged for no forgiveness for himself, but entreated that his wives and children might be provided for, out of the riches of his master's bounty. But on the following day, when preparations were made for carrying 
this sentence into effect, the Kaganawha (black Mamelukes), and Shouaa chiefs about the sheikh's person, fell at his feet, and notwithstanding the haughtiness of Barca Gana's carriage to them since his advancement, entreated to a man pardon for his offences, and that he might be restored to favour. The culprit appearing at this moment to take leave, the sheikh threw himself back on his carpet, wept like a child, and suffered Barca Gana, who had crept close to him, to embrace his knees, and calling them all his sons, pardoned his repentant slave. No prince of the most civilized nation can be better loved by his subjects than this chief; and he is a most extraordinary instance, in the eastern world, of fearless bravery, virtue, and simplicity. In the evening, there was great and general rejoicing. The timbrels beat; the Kanemboos yelled, and struck their shields; every thing bespoke joy : and Barca Gana, in new tobes and a rich bornouse, rode round the camp, followed by all the chiefs of the army.

June 18.-We commenced our return to Kouka, after an expedition to me very interesting, and one in which the sheikh had displayed a vast deal of tact and good management; for although he threatened the extermination of the Munga people, yet nothing could have been more injurious to his interests than carrying such threats into execution, had he, indeed, been sufficiently strong to have done so. They are a powerful people, and can bring twelve thousand bowmen into the field; their arrows are much longer than those of the Felatahs, and they have a way of poisoning them more fatally than those people. A nation possessing such a force as this amongst his own people,-who, from their situation on the frontier, were constantly exposed to the attacks both of the Felatahs and the Tuaricks, and by being more accustomed to warfare, were consequently better troops than any in the kingdom of Bornou,-it became a matter of great importance to the sheikh to conciliate by fair means, if it were practicable, and he was perfectly alive to the policy of such 
a proceeding. The Mungowy nearly all fight on foot, while Bornou may not improperly be called an equestrian nation. The infantry here, however, as in our own quarter of the globe, most commonly decide the fortune of war; and the sheikh's former successes may be greatly, if not entirely, attributed to the courageous efforts of the Kanem spearmen, in leading the Bornou horse into the battle, who, without such a covering attack, would never be brought to face the arrows of their enemies. No use had ever yet been made of the accession of strength to Bornou by its junction with the Munga people, and the sheikh had this in view when he planned the present expedition. All these considerations had their weight with him, as well as the numerical force with which he had to contend, and he availed himself of the superstition of the people, and his own fame as a Malem (writer), to do that which, probably, by the effect of his arms alone, it might have been difficult to accomplish. He is reported to have spent three successive nights in writing charms : the effects of which were, that the spears of some of the enemies' chiefs were found in the morning blunted and hacked, whole quivers of arrows were found broken also, and their arms changed from one hut to another; other chiefs were seized with sickness, and all with fear. My rockets are also said to have struck terror indescribable into the hearts of the Mungowy. Their chief, Malem Fanaamy, declared, " that to withstand a sheikh of the Koran who performed such miracles was useless, and, at the same time, haram (sin)." This confession of his inability to contend with El Kanemy determined the people to submit.

Some of the Munga people were brought to me; they were completely Bornou, and had all the simplicity, good nature, and ugliness, which are the particular characteristics of that people. Malem Fanaamy himself was a sort of lusus naturæ; Nature had set a peculiar mark upon him, by covering one side of his face with a thick beard, while on the other not a hair was to be seen. This of 
itself, amongst a people so utterly ignorant, was sufficient to gain him disciples, who were ready to believe him gifted with superior powers. In these untraversed climes, a very little learning indeed is sufficient to raise a man's fame and fortune to the highest pitch. Persons who have been to Mecca, of the meanest capacities, who amuse them with tales of the countries and people they have seen on the road, are treated with the greatest respect, and always provided for; indeed every house is open to them : and any European travelling in these countries might acquire an influence by these means, which would enable him to carry all his objects into effect with great facility.

On the 19th of June we returned to Kabshary, and found that great progress had been made in rebuilding the town. The sheikh gave a sum of money towards completing the work, and exempted the inhabitants from tribute for a season; and all, therefore, was rejoicing. The Alowany Shouaas are here in very great force. We had some visits from the women in the evening, who were really beautiful; and although of a sort of dingy copper colour, are here called white, and consequently held in but little estimation by the natives-black, and black only, being considered by them as desirable. I bathed this morning in the Gambarou, while poor Dr. Oudney rested on the banks : live muscles are in plenty, and we found some very pearly oyster-shells at the bottom of the river.

While we remained at Kabshary, we encountered another violent storm, and were much amused at the economy of the Shouaas when the storm approached. I saw all were extremely busy digging holes in the sand with their spears, evidently too small for them to get into themselves, and we were not a little surprised at seeing them presently bury their shirts and trowsers two or three feet deep in the sand, which, on the rain subsiding, they dug up, and put on, quite dry, with an air of great comfort and satisfaction. They never are affected by thus exposing their naked bodies to the fury of the 
tempest, while we, who were always covered, had colds, agues, and pains, that they were entirely free from.

We had news to-day that the people of Waday had, with a large army, visited Begharmi, that persecuted country, and again pillaged all the towns; and also that our huts had been broken into at Kouka, and some, if not all, of our property stolen. The first report turned out a false one, but the second, to our sorrow, was too true. Hillman had been confined fifteen days to his bed with ague, and during this time, in the night, the robbery was effected.

June 23.-We proceeded on our return, and again pitched our tents on the banks of the Muggaby. In all the woods are flocks of wild animals, called by the Bornouese korookoo, and by the Arabs el buger-achmer, the red bullock: some of these were disturbed today, and one got into the midst of our horsemen; it has immense horns, and is something between the ox and the antelope. Spears were struck at him without number, but he effected his escape, carrying off several sticking in his flesh. The horses were exceedingly alarmed, and many of their riders measured their lengths on the sand. The two kafilas from Soudan passed us to-day, on their way to Kouka ; they consisted of one hundred and fifty slaves, with about twenty merchants and their servants, and thirty camels. Most of the people ran to the outskirts of the camp to see them pass, it being the custom, on these occasions, to dress out these poor victims of the most cruel avarice that certainly ever entered into the breast of man, in rags of different colours, only to be taken from them again on the procession being over. The merchants, who gratify their vanity the most in this way, lose, it is said, fewer slaves; but I observed several of these before me, whose unbidden tears flowed down their cheeks as they drew their mantle close round them, seeming to wish by that means to stifle their misery with the appearance of it.

It was intended this evening to have killed an hippopotamus, an animal which exists in great numbers in the lake on the borders of 


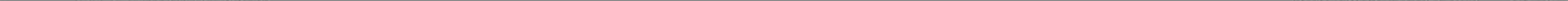


which we were encamped, but a violent thunder-storm, to our great disappointment, prevented our witnessing so novel a species of sport. The flesh is considered a great delicacy. On the morrow we had a full opportunity of convincing ourselves that these uncouth and stupendous animals are very sensibly attracted by musical sounds, even though they should not be of the softest kind: as we passed along the borders of the lake Muggaby at sunrise, they followed the drums of the different chiefs the whole length of the water, sometimes approaching so close to the shore, that the water they spouted from their mouths reached the persons who were passing along the banks. I counted fifteen at one time sporting on the surface; and my servant Columbus shot one of them in the head, when he gave so loud a roar, as he buried himself in the lake, that all the others disappeared in an instant.

We made a long march to Dummasak, when we halted until the afternoon of the next day. The army here dispersed, and the Shouaas and Kanemboo went off to their respective homes.

By daylight we began to move. The sheikh sent for us to ride near him, and, accompanied by nearly all the people who had remained behind, and who came out thus far to welcome the successful return of their prince, we arrived once more at the capital, amidst the shouts of the men, and the shrieks of the women, to take possession of our old habitations.

The kafila which came from Soudan during this expedition brought a young fighi from Timboctoo, the son of a Felatah chief of D'jennie, named Abdel Gassam ben Maleky. He was on his way to Hage, and had left Timboctoo, as is the custom, without any thing beyond the shirt on his back, the rags of which he exchanged on the road for a sheep's skin, subsisting entirely on charity. He was a very fine and intelligent lad, of about sixteen, of a deep copper colour, but with features extremely handsome and expressive. $\mathrm{He}$ was five months from D'jennie, and greatly exhausted by fatigue

$\triangle \mathrm{A}$ 
and the want of nourishing food : his whole wardrobe was his sheep's skin; and although the sheikh gave him a tobe, he said he almost thought it a sin to indulge in the luxury of putting it on. We were on the expedition to Munga when he arrived, and about the time of our evening meal, Abdel Gassam generally made his appearance at our tents : bad as the fare was, he found it preferable to the cold mess of flour and water he got elsewhere. He knew little or nothing of the road by which he had come to Kano, not even the names of the places he had halted at. Abdel Gassam said he could scarcely believe such good people as we were could be any thing but Moslem : but he had heard of Christians before ; and when I asked how, and where, he gave the following account:-

"Many years ago, before I was born, white men, Christians, came from Sego to D'jennie, in a large boat, as big as two of our boats. The natives went out to them in their canoes; they would not have done them any harm, but the Christians were afraid, and fired at them with guns, and killed several in the canoes that went near their boat: they proceeded to Timboctoo, and there the sultan sent to them one of his chiefs, and they held a parley. The Christians complained that the people wanted to rob them. The sultan was kind to them, and gave them supplies. Notwithstanding this, they went off suddenly in the night, which vexed the sultan, as he would have sent people with them, if they had not been afraid of them a little: and he now sent boats after them, to warn them of their danger, as there were many rocks in the belly of the river, all pointed. However the Christians went on, and would not suffer the sultan's people to come near them, and they all perished." My informant never heard that any thing belonging to them was saved, but remembers himself seeing à man often with his father, who was in one of the canoes that followed them, and who had seen them strike against the rocks-indeed he brought the news to Timboctoo. Their appearance excited a great sensation amongst the people;- 
had frequently heard people talk about the Christians, and the large boat, for a whole day, at his father's; - to this day they talk about them. They had guns fixed to the sides of the boat, a thing never seen before at Timboctoo, and they alarmed the people greatly.

Abdel Gassam was a sort of prodigy, and could repeat the Koran from the beginning to the end. I repeatedly asked him what they would do to us, if we were to go to Timboctoo? "Why," answered he, " do by you as you now do by me, feed you. The sultan is a great man, with a large heart, and is kind to strangers. Many whites, but not like those in the great boat, come to D'jennie, and also the servants of these people, who he thinks were Christians, but they do not go to Timboctoo: they come from the great water; and the Felatahs at D'jennie, by their means, supply Timboctoo with cloth and silk, yellow and red, and guns, which are much sought after. Does not know what these white people take back, but always heard, slaves and gold dust. The sultan of Timboctoo is a very great man, never goes out to ghrazzie; but his slaves go, and bring back many slaves, mostly females, from the Kerdy countries, by which he is surrounded. At D'jennie and Melli, which are both subject to Timboctoo, the population is mostly Felatah. The whole road to Timboctoo is inhabited by Moslems; but to the north and south of the route are Kerdies, who sometimes attack kafilas; but they are very much afraid of Bello, who protects merchants. Kashna, Kano, Houssa,- one language; Timboctoo, D'jennie,-one language; but they also speak Felatah. At Sego the population is Negro, Kerdy, Kaffir. All communication between Sego, D'jennie, and Timboctoo, is by water : the river is very large, and called Qualla; and Kabra is the place where every thing going from, or coming to, Timboctoo, is embarked or disembarked. Kabra is five hours distant only from Timboctoo: always understood that this great river, which has many names and branches, went from Nyffe south,

$$
\text { A } 42
$$


between high mountains. The river at Kano is not the same; indeed, believes it is only a lake, and no river."

This information, as far as it goes, may, I conceive, be relied on. Unlike nearly all the Moorish traders, who are often tutored by others, who have been rewarded for describing probably what even they never saw, and come prepared to say any thing that will best please you, this lad undoubtedly had never been questioned by any one previous to his answering my inquiries: he knew but little Arabic, and had scarcely been noticed in his long journeys, during which he had been handed over from one kafila to another.

He left Kouka in the month of August, in company with an old fighi, for Waday, with a small leather bag of parched corn, and a bottle for his water. I gave him a dollar to pay for his passage across the Red Sea, which he sewed up in his sheep's skin : I however heard afterwards, that he had been drowned in crossing one of the branches of the Tehad. My informant was a Waday Shouaa: but if they found out that he had the dollar, he was most likely murdered for the sake of such a booty.

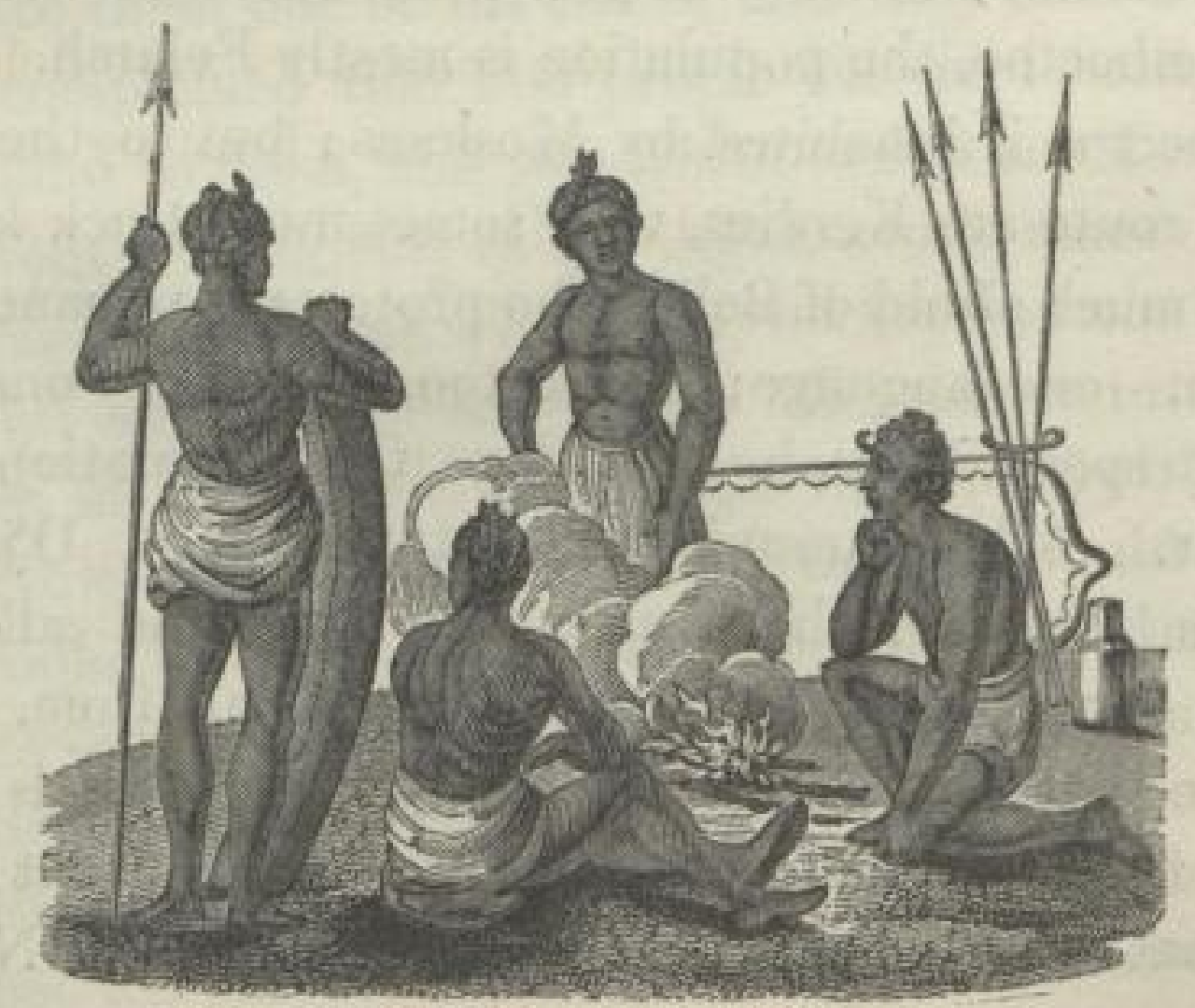




\section{CHAPTER V.}

THE sheikh gave us an interview in his garden this afternoon : the lemon and fig trees exhibited some fruit, the appearance of which was gratifying. Knowing we had news from England, he asked several questions about the Morea, where the Greeks and Turks had been fighting. He had read some account of the former splendour of that country, and he was pleased with some of the corroborations we gave him of their truth. He again started the subject of the shape of the globe, and wished to be acquainted with the method in which its shape had been ascertained: some of his books, he said, made it square. A phosphorus box, which had been brought him from Tripoli, and of which he knew not the use, was now produced, and on the match coming out lighted, himself and all the spectators were delighted beyond measure. I was this morning going on a hunting excursion to the Tchad with some Shouaas of Beni Hassan, but as it was Sunday I postponed my sport: they however went, and brought back a very young elephant, not more than two feet and a half high, and yet so powerful, that three men were obliged to hold him for the purpose of pouring a little milk down his throat. Achmet-ben-Sheneen, an Arab of Augela, a wretched sufferer, came constantly to the Doctor for medicine; and on seeing him we could not refrain from blessing God's providence in our misery, for sparing us from such afflictions as had fallen upon him. Nearly two years before, in an action with La Sala Shouaas, whom the sheikh conquered, this poor fellow had received three dreadful wounds; one in the head, which had left a 
deep scar; another in the arm, which, as the spear was poisoned, had never healed, but was still an open wound, extending several inches from the elbow downwards; and in the third, the spear had gone in at his mouth as he lay on the ground, and carrying away part of the jaw and teeth, had penetrated quite through his cheek. A short time after his return from the expedition, he was seized with what the Doctor called the Greek leprosy, covering great part of his body with a foul black eruption, and from which he was now suffering, accompanied by an irritation almost insupportable.

Doctor Oudney and Hillman were now both too ill to join us at meal times; the heat of the day, and dampness of the evenings, affected us all greatly. I used, notwithstanding, to go out in the morning and shoot a couple of ducks or a goose, which helped us out at dinner, although they were dreadfully tough and fishy. 'The country was now assuming a more interesting appearance from the crops of gussub that had sprung up all round Kouka, on which the slaves of all the inhabitants had been busily employed during the last month, as they sow at the commencement of the rainy season.

In a country where so little is cultivated, there is always an abundant choice of land; and a planter takes possession of any spot that has not been occupied the preceding year, and it then becomes exclusively his property. In two months from the time of sowing they gather the harvest, and this is the only labour of the year./

We had a curious trial this morning before the sheikh, the result of which furnishes a singular proof of his simplicity and submission to the word of the Prophet. The circumstances were these: a Shouaa had stabbed a man the night before, upon some disagreement, and death was the consequence. The brother of the defunct demanded blood, and on application to the kadi, it came out in evidence that the Shouaa had desired the deceased to quit his door, three several times, if he had any faith in the Prophet; but he still continued to resist, and aggravate him, till at last he stabbed him in 
six places. The kadi's decision was, that upon so solemn a caution, the unfortunate man should have retired; - that his not doing so was a proof he had no faith in the Prophet; was a Kafir, and was the cause of his own death, and therefore that the murderer should not suffer punishment. The accuser, however, appealed to the sheikh, who told him, that, certainly, by God's law, communicated to the Prophet, and written in the g'tab (the book), an eye for an eye, a tooth for a tooth, and life for life, should be given-but recommended his taking a fine instead of blood. The sturdy Arab, however, was unmoved, and called loudly for justice; and the sheikh then said, he had the law in his own hands, and he might do as he pleased. The prisoner was then taken outside of the walls, and the brother of the deceased beat his brains out with an iron-headed club, which the Shouaas sometimes carry. This was considered a very extraordinary occurrence in Bornou.

I continued to work at the Arabic and Bornou languages; and, besides this, I usually visited Barca Gana two or three times a week, and sometimes he came to me, so that my time rarely hung heavy on my hands; but he always came mounted, and with so many attendants, that my little hut was put in disorder for the whole day after. I believe he entered no person's habitation in the town but my own, except the sheikh's. No great man here ever visits his inferior, or moves from his own house to the sheikh's, without a retinue agreeable to his rank; and the kashella, on remonstrating with me for coming through the streets alone, was surprised when I told him that even our king did the same; and, often habited like his subjects, rode attended only by a single servant. Convinced as he was before of his importance, this astonished him greatly. "Why," said he, "were the sheikh to do so, nobody would respect him :"and replied I, " in England the oftener the king does this the more he is both loved and respected."

Two decisions of the sheikh lately had created a considerable 
emotion amongst the people. The slave of one man had been caught with the wife of another, a free man, and the injured husband demanded justice. The sheikh condemned both the man and the woman to be hanged side by side : the owner of the slave, however, remonstrated, and said that the decision, as far as respected the woman, was just; for she was always endeavouring to seduce his slave from his work, and that if he (the sheikh) condemned his slave to death, the man, whose wife was the cause of it, ought to give him the value of his slave, as he was poor: this the husband objected to. "Ah!" exclaimed the sheikh, " how often is a man driven to his destruction by woman; yet of all his happiness, she is the root, or the branch." He himself paid the value of the slave to the owner, and the next morning the guilty pair were suspended outside the walls.

August 8.-Last night a man brought a large bird, called oubara, a smaller species of which the bashaw's sons hunt daily, in the neighbourhood of Tripoli, with their hawks: this was exceedingly large, weighing as much as twelve pounds; and we gave him about two shillings for his present, in coarse cloth (gubbuk); and before breakfast this morning, he brought another still larger; but finding we had spoiled the market, for this I only gave him half as much. These birds are peculiar for the brilliancy of their large eyes, which exceeds that of the gazelle*, and the flesh very much resembles our pheasants in flavour.

In these southern climes, all matters of business, as well as pleasure, are transacted before the generality of people in England have well finished their night's rest, and this morning I rode out by daylight to see the ceremony of a Bornou wedding. The lady was from Angornou; and the bridegroom's friends, to the number of twenty

* The most beautiful Jewess in Tripoli is called Mesrouda-eyum el Oubara (Mesrouda, with the eye of the Oubara). 
or thirty, all mounted and in their best clothes, went to give her weleome: she was mounted on a bullock, whose back was covered with blue and white turkadees, and followed by four female slaves, laden with straw baskets, wooden bowls, and earthen pots; while two other bullocks carried the rest of the dowry, which consisted of a certain number of turkadees and tobes. She was attended by her mother, and five or six young ladies, who acted as bride's maids. We galloped up to them repeatedly, which is the mode of salutation. The women cover their faces, and scream their thanks; the men, however, wheel their horses quickly, and return with their eyes cast to the ground, it being considered as extremely indelicate for them to look upon the bride. The lady, after this, proceeds to the bridegroom's house with her mother, and there remains shut up until the evening, when she is handed over to her justly impatient lord: for the whole day he is obliged to parade the streets with a crowd after him, or sit on a raised seat, ̀̀ la sultan, in his house, dressed in all the finery he can either borrow or buy; while the people crowd in upon him, blowing horns, beating drums, and crying " Engouberon degah! Alla Kabunsho! Alla Kiara!" "May you live for ever! God prosper you! Grey hairs to you !" to all which he makes no answer; but looks more foolish than one could suppose it possible for any man in so enviable a situation as that of a bridegroom to do.

August 11. The sheikh sent this morning to say, that, as we mentioned yesterday the state of our funds, any money that we stood in need of he would immediately furnish us with-that while we were under his protection, we should want for nothing: we, however, said with every feeling of gratitude, that, as we were not quite pennyless, we would wait a few days, until all the people arrived from Soudan.

It is quite impossible to describe the value of his kindness to us on all occasions; and this last proof of his liberality to poor wan-

B $\mathbf{B}$ 
derers, whose country he scarcely knew the name of before our arrival, surpassed all we could have expected. Knowing us through the medium of the bashaw of Tripoli only, his disinterested conduct could have been alone the dictation of a generous confidence; and his own penetration and sagacity had long since convinced him of the perfect innocence of our intentions in visiting his country, notwithstanding the injurious reports to the contrary, which had been communicated to his subjects, through the ill will or ignorance of some of the Fezzan merchants : he had sent me apparel from his own house on hearing the news of my forlorn state, after escaping out of the hands of the Felatahs, and had astonished the people about him by his exclamations of sorrow on the first report reaching him of my death. Kaffir as they thought me, he mentioned my escape in his letter to Barca Gana-which met us on our return-as a proof of the protection of God's providence, in a manner which made a visible alteration in the conduct, not only of the chief, but of the whole army, towards me; and every part of his conduct tended to convince us, that his protection and confidence proceeded more from the opinions he had formed of the grandeur and generosity of the English nation (and, we were willing to flatter ourselves, from his approbation of our conduct), than from any hope of repayment or remuneration from his ally the bashaw.

The constant sickness of Doctor Oudney, who, nearly ever since our return from Munga, had been confined to his hut; - Hillman's frequent attacks of ague and delirium, and the uncertainty as to the manner in which any supplies were to be obtained, to enable us either to proceed or return, tended but little to keep up our spirits; -my eyes had for some months been too weak to allow of my reading in the evening, or, indeed, of bearing the light in the hut for any length of time together; and we separated, from a mutual repugnance to conversation, from the dreariness of our prospects, almost immediately after our evening meal. 
We had frequent and violent showers of rain, with thunder, and most vivid lightning; the waters covered the face of the country in extensive lakes, and our excursions in search of game were now confined to the immediate neighbourhood of our residence. The gussub had increased in height greatly; and, at this season of the year, there are other reasons besides the falls of rain which induce people to remain in their habitations-when the great lake overflows the immense district which, in the dry season, affords cover and food by its coarse grass and jungle to the numerous savage animals with which Bornou abounds, they are driven from these wilds, and take refuge in the standing corn, and sometimes in the immediate neighbourhood of the towns. Elephants had already been seen at Dowergoo, scarcely six miles from Kouka;/ and a female slave, while she was returning home from weeding the corn to Kowa, not more than ten miles distant, had been carried off by a lioness : the hyænas, which are every where in legions, grew now so extremely ravenous, that a good large village, where I sometimes procured a draught of sour milk on my duck-shooting excursions, had been attacked the night before my last visit, the town absolutely carried by storm, notwithstanding defences nearly six feet high of branches of the prickly tulloh, and two donkies, whose flesh these animals are particularly fond of, carried off in spite of the efforts of the people. We constantly heard them close to the walls of our own town at nights, and on a gate being left partly open, they would enter, and carry off any unfortunate animal that they could find in the streets.

There are a particular class of female slaves here, to whom the duty of watching and labouring in the fields of grain is always allotted. I have before said, that all laborious work is performed by that sex we consider as the weakest, and whom we employ in the more domestic duties only - and it is to them this perilous work is assigned. The female slaves from Musgow, a description of whom I have somewhere else given, are never bought by the Tripoli or

B B 2 
Fezzan traders: their features, naturally large and ugly, are so much disfigured by the silver stud which they wear in the under lip, that no purchaser would be found for them; besides the loss of the two front teeth, which are punched out to make way for the silver which goes quite through into their mouths, the weight of the metal, after a year or two, drags the lip down so as to make it quite lie on the chin, and gives a really frightful appearance to the face: these poor creatures, therefore, who are generally of a strong make, and patient under their sufferings, guard the crops, and collect the harvest, and a year seldom passes without several of them being snatched away by the lions, who, crouching under cover of the ripening corn, spring on their prey and bear it off.

August 18.- The twelfth day of the new moon, which was the 17 th of the month, was a day of general feasting and rejoicing. Garments, according to the estimation in which the giver holds the receiver, are distributed by all great people to their followers : the sheikh gave away upwards of a thousand tobes, and as many bullocks and sheep. It is the custom, on the morning of the Aid-Kebir*, for the sovereign with his suite to mount, and, after praying at a certain distance from the town, to return to it with all his people skirmishing before him. The sheikh had been suffering from an attack of the ague, and, therefore, this ceremony did not take place; the people, however, drew bad omens from the circumstance, and said, that the sheikh not having mounted and prayed with his people was not right.

On the day after, the sheikh sent us word that Hadgi Ali BooKhaloom was on his way from Kano, and within two or three days of Kouka: this was the most gratifying intelligence that could have reached us, as our funds were all but exhausted, and we lived en-

* The anniversary of Abrabam's offering up Isaac, or the meeting of Pilgrims at Mecca. 
tirely on the provisions furnished us by the sheikh, with the exception of a little milk and a few fowls, which we purchased. On the 21 st he arrived, and very much altered in appearance for the worse, as well as most of the people who had accompanied him ; the Fezzaneers had all suffered exceedingly from the ague and fever, which disorders had carried off a greater number of the Fezzan and Tripoli merchants than any preceding year. The sheikh appeared pleased at Hadgi Ali's return, said he hoped all would be now soon arranged, and that the courier from Tripoli would not long delay making his appearance; he had calculated upon his returning by the Aid-Kebir, and his non-arrival gave him uneasiness on many accounts. Private information, it was said, had by several channels reached the sheikh, that the bashaw had it in contemplation to send an expedition for the purpose of taking possession of Bornou, under the joint command of Mukni the late, and Mustapha the present, sultan of Fezzan : this intelligence was also accompanied by an assurance, that while the English remained he was safe. Scarcely any line of policy could be more injurious to the interests of the bashaw of Tripoli, or his subjects, than a measure of this nature. He obtained slaves almost exclusively through the medium of the sheikh's territory, which, since he had held the reins of government, was sufficiently safe for travellers, to induce merchants with large capitals for this country to proceed by way of Bornou to Soudan. The numbers of kafilas between that country and Fezzan had, within the last five years, greatly exceeded any former period; and in an equal proportion did the respectability of those traders who now accompanied them exceed that of the merchants previously in the habit of passing through Bornou. By an intercourse with these travellers, a great variety of merchandise was brought into the interiorthe ideas of the natives became enlarged, and, consequently, their desires increased. Trade was, in fact, but just beginning to be prosecuted with vigour by the inhabitants of eastern Soudan. Eu- 
ropean goods of all descriptions, used by the Soudanees, were becoming every day in greater request, and the whole of their country might, by the bashaw's constantly keeping up an amicable understanding with the sheikh, have been supplied exclusively by the Tripoli merchants.

With a knowledge of these facts, it was almost impossible to believe that the reports of the bashaw of Tripoli's intended expedition could have any real foundation; yet the report, credited as it was by the majority of the Bornou people, was of itself sufficient to excite in us excessive alarm, both for our own safety, as well as for the success of our mission. The sheikh caused it to be understood, both here and at Angornou, that the kafila, about to leave Kouka for Fezzan, would be the last in the present state of affairs; at the same time, he relaxed nothing of his personal kindness and attention to us.

The violent rains and stormy nights continued, as did our sickness and loss of appetite. Hillman and myself were suffering constantly from a prickly heat upon the skin, which was almost insufferable during the day, and prevented our sleeping at night. All the quadrupeds, as well as bipeds, transplanted from the countries bordering upon the great ocean, appeared to suffer alike. Within the last ten days, three of our camels, Doctor Oudney's mule and his horse, the last of our Tripoli animals but one, had died, and the remaining three camels, out of the nineteen we brought here, were turned into the inclosure to take their chance, while the man was discharged who had hitherto been paid for taking care of them. /

August 27.-These things were cheerless and discouraging indeed. We had still excessive rains; and notwithstanding the great power of the sun for some hours in the middle of the day, so damp was the air, that for several days together my blankets were never dry, the rain always coming through the roof of the cousie (hut) at night. 
I had been for some time waiting for a favourable day to accompany two or three Shouaas of Tirab to the Tchad, in search of buffalos : they went several times, and usually killed one, although I never could persuade them to bring me the head: some of the meat, and a piece of the skin, was all they would load their horses with for so many miles. /Their manner of killing these animals is curious, and rather perilous - they chase them in the swamps, where they now feed, in preference to nearer the lake, and as their horses are trained so as to go quite close to them as they run, the rider is enabled to get his foot well fixed on the buffalo's back: with singular skill, he then strikes, just behind the animal's shoulder, one or two spears, if he can place them $/$ pierced with these, the animal is able to run but a short distance, then, with the assistance of his companion, but frequently alone, he dismounts and despatches his prey : it sometimes happens, that the buffalo, by quickly turning his head before they strike, oversets both horse and rider. A Shouaa friend of mine had his horse completely ripped open, and killed on the spot, only a few days since, by the sudden twist which the animal gave his head, catching the horse with his pointed horn. Yesterday I was again disappointed, from the badness of the weather: three Shouaas went, and narrowly escaped being caught by the Biddomahs-as two hundred boats made their appearance at different places on the banks of the Tchad, carrying from ten to fifteen men each, and the sportsmen were very nearly caught by the crews of two that came near the town of Koua. News came in this morning that they had carried off upwards of thirty persons from the neighbourhood of Woodie, and amongst them the nephew of the sheikh-el-Blad (governor of the town). On these occasions, when any person of rank gets into their hands, they demand a ransom of from two to three thousand bullocks, or a proportionate number of slaves. / No sultan has any power over these islanders; they will pay no tribute to any one, nor submit to any prescribed government: some of them 
lately paid a visit to the sheikh, and although they brought him only a few slaves, that they had stolen from the Begharmi side of the water, yet he received them kindly, and gave them fine tobes and red caps. Their visit was principally to see if the reports of the sheikh's power were true; but notwithstanding their kind reception, on returning they carried off three girls from within ten miles of Kouka. These islands lie on the eastern side of the Tchad, and on embarking from the west, they described the voyage as five days of open sea previous to arriving at the islands, which are numerous; the two largest are named Koorie and Sayah. They have a language of their own, although resembling that of Kanem. Their arms are spears and shields, and they fight with every body around them, Waday, Begharmi, and Bornou. They believe in a divine power, which rules every thing, but are not Musselmans. They have a strong arm, they say, and a cunning head, instead of a large country, and much cattle; therefore they must take from those who are richer than themselves. / The Bornou people say, "the waters are theirs ; what can we do?" It is said they have nearly one thousand large canoes. They are not a sanguinary or cruel people; and when prisoners are taken in battle and wounded, they do not kill, but cure them; and if no ransom is offered, they give them wives, and they remain as free as themselves. I

Aug. S0.- Hadgi Ali Boo-Khaloom had been now returned more than a week, and nothing satisfactory had ever been extracted from him as to the money left in his brother's hands. I had great fears of his honesty from the first, and urged the necessity of our taking some decided measures with him. We accordingly summoned him to appear before the sheikh; the result of which was, our failure for want of sufficient documents, and the tergiversation of the Arabs. The official document of this trial, translated from the Arabic, will be found in the Appendix.

We received visits of condolence from several of our Bornou 
friends, who were all extravagant in their abuse of Hadgi Ali. "Are these your Mourzuk friends," said they, "who were to assist you with every thing? Why, this is robbing you. However, they called God to witness to a lie, and they will die soon : only wait a day or two."

Sept. 1.-Dr. Oudney now cupped himself on the chest for the second time, and found some little relief. Feeling that our situation required an appearance of spirit and determination, I sent for Abdal Wahad, an Arab of Zehren, distantly related to Boo-Khaloom, and to whom, on two occasions of distress, I had been kind, and upbraided him with his falsehood and ingratitude; nor was my remonstrance altogether without effect. He acknowledged that " his heart had been too big for his stomach ever since he left the palace : that his eyes had been dim, and he had enjoyed no rest; for," said he, "I swore to myself to be as faithful to you as to a brother !" " All this is very fine," said I; "but what proof will you give of this remorse?" "Every proof," he replied; " Hadgi Ali will come this very day and acknowledge the debt-that must be the consequence. I have been to the sheikh, and said how you had assisted me; and that I had sworn, and could not see you wronged." Even as Abdal Wahad predicted, so it happened. Karouash came in the course of the day to say that Abdal Wahad had been at his house, and told him the debt was just, and that he had reported the conversation to the sheikh. The sheikh's answer was, "He is quite right; after what the rais Khaleel said, every one would have known where the justice lay; for the English have not many words, but they are true ; and the Arabs, you know, will lie a little (kidip shouie shouie)."

In the evening Hadgi Ali came himself; he made, however, but a blundering excuse, saying he had never inquired into it-did not even know whether we gave any money or not to Boo-Khaloom; but that now he knew, and God forbid he should ever be otherwise than friendly with the English, and that not only two, but five thou- 
sand dollars were at our service. All this, however, ended in his begging us to wait until he had sent off his kafila to Mourzuk, and that then he would try to give us eight hundred or one thousand dollars in tobes, or gubbuk *, for not ten dollars in money had he; and the rest he hoped we would wait for, until he sent to Soudan. Unsatisfactory as this was, we thought it better not to make objections, merely saying that we were without money, and begging that he would settle it as soon as he possibly could.

Mr. Clapperton was again seized with fever, so violent as to give us all great uneasiness, and render him delirious for twenty-four hours; and from an idea that the disorder was infectious, the Bornou people could scarcely be persuaded to come near our huts. Doctor Oudney each day became weaker and weaker; Hillman was gaining a little strength: while I might be considered as the best of the party, although often suffering from headaches, and pains in the chest, with what gave me more uneasiness than all, increasing dimness of sight. I, however, kept up my spirits, visited Barca Gana and Mai Meigamy, nearly every day; and found amusement in entering into all their troubles and fears lest the bashaw should send a ghrazzie into the country.

Since the feast day of the Aid Kebir there had been on an evening an assembly of persons before the sheikh's gate; when the most athletic and active of the slaves came out and wrestled in the presence of their masters, and the sheikh himself, who usually took his post at a little window over the principal gate of the palace. Barca Gana, Ali Gana, Wormah, Tirab, and all the chiefs, were usually seated on mats in the inner ring, and I generally took my place beside them. Quickness and main strength were the qualifications which ensured victory: they struggled with a bitterness which could scarcely have been exceeded in the armed contests of

\footnotetext{
- Strips of cotton, so many fathoms of which go to a dollar.
} 
the Roman gladiators, and which was greatly augmented by the voices of their masters, urging them to the most strenuous exertion of their powers. A rude trumpet, of the buffalo's horn, sounded to the attack; and the combatants entered the arena naked, with the exception of a leathern girdle about the loins; and those who had been victorious on former occasions were received with loud acclamations by the spectators. Slaves of all nations were first matched against each other; of these the natives of Soudan were the least powerful, and seldom victors. The most arduous struggles were between the Musgowy and the Begharmi negroes: some of these slaves, and particularly the latter, were beautifully formed, and of gigantic stature; but the feats of the day always closed by the matching of two Begharmis against each other-and dislocated limbs, or death, were often the consequence of these kindred encounters. They commence by placing their hands on each other's shoulders; of their feet they make no use, but frequently stoop down, and practise a hundred deceptions to throw the adversary off his guard; when the other will seize his antagonist by the hips, and after holding him in the air, dash him against the ground with stunning violence, where he lies covered with blood, and unable to pursue the contest. A conqueror of this kind is greeted by loud shouts, and several vests will be thrown to him by the spectators; and, on kneeling at his master's feet, which always concludes the triumph, he is often habited by the slaves near his lord in a tobe of the value of thirty or forty dollars; or, what is esteemed as a still higher mark of favour, one of the tobes worn by his chief is taken off, and thrown on the back of the eonqueror. I have seen them foam and bleed at the mouth and nose from pure rage and exertion, their owners all the time vying with each other in using expressions most likely to excite their fury : one chief will draw a pistol, and swear by the Koran that his slave shall not survive an instant his defeat, and, with the same breath, offer him great rewards if he

c c 2 
conquers. Both of these promises are sometimes too faithfully kept; and one poor wretch, who had withstood the attacks of a ponderous negro, much more than his match, from some country to the south of Mandara, for more than fifty minutes, turned his eye reproachfully on his threatening master, only for an instant; when his antagonist slipped his hands down from the shoulders to the loins, and by a sudden twist raised his knee to his chest, and fell with his whole weight on the poor slave (who was from Soudan), snapping his spine in the fall. Former feats are considered as nothing after one failure; and a slave, that a hundred dollars would not purchase to-day, is, after a defeat, sold at the fsug, maimed as he is, for a few dollars, to any one who will purchase him.

The skin of a noble lion was sent me by the sheikh, which had been taken near Kabshary, measuring from the tail to the nose fourteen feet two inches. He had devoured four slaves, and was at last taken by the following stratagem: the inhabitants assembled together, and with loud cries and noises drove him from the place where he had last feasted; they then dug a very deep blaqua, or circular hole, armed with sharp pointed stakes; this they most cunningly covered over with stalks of the gussub; a bundle of straw, enveloped in a tobe, was laid over the spot, to which a gentle motion, like that of a man turning in sleep, was occasionally given by means of a line carried to some distance. On their quitting the spot, and the noise ceasing, the lion returned to his haunt, and was observed watching his trap for seven or eight hours-by degrees approaching closer and closer,- and at length he made a dreadful spring on his supposed prey, and was precipitated to the bottom of the pit. The Kabsharians now rushed to the spot, and before he could recover himself, despatched him with their spears.

Mr. Clapperton's illness had increased to an alarming height:he had upwards of twenty-four hours' fever, and delirium without cessation. These attacks, just about the time the rainy season is at 
an end, are very prevalent, and often fatal to the white people from the sea, as the Arabs are called. How much more violently must they effect the natives of more temperate lands?

Mr. Hillman was again assailed by ague, and disordered intellect, which threw him back into his former state of weakness. For two days out of the last three, I had alone appeared at our mess bench for the evening meal. Two of my companions were quite delirious in bed; and Dr. Oudney, who had for a month taken nothing but a little sour milk, three times a day, never left his hut except from necessity. These were very trying moments, and sufficient to destroy the appetite of a more healthy person than myself: still I had much to be thankful for, and I endeavoured to bless God, and ate with cheerfulness.

We had now been five days without rain; the thermometer was as high as $89^{\circ}$ in the middle of the day in the shade, and we began to think summer was again coming. It may appear incredible, that with such a temperature we should wish for an increase of heat; but the dampness of the atmosphere, and the millions of flies and musquitoes, beyond all conception, that accompanied it, rendered it almost impossible to enjoy any thing like repose, either by day or night. The annoyance of these insects $I$ had experienced at Lisbon, Naples, and in the other parts of Italy and Sicily, but neither in numbers, nor in peace-disturbing powers, were they to be compared with these. Towards the evening, a fire in the hut, made of damp straw and weeds, was sometimes the means of procuring a few hours' tranquillity; but the remedy was in itself so disagreeable, that it was only resorted to in despair : a fire of this kind, however, seldom fails to expel the intruders, from the thick and suffocating vapours which arise from it.

The horses also suffered dreadfully from the same annoyance; and to keep them from injuring themselves, wherever they can 
reach with their teeth, the negroes are obliged to keep a fire the greater part of the day, particularly at the hours of feeding, close to their heads; and notwithstanding the natural dislike those animals have to flames and smoke, they will hang their heads over the fire, so as to suffer themselves to be all but scorched, in order to obtain a little rest from their persecutors. Of scorpions we had seen but few, but the white and black ants were like the sands in number : the white ones made their way into every trunk, of whatever sort of wood they were made, as if it had been paper. And on the late expedition, during a halt of three days, in a spot where they were more than usually numerous, a mat and a carpet on which I slept were completely destroyed by them. They tell a story of an Arab having lain down to sleep near old Birnie, just over a nest of these destructive insects, covered up in a barracan, and that in the morning he found himself quite naked, his covering having been eaten to the last thread. The wooden supports of a sort of shade which $I$ had erected in the front of my hut, in a little more than three months these destructive insects had perforated with so many millions of holes, as to reduce it to a powder, and a new one was obliged to be placed in its room. The black ant was no less persevering in attacks upon our persons; her bite was nearly as bad as a scorpion, and so sharp as to excite an involuntary exclamation from the sufferer; indeed, for weeks together, my skin had, from these insects alone, more resembled that of a person afflicted with the measle than any thing else that I can compare it to. Oil, unfortunately, we had none, which is both a preventive and a cure; the only substitute I could obtain was a little fat rubbed over the body, and this seldom failed of giving me relief.

The kafila for Mourzuk left Kouka on the 13th: several Arabs, who had determined on remaining here some time, took their departure in consequence of their fears of the bashaw's visit. Nothing 
had arrived, and, in the absence of authentic intelligence, all was alarm and confusion, and reports of every kind arose: they said the kafila, which had been expected more than two months, could not be delayed from any other cause than the hostile intentions of the sultan : trusty persons were accordingly stationed at the commencement of the desert to give the earliest information of any thing approaching, and no assurances of ours had the least effect in calming the fears of the natives.

Mr. Clapperton's illness increased; and one night, while all were asleep, he made his way to the hut where the only servant slept who was not sick, begging for water; his inside, he said, was burning; the delirium had just then left him; he was too weak to return to his hut without the assistance of Columbus, who supported him in his arms; he was still dangerously ill; and four persons of our establishment, besides Doctor Oudney, were confined to their beds at this time with this same disorder: the symptoms of all were similar.

Sep. 25.-After a most restless night, I rose by daylight, and taking my old negro, Barca, rode in the direction of Dowergoo. The harvest was abundant, and they had already begun to lop off the heads of the long gussub; the tamarind trees, which lose all their leaves at the commencement of the rains, were budding with great beauty, and had a bright carnation colour; the waters had already decreased very considerably; and the season appeared highly favourable for an expedition in some previously untrodden path: every thing else was, however, against the attempt; for, added to our poverty, I was the only one of our party capable of mounting a horse. On my return I visited my patients, for Doctor Oudney could not move from his hut; and the small-pox raged amongst the slaves of two of our friends, added to the fever of the season. Out of twelve slaves who were seized, two had died; and the only child of Mohamed-el-Wordy had now taken it from his slave. They are not ignorant of inoculation, and it is performed nearly in the same 
manner as amongst ourselves, by inserting the sharp point of the dagger, charged with the disease; they never give any medicine, but merely roll the invalid in a barracan, and lay him in a corner of the hut until the disorder takes a turn.

The castor tree is found in this neighbourhood, and is commonly used as a medicine. There is also another tree, of which they either chew the blossom or steep it in water, which has the effect of an emetic.

The weather continued to improve upon us, though the heat increased; and some days the thermometer was at $97^{\circ}$ and $98^{\circ}$, but we had fewer mosquitoes, and a clearer atmosphere. Doctor Oudney had been violently attacked, first in his right, and then in his left eye, with an inflammation, which left him no rest by day or night; he, however, within the last two days, got out for an hour in the evening. Mr. Clapperton also, who had been in a state of extreme danger for many days, appeared to have passed the crisis of his attack-cool blood flowed once more in his veins, and consciousness was restored to his mind: he was however emaciated, and in a dreadful state of weakness, and his eyes could scarcely be said to have life or expression in them; he had been supported outside his hut for the last two days, and we began to hope he would recover.

Sep. 28.-During the confinement of Doctor Oudney, I had occasionally seen the sheikh about every seven days; he was always anxious in his inquiries after him, and seemed much surprised that, having such excellent medicines for other people, he should not be able to cure himself: and as this day the doctor seemed to think himself a little better, we went together to the sheikh. Dr. Oudney at once told him that he wished to go to Soudan; and as he had not given me the slightest intimation of this being his intention, I was really as much surprised as the sheikh himself. "What is your object?" said he: "why, the courier has not yet brought the bashaw's 


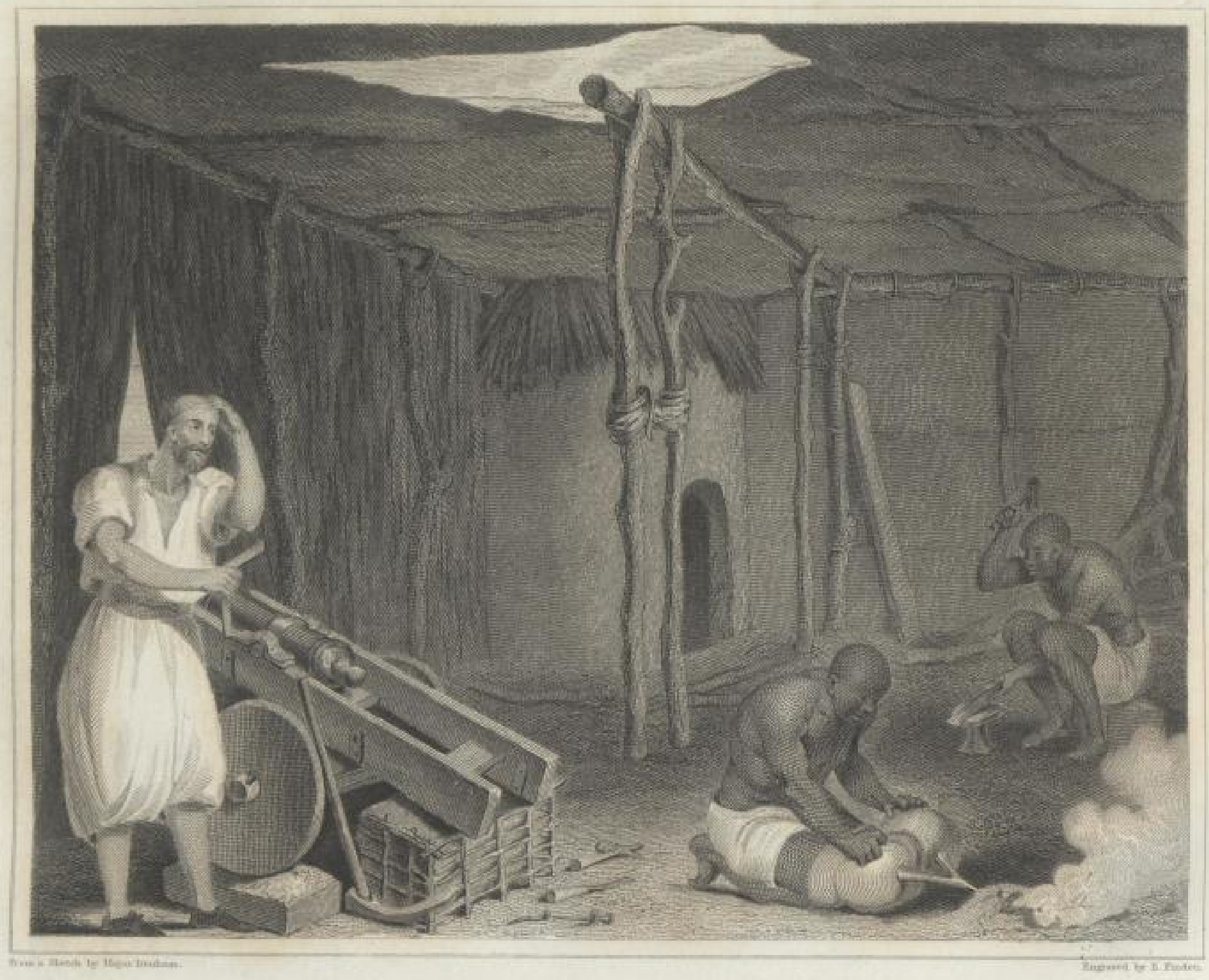

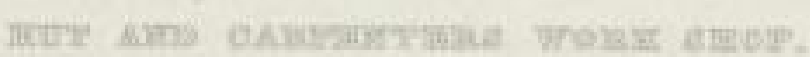

7 SLUB

Wir führen Wissen.
Leibniz-Institut für Länderkunde 
directions." Doctor Oudney replied, "My wish is to see the country - I cannot live here-I shall die. While travelling, I am always better."

Hillman had been for a long time employed in making a guncarriage for a four-pounder, which the sultan of Fezzan had formerly brought as a present to the sheikh : the scarcity of iron, the awkwardness of the negro blacksmiths, and clumsiness of their work when finished, were so distressing to the correct eye of an English shipwright, that even after the carriage was completed-and considering the means he had, it was very well done-Hillman was far from being satisfied with his work: not so, however, the sheikh. We took it to him this afternoon, and he was greatly pleased and surprised at the facility with which its elevation could be increased or decreased : both this and the wheels were subjects of great wonder. During the work, on several occasions, the sheikh had sent Hillman presents of honey, milk, rice, wheat, and sweet cakes, all of which he had shared with his companions. On one occasion, after he had finished a large chair, which pleased the sheikh excessively, he sent him a bag of gubbuk (money of the country): this, after inquiring what it was, he returned, with the true and honest pride of an English seaman, saying, "No! the king of England pays me-I don't want that; but I am much obliged to the sheikh, nevertheless."

The season seemed now to prove very unhealthy both to the natives and ourselves, and from six to ten bodies were seen carried out daily from the city gates. My poor friend Mai Meegamy was attacked, among the rest, by this dreadfully prevalent complaint, and he sent for me by daylight. I found him in an alarming state of fever, with a fit of the ague on him at the time: after consulting with Doctor Oudney, who was unable to visit him, I gave him a strong dose of emetic tartar, and in two days had the pleasure of seeing him quite recovered. The effect of the emetic tartar was to him a matter of the greatest astonishment: at the first sight of the

D D 
dose he was unwilling to take it, and asked what a little white powder like that could do for him: he was very shortly, however, convinced, that the quantity I had prescribed was quite sufficient. " What wonderful medicine!" said he: " why, if I had swallowed so much," taking up a little sand in his hand, " what would have become of me! Wonderful! wonderful! the English know every thing: why are they not Musselmen?"

This day, a large guana and a young crocodile were brought to me by one of the Shouaas: they had been killed on the banks of the Shary, five days distant, and were in pretty good preservation. I proceeded to dry them in the way mentioned by $\mathrm{Mr}$. Burchell; and although this was a matter I had never before had the least experience in, or taste for, yet I became every day more and more interested in the collections and preservations of our specimens of birds and other animals.

The sheikh sent us three birds*, which had been taken in their nests at Loggun: they are very scarce, and much esteemed, their flesh being used as a medicine for many disorders, placed hot to the part affected, particularly for an enlargement of the spleen. They feed on insects, fish, snakes, and serpents, the latter of which they have a particular instinct of discovering. This bird discovers their vicinity while yet many feet under ground, digs on the spot, destroys the nest, and feeds on the venomous inhabitant and its eggs : although larger than a turkey-cock, they were so young as to be unable to walk; indeed, the feathers were not all perfect, and I determined on endeavouring to rear one of them to more mature age and beauty. I had, indeed, already a little menagerie, which, if I would have allowed it, the sheikh would have added to daily, and $I$ found in them great amusement-I might almost say much comfort. My collection consisted, besides my Loggun bird, of two

* Abyssinian hornbill. 
monkeys, five parrots, a civet eat, a young ichneumon, and a still younger hyæna : they had all become sociable with each other, and with me, and had their separate corners allotted them in the inclosure that surrounded my hut, except the parrots and the monkeys, who were at liberty; and while sitting in the midst of them of a morning, with my mess of rice and milk, I have often cast my thoughts to England, and reflected with deep interest on the singular chances of life by which I was placed in a situation so nearly resembling the adventurous hero of my youthful sympathies, Robinson Crusoe.

Our whole household now began to revive, and on Sunday we all met in the evening about sun-set, before the doors of our huts, and enjoyed the cool breeze for more than half an hour; even Doctor Oudney, whose eyes had ceased to be so painful, joined us -we had not enjoyed such a coterie for many months. A very hale strong negro woman, the mother of Mr. Clapperton's servant, had taken the fever from her son, who had been more than a month laid on his back, and reduced her almost to death's door. She was a Koorie from one of the islands to the east of the Tchad, and had sent for several fighis, who, after writing mysterious words, decided on her case as hopeless. At last an old Hadgi, more than seventy years of age, was requested to come to her:-he was a miserable old wretch, carrying nothing but an ink-bottle, made of a small gourd, and a few reed pens; but he set about his business with great form, and with the air of a master; and, in the evening, Zerega, my negro's wife, came to me, quite in raptures at the following wonderful story: he said the woman was certainly enchanted, probably by the kaffirs, meaning the English, but, "By the head of the prophet," he should drive the devil out of her, and which he called shetan (the devil). He wrote a new gidder (wooden bowl) all over sentences from the Koran ; he washed it, and she drank the water; he said "Bismullah" forty times, and some other words, when she screamed out, and he

D 12 
directly produced two little red and white birds, which he said had come from her. "What did you do in that poor woman? she is not young," said the fighi; " why perplex her? why did not you come out of her before?" "We did not wish to hurt her much," said the birds; " but she has been kaffiring, old as she is, and must be punished: there are others in her yet who will not come out so easily; but now, since you are come, she will not die, but she had better take care for the future: we jumped into her when she went to the market ; and she knows what she did there." The poor woman shed an abundance of tears, and acknowledged that she had been a little thoughtless on the preceding market-day. The fighi was rewarded with her best Soudan shift, and they were all made happy at the news of her recovery.

October 7.-About three thousand of the sheikh's spaheia (horsemen) had lately come in from the Tchad, Shary, and the different towns south and west of Angornou, in order that they might undergo a general inspection : their horses were in good condition. An extremely careful inspection took place by the sheikh himself, and punishment was instantly inflicted on any one who had a young horse, if it appeared to have been neglected : but those whose horses were old were excused, and the animal changed.

October 8.-A circumstance happened yesterday, which I acknowledge a good deal irritated my feelings. A Tripoli merchant had intrusted to one of the Mesurata a parcel of coral, to take for him to Angornou : it was, however, never forthcoming, and he declared that he had lost it on the road. The Koran law would not, in that case, oblige the loser to make good the loss-a thing lost is God's will, and nobody's fault. A servant of the owner, however, unluckily saw the coral afterwards in the Mesurata's house; the merchant, therefore, appealed to the kadi, as, if he succeeded in proving this, the value would be recoverable. This servant had been for some time out of employ, and had assisted at our huts during 
the time that we had so many of our party sick. The kadi took this man's oath, and was about to decide, when some one said, "Why, he eats bread and salt with the Christians." "How !" said the kadi ; " is that true ?" "Yes," replied he, "I have eaten their bread, but it was because no one else would feed me; but I don't hate them the less for that." " Turn him out," said the kadi : "Staffur allah! God forbid that any one who has eaten with Christians should give justice by the laws of Mahommed!" His evidence was accordingly refused, and the merchant lost his cause. A Bornouese, a friend of mine, who was present, asked the kadi, with much simplicity, whether really these Christians were such bad people: " they seem kind," said he ; " and if they are so very bad, why does God suffer them to be so rich, and to know things so much better than we do?" "Don't talk about them," said the kadi, "don't talk about them-please God, those who are here will die Mislem : as to their riches, let them enjoy them. God allows them the good things of this world, but to Mislem he has given paradise and eternity." "Geree! geree !' (true ! true!) was re-echoed from each ; and the fatah was immediately recited aloud.

We had now received intelligence that the kafila which had left this place from Mourzuk, nearly a month since, was detained at Woodie, in consequence of the Tibboos having filled the wells between that place and Billma. Such of the Arabs as remained of our escort, after their return from Munga, left Kouka with the first kafila for Tripoli : they were all my professed friends; but, notwithstanding the miserable state in which they were, I had not the means of assisting them; the few dollars each man had received from the bashaw on quitting Tripoli, and all they possessed besides, being lost at Mandara, and they knew I was precisely in the same situation. One man in three or four sold his gun, an Arab's greatest treasure, to provide them with water, skins, and corn, for their journey. Added to this, they were all weakened by sickness and wounds : 
the fancied riches they were to be masters of, by Boo-Khaloom's victories over the Kerdies, had vanished into air, and they were about to return to their families after a year's absence, even poorer than they left them.

That the desperation natural to an Arab should be excited by such circumstances was not to me a matter of surprise. I cautioned them, however, against returning to Tripoli with unclean hands: they promised fair enough, and even shuddered when I reminded them of the bashaw's summary mode of punishing; all was, however, without effect; for, on arriving at the Tibboo country, they proceeded to the well Daggesheinga, a retreat which had been shown to Boo-Khaloom in confidence, on his last journey, by Mina Tahr, the road to which they too well remembered, and surprising the flocks of the Tibboos, and killing three of their people, marched off four hundred and upwards of their best maherhies: this had exasperated the Tibboos almost to madness; and they filled up all the wells, swearing they would be repaid, or that no kafilas should pass through their country. This news made us tremble for our supplies; but evils seemed to be crowding thick upon us, from all quarters. We discovered too, or thought we discovered, that the people now treated us with less respect, and were more lavish of the contemptuous appellations of kaffir, kelb, insara, unbeliever, dog, christian, both to me and to our servants than formerly; and as the opinion of the oi polloi in all these countries is usually governed by authority, I concluded we had also lost ground in the estimation of the chief. A Bornou boy whom I had taken some notice of, and who used to come to me almost every day to talk Bornouese, was hooted in the streets, and called insara; and when we turned him from the huts for stealing nearly two dollars in strips of cloth, the money of the country, the people all exclaimed against such an act, as, by kaffiring with Christians, they said that the misfortune of being supposed a thief had come upon him. 
October 10.-We had to-day a fresh breeze from the north-west, which was delightfully invigorating, and the natives promised us some few days of cold dry weather, which was to carry off all the fever and agues. This strongly reminded me of the Spanish villagers in Old Castile, who, during the sickly months of July and August, were, upon an average, three out of four confined to their beds with a very similar complaint: like these people, they took no medicines, but always said, "When the cold winds come we shall be better." The winds in Bornou are regular and periodical : previous to our going to Munga, east and south-east winds were nearly constant ; when the rainy season commenced, we had them from the south-west, with a thick atmosphere, a sultry, damp, and oppressive air. Previous to a storm, gusts of wind would accompany the black clouds which encompassed us, and blow with great force from the northeast ; these winds, however, were not accompanied by such violent or lasting rains; but when the clouds formed themselves to the south-east, they were tremendous, accumulating, as it were, all their force, and gradually darkening into a deeper and more terrifie black, with frequent and vivid forked lightning, accompanied by such deafening and repeated claps of thunder, as shook the ground beneath our feet like an earthquake. The rain always at these times burst upon us in torrents, continuing sometimes for several hours ; while blasts of wind, from the same quarter, drove with a violence against our unsheltered huts, that made us expect, every instant, low as they were, to see the roofs fly from over our heads, and deprive us of the trifling protection they afforded. After these storms, the inclosures round our huts were often knee deep in water, and channels were formed, with all possible speed, in order to prevent the huts themselves from being inundated. At the full and change of the moon these storms were always most violent.

Oct. 16. - " How use doth breed a habit in a man." Miserably solitary as were all my pursuits, disheartening as were my prospects, 
and demi-savage as was my life altogether, I was incapable of accounting, even to myself, for the tranquillity in which my days glided away. The appetite with which I generally devoured the rice or paste, which formed my lone repasts, for no one could endure the smell of food but myself, so heavy was sickness upon them; the satisfaction felt in my morning and evening visits to Barca Gana, and the plans, full of hope of further progress, which floated in my imagination, when at night I laid my head upon my pillow, frequently excited in my mind the most proud and grateful sensations.

I had been fully employed (convinced that I was best consulting the interests of the mission, the primary object of all my thoughts, by cultivating the favour and good will of the sheikh), during the two last days in superintending the manufacture of cartridges, for the two field-pieces, which were now both mounted, as we had plenty of very good paper for the purpose with us. In this I succeeded to my wishes; but the providing of balls was a great dificulty; and after trying a number of musket-balls in a small linen bag, which would not answer, I succeeded in getting from the negro blacksmith, by means of a paper model, a small tin canister, the size of the mouth of the piece, and holding sixteen musket balls. The sheikh's delight was extreme at this acquisition to his own implements of war, and he became impatient to see the guns exercised. I offered, if he would appoint six of his best slaves, three to each gun, that I would instruct them as well as I was able-as firing them quick was a very material augmentation of their utility; and $I$ at the same time strongly recommended his holding forth to his people the promise of reward, in the event of their being brought safe out of battle; and that the punishment would be most severe in case they were deserted, and fell into the hands of an enemy. The sheikl's preparation for war had been carried on for the last two months with great vigour; his whole armoury had been re- 
novated; and he told me, exultingly, that he had two hundred guns, pistols, and carbines-although from the locks of full fifty it would have been in vain to attempt producing fire.

The sheikh had, in the beginning of his conquests, seen the advantage of encouraging the discontented of other countries to settle in his new towns; and, besides the Kanemboo who accompanied him, he had Tuaricks, Tibboos, Arabs, and Begharmis, - and on those he appeared to rest his chief reliance. To check this warlike spirit was far from his wish or interest; for by indulging it, he not only enriched himself, and his people, and strengthened his power, but might also hope to render it eventually a source of strength, prosperity, and permanency to his kingdom.

Notwithstanding the business of war appeared so fully to occupy the sheikh's thoughts, yet his anxiety for a reformation, as despotic as it was impracticable, amongst the frail of his woman-kind, was still uppermost in his mind; an instance of which occurred when two of these unfortunates fell into his hands, whose sinnings were placed beyond all doubt by the activity of the spies he employed to watch over this department; and although his decisions on ordinary occasions were ever on the side of mercy, these poor girls were sentenced to be hanged by the neck until they were dead*. The agitation and sorrow which the threatened execution of these two girls, who were both of them under seventeen, excited in the minds of all the people, were most creditable to their feelings; and although on other occasions their submission to the decrees of their chief was abject in the extreme, yet on this (to say the least of it) rigorous sentence being made public, loud murmurs were uttered by the men, and railings by the women. The lover of one of the girls swore that he would stab any man who attempted to place the

* In Tripoli, the father or mother is generally the executioner, to avenge the sin, and at the same time wipe the stain from the family, and prevent public execution,

E E 
rope. He had offered to read the fatah with her*, which offer had been refused. The general feeling was pity, and the severity of the punishment caused the sin to be almost forgotten, which would not have been the case had the penalty been of a more lenient nature: indeed, it was natural that pity should be felt-notwithstanding all one's morality, it was impossible to feel otherwise. The day after (for punishments are summary in eastern countries) was fixed for the expiation of their crime, but a fighi, nearly equal to the sheikh in skill, took upon himself to remonstrate, and declared such punishments were themselves haram (sins), for in no part of the Koran could an authority be found for such a sentence. To disgrace or set a mark on such culprits was the law of the Prophet, not death; -and that should these poor offenders suffer, God would avenge
their death on the country, and sickness, with bad crops, would come upon them. The sheikh for a long time continued inexorable, and observed that riches, plenty, and prosperity, without virtue, were not worth possessing-the punishment of the two girls, however, was eventually commuted to that of head-shaving, a heavy disgrace, and which was performed in the public street.

The ceremony of the trial of the brass guns, for which, after consulting Mr. Clapperton, who was too ill to undertake it himself, I had succeeded in making charge and wadding, took place this afternoon, before the sheikh and a thousand spectators. The distance to which they threw the balls, and the loudness of the report, created the greatest astonishment: but I could not persuade the sheikh to suffer a second canister to be shot: "No, no!" said he, "they are too valuable; they must not be thrown away : curses on their race! how these will make the Begharmis jump!" I had cut them out a harness in paper as a pattern, which had been tolerably made in leather: this was attached to each gun, with a man mounted on the mule that

* Marry her. 
drew it; and altogether the guns had a farbetter appearance and effect than I expected. The carriages answered extremely well-were very steady; and I much regretted that poor Hillman, to whom all the credit of mounting them belonged, was confined to his mattress, and unable to see how well they answered: but the sheikh's anxiety would not brook delay.

Nov. 9.-The cool winds which had prevailed for the last fifteen days had so purified the air, that disease appeared to be taking its departure, and a season of health about to succeed in its turn. These long-wished-for breezes generally came on about ten in the forenoon, and continued until two hours after mid-day. They had a great effect on the natives, and appeared considerably to invigorate ourselves. Both Mr. Clapperton and Hillman were now able to walk about with the assistance of a stick : they were both, however, sadly pulled down, and enfeebled.

The two expeditions, one for Kanem and the other to Begharmi, were now said to be in readiness for departing after the feast, or Aid-of-Milaud, which was to be kept on the 16 th and two following days. I had determined on accompanying one of them, whether a supply of money arrived or not, as the season of the year was too valuable to be wasted. This was the first opportunity that had offered of a movement to the eastward in any direction, and it was not to be lost. I had one camel and one horse, and, as before, I was determined on taking my chance with the ghrazzie, and faring as well as circumstances would allow me. The feast was ushered in with all the customary rejoicings, and gifts were distributed by all the great people; nor were we forgotten by the sheikh, who sent us two bullocks* and three sheep, and two jars of honey, which in our situation was no mean present; for as sickness began to subside amongst us, our appetite increased.

- The horn of one of these animals measured two feet, six inches, and three-quarters, in circumference.

E $\mathrm{E} 2$ 
Nov. 21. - The feast, Aid-of-Milaud (the birth-day of Mohammed) is attended with nearly similar rejoicings to the other feast days; but instead of wrestlings amongst the men, the ladies, on this occasion, dance according to the fashion of their country. The motions of the Kouka women, though the least graceful, are certainly the most entertaining; all, however, form a striking contrast to the lascivious movements of the Arab and Barbary dancers-every thing here is modest, and free from any indelicacy. To commence with those of the capital, who also first appear in the circle, the Koukowy advance by twos and threes, and after advancing, retiring, and throwing themselves into various attitudes, accompanied by the music from several drums, they suddenly turn their backs to each other, and suffer those parts which are doomed to endure the punishment for all the offences of our youth to come together with all the force they can muster, and she who keeps her equilibrium and destroys that of her opponent, is greeted by cheers and shouts, and is led out of the ring by two matrons, covering her face with her hands. They sometimes come together with such violence as to burst the belt of beads which all the women of rank wear round their bodies just above the hips, and showers of beads would fly in every direction: some of these belts are twelve or sixteen inches wide, and cost fifteen or twenty dollars. Address is, however, often attended, in these contests, with better success than strength; and a well managed feint exercised at the moment of the expected concussion, even when the weight of metal would be very unequal, oftentimes brings the more weighty tumbling to the ground, while the other is seen quietly seated on the spot, where she had with great art and agility dropt herself. The Shouaas were particularly happy in these feints, which were practised in different ways, either by suddenly slipping on one side, sitting or lying down. I had not seen so many pretty women together since leaving England, for, as compared with the negresses, the Shouaas are almost white, and their features particularly 
handsome; such an assembly was to us novel and gratifying. I was, however, sometimes surprised to find how much I became accustomed to the sight of these swarthy beauties, even so as to be able to look at them with pleasure. The women of Bornou and Begharmi danced with a much slower motion, and accompanied themselves by singing: the former wear simply a blue wrapper or scarf over the shoulders, and holding each end of the wrapper with the arms extended, frequently threw themselves into very pleasing and graceful, if not elegant, attitudes; while the latter, with their hands before them, sometimes clasped together, sometimes crossed on the breast, and sometimes with only just the tips of the fingers meeting à la Madonna, appeared to sing a tale of extreme interest to the bystanders; this was accompanied by sinkings of the body, and bendings of the head, from side to side-all finished by sitting down and covering their faces, when they were led out of the circle by the elder women.

The Arabs and chiefs from Angornou and the neighbouring towns came into Kouka in the evening, and the sheikh, accompanied by full one thousand horsemen, rode round the walls, preceded by seven flags, and after praying at some distance, returned to the palace: his new-trained footmen with guns were present, who skirmished with the horse: and on asking me how they fired, he said, "I have full two hundred guns-where are the Begharmis now?-the dogs!" This was repeated the two following days: blessings were asked on the expedition about to depart, and the disposition made. Two days out of three $I$ accompanied them, and rode for a short time by his side, and very much pleased he appeared to be by the attention. We had no news, however, of the courier, and our spirits were greatly depressed by the report of his being lost on the road.

Nov. 25.-The season of the year had arrived when the sovereigns of these countries go out to battle, and the dread of the 
bashaw's expedition had prevented the sheikh 'from making an inroad into the Begharmi country; they, in consequence, took the opportunity of attacking him, notwithstanding their discomfiture in five different former expeditions, when at least twenty thousand poor creatures were slaughtered, and three-fourths of that number at least driven into slavery. The Begharmis had once more come down to the south side of the Shary, and induced the people of Loggun to declare for them. The boats of Loggun were to bring the Begharmis over the river, and then all were to pour into the sheikh's dominions. We were in sad confusion at Kouka on hearing the news, and the sheikh prepared to muster his forces with all despatch.

Nov. 29.-At our audience this morning we were detained for some time, while a case was decided in which several Kanemboo chiefs were charged with not having, on some former occasions, treated the sheikh's people with kindness. The disaffected sheikhs were buffeted even in the presence, by the Bornouese, taken out, and three of the worst of them strangled in the court-yard *.

Dec. 3.-Although, by the arrival of a messenger from Munga, the immediate alarm of the Felatah attack from the south-west was considerably abated, yet they continued increasing in force, and at not more than five days distance. The Begharmis were also still on the south bank of the Shary, close to the river, and unless alarmed by the sheikh's preparations, were confidently reported to have the intention of attacking him when the waters had sufficiently subsided to render it practicable, which was expected in less than a month. The expedition for Kanem accordingly left this day, under the charge of Ali Gana, the sheikh's kaganawha †, and next in command after Barca Gana, and another was said to be intended to the south-west.

The news of the last month, both from the Begharmi side and

- On these occasions the sheikh merely moves his finger, which is the signal for immediate execution.

+ Black Mameluke. 
the Kanem, from the south-east and the east, had been of the worst description : a direful war of extermination had been for years carried on between Bornou and Begharmi, the fury of which had not in the least abated. No males were spared on either side, except on terms worse perhaps than death. The sultan of Bornou had more than two hundred youths under twenty, from Begharmi, in his harem, as eunuchs; while the sultan of Begharmi (who was said to have nearly one thousand wives) had treble that number of unfortunate Bornouese and Kanemboo eunuchs, chosen out of the most healthy young men who had fallen into his hands as prisoners, and spared from the general massacre for the purpose of serving him in that capacity. Even the moral, and in many respects the amiable, sheikh had more than thirty Begharmi lads thus qualified to enter the apartments of his wives and princesses.

As I was one day taking shelter, in the portico of the sheikh's garden, from the violence of a sudden storm of rain, the chief of those privileged persons brought me to see about a dozen of this corps, who were just recovering from the ordeal of initiation, which they had gone through: thin and emaciated, though fed and taken the greatest care of (for they become extremely valuable, and will sell to any Turkish merchant for two hundred and fifty or threé hundred dollars), these poor remnants of promising healthy young men passed before me. I could not contain my emotion, or disguise the distress which was apparent in my countenance, so that the old hardened chief of the seraglio, who seemed happy that so many of his fellow-creatures were reduced to the same standard as himself, exclaimed, "Why, Christian, what signifies all this? they are only Begharmis! dogs! kaffirs! enemies!-they ought to have been cut in four quarters alive, and now they will drink coffee, eat sugar, and live in a palace all their lives."

The late intelligence from Waday side, by which route I had 
always indulged hopes of advancing, some distance at least, very much tended to weaken those hopes. The contention between Waday and the sheikh, for the possession and government of Kanem, had, for the last year or two, been violent; and now open hostilities had . commenced between him and the sultan. It was true, that no kafila had passed between Bornou and Waday for five years, and the only person that had left the former place, since our arrival, for Waday, had been the young Fighi from Timbuctoo, on his way to Musser (Cairo), who had accompanied a Fakeer* on his return to Waday. A party of Shouaas had once, indeed, since our residence at Kouka, come from the borders of the Waday country, beyond Kanem, to sell a few camels; but it was generally supposed here, they came merely as spies : they were the most lawless set themselves; and the account they gave of the road was merely to induce some of the Arab merchants to take their advice, when they would have been the first to plunder them $\dagger$. Since the death of the good sultan Sabon, as he was called, no intercourse had been attempted either from hence, or even from Fezzan. The only man who escaped from the last kafila, five years ago, was now here, and gave the following account of the treatment he received : he was named Abde Nibbe, the confidential servant of the kaghia $\ddagger$ of the bashaw ; and had gone from Tripoli to Waday, by the way of Mourzuk, having been intrusted with a very considerable sum of the kaghia's, with which he was to trade : they arrived at Waday in safety, and at Wara the capital ; and after residing there more than twenty days, during which time he had purchased

- A religious mendicant: the name is nearly the Arabic for poverty.

+ Soon after this, I made an offer to two Arabs, both of whom had formeriy been at Waday, that I would give them each two hundred dollars, if they would accompany me : this is a sum for which an Arab will almost do any thing; but they refused, saying "No! no! what is money without life? the Waday people will kill us all."

$\ddagger$ Governor of the palace. 
thirty-seven slaves, and was apparently upon friendly terms with the natives, one morning they entered his hut, seized all his property, stripped and bound him, and, when naked, he was carried before the chief who acted as regent, Sabon's son the sultan being but an infant. Abde Nibbe there found forty persons, consisting of his fellowtravellers and their followers, bound in the same manner as himself: after being insulted in every possible way, they were taken outside the town, in order to have their throats cut. Abde Nibbe, who was a powerful fellow from Towergha*, after seeing many of his companions suffer themselves patiently to be massacred, feeling the cord with which his hands were tied but loosely fastened, determined on making an attempt, at least, to save his life: he burst the cord asunder, and ran towards the hills ; twice they caught him, and twice he escaped from their keeping, carrying with him three wounds from spears, and one from a knife, which very nearly severed his right hand from his body : night, however, came on, and creeping into a hole, which had been, and still might be, the habitation of a brood of hyænas; there he remained three nights and three days, until raging hunger forced him to quit his retreat-where, however, to go was the questionwho could he trust amongst so barbarous a people? One person alone came to his mind as likely to assist him in this extremity-in whose hands alone he conceived his life would be safe. Was it his brother, or his sworn bosom friend? No: it was man's never failing, last, and best consolation, woman : one to whom he had been kind in his prosperity, whom he had been intimate with; and he felt assured that she would not be ungrateful, and never betray his confidence. Was he mistaken? No : she received him, fed him, washed his wounds, and for seven days concealed him; when, at last, he was discovered, and carried again before the chief. After asking how he escaped, the governor said, " I will keep you in my

\footnotetext{
- A town near Mesurata.
} 
service, give you a horse, and see whether you will fight as well for me as you did for yourself." Abde Nibbe remained more than two months in this situation, drawing water, carrying wood, \&c. when he heard that a kafila was about to leave Waday, consisting of a few merchants only, the remains of his own, and former ones, who had bought their lives at a very high price: taking advantage, therefore, of a dark night, he once more escaped and joined them. They lent him a gun and some ammunition to protect him from the wild beasts, which were very numerous, and advised his quitting the kafila before day for the woods : he moved nearly parallel with the kafila, and at night again joined them. In this way he moved for five days, when the Waday horsemen gave up the pursuit, and returned without him.

December 14.-Doctor Oudney and Mr. Clapperton left Kouka this day, for Kano, with a kafila of nearly twenty merchants, beside servants : this was the eighth kafila that had gone to Soudan, since our arrival here; and as no other was expected to go for many months in consequence of the non-arrivals from Mourzuk, and the other parts of Fezzan, Doctor Oudney, notwithstanding the extremely debilitated state to which he was reduced, determined on accompanying this, if the sheikh would allow him. El Kanemy not only gave his instant permission, but did his utmost to forward his views, and to secure his safety: he charged Mohammed-el-Wordee, the principal person of the kafila, to assist them in every way, and gave them letters to the sultan of Kattagum, to the sultan of Kano, and also to a Moor, residing at Kano, named Hat-Salah, with whom he had great influence, and to whose care he confided them as friends of his own, and the best of Christians.

December 16.-Yesterday Barca Gana, with an expedition nearly twelve hundred strong, marched to the south-west, to a place called Kaka; from whence he was to proceed against a Felatah town, called Monana, which was said to be the rendezvous for the sheikh's 
enemies : his orders, however, were more to ascertain in what strength the Felatah really were, and what were their intentions, than to attack them.

December 21.-To my inexpressible delight, Karouash came with intelligence that a small kafila had arrived at Woodie from Mourzuk, that an Englishman accompanied them, and that this was followed by another, a more numerous one, which they had quitted at Zow.

The following was a day of great anxiety; and on the $23 \mathrm{~d}$ instant, very soon after daylight, I was overjoyed at seeing, instead of Mr. Tyrwhit, whose bodily infirmities made me always consider his joining me doubtful, a robust, healthy-looking young man, with a double-barrelled gun slung at his back. When he presented himself at the door of my hut, his very countenance was an irresistible letter of introduction, and I opened the packages which were to account for his appearance with considerable eagerness. Mr. Tyrwhit, I found, had been prevented by sickness from profiting by the consul's recommendation; and that on application being made to the governor of Malta for a substitute, Mr. Toole, an ensign in the 80th regiment, had volunteered to join me, and left Malta at twenty hours' notice. He had made the long, dangerous, and difficult journey from Tripoli to Bornou, in the short space of three months and fourteen days, having left that place on the 6 th of September; and overcoming all obstacles by perseverance and resolution, both at Mourzuk and in the Tibboo country, had arrived here with only the loss of five camels.

The arrival of this kafila with Mr. Toole, and the supplies which he brought, gave a most favourable turn to my situation at Kouka. I had now money, health, and a desirable companion : even an attack might lead to our pursuing an enemy, and by that means getting out of the sheikh's dominions; and " God send the fair goddess, deep in love with us," was our constant prayer, as, on the least favourable

$$
\text { F F } 2
$$


opportunity offering, I had determined to make a start in one direction or another. At one time, indeed, Pandora's sealed casket seemed literally to have burst over our heads,-strife, war, famine, falsehood, and a thousand other evils, surrounded us. Still, however, hope remained in the box; so did we attach ourselves to this neverfailing sheet-anchor, and despondency took wing as we abandoned ourselves without reserve to the sympathies she inspired.

Jan. 3, 1824.-My friend Tirab, the Shouaa generalissimo, had long promised to kill me an elephant, as he expressed himself; and this day, about noon, a messenger came to our huts, saying, that, after hunting an enormous male elephant for five hours, they had at length brought him to a stand, near Bree, about ten miles northeast of Kouka. Mr. Toole and myself instantly mounted our horses, and, accompanied by a Shouaa guide, we arrived at the spot where he had fallen, just as he breathed his last.

Although not more than twenty-five years old, his tusk measuring barely four feet six inches, he was an immense fellow. His dimensions were as under:

\begin{tabular}{|c|c|c|c|}
\hline Length from the proboscis to the & tail & 25 & 6 \\
\hline Proboscis & - & 7 & 6 \\
\hline Small teeth & - & 2 & 10 \\
\hline Foot longitudinally & - & 1 & 7 \\
\hline Eye & - & & 2 by $1 \frac{1}{2}$ \\
\hline From the foot to the hip-bone & - & 9 & 6 \\
\hline From the hip-bone to the back & - & 3 & 0 \\
\hline Ear - & - & 2 & 2 by 26 \\
\hline
\end{tabular}

I had seen much larger elephants than this alive, when on my last expedition to the Tchad; some I should have guessed sixteen feet in height, and with a tusk probably exceeding six feet in length. /The one before me, which was the first I had seen dead, was, however, considered as of more than common bulk and stature ; 
and it was not until the Kanemboo of the town of Bree came out, and by attracting his attention with their yells, and teasing him by hurling spears at his more tender parts, that the Shouaas dared to dismount; when, by ham-stringing the poor animal, they brought him to the ground, and eventually despatched him by repeated wounds in the abdomen and proboscis : five leaden balls had struck him about the haunches, in the course of the chase, but they had merely penetrated a few inches into his flesh, and appeared to give him but little uneasiness. The whole of the next day the road, leading to the spot where he lay, was like a fair, from the numbers who repaired thither for the sake of bringing off a part of the flesh, which is esteemed by all, and even eaten in secret by the first people about the sheikh: it looks coarse, but is better flavoured than any beef I found in the country. / Whole families put themselves in motion, with their daughters mounted on bullocks, on this occasion, who, at least, hoped as much would fall to their share as would anoint their heads and persons plentifully with grease at the approaching fsug. The eyes of this noble animal were, though so extremely small in proportion to his body, languid and expressive even in death. His head, which was brought to the town, I had an opportunity of seeing the next day, when I had it opened; and the smallness of the brain is a direct contradiction to the hypothesis, that the size of this organ is in proportion to the sagaciousness of the animal. His skin was a full inch and a half in thickness, and dark gray, or nearly black, hard, and wrinkled : his ears, large and hanging, appeared to me the most extraordinary part about him, particularly from the facility with which he moved them backwards and forwards : his feet are round, undivided, and have four nails, or hoofs, for they cannot be called toes, two in the front of the foot, about an inch in depth, and two inches in length, which join each other, with two smaller ones on each side of the foot. In Africa they are scarcely ever taken alive, but hunted as a sport, for 
the sake of their flesh; and also in order to obtain their teeth, which, however, as they are generally small, are sold to the merchants for a very trifling profit. /The manner of hunting the elephant is simply this : from ten to twenty horsemen single out one of these ponderous animals, and, separating him from the flock by screaming and hallooing, force him to fly with all his speed; after wounding him under the tail, if they can there place a spear, the animal becomes enraged. One horseman then rides in front, whom he pursues with earnestness and fury, regardless of those who press on his rear, notwithstanding the wounds they inflict on him. He is seldom drawn from this first object of his pursuit; and, at last, wearied and transfixed with spears, his blood deluging the ground, he breathes his last under the knife of some more venturesome hunter than the rest, who buries his dagger in the vulnerable part near the abdomen : for this purpose he will creep between the animal's hinder legs, and apparently expose himself to the greatest danger: when this cannot be accomplished, one or two will ham-string him, while he is baited in the front; and this giant of quadrupeds then becomes comparatively an easy prey to his persecutors.

Jan. 12.-Karouash came to us this evening, with his dark Arab eyes, sparkling with somewhat more than vivacity; and it was not long before we found out the cause. The people of Gulphi, who inhabited a town close to the banks of the Shary, had no other means of raising their grain (the land surrounding their walls being all tributary to the sheikh) than by planting it on the south bank of that river; reaping in the season, and carrying the produce to their city by means of their flat-bottomed boats. They had, of late, been so little interrupted in their agricultural pursuits, by the boats of the neighbouring towns, that a village of huts had sprung up on this portion of land; and labourers, to the number of three or four hundred, resided there constantly. The hostile movements of the Begharmis had, however, made the sheikh's people more on the alert 
than formerly; and passing over the river in their own boats, accompanied by several deserters from Gulphi, who, traitor-like, consented to bear arms against the land that gave them birth, and lead its enemies to the pillage of their brethren, the people of Maffatai and Kussery had, a few nights before, made an attack on this village, putting to death all the males, even while they slept; and, as usual, dragging the women and children to their boats, returned to their homes without the loss of a man, after setting fire to all the huts, and more than four hundred stacks of wheat and gussub. The effects produced by this midnight expedition, and which was celebrated by singings and rejoicings throughout Kouka, were indeed of a nature favourable to my prospects, notwithstanding the shock humanity received from the cause. The Begharmis, who had occupied the southern banks of the Shary for months, obliging even the Loggun people to supply them with provisions, took such alarm at this attack of the sheikh's people, that they struck their camp, and retired immediately on the news reaching them; and the Loggun nation as quickly sent off to the sheikh a deputation, with sixty slaves, and three hundred bullocks, congratulating him on the event.

I determined on making immediate application for permission to visit this country; so full of interest, both from its situation, and the waters by which it was reported to be bounded. No time was to be lost, for the return of the enemy might be as sudden as his flight; and again I might have my intentions frustrated. I had been eleven months endeavouring to visit this country-but to climb steep hills requires a slow pace at first.

Jan. 18.-The sheikh, who had never, on any one occasion, neglected making every possible arrangement for carrying my wishes into execution, had not only instantly complied with my request to seize this opportunity of visiting Loggun, but sent this morning Karouash to advise with me as to my proceedings, and to 
recommend my going without loss of time. "Bellal shall go with you," said he; "who has been in my confidence for seventeen years, and to whom I could trust my own life, or that of my children, who are even dearer to me than life itself."

But in the morning we found a brown horse, which had carried Mr. Toole from Tripoli, dead within our inclosure: both this and a black one, which his Arab had been mounted on by the bashaw, had scarcely eaten any thing since their arrival here. Our departure was therefore put off for this day. Troubles, however, never come alone. In the evening the camels I intended to take with me were missing; and although the people were out looking for them until midnight, we had no tidings. In the night I was called up, as Mr. Toole's other horse was dying: no blood could be got from him; and after staggering about, in a way resembling intoxication, he died before daylight.

Jan. 22.-Karouash, Ben Taleb, and even the sheikh, now exclaiming against our going out, "Wonderful! Wonderful!" said they, " it is written you are not to go." The delay perplexed me, although to go, and quickly, I was determined; the time was precious, for I did not wish the news of my intentions to precede me. Towards night my camels were found; and the sheikh, hearing that we had been inquiring for a horse to purchase, sent a very smart black galloway to Mr. Toole as a present. We had now seen die on our hands, in the space of nine months, thirty-three camels, six horses, and one mule.

On the 23d I intended being off by daylight; but it was the afternoon before I could accomplish my wish. The sheikh had given me Bellal: " He will obey your orders in every thing," said he; " but you are going amongst people with whom I have but little influence.” Bellal, who was one of the handsomest negroes I almost ever saw, and a superior person, was attended by six of his slaves, two of whom were mounted; these, with ourselves and two camels, formed 
our party. While I was waiting to take leave of the sheikh, a note was brought me from Dr. Oudney, by a Bornouese from Katagum : it had no date, and was indeed his last effort. The acknowledgment of being weak and helpless assured me that he was really so; for during the whole of his long sufferings a complaint had scarcely ever escaped his lips. On the sheikh's saying to him, when he first expressed his wish to accompany the kafila, "Surely your health is not such as to risk such a journey ?" he merely replied, "Why, if I stay here, I shall die, and probably sooner, as travelling always improves my health."

His letter, though short, expresses great satisfaction at the treatment he had met with on his journey, and also from the inhabitants of the country.

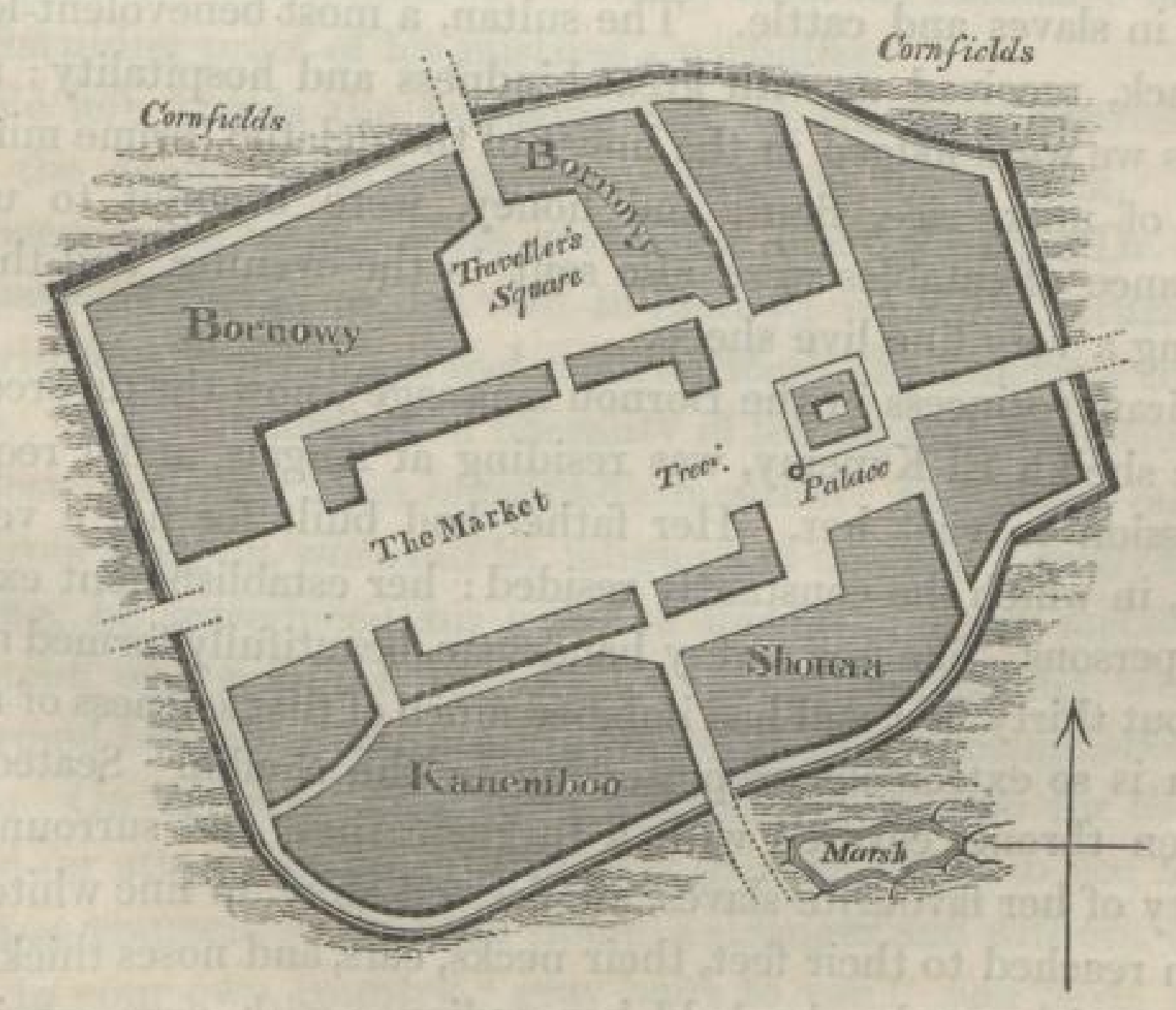

G G 


\section{CHAPTER VI.}

EXCURSION TO LOGGUN, AND DEATH OF MR. TOOLE.

Jan. 1824.-WE passed the night of the 24th at Angornou, and proceeded, without leaving the lake at any great distance, for two days, when we arrived at Angala, one of the ancient governments subject to Bornou. The present sultan was the first friend and supporter of El Kanemy ; and, twenty-five years ago, when he was only a merchant, betrothed to him his daughter Miram in marriage, with a large dower in slaves and cattle. The sultan, a most benevolent-looking old black, received us with great kindness and hospitality; and as soon as we were lodged in the house of the delatoo (prime minister), bowls of milk, rice, flour, and honey, were brought to us; an abundance of eatables were also sent in the evening, and the next morning a very fine live sheep.

Miram (princess in the Bornou language), now the divorced wife of the sheikh El Kanemy, was residing at Angala, and I requested permission to visit her. Her father had built for her a very fine house, in which she constantly resided : her establishment exceeded sixty persons. She was a very handsome, beautifully formed negress, of about thirty-five, and had imbibed much of that softness of manner which is so extremely prepossessing in the sheikh. Seated on an earthen throne, covered with a turkey carpet, and surrounded by twenty of her favourite slaves, all dressed alike, in fine white shirts, which reached to their feet, their necks, ears, and noses thickly ornamented with coral; she held her audience with very considerable 
grace, while four eunuchs guarded the entrance; and a negro dwarf, who measured three feet all but an inch, the keeper of her keys, sat before her with the insignia of office on his shoulder, and richly dressed in Soudan tobes. This little person afforded us a subject of conversation, and much laughter. Miram inquired whether we had such little fellows in my country, and when I answered in the affirmative, she said, "Ah gieb! what are they good for? do they ever have children ?" I answered "Yes; that we had instances of their being fathers to tall and proper men." "Oh, wonderful !" she replied: "I thought so; they must be better then than this dog of mine; for I have given him eight of my handsomest and youngest slaves, but it is all to no purpose. I would give a hundred bullocks, and twenty slaves, to the woman who would bear this wretch a child." The wretch, and an ugly wretch he was, shook his large head, grinned, and slobbered copiously from his extensive mouth, at this flattering proof of his mistress's partiality.

We left Angala the following day, to the great distress of our host, the delatoo, who would have feasted us for a week. A child had been borne by one of his wives, just about the time Dr. Oudney had passed through on his visit to Showy; which, in return for his prescriptions, the delatoo had named Tibeeb, the Doctor's travelling name. Indeed, there was a liberality of feeling and toleration about our host deserving most honourable mention; and when, on my return from Loggun, worn out by fatigue and anxiety, I really required nursing, he introduced his sister, a female of most matronly deportment, who superintended the process of shampooing, which was performed by one of her best looking and most accomplished handmaids. On my expressing my thanks to the delatoo for these unlooked-for attentions, he replied, " It grieved us all to see so great a man as yourself, so far from home, a stranger and without women; when in your own country, ' gray hairs to you !' you have, at least, a hundred, I dare say!"

G G 2 
On the 23d we reached Showy, on the banks of the river Shary : the magnitude of the stream drew from us both an involuntary exclamation of surprise; it appeared to be full half a mile in width, running at the rate of two to three miles an hour, in the direction nearly of north. In the centre of the river is a beautiful island, nearly a mile in length, in front of the town. Showy forms part of the district of Maffatai, and is governed by a kaid : and this person, who treated us with great attention, proposed that we should proceed down the stream to the Tehad, according to the sheikh's directions.

On the $2 d$ of February we embarked, accompanied by the kaid and eight canoes, carrying ten and eleven men each: ploughing the stream with their paddles, for nearly eight hours, they brought us, by sunset, to a spot called Joggabah (or island, in the Mekkari language), about thirty-five miles from Showy. The river, full as it is of water at this season, had a highly interesting appearance : one noble reach succeeded another, alternately varying their courses by handsome sweeps, some of them three and four miles in length; the banks were thickly scattered with trees rich in foliage, and all hung over with creeping plants, bearing various coloured and aromatic blossoms, amongst which the purple convolvolus flourished in great beauty: several crocodiles, from eight to fifteen feet in length, were slumbering on the banks, which, on our near approach, rolled into the stream, and disappeared in an instant. The natives appeared to fear them but little in shallow water, but dived in with great boldness after the ducks we shot, and a large iguana that we struck while sleeping on a tamarind tree, and which fell headlong into the river. Joggabah is a beautiful feature in the scenery, as well as a pro-

- In a subsequent visit I had an opportunity of measuring the river just below Shary, and found it 650 yards. 



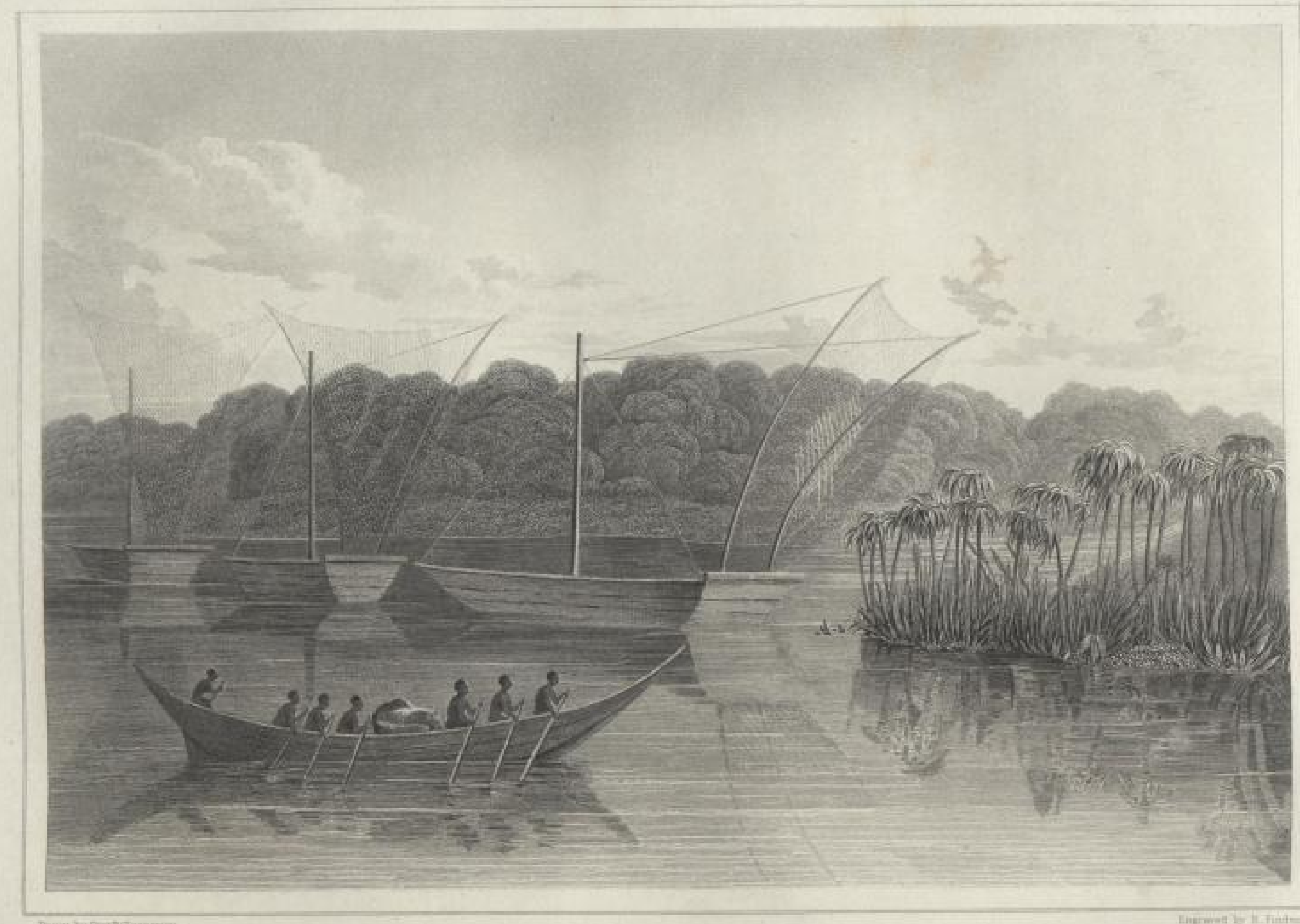

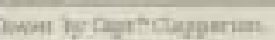

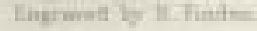

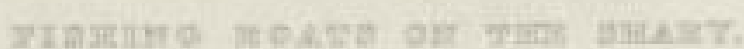

7 SLUB

Wir führen Wissen.
Leibniz-Institut für Länderkunde 
minent one; and is seen for nearly six miles in proceeding down a very wide, handsome reach, which we called Belle-vue Reach. The river is here quite as wide as at Showy, which, with this exception, I take to be the widest part.

This island is high ground, with steep and nearly perpendicular banks, and a depth of ten feet water close to the edge : the canoes moor up to the shore; the stream runs strong and clear; and the landing is on a fine dry sandy beach : it extends to the Tchad north, a distance of twelve or fifteen miles, and has two handsome streams bounding it, which run north-east and north-west, and by which the Shary takes its way into that immense lake. It abounds with game: and we had fish in abundance, venison, the flesh of a buffalo, and wild ducks, for supper, all roasted on wooden spits.

We pitched our tent on the jutting head, where, a few years ago, stood a negro town : the inhabitants, however, were refractory, committed piracies on the Showy people, and in consequence the sheikh determined on exterminating them. They were in league with the Biddoomah, who were now kept to their own islands. Joggabah we found uninhabited, and covered with jungle and prickly underwood, in that part where we passed the night: we saw thirty porcupines, and killed a centipede and two scorpions under our mats. We had two canoes rowing guard the whole night on account of the Biddoomah. By daylight we re-embarked, and proceeded by the north-west branch for more than two hours, keeping nearly the same direction : we passed several marshy floating islands, covered with rushes, high grass, and papyrus, apparently dividing the water into different streams, when we found ourselves in that sea of fresh water, the Tchad, which we named Lake Waterloo, and into which the Shary empties itself. It was my intention to have proceeded quite round the island to the east, and to have returned by the other branch; but after making about two miles in the open 
lake, a heavy swell from the north-east caused so much water to come into the canoes, and so much labour to the men, that we gave up that idea. After our return to the south side of the island we followed the north-east branch, and found it vary but little in appearance. During our passage, by keeping the deepest water, and avoiding the convexities of the stream, we, at this season, met with no impediments; and had nowhere less than three feet water. We passed many small islands, all of which, near the mouth, were destitute of trees, but covered with reeds (among which was the papyrus), bamboos, and very tall grasses: the quantity of water-fowl was immense, of great variety, and beautiful plumage. The nearest Biddoomah island is said to be three days voyage on the open lake, from the mouth of the river, in a north-east direction, say ninety miles, during two of which these canoes lose sight of land: with an excellent telescope I could discern nothing but the waste of waters to the north or east. /The Biddoomah are a wild and independent people, who carry on a piratical war with all their neighbours : they send out fleets of sixty or one hundred canoes; and they are reported as terrible kaffirs./

We now commenced our return, and a laborious business it was, rowing or paddling against the stream : the paddles were only resorted to when, now and then, a headland sheltered them from the wind and current; and so cautious were the men of Showy, that it was near midnight before we landed on a spot named Buffalo Bank. We had endured two days of burning heat and exposure to the sun, and a night of watchfulness and torture from the insects; added to this, we had lived entirely on Indian corn, boiled in the canoes during the day: we were also constantly ankle deep in water, from the leaking of the canoes. The banks were here, for some miles inland, thickly clothed with handsome trees encompassed by creeping shrubs in full blossom, while large antelopes and buffaloes were starting from the 
thickets where they had fixed their lairs. We disturbed a flock of several buffaloes on our making the shore; and hippopotami came so close to us as to be struck by the paddles: here, and at the confluence of the two branches, we found the greatest depth of water. The most desirable route for us now to have pursued would have been to have gone from hence to Loggun by water, but Gulphi lay in our way, and it was impossible. To follow the direction of the river, therefore, as nearly as we could, by moving in a line parallel to its banks, became our next anxiety.

Previously, however, we again embarked, and visited a spot called Dugheia, within a day's journey of Gulphi, higher up the stream. Dugheia is a ford and a ferry, where the sheikh, with all his people, pass the stream on their expeditions against the Begharmis : the ford is in a slanting direction, and between two sinuosities. When the river is at its greatest height, the water reaches up to the neck; it was now not above the arm-pits of a good sized man. The infantry, placing their spears and bags of corn on their heads, in their shields, cross with ease : the cavalry are moved over in canoes, and the horses swam at the sterns. The appearance of the river is similar both above and below Showy: excepting that above there are more picturesque islands; on one of which we passed the night, and named it Red Heron Isle, as my poor friend shot there a bird of that species.

On the 8th of February we returned to Showy, and the day following pursued our route by Willighi and Affadai. Willighi is a walled town of considerable strength; indeed the Begharmis always pass it by on their predatory excursions. The walls are nearly fifty feet high, with watch-towers erected on the salient angles, where there are constant sentinels. The sultan also lives in a sort of citadel with double walls, and three heavy gates in each wall, strongly bound with iron. Borgomanda, the reigning sultan of 
Begharmi, and Cheromah (which means heir-apparent), send annual presents to Mai Dundelmah, the sultan of Willighi; but he is a hadgi, and holds the sheikh of Bornou in too high estimation to forsake his fortunes. Before arriving at Willighi, which is only a day's journey from Gulphi, we recrossed the Gurdya, a considerable stream running from the Shary into the great lake.

Feb. 10.-We left Willighi, after presenting the sultan with two knives, two pairs of scissors, a turban, and a red cap, and in about two hours arrived at another ford of the water Maffatai. These fords are known by the natives of the neighbouring towns only, who are always hired as guides. The water was up to the body of the horse; and a weak camel, by encountering the load of another, was thrown off the causeway into twelve or fourteen feet of water. We crossed, this day, three deep marshes, besides the river, which, the Willighi guide informed us, extended to the river, at one of which we were detained nearly an hour before we could venture a passage: the water reached to our saddles. After the rainy season, canoes come from Showy to the neighbourhood of Willighi, for a wood which is here abundant, called by the natives kagam, and another called korna, with which they build their canoes, and make their paddles. The fruit, also, of a species of locust tree, which the natives call kadellaboo, is here gathered. We rested under the shade of a beautiful large tree of this description, bearing a flower of a deep crimson colour; a yellow jessamine, with a delicious odour, was creeping around it, while other delicate aromatic plants grew in wild profusion. Nevertheless, the paths through these woods, though literally strewed with flowers, were nearly impassable from the overhanging branches of thorny shrubs, which not only tore our shirts and cloaks, but were sufficiently strong to drag the loads from the backs of the camels: we were nearly twelve hours in making twenty-two miles. When we arrived at the town of Affadai, our 
people were too tired to cook the rice we had with us, and the kadi merely sent us flour and water paste, and leban (sour milk): at the same time promising to kill a sheep the next day, if we would stay. We, however, departed early on the following morning, and came, towards evening, to a place called Kala, a wretched nest of huts, although surrounded by a wall, and having strong gates.

On the 12th we moved on, and, after crossing a long and deep marsh, we halted, about noon, for an hour or two, at a town called Alph, which stood on a foundation of earth artificially raised in the midst of a swamp extending for miles in every direction. We shot several cranes; one of a beautiful white, with a yellow beak, and dark hazel eyes, with a yellow rim. We now began to approach Kussery, and again came to the banks of the river Shary, leaving Gulphi to the eastward. This route is but seldom traversed: it is a continued succession of marshes, swamps, and stagnant waters, abounding with useless and rank vegetation: flies, bees, and mosquitos, with immense black toads, vie with each other in a display of their peacedestroying powers. I

I had, with grief, for several days, observed in my companion symptoms which gave me great uneasiness : his stomach constantly refused our coarse food of fish and paste; but as he complained but little, I hoped a day or two at Kussery would restore his wonted good health and spirits. Kussery, however, unfortunately, was the last place one should have chosen for rest and tranquillity: during several hours in the day, the inhabitants themselves dare not move out, on account of the flies and bees. The formation of the houses, which are literally one cell within another, five or six in number, excited my surprise; which was not a little increased when I found that they were built expressly as a retreat from the attacks of these insects. Still I was incredulous, until one of our people, who had carelessly gone out, returned with his eyes and head in such a state, that he was extremely ill for three days. Kussery is a strong walled

H $\mathrm{H}$ 
town, governed by an independent sultan, named Zarmawha, who has twice been in rebellion against the sheikh. Bellal was obliged to take off his red cap and turban, and enter the presence with his head and feet bare- a ceremony which had previously been dispensed with on our journey. The sultan merely peeped at us through a lattice-work of bamboo, but inquired particularly, why I turned my face towards him as I sat. I, of course, replied, that turning my back would be, in my country, a gross affront; at which he laughed heartily. We had a separate letter to this prince from the sheikh: he seemed, however, to pay but little respect to it, or the bearer, Bellal, while to me he was most attentive. We had ten dishes of fish and paste, which regaled our attendants sumptuously; and one of his own household took up his residence at our huts. The fish was stale, and offensive to more senses than one, which the natives rather prefer, as we do game that has hung some time. The sultan's officer, however, seeing that I could not touch these Kussery delicacies, quickly brought me a mess made of fresh fish, which, though a little oily, was not unpalatable, with a large bowl of leban. Salt is here scarcely known, and therefore not eaten with any of their meals : out of the small stock I had brought, the townspeople were always begging little lumps, which they put into their mouths, and sucked with as much satisfaction as if it had been barley sugar.

I gave the sultan, in the morning, a parcel of beads, two pairs of scissors, a knife, two turkadees, and a turban; on which he said "we were a great people, a race of sultans, and would bring good fortune to his dominions !' I must not omit to mention a visit which I received from the sultan's sister. She had been some time divorced from her husband, who had gone over to the Begharmis. The officer in attendance on us announced her with great secrecy, about ten o'clock at night. For the only light in our hut we were indebted to the pale moonbeams which shone through the door-way, as we had 
neither candles nor lamp; and I had been some time fast asleep when she arrived. Her attendants, three in number, waited for her at the entrance, while she advanced and sat herself down beside my mat: she talked away at a great rate, in a sort of whisper, often pointing to my sick friend, who was at the further end of the hut; and did not appear at all to wish for any reply. After remaining nearly half an hour, and feeling and rubbing repeatedly my hands, face, and head, which she uncovered by taking off my cap and turban, she took her leave, apparently much gratified by her visit.

The river here is a wide, handsome stream, and the walls extend quite to the banks, and have two water-gates; the character is the same as nearer its embouchure. I passed one of these water-gates at sunset, and was much struck by the beauty of the landscape, with the fishing canoes just returning towards Loggun : the stream sweeps off to the south-south-west, and then to the south. Loggun was said to be thirty miles distant by the river. Here my poor friend declared it impossible to remain, and we moved on towards Loggun the next morning. We could advance, however, but a few miles. Mr. Toole's sufferings were most acute; he twice fainted, and we lifted him on and off his horse like an infant, so helpless had he become. What added also to our distress was, that from this time until the evening of the 16th, the Shouaa Arabs, who occupy the frontier of the Loggun country, refused to allow us to pass until the sultan had been consulted, and a number of his questions answered as to the purpose of our visit. We were now close to the river, and notwithstanding the heat, the only means we had of defending either ourselves or our animals from the torture of the millions of insects that beset us, was by lighting fires at the entrance of our tent, and constantly supplying them with weeds and wet straw : the thick suffocating smoke arising from this description of fire afforded us temporary relief. I rode down to the river, which here flows with great beauty and majesty past the high walls of this

н н 2 
capital of Loggun; it comes direct from the south-west, with a rapid current. We entered the town by the western gate, which leads to the principal street : it is as wide as Pall Mall, and has large dwellings on each side, built with great uniformity, each having a courtyard in front, surrounded by walls, and a handsome entrance, with a strong door hasped with iron: a number of the inhabitants were seated at their doors for the purpose of seeing us enter, with their slaves ranged behind them. At first they took but little notice of us : indeed, our appearance could not have been very imposing: one of our party was laid on a camel, and another supported on his horse by two persons, who walked on each side of him, while he raved most incoherently from the violence of the fever by which he was consuming. At length, however, a person of apparent consequence advanced towards my horse, bending nearly double, and joining his hands (the first salutation of the kind that I had seen), followed by his slaves stooping still lower than himself. After explaining that he was deputed by the sultan to welcome kab n'jaffy (the white man), and repeating frequently that he was kaffama (my friend), he preceded our party; and, as we moved on, each assembly that we passed rose from the ground, advanced towards us, and saluted us in the same manner as I have already described. We were at length conducted to our habitation, which consisted of four separate huts, well built, within an outer wall, with a large entrance hall for our servants: in the most retired and quiet spot I spread the mat and pillow of my patient, who was in a sad state of exhaustion and irritation.

The next morning I was sent for to appear before the sultan: ten immense negroes, of high birth, most of them gray-bearded, bare-headed, and carrying large clubs, preceded me through the streets, and I was received with considerable ceremony. After passing through several dark rooms, I was conducted to a large square court, where some hundred persons were assembled, and all 


\section{ㄱ SLUB}




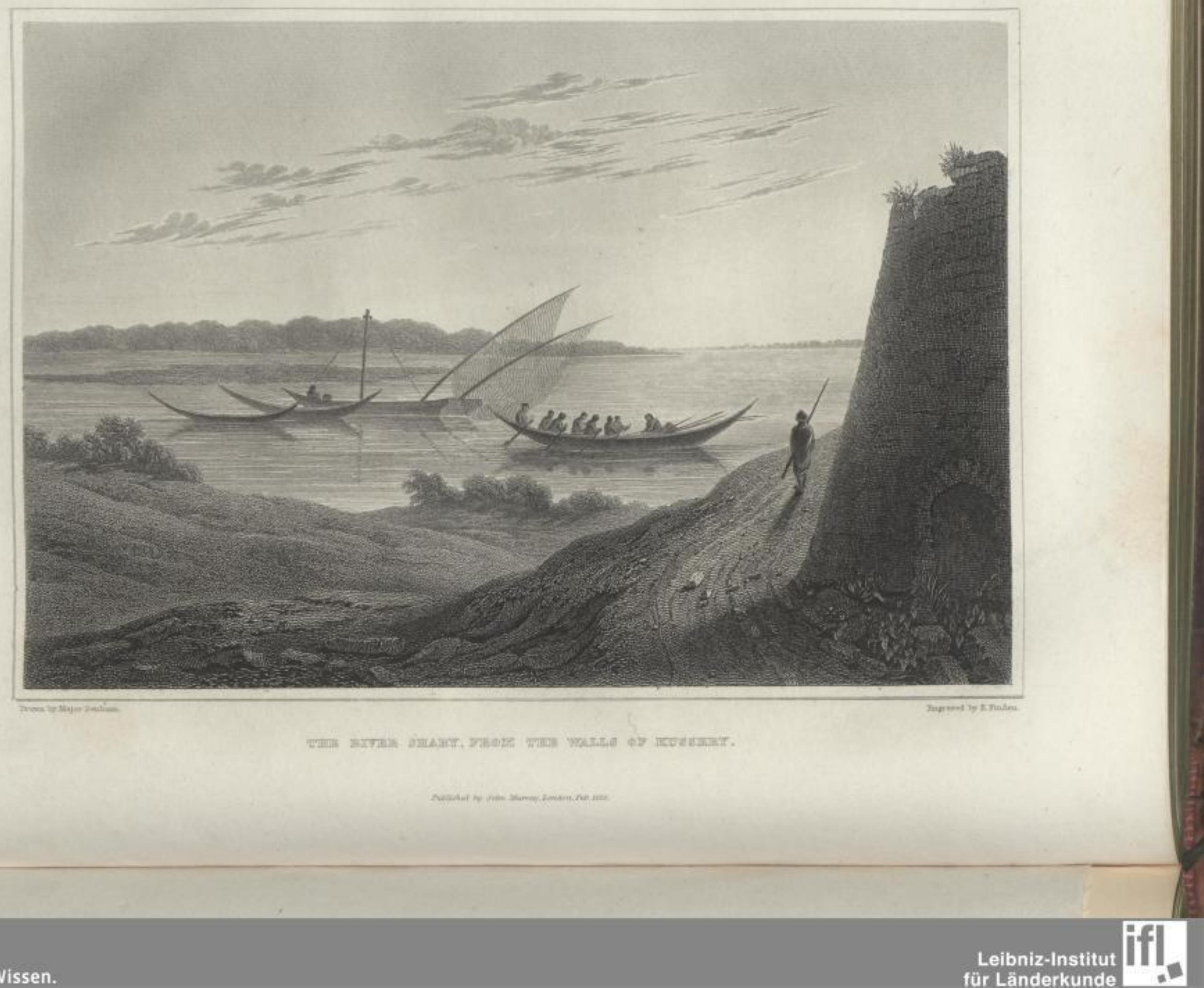


seated on the ground: in the middle was a vacant space, to which they led me, and I was desired to sit down also. Two slaves, in striped cotton tobes, who were fanning the air through a lattice-work of cane, pointed out the retirement of the sultan. On a signal, this shade was removed, and something alive was discovered on a carpet, wrapped up in silk tobes, with the head enveloped in shawls, and nothing but the eyes visible: the whole court prostrated themselves, and poured sand on their heads, while eight frumfrums and as many horns blew a loud and very harsh-sounding salute.

My present, a red bornouse, a striped cotton caftan, a turban, two knives, two pairs of seissors, and a pair of red trowsers, was laid before him : he again whispered a welcome, for it is considered so extremely ill-bred in a Loggun gentleman to speak out, that it is with difficulty you can catch the sound of their voices.

He examined me very minutely, when the shade was again drawn. I begged for permission to embark on the Shary, and was told he would consider of it. He particularly inquired if I wished to purchase b'lowy, or handsome female slaves, which I assured him I did not; "because," said he, "if you do, go no farther: I have some hundreds, and will sell them to you as cheap as any one."

/Loggun, the eapital of which country (Kernuk) is on the banks of the Shary, and in $11^{\circ} 7^{\prime}$ north latitude, is a very populous country. Kernuk has fifteen thousand inhabitants at least. They speak a language nearly Begharmi. The Shouaas are all round them, and to them they are indebted for the plentiful supply of bullocks, milk, and fat, with which the market abounds: these necessaries are paid for by tobes, and blue cotton in stripes, which the Loggun people make and dye of a very beautiful colour. They have, also, a metal currency in Loggun, the first I had seen in Negroland : it consists of thin plates of iron, something in the shape of the tip with which they shoe race-horses : these are made into parcels of ten and twelve, 
according to the weight, and thirty of these parcels are equal in value to ten rottola, or a dollar.

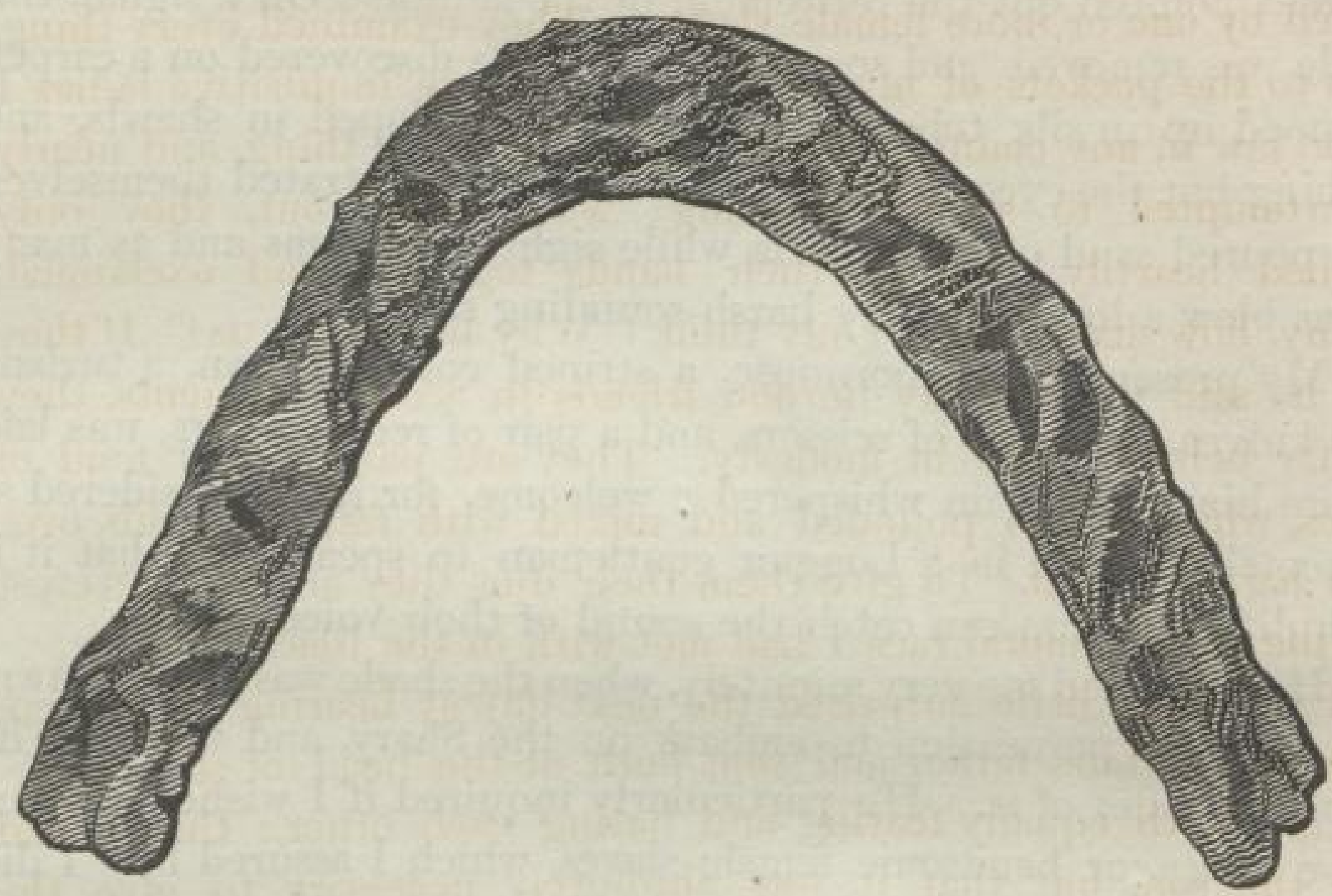

The money market, however, of Loggun, has its fluctuations: the value of this "circulating medium" is settled by proclamation, at the commencement of the weekly market, every Wednesday; and speculations are made, by the bulls and bears, according to their belief of its rise or fall. Previous to the sultan's receiving tribute or duty on bullocks or indigo, the delatoo generally proclaims the currency to be below par; while, on the contrary, when he has purchases to make for his household, preparatory to one of their feasts, the value of the metal is invariably increased. The proclamation of the value of the metal always excites an amazing disturbance, as if some were losers and some gainers by the variation.

They are a much handsomer race than the Bornouese, and far 
more intelligent-the women particularly so; and they possess a superior carriage and manner to any negro nation $I$ had seen. The ladies of the principal persons of the country visited me, accompanied by one or more female slaves. They examined every thing, even to the pockets of my trowsers; and more inquisitive ladies I never saw in any country : they begged for every thing, and nearly all attempted to steal something; when found out, they only laughed heartily, clapped their hands together, and exclaimed, "Why, how sharp he is! Only think! Why he caught us !" If they may be said to excel my Bornou friends in accomplishments, they fall far behind them in modesty. They are passionately fond of cloves, which, when pounded and mixed with fat, they rub over their hair and skin. To give them their due, they are the cleverest and the most immoral race I had met with in the Black country.

I was not a little surprised the next day at hearing that there were two sultans, father and son, both at the head of strong parties, and both equally fearing and hating each other: that I had seen the son, but that it was absolutely necessary to give the elder at least as much as I had given the younger one. I remonstrated; but Bellal assured me that his slaves were the most expert thieves in the kingdom-that no walls could stop them if the sultan once gave the word "Forage." There was no alternative; so putting ten dollars in a stocking, and tying up in a French silk handkerchief two strings of coral, and a few cloves, with six gilt basketbuttons, I presented him with them, and had the pleasure of hearing that his majesty was highly gratified by the present. Of the bad terms on which these rival sultans were, notwithstanding their consanguinity, I had pretty good proofs, by their both sending to me for poison in secret; " that would not lie," to use their own expression. The mai n'bussa, the young sultan, as the son was called, sent me three female slaves, under fifteen years of age, as an inducement; whom I returned, explaining, in pretty strong terms, our 
abhorrence of such proceedings; for which I had the satisfaction of hearing myself, and all my countrymen, pronounced fools a hundred times over.

On the 19th, my poor colleague seemed a little better: he had slept, and was more calm and easier. I left him in the morning for the purpose of proceeding up the river, and returning the next day, or the day after that. The Shary, after leaving Kussery, makes a sweep nearly due south, when it winds to the south-west; and nearly on the apex of the sinuosity, if I may so express myself, stands the capital of Loggun. The river is here not more that 400 yards in breadth. The canoes are different from those of Showy, measuring nearly fifty feet in length, and capable of carrying twenty or twentyfive persons : they are built of two fine-grained woods, called kagam and birgam, which grow in abundance along the banks from Williky to Loggun : the planks are often from two to three feet wide.

It was near noon, when we had ascended but a few miles, that a canoe was seen following our track, with a speed denoting some extraordinary occurrence; and on their reaching us, and reporting the cause of this haste, such confusion took place amongst my party, that out of seven canoes which accompanied me, not one remained; all made for the shore; and it was with some difficulty that we could persuade our own to return with us to Loggun. We now found that the Begharmis were again on the Medba, and coming towards Loggun. The sultan, on our return, sent for us, and desired the sheikh's people to quit his dominions instanter. I told him that I came expressly to remain some time; that Bellal might return; but that for myself, I was his subject, and must remain under his protection; added to which I had a sick friend, and a sick servant, and that I could not move. This, however, he would not hear of. Bellal was desired to quit Loggun, and to take all of us with him. "More than half my people are Begharmi," said the sultan; " I have no protection to give-go, go! while you can." Obliged to obey, I 
raised my suffering friend, who was unable to assist himself in any way : we set him on a horse, and with no provisions but a sack of parched corn, which the sultan gave us, at four o'clock the same day we quitted the walls, when the three gates were shut upon us, one after the other, with great satisfaction, by an immense crowd of people.

It was late at night when we halted near some deserted cattle sheds, of the Shouaa Arabs, who had fled; and in one of which we laid my exhausted companion, while I kept watch on the outside. From this time, until the night of the 21st, when we came to a small village called Tilley, on the banks of Gambalarum, we had scarcely any rest, and but little food. Bellal and his slaves becoming impatient, I had ridden on with him in front, for the purpose of keeping him always in sight, while I left Mr. Toole in charge of Columbus, who was sufficiently recovered to attend to all his wants; occasionally, however, going back myself, and urging them to keep up as much as possible. It had now been dark for four hours, and the road was winding, thickly wooded, and intricate. Bellal proceeded to search for the ford, preparatory to crossing the stream : to this I decidedly objected, until our companions and baggage came up; knowing that our doing so must depend on the state of my patient. He made various objections, but as I dismounted, and began gathering wood for a signal-fire, he gave up the point : they answered immediately the glare of the flame, and curling smoke, by a shot; and Bellal and I proceeded in the direction of the sound, for the purpose of conducting them to the spot we had rested on: a second and a third shot, however, were necessary before we could meet, so intricate were the paths. I found Mr. Toole perfectly senseless, and we laid him on a bed of unripe indigo, near our fire, wrapped up in his blanket, while a little warm tea was prepared for him, and he soon after fell into a sound sleep. Bellal now recommenced searching for the ford, which I allowed him to do; fully determined, however, not to disturb my companion until morning, unless the danger of 
our situation should increase: he returned soon after midnight, and pronounced the river not fordable, either above or below the town. We were obliged, therefore, to load instantly, and proceed by a more northerly route, where our danger was greater. My companion allowed himself to be moved, with great patience; and Bellal, of whose bravery and kind-heartedness I had seen many proofs, shed tears on observing the sad change, which disease had effected in my once lively and active comrade. He declared that his anxiety was more on our account than, on his own, as he never would see the sheikh's face, or Kouka, if any thing happened to us. We passed the walls of Affadai soon after daylight, from whence the people were flying in all directions, and rested for the night at Yrun, after fording the river at Solon: here the natives had determined on making a stand; and three of the four gates were built up, while the fourth had only space sufficient left for a man to force himself through. The kaid sent to invite us to remain ; and furnished us with milk, and fresh fish, as well as with corn for our halffamished animals. We raised a tent over Mr. Toole, where he lay on the ground, and twice, during the night, gave him rice and tea; after which, to my inexpressible delight, he slept. On the following day we reached Angala, a place of comparative safety, and where we were sure of protection. On passing over the plain which leads to this city, I shot a very large korrigum, a species of antelope, with long annulated horns, nearly as large as a red deer. At Angala we took up our old quarters, at the house of the delatoo; and Mr. Toole, on being told where he was, exclaimed " Thank God! then I shall not die!" And so much better was he for the two following days, that I had great hopes of his recovery : about four o'clock, however, on the morning of the 26th of February, those hopes were at an end. A cold shivering had seized him, and his extremities were like ice. I gave him both tea and rice-water; and there was but little alteration in him, until just before noon, when, without a struggle or a groan, he expired, completely worn out and exhausted. 
The same afternoon, just as the sun was sinking below the horizon, I followed his remains to their last resting-place, a deep grave, which six of the sultan of Angala's slaves had prepared, under my direction, to the north-west of the town, overhung by a clump of mimosas in full blossom. The delatoo, or prime minister, attended the procession with his staff of office, and a silent prayer breathed over all that remained of my departed friend, was the best funeral service circumstances allowed me to perform. After raising over the grave a pile of thorns and branches of the prickly tulloh, several feet high, as a protection against the flocks of hyænas, who nightly infest the burying-places in this country, I returned to the town. In the course of my life, I had seen many of my less fortunate companions pay the great debt of nature-their deaths generally caused by severe and painful battle wounds; but the recollections left on my mind by the calm departure of my amiable and suffering companion exceeded all former ones in acuteness-proving, that in grief, as in pleasure, sensations of the more quiet and gentle kind often make a deeper impression on the heart than those of a fiercer or more violent nature. Not by me alone, however, was he lamented even here; so pleasing were his manners, and so various his acquirements, that his friends and relations have much to regret in his loss; but they may also be proud of having had him for a connexion.

Mr. Toole possessed qualifications which rendered him particularly useful on a service of this nature. He was persevering and intrepid, and of a most obliging, cheerful, and kind disposition : only once did he declare his incapability to proceed, and refused to be lashed on the camel; but when I sat down on the ground beside him, and Bellal and the sheikh's people prepared to leave us, he cried out, "No! no! heed me not: tie me on once more; but, pray, gently: you will not leave me alone! and I shall be the cause of others falling into unnecessary peril."

If the readiness with which he volunteered his services to the government of Malta, to join me at Bornou, entitles him to 
praise, his manner of performing the journey from Tripoli gives him a claim to still greater. Including his delays, which were several and vexatious, he arrived in one hundred and eight days at Kouka, which, considering the people he had to deal with, required very extraordinary efforts, great temper, and good management. Notwithstanding the expedition he used, but five camels died on this long journey, which, for a commencement, was a very severe campaign; and his constitution, though strong, was not sufficiently seasoned to support the fatigues and privations to which he was from necessity exposed.

Mr. Toole had scarcely completed his twenty-second year, and was in every sense a most amiable and promising young officer. To his fate he was perfectly resigned; and on the day previous to that of his death, when I mentioned to him his return to Kouka, he smiled, shook his head, and said, "No! no! it is all over." Nearly his last words were expressive of hopes that, through Earl Bathurst's recommendation, his next brother might succeed to the ensigncy in the 80th regiment, which would become vacant in the event of his death; and this request was no sooner made known to his lordship than it was immediately complied with.

An immediate return to Kouka became, on the death of my companion, the most desirable step to be taken; and, during the evening of the next day, accompanied by Bellal, I left Angala. The Begharmis were now scouring the country in every direction; notwithstanding, we arrived at Angornou on the 1st of March, with only the loss of two camels. Here I met the sheikh with a large force, which he had hastily collected for the purpose of attacking these invaders. He was, as usual, full of kindness, and sent word to the person whom he had left in charge at Kouka, to do every thing for me that I requested. All his people were in alarm, and seemed to doubt greatly what would be the issue of the approaching contest. On the $2 \mathrm{~d}$ of March I returned to Kouka; and, on the following day, had an attaek of fever myself, which, though a slight 
one, confined me for ten days to my mat: my illness, however, I do not consider at all attributable to climate-deprivation of rest, fatigue, heat, and anxiety of mind, brought on the attack, from which I speedily recovered. My greatest suffering had ever been in my eyes; and a violent discharge from them greatly relieved me.

Although success had certainly not attended my endeavours in this instance, yet the excursion had not been without its advantages. Our knowledge of the country, and the people by whom it was inhabited, was considerably increased : the district we had penetrated was one where kafilas do not go, or where straggling Moorish merchants ever venture to present themselves; and treacherous indeed must the character of that people be, where the love of gain will not induce the avaricious and persevering Moor to carry on his traffic. The being foiled in my attempt to get up the stream from Loggun, was a circumstance I much regretted; but from the confirmation received there of the report I had previously heard, of a more southerly branch of the Shary, running through a mountainous country to the eastward, I have no doubt of that being the fact; and had not events beyond the power of human control prevented my residence for a short time at Loggun, this stream would, I am inclined to think, have been found to extend to Adamowa, and from thence to the lake Fittre.

Loggun itself is more healthy and abundant than any other part of the banks of the Shary. Gussub, gafooly, ground nuts, mangoes, and onions, are in great plenty, as well as honey, butter, milk, and beef. There is a market every evening, where fish and flesh may be purchased in any quantities. Salt is extremely scarce, and apparently but little esteemed, or the want of it regretted : they sometimes use, as a substitute, fine trona, which is, however, dreadfully bitter and nauseous./The trees are numerous, and much larger than those of Bornou, although most of them are acacias: the locust, with its blood-red blossom, is the most striking, with the exception of the kuka, or kukawha, and this I never saw in flower.

The inhabitants of Loggun, of both sexes, are industrious, and 
labour at the loom more regularly than in any part of the sheikh's dominions; almost every house has its rude machinery for weaving, and the finer and closer linen is here produced; the width, however, is invariably the same as the Bornou gubka, not exceeding six or seven inches. In one house I saw five looms at work : the free people usually perform this labour, while the female slaves prepare the eotton, and give it the deep blue dye so esteemed amongst them, by their ineomparable indigo: the glazing is also another and very important part of their manufacture: the linen, which, previous to its being dyed, is generally either made up into tobes, or large shirts, or into lengths of fifteen or sixteen yards, which is equal to the size of a turkadee, is, after three steepings, and as many exposures to the sun, laid in a damp state on the trunks of large trees, cut to a flat surface for the purpose, and are then beaten with a wooden mallet, being at the same time oecasionally sprinkled with cold water and powdered antimony, kohol; by this means, the most glossy appearance is produced: the constant hammering attending this process during the whole day, really sounds like the busy hum of industry and oecupation.

Neutrality has been the policy of Loggun during the whole of the wars that have laid waste Bornou : she has, at times, made great sacrifices to preserve it, but peace has been her reward; and should confidence and tranquillity be established by El Kanemy's exertions in those provinces bordering on the great track of kafilas, Loggun will be a profitable resort for merchants : they are any one's people who can gain an influence over them, and appeared to care as little abont the Mohammedan forms of religion as we did ourselves. The surrounding country abounds with eattle, and wild animals of every deseription found in Africa. They are a remarkably handsome, healthy, and good-looking race. In the immediate neighbourhood of the great river, some of the towns are extremely healthy; Showy in particular; and from thence to its embouchure, the banks are high and seldom overflowed: the eurrent runs with great strength 
along the perpendicular sides of what I have called Buffalo bank, where there is great depth of water, and a firm sandy bottom. Towards Kussery, again, they are said to be sickly; but this is accounted for by the marshy nature of the country round about them ; and the windings of the river, which here, by causing a convexity, gives shallow water, a languid current, and low marshy ground. The overflowings, also, of the smaller streams, leave here stagnant lakes, of several miles in extent, which are filled with unsightly useless shrubs: the woods are not cleared; and the wind has therefore but little power to disperse the foul exhalations, which arise from these unwholesome fens. The innumerable hosts of flies and insects appear to cause the inhabitants of the banks of this river to complain more than either the heat or the climate. Chickens are frequently destroyed by them, soon after they are out of the shell: a chief told me, near Kussery, that, during the last two years, he had lost two children, who were literally stung to death; and from our own observation and sufferings, this does not appear to be an exaggeration.

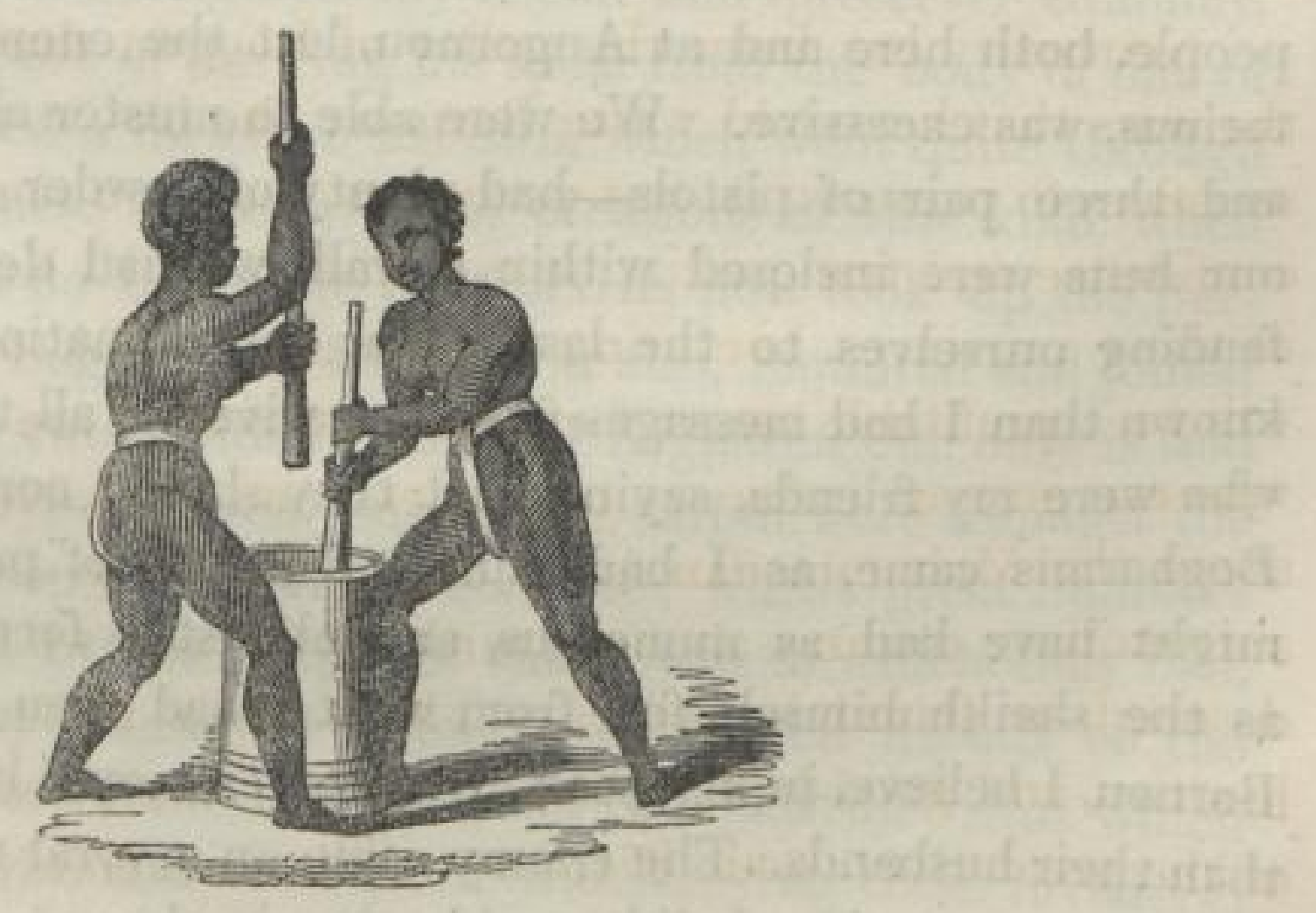




\section{CHAPTER VII.}

\section{JOURNEY TO THE EASTERN SHORES OF THE LAKE TCHAD.}

March 7, 1824.-The courier which I had sent to Kano, with a supply of necessaries for my countrymen, on Mr. Toole's arrival, returned to Kouka, bringing a confirmation of the report which had before reached me, of the death of Dr. Oudney, at a place called Murmur, near Katagum, on the 12 th of January.

I had left the sheikh in full march to drive back the Begharmis, and he now took up a position near Angala, within five miles of the enemy, who had commenced plundering in their rear, and were moving off all they could gather to the south side of the river : their force, also, it was said, increased daily, and the alarm of the people, both here and at Angornou, lest the enemy should be victorious, was excessive. We were able to muster about seven guns, and three pair of pistols-had plenty of powder and ball; and as our huts were inclosed within a wall, we had determined on defending ourselves to the last. Our determination was no sooner known than I had messages from the wives of all the sheikh's chiefs who were my friends, saying that they should come to me, if the Begharmis came, as I had guns and plenty of powder; so that 1 might have had as numerous, and almost as formidable, an army as the sheikh himself, for, from what I had seen of both sexes in Bornou, I believe, in my heart, the women would have fought better than their husbands. The enemy came on several times, and offered battle; but as the sheikh could not get them in the situation he wished for, he refused the combat. 
On the 28th, however, the struggle commenced. The Begharmis became bold in consequence of the sheikh's apparent unwillingness to fight, and they at length ventured to attack him in the plain to the south-east of Angala, on the edge of which he had halted. The kafila, which had departed for Soudan, had deprived him of at least thirty of his Arabs; and the few that remained, with some forty Musgow slaves, who had been trained to the firelock, being his great dependence, he placed them on his flanks. No sooner had the Begharmis cleared the wood, than the sheikh, hoisting his green flag in the centre, and surrounded by his Kanemboo spearmen, moved rapidly on : the two guns in front, which Hillman had mounted, with the Arabs and musketeers, right and left of them. The Begharmis, also, came on with great coolness in a solid mass, five thousand strong, with two hundred chiefs at their head: they made directly for the centre, where the sheikh had raised the standard of the Prophet, but were repulsed by a discharge from his artillery : they now fell upon Barca Gana's flank, which was attacked with such determined bravery, that all, except himself and a chosen band, gave way: and here fell my friend and preserver Maramy, who, while in the act of drawing his spear from the body of one of their chiefs, received a thrust in his own, which went quite through him. The Bornouese horse, who, on occasions of this kind, when the road is opened for them, are most active, now took up the pursuit of the routed Begharmis : the Arabs, also, mounted and joined them; and of the two hundred chiefs of Begharmi one only is said to have escaped alive. Seven sons of the sultan were amongst the killed, and seventeen hundred of less note; whilst great numbers were put to death by the people of the towns to which they fled, who now, as if by magic, all became the stanch friends of the sheikh. The water of the little stream, Gambalarum, near which the battle was fought, also lent its aid in destroying these invaders; and many were drowned in attempting its passage: but above all, 
“ The guns! the guns! the guns! Oh, wonderful! how they made the dogs skip ! - Oh, the guns !' were words in every body's mouth. My friend, the sheikh, however, thought there was a little too much of this, for on the second day, he said, " True, the guns are wonderful, 'tis true! - but I lifted my hands, and said, Sidi absolam, sidi abdel garda! and from that moment the victory was yours." It is said that, on the morning of the battle, the sheikh appeared at the door of his tent, with the English double-barrelled gun in his hand, and his English sword slung over his shoulders, clothed in the dress of a simple trooper, saying it was his intention to fight on foot, at the head of his Kanemboos; - that he expected all the Arabs to follow his example, and encourage the slaves, who were but young in the use of the firelock: that if it pleased God to grant their enemies the victory, flight was out of the question; they had nothing left but to die before their wives and children were torn from them, and escape so appalling a sight.

April 4.-Nothing could exceed the joy of the people at having obtained the victory: the men walked about all day in their new tobes, and the women danced, sang, and beat the drum, all night. My hut was thronged with visitors, all recounting their own feats, and bewailing their friends - sending the Begharmis to the devil, and asking for presents on their return, all in the same breath. I had a private interview with the sheikh, and offered him my hearty congratulations : he was as kind and friendly as ever, talked a good deal about the signal manner in which the Kaffirs had been delivered into his hands, and mentioned most feelingly the death of my poor companion Mr. Toole, whom he was very partial to-asked if his mother and father were living, and turning to Tirab, who was near him, said, " How could they send him so far off?"

The plunder was said to have amounted to four hundred and eighty horses, and nearly two hundred women, with two eunuchs, and the baggage of the princes, which was carried on bullocks and 
asses. Fifty of their women were sirias * of great beauty, belonging to the sultan's sons, and these were all given up to the sheikh. But while all these rejoicings were going on without, the climate was at work within. Omar, an Arab who had lived several years in the service of the consul at Tripoli, and had accompanied Mr. Toole, at his recommendation, a hearty lively fellow, was so severely attacked by the fever, that in seven days we laid him in the earth. Columbus, who had been ill ever since he caught the fever from Mr. Toole, again took to his bed, and seemed to be more debilitated than ever.

April 15.-Although my funds did not exceed eight hundred dollars, yet I determined to see and talk to the sheikh on the subject of an eastern journey + . " It is not in my power to send you to the eastward," said he, "or you should not want my assistance. You have seen enough yourself of the dispositions of the inhabitants of the countries towards me, and their power, to know that this is true. It has pleased God to grant me a victory now, which may lead to quieter times ; even the pilgrims have not for years gone by the Lake Fittre to Hadge. I am as anxious as you are, and with more reason, to open a road with Egypt from hence: I cannot, nor can my people, now go to Mecca, without passing through the bashaw of Tripoli's territories, and there are reasons which make that disagreeable. Why not try it from Egypt, where you have many friends, and return from this way by Fezzan ?- that would be easier." The sheikh has a most singular manner of delivery, and I scarcely ever

* Slaves worthy of being admitted into the seraglio.

† The best information $I$ had ever procured of the road eastward was from an old hadgi, named EI Raschid, a native of the city of Medina : he had been at Waday and at Sennaar, at different periods of his life; and, amongst other things, described to me a people east of Waday, whose greatest luxury was feeding on raw meat, cut from the animal while warm, and full of blood: he had twice made the attempt at getting home, but was each time robbed of every thing; yet, strange to say, he was the only person I could find who was willing to attempt it again.

K к 2 
met with any person who expressed himself so clearly, and with so few words. I replied, "that if I could not proceed in the way I wished, I should return, and either take his advice about Egypt, or wait till better times : that the King of England, upon hearing from me of his kindness, his willingness to assist us, and his friendship, would send some other Englishmen, with proofs of his good will, who would claim his assistance in getting to Sennaar." "God keep you from evil!" said he; " but tell your great king to send you again : here you are known, and loved by the people; and know them, and their language : we all will wish to see you againwhat shall we do with a stranger?"

The sheikh sent this day for Columbus: "You have lived greatly," said he, " amongst Mussulmans; why do not you say, La il la ilallah : shed, shed, and paradise is open to you?" Columbus, who knew Turks perfectly, replied, "If it is written, so it will be :" "True," said the sheikh, " but death is near. I, however, still think you love Mussulmans, and are a believer in your heart: true, the time may not be yet come;-pray God it may come, and quickly, both for you and Sahaby Khaleel (meaning me). I have sent to speak to you, and I think you will tell me the truth:-what is this wish of Khaleel's to go to Egypt? I think he is my friend, and I think the English are my friends; but a man's head is always his best friend. I fear they wish to overthrow the Mussulman power altogether." The reply of Columbus was, "As far as I know they want to do no such thing: they wish to see, and to describe the country, with its inhabitants; and if the English are the first to do so, they will pride themselves greatly in consequence." "And is that all ?" replied the sheikh; "Oh! wonderful : no one would believe it, -no one does here but myself, but I do, because they say so, and they are not liars."

April 30.-Every thing had been in preparation for a ghrazzie, upon an extensive scale : its destination was a secret; but I inquired 
of the sheikh, and added, that I hoped he would allow me to accompany him. To this he consented; and, in the evening, sent me word that they should pass the river at Showy, anèi proceed northeast towards Fittre, for the purpose of annihilating, if possible, the Shouaas La Sala of Amanook, who were in that direction, and allies of the sultan of Begharmi. Amanook was a determined warrior, as well as a terrible fighi. In his escape, after the late fight, his horse had fallen with him, and some followers of Maffatai came upon him; they were about to finish him, when he discovered himself, and by a promise of one thousand bullocks was allowed to escape, one of the men giving him a horse: this horse also knocked up previous to reaching the river, and Amanook saved himself by creeping into the warren of some wild hogs (foul disgrace to a believer!) when after remaining a night and a day, he ventured out, and escaped by swimming across.

The story got to the sheikh's ears, and the Maffatai Sultan was sent for. These worthies having quarrelled in the division of the spoil, one of them betrayed the rest: and all of them were hanged accordingly, even he who informed; and the sultan, having been kept in a state of great alarm for several days, was at length released, on the payment to the sheikh of twenty bullock loads of tobes, nearly one thousand dollars, for having such people in his kingdom.

On the 4th of May we left Kouka for Angornou, for the purpose of proceeding on the ghrazzie. Rhamadan had now begun two days, and strong objections were made by the Kanemboos and Shouaas to proceeding : they had been nearly two months in the field already, and they were most anxious to prepare for the sowing season, which was now approaching; the difficulty, however, of fasting from sunrise to sunset, while on a campaign at this hot season, for the thermometer was $102^{\circ}$ and $104^{\circ}$ each day, and the sin of breaking the Rhamadan, by doing otherwise, were made the grounds of objection, and could not fail of having their weight with the sheikh. On 
the 8 th, therefore, we all returned, and the expedition was put off for a month.

From this ime, until the 19th instant, we were in a state of great tranquillity : every body was suffering from the severity of the Rhamadan, which was unusually oppressive this year-the days were thirteen hours long, and the heat excessive.

On the 19th instant I had news of Mr. Tyrwhit's arrival at the river Yeou, and on the 20th I went out to meet him at the resting place, called Dowergoo. This gentleman His Majesty's Government had kindly sent out to strengthen our party, without knowing how fatally the climate had weakened us : he was the bearer of presents to the sheikh, in acknowledgment of the kind reception we had experienced, and was also accompanied by the sheikh's children, so long detained at Mourzuk by the intrigues and contrivances of the late bey, Mustapha, the sultan of F ezzan.

On the $22 \mathrm{~d}$ instant we delivered the presents from his Majesty in full form, consisting of two swords, of very beautiful workmanship, two pair of pistols, a dagger, and two gold watches: the delight, nay eestasy, with which these well-selected specimens of our manufactories were received by El Kanemy, was apparent in every feature of his intelligent countenance, and in the quick glances of his sparkling and penetrating eye. The dagger, and the watch with the seconds movement, were the articles which struck him most forcibly; and when I mentioned, that, agreeably to his request, a parcel of rockets had also been forwarded, he exclaimed, "What, besides all these riches! there are no friends like these! they are all truth; and I see, by the Book, that if the Prophet had lived only a short time longer, they would have been all Moslem !"

June 1.-The Rhamadan was now over, and we had, in the place of fasting and complainings, feastings and rejoicings: the oftener in the twenty-four hours a man could afford to eat meat, the greater person he was considered. The heat had been very oppressive, and 
the people complained dreadfully, as the sheikh admitted of no excuse for breaking the Rhamadan : any man who was caught suffering his thirst to get the better of him, or visiting his wives between sunrise and sunset, was sentenced to four hundred stripes with a whip made of the skin of the hippopotamus - a dreadful punishment. An hour or two before the sun went down, sometimes more than a dozen of the class to whom labour rendered the deprivation of liquid for so many hours far more insufferable, would lay themselves near the well, and have buckets of water thrown over them, the only relief that could be allowed, and which appeared greatly to revive them, even when almost fainting with thirst. With the feast of the Aid, however, finished all their sufferings, and also the recollection of them; for the wrestlings now took place in front of the sheikh's house, as before, and the evening dances at the gates of the town were crowded with many picturesque groups. I had, several times during the fast, paid the sheikh a visit by his desire, soon after sunrise, the only time in the day, at this season, that he is visible: our meeting was always in his garden, which a few pomegranate and lime trees made really here a refreshing spot, which was not a little increased by the troughs of water which reached from the well all round this miserable, though royal, nursery-ground, and refreshed the roots of the languid and drooping trees. Our conversation chiefly related to the war with Tunis, which he seemed to think of great importance, and added, that, friends as we were with all Mussulmans, our taking up the cause of their enemies seemed very unaccountable. I endeavoured to explain it to him, that we were enemies to cruelty and blood-shedding, let who would be the perpetrators; that we as often prevented Greeks from massacring Turks, and always released prisoners of either faith, whenever our cruisers found them confined in the ships of their enemies. I do not know that I should have succeeded in satisfying him entirely of our disinterested conduct, had it not been for Shrief Hashashy, a 
very respectable Moor, who, having been robbed of every thing on the road from Soudan, was now recovering himself a little by the sheikh's liberality to the distressed: he was present, and certainly helped me out greatly. "Will my lord listen to me?" said he: "what the rais has just told my lord, I can vouch for the truth of. My lord knows, that the brother of my heart, my youngest brother, Ab'deen, trades to Smyrna and Suez: he fell into the hands of these worst of kaffirs, and with twenty others, Moslem, was taken out of a Greek vessel, with their hands bound ready for execution, by an English captain, who fed and clothed them, and landed them at Smyrna. In short, the English, as I have heard, and believe, made war for twenty years, for no other purpose but to obtain peace." "Wonderful!" said the sheikh; "but where is the profit of all this ?" "That, my lord must inquire of themselves : their wars cannot bring them profit, but, on the contrary, must cost them great sums." "But what will they do with Tunis ?" said the sheikh, turning to me; " they have many large-mouthed guns, and plenty of gunpowder :can three or four ships force them to do as you wish?-No charms will have any effect, believe me, for they have a fighi of great power and knowledge." "Probably so," returned I; " we seldom fight with such weapons-indeed it is probable there will be no fighting at all. If these four ships prevent all intercourse between them and the other nations with whom they trade, will they not be glad to listen to reason for the sake of obtaining peace, and a renewal of their trade and free intercourse?" " True, true," said the sheikh, "most true; you are a thinking people."

June 4.-This afternoon, I was sent for to the palace in a most violent hurry, as one of the young princes had swallowed a fish-bone, or a piece of wood, and was choking. I hurried on my bornouse, and made the best haste I could; and although the distance was not above five hundred yards, the sand, which is always nearly up to the ancles in the streets, prevented the possibility of moving very 
quick; and the Aga Gana, and Mady Sala, two of the sheikh's negro chamberlains, who had been sent for me, soon got some way in advance: they made signs, and called out to me, in great distress, to come on ; which I answered with, the perspiration flowing down my cheeks, "Softly! softly !" This answer, it seems, did not accord with their impatience, which was in proportion to that their master had displayed in despatching them for me; without a word, therefore, they both eame running back to me, seized me in their arms, and in about three minutes placed me on the steps leading to the sheikh's terrace. Had they desired any of the four slaves by whom they were each of them followed to have done this, I certainly should have been inclined to rebel; but when these lords of the bedchamber themselves condescended to bear me in their arms, which they did with great gentleness, I took it, as I have no doubt it was meant, in good part.

I found the young prince with something or other in his throat, which would neither come up nor go down. I at first thought of covering a pistol ramrod with rag, and introducing that, but I afterwards determined to try some large pills of wax candle, of which I was first obliged to swallow three myself, to show the little fellow how ; and at last, by dipping them in honey, I did get him to gulp a couple, when, to my great joy, the obstruction was removed, and the sheikh highly delighted. I had already acquired the name of tibeeb (doctor), but this operation raised my fame exceedingly.

While I was waiting in the palace, in consequence of this accident, a punishment took place, probably only equalled in severity by that of the knout in Russia, and which, as is often the case in that country, caused the death of the culprit before the morning. In this instance the unfortunate man had been found, by the spies of the kadi (who are always on the alert), slumbering in his amours, and was now to pay the penalty of his carelessness. In the middle of the day, during the Rhamadan, he had been seen asleep in his hut, 
and the wife of another man (a merchant), who had been some time absent in Soudan, stretched by his side; they were therefore, without any hesitation, presumed guilty of having broken the Rhamadan. He was sentenced to receive four hundred stripes, and his partner half that number. Her head was first shaved, her dress and earrings, arm-lets, leg-lets, \&c. were given to the informer; she was taken up by four men, with only a cloth round her middle, by means of which she was suspended, in a manner not to be described, while a powerful negro inflicted the full number of lashes she was condemned to receive. This took place inside the court-yard of the palace : she was afterwards carried home senseless. The man received his punishment in the dender, or square, suspended in the same manner, but with eight men, instead of four, to support him : an immense whip, of one thick thong eut off from the skin of the hippopotamus, was first shown to him, which he was obliged to kiss, and acknowledge the justness of his sentence. The fatah was then said aloud, and two powerful slaves of the sheikh inflicted the stripes, relieving each other every thirty or forty strokes: they strike on the back, while the end of the whip, which has a knob or head, winds round, and falls on the breast or upper stomach: this it is that renders these punishments fatal. After the first two hundred, blood flowed from him upwards and downwards, and in a few hours after he had taken the whole four hundred, he was a corpse. The agas, kashellas, and the kadis, attend on these occasions. I was assured the man did not breathe even a sigh audibly. Another punishment succeeded this, which, as it was for a minor offence, namely, stealing ten camels and selling them, was trifling, as they only gave him one hundred stripes, and with a far less terrific weapon.

June 16.-Every thing was now prepared for the expedition to the eastern side of the Tchad, and Mr. Tyrwhitt determined on accompanying me.

On the 17th of June we reached Angornou, and from thence the 


sheikh despatched the ghrazzie, with Barca Gana, the chief, Ali Gana, the second, and Tirab, the third in command. At an interview which I had this morning, he called them all towards him, and said, "This is the duty of you all, take care of these strangers : they wish to go round by Kanem, which must be done, if possible: let them have twenty horsemen, or more, if necessary."

On entering the town of Angala, on the 19th, Bellal, who had accompanied Mr. Toole and myself on the excursion to Loggun, again pointed out the place where we had deposited my unfortunate friend. I went to the spot to see that it was not disturbed; and a peaceful depository it had proved for his remains : every thing remained just as I had left it, even to the branches which covered his grave, and I was fearful, by exciting observations, to risk their disturbance.

On the 20th we reached Maffatai, and took possession once more of my old quarters in Birmah's house. The host, however, was from home, getting his gussub into the ground; his eldest wife did the honours : she also gave me a little more of her company than before, and told me, very good-naturedly, that she could do many things now, that she could not when the lord was at home. Nothing, indeed, could exceed the kindness with which my hostess, who was called Ittha, did all she could to show how welcome a visitor I was. "Birmah," she said, "must stay and get in the corn, but she hoped I should not miss him." During the first day she came repeatedly with her sister Funha, a negress with an expression of countenance more pleasing than I had ever before seen, of about eighteen, who, Ittha said, was most anxious to see me, from what she had told her formerly. Luckily, she added, Funha had divorced her husband only two days before, or she could not have had that pleasure. Ittha, with all the familiarity of an old acquaintance, uncovered my hands, arms, and breast, to show to her sister my extraordinary whiteness. It seemed to surprise her greatly; but nevertheless I

L 12 
was pleased to observe that it did not appear to excite either much alarm or disgust: but what certainly seemed to both the greatest wonder, was the sight and touch of my head, which had just been shaved; it was literally passed from the hands of one to the other, with so many remarks, that some minutes elapsed ere I could be allowed to replace my turban. When, at length, they left me, Ittha exclaimed, pressing my hand with both hers, that I was fit to be a sultan, mai, mai, wolla! and that Funha should shampoo me, and try to bring on sleep, as I must be tired and fatigued by the heat of the sun. This, however, was not all: towards evening, more than a dozen of Ittha's friends, the principal ladies of the town, came, in consequence of the liberty she enjoyed while the goodman was away, to have a look at the bulfulk (white man), each bringing me something - a few onions, a little rice, or a bowl of milk, as a present. Funha performed all the duties imposed on her to perfection. I had a supper of pounded rice, milk, and honey, with something like bread made into cakes : and verily I began to think, like Ittha herself, that I not only deserved to be a sultan, but that I had really commenced my reign.

We moved to Showy, and crossing the Gurdya by a slanting ford, came more to the eastward than before, and by a nearer route. I was here greatly amused with seeing a party of girls skipping in a long rope, just as we do in England, and the fear of losing my dignity alone prevented my speedily joining them. They performed well; but then it must be recollected that they were totally unincumbered with drapery or any covering whatever, although good-sized young ladies of twelve or thirteen years old. The inhabitants of Showy are a most indolent happy people : half the night is passed in fishing, which is their sole support; and towards evening, each day, the sound of the drum calls them to the open space in the centre of their huts, when the men form themselves into circles, and dance in a most 



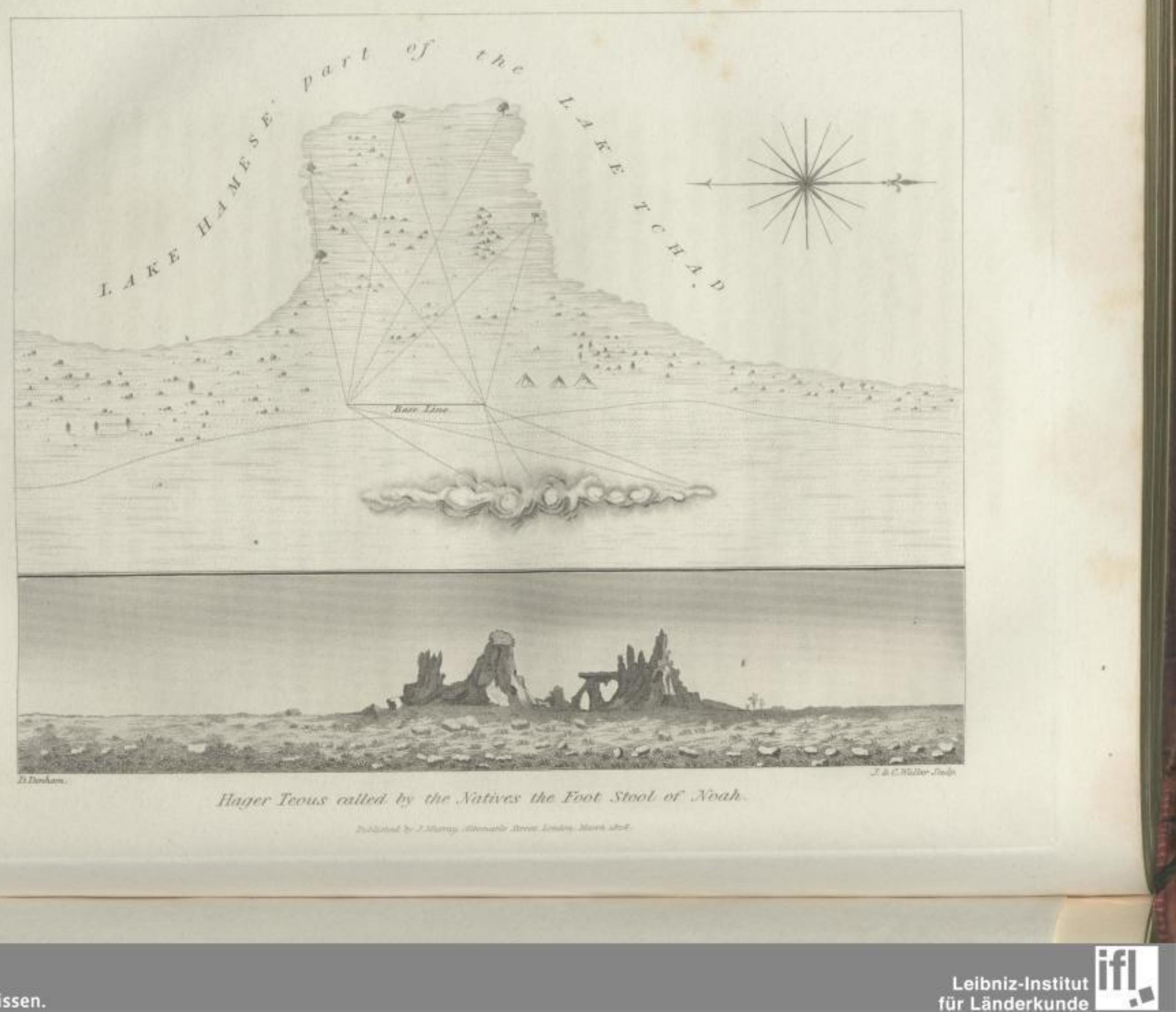


uncouth though joyous manner. The women all assemble at a certain part of the circle, sitting on the ground with their faces covered, and salute the most active with loud screams of approbation.

June 24.-We crossed the Shary with but little less water than we had found six months before, and passing the day on the east bank, we moved again in the evening: we saw twelve crocodiles basking on the banks. A large party of Shouaas were passing on rafts, swimming their sheep and bullocks, which they drive over in flocks, one being first forced into the river, and dragged over by a line run through the cartilage of the nose. Women often perform this duty, showing great strength and agility in swimming and curbing these powerful animals. We made nine miles, passed quantities of ghrwka (castor-nut tree), and at noon arrived at lake Hamese, which is part of the Tchad, and halted at some Shouaa huts of the Beni Hassan tribe, at a place called Zeabra. In continuation of our course, we halted, in the afternoon, at Berbeeta, where we encountered a terrible storm, and were sadly bitten by mosquitoes.

A little to the northward of the road, and at the head of the lake Hamese, are some very curious rocks of red granite standing in an immense plain, at a great distance from any mountains of a corresponding structure: one is of a conical form, and distant about three hundred yards from the others, which are connected. The space between Kou Abdallah, the name of the first, and the other three is covered with loose fragments of rock of different sizes, and it is natural to suppose they were all formerly united: the three are called Hager Teous by the Bornouese, and by the Shouaa Bete Nibbe Mohammed. I had dismounted for the purpose of approaching nearer to the base of the single rock, over the broken fragments by which it was surrounded, principally for the purpose of procuring some specimens, when those who were waiting in the plain exclaimed, "A lion! a lion! a lion!" I began to look around me with great anxiety, and quickly perceived a large female panther, big with 
young, bursting from the shade of the loose fragments just before me, and, frightened at the cries of the negroes, was running up the rock. These are the most dangerous animals that are here met with, although they never attack when several persons are together; my being in advance was what alarmed the rest. The animal, however, passed quietly away.

June 26.-We still kept near the swamps which surround the Tehad, and halting as usual for two hours in the heat of the day, by sunset we had made nineteen miles, winding, and arrived at the huts of the Biddomassy Shouaa, where Barca Gana was encamped.

June 27.-Proceeded fifteen miles, and found the Dugganah Shouaa were about three miles before us, with Malem Chadely, and a small body of the sheikh's people who had preceded us. We forded to-day eight waters, branches of the lake, some up to the body of the horse; while the camels took a more circuitous route, and passed beyond the waters on perfectly dry ground. Amanook's people, we found, had fled.

June 28.-Although on our arriving at the camp of the Dugganah a long parley was held, and a number of questions asked of sheikh Hamed, as to Amanook's numbers, and his hiding-place, yet the first object of the expedition did not appear until just before daylight this morning, when the whole body mounted, and in fifteen minutes were moving towards Kanem Mendoo, one day from Maou, the capital; from whence the Waday's had driven the sheikh's friends. Mendoo had thrown off the sheikh's government, and Edershi Gebere, nephew of the Fugboo, that had been put to death by the order of Mustapha L'Achmar the sultan of Fezzan, now ruled as khalifa. The sheikh's object had been to catch him by surprise; and for this reason Amanook and $\mathrm{La}$ Sala were always held out as the sole destination of the army. Mendoo was nearly in my road, and it was therefore necessary that it should be cleared first of these rebels. Barca Gana sent in the night for Bellal, and desired him 
to acquaint me with his intention, and that as he should merely halt to sully (pray) and water the horses, from his starting until the sun should be three fathoms high on the following day, when he should surround Mendoo; that the sheikh wished me to remain where I then was until his return, which would be in four days, when he trusted I should be able to proceed in safety. I should have preferred going on, and leaving Mendoo to him, have passed on round the Tchad; but he would not hear of such an arrangement, and as I was kept in ignorance of this plan until the whole army was actually in motion, $I$ had no alternative. Not a camel went with them, and all the baggage and siriahs were left in the camp. Bellal now became the chief, and with the assistance of the Shouas and Arabs, the camp was intrenched, trees were cut down, and a sort of abbattis quickly formed for our protection. Our situation was, however, one of jeopardy and inconvenience, as nothing but their ignorance of our movements could save us from an attack from Amanook's people, to whom we should have been a fine booty and an easy prey. From our vicinity to the Tchad, the swarms of flies in the day, and mosquitoes at night, were so great, that we were obliged to resort to our old remedy of lighting fires, and living in the smoke, in order to obtain a little peace.

June 29.-The Dugganah ehief, Tahr, came to my tent to-day, attended by about twenty people, who all sat down behind him bareheaded, while he had on a dark blue cotton cap. He had a fine, serious, expressive countenance, large features, and a long bushy beard: these are the particular characteristics of these Shouaas-they differ from the Shouaas to the west, who have mixed more with the natives. Tahr might have sat for the picture of one of the patriarchs; and an able artist would have produced a beautiful head from such a study. Their mode of salutation is by closing their hands gently several times-as we applaud-and then 
extending the palms of both flat towards you, exclaiming, "L'affia? -Are you well and happy?"

Tahr, with his followers, after looking at me with an earnestness that was distressing to me for a considerable time, at last gained confidence enough to ask some questions, commencing, as usual, with "What brought you here? they say your country is a moon from Tripoli." I replied, " to see by whom the country was inhabited; and whether it had lakes, and rivers, and mountains like our own." "And have you been three years from your home? Are not your eyes dimmed with straining to the north, where all your thoughts must ever be? Oh! you are men, men, indeed! Why, if my eyes do not see the wife and children of my heart for ten days, when they should be closed in sleep they are flowing with tears."

I had bought a sheep for a dollar, a coin with which he was not conversant; and he asked if it was true that they came out of the earth? The explanation pleased him. "You are not Jews?" said he. "No," said I. "Christians, then ?" " Even so," replied I. "I have read of you: you are better than Jews," said he. "Are Jews white, like you?" " No," replied I; " rather more like yourself, very dark." " Really ;" said the sheikh : "Why, are they not quite white? They are a bad people." After staying a full hour, he took my hand, and said, "I see you are a sultan : I never saw any body like you. The sight of you is as pleasing to my eyes, as your words are to my ear. My heart says you are my friend. May you die at your own tents, and in the arms of your wives and family." "Amen," said I; and they all took their leave.

June 30.-Tahr paid me another visit to-day. The Dugganahs were formerly Waday, and were strong enough to have great influence with the sultan; but by quarrelling among themselves, they lost their influence, and became subject to the Waday sultans. They generally passed one part of the year in the Bahr-al-Ghazal, 
and the other part by lake Fittre : in these two spots had been the regular frigues, or camps, for several generations. Sheikh Hamed his father, the present chief, who had more than one hundred children, found that another tribe of Dugganah had been intriguing with the sultan of Waday against him, and that he was to be plundered, and his brethren to share in the spoil. On learning this, he fled with his flocks and his wives, offered himself to the sheikh, El Kanemy, and had since lived in his dominions. The account he gave of the Tchad was this-it formerly emptied itself into the Bahr-el-Ghazal by a stream, the dry bed of which still remained, now filled with large trees and full of pasture : it was situated between the N'Gussum and Kangarah, inhabited by Waday Kanemboos. "I could take you there," said he, "in a day ; but not now-spears are now shining in the hands of the sons of Adam, and every man fears his neighbour." He had heard his grandfather, when he was a boy, say, " that it there gradually wasted itself in an immense swamp, or, indeed, lake* : the whole of that was now dried up. They all thought," he said, "the overflowings of the Tchad were decreasing, though almost imperceptibly. From hence to Fittre was four days : there was no water, and but two wells on the road. Fittre," he said, "was large; but not like the Tchad. His infancy had been passed on its borders. He had often heard Fittre called the Darfoor water and Shilluk. Fittre had a stream running out of it-was not like the Tchad, which every body knew was now a still water; a river also came from the south-west, which formed lake Fittre; and this and the Nile were one : he believed this was also

- Sidi Barca, a holy man, was killed by the Biddomahs at the mouth of this river; and from that moment the Bahr-el-Ghazal began to dry, and the water ceased to flow. A Borgoo Tibboo told us at Mourzuk, that the Bahr-el-Ghazal came originally from the south, and received the waters of the Tchad; but that now it was completely dried up, and bones of immense fish were constantly found in the dry bed of the lake. His grandfather told him that the Bahr-el-Ghazal was once a day's journey broad.

M $\mathbf{M}$ 
the Shary; but he knew nothing to the westward: it, however, came from the Kerdy country, called Bosso, and slaves had been brought to Fittre by it, who had their teeth all pointed and their ears cut quite close to their heads." Tahr wished to purchase our water skins, "for," said he, "we can get none like them; and either to Fittre, or Waday, we pass a high country, and find but few wells." The Biddoomah sometimes pay them a visit; and although generally professing friendship, always steal something. The last time, they sold them a woman and a boy; which by Barea Gana's people were recognized as the same they, the Biddomahs, had stolen from the neighbourhood of Angornou six months before: they were of course restored without payment. The hyænas were here so numerous, and so bold, as to break over the fence of bushes in the middle of a thunder-storm, and carry off a sheep from within five yards of my tent.) We had news that Barca Gana had found Mendoo deserted, and was disappointed in catching the khalifa.

The Shouaas live entirely in tents of leather, or rather of rudely dressed hides, and huts of rushes, changing but from necessity, on the approach of an enemy, or want of pasturage for their numerous flocks : they seldom fight except in their own defence. The chiefs never leave their homes, but send bullocks to the markets at Maffatai and Mekhari, and bring gussub in return : their principal food, however, is the milk of camels, in which they are rich, and also that of cows and sheep; this they will drink and take no other nourishment for months together. Their camps are circular, and are called dowera*, or frigue, with two entrances for the cattle to enter at and be driven out. 'They have the greatest contempt for, and hatred of, the negro nations, and yet are always tributary to either one black sultan or another: there is no example of their ever having peopled a town, or established themselves in a permanent home.

* Dowera is the plural of dower, a circle. 


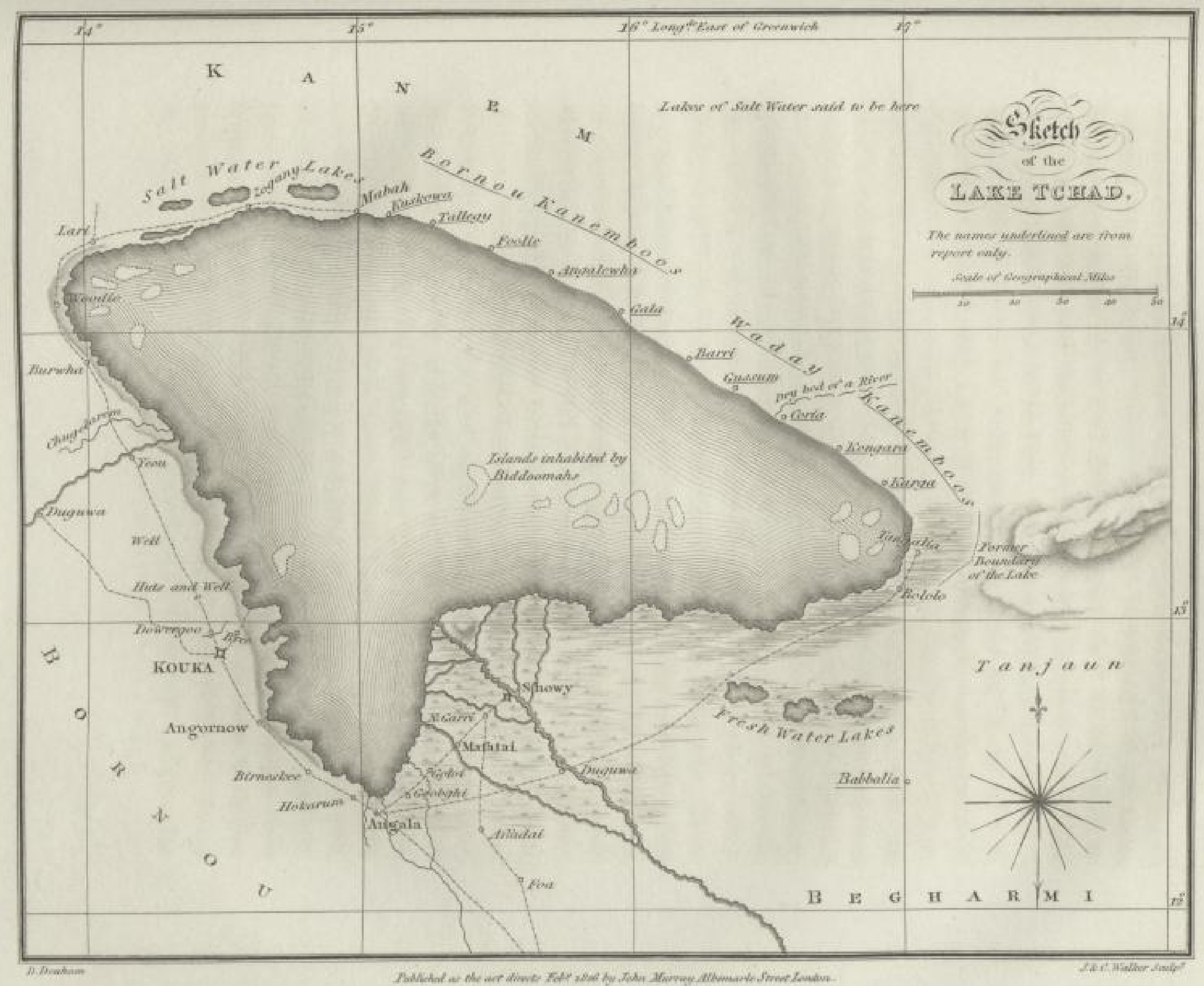

\section{그 SLUB}

Wir führen Wissen. 
For several days we were kept in the greatest suspense. No news arrived from the army. Reports varied: it was said Barca Gana had pushed on to Maou and Waday; again, that he was gone to the islands. We had thunder and rain, with distressing heat, and flies, and mosquitoes to torture. Bellal would not go on, and I would not go back: we were consuming daily our store of rice, with eight days before us to Woodie, through a country without supplies.

July 6.-On the evening of yesterday, Barca Gana, with the chiefs, and about half their force, returned; the remainder had been obliged to halt on the road, to refresh their horses. He had pushed on to Maou after Edirshe Gebere, a Shouaa chief of Korata Mendooby. Fugboo Kochamy, as he was called, was the fourth khalifa whom the sheikh had placed at Maou (his three predecessors having been strangled by the Waday people); he was first cousin toEdirshe, who, affecting friendship for him, lulled his suspicions, and one night attacked him in his capital. Kochamy made a gallant defence; he killed nine of them with his spear, but was at length overcome, and died, with eleven others of the sheikh's allies. Fugboo Jemamy, his brother, alone escaped: to assist Jemamy was the object of Barca Gana. Edirshe had news of their movements, notwithstanding they went nearly fifty miles in a day and night, and appeared first at Mendoo, and then at Maou, on the day after they left us. Edirshe had fled with all his cattle and women: they found them about ten miles from Maou, entrenched within a circular eamp, with all their cattle, women, and children, strongly defended with stakes; their bowmen were all distributed between the stakes, and in front of the entrenchment: they saluted their enemies with shrill cries on their approach, and the sheikh's people, after looking at them for a day and a night, without any provisions for either men or horses, dared not attack them. Disappointed, therefore, in their hopes of plunder M M 2 
and revenge, the whole returned here, their horses and men nearly in a state of starvation.

July 10.-We were all anxiety this day. Barca Gana was nearly one thousand strong, and about four hundred Dugganahs joined him, besides furnishing him with nearly one hundred horses. Amanook was one of the sheikh's most troublesome remaining enemies; the sheikh had, on various occasions, and lastly, when he joined the Begharmis in their attack on Bornou, very severely crippled him, and destroyed more than half his force: the design now was to annihilate the remainder, and secure, if possible, the person of this inveterate foe, who kept alive the hostile feeling both on the Begharmi and Waday side. Amanook, however, was not to be taken by surprise, and he gave the sheikh's troops such a proof of what might be done by a handful of men, bold of soul, and determined to defend an advantageous situation, that they will not easily forget. Just before sunset a Fezzanneer, who had lately entered into the sheikh's service, returned to the camp, giving an account of Barca Gana's complete discomfiture, and Bellal and myself immediately mounted our horses in order to learn the particulars. The Tchad*, which in this part forms itself into innumerable still waters, or lakes of various extents, and consequently leaves many detached spaces of land or islands, always afforded the La Sala Shouaas, and the Biddomah, natural defences, which their enemies had ever found it extremely difficult to conquer. In one of these situations, these very La Salas, with Amanook at their head, kept the sultan of Fezzan, with two

- There is a prevailing report amongst the Shouaas that from a mountain, south-east of Waday, called Tama, issues a stream, which flows near Darpoor, and forms the Bahr el Abiad; and that this water is the lake Tchad, which is driven by the eddies and whirlpools of the centre of the lake into subterranean passages; and after a course of many miles under ground, its progress being arrested by rocks of granite, it rises between two bills, and pursues its way eastward. 
thousand Arabs, and all the sheikh's army, several days in check, and killed between thirty and forty of the Arabs before they surrendered. On this occasion Amanook had taken possession of one of these islands, which, to attack with horsemen alone, in front of an opposing enemy, was the height of imprudence. A narrow pass led between two lakes to a third, behind which Amanook had posted himself with all his cattle, and his people, male and female: the lake, in front of him, was neither deep nor wide, but full of holes, and had a muddy deceitful bottom on the side from whence the attack was made.

The sight of the bleating flocks, and lowing herds, was too much for the ravenous troops of the sheikh, irritated by their recent disappointment; and notwithstanding the declaration of Barca Gana, that he wished to halt on the opposite side of the water, and send for spearmen on foot, with shields, who would lead the attack, the junior chiefs all exclaimed, "What! be so near them as this, and not eat them? No, no! let us on! This night these flocks and women will be ours." This cry the sheikh's Shouaas also joined in, ever loud in talk, but rearmost in the fight, as the sequel proved. The attack commenced : the Arabs, of whom there were about eighty, led the way with the Dugganah. On arriving in the middle of the lake the horses sank up to their saddle-bows, most of them were out of their depth, and others floundered in the mud: the ammunition of the riders became wet, their guns useless, many even missed the first fire, and they were unhorsed in this situation. As they approached the shore, the La Sala hurled at them, with unerring aim, a volley of their light spears, a very formidable missile, which they followed up by a charge of their strongest and best horse, trained and aecustomed to the water; while, at the same time, another body, having crossed the lake higher up, came by the narrow pass, and cut off the retreat of all those who had advanced into the lake. The Shouaas, on the first appearance of resistance, had, as usual, gone 
to the right about, and left those, under whose cover they meant to plunder, to fight it out by themselves: the slaughter now became very desperate amongst the sheikh's people. Barca Gana, although attacking against his own judgment, was of the foremost, and received a severe spear wound in his back, which pierced through four tobes, and an iron chain armour, while attacked by five chiefs, who seemed determined on finishing him; one of whom he thrust completely through with his long spear. By crowding around him, and by helping him quickly to a fresh horse, his own people and chiefs saved him, and thirty of them remained either killed or in the hands of the La Sala : but few of those who were wounded in the water, or whose horses failed them there, escaped. We found Barca Gana, with the other chiefs, seated near the second water; he was in great pain from his wound, and the whole army dreadfully disheartened: they had not more than forty followers in all. We vainly waited until sunset, in the hopes of the missing making their appearance, but we were disappointed, and returned to the camp. By this desertion of the sheikh's Shouaas, the Dugganahs suffered severely : anxious to show their sincerity to the sheikh, they had gone on boldly, and their loss exceeded one hundred; eighteen of the Arabs were also missing. The night was passed in a state of great anxiety, from the fear of an attack on our camp; and the sense of our unjoyous situation was constantly awakened by the melancholy dirges which the Dugganah women were singing over their dead husbands, really so musically piteous, that it was almost impossible not to sympathize in their affliction.

The Dugganah, from being the humblest of allies, now became rather dictatorial, and told the general very plainly that they could fight better without him than with him: they refused him both bullocks and sheep, and said they must keep them to pay the ransom of their people.

Amanook, who it seems had no idea of following up his victory 
by an attack on our camp, which he might have done successfully, and carried off all the chiefs, siriahs, and camels, sent word this evening that he would now treat with nobody but the sheikh himself; that he had declared to the general, before he attacked him, that he feared no one but God, the Prophet, and the sheikh, and wished for peace: "They would not listen to me," said he, " but attempted to take by force what was their master's before; for all we had was the sheikh's, and is still. By God's help my people overcame them, but that is nothing; I am to the sheikh, in point of strength, as an egg is to a stone: if he wishes peace, and will no more molest me in my wilds, peace be with us-I will give up his people, his horses, and his arms, that have fallen into my hands; if not, I will keep them all, and may be add to their number. We are not easily beaten : by the head of the Prophet, I can and will, if I am forced, turn fish, and fly to the centre of the water; and if the sheikh comes himself against me, I will bring Waday against him."

July 8.- The chiefs all refused to withdraw their forces on this offer of Amanook: they sent word that he was not to be depended on, so often had he deceived them. Nothing but an unconditional return of all the spoil would satisfy them. In a long conversation which I had with Barca Gana, whose wound was now fast healing from the dressing of burnt fat and sulphur, which I had applied, he assured me that they should not make another attempt on this bold chieftain : he, however, advised my returning to Kouka. "The excursion," said he, "you wish to make was always dangerous, it is now impracticable; we must wait for the sheikh's appearance before we can do any thing, and I think, from the advanced state of the season, as the rains have now begun to fall, you will find that the sheikh will not come, and that we shall all return."

By being ten days encamped* close to the frigue of the Dug-

- During the whole of this time both ourselves and our animals drank the lake water, which is sweet, and extremely palatable. 
ganah Shouaas, we had a better opportunity of observing these curious people : they were a superior class to any I had met with ; they were rich in cattle, and in camels, and seemed to live in plenty, and patriarchal simplicity. The sheikh had greatly encouraged their taking refuge with him on their disagreement with Waday, and had promised them protection, tribute free, provided they were faithful. Both the men and women were comely, particularly the latter, who, when they found that we paid for what we wanted in little bits of coarse karem (amber), with which I had provided myself, brought us, night and morning, frothy bowls of milk, which formed by far the best part of our repasts. There is something so curious and singularly interesting and expressive in the Shouaa manners and language, that I am at a loss how to describe it. A girl sits down by your tent with a bowl of milk, a dark blue cotton wrapper tied round her waist, and a mantila of the same thrown over her head, with which she hides her face, yet leaves all her bust naked; she says, "A happy day to you! Your friend has brought you milk: you gave her something so handsome yesterday, she has not forgotten it. Oh! how her eyes ache to see all you have got in that wooden house," pointing to a trunk. "We have no fears now ; we know you are good; and our eyes, which before could not look at you, now search after you always : they bid us beware of you, at first, for you were bad, very bad; but we know better now. How it pains us that you are so white!"

As we had not more than four days' provision, I determined on returning after another interview with Barca Gana : we left Tangalia, and returned to the spot where we had left the Biddomassy, and had scarcely pitched our tents when a storm came on, which lasted till midnight: but bad as it was, it was preferable to the stings of the musquitoes and flies which succeeded it. Notwithstanding we had fires inside the tent, which nearly stifled us, no sleep was to be obtained.

On the 11 th we arrived at Showy, after a very tedious march, 
and losing our way for three hours : the woods are, indeed, most intricate and difficult; and as all the Shouas had moved up towards Barca Gana, we could get no guides. We saw five giraffees (cameleopards) to-day, to my great delight; they were the first I had seen alive, and notwithstanding my fatigue and the heat, Bellal and myself chased them for half an hour: we kept within about twenty yards of them. They have a very extraordinary appearance from their being so low behind, and move awkwardly, dragging, as it were, their hinder legs after them : they are not swift, and unlike any figure of them I ever met with. Passing the Shary was attended with very great difficulty; the stream was extremely rapid, and our horses and camels were carried away from the sides of the canoe, to which they were lashed: we lost a camel by this passage ; these animals have a great dislike to water, and after swimming a stream are often seized with illness, and are carried off in a few hours.

July 12.-Left Showy, and once more found ourselves at Maffatai. The rest, and fish bazeen, with which we were here regaled, with the deep shade of Burmah's spacious mansion, greatly recovered us. The skin of my face all came off, and I slept nearly the whole day after our arrival : the sun, rain, flies, and musquitoes, altogether had fatigued me more than any former journey.

On the 15 th we pursued our route homeward by a new course, and haited close to the Gambalarum, on the ground the Begharmis had escaped over, after their rencontre with the sheikh : the ground was strewed with skeletons.

July 16.-After a long and fatiguing march we reached some Felatah huts, about sunset. The water, after crossing Maffatai, is all sad muddy stuff; and the nearer you approach Angornou, the blacker the soil is, and the worse it becomes. We to-day crossed the Molee, a small stream which runs to the Tchad. The whole of this road, indeed the whole country from Angala, is an inclined

N N 
plane towards the Great Lake, and during the rains it is impassable: they were now every where sowing their grain, and in many places they were reaping the Indian corn. Since leaving Maffatai, we had nothing besides a little rice, to which I added a duck or two, which I made it part of my business to search after, and shoot.

July 17.-We this day reached Angornou, very much fatigued with our journey; we had a drenching night of it, and crept into our friend Abdi Nibbe's hut, with great joy: the worst of these storms were that they spoiled the only meal we could get time to cook in the twenty-four hours; and our tents, which rarely withstood the blasts, on falling, exposed all our stores as well as ourselves to the pelting of the storm.

On my arrival again at Kouka I found that Captain Clapperton, with a small kafila, had returned from Soudan : it was nearly eight months since we had separated, and although it was midday I went immediately to the hut where he was lodged; but so satisfied was I that the sun-burnt sickly person that lay extended on the floor, rolled in a dark blue shirt, was not my companion, that I was about to leave the place, when he convinced me of my error, by calling me by my name : the alteration in him was certainly most striking. Our meeting was a melancholy one: he had buried his companion, and I had also closed the eyes of my younger and more robust colleague, Mr. Toole. Notwithstanding the state of weakness in which I found Captain Clapperton, he yet spoke of returning to Soudan after the rains.

July 28. - I had now determined on proceeding by Woodie to Kanem, and approaching as near as possible to Tangalia, the spot where I had left Barca Gana, when I had passed by the southern extremity of the lake; and if I succeeded, and returned before the departure of the kafila after the Aid Kebir, I fostered a hope of retracing my steps across the desert, with all the satisfaction of a man 
who had accomplished to the full the duties that had been assigned him. Yagah Menamah, the chief eunuch of the sheikh's favourite wife, came to me soon after daylight, and presented me with two kansara, or fly-flappers, made of the tail of the camelopard; and in her name said that she had burnt salt for my departure, praying that neither the devil nor any of his imps might be able to play me any malicious tricks on my journey. The sheikh had consented to Mr. Tyrwhitt's remaining as consul: and on my inquiring whether he would protect one or two English merchants, if they came to his country-"Certainly: why not?" said he, " and assist them to the extent of my power; but they must be small traders, or the journey will never pay them." He expressed his wish to write to the king, and added, " whatever I can do in Soudan, remember I am ready. I have influence there certainly, which may increase, and probably shortly extend to Nyffe. As to yourself, I shall write to beg the king will send you here, with any English whom he may wish to visit Bornou. You are known, and might now go any where in Bornou without fear. Even the Shouaas on the frontiers, and the Duggenah, all know Rais Khaleel: but this has not been done hastily; you have been nearly eighteen months amongst us, and you remember when you could not go to Angornou without inconvenience. I then thought you would never be as much at liberty here as you are. Time and yourself may be thanked for this, not me; for I could not, by any orders I might have given, have done for you what your mixing freely with the people, and gaining their good will, has brought about-and yet you are a Christian !"

July 30.-This morning the sheikh sent to Mr. Clapperton, Mr. Hillman, and myself, as a present, a very fine camel, a horse, and two water-skins, two leopard skins, and two dressed-leather sacks. In the course of the morning another cargo was brought to me, consisting of eight elephants' tusks, with the horns of three other 
animals. The horns were, first, the maremah, a long horn similar to one I had seen at Kabshary - the animal has two, bending backwards at the point; kirkadan, a two-horned animal; another animal, with one long horn and a second shorter just above it, nearly between the eyes of the animal, was described to me as having, on the sheikh's late expedition to Gulphi, carried a man and horse, spiked on his horn, more than one hundred yards, when, frightened by the cries of the people, he dropped them, and made his escape: the man was unhurt, but the horse died.

Aug. 6.-This was the Aide Kebir, the principal feast of the Mussulmans during the year, in commemoration of God's staying the hand of Abraham in the place Jehovah-jireh, when about to sacrifice his son Isaac: all who can muster a sheep or a goat kill it on this day, after prayers. The sheikh sent the day before, to know if we kept the feast; and when we met, repeated his question. I replied, that we believed the interposition of the Divine Power in saving Isaac to be a signal proof of God's mercy and love to all his creatures ; for remember," said I, " he is the God of many, not of Mussulmans alone ; and that our father Abraham's great and implicit faith in the existence of that mercy, was what obtained for him all the blessings God promised him."

He sent us two very fine sheep, and we killed and feasted with the rest. Early in the morning, the sheikh, with his sons and all his court, mounted, according to custom, to welcome the Aid, by praying outside the town, and firing and skirmishing on their return : the assembly was not so large as on former occasions, in consequence of the absence of the chiefs in Kanem; indeed every thing went off extremely flat, owing to the defeat of the sheikh's people. Contrary to custom, no presents were made by him, and no dresses were distributed to the slaves: instead of the glossy new tobes which on. former occasions shone on the persons of the footmen who ran by 
the side of his horse, they were now clothed with torn, discoloured ones, and every thing wore the appearance of gloom and disgrace. On these days, the custom is also for the women to assemble, dressed in all their finery, in the street, before the doors of their huts, and scream a salutation to the passing chiefs : it was one of the best parts of the ceremony, but this year it was omitted. The sheikh, whose unamiable trait was, as I have before observed, visiting the weaknesses of the female part of his subjects with too great severity, had, during my absence, given an order which would have disgraced the most absolute despot that ever sat on a throne: the gates of his town were kept shut at daylight one morning, and his emissaries despatched, who bound and brought before him sixty women who had a bad reputation; five were sentenced to be hanged in the public market, and four to be flogged; which latter punishment was inflicted with such severity, that two expired under the lash. Those who were doomed to death, after being dragged, with their heads shaved, round the market on a public day, with a rope round their necks, were then strangled, and thrown, by twos, into a hole previously prepared, in the most barbarous manner. This diabolical act, for it deserves no better name, armed all tongues against him. The Bornouese, who are a humane and forgiving people, shuddered at so much cruelty : and so much influence had the ladies in general with their husbands, that more than a hundred families quitted Kouka, (to which place they were before daily flocking), to take up their abodes in other towns where this rigour did not exist. In Kouka, they declared there was no living, where only to be suspected was sufficient to be doomed to a cruel and ignominious death; and where malicious spies converted " trifles light as air, into confirmation strong." Those who remained, though the women of his particular attendants, refused flatly to scream him a welcome, and the pro. cession passed through the streets in silence. 
Aug. 7.-I was now on the eve of departing for Kanem, to proceed by Woodie to the north-east of the lake. Mr. Clapperton had been ill with sore legs and an attack of dysentery, but was better. Mohammed Bousgayey, an Arab, who left this place with Doctor Oudney and Mr. Clapperton, came to my hut : he had gone on from Kano, with four or five Arabs, to Yeouri and to Nyffe, and had stayed some time at a place called Gusgey on the Quolla, two days west-south-west nearly, from Yeouri. The Quolla he described to be here as wide as to the market outside the walls and back, which must have been nearly two miles: they were all kaffirs, he said, but not bad people. The sultan Mahmoud had several hundred guns, and powder, which were brought from the bahr kebir (great water), and arrack (rum), in plenty; which was brought in large glass bottles. At eight days distance only from Yeouri, large boats came to a place called Yearban, but it is not on the bahr kebir. Katungah is the great port, which is at some distance: to both of these places people he called Americans came; they were white, and Christians : they always demand gum arabic and male slaves, for which they will pay as high as sixty and seventy dollars each. Sultan Mahmoud produced to him two books, which he said were like mine; and told him, that a man, whose beard was white, had lived nearly three years with no money; that he wished to go, but had no means, and that he died. Bousgayey said the sultan had offered him the book; which he refused, as he did not know what he could do with it; but that now he was going back, and should bring it.

In the afternoon we went to pay our respects to the sheikh, in honour of the feast. He received us but coolly: and I was scarcely seated on the sand, when I saw near me a little shrief from Marocco, named Hassein, who, though once or twice our friend, I was always in fear of, being aware both of his cunning and his influence. Almost the first question of the sheikh's was, as to the distance of our 


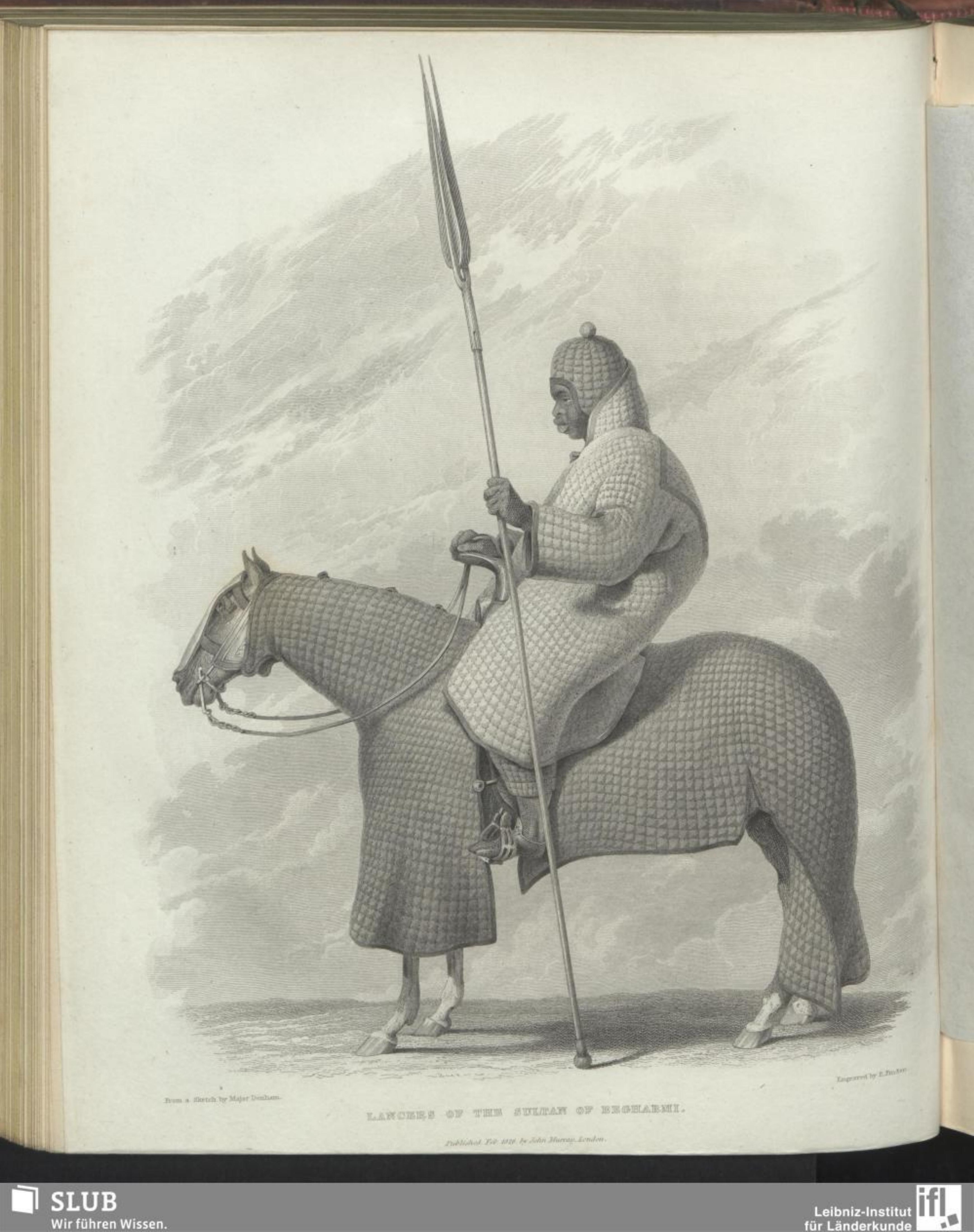


country from India: and when told it was four months by sea, he said, "What could induce you to go so far from home-to find it out, and fight with the people?" We replied, " that we had plenty of ships, and were great lovers of discovery; that the French and the Dutch had been there before us ; and we were always jealous of our neighbours doing more than ourselves." "And now it is all yours," said he, " and governed by your laws !" Our reply was, "that we only kept possession of the part near the sea-that their own laws were in full force-but that even Mussulmans often preferred the English laws to their own." Wonderful!" said he, " and you went at first with only a few ships, as friends?" "We are friends now," said I, " and by trade have not only made ourselves rich, but the natives also." "By God!" said the Marroquin, " they eat the whole country - they are no friends : these are the words of truth." We had then a few remarks (not good-natured ones) as to the right of dictating to Algiers and the other Barbary powers. Algiers we described as unfaithful to their word, and little better than pirates.

Aug. 11.-Soon after daylight, Karouash, with Hadgi Mustapha, the chief of the Shouaas, and the sheikh's two nephews, Hassein and Kanemy, came to our huts. Hadgi Mustapha had been one of the original four hundred who commenced the liberation of Bornou from the Felatahs. They were attended by more than a dozen slaves, bearing presents for us, for King George, and the consul at Tripoli. I had applied for a lebida*, after seeing those taken from the Begharmis: the sheikh now sent a man, clothed in a yellow wadded jacket, with a scarlet cap, and mounted on the horse taken from the Begharmis, on which the sultan's eldest son rode. He was one of the finest horses I had seen; and covered with a scarlet

- Horse covering. 
cloth, also wadded. "Every thing," Hadgi Mustapha said, "except the man, is to be taken to your great king." He also brought me twelve very beautiful tobes, of every manufacture, from Nyffe to Loggun and Waday, four parrots, and a box of zibet. For the consul he also sent six tobes, and a small box of zibet, worth thirty or forty dollars, with two parrots.

August 13.-The long expected kafila arrived from Soudan, which was a signal for our departure : they had been fifty days on the road from Kano, in consequence of the waters; and had they been delayed much longer, the season would have been so far advanced as to have prevented the departure of all those merchants that had many slaves : going, as they do, poor creatures, nearly naked, the cold of Fezzan, in the winter season, kills them by hundreds. With the Soudan kafila came Khalifa, a Moor and a fighi; he had been at Saralo, as he called Sierra Leone, and desired to be brought to me, as he knew English. He certainly knew enough to convince me of his truth, when he asserted that he had met my countrymen. "Gun, cap, and water !" he kept continually saying: and my Bornou friends were not a little surprised when I told'them it was the language of my country. He spoke greatly of some person he called the Doctor*, whom he had seen at Bammakoo and Bunjalow, a good looking man, with a red beard, and long projecting nose, with bad front teeth. He gave away many things, wrote a great deal, and was much liked by all the people. Two persons were with the Doctor, whom he believed were French, and had come from Ender; one was called Gentleman, and the other Fausta, or Forster ; " but they held their heads down, and did not talk to the people like the Doctor," said Khalifa. " "The Doctor," he said, " wanted to go to Sego, but the sultan would not allow him to come to his country,

* This was, no doubt, Doctor Docherd, sent by Major Gray. 
and would not even look at the presents he sent him, as he feared they had charms which would kill him, either by the sight or smell. He, however, sent him slaves, and horses, which he, the Doctor, also returned, saying that he wanted nothing but to see the country and the rivers. The sultan of Sego replied, he had heard that his (the doctor's) king had water all round his country, and he might go and look at that. Khalifa said the Sego people were Kaffirs, and knew not God, therefore were afraid of Christians; but the Moors knew them, and liked them. When the present king of Sego's father was alive, he, Khalifa, then a boy, remembered Christians going to D'Jennie and Timboctoo, and hearing that the Tuaricks killed them in their boat near Nyffe"*."

On Monday, the 20th of the Mohamedan month del Khadi, and the 16th of August, we took our final leave of Kouka, and not without many feelings of regret, so accustomed had we become, particularly myself, to the people. In the morning I had taken leave of the sheikh in his garden, when he had given me a letter to the king, and a list of requests: he was all kindness, and said he had only one wish, which was that I might find all my friends well, and once more return to them. He gave me his hand at parting, which excited an involuntary exclamation of astonishment from the six eunuchs and Karouash, who were the only persons present.

- This man informed me that Timboctoo was now governed by a woman, a princess, named Nanapery: this account was confirmed by Mohammed D'Ghies, after my return to Tripoli, who showed me two letters from Timboctoo. He also gave me some interesting information about Wangara, a name $\mathbf{I}$ was surprised to find but few Moors at all acquainted with. I met with two only, besides Khalifa, who were able to explain the meaning of the word: they all agreed that there was no such place; and I am inclined to believe the fol. lowing account will be found to be the truth. All gold countries, as well as any people coming from the gold country, or bringing Goroo nuts, are called Wangara. Bambara is called Wangara. All merchants from Gonga, Gona-Beeron, Ashantee, Fullano, Mungagana, Summatigilia, Kom, Terry, and Ganadogo, are called Wangara in Houssa; and all these are gold countries. 
I preceded the kafila for the following reason: I had, ever since my return from Tangalia, determined to attempt the east side of the Tchad, by Lari, previous to returning home. Many had been the objections, many the reports of danger from the Waday people and Amanook, who had now boldly forsaken the lake, and was encamped at no great distance from Barca Gana, to whom he twice paid a night visit, and had been beaten back. I, however, told the sheikh I could take no present, or promise to the execution of any commission, unless this duty was accomplished, or at least until I had done my utmost, and that I would take care not to go into danger. Bellal, my old companion, was once more appointed to attend me, and we moved with two camels, lightly laden; for the more train, always the more trouble and the more expense. All my friends then in Kouka mounted to escort me from the town: the women assembled outside the gate, and screamed an adieu; and I am persuaded our regrets were mutual.

About midnight, while we were all asleep at Dowergoo, a despatch came to say, that the skin of a camelopard had been brought to Kouka, which the sheikh had procured for me. Columbus, therefore, returned to prepare it for preservation, while we moved on to N'Gortooah: he came up again in the evening, and reported, that though small, it was a fine specimen. On Wednesday we slept at Kaleeluwha, and on the 23d came once more on the Yeou, now a considerable stream, full of water, and running towards the Tehad, at the rate of three miles an hour*. My feelings on seeing this river for a second time were very different to what they had been

- An intelligent Moor of Mesurata again told me, this water was the same as the Nile; and when I asked him how that could be, when he knew that we had traced it into the Tchad, which was allowed to have no outlet, he replied, "Yes, but it is nevertheless Nile water-sweet." I had before been asked if the Nile was not in England; and subsequently, when my knowledge of Arabic was somewhat improved, I became satisfied that these questions had no reference whatever to the Nile of Egypt, but merely meant running water, sweet water, from its rarity highly esteemed by all desert travellers. 
when I first looked on its waters. We then had an escort of two hundred men, and yet could not feel ourselves in perfect safety one hundred yards from our tents. Now I had only one attendant-the people about me were all natives, and I wandered about the banks of the river with perfect freedom, and slept with my tent door open, in as great security as I could have done in any part of England, had I been obliged so to travel. Other feelings also obtruded themselves; I was about to return home, to see once more dear friends, and a dear country, after an absence of nearly three years, on a duty full of perils and difficulties: two out of four of my companions had fallen victims to climate and disease, while those who remained were suffering, in no small degree, sickness and debility from the same causes: I was in health, and notwithstanding the many very trying situations, in which we had all been placed, some of them of great vexation and distress, yet had we been eminently successful.

In the afternoon Bellal accompanied me down the river, about nine miles, where, increasing in width to about one hundred yards, it flows into the Tchad, with a strong and deep current of water. On its banks are five considerable villages of Kanemboos, called Ittaquoi, Belagana, Afaden, Yeougana, and Boso. At Belagana, the sheikh has a large inclosure of huts, within a wall, where he generally has from five hundred to eight hundred slaves of both sexes, under the charge of four eunuchs, who are employed in preparing cotton, and spinning the linen (gubbok), of which the tobes are made.

The manner of fishing in the Yeou, a very considerable source of commerce to the inhabitants of its banks, must not be omitted: dried fish from the Yeou is carried to all the towns to the southwest, quite as far as the hills; and at this season they are usually taken in great numbers. The Bornouese make very good nets of a twine spun from a perennial plant called kalimboa: the implements for fishing are ingenious, though simple: two large gourds are

$$
\text { ०0 } 2
$$


nicely balanced, and then fixed on a large stem of bamboo, at the extreme ends; the fisherman launches this on the river, and places himself astride between the gourds, and thus he floats with the stream, and throws his net. He has also floats of cane, and weights, of small leathern bags of sand: he beats up against the stream, paddling with his hands and feet, previous to drawing the net, which, as it rises from the water, he lays before him as he sits; and with a sort of mace, which he carries for the purpose, the fish are stunned by a single blow. His drag finished, the fish are taken out, and thrown into the gourds, which are open at the top, to receive the produce of his labour. These wells being filled, he steers for the shore, unloads, and again returns to the sport.

25th.-At Woodie I met Barca Gana, Ali Gana, and Tirab, with their forces, on their return from Kanem : they had been out, some of them five months, had made the complete tour of the lake, and were in a sad plight, with scarcely thirty horses left, having literally fought their way : Amanook had twice attacked them, and had sent off all his flocks and women to Begharmi, but had not gone himself, and they were so reduced as not to be able to do any thing to prevent him. They were so badly off for every thing, that they were obliged to come down on Kanem for supplies: the people refused them any assistance, and after being half starved, they were obliged to make a running fight of it, and get home as well as they could. The Kanem people were all in a state of mutiny, and the Dugganah had gone off towards Waday. This was sorry news; Bellal wanted to turn back. I saw Barca Gana, who said, " It is dangerous, but I think you may go on if you wish it. I would give you eighteen men, but you are better without them: they expect the sheikh, and going with Bellal, wanting but little, and paying for that, for the crops have failed them, you will have little to fear; but you cannot go beyond the Bornou Kanemboos with less than one hundred men." 


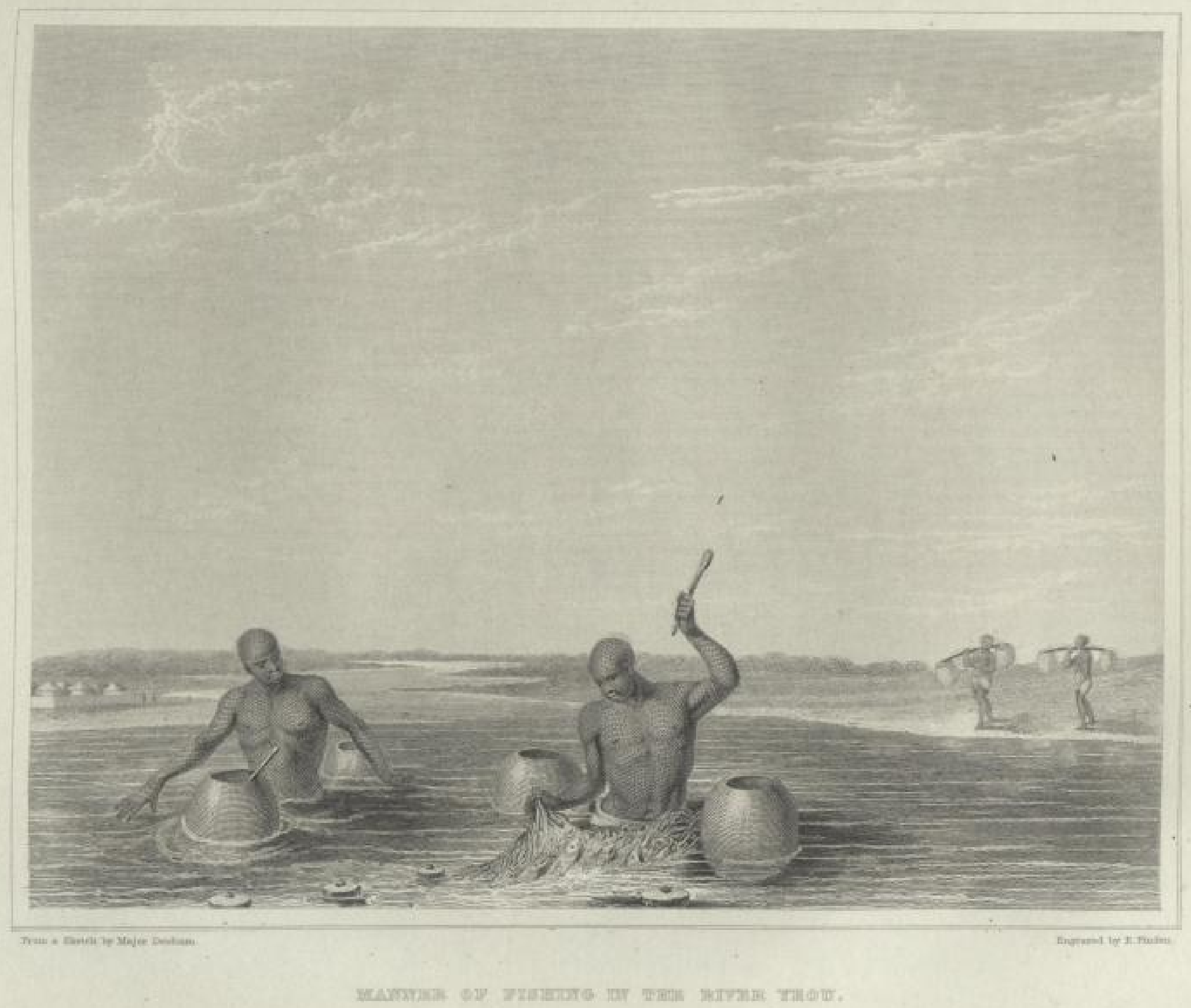

\section{SLUB}

Wir führen Wissen.

Leibniz-Institut für Länderkunde 


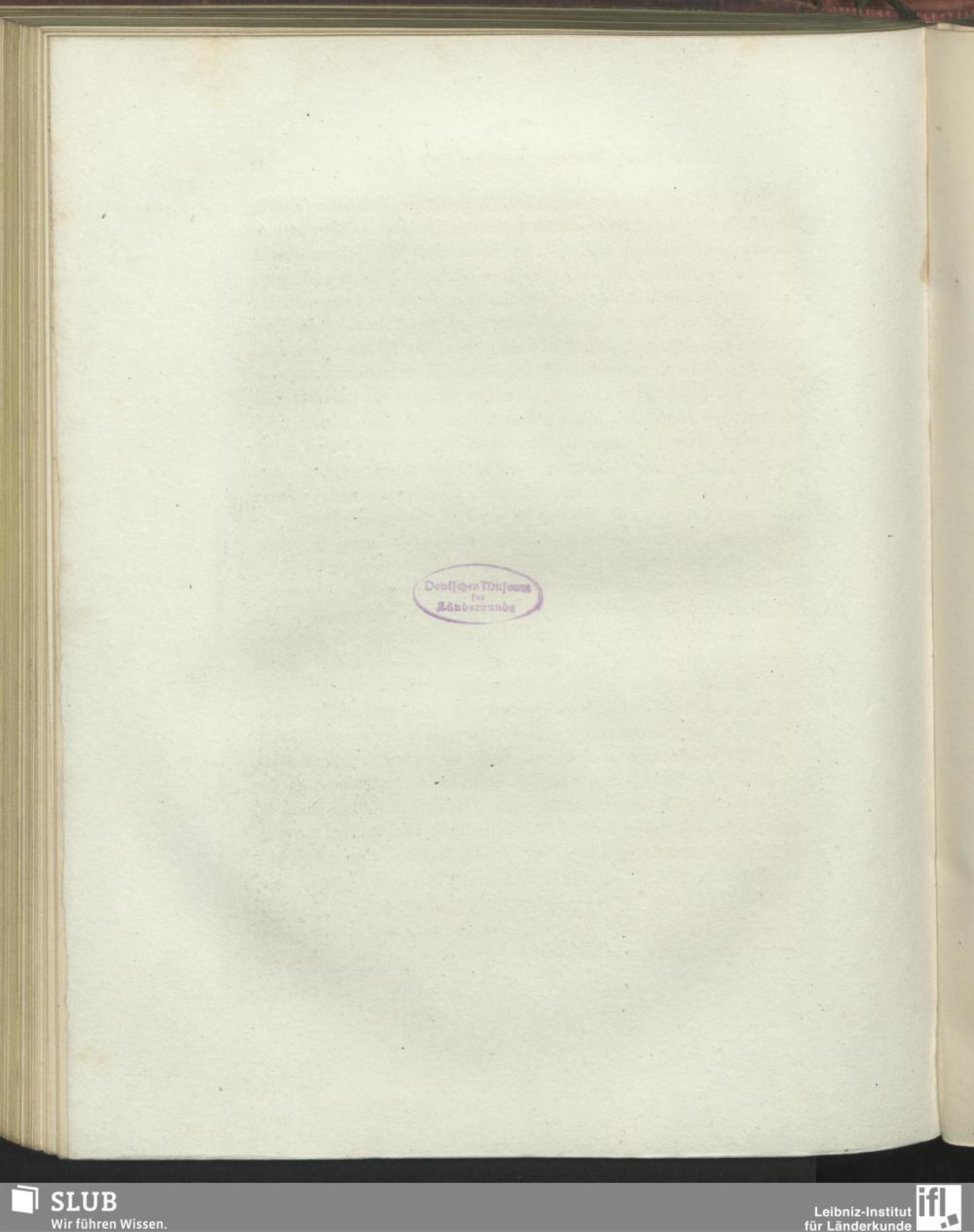


With this advice I determined on going on, and after halting the whole of Sunday, on the 27th I proceeded. Barca Gana had, on his return, bivouacked in the wadey where once the Bahr-al-Ghazal ran from the Tchad; the valley is now filled with trees and grass. This was the fourth time Barca Gana had raised his tents in the same place*, as the sheikh had before informed me. This valley runs between Kangara and N'Gussum, less than twenty miles from Tangalia. We were overtaken by so dreadful a storm, that we halted, and pitched the tent on a high sand-hill within five miles of N'Gygami. Near this hill we had a beautiful view of the open lake, with several floating islands, when the storm cleared away. The Biddomahs are constantly landing hereabouts; and we met some poor people who had been robbed of their whole flock of goats, with their daughter, only the day before-indeed no single travellers can pass this road. Towards evening, we saw their canoes in the offing; and below us, in the low grounds, three Biddomahs making for the lake:-they saw us, and quickened their pace. For safety we all slept outside the huts of N'Gygami: this ground is the highest part of the borders of the lake, and here deep water commences immediately off the shore, while, in some parts, miles of marsh are to be waded through previous to arriving at the lake. Tuesday, we made Lari, where we were to find a Malem fighi, whom the sheikh had ordered to proceed with us.

Aug. 29.-Moved from Lari. Here we found four men, with a chief whom Barca Gana had left at Kuskoua, returning, as the people would give them no provisions. It was near sunset when we reached Zogany, thirty miles; the country was quite a flat, covered with a plant resembling a heath which I had seen nowhere else; and

- Each time Barca Gana had encompassed the lake, he had with him a force of from four hundred to eight hundred cavalry; the passage of a river, therefore, or rumning stream, could never have escaped his observation. 
in many parts I observed incrustations of trona. This heath is called kanuskin: the camels eat it; and in the neighbourhood of trona it is generally found.

Aug. 30.-After a night of intolerable misery to us all, from flies and mosquitoes, so bad as to knock up two of our blacks, we mounted and advanced; and leaving our tents, for Bellal would not carry them on, we proceeded to Garouah and Mabah;-which are full of people, and though annually pillaged by Tuaricks and Tibboo Arabs, yet still they will not quit their native soil. The character of the country here, which is different to the south or west sides of the lake, extends to Gala, where the land is again varied, and a little higher: for many miles on this side we had one continued marsh and swamp. I was at the northernmost part of the lake, and pursuing a course first to the west, and then to the eastward of south, for five or six miles, nearly up to the body of the horse in water, and with reeds and high grass overtopping our heads, I at last got a sight of the open lake. We disturbed hippopotami, buffaloes, enormous fish, and innumerable hosts of insects. At the commencement of the water it had a taste of trona, which, as we advanced, became gradually sweeter: indeed, all the people say, when you ask if this water you drink so strong of trona is the lake? La! la! inki kora kora kitchi engobboo tilboo baco. (No! no! the water of the great lake is very sweet, no trona).

Completely fatigued, we returned to the village of Chirgoa, near which our tents were pitched: this was a most distressing day, and we had been on our horses nearly thirteen hours. Garouah is twelve miles from Zogany, and Mabah twenty. We were some way in advance of the latter, but to Kuskoua I could not induce my guide to venture; and so many proofs had I seen, not only of his bravery, but his desire to satisfy my curiosity, that I could not doubt his fears were just. Notwithstanding our fatigue, no rest could we obtain, and another night was passed in a state of suffering and 
distress that defies description: the buzz from the inseets was like the singing of birds; the men and horses groaned with anguish; we absolutely could not eat our paste and fat, from the agony we experienced in uncovering our heads. We at last hit upon an expedient that gave us a little relief: as they came at intervals, in swarms, we thought they might also be driven off in the same quantities; and we found, by occasionally lighting a line of fires with wet grass, to windward of our tents, that the smoke carried off millions, and left us a little at ease. I do not think our animals could have borne such another night; their legs and necks were covered with blood, and they could scarcely stand, from the state of irritation in which they had been kept for so many hours.

On Friday we returned to Lari by the lower road, where there are frequent large detached pieces of water, strongly impregnated with trona. On the road, to-day, we fell in with a tribe of the Biddomah, who had, during the last three months, taken up their abode on the sheikh's land, and asked for what was instantly granted them, permission to remain. Internal wars cause these fallings off of one tribe from another, which the sheikh encourages: only one of their chiefs could ever be induced to proceed so far as Kouka. The sheikh takes no notice, and suffers them to do as they please: he sent them tobes, and a fighi, and desired they would learn to pray : and they are now beginning, as my guide said, to have the fear of God. They were the most savage beings I had seen in the shape of men, except the Musgowy; and we had sat some time under a tree before they would come near us. The men, until they are married, wear their hair, and collect as many beads and ornaments as they can, which they wear round their necks; their hair is long and plaited, or twisted in knots; they have ear-rings also : and this collection of beads and metal is always given to the wife on their marriage. The upper part of the face is very flat, and the eye sunk; they have large mouths, and long necks; a sulky, reserved look 
about them, any thing but agreeable: they have no style of salutation like other negroes, who greet strangers over and over again, sitting down by them:- these stand up, leaning on a spear, and look steadfastly at you without speaking. I gave a little boy some white beads, which were directly tied round his neck, I suppose as the commencement of his marriage portion. They, however, at length, produced some sour milk; and some of them came round my horse when I mounted, and nodded their heads at me when I rode off, which I returned, much to their amusement.

When we arrived at Lari, which was comparatively free from flies, the horses lay down, and, stretching themselves out, fell asleep in a way, and with an expression of enjoyment, I never saw animals do before, and did not look for their nose-bags until after midnight. We here found that one of Barca Gana's people had the night before lost his horse, which had been stolen by the Biddomahs we saw on the look out.

Kanem, the most persecuted and unfortunate of negro countries, was daily becoming more miserable; they were pillaged alternately by the Fezzaneers, the Tuaricks, and the Waday people. Between the latter and the sheikh they hung for protection, and from neither could they obtain what they sought: the country was becoming abandoned, and the villages deserted, part taking refuge in Waday, and part in the sheikh's dominions: the land communication between Bornou and Kanem was too difficult and distant, either by the south or north, for the sheikh to render them any effectual support.' An army almost every year went to Kanem for this purpose, but they usually returned with the loss of horses, camels, and men, and were seldom able much to annoy their enemies, the Wadays. This year his expedition had been upon a larger scale, and his losses were greater than on any former occasion.

In consequence of the waters, which fill the rivers at this season, the ford across the Shary had become impassable, and they were 



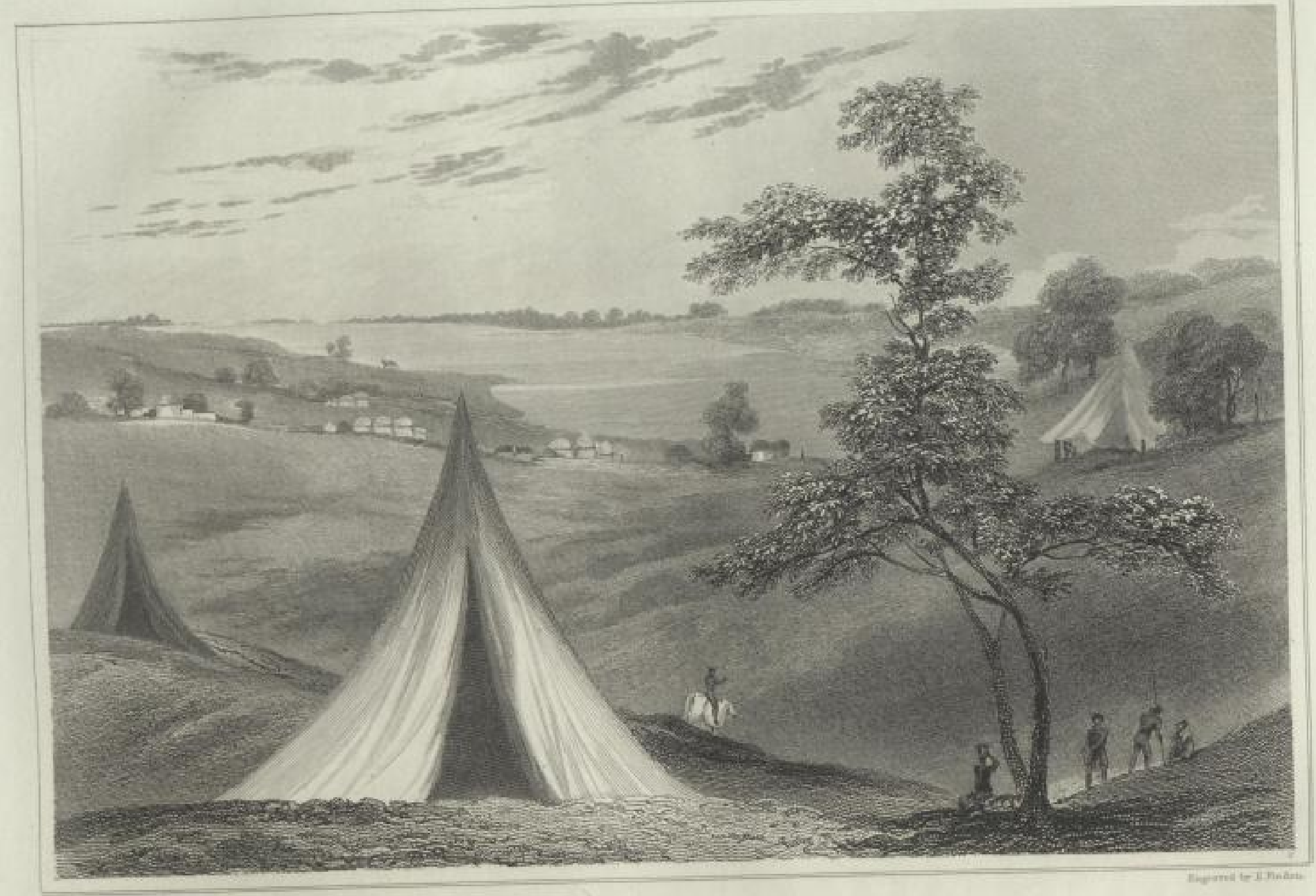

3.

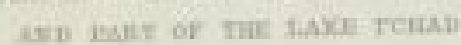

7 SLUB

Wir führen Wissen.

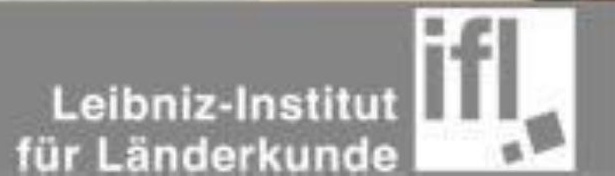


therefore obliged to return home through Kanem. Not the least assistance would any of the towns give them, except Gala, and a more wretched state I never saw men in: some of the chiefs on foot, without horses; and those who were mounted, bestriding sorry animals, with torn appointments : they all said, fighting without the sheikh was useless, as he alone could lead them to victory.

Sept. 3.-I had now been six days at Woodie, waiting the arrival of my companions with our camels, and the kafila of merchants whom we were to accompany to Fezzan. Woodie is no very pleasant place of sojourn, as the Biddomah have a sort of agreement with the kaid to be allowed to plunder all strangers and travellers, provided the property of the inhabitants is respected. We were, however, told to be on our guard, and not without reason. Our tents were pitched near each other, and a look-out kept up the whole night, notwithstanding which they paid us a visit, during a storm of thunder and rain, and from the entrance of Bellal's tent, only eight paces from my own, stole both his horses. Although six or seven negroes were sleeping quite close to them, they got completely off, and had an hour's start before even the loss was discovered. Bellal pursued them, with about a dozen people, quite to the lake, tracing their footsteps in the sand, which was not difficult after the rain; but finding here that they had embarked, the pursuit was given up.

At length, however, on Tuesday the 14th, we had assembled our kafila, and we moved on towards the desert: on the $22 \mathrm{~d}$ of September, in the afternoon, we halted half way to the well of Beere Kashifery.

Sept. 23.-We made the well soon after mid-day; and fortunately for us we brought some water with us, for the power of our friend Mina Tahr here began to appear. This well was guarded, and we were told, that until the sheikh Mina appeared, not a drop was to be drawn. It required some exertion of patience and forbearance, 
in a sultry oppressive day, with the thermometer at $110^{\circ}$ in the tent, to be obliged to drink muddy water from goat skins, when a well of the best water between Kouka and Bilma was under our feet: but we were inured to hardships and contradictions, and submitted, I hope, like good Christians. Towards evening the Tahr appeared on the hills to the north-west, attended by his troop: he seemed vastly glad to see us; said " the well was ours-that our water-skins should be filled, and camels watered, before any body, and for nothing; and then," said he, "sultan George the Great must be obliged to Mina Tahr, the wandering chief of Gunda, and that will give more pleasure to Tahr's heart than payment : and who knows," said he, "but when sultan George hears this, he may send me a sword ?"

Sept. 24.-In consequence of the number of camels to be watered, and the large flocks of the Tibboo, it was not until the evening that our animals could drink; and even then we were almost obliged to take possession of the well by force. Our old Maraboot was struck by a spear, as well as our servants; and it was not until after I had mounted a horse and repaired to the well myself, accompanied by the Tahr, that we could complete this most important business of the day.

In the evening Tahr came for his present. I gave him a tobe from Soudan, a red cap, and a turkodie: the tobes and cap he looked at, and said, " Ah! this is very well for me; I am one, but my wives are three:- what shall I do with one turkodie?" Tahr now began a speech: he was greatly distressed that he had nothing to send sultan George. "By the head of Mustapha !" said he, "I consider him as much my master as the bashaw ;--ay and more-for you say he sent you to see me, which is more than the bashaw ever did. I can send him a tiger-skin, and I will write him a letter-for Tahr's enemies are never quiet, and he has no time to kill ostriches now. The well Beere Kashifery, whose waters are here like gold, and 
better than gold, and all that Kashella Tahr and the Gunda Tibboos have to give, shall always be, as long as he or his children govern, at the service of sultan George Inglesi." He now asked for water, and began washing the ink from a paper which had previously been ornamented with a charm, drinking the dirty water, and rubbing it over his head and neck: when this was finished, he laid the paper in the sun; and I was a little amused when I found, that it was on this dirty scrap that he intended writing to king George.

Sept. 25.-In the afternoon of this day we left Beere Kashifery, taking a very hearty leave of Tahr. In order to save my camels, who had seventeen skins of water to carry in addition to their loads, as we were to be four days on our road to Aghadem, I hired a maherhy to carry two heavy boxes to Bilma, for seven dollars. The moon, which was in its first quarter, assisted us after sunset, but we were obliged to move on for at least two hours after she had sunk quietly to rest. We halted for a few hours, at a spot called Geogo Balwy (honey spot), and a little after midnight proceeded on our dreary way. There was great difference of opinion as to our route, which, probably, by following our own back bearings, we might have found better ourselves: but we were not yet quite so bold in the desert as on the main; and I insisted on the Mina Hamedee, the guide whom the sheikh had given us, being allowed his own way, and my confidence was not misplaced. By daylight on Sunday we discovered the foot-marks of the camels and slaves of Hadge-Boo-Said, a Fezzan merchant, who had absolutely been in the right track, but had turned back, and gone southerly. Numbers now exclaimed that we were wrong: there appeared, however, no sort of timidity about our guide; he looked confident, and bore the abuse that was levelled at him on all sides, with great coolness : and there was a sort of conscious ability about him that determined me to rely completely on his judgment alone. No man is ever afraid of doing what he knows he can do well; and in most cases a sense of

P P 2 
power gives confidence: so it proved with my Tibboo. We continued travelling another night and day in these most dreary wastes, with nothing but the wide expanse of sand and sky to gaze upon.

On Monday the 27th of September, a little before noon, we observed something in the distance, which had the appearance of a body of men moving towards us; but from the effect of the mirage assuming different shapes, and sometimes appearing twelve or fifteen feet above the surface of the desert, the Arabs declared it to be a Tuarick party on the forage, and all our followers loaded and prepared for action. On their approach, however, we found to our great joy that it was a kafila from Fezzan: they had been as much alarmed at us as we at them, and were all formed, in front of their camels several hundred yards, in extended order, as the Arabs always fight: they gave us some Fezzan dates, which were a great luxury; and some of the traders who were short of water exchanged a jar of butter, worth at least two dollars, for every full skin they could so purchase. They told us the road was perfectly safe, although their fears of falling in with the Tuaricks had detained them seventytwo days on the journey from Mourzuk.

It is scarcely possible to convey an idea of the sensations of all parties on a meeting of this nature on the desert. The Arabs were equally alive to these feelings as ourselves; and, in their usual wild expressive manner, sang, for days after such a rencontre, ballads descriptive of the event*.

- The following lines may be taken as a sample, at least, if not a literal translation, of their poetical sketches on these ocean meetings.

THE Arab rests upon his gun,

His month of labour scarce begun

Of passing deserts drear:

Straining his eyes along the sand,

He fancies in the mist, a band

of plunderers appear. 
We halted at noon, at a place called Gassooma-foma. In the afternoon we moved again; and the guides told me that the road was so difficult that, until the moon fell, we should make the best of our

Again he thinks of home and tribe, Of parents, and his Arab bride

Betrothed from earliest years:

Then high above his shaven head, The gun that fifty had left dead

Rallies his comrade's fears.

"Yeolad boo! yeolad boo!

"Sons of your fathers! which of you

"Will shun the fight and fly ?"

They rush towards him, bright in arms,

Thus calming all his false alarms

By promising to die.

The sounds of men, as objects near,

Strike on the listening Arab's ear

Laid close upon the sand:

He hears his native desert song,

And plunges forth his friends among

To seize the proffered hand.

Asalam? Asalam? from every mouth;

What cheer? what cheer? from north and south,

Each earnestly demands :

And dates and water, desert fare,

While all their news of home declare,

Are spread upon the sands.

But, soon ! too soon! the kaflas move;

They separate again, to prove

How desolate the land!

Yet, parting slow, each seeks delay,

And dreading still the close of day,

They press each other's hand. 
way, and then rest. On these occasions we pitched no tents, but laid the boxes together; and, either with a little boiled kouskosou, or still oftener without, soon forgot our fatigues in sleep. When we saw the black ridge that extends along the wadey of Aghadem, the negroes, female slaves, and followers, set up screams of joy, and began dancing and singing with all their might. It was almost noon when we got to the well, and several slaves, belonging to an old Shouaa who was going to Hage, were speechless from want of water; yet they ran several miles to reach the well, like things distracted, with their mouths open, and eyes starting from their heads.

On the $2 \mathrm{~d}$ of October we left Aghadem, and by the help of a blessed moon we were enabled to travel until near midnight, without losing our way. A very sharp storm of wind from the east obliged us to halt; and we had scarcely time to shelter ourselves with the skins and boxes, before it came on with most disagreeable force: this detained us until daylight, when we rose from between the hillocks of sand that had formed on each side of us in the night.

We had the satisfaction throughout our journey to find, that, young as we were at desert travelling, yet we got on as well, if not better, than our companions; and though children of the soil, they always looked to us, instead of us to them, both for safety and protection, as well as for the direction of the route. It was noon on Thursday the 7th, when we made Zow, an oasis situated under some high black sandstone hills, where there is good water and ahgul in abundance for the camels, who had scarcely broken their fast since leaving Dibla. Zow is most appropriately named " difficult," from the road which leads to it-a frightful sandy waste of moveable sand hills, exceeding fifty miles. Some little girls, and children of the kafila, panting with thirst, augmented by fever and illness, were scarcely able to creep along the deep sand : the whip shaken over the head urged them on-for in justice it must be said, the Arabs use it but rarely in any other way-and not to urge them on would be still 
more cruel, for the resolution and courage of these poor things would never carry them through; they would lie down, and if sleep once overcame them, so as to be left behind, death would be inevitable.

Oct. 11.-We arrived at Bilma. Without the supply of dates, which are procured here, kafilas would often suffer extreme hunger, so scarce are provisions, and so difficult is the transport : all followers from hence agree to have one meal per day of dates, and one of flour and fat; while, previous to arriving at Bilma, they are obliged to have two of flour and fat. Slaves of poor merchants will for twenty days together be fed by a handful of dates, night and morning, and they generally thrive well on this nourishing food.

Oct. 15.-We laid in a stock of dates for the next fourteen days, and man and beast were nearly subsisted upon them : a camel-load is worth from four to five dollars ; they will, however, take camels' flesh eagerly instead of money, or Soudan goods at one hundred per cent. profit. Our tents were surrounded by daylight with women and men; the former to sell us their commodities, and the latter to look on.

Oct. 17.-We had another day of rest, and were pretty tranquil. The women came in throngs to our tents, and were willing to sell us corn and dates, for either dollars or Soudan tobes, at one hundred and fifty per cent. profit: two lean goats they asked me four dollars for; and for a sheep, six. A great deal of bustle was made about the settlement of the dispute with the Mesurata Arabs, and the Tibboo: "TheBook" was to be referred to, but HadgeMohammed Abedeen, the brother of the kadi at Mourzuk, would not open the leaves until the relations of the deceased swore to rest satisfied with his decision. This preliminary being arranged on Monday morning, the parties all assembled : the kadi, Hadge Ben Hamet, and Ben Taleb, the chief merchants of our kafila, were present : they found, by the Koran, that if any man lifts his hand higher than his shoulder, 
in a menacing attitude, though he should not be armed, the adversary is not to wait the falling of the blow, but may strike even to death. The law was, of course, in favour of the Arab, as he proved the Tibboo's having his hand, armed with a spear, raised above his head, when he shot him dead. On this being declared, the Arabs ran about, throwing their guns over their heads, shouting and, what we should call crowing, to such a degree, that I fully expected the Tibboos would be aggravated to renew hostilities.

Oct. 25.-From hence we were to proceed by a different route to that by which we went to Bornou : crossing, therefore, another part of the range, we moved until night, and halted in what appeared to us a beautiful oasis, under a ridge of dark sand hills. This spot of dingy fertility extended several miles to the west, and afforded us water, grass, and wood, for that and the two following days, which were to be passed in deserts. A few miserable inhabitants had fixed themselves here, for the sake of a small crop of dates, yielded by a few palms : they were all anxious to exchange the produce of their valley for a blue or a white shirt of the coarsest kind,-a luxury they were the more in want of from possessing no other clothing. This is by far the best road; soft sand gravel, instead of rough broken stones; and the kafilas prefer it on account of the wells. The oasis is called Seggedem. From hence, eight days' distance, is a Tibboo town, and by this road kafilas sometimes pass to Ghraat.

Oct. 26.-We left Seggedem after a blowing night, which either overset the tents, or buried them several feet in the sand. Towards evening we rested, and starting again at daylight, made the wells of Izhya by noon next day.

From El Wahr to Meshroo are three very fatiguing days without water, or a single vestige of verdure. We were not able to reach the well, and halted short of the Beeban el Meshroo, the pass leading to the well, nearly four miles. On Sunday, the 8th of 
November, we arrived at the well,- - watered our weary camels, and our more weary men, and again pursued our route until night, when we pitched westward of the well of Omhah; and after one more dreary day, at night (Nov.9th) we slept under the palm trees which surround Tegerhy, the most miserable inhabited spot in Fezzan, nay, in the world, I might almost say, and yet we hailed it with inexpressible joy, after the pitiless deserts we had passed.

The fatigue and difficulty of a journey to Bornou is not to be compared with a return to Fezzan: the nine days from Izhya to Tegerhy, without either forage or wood, is distressing beyond description, to both camels and men, at the end of such a journey as this. The camels, already worn out by the heavy sand-hills, have the stony desert to pass; the sharp points bruise their feet, and they totter, and fall under their heavy loads : the people, too, suffer severely from the scanty portion of provisions, mostly dates, that can be brought on by these tired animals,-and altogether it is nine days of great distress and difficulty. There is something about El Wahr surpassing dreariness itself: the rocks are dark sandstone, of the most gloomy and barren appearance; the wind whistles through the narrow fissures, which disdain to afford nourishment even to a single blade of wild grass; and as the traveller creeps under the lowering crags, to take shelter for the night, stumbling at each step over the skeleton of some starved human being, and searching for level spots on the hard rock, on which to lay his wearied body, he may fancy himself wandering in the wilds of desolation and despair.

On the day of our making $\mathrm{El} \mathrm{Wahr,} \mathrm{and} \mathrm{the} \mathrm{two} \mathrm{following} \mathrm{days,}$ camels in numbers dropped and died, or were quickly killed, and the meat brought on by the hungry slaves. Kafilas are obliged to rely on the chance of 'Tibboos and Arabs from Mourzuk hearing of their having passed the desert, and bringing them supplies; should these fail, many poor creatures must fall a sacrifice for the salvation of the rest. These bringers of supplies usually sell their dates and

Q Q 
corn to eager buyers, at about four times the price they could obtain for them in Fezzan; besides which, the merchants gladly hire their unburthened camels to quicken their passage to a better country.

A Tibboo trader, who was returning to his own country from Fezzan, gave me a gratifying proof of the confidence he was willing to place in the word of an Englishman. It was nearly night, and I was in front of the camels: he had dates to sell, and mine were expended, but I told him that my money was in my trunk, and that my camels were too tired for me to unload them : "God bless you !" said he, "why, I wish you would buy all I have, camels and all : I know who the English are! Are they not almost Mislem, and people of one word? Measure the dates, and go on :-pay the kaid at Mourzuk."

We here voraciously bought up a few bad onions, to give a little flavour to our insipid meal of flour and water; and soon after, the kaid brought me a sheep, the only one in the town, which we cut up and divided, so that we had a sumptuous meal about nine o'clock in the evening.

On Sunday the 14th of November, by easy journeys we reached Gatrone, which, before so miserable in our eyes, now really seemed a little Paradise; and the food which the old hadge who governs there sent us, of the same kind we before thought so unpalatable on our outward voyage, now seemed delicious. I literally got up at daylight to feast on a mess of hot broth and fresh bread, most highly peppered, and made as good a meal as ever I did in my life.

At Gatrone, as well as at Tegerhy, our tents were pitched in a palm grove, the trees shading us during the day from the sun-beams, and at night from the easterly winds: the gentle moaning of the breeze through its slowly-waving branches was to us a most pleasing novelty; and the noble, nutritious, and productive palm, seemed in our eyes fully to merit the beautiful lines of Abulfeda :

"The stately date, whose pliant head, crowned with pendent 
clusters, languidly reclines like that of a beautiful woman overcome with sleep."-Abulfeda Descr. Egypt, a Michaelis, p. 6.

To do them justice, the Fezzan people seemed as glad we were come back, as we were ourselves. "To go and come back from the black country! Oh, wonderful !-you English have large hearts !God bless you! - the poor doctor to die too, so far from home!Health to your head! it was written he was to die, and you to come back.-God is great!-and the young Rais Ali too! (Mr. Toole) -Ah! that was written also:-but he was a nice man-so sweet spoken. Now you are going home: well, good fortune attend you! How all your friends will come out to meet you with fine clothesand how much gunpowder they will fire away!"

At the mosque of Sidi Bouchier the usual prayer was offered for our safe arrival in our own country; and on the 21 st of November, Sunday, we made our entry into Mourzuk, and took possession of our old habitation.

Nov. 21.-All weleomed our return: we had bowls of bazeen and kouskosou night and morning, and visitors from daylight until long after sunset, notwithstanding we had no tea, coffee, or sugar, to regale them with, as on our former residence amongst them. The new sultan, Sidi Hassein, who succeeded Mustapha, had only arrived the day before us; and as he had entered in mourning on account of the death of the bashaw's wife, the Lilla Gibellia*, no rejoicings were allowed on the occasion : he however sent us two fat sheep, a large pot of olives, and two sacks of wheat; we had therefore a little rejoicing of our own. The two Lizaris, Mohammed and Yusuf,

- She was taken prisoner in an expedition against the people of Khalifa Belgassum, in the Gibel, by Bey Mohamed, who, though in love with her himself, was obliged to give her up to his father, who was struek with her eyun kebir (large eyes). She also loved the bey, but was obliged to give herself to the bashaw. This is said to have been the cause of the first disagreement with his father. She, by her influence, made Belgassum, her old master, kaid over eight provinces.

Q Q 2 
Captain Lyon's friends, were amongst the foremost to pay us attention, as well as old Hadge Mahmoud, who exclaimed continually, " Thank God, you are come back! - who would have thought it !how great and good God is, to protect such kaffirs as you are! Well! well! notwithstanding all this, I love you all, though I believe it is haram $(\sin ) . "$

Though many degrees nearer our own fair and blue-eyed beauties in complexion, when moderately cleansed and washed, yet no people ever lost more by comparison than did the white ladies of Mourzuk, with the black ones of Bornou and Soudan. That the latter were "black, devilish black," there is no denying; but their beautiful forms, expressive eyes, pearly teeth, and excessive cleanliness, rendered them far more pleasing than the dirty half-casts we were now amongst. A single blue wrapper (though scarcely covering) gave full liberty to their straight and well-grown limbs, not a little strengthened, perhaps, by four or five daily immersions in cold water; while the ladies of Mourzuk, wrapped in a woollen blanket, with an under one of the same texture, seldom changed night or day, until it drops off, or that they may be washed for their wedding; hair clotted, and besmeared with sand, brown powder of eloves, and other drugs, in order to give them the popular smell; their silver ear-rings, and coral ornaments, all blackened by the perspiration flowing from their anointed locks, are really such a bundle of filth, that it is not without alarm that you see them approach towards you, or disturb their garments in your apartments.

The bashaw was said to have had an engagement with the Arabs, who were in rebellion against him, and to have defeated them; after which they had fled all to the Gibel, which had been long the rendezvous of the disaffected; we therefore determined on our immediate departure, after having sold the six remaining camels, out of twenty-four, which I had brought with me from Kouka, for twenty-one dollars-sore backed miserables that they were! The 
Maherhies, though handsomer and more fleet, do not bear fatigue like the Salamy or Tripoli camels.

On the 12th of December we were ready for our departure, and on the 13th we took our leave, the sultan having given us an order, or teskera, on all the towns of Fezzan, for every thing we might stand in need of. The cold of Mourzuk had pinched us all terribly; and notwithstanding we used an additional blanket, both day and night, one of us had colds, and swelled necks, another ague, and a third, pains in the limbs-all, I believe, principally from the chillness of the air; yet the thermometer, at sunrise, was not lower than $42^{\circ}$ and $43^{\circ}$.

On the 18th we reached Sebha, and found our old friend, sheikh Abdallah-ben-Shibel, whose hospitality we had before experienced; with abundance of kouskousou and meat, with highly peppered broth, prepared for us. The daughter of my friend Abdallah, who was now married, and a mother, and to whom I had two years before given a very simple medicine but once, which she was convinced had cured her of the jaundice, sent me two very pretty straw fans for the flies; they were made of the date leaf, in diamonds, coloured red, black, and yellow; the red is produced by foor, or madder root; the yellow with dried onion leaves, steeped in water; and the black by nil, or indigo.

At Sebha, Timinhint, and Zeghren, we were fed with the best produce of their crisine. Omul Hena, by whom I was so much smitten on my first visit to this place, was now, after a disappointment by the death of her betrothed, with whom she had read the fatah just before my last visit, only a wife of three days old. The best dish, however, out of twenty which the town furnished, came from her; it was brought separately, inclosed in a new basket of date leaves, which I was desired to keep; and her old slave who brought it inquired, "Whether I did not mean to go to her father's house, and salaam, salute, her mother?" I replied, "Certainly :" 
and just after dark the same slave came to accompany me. We found the old lady sitting over a handful of fire, with eyes still more sore, and person still more neglected, than when I last saw her. She however hugged me most cordially, for there was nobody present but ourselves : the fire was blown up, and a bright flame produced, over which we sat down, while she kept saying, or rather singing, "Ash harlek? Ash ya barick-che fennick?"- " How are you? How do you find yourself? How is it with you?" in the patois of the country, first saying something in Ertana, which I did not understand, to the old slave; and I was just regretting that I should go away without seeing Omul-hena, while a sort of smile rested on the pallid features of my hostess, when in rushed the subject of our conversation. I scarcely knew her at first, by the dim light of the palm wood fire; she however threw off her mantle, and, kissing my shoulder (an Arab mode of salutation), shook my hand, while large tears rolled down her fine features. She said "she was determined to see me, although her father had refused." The mother, it seems, had determined on gratifying her.

Omul-hena was now seventeen: she was handsomer than any thing I had seen in Fezzan, and had on all her wedding ornaments : indeed, I should have been a good deal agitated at her apparent great regard, had she not almost instantly exclaimed, "Well! you must make haste; give me what you have brought me! You know I am a woman now, and you must give me something a great deal richer than you did before : besides, I am Sidi Gunana's son's wife, who is a great man; and when he asks me what the Christian gave me, let me be able to show him something very handsome." "What!" said I, " does Sidi Gunana know then of your coming ?" "To be sure," said Omul-hena, " and sent me : his father is a Maraboot, and told him you English were people with great hearts and plenty of money, so I might come." "Well, then," said I, "if that is the case, you can be in no hurry. She did not think so; and my little present 
was no sooner given, than she hurried away, saying she would return directly, but not keeping her word. Well done, simplicity! thought I : well done unsophisticated nature! no town-bred coquette could have played her part better.

After a day's halt, on the $22 \mathrm{~d}$ we moved to Omhul Abeed, distant only a few miles, where water and wood are collected for the desert between that place and Sockna, which usually, at this season, when the days are short and nights cold, occupies five or six days.

Dec. 25.-On our fourth Christmas day in Africa, we came in the evening to Temesheen, where, after the rains, a slight sprinkling of wormwood, and a few other wild plants were to be seen, known only to the Arabs, and which is all the produce that the most refreshing showers can draw from this unproductive soil. We had here determined on having our Christmas dinner, and we slaughtered a sheep we had brought with us, for the purpose; but night came on, before we could get up the tents, with a bleak north-wester; and as the day had been a long and fatiguing one, our people were too tired to kill and prepare the feast. My companions, however, were both something better: Hillman had had no ague for two days; and we assembled in my tent, shut up the door, and with, I trust, grateful and hopeful hearts, toasted in brandy punch our dear friends at home, who we consoled ourselves with the idea, were, comparatively, almost within hail.

The next day, before we had loaded our camels, a pelting rain came on, with a beating cold wind from the north-west, which pinched us severely; however, we started; but scarcely had we entered the wadey, at the approach to which we had passed the night, than the slaves kindled fires under the trees, round which, indeed, we all took shelter : they, however, poor creatures, complained bitterly; and as the camels had not eaten any thing for three days previous, we determined on suffering them to enjoy such 
pasturage as the wadey afforded, while we slaughtered our sheep, and kept the feast.

Every thing was so cold and damp, that the poor slaves, who accompanied our kafila, half-clothed as they were, crowded round the fires in preference to sleeping: they were, however, always gay and lively on the march, when the warm sun and exercise had given a little circulation to their blood; the Arabs, to do them justice, fed them to their hearts' content, and, even to this, we usually added something.

Arrived at Sockna, I was lodged in the house of Hadge Mohammed Boofarce, a place with four whitewashed walls and date beams; but by the help of a brass pan, and a hole in the ground, I managed to keep a pretty good fire, without much smoke. I had neither host nor hostess. The house was in the charge of one Begharmi slave, who had been twenty-four years in bondage: he was pleased greatly when he found that I had been near his home, and the names of some of the towns made him clap his hands with pleasure; but when I asked him whether he should like to return, he had sense enough to answer, "No! no! I am better where I am. I have no home now but this; and what will my master's children do without me? He is dead; and his son is dead: and who will take care of the garden for his wives and daughters, if Moussa goes?No! he is a slave still, and so much the better for him; his country is far off, and full of enemies. Here he has a house, and plenty to eat, thank God! and two months ago they gave him a wife, and kept his wedding for eight days." The siriah of a Sockna merchant, who had gone to Soudan, leaving her pregnant, had, by becoming a mother, gained her freedom, and taking Moussa for a husband, they were put in charge of his mistress's unoccupied house for a residence.

Jan. 5.-We left Sockna, passed El Hammam on the 6th, slept in Wadey Orfilly, and on the morning after, Mr. Clapperton and my- 




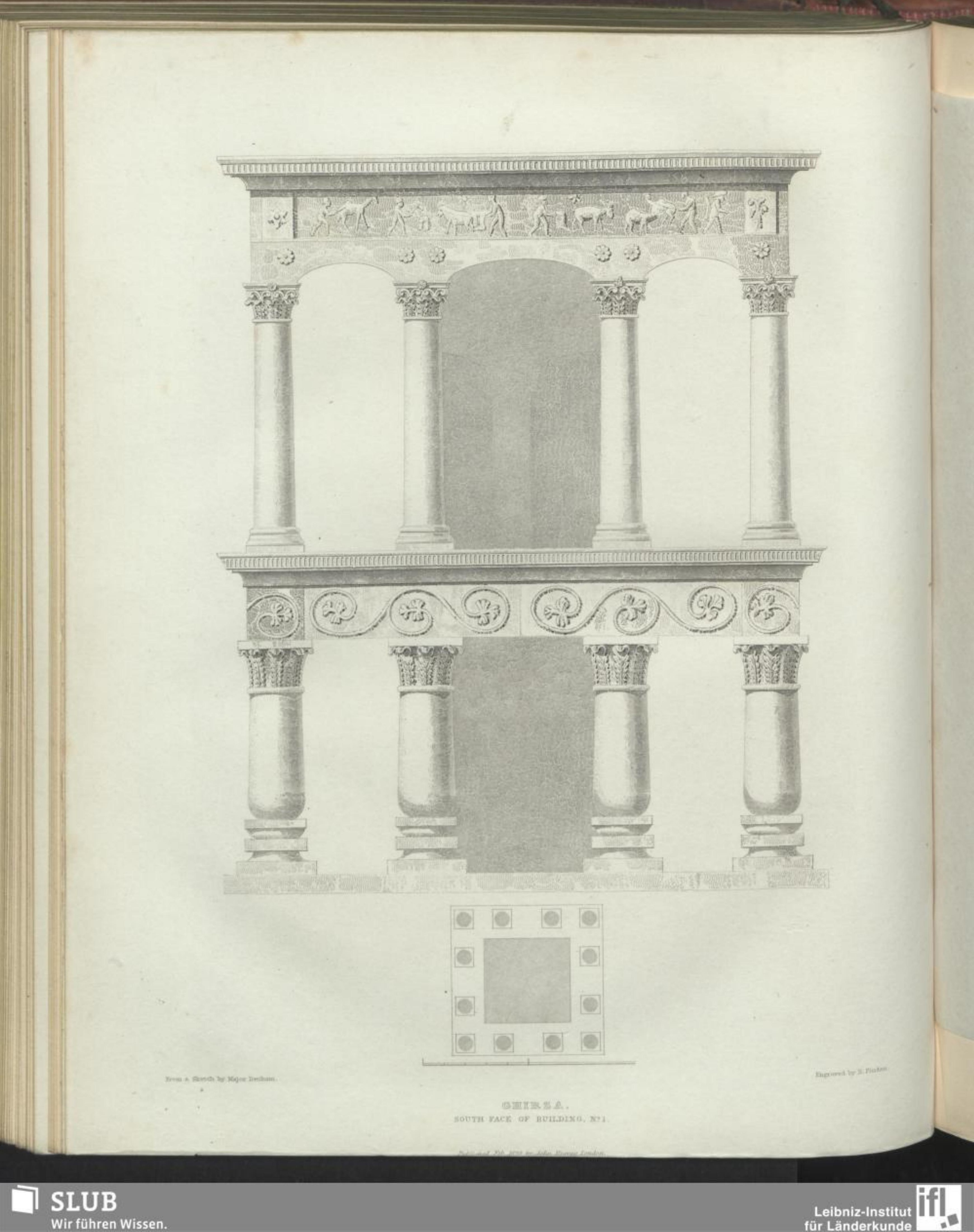


self separated, as I wished to return by Ghirza, while he was rather desirous of keeping the old road by Bonjem. A continuation of wadeys furnished us at this time of the year with food for camels and horses; and, close under low hills of magnesian limestone, at Jernaam, we filled our water-skins for five days' march.

Jan. 11.-A cold morning, with the thermometer at $42^{\circ}$, delayed us till nine o'clock before we could make a start. We passed two wadeys before coming to that where we were to halt: near one of these, called Gidud, were heaps of stones, denoting the restingplace of two Arabs, who had died in a skirmish, about two months before, and some characters, which to me were hieroglyphics, were marked out distinctly in the gravel near their graves; and upon inquiry, I found they told the tale of death, and the tribes to which they belonged. At sunset we halted at Bidud.

Nothing particular, till our arrival at Ghirza on the 13th. We found here the remains of some buildings, said to be Roman, situated about three miles west-south-west of the well, and which appeared to me extremely interesting: there must have been several towns, or probably one large city, which extended over some miles of country, and the remains of four large buildings, which appear to have been monuments or mausoleums, though two of them are nearly razed to the earth. Those which I thought interesting and capable of representation, I sketched: the architecture was rude, though various : capitals, shafts, cornices, and entablatures, lay scattered about; some of curious, if not admirable, workmanship. 
No. 1.

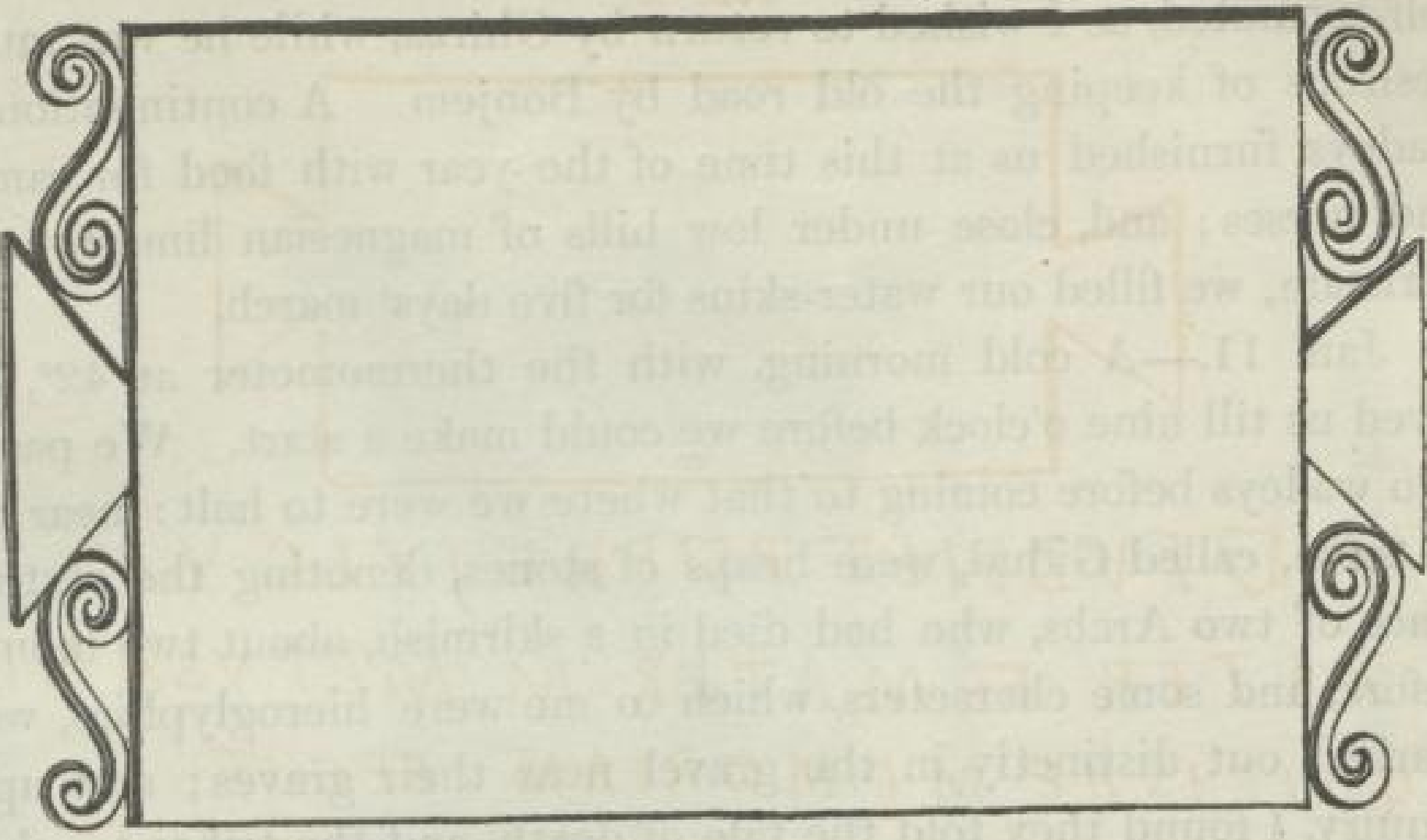

MVCHVLAMESOVARNYCHS $N$ PATER ETMU IMARCHI $N \mid M M I R E E \& 3 \quad C C \vee R A S A$ $N$ QVIEISHEC MEMORI $\triangle M F E C E R V \Leftrightarrow 33$ ISCVSSI $M V S R A T I$ SS MTOAD EAER\&OCA \& ES $S V M$ IOSA SS ERC'.S VSI.N N VMMO* Fs, SI \&WS IA RESNVMERDO VÁG\&CI NIAOVINCES, gNA IOS CE NROSTRETE ES: 1 : IOP ELS AVIPVSE - , it " " - I YISITENIESS HESNL 
RETURN TO TRIPOLI.

No. 2.

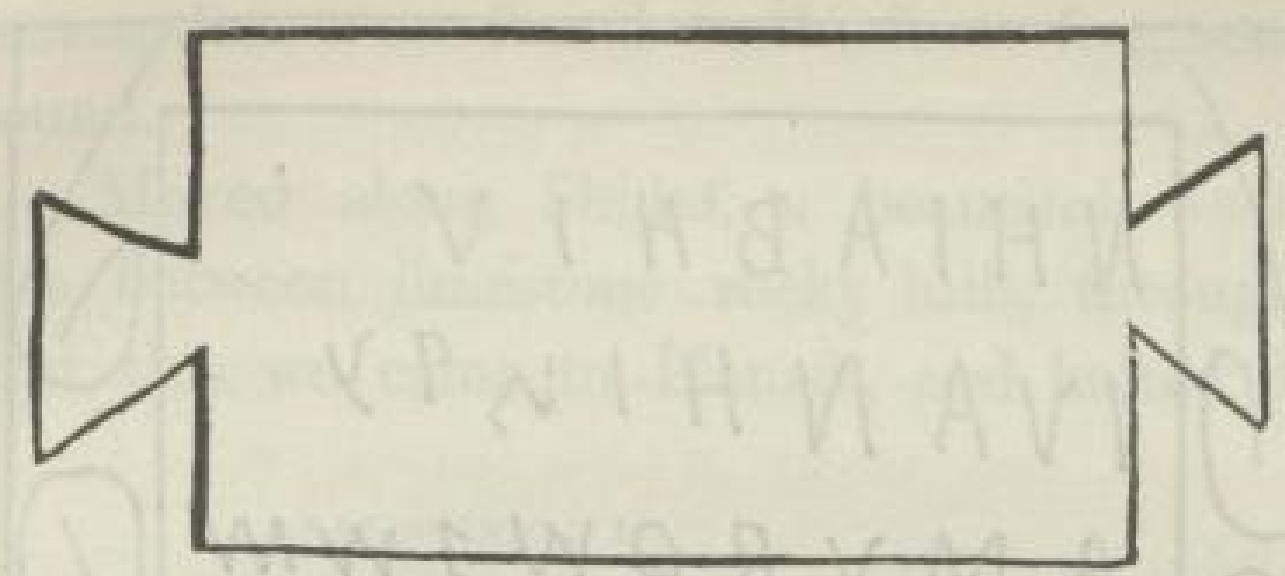

MDFVDEIET POPHE $X \angle C \vee M$

PATER ET MATER M METVSANIS

Q VIEISHE MEMORIAM FECIT

DISCVSSIRATIOCINIO A\&S AEROC

ATVM EST SVMLTOS $A$ \&...SEDES

INNVMO*EOLLIS N=3MILIA

PRETER CIBARIAS OMLSBVS

FELICITER LECAN \# - SITE

NT FILOS ET NEPOTES MEOS

ETTAI ESFACIANT

No. 3.

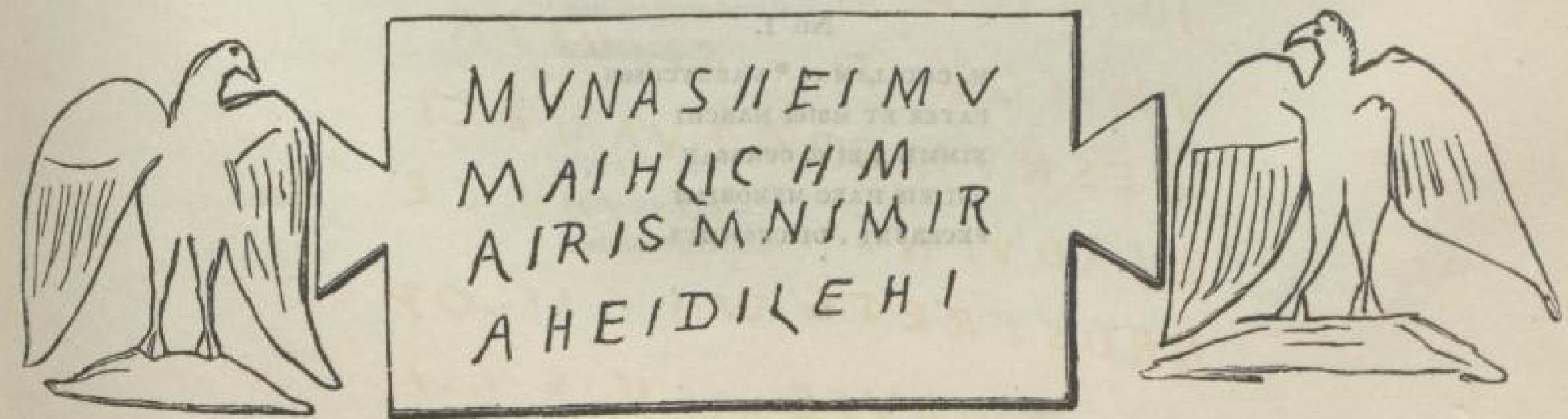


No. 4.

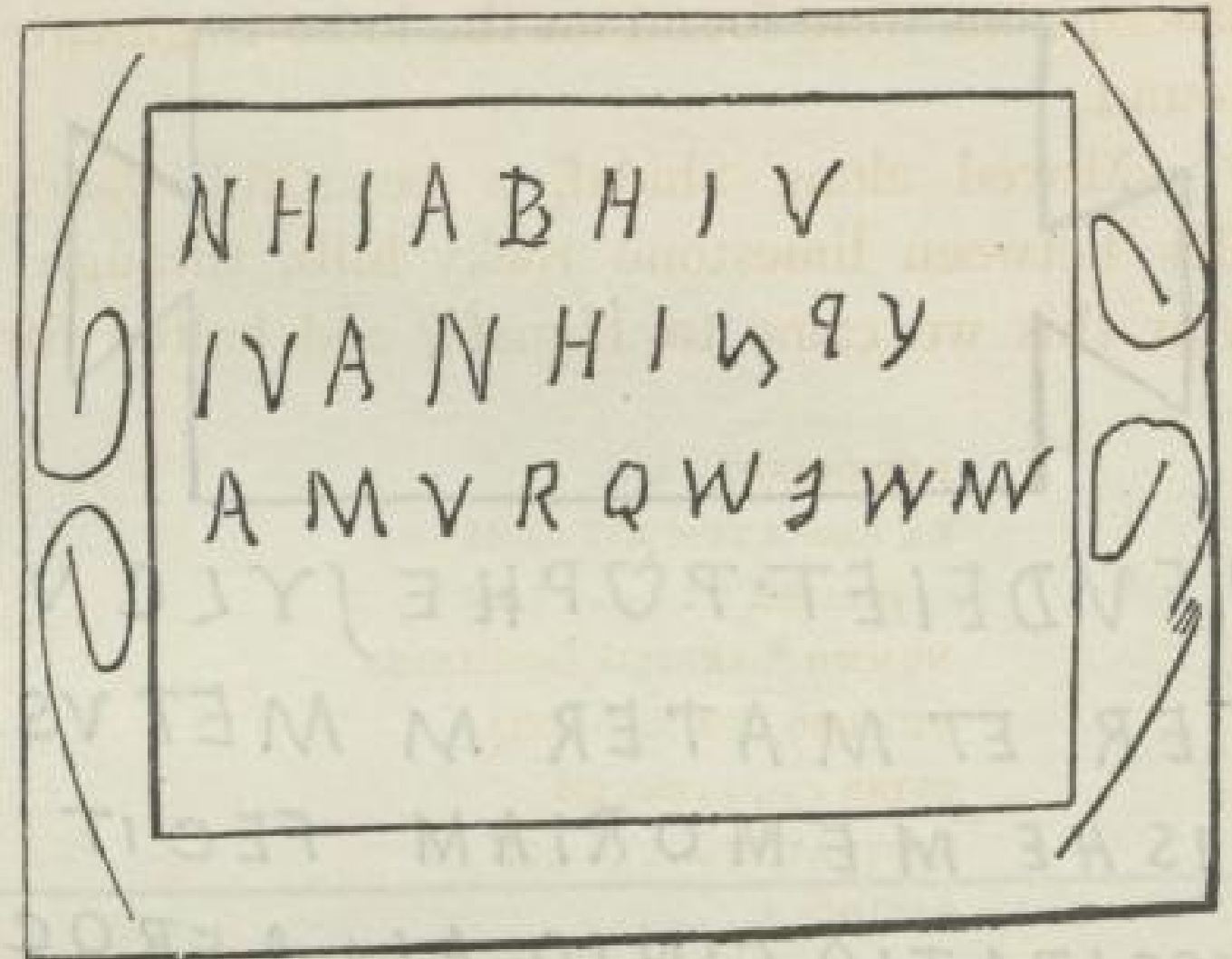

The inscription $\%$, No. 1, was on a tablet fixed on the east face of the building, of which the elevation gives the south side. The entrance to all the buildings was from the east, and by fourteen

* Dr. Young has been so good as to examine these inscriptions, but has not succeeded in ascertaining their probable date. He observes, that the two principal inscriptions, Nos. 1 and 2, are clearly tributes of children to the memory of their parents. They seem, from the legal expression "discussi ratiocinio," to be of the times of the lower empire, these words being applied in the pandect to the settlement of accounts: they each allude to the expenses of some public entertainment. The termination is remarkable for the prayer, that their parents might revisit their descendants on earth, and make them like themselves. The names seem to be altogether barbarous: the second character, like a heart, is not uncommonly found in inscriptions standing for a point.

No. 1.

M. CHULLAM et * vARNYCHsan

PATER ET Mater MARCH

NTMMTrE Et C. CURASAN

QUI EIS HAEC MEMORIAM

FECERUNT . DIsCUsstMUS 
steps to the base of the upper range of pillars, now totally destroyed. The other inscriptions were found on the loose fragments which lay scattered around.

Jan. 17.-Moved along Shidaf, a beautiful wadey, extending ten miles between limestone rocky hills, through which we passed. After this we came to Hanafs, and halted fifteen miles

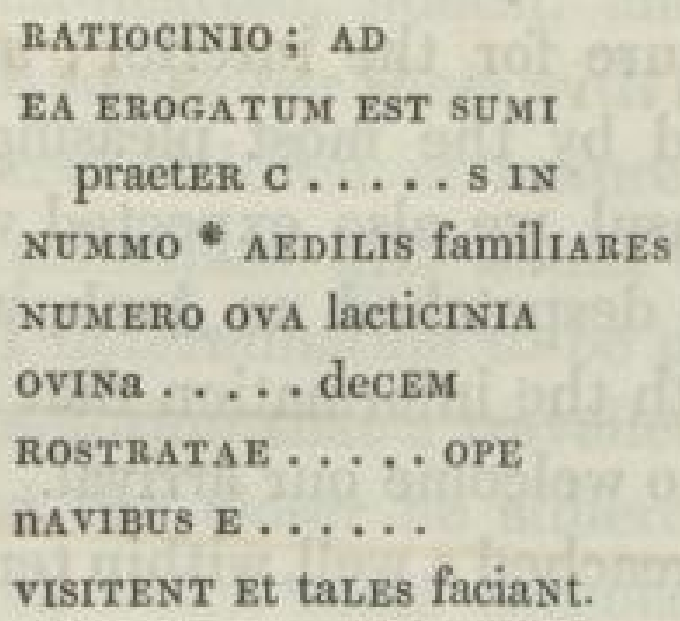

No. 2 must be read nearly thus :M. FUDEI ET P. PHESULCUM PATER ET MATER M. METUSANIS QUI EIS HAEC MEMORIAM FECIT. DISCUSSI RATIOCINIO; AD EA EROGATUM EST SUMI ....

IN NUMMO * AEDILIS A FAMHLIA PRAETER CIBARIAS OMniBUS FELICITER LEgAtas , VISITENT FILIOS ET NEPOTES MEOS ET TALES FACIANT.

No. 3.

MUNAS II ET MUMAI filii MATris MNIMIRA HAEDILEHS.

\section{No. 4 ,}

NHIABH JURe

JURANDo tene-

AMUR QUTrTTUM. 
to the east, where we found some other ruins, of a character similar to those of Ghirza: two inscriptions were perceivable, but perfectly unintelligible, and obscured by time.

On the 20th we once more saw Benioleed, and on the 24th, passed Melghra, and the plain of Tinsowa. Melghra was the place where we had taken leave of $\mathrm{Mr}$. Carstensen, the late Danish consulgeneral at Tripoli, and many of our friends, who accompanied us thus far on our departure for the interior; and our return to the same spot was attended by the most pleasing recollections. Our friend, the English consul, we also expected would have given us the meeting, as he had despatched an Arab, who had encountered us the night before, with the information that he was about to leave Tripoli a second time to welcome our arrival.

On the day after, we reached a well, within ten miles of Tripoli ; and previous to arriving there, were met by two chaoushes of the bashaw, with one of the consul's servants : we found the consul's tents, but he had been obliged to return on business to the city; and the satisfaction with which we devoured some anchovy toasts, and washed them down with huge draughts of Marsala wine, in glass tumblers-luxuries we had so long indeed been strangers to-was quite indescribable. We slept soundly after our feast, and on the 26th of January, a few miles from our resting-place, were met by the consul and his eldest son, whose satisfaction at our safe return seemed equal to our own. We entered Tripoli the same day, where a house had been provided for us. The consul sent out sheep, bread, and fruit, to treat all our fellow-travellers; and cooking, and eating, and singing, and feasting, were kept up by both slaves and Arabs, until morning revealed to their happy eyes, and well filled bellies, the " roseate east," as a poet would say.

We had now no other duties to perform, except the providing for our embarkation, with all our live animals, birds, and other specimens of natural history, and settling with our faithful native at- 
tendants, some of whom had left Tripoli with us, and returned in our service: they had strong claims on our liberality, and had served us with astonishing fidelity in many situations of great peril ; and if either here or in any foregoing part of this journal it may be thought that I have spoken too favourably of the natives we were thrown amongst, I can only answer, that I have described them as I found them, hospitable, kind-hearted, honest, and liberal : to the latest hour of my life I shall remember them with affectionate regard; and many are the untutored children of nature in central Africa, who possess feelings and principles that would do honour to the most civilized Christian. A determination to be pleased, if possible, is the wisest preparatory resolution that a traveller can make on quitting his native shores, and the closer he adheres to it the better: few are the situations from which some consolation cannot be derived with this determination; and savage, indeed, must be that race of human beings from whom amusement, if not interesting information, cannot be collected.

Our long absence from civilized society appeared to have an effect on our manner of speaking, of which, though we were unconscious ourselves, occasioned the remarks of our friends : even in common conversation, our tone was so loud as almost to alarm those we addressed; and it was some weeks before we could moderate our voices so as to bring them in harmony with the confined space in which we were now exercising them.

Having made arrangements with the Captain of an Imperial brig, which we found in the harbour of Tripoli, to convey us to Leghorn, I applied, through the consul-general, to the bashaw for his seal to the freedom of a Mandara boy, whose liberation from slavery I had paid for some months before : the only legal way in which a Christian can give freedom to a slave in a Mohammedan country. The bashaw immediately complied with my request *; and, on Colonel

* The following is a loose translation of the document :- " Praise be to the only God, and peace to our Prophet Mohamed, and his followers !-Made free by Rais Khaleel-ben- 
Warrington's suggesting that the boy was anxious to accompany me to England, he replied, with great good humour, "Let him go, then; the English can do no wrong." Indeed, on every occasion, this prince endeavoured to convince us how rejoiced he was at our success and safe return. He desired Colonel Warrington to give him a fête, which request our hospitable and liberal consul complied with, to the great satisfaction of the bashaw. The streets, leading from the castle to the consulate, were illuminated, and arched over with the branches of orange and lemon trees, thick with fruit. The bashaw arrived at nine in the evening, accompanied by the whole of his court in their splendid full dresses, and, seated on a sort of throne, erected for him, under a canopy, gazed on the quadrilles and waltzes, danced by the families of the European consuls, who were invited to meet him, with the greatest pleasure. He took the English and the Spanish consul-generals' wives into the supperroom, with great affability: and calling Captain Clapperton and myself towards him, assured us he welcomed our return as heartily as our own king and master in England could do. No act of the bashaw's could show greater confidence in the English, or more publicly demonstrate his regard and friendship, than a visit of this nature.

Very shortly after this fête we embarked for Leghorn, and after experiencing heavy and successive gales, from the north-west, which obliged us to put into Elba, we arrived in twenty-eight days. Our quarantine, though twenty-five days, quickly passed over. The miseries of the Lazaretto were sadly complained of by our

Inglise, a young black, called Abdelahy, of Mandara, from the hands of Abdi Nibbe-benAttaia Towerga, for the sum of thirty-six Spanish dollars, which the said Abdi Nibbe has received-Rais Khaleel giving freedom to the said slave, over whom he has no power, nor any other person whatever; and the said Abdelahy is in full enjoyment of all the privileges of Musselmans. In the presence of us, the parties being in possession of their senses and faculties. Given this 16 Rabbia-attani, 1240, di Hegira-Mohamed-ben-Zein-Abeedeenben-Hamet-Ben-Mohamed-Ben-Omeran, Mahmoud-ben-Hagi, Solyman." 
imprisoned brethren; but the luxury of a house over our heads, refreshing Tuscan breezes, and what appeared to us the perfect cookery of the little taverna, attached to the Lazaretto, not to mention the bed, out of which for two days we could scarcely persuade ourselves to stir, made the time pass quickly and happily. On the 1st of May we arrived at Florence, where we received the kindest attention and assistance from Lord Burghersh. Our animals and baggage we had sent home by sea, from Leghorn, in charge of William Hillman, our only surviving companion. Captain Clapperton and myself crossed the Alps, and on the 1st of June following, we reported our arrival in England to Earl Bathurst, under whose auspices the mission had been sent out. 


\section{SUPPLEMENTAL CHAPTER ON BORNOU.}

Bornou, a kingdom of Central Africa, is comprehended, in its present state, between the 15th and 10th parallel northern latitude, and the 12th and 18th of east longitude. It is bounded on the north by part of Kanem and the desert; on the east, by the Lake Tehad, which covers several thousand miles of country, and contains many inhabited islands; on the south-east by the kingdom of Loggun and the river Shary, which divides Bornou from the kingdom of Begharmi, and loses itself in the waters of the Tchad; on the south by Mandara, an independent kingdom, situated at the foot of an extensive range of primitive mountains ; and on the west by Soudan. The heat is excessive, but not uniform; from March to the end of June being the period when the sun has most power. At this season, about two hours after noon, the thermometer will rise sometimes to 105 and 107; and suffocating and scorching winds from the south and south-east prevail. The nights are dreadfully oppressive; the thermometer not falling much below $100^{\circ}$, until a few hours before day-light; when 86 or 88 denote comparative freshness. Towards the middle of May, Bornou is visited by violent tempests of thunder, lightning, and rain. Yet in such a dry state is the earth at this time, and so quickly is the water absorbed, that the inhabitants scarcely feel the inconvenience of the season. 
Considerable damage is done to the cattle and the people by the lightning They now prepare the ground for their corn; and it is all in the earth before the end of June, when the lakes and rivers begin to overflow; and from the extreme flatness of the country, tracks of many miles are quickly converted into large lakes of water. Nearly constant rains now deluge the land with cloudy, damp, sultry weather. The winds are hot and violent, and generally from the east and south.

In October the winter season commences; the rains are less frequent, and the harvest near the towns is got in ; the air is milder and more fresh, the weather serene: breezes blow from the northwest, and with a clearer atmosphere. Towards December, and in the beginning of January, Bornou is colder than from its situation might be expected. The thermometer will, at no part of the day, mount higher than 74 or 75 ; and in the morning descends to 58 and 60 .

It is these cold fresh winds from the north and north-west that restore health and strength to the inhabitants, who suffer during the damp weather from dreadful attacks of fever and ague, which carry off great numbers every year. The inhabitants are numerous; the principal towns or cities are thirteen. Ten different languages, or dialects of the same language, are spoken in the empire. The Shouas have brought with them the Arabic, which they speak nearly pure. They are divided into tribes, and bear still the names of some of the most formidable of the Bedouin hordes of Egypt. They are a deceitful, arrogant, and cunning race; great charm writers; and by pretending to a natural gift of prophecy, they find an easy entrance into the houses of the black inhabitants of the towns, where their pilfering propensities often show themselves. The strong resemblance they bear, both in features and habits, to some of our gipsy tribes, is particularly striking. It is said that Bornou can muster 15,000 Shouaas in the field mounted. They are the s s 2 
greatest breeders of cattle in the country, and annually supply Soudan with from two to three thousand horses. The Bornou people, or Kanowry, as they are called, have large unmeaning faces, with fat Negro noses, and mouths of great dimensions, with good teeth, and high foreheads. They are peaceable, quiet, and civil: they salute each other with courteousness and warmth; and there is a remarkable good-natured heaviness about them which is interesting. They are no warriors, but revengeful; and the best of them given to commit petty larcenies, on every opportunity that offers. They are extremely timid; so much so, that on an Arab once speaking harshly to one of them, he came the next day to ask if he wished to kill him.

As their country produces little beside grain, mostly from a want of industry in the people, so are they nearly without foreign trade.

In their manner of living, they are simple in the extreme. Flour made into a paste, sweetened with honey, and fat poured over it, is a dish for a sultan. The use of bread is not known; therefore but little wheat is grown. Indeed it is found only in the houses of the great. Barley is also scarce; a little is sown between the wheat, and is used, when bruised, to take off the brackish taste of the water.

The grain most in use amongst the people of all classes, and upon which also animals are fed, is a species of millet called gussub. This grain is produced in great quantities, and with scarcely any trouble. The poorer people will eat it raw or parched in the sun, and be satisfied without any other nourishment for several days together. Bruised and steeped in water, it forms the travelling stock of all pilgrims and soldiers. When cleared of the husk, pounded, and made into a light paste, in which a little meloheia (the eboo ochra of Guinea) and melted fat is mixed, it forms a favourite dish, 
and is called kaddell. Kasheia is the seed of a grass, which grows wild and in abundance near the water. It is parched in the sun, broken, and cleared of the husk. When boiled, it is eaten as rice, or made into flour; but this is a luxury.

Four kinds of beans are raised in great quantities, called mussaqua, marya, kleemy, and kimmay, all known by the name of gafooly, and are eaten by the slaves, and poorer people. A paste made from these and fish was the only eatable we could find in the towns near the river. Salt they scarcely knew the use of. Rice might have been cultivated in Bornou, before it became the scene of such constant warfare as has for the last fifteen years defaced the country. It is now brought from Soudan, in the neighbourhood of Maffatai : in Bornou, it is scarce, and of an inferior quality. Indian corn, cotton, and indigo, are the most valuable productions of the soil. The two latter grow wild, close to the Tchad and overflowed grounds. The senna plant is also found wild, and in abundance. The indigo is of a superior quality, and forms a dye which is used in colouring the tobe (the only dress the people wear) dark blue, which probably is not excelled in quality in any part of the world. The only implement of husbandry they possess is an ill-shaped hoe, made from the iron found in the Mandara mountains; and the labours of their wretched agriculture devolve, almost entirely, on women. Most of their grain is reaped within two or three months of its being scattered on the earth (for it can scarcely be called sowing); and probably there is no spot of land between the tropics, not absolutely desert, so destitute of either fruit or vegetable as the kingdom of Bornou. Mangoes are only found growing in the neighbourhood of Mandara and to the west; and with the exception of two or three lemon, or rather lime trees, and as many fig trees, in the garden of the sheikh at Kouka, raised on a spot of ground watched by himself, the care and culture of which give employment to about fifty negroes, not a 
fruit of any description can be found in the whole kingdom. Date trees there are none south of Woodie, four days north of Kouka, where they are sickly, and produce but an indifferent fruit. Onions are to be procured near the great towns only, but no other vegetable. The people indeed have nothing beyond the bare necessaries of life; and are rich only in slaves, bullocks, and horses. Their dress consists of one, two, or three tobes, or large shirts, according to the means of the wearer : a cap of dark blue is worn on the head by persons of rank. Others, indeed generally all, go bare-headed; the head being kept constantly free from hair, as well as every other part of the body. They carry an immense club, three or four feet in length, with a round head to it, which they put to the ground at every step, and walk with great solemnity, followed by two or three slaves : they have what we should call a rolling gait. Red caps are brought by the Tripoli and Mesurata merchants; but are only purchased by sultans and their immediate attendants. They are Musselmans, and very particular in performing their prayers and ablutions five times a day. They are less tolerant than the Arabs; and I have known a Bornouese refuse to eat with an Arab, because he had not sully'd (washed and prayed) at the preceding appointed hour.

They seldom take more than from two to three wives at a time, even the rich, and divorce them as often as they please, by paying their dower. The poorer class are contented with one. The women are particularly cleanly, but not good-looking: they have large mouths, very thick lips, and high foreheads. Their manner of dressing the hair is also less becoming than that of any other Negro nation I have seen : it is brought over the top of the head in three thick rolls; one large, one in the centre, and two smaller on each side, just over the ears, joining in front on the forehead in a point, and plastered thickly with indigo and bees' wax. Behind the point it is wiry, very finely plaited, and turned up like a drake's tail. The 
Scarin, or tattoos, which are common to all Negro nations in these latitudes, and by which their country is instantly known, are here particularly unbecoming. The Bornouese have twenty cuts or lines on each side of the face, which are drawn from the corners of the mouth, towards the angles of the lower jaw and the cheek-bone; and it is quite distressing to witness the torture the poor little children undergo who are thus marked, enduring, not only the heat, but the attacks of millions of flies. They have also one cut on the forehead in the centre, six on each arm, six on each leg and thigh, four on each breast, and nine on each side, just above the hips. They are, however, the most humble of females, never approaching their husbands except on their knees, or speaking to any of the male sex, otherwise than with the head and face covered, and kneeling. Previous to marriage, there appears to be more jealousy than after.

Adultery is not common : the punishment is very severe, if caught in the fact, and secured on the spot; and this is the only evidence on which conviction is granted. The guilty couple are bound hand and foot, cast on the ground, and their brains dashed out by the club of the injured husband and his male relations.

Girls rarely marry until they are fourteen or fifteen; often not so young. The age of puberty does not arrive here at so early a period as in Barbary; females there not unfrequently becoming mothers at the age of twelve, and even eleven. In Bornou, such a circumstance is unknown: for a woman to have twins is extremely rare; and to make them believe that more were ever brought into the world at one time, in any country, would be difficult.

The domestic animals are dogs, sheep, goats, cows, and herds of oxen, beyond all calculation. The Shouaas on the banks of the Tchad have probably 20,000, near their different villages; while the shores of the great river Shary could furnish double that number. They also breed multitudes of horses, with which they furnish the Soudan market, where this animal is very inferior. 
The domestic fowl is common, and is the cheapest animal food that can be purchased : a dollar will purchase forty. They are small, but well flavoured.

The bees are so numerous, as in some places to obstruct the passage of travellers. The honey is but partially collected./That buzzing noisy insect, the locust, is also a frequent visitor. Clouds of them appear in the air; and the natives, by screams and various noises, endeavour to prevent their descending to the earth. In the district where they pitch, every particle of vegetation is quickly devoured. The natives eat them with avidity, both roasted and boiled, and formed into balls as a paste./

The game is abundant, and consists of antelopes, gazelles, hares, an animal about the size of a red deer, with annulated horns, called koorigum, partridges very large, small grouse, wild ducks, geese, snipes, and the ostrich, the flesh of which is much esteemed. Pelicans, spoonbills, the Balearic crane, in great numbers, with a variety of other large birds of the crane species, are also found in the marshes. The woods abound with the Guinea fowl.

The wild animals are, the lion, which in the wet season approaches to the walls of the towns, panthers, and a species of tigercat, are in great numbers in the neighbourhood of Mandara, the leopard, the hyena, the jackal, the civet cat, the fox, hosts of monkeys, black, grey, and brown, and the elephant,/the latter/so numerous as to be seen near the Tchad in herds of from fifty to four hundred. This noble animal they hunt, and kill for the sake of his flesh, as well as the ivory of his tusk. The buffalo, the flesh of which is a delicacy, has a high game flavour. The crocodile and the hippopotamus are also numerous; and the flesh of both is eaten. That of the crocodile is extremely fine: it has a green firm fat, resembling the turtle, and the callipee has the colour, firmness, and flavour of the finest veal. The giraffe is seen and killed by the buffalo hunters in the woods and marshy grounds near the Tchad. / Reptiles are numerous; they 
consist of scorpions, centipedes, and disgusting large toads, serpents of several kinds, and a snake said to be harmless, of the congo kind, sometimes measuring fourteen and sixteen feet in length.

/ The beasts of burden used by the inhabitants are the bullock and the ass. A very fine breed of the latter is found in the Mandara valleys. Strangers and chiefs, in the service of the sheikh or sultan, alone possess camels. The bullock is the bearer of all the grain and other articles to and from the markets. A small saddle of plaited rushes is laid on him, when sacks made of goats-skins, and filled with corn, are lashed on his broad and able back. A leather thong is passed through the cartilage of his nose, and serves as a bridle, while on the top of the load is mounted the owner, his wife, or his slave. Sometimes the daughter or the wife of a rich Shoua will be mounted on her particular bullock, and precede the loaded animals ; extravagantly adorned with amber, silver rings, coral, and all sorts of finery, her hair streaming with fat, a black rim of kohol, at least an inch wide, round each of her eyes, and I may say, arrayed for conquest at the crowded market./ Carpets or tobes are then spread on her clumsy palfrey: she sits jambe deçà jambe delà, and with considerable grace guides her animal by his nose. Notwithstanding the peaceableness of his nature, her vanity still enables her to torture him into something like caperings and curvetings.

The price of a good bullock is from three dollars to three dollars and a half.

The Bornou laws are arbitrary, and the punishment summary. Murder is punished by death : the culprit, on conviction, is handed over to the relations of the deceased, who revenge his death with their clubs. Repeated thefts by the loss of a hand, or by burying the young Spartan, if he be a beginner, with only his head above ground, well buttered or honeyed, and so exposing him for twelve or eighteen 
hours, to the torture of a burning sun, and innumerable flies and mosquitoes, who all feast on him undisturbed. These punishments are, however, often commuted for others of a more lenient kind. Even the judge himself has a strong fellow-feeling for a culprit of this description. When a man refuses to pay his debts, and has the means, on a creditor pushing his claims, the cadi takes possession of the debtor's property, pays the demand, and takes a handsome per centage for his trouble. It is necessary, however, that the debtor should give his consent; but this is not long withheld, as he is pinioned and laid on his back until it is given; for all which trouble and restiveness, he pays handsomely to the cadi; and they seldom find that a man gets into a scrape of this kind twice. On the other hand, should a man be in debt, and unable to pay, on clearly proving his poverty, he is at liberty. The judge then says, " God send you the means ;"- the bystanders say, "Amen :" and the insolvent has full liberty to trade where he pleases. But if, at any future time, his creditors catch him with even two tobes on, or a red cap, on taking him before the cadi, all superfluous habiliments are stripped off, and given towards payment of his debts.

The towns generally are large, and well built; they have walls, thirty-five and forty feet in height, and nearly twenty feet in thickness. They have four entrances, with three gates to each, made of solid planks eight or ten inches thick, and fastened together with heavy clamps of iron. The houses consist of several court-yards, between four walls, with apartments leading out of them for slaves; then a passage, and an inner court, leading to the habitations of the different wives, who have each a square space to themselves, enclosed by walls, and a handsome thatched hut. From thence also you ascend a wide stair-case of five or six steps, leading to the apartments of the owner, which consist of two buildings like towers or turrets, with a terrace of com- 
munication between them, looking into the street, with a castellated window. The walls are made of reddish clay, as smooth as stueco, and the roofs most tastefully arched on the inside with branches, and thatched on the out with a grass known in Barbary by the name of lidthur. The horns of the gazelle and the antelope serve as a substitute for nails or pegs. These are fixed in different parts of the walls, and on them hang the quivers, bows, spears, and shields of the chief. A man of consequence will sometimes have four of these terraces and eight turrets, forming the faces of his mansion or domain, with all the apartments of his women, within the space below. Not only those en activité (as the French would say), but those on the superannuated list, are allowed habitations. Horses and other animals are usually allowed an enclosure near one of the court-yards forming the entrance. Dwellings, however, of this description are not common. Those generally used by the inhabitants are of four kinds :-

Coosie, which is a hut built entirely of straw.

Bongo, a hut with circular mud walls, thatched with straw.

$N^{\prime}$ Geim kolunby, and fatto-sugdeeby,--huts of coarse mats, made from the grass which grows near the lake, Our dwellings were called bongos, and were about eight feet in diameter inside, about the shape of a hay-stack, and with a hole at the bottom, about two feet and a half high, which we used to creep in and out at. Air, or light holes, we were obliged to dispense with, as they admitted both flies and mosquitoes, which were worse than darkness.

Their utensils are few, and consist of earthen pots, which they make beautifully for cooking, and wooden bowls for dishes. Water, which is their only beverage, is drunk from a large calabash, which grows wild near the rivers, after being cooled in earthen jars. They sleep on mats covered with the skins of animals. Married women are extremely superstitious, in having their beds covered 
with the skins of particular animals when their husbands visit them; and never fail to predict the fate and fortune of a child, in consequence of these arrangements. A panther or a leopard's skin is sure to produce a boy, or nothing. Should the father be a soldier, and a chief, the boy will be a warrior, bold, but bloody. A lion's skin is said to prevent child-bearing altogether; yet exceptions to this rule sometimes occur. It is then always a boy, and a wonderful one. He puts his foot on the necks of all the world, and is alike brave, generous, and fortunate. Leather cushions of various colours, and fancifully ornamented, are brought from Soudan, and are used as pillows by persons of superior rank ; who also have a small Turkey carpet, on which they sit or sleep, and the price, of which is a young female slave.

The amusements of the people consist in meeting together in the evening, either in the court-yard of one of the houses of the great, or under the shades formed with mats, which are in the open places of the town, where prayers are said at the different appointed hours by the Iman or priest. Here they talk, and sometimes play a game resembling chess, with beans, and twelve holes made in the sand. The Arabs have a game similar to this, which they play with camels' dung in the desert; but the Bornouese are far more skilful.

Like the birds, their day finishes when the sun goes down; but very few, even of the great people, indulge in the luxury of a lamp, which is made of iron, and filled with bullocks' fat. They have no oil. A few jars are brought by the Tripoli merchants from the valleys of the Gharian, as presents only. Soap is also an article they are greatly in want of. An oily juice, which exudes from the stem of a thorny tree, called Kadahnia, or mika dahniah, resembling a gum, enables the people of Soudan to make a coarse soap, by mixing it with bullocks' fat and trona. It is something like soft soap, and has a pleasant smell. This is brought in small wooden boxes, holding less than half a pound, which sell for seven rottala each, two-thirds of a 
dollar. From this tree is also procured a nut, from which a purer oil is extracted, which they burn in Soudan, and is also used by the women, to anoint their heads and bodies. This tree is not found in Bornou.

The skin of their sheep is covered with a long hair ; wool therefore they have none. / Brass and copper are brought in small quantities from Barbary. $X$ A large copper kettle will sell for a slave. The brass is worked into leglets, and worn by the women.

A small brass basin tinned is a present for a sultan, and is used to drink out of. Four or five dollars, or a Soudan tobe, will scarcely purchase one. Gold is neither found in the country, nor is it brought into it. The Tuaricks are almost the only merchants visiting Soudan who trade in that metal, which they carry to Barbary and Egypt. It is said the sheikh has a store, which is brought him directly from Soudan.

Iron is procured in the Mandara mountains, but is not brought in large quantities, and it is coarse. The best iron comes from Soudan, worked up in that country into good pots and kettles. The money of Bornou is the manufacture of the country. Strips of cotton, about three inches wide, and a yard in length, are called gubbuk; and three, four, and five of these, according to their texture, go to a rottala. Ten rottala are now equal to a dollar.

The government of Bornou has ever been, until during the last fifteen years, an elective absolute monarchy, the brother sometimes succeeding, to the exclusion of the son. Achmet Ali, who, descended from a royal line of ancestors, was sultan in 1808, contended for several years with a powerful people from the westward, called the Felatah. These people had gradually been increasing in power for more than half a century, had established themselves firmly in Soudan; where Bello their chief, assuming the government, dictated laws to a numerous and powerful black population.

Soon after the conquest of Bornou by the Felatahs, El Kanemy 
formed a plan for delivering that country from the bondage into which it had fallen; and, stirring up the Kanemboo to assist him by a well planned tale of having been called by a vision to this undertaking, he made his first campaign with scarcely 400 followers, and defeated an army of the Felatahs nearly 8,000 strong. He followed up this victory with great promptitude and resolution, and in less than ten months had been the conqueror in forty different battles.

He refused the offer of being made sultan; and placing Mohammed, the brother of sultan Achmet, on the throne, he, first doing homage himself, insisted on the whole army following his example. The sheikh built for Sultan Mohammed his present residence, New Birnie, establishing himself at Angornou, three miles distant, and retaining the dictatorship of the kingdom, pro tempore. Such a commencement was extremely politic, on the part of the sheikh ; but his aspiring mind was not calculated to rest satisfied with such an arrangement.

The whole population now flocked to his standard, and appeared willing to invest him with superior power, and a force to support it. One of the first offers they made was to furmish him with twenty horses per day, until a more regular force was organized, which continued for four years *. He now raised the green flag, the standard of the Prophet, refused all titles but that of the "servant of God !" and after clearing the country of the Felatahs, he proceeded to punish all those nations who had given them assistance, and with the slaves, the produce of these wars, rewarded his faithful Kanemboo and other followers for their fidelity and attachment.

- Tirab, his favourite Shouaa chief, was intrusted with this duty, and acquired the name of Bagah-furby, Gatherer of horses.

A horse of the best breed in this country, which was sent by the Sheikh of Bornou as a present to His Majesty, is described by Mr. Sewell as possessing great strength, to be supple, and extremely active. He also adds, " Fis movements remind me strongly of the brown Dongala horse, whose picture I have." 
Even in the breasts of some of the Bornouese, successful war had raised a passion for conquest: their victories, no less a matter of surprise than delight, crest-fallen and dispirited as they were, gave a stimulus to their exertions, and they became accustomed to warfare and regardless of danger.

For the last eight years the sheikh has carried on a very desperate and bloody war with the sultan of Begharmi, who governs a powerful and warlike people, inhabiting a very large tract of country south of Bornou, and on the eastern bank of the Shary. Although meeting with some reverses, and on one occasion losing his eldest son in these wars, who was greatly beloved by the people, he has, upon the whole, been successful ; and is said to have, from first to last, destroyed and led into slavery more than thirty thousand of the sultan of Begharmi's subjects, besides burning his towns and driving off his flocks.

The late sultan of Bornou, who always accompanied the sheikh to the field, also lost his life in these wars: his death was attributable to his immense size and weight; the horse he rode refused to move on with him from fatigue, although at the time not more than 500 yards from the gates of Angala, and he fell into the hands of the enemy. He died, however, with great dignity, and six of his eunuchs and as many of his slaves, who would not quit him, shared his fate. A sultan of Bornou carries no arms, and it is beneath his dignity to defend himself: sitting down, therefore, under a tree, with his people around him, he received his enemies, and hiding his face in the shawl which covered his head, was pierced with a hundred spears.

Ibrahim, his brother, succeeded him, who is now not more than twenty-two years old. The sultanship of Bornou is but a name: the court still keeps up considerable state, and adheres strictly to its ancient customs, and this is the only privilege left them. When the sultan gives audience to strangers, he sits in a kind of cage, made 
of the bamboo, through the bars of which he looks on his visitors, who are not allowed to approach within seventy or eighty yards of his person.

Their dresses are extremely rich, and consist of striped silks and linens of various colours, from Cairo and Soudan. When they take the field, their appearance is truly grotesque : the sultan is preceded by six men, bearing frum-frums (trumpets) of cane, ten feet long: an instrument peculiar to royalty, but which produces a music neither agreeable nor inspiring. Their own heads, and those of their horses, are hung round with charms, sewed up in leather cases, red, green, and white; and altogether, with their wadded doublets and large heads, they would be more apropos in a pantomime than in a field of battle.

At the present moment there is but one power in central Africa to be at all compared to the sheikh of Bornou in importance,-that of Bello, the Felatah chieftain; and from the sensation created throughout the neighbourhood of Kano and Kashna, on his late defeat of the Begharmi force, I imagine he would find but little difficulty in extending his empire in that direction : he has, turned all his victories to the advantage of those for whom he conquered, by attending to their improvement in moral and religious duties. His subjects are the most strict Mussulmans in all the black country, and their respect for us gradually increased on ascertaining that we really had a religion of our own, and obeyed its ordinances by praying, if not by fasting, - which they at first doubted. Our determination to travel fearlessly and boldly in our own characters, as Englishmen and Christians, mistrusting no one, so far from proving an impediment to our progress, as we were assured from all quarters it would do, excited a degree of confidence to which we may, in a great measure, attribute the success which has attended our steps.

Wherever El Kanemy has power, Europeans, and particularly Englishmen, will be hospitably and kindly received. 
Bornou was always infested by robbers, who way-laid and plundered travellers within sight of the walls of the capital : such an event now never occurs, and the roads through the sheikh's government are probably as safe as any even in happy England itself.

Although harassed by the constant wars in which he has been engaged, yet has not the sheikh been unmindful of the benefits which an extended commerce would confer upon his people, nor of the importance of improving their moral condition, by exciting a desire to acquire, by industry and trade, more permanent and certain advantages than are to be obtained by a system of plunder and destructive warfare. Arab or Moorish merchants, the only ones who have hitherto ventured amongst them, are encouraged and treated with great liberality. Several of them are known to have returned, after a residence of less than nine years, with fortunes of fifteen and twenty thousand dollars; and which might, perhaps, by a more intelligent trader, have been doubled, as the commodities with which they barter are mostly European produce, purchased at Tripoli, at prices full two hundred and fifty per cent. above their prime cost.

The usual calculation of a Moorish merchant is, that a camel load of merchandize, bought at Mourzuk for 150 dollars, will make a return, in trading with Bornou, of 500 dollars, after paying all expenses. Persons in Fezzan will send three camel loads in charge of one man, and, after paying all the expenses out of the profits, give him a third of the remainder for his labour.

From the circumstance, however, of there being no direct trade from this country with Tripoli, or, I believe, with any of the ports of Barbary, English goods (the demand for which is daily increasing amongst a population of not less than five millions), within six hundred miles of the coast, are sold at enormous prices, although frequently of the very worst description *.

* The articles most in request amongst the Negro nations are :-

Writing paper, on which the profit is enormous.

U U 
The principal return which Moorish merchants obtain for their goods consists in slaves; but Bornou is scarcely any thing more than a mart or rendezvous of kafilas from Soudan. These unhappy victims are handed over to the Tripoli and Fezzan traders, who are

Coral barrelled, and imitation coral.

Printed cottons of all kinds, with a great deal of red and yellow in the pattern.

Coloured silks, in pieces for large shirts and shifts, of the most gaudy patterns.

Imitations of damask, worked with gold thread, and flowers.

Common red cloth.

Green do

White barracans, purchased in Tripoli.

Small looking-glasses.

White bornouses, purchased in Tripoli.

Small carpets, five or six feet long, purchased in Tripoli.

English carpets of the same size would sell better, and might be bought at one-third of the price of Turkish ones.

Ornamented cheap pistols, with long barrels.

Common razors.

Red caps, purchased in Tripoli.

Turbans of all descriptions, large amber, for the Kanemboo women, and the Shouaas.

Common China basins, much esteemed.

Coffee cups.

Brass basins, tinned in the inside

Red breeches, made up.

Cotton caftans, striped, made up.

Pieces of striped cotton.

Handkerchiefs, and coarse white muslin.

Large shirts or tobes, ready made, of striped cottons, and white calico.

$\left.\begin{array}{l}\text { Coarse white calico. } \\ \text { Fine do. do. }\end{array}\right\}$ much esteemed.

Frankincense,

$\left.\begin{array}{l}\text { Ottaria, } \\ \text { Spices, }\end{array}\right\}$ purchased of the Jews in Tripoli, or Leghorn.

The beads most in demand, indeed the only ones that they will purchase, are :-

H'raz-el mekka, white glass beads, with a flower.

Merjan tiddoo, mock coral.

Quamur, white sand beads. 
waiting with their northern produce to tempt the cupidity of the slave merchants of Soudan. I think I may say, that neither the sheikh himself, nor the Bornou people, carry on this traffic without feelings of disgust, which even habit cannot conquer. Of the existence of a foreign slave trade, or one which consigns these unfortunates to Christian masters, they are not generally aware at Bornou; and so contrary to the tenets of his religion - of which he is a strict observer-would be such a system of barter, that one may easily conclude, the sheikh of Bornou would be willing to assist, with all the power he possesses, in any plan which might have for its object the putting a final stop to a commerce of this nature.

Already the desire of exchanging whatever their country produces, for the manufactures of the more enlightened nations of the North, exists in no small degree amongst them : a taste for luxury, and a desire of imitating such strangers as visit them, are very observable; and the man of rank is ever distinguished by some part of his dress being of foreign materials, though sometimes of the most trifling kind. It is true that these propensities are not yet fully developed; but they exist, and give unequivocal proof of a tendency to civilization, and the desire of cultivating an intercourse with foreigners.

Every approach which the African has made towards civilization, even to the knowledge of, and the belief in, the existence of a Supreme Being, is attributable to the intrepid Arab spirit, which, despising the dread of the apparently interminable deserts that

Quamar m'zein, small black beads, with yellow stripes.

H'raz-el pimmel, ant's head bead, with black stripes.

Contembali, red and white.

Hazam el bashaw, the bashaw's sash.

Sbgha m'kerbub, red pebble, from Trieste.

Sbgha toweel, long bead.

H'shem battura, Arab's nose, a large red bead.

Arms of all descriptions, of an inferior quality, will always meet with a ready sale, as well as balls of lead, and what we call swan-shot.

บ 42 
separate the Black from the White population, has alone penetrated to any extent into the country of these before unenlightened savages, - carrying with him his religion and his manners, and converting thousands to the Mohammedan faith.

The eagerness with which all classes of people listened to our proposals for establishing a frequent communication by means of European merchants, and the protection promised by the sheikh to such as should arrive within the sphere of his influence, particularly if they were English, excites an anxious hope that some measures will be adopted for directing the labours of a population of millions to something more congenial to the humanity and the philanthropy of the age we live in, than the practice of a system of predatory warfare, which has chiefly for its object the procuring of slaves, as the readiest and most valuable property to trade with, on every appearance of the merchants from the north at their markets.

Every probability is against such a barter being preferred by the African black. Let the words of the sheikh himself, addressed to us in the hearing of his people, speak the sentiments that have already found a place in his bosom :- - You say true, we are all sons of one father! You say, also, that the sons of Adam should not sell one another, and you know every thing! God has given you all great talents, but what are we to do? The Arabs who come here will have nothing else but slaves: why don't you send us your merchants? You know us now ; and let them bring their women with them, and live amongst us, and teach us what you talk to me about so often, to build houses and boats, and make rockets." The reader will conceive with what exulting hearts we heard these words from the lips of a ruler in the centre of Africa.

The return which European traders might, in the first instance, obtain, would not, probably, be sufficient to employ large capitals, but that would annually improve; and the great profits would, in some measure, compensate for the deficiency. The propensity in 
the natives to war upon and plunder their neighbours, from the profit arising from such a system, would gradually subside, when other more profitable occupations were encouraged amongst them. The Kanemboos who inhabit the northern and eastern borders of the lake Tchad are a bold and hardy people, extremely expert with the spear, swift of foot, and practised hunters.

The tusk of the elephant, the horns of the buffalo, both which may be obtained at a very low price, and in exchange for English goods, are eagerly bought even at Tripoli, and at all the European ports in the Mediterranean, at high prices : the cultivation of indigo, also, of a very superior kind, might be carried to any extent, as it now grows wild, as well as senna, in many parts of the country. The zibet, or musk from the civet cat, is also to be procured, about two hundred per cent. lower than it will sell for in Tripoli.

The following are the prices in Bornou, of some of those articles which would be most esteemed in Europe, viz.-

Ostrich skins, from three to six dollars each.

Elephants' teeth, two dollars the $100 \mathrm{lbs}$.

Raw hides may also be purchased, at about two dollars for 100 skins.

Probably the strong desire of the sheikh to improve the state of his country, and the habits of his people, cannot be better exemplified than in his having given me the designs for three coins, which he entreated might be laid before the king of England, with his request to have the stamp and apparatus for striking money, so that he might introduce a more convenient medium of exchange than the one at present in use amongst them; one of these pieces of money he intended should be of gold, a second of silver, and the third of iron. This chief, also, as well as all the principal people, entreated that some one of our party should remain in their country, "to receive," as they said, "the English merchants that were coming." And it was under the idea of securing to ourselves the great advan- 
tages we had gained, by so firm a footing in the very centre of Africa, as the sheikh's friendship enabled us to boast of, that I recommended Mr. Tyrwhitt's remaining at Kouka, with all the privileges granted to Barbary consuls, until the pleasure of His Majesty's Government should be known.

I consider the establishment of a friendly intercourse with this potentate beyond the Great Desert, by whose means the unknown parts of Africa may at no distant period be visited, of the greatest importance, in every point of view. By encouraging a commercial intercourse, all the objects of African discovery must be advanced: not alone will the cause of science and research be benefited, but the real philanthropist must see, that an opening is now made, by means of which, with judicious arrangements, thousands of his fellow beings may be saved from slavery.

1. Until introduced by the Moors, the trading in slaves was little known amongst them; the prisoners taken in battle served them, and were given as portions to their children, on their marriage, for the same duties; but they were seldom sold. Even now the greater part of the household of a man of rank are free, with the exception of the women, who often die in the service of the master of their youth. They are treated always like the children of the house, and corporal punishment is a rare occurrence amongst them. I have more than once known a Bornouese, on his morning visit to my hut, say, with tears, that he had sent a slave to be sold, who had been three years a part of his family : then he would add, " but the devil has got into her, and how could I keep her after that?"

In short, it is to the pernicious principles of the Moorish traders, whose avaricious brutality is beyond all belief, that the traffic for slaves in the interior of Africa not only owes its origin, but its continuance. They refuse all other modes of payment for the articles which they bring with them; they well know the eagerness with which these articles are sought after; and by offering what appears 
to the natives an amazing price, tempt them to sell their brethren, to the most inhuman of all human beings, while they gain in Fezzan, Bengazi, and Egypt, sometimes a profit of 500 per cent. I am not, however, without hopes, that a more extended intercourse with Barbary might detach even the proverbially unfeeling Moor from dealing in human flesh; and it was with feelings of the highest satisfaction that I listened to some of the most respectable of the merchants, when they declared, that were any other system of trading adopted, they would gladly embrace it, in preference to dealing in slaves: knowing, too, how often we interfered to ameliorate the situation of any of these unfortunates, when they were oppressed or ill-treated, they would continually point out to us, as if to excite our approbation, how well dressed, and well fed, their own slaves were, in comparison with those of others, as we traversed the Desert, on our return to Tripoli.

D. D. 


\title{
J O U R N A L
}

\author{
OF \\ A N E X C URSIO N,
}

ETC. ETC.

\section{ㄱ SLUB}




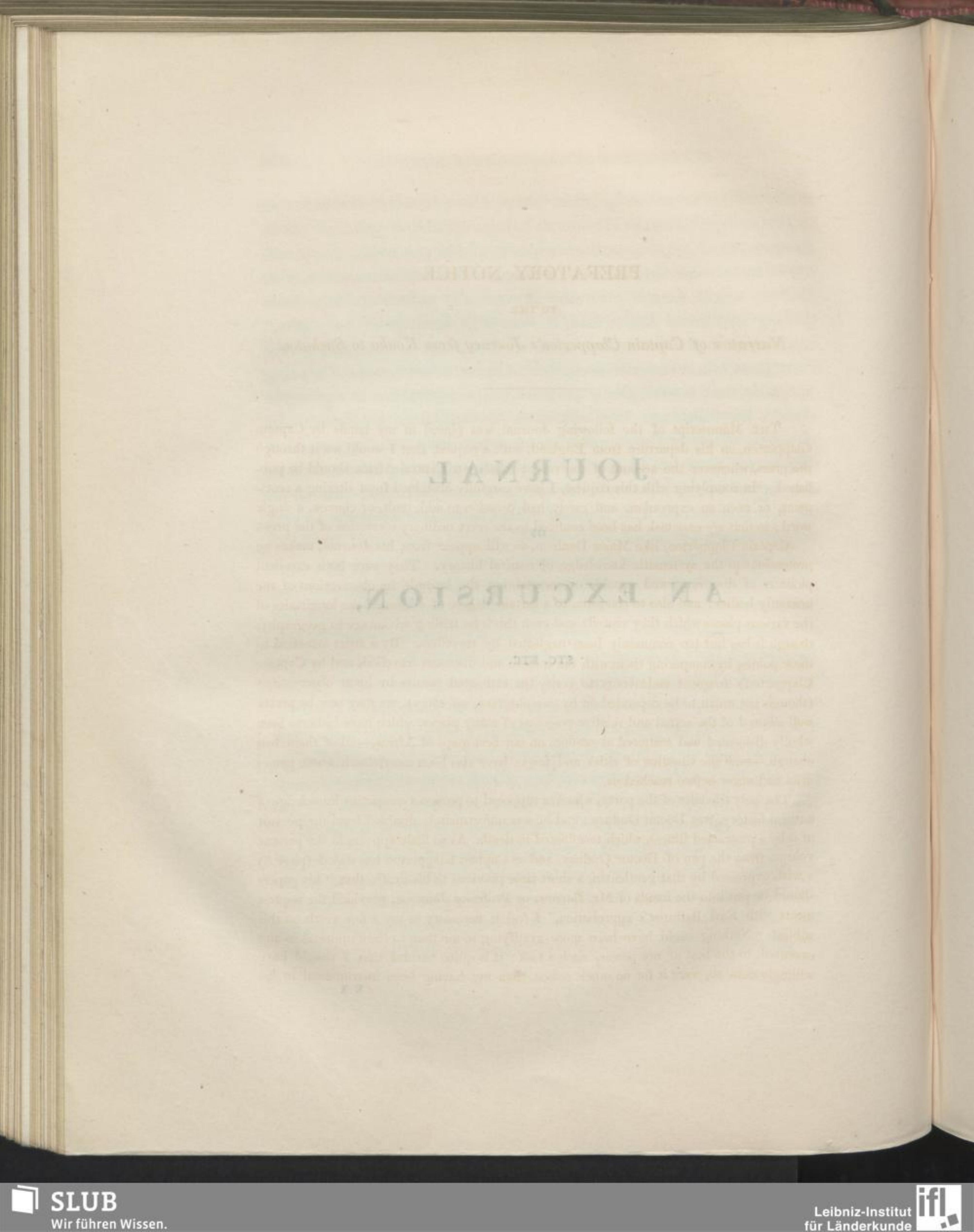




\section{PREFATORY NOTICE}

TO THE

Narrative of Captain Clapperton's Journey from Koulka to Sackatoo.

The Manuscript of the following Journal was placed in my hands by Captain Clapperton, on his departure from England, with a request that I would see it through the press, whenever the account of the recent mission to Central Africa should be published. In complying with this request, I have carefully abstained from altering a sentiment, or even an expression, and rarely had occasion to add, omit, or change, a single word; so that my easy task has been confined to the mere ordinary correction of the press.

Captain Clapperton, like Major Denham, as will appear from his Journal, makes no pretensions to the systematic knowledge of natural history. They were both excellent pioneers of discovery, and capable of ascertaining the latitude by observations of the heavenly bodies; and also to compute, to a certain degree of accuracy, the longitudes of the various places which they visited: and even this is no trifling advantage to geography, though it has but too commonly been neglected by travellers. By a strict attention to these points, by comparing them with the courses and distances travelled, and by Captain Clapperton's frequent endeavours to verify the estimated results by lunar observations (though not much to be depended on by one observer, on shore), we may now be pretty well assured of the actual and relative positions of many places, which have hitherto been wholly dislocated and scattered at random on our best maps of Africa,-all of them bad enough, - and the situation of cities and towns have also been ascertained, whose names even had never before reached us.

The only traveller of the party, who was supposed to possess a competent knowledge of natural history, was Doctor Oudney ; and he was unfortunately disabled from the pursuit of it by a protracted illness, which terminated in death. As so little appears in the present volume from the pen of Doctor Oudney, and as Captain Clapperton has stated (page 5) a wish expressed by that gentleman, a short time previous to his death, that " his papers should be put into the hands of Mr. Barrow, or Professor Jameson, provided the request meets with Earl Bathurst's approbation," I feel it necessary to say a few words on this subject. Nothing could have been more gratifying to me than to have undertaken and executed, to the best of my power, such a task: it is quite natural that I should have willingly done so, were it for no other reason than my having been instrumental in his 
appointment, from the strongest testimonials in his favour which $\mathrm{I}$ had received from Professor Jameson, whose acquirements in natural history stand so deservedly high in public estimation, as to entitle any recommendation from him to immediate attention. Unfortunately, however, for this branch of science, Doctor Oudney, at a very early stage of their journey, caught a severe cold, which fell on his lungs, and which rendered him, on their arrival in Bornou, nearly incapable of any exertion. It will be seen from Major Denham's Narrative, how frequently and how seriously, not to say alarmingly, ill, he became from the first moment of their arrival in Bornou. In a letter addressed to Mr. Wilmot Horton, of the date of the 12th September, 1823, Doctor Oudney says, "I send you a simple itinerary from Fezzan here; that to the river Shary, and the borders of Soudan, and my remarks on Bornou, I must leave till another time. I cannot write long; one day's labour in that way makes me ill for a week."

No account of these journeys to the river Shary, and the borders of Soudan, appear among his papers; nor any materials respecting them, beyond what are contained in a very general account of the proceedings of the Mission, in an official letter addressed to the Secretary of State. The papers, delivered to me by Captain Clapperton, consisted of an account of an excursion, jointly performed by these gentlemen, from Mourzuk to Ghraat, the first town in the Tuarick country:- some remarks on the journey across the Great Desert, which appear not to have been written out fair :-and the rest, of mere scraps of vocabularies, rude sketches of the human face, detached and incomplete registers of the state of the temperature, and a number of letters to and from the Consul at Tripoli, respecting the pecuniary and other affairs of the mission, wholly uninteresting, and of which no use whatever could be made.

The Journey to Ghraat above mentioned, I have caused to be printed at the end of the Introductory Chapter, with which it appears to be partly connected, omitting some trifling details, of no interest whatever ; and I requested Major Denham to add a few foot-notes, chiefly geological, to his own Journal across the Great Desert. It seems to have been well known to the party that Doctor Oudney could not possibly survive the journey into Soudan ; and, indeed, he was well aware of it himself; but his zeal to accomplish all that could be done, would not suffer him to remain behind. It was that zeal which led him to undertake the journey to Ghraat, which not a little increased his disorder; for, to say the truth, he evidently was labouring, while in England, under a pectoral complaint; but when I told him so, and strongly advised him not to think of proceeding (as I had before done to his unfortunate predecessor Ritchie), he, like the latter, persisted that, being a medical man, he best knew his own constitution, and that a warm climate would best agree with it. Neither of them, however, seem to have calculated on the degree of fatigue, and the sudden changes of temperatiure, to which they were necessarily to be exposed.

With every disadvantage of collecting, preserving, and bringing home from so great a distance, and over so dreary a desert of twelve hundred miles, specimens of natural history, it will be seen, by reference to the Appendix, that this department of science has not been neglected.

JOHN BARROW. 


\section{JOURNAL}

OF

\section{A N EXCUSION,}

ETC. ETC.

\section{SECTION I. \\ FROM KOUKA TO MURMUR, WHERE DR. OUDNEY DIED.}

From our first arrival in Bornou, we intended to avail ourselves of the earliest opportunity of exploring Soudan. Our preparations being at length completed, and the sheikh having consented to our departure, although with some degree of reluctance, Dr. Oudney, notwithstanding the infirm state of his health, and myself, were ready to set out on the 14th December, 1823. Accordingly we sent off our camels and servants in the morning, and went in person to take leave of the sheikh. On this occasion we found him in an inner apartment, attended by two or three servants only. He asked us, as he had often done before, if, in the course of our travels, we proposed going to Nyffee. We answered, yes, if the road was open. He replied, it was a great distance; and he feared we were not likely to return to 
Kouka. We told him we hoped to return, if possible, before the rains set in ; but however that might be, we assured him we should ever retain a grateful sense of his exceeding great kindness towards us. He bade us farewell in the most affectionate manner. About noon we left the town, accompanied by our comrade, Major Denham, and most of the principal inhabitants. Even Hadje Ali Boo Khaloom, with whom we had frequent occasion to be dissatisfied, joined the train : they attended us to the distance of four or five miles, and then took leave; our friend, the cadi Hadje Mohamed Zy Abedeen, having first repeated the Fatha, or first chapter of the Koran. We halted at the village of Fuguboo Thorio, where our servants had pitched our tents, being distant from Kouka about ten miles.

Our party consisted of Dr. Oudney and myself, two servants, Jacob the Jew, a sort of major domo, and three men of Fezzan. We had three saddle horses, and four sumpter camels ; the servants, except Jacob, were on foot. There were also in the kafila (commonly pronounced goffle) twenty-seven Arab merchants, two of whom were shreefs, or descendants of the Prophet, one from Tunis, the other from Houn, near Sockna, and about fifty natives of Bornou. The Arabs were mostly mounted on horses, which they intended for sale; some having besides a led horse. The Bornouese were on foot; one of them, a hadje or Mahometan pilgrim, who had visited Mecca, would on no account stay behind at Kouka, but persisted in accompanying us, for the express purpose of having his hand regularly dressed by Dr. Oudney : he had been wounded by the accidental bursting of a gun; he invariably pitched his tent close to that of the Doctor, whom he always regarded with the utmost respect.

Dec. 15.-We started at seven o'clock. The road was the same we had travelled on a former visit to Old Birnee. We were no longer annoyed with the noise and confusion in pitching the tents, or with the clamours of obstreperous camel drivers; which we had formerly experienced when under the guidance of Boo Khaloom. 
The weather too was clear, cool, and pleasant. A little after midday we halted at the wells of Budjoo ; distance, north-west by north, seventeen miles.

Dec. 16. -We met several kafilas from Gubsharee and the surrounding country, going to Kouka. Their heavy goods were carried on bullocks; the smaller packages, weighing from twenty to thirty pounds, were borne on men's heads. The bearers poise their burdens with much dexterity and ease to themselves, by cords hanging from the sides of the packages, which are carried lengthwise on the head; by this simple contrivance they avoid the fatiguing posture of keeping the arm raised. We halted about three o'clock in the afternoon.

We still pursued the Old Birnee road: we saw several of the large red and white antelopes, called by the Arabs mohur. We encamped on the margin of one of the lakes, formed by the overflowing of the Yow ; the river was only about a quarter of a mile distant from us, to the north. It had now fallen fully six feet, and its current might be about three miles an hour.

Dec. 18.-We travelled along the banks of a chain of small lakes formed by the Yow, once, perhaps, its original channel. I observed, by the roadside, the tracks of various wild animals, - among others of the hippopotamus and lion. We passed one of the country fairs, held on a small hill, near the ruins of a large town which had been destroyed by the Felatahs. We halted at Damasak, near an encampment of the sheikh's cowherds; who, on hearing that we were in the kafila, brought us an abundant supply of milk.

Dec. 19.-As the low grounds from Damasak to Mugabee, about ten miles distant, were inundated, we were obliged to make a long circuit by an upper road, frequently wading across hollows filled with water. At noon we had to halt on the banks of one of those temporary rivers which are formed during the wet season : it still contained a considerable body of water, which was running at the rate of about two miles an hour. We met here several kafilas of loaded 
bullocks, on their way from Gubsharee and Soudan. The people were busily floating their goods over the river on rafts, made of bundles of reeds; but there being too few in number to transport our baggage, it was necessary to make new rafts for ourselves. We therefore pitched our tents ; and one man was sent by each of the Arab merchants to cut long reeds, which are readily made into rafts, by lashing bundles of them across two long poles.

I proceeded two or three miles up the banks of the river, which last summer did not contain a drop of water. The lower road certainly exhibited the appearance of being overflowed during the rains ; but nobody, from merely seeing it in that state, could suppose that for nearly one half of the year it is a broad sheet of water, or that the upper road itself is traversed, for the same period, by several large streams falling into the Yow. The ferry-dues, paid to the people who swim over with the rafts, are a rotal for every camel load of goods : the rotal is now merely nominal, and represents a pound of copper, eight or ten of which are equivalent to a Spanish dollar. The bullocks, horses, and camels, are made to swim over, together with the negro slaves.

Dec. 20.-Hitherto the atmosphere had been clear and serene, but to-day it became hazy, and was particularly cold about day-break. Hadje Ali, the invalid alluded to, having a very large raft, we ferried over our baggage upon it without the smallest accident, by means of a rope fastened to each end. It was far otherwise with the Arabs a little lower down the river; there was nothing but hubbub and bustle among them : many, through ignorance or obstinacy, had their goods much damaged. The greatest difficulty was with the camels and female slaves; the women screamed and squalled with great vehemence; several of the men seemed almost in as great a panic as the ladies, especially those of Fezzan, none of whom could swim; and some of them jumped off the raft into the water three or four times, before they could muster courage to cross. The camels 
occasioned a great deal of trouble, one man having to swim before with the halter in his teeth, while another kept beating the animal behind with a stick, which every now and then attempted to turn back, or bobbed its head under water. Before all had crossed, it was too late to continue our journey that day; we therefore encamped on the west bank for the night.

Dec. 21.-We still travelled along the upper grounds, on account of the extent of the inundation. Yet the earth itself was so dry, that we were put in some slight danger by a kafila, near Old Birnee, carelessly setting the grass on fire in the course of the night: the fire advanced rapidly, like a sea of flame, and must have put us all to flight had we not had the good fortune to obtain shelter within the ruined walls of the city, which checked a little the progress of the conflagration. We did not halt, however, but continued our route to a town called Bera, on the banks of a beautiful lake, likewise formed by the overflowing of the Yow. Immediately there was quite a fair in our camp, the townswomen coming with gussule or Guinea corn, bean straw, cashew nuts, and milk; which they offered in exchange for glass beads and gubga, or native cloth. The beads in greatest request are pretty large, of a chocolate colour, with a small spiral white ring round the middle, and are called by the natives conteembalee, or Muckni ; the latter appellation is derived from a sultan of Fezzan of that name, who was originally a merchant, and first brought these beads into fashion. A single bead exchanged for a quart of Guinea corn. The gubga is narrow cotton cloth, of native manufacture, about a palm in width; forty fathoms of which are usually valued at a dollar. The value of commodities in barter seems to be maintained with a certain stability, somewhat like the money rate of exchange in Europe, by fixing a local standard price for those articles in greatest demand, in lieu of the fictitious par of exchange, which, with us, powerfully influences and indirectly regulates all money transactions.

Dec. 22.-We crossed over a neck of land formed by a bend of 
the river to a town called Dugamoo, where we halted. The banks of the river are every where studded with towns and villages.

Dec. 23.-The morning was cold. Dr. Oudney had been very unwell during the night, and felt himself extremely weak. At eight o'clock we left Dugamoo, and, following a winding path, nearly due west, we reached Deltago, having passed a number of towns and villages, one of which, called Kukabonee, was of considerable size, and contained perhaps 5000 or 6000 inhabitants. The country to the west of Old Birnee rises in gentle undulations of hill and dale. There are very few trees, except on the banks of the Yow. The soil is chiefly a red clay. The inhabitants raise great quantities of Guinea corn, and beans something like calavances. We had a very plentiful market. The people here preferred coral, and the beads called conteembalee, in exchange for grain, \&c. to native cloth. Gunpowder was much sought after as a medicine. To-day we gave a sheep as a boozafer or gift, by way of footing, which all pay who travel this way for the first time; a practice akin to our usage on doubling capes, or crossing the tropics and line. Cotton seed bruised is very much used for feeding sheep, bullocks, asses, and camels. These animals soon become extremely fond of it : it is an excellent food for fattening them. In the evening gussule was sent for our horses and camels, as had been done in the other towns : we passed as soon as the people learned we were the friends of the sheikh.

Dec. 24.-Dr. Oudney felt himself much better. We halted to-day, on account of one of the merchants' camels falling lame; the owner was obliged to send to Dugamor to buy another. The kafila kept a grand boozafer day, and all merchant new-comers paid a dollar apiece, or gave its value in goods.-Time is to these people of no importance : whatever accidental occurrence takes place to detain them, they bear the delay with perfect indifference.

Dec. 25.-The weather clear and cool. We left Deltago, and, winding along the banks of the river, or occasionally cutting off a 
bend by a cross path, we reached Bedeekarfee. There is more wood here than we had yet seen, and the soil is still a strong red clay. Villages and towns are numerous; the inhabitants principally belong to the Alluanee tribe of Shouah Arabs. The town of Bedeekarfee is large and populous. The governor, commonly called in this and other African towns Sultan, although holding a subordinate command, had seen us when we were on the expedition to Munga with the sheikh of Bornou. On our arrival he came out to meet us, and gave us a very cordial reception. He was an elderly man, much afflicted with a urinary disorder, for which he consulted Dr. Oudney. His dwelling, large, extremely clean, and constructed after the manner of the country, consisted of a spacious quadrangular enclosure, surrounded with mats fixed to high poles, within which were several small round huts, also of matting, with thatched conical roofs, each surmounted by an ostrich egg. In outward appearance, these huts somewhat resemble our bee-hives. Their walls are frequently made of clay. The ostrich egg is a distinctive mark of the occupant being a man of rank. The floor inside is covered with sand; and the only furniture is a bench to supply the place of a bedstead, and a few mats for squatting upon, besides some carved or coloured gourds and wide-mouthed earthen jars, piled above one another, and intended to combine ornament with utility. There is but one opening or door-way, which is round at the top, and closed by a wicket. The door always faces to the west, on account of the prevailing rains coming from the opposite quarter. The grand entrance of the enclosure is often a hut erected at the western side of the square, with an open thoroughfare, where a black slave officiates as porter. Each separate hut is called a coozee.

The Arab women of this place are really beautiful; they wear their hair differently from their countrywomen elsewhere: the fashion of it is such, that at a distance it might be mistaken for a helmet,-a large braid on the crown having some semblance to a crest, 
and the side tresses being neatly plaited and frizzled out at the ends. There are also many women of Bornou among them, who imitate the same style.

Guinea fowls abound in this part of the country: I went out after we halted, and shot five of them, besides a wild duck and a quail. Mohamoud El Wordee, one of two Fezzanee merchants, to whom we were particularly recommended by the sheikh of Bornou, and who had always appeared to me to be a man of strong natural sense, was thrown into a sad fright by losing a charm or amulet off his horse's neck, with a number of which almost all are equipped. This charm is nothing more than a short sentence from the Koran. Had he lost an only child he could scarcely have been more afflicted. I gave him a scrap of paper to make another, which Hadje promised to write out for him.

Dec. 26.-This morning after sunrise, Fahrenheit's thermometer stood at $49^{\circ}$. The merchants were busily employed firing off their guns and putting them in order for the Bedites, an ancient race of native Bornouese, who have not embraced Islamism, and who occupy an adjoining territory, chiefly protected by its natural fastnesses. They are held both in dread and abhorrence by all the faithful. Every thing being ready at eleven o'clock, we broke up our encampment. Our kafila was now of an immense size. We had been joined at Bedeekarfee by 500 people at least, who were waiting there for an Arab kafila to pass through the Bedee country; for all Arabs are esteemed by the natives here extremely formidable, as well from the possession of fire arms, as from their national intrepidity. Their muskets, however, in comparison of those of Europe, are of the meanest quality ; and so uncertain in their fire, that they are hardly worth more than their weight as old iron. The courage, too, of most of these Arabs is very questionable. When successful they are overbearing and cruel in the extreme, and in bad fortune are in like degree servile and abject. 
The natives of Haussa carry their merchandise on the head, and go armed with bows and arrows. Those of Bornou convey their goods chiefly on asses and bullocks, and are armed with spears. The Haussa merchants deal in tobacco, Goora nuts, Koghelor or crude antimony, cotton cloth in the web, or made into dresses called tobes and turkadees, and tanned goat skins. Goora nuts are the produce of Ashantee and other parts near the west, and are chewed by all people of consequence, on account of their agreeable bitter taste, not unlike that of strong coffee, and the supposed virtue of curing impotency. They are even in great esteem as far as Fezzan and Tripoli, where they bring the exorbitant price of two dollars a score, Crude antimony in powder is applied by both sexes to the eye-lashes, to render them dark and glossy. Native cloth, or gubga, as before mentioned, is extremely narrow, seldom more than four inches in width. The tobe is a large shirt with loose hanging sleeves like a waggoner's frock, generally of a dark blue colour, and is an indispensable part of male attire throughout central Africa. The turkadees are articles of female dress, commonly of blue cotton cloth, about three yards and a half long and one broad. Sometimes they are made of alternate stripes of blue and white (of the breadth of African cloth), or are all white, according to fancy. Women of better circumstances commonly wear two turkadees, one round the waist, and another thrown over the shoulders. These articles are bartered in Bornou for trona or natron, common salt and beads; which, together with coarse tobes, are also carried by Bornouese adventurers to Haussa. Our road lay over an elevated clayey plain, with low trees, most of them mimosas. We passed the ruins of several towns, and such of our travelling companions as were best acquainted with the country informed us it was well peopled before the Felatah invasion. At sunset we halted, being already in the Bedee country.

Dec. 27.-The temperature this morning was remarkably low, and the water in our shallow vessels was crusted with thin flakes of 
ice. The water skins themselves were frozen as hard as a board*. These water skins, by the way, are goat skins, well tanned and seasoned, stripped from the carcass over the animal's head. They are extremely convenient on a tedious journey over arid wastes and deserts. The horses and camels stood shivering with cold, and appeared to suffer much more than ourselves. The wind during the night was, as usual, from the north, and north-north-west. Dr. Oudney was extremely ill, having become much worse from catching a severe cold. We now travelled south-south-west, over a country of much the same kind of soil as that above described. As we approached the low grounds it was better wooded, and the trees were of greater size and variety. Of these, the most remarkable were the kuka and the goorjee.

The kuka is of immense size, erect and majestic; sometimes measuring from twenty to twenty-five feet in circumference. The trunk and branches taper off to a point, and are incrusted with a soft, glossy, copper-coloured rind, not unlike a gummy exudation. The porous spongy trunk is straight, but the branches are twisted and tortuous. The leaves are small, somewhat like the young ash, but more pulpy, and growing in clusters from the extremities of the lesser twigs. The tree is in full leaf and blossom during the rainy months of June, July, and August. The flowers are white, large, and pendulous, somewhat resembling the white garden lily. The fruit hangs by a long stalk, and is of an oval shape, generally larger than a cocoa nut, with a hard shell full of a powdery matter, intermixed with reddish strings and tamarind-like seeds. In its unripe state it is of a beautiful velvety dark green colour, and becomes brown as it approaches maturity. The tree, whether bare of its leaves, in flower, or in full bearing, has a singularly grotesque naked

* It is much to be regretted that the state' of the thermometer was not here noted; more particularly as a question has arisen as to the correctness of this statement, which is however repeated by Dr. Oudney almost in the same words. 
appearance; and, with its fruit dangling from the boughs like silken purses, might, in the imagination of some Eastern story-teller, well embellish an enchanted garden of the Genius of the Lamp./The leaves are carefully gathered by the natives, dried in the sun, and used for many culinary purposes. Boiled in water they form a kind of clammy jelly, giving a gelatinous consistence to the sauces and gravies in most common use. / I have also eaten them boiled with dried meat, according to the custom of the country, but did not much relish such fare. Both leaves and fruit are considered, to a certain degree, medicinal. The leaves, mixed with trona and gussub, are given to horses and camels, both for the purpose of fattening these animals, and as a cooling aperient: they are administered to the former in balls, and to the latter as a drench. The white mealy part of the fruit is very pleasant to the taste, and forms, with water, an agreeable acidulous beverage; which the natives, whose libidinous propensities incline them to such remarks, allege to possess the virtue of relieving impotency.

The goorjee tree much resembles a stunted oak, with a beautiful dark red flower, when in full blow rather like a tulip. The natives make use of the flower to assist in giving a red tinge to the mouth and teeth, as well as in seasoning their food. These two trees are generally found on a strong clayey soil, and are peculiar to Haussa and the western parts of Bornou.

At noon, we came in sight of a lake called Tumbum, apparently formed by some river in the rainy season. All the country to the southward and westward, as far as the eye could reach, was a dismal swamp. Just as we arrived within a short distance of the lake,-at the very spot in which of all others the Arabs said we were most likely to encounter the Bedites, - two men made their appearance. They were dressed in the Bornouese costume; a loose tobe and drawers, with a tight cap, all of blue cotton cloth. Each carried on his shoulder a bundle of light spears, headed with iron. I was a 
little way in front of our party, and first met them; they saluted me very civilly, and I passed on without further notice, when the other horsemen meeting them, and putting some questions, which the strangers did not answer to their satisfaction, immediately seized, stripped, and bound them. Considering it a matter in which I had no authority to interfere, I merely requested that their drawers might be returned to them, remarking, it was better not to treat them ill, as they might prove to be honest men. "Oh ! d-n their fathers," (the strongest imprecation in Africa), replied the captors, "they are thieves; what would they be doing here if they were honest men ?" I still urged the propriety of taking them to Bedeguna, at least, to afford them a chance of being recognised by the townspeople, before treating them as robbers. I now rode off to water my horse; when I returned, I found the magnanimous EI Wordee guarding the two unfortunate wretches, one of whom was a Shouah Arab, and the other a Negro. The latter, while I was absent, had received a dreadful cut under the left ear from a Bornouese, who pretended that the Negro had attempted to escape; an attempt little likely in his desperate situation. Notwithstanding the wound, they were leading the poor fellow by a rope fastened round his neck. He was covered with blood, and Dr. Oudney assured me, if the wound had been a little lower down it must have caused instant death. I could not refrain from beating the merciless Bornouese ; and I obliged him to use his own tobe in binding up the wound, at the same time threatening to lodge the contents of my gun in his head, if he repeated his cruelty. The occasion prompted me to impress on the minds of the Arabs generally how unworthy it was of brave men to behave with cruelty to their prisoners, and to suggest, that it would be far better to sell them, or even to put them to death, than wantonly to inflict such barbarities. The Arabs threw the blame on the Bornouese, and although evidently exulting in secret over their captives, they were fairly shamed into 
good behaviour, and promised to liberate the men if innocent, or, if guilty, to surrender them to justice at Bedeguna.

Our road skirted the border of the great swamp, and we arrived at Bedeguna at sunset. The galadema, literally "gate-keeper," or governor, was a Felatah, and a particular friend of Mohamoud El Wordee, by whom we were introduced to him. He was tall and slender, with a high arched nose, broad forehead, and large eyes; and, indeed, altogether as fine a looking black man as I had ever seen. His behaviour, too, was at once kind and dignified. Besides his native language, he spoke with fluency Arabic, and the tongues of Bornou and Haussa. He asked us a great many questions about England, of which he had heard; and said his master, the Sultan of the Felatahs, would be glad to see us. He applied to Dr. Oudney for medicines, on account of a urinary obstruction, a disease very prevalent in this country. We made him a present of a small paper snuff-box full of cloves; he sent us, in return, a plentiful supply of milk.

The territory of Bedeguna, or little Bede, formerly belonged to Bornou. The inhabitants are Bornouese, and speak their native language. The territory includes many towns and villages, and produces much gussub, Indian corn, wheat, and cotton. Herds of cattle are also numerous. The principal implement of agriculture is a hoe made of native iron, of their own manufacture. They reap with a crooked knife, and merely cut off the ears of corn, which they store in round thatched huts of clay, or matting, raised on wooden blocks from the ground. The grain is cleaned from the husk by hand rubbing, and ground into flour between two stones. We saw no plough to the southward of Sockna, a town between Tripoli and Fezzan./ I inquired of the governor about the source of the swollen river we crossed on a raft between Gateramaran and old Birnee, which again presented itself close to our present encampment. He told me it rose in the country of Yacoba, among 
rocky hills, and, running to the eastward of old Birnee, soon afterwards entered the Yow. On questioning him further about Yacoba, the name of the country, he said it was the sultan's name; for the people were infidels, and had no name for their own country. The river, he added, was distinguished by the appellation of the Little River, and in these parts did not dry up throughout the whole year.

The country to the south-east and south-west appears to be an entire swamp, overflowed of course in the rainy season. Felatahs are in features, and in the manner of wearing the turban, very like the inhabitants of Tetuan in Morocco. They are here much esteemed by the people whom they rule for the impartial administration of justice, and were uniformly kind and civil to us. Our two prisoners happened to be well known, having only left the town that moining. They were accordingly liberated, but their clothes were not restored.

We were not a little indebted to the Arab merchants for the good name they gave us. They almost looked upon us as of their own nation; and although Kafirs, we, as Englishmen, were allowed to rank at least next to themselves. I really believe they would have risked their lives in our defence. Travelling in a kafila was much more pleasant than any mode we had hitherto tried; all being ready to oblige one another, and all vying in attention to us. The lake Zumbrum is about twelve miles south-south-west from Bedeguna.

Dec. 28. - At sunrise to-day the thermometer was at $45^{\circ}$. Our new friend, the governor, accompanied us two or three miles out of town. At parting he prayed God to bless us; and, laying his hand on his forehead, said he hoped we should ever continue friends. The road at first followed the borders of the marsh, by the side of the Little River, which suddenly breaks off to the southward, at a town called Goobeer. There we filled our goat skins with water. We continued our course, and shortly came to a strong red clay soil, densely covered with grass so long that it actually overtopped our 
heads, although on horseback. At sunset we halted in the woods for the night. The horses and beasts of burden were last watered, when we filled our water skins. Dr. Oudney was attacked with ague, but luckily the evening proved very mild. For two or three nights past he has had a fire in his tent, which seemed to abate the violence of his cough. This evening, addressing me with resigned composure, he said, "I feel it is all over with me. I once hoped to conduct the mission to a successful termination, but that hope has vanished. Whenever my death takes place, I wish my papers to be put into the hands of Mr. Barrow, or Professor Jameson, provided the request meets with Earl Bathurst's approbation." As this was a painful subject, I did not encourage its renewal, and, according to this solemn injunction of my lamented friend, I have delivered all his papers to Mr. Barrow.

Dec. 29.-After toiling two hours through a thickly wooded country, we came in view of a large plain, with numerous towns and villages. We found the towns by no means so neat as in Bornou, the coozees, or huts, being much smaller, and often in bad repair. The people raise great quantities of grain, principally gussub. We saw five ostriches, which made off from us with great speed. Dr. Oudney was a great deal better. In the afternoon we arrived at Sansan. Our horsemen skirmished a little in front of the caravan before entering the town, and then galloped up in pairs to the governor's door, firing off their muskets. 'This is the common compliment paid by kafilas in such cases. The governor was absent on an expedition, headed by the governor of Katagum, against the Bedites, who are in the immediate neighbourhood. As before observed, the Bedites have never received the doctrines of Mahomet; and, although speaking the language of Bornou, and acknowledging a kind of nominal sovereignty of the Bornouese sultan, they are every where regarded as a race of outlaws, whom it is incumbent on every good Mussulman, Bornouese, or Felatah, to enslave or murder. This 
race is said to have no religion; but their common practice of first holding up to heaven the carcass of any animal, killed for food, belies their being atheists - a reproach attributed to them solely by their enemies. On the contrary, it harmonizes with those universal feelings of reverence and awe for a Supreme Being, which have ever existed among all nations, and in all ages. 'The favourite food of this persecuted tribe is said to be dogs, which they fatten for the purpose. Their country is of small extent, defended by impenetrable morasses and forests, by which alone they preserve a precarious and dangerous independence.

At Sansan we were waited upon by the principal native inhabitants, and the resident Arabs. Among the Arabs there was a cousin of the sheikh of Bornou, Hadje El Min El Hanem. The reports of our travelling companions, the merchants, contributed very much to exalt our character wherever we went.

Dec. 30.-At noon I found the latitude of our encampment to be $12^{\circ} 20^{\prime} 48^{\prime \prime}$ north by meridian alt. of lower limb of sun. Sansan in Arabic signifies " the gathering," where the scattered parties of an army assemble previous to an expedition. The town had its name from a late sultan of Bornou, making it the rendezvous of his army when he went to conquer Haussa. The place where he pitched his tent is still held in great veneration, and the buildings around it were first erected by his army. The neighbouring district also abounds in towns and villages, which, together with Bedeguna and Sansan, are under the governor of Katagum, who is himself subordinate to the governor of Kano. Sansan is formed of three distinct towns, called Sansan Birnee, Sidi Boori, and Sansan Bana. The principal one, in which the governor resides, is Sansan Birnee, or Sansan Gora, signifying " the walled," from a low clay wall in ruins, surrounded by a dry ditch almost filled up. The mosque is without a roof, and the huts and houses of the inhabitants are old and dilapidated. Sidi Boori, another of the three towns, having a significa- 
tion so indecent that I must forbear to translate it, is about half a mile west of Sansan Birnee, and inhabited by Shauah Arabs. The third town, called Sansan Bana, or, " of the banners," where the sultan's tent stood, is about a mile distant from Sansan Birnee, and is inhabited by Bornouese, who are here in great numbers, and were first brought by force from Old Birnee, and other towns of Bornou. At present they are quite reconciled to the change, and now remain from choice.

The sister of the sultan of Bornou, having been made captive by the Felatahs, was living here with her husband in great obscurity, although her brother, the sultan, is surrounded by all the barbaric magnificence of central Africa. She came out to meet the kafila, along with several of her countrywomen, from whom she was nowise distinguished in attire. The dress of Bornouese women consists of one or two turkadees, blue, white, or striped, as before described. The turkadee is wrapped rather tightly round the body, and hangs down from the bosom, below the knees. If a second is worn, as by women of some consideration, it is commonly flung over the head and shoulders. Their sandals are the same as those of men, of tanned leather, or of the undressed hide, according to their circumstances. The hair is plaited in five close tresses,-one like a crest along the crown, and two at each side, and thickly bedaubed with indigo. They dye their eyebrows, hands, arms, feet, and legs of the same colour, except the nails of the fingers and toes and the palms of the hands, which are stained red with henna. They blacken the eyelashes with crude antimony in powder. The ornaments for the ear are not pendent like ours, but little green studs, or buttons, fixed in the lobe. The very poorest wear strings of glass beads round the neck, and the wealthy are adorned with armlets and anklets of horn or brass. Ornaments of silver are very rare, and of gold hardly ever seen.

Dec. 31. At sunrise the thermometer was $42^{\circ}$. Being market

$$
d
$$


day, I took a stroll to see what was going on. The market-place was on a rising ground, a little to the south of Sansan Birnee. The place of itself is a little village. The goods were exposed for sale in booths, or houses, open at the side next the street. The different wares were arranged each in its particular quarter,--knives, scissors, needles, and beads; silken cords and pieces of silk; sword slings and koghel cases; gubga tobes and turkadoes; beef, mutton, and fowls; gussub, beans, Indian corn, \&c. They have four different kinds of Indian corn, - the yellow, the red, the white, and the Egyptian. The last is reckoned the best. There were stalls, besides, for making and mending every thing in common use. Bands of music, composed of drums, flutes, and a kind of guitar, with strings of horsehair, called the Erbale, each after its own rude fashion, were parading from booth to booth, to attract the attention of customers.

Jan. 1, 1824.-Dr. Oudney was now very unwell. This morning we had a visit from an ex-governor, of the name of Jesus, who had left the army last night. He told us the commanders would to-day commence their return to their different governments, as they were unable to penetrate into the Bede territory. This person gave us several broad hints to make him a present; but we found ourselves too poor to understand him. At eight o'clock in the morning we resumed our journey, over a level country. The winding road was little broader than a footpath. We passed numerous small towns and villages, with plantations of cotton, gussub, and Indian corn. There was more wood as we re-approached the Yow, and the villages and cotton plantations were also more numerous. We halted at a village called Obenda, not above a quarter of a mile distant from the Yow. We could procure no milk for Dr. Oudney, and his appetite was much worse. We had nothing but kouskasoo and dweeda. The former is a well known preparation of wheaten flour steamed over meat, and in very general use among the Moors and Arabs. The dweeda is also of wheaten flour, and a kind of coarse macaroni. 
Jan. 2.-Dr. Oudney was this morning in a very weak state. I bought a pound of coffee for three dollars from one of the merchants of our kafila, as a cup of coffee was all that he could take. To-day we followed a very troublesome zigzag track, for regular road there was none. We passed many villages, adjoining to which were long double rows of granaries. At first we were much puzzled with the novelty of their appearance; but on a closer examination we found they were constructed of matting in the usual way, and raised on poles to prevent white ants and grubs from getting at the grain. Near the Yow there were large fields of wheat, and plantations of cotton. The people were then raising the second crop of wheat, by means of irrigation.

A little before mid-day we crossed the Yow. Its channel is here about 150 yards in breadth; but the stream of water was almost dry. In order to take fish, the river was barricadoed by a row of fish-pots, made of split bamboos. They are of a conical shape, about five feet in diameter at the mouth, and secured by poles and spars at the distance of three feet from one another, the interval being filled up with reeds to prevent the escape of fish. At this period not more than a third of the aperture was covered with water./ The city of Katagum stands about half a mile from the river, which we had no sooner crossed than we were met by a servant of the governor on horseback. He presented us with a small basket of Goora nuts, called, by the Arabs, the coffee of Soudan. After delivering the present, the servant returned at full speed to a party of horsemen at a little distance, who appeared to be the attendants of some great personage. The party then came to us at a gallop, brandishing their spears. Their leader remained behind, as well as their band of music. The horsemen, after saluting us, wheeled round, and rode on before us, the drummers beating their drums, and two bards singing the praises of their master in the following ditty, which I took down in writing; one responding in a clear shrill voice 
the words of the chorus, while the other sang, or rather bawled aloud :-

Bi, kora, nama, da birkin safay :

Ah ! mi tuga yumma.

Bokri mi tugiamasso:

Ah! mi tuga yumma.

Manoganinka wykigani :

Ah! mi tuga yumma.

My daikee ya fruss undunga:

Ah! mi tuga yumma.

Fuda da goma baka soranko.

Ah! mi tuga yumma.

Kazibda goma bindiga da bia :

Ah! mi tuga yumma.

Gewa nagege avana do dona :

Ah! mi tuga yumma.

Camaraka hamen sirkino:

Ah! mi tuga yumma.

Girtho magaje wali:

Ah! mi tuga yumma.

Allahu Akber you do dona:

Ah! mi tuga yumma.

Allahu Akber you Zaramina:

Ah! mi tuga yumma.

\section{Which may be thus translated :-}

Give flesh to the hyenas at day-break :

$\mathrm{Oh}$ ! the broad spears.

The spear of the sultan is the broadest :

Oh ! the broad spears.

I behold thee now-I desire to see none other

Oh! the broad spears.

My horse is as tall as a high wall:

Oh! the broad spears.

He will fight against ten, he fears nothing :

Oh! the broad spears. 
He has slain ten-the guns are yet behind:

$\mathrm{Oh}$ ! the broad spears.

The elephant of the forest brings me what I want :

Oh! the broad spears.

Like unto thee-so is the sultan :

$\mathrm{Oh}$ ! the broad spears.

Be brave ! be brave! my friends and kinsmen :

$\mathrm{Oh}$ ! the broad spears.

God is great ! - I wax fierce as a beast of prey :

Oh! the broad spears.

God is great!-To-day those I wished for are come :

$\mathrm{Oh}$ ! the broad spears.

Meanwhile, the leader with his horsemen proceeded before us to the city. We halted at a place allotted to us and the Arabs, the Bornouese having left us to pursue their journey, as the dangers of the road were past. About three in the afternoon, we saw the governor, with all his attendants, coming to visit us. Mohamoud El Wordee had mats spread under a tree for his reception, and requested us to remain a few minutes in our tents. When sent for, we found the governor sitting on the mats, surrounded by the Arab merchants and his armed attendants. He received us in the kindest manner, and said it was quite an ayd, or feast, for him to see us, and would also prove highly gratifying to his master, the Sultan of the Felatahs, who had never seen an Englishman before. He assured us, we should find every thing here the same as at Kouka, with the sheikh of Bornou. Dr. Oudney now presented the sheikh's letter, which he handed to one of his attendants. The Arab merchants were loud in our praises, and particularly expatiated on the circumstance of our nation being ever in strict alliance with the Sublime Porte, and of having frequently assisted the Grand Signor. The governor, who was named Duncowa, was a stout, tall fellow, blunt and good natured, and lavish in his promises. We shook hands at parting, which is the custom of the Felatahs, or Felanees, 
as they call themselves. On his return home he sent us some wheat, of which we were in great want, with honey, and Goora nuts. By the advice of Mohamoud $\mathrm{El} \mathrm{Wordee,} \mathrm{we} \mathrm{sent} \mathrm{a} \mathrm{present} \mathrm{of} \mathrm{a} \mathrm{few}$ cloves, and a little cinnamon, in return; which, however small, is every where the proper acknowledgment on such occasions. On account of the scantiness of our own stock of every thing, we now heartily wished for no more presents.

After the governor left us, we were waited upon by a Tripoline merchant, of the name of Hameda, a good-looking, civil sort of man, and extremely rich. He possessed no less than five hundred slaves, and had a great number of horses. He was second only to the governor in all Katagum, and had served with the Felatahs in most of their wars. Referring to the result of the recent expedition, I remarked it would have been better if the Felatahs had not gone at all against the Bedites, who would now be emboldened in their depredations. He replied, the Felatahs had become rich, and were now afraid of blows : it was otherwise with them when poor ; their head men then led them to battle, dauntlessly braving danger and death, whereas now-a-days their chiefs lagged behind, and sent their people forward to the combat, who, in turn, dreaded a broken head as much as their superiors, and would no longer fight, if it might anywise be avoided.-Hameda had occasion to consult Dr. Oudney, who strongly recommended his immediate return to Tripoli, to undergo a surgical operation. He seemed very grateful, and offered us his house, and whatever the country afforded. He sent milk for Dr. Oudney, and bazeen, or flour-pudding, for me. Bazeen is made of wheat, barley, or Guinea corn, and eaten with butter or sauce.

Dr. Oudney underwent here, as usual, much fatigue,-more, indeed, than his strength was equal to; for the news of our arrival spread before us, and at the different towns and villages through which we passed, they brought to us all the sick to be cured. Nor was it the sick alone who sought advice, but men and women, of all 
descriptions; the former for some remedy against impotency, and the latter to remove sterility. Many came for preventives against apprehended or barely possible calamities ; and, in anticipation of all the imaginable ills of life, resorted to us in full hope and confidence of our being able to ward them off. The women were particularly fanciful in these matters, and were frequently importunate to receive medicines that would preserve the affections of their gallants, ensure them husbands, or, what was highly criminal, effect the death of some favoured rival. The governor made us a present of three sheep, and sent the Arab merchants eight bullocks.

Jan. 3.-Dr. Oudney was a little better, but still very weak. Having early prepared our presents, which consisted of one of our tea-trays, ten yards of red silk, an Indian palempore, or bed coverlet, a piece of white linen cloth, with gold stripes, of Egyptian manufacture, a pound of cinnamon, and a pound of cloves, we waited on the governor at eight o'clock in the morning, accompanied by Mohamoud El Wordee. We stopped about a quarter of an hour in the house of Hameda, till the governor was ready to receive us. When introduced, we found no parade of armed men, as at Kouka, and the other towns in Bornou. Duncowa was sitting under a rude canopy, on a low bank of earth about six feet square. There were only three old men with him. We shook hands, and sat down on the floor before him. He importunately laid hold of me, and wished me to sit by his side. I, however, declined so high an honour. We were presented with Goora nuts, and he repeated the promises he had made yesterday. When we displayed our presents, and explained the use of the tray, and what it was made of, he was highly delighted; and asked us if we wanted slaves, or what else, for every thing he had or could procure was at our disposal. With regard to slaves, we told him a slave was unknown in England, and the moment one set foot on our shores, he was instantly free. We also explained our great endeavours to put 
a stop to the slave trade on the seacoast, and that.our king and master (to use the African idiom) had given immense sums to have it abolished; besides sending, every year, several large ships to capture vessels engaged in that traffic, and to set the slaves at liberty. "What, then, do you want?" he asked, with some surprise. We answered, we only desired his friendship, and condescending permission to collect the flowers and plants of the country, and to visit its rivers. "Wonderful !" he exclaimed, "you do not want slaves, you do not want horses, you do not want money, but wish only to see the world? You must go to the sultan Bello, who is a learned and pious man, and will be glad to see men who have seen so much. You shall have all, and see all, that is in my province; and I am sure my master will grant eviery thing you wish." He then descended from the seat of honour, sat down on the floor by our side, and shook hands with us. This is the greatest compliment one man of rank can pay to another in this country.

One of their lucky omens took place at the moment. My servant, who had assisted in bringing the presents, got up to receive the Goora nuts presented to me by the governor's orders, and in rising he overturned a pot of honey which had also been given to us, but without breaking it, the honey running out on the floor. Had the pot been broken, the omen would have been unfortunate. As it was, the governor was highly elated, and graciously ordered the poor to be called in to lick up the honey. They immediately made their appearance, equally rejoiced at the lucky omen, and upon their knees quickly despatched the honey, not without much strife and squabbling. One man came off with a double allowance, happening to have a long beard, which he carefully cleaned into his hand for a bonne bouche, after the repast on the ground was finished.

We took leave of the governor and returned to our tents, where a great concourse of men and women flocked to Dr. Oudney for medicines. In the evening we had boiled dried meat, with bazeen, 
and excellent bread, sent us by our friend Hameda; also milk from the governor, and a live sheep from a black shreef, who had applied to Dr. Oudney for advice. To-day the Doctor felt himself very weak, in consequence of a diarrhøea, and the want of proper comforts in his infirm condition. At noon I took an observation of the sun. At first the natives eagerly crowded round me, but sat down very quietly at a little distance, on telling them they were in my way. I was asked the old question every where repeatedly, if I was looking at my country. I explained to them, as well as I was able, that I merely ascertained in this manner how far south I had come from home.

Jan. 4th.-The weather cold and hazy,--thermometer $48^{\circ}$. Mohamoud El Wordee having gone to a city called Hadeeja, one day's journey to the northward, where he was to remain a day or two, it was agreed beforehand we should go into the town and live in $\mathrm{Ha}$ meda's house until El Wordee's return, as the kafila was to proceed to Kano the following day. At sunrise the governor sent to us to come into town, but on account of Dr. Oudney's illness, we waited till the heat of the day. About noon we had the camels loaded, and Dr. Oudney and I rode forward, accompanied by the governor's people and Hadje ben Hamed, the sheikh of the kafila, or chief who regulates its march, stage, and route. On entering the town, we were conducted to a house that adjoined Hameda's, which we supposed to be his. The people around us, after consulting together, told us we had better go and see the governor. Dr. Oudney assented, but wished first to wait for our baggage. The people, however, urged us to go without further delay; and we complied with their entreaties. The governor met us at the gate of his residence, took us by the hand, and led us first to one coozee, then to another, saying, " This is for you,--that is for the Doctor,-there is a place for your horses." Seating himself on a mat, he bade us sit down. Our baggage was brought to us in a few minutes. " $\mathrm{Ab}$ - 
dullah," said he, addressing me by my travelling name, "show me the glass with which you look at the sun." It seemed the people had told him what they saw me doing yesterday. I had now to explain to him the use of my compass, sextant, spy-glass, and other instruments. He begged of me a little of the quicksilver used for an artificial horizon in taking observations. This was like asking me to part with my heart's blood; but as he was a governor, and evidently a man of considerable influence, I could not refuse him. I took much pains to make him understand the use of the watch and sextant. I easily made him comprehend the latter, by telling him it was to enable me to find out the distance north or south, from any other place: illustrating the matter, by telling him the north star was higher in the heavens at Mourzuk than here, and still higher at Tripoli; a circumstance the natives of these countries all confirmed, to whom I shifted the trouble of making further explanations. The telescope next was an object of surprise. He said all the places he saw were brought near to him, and ascended the walls and house tops to have a better view. Each of his attendants also had a peep; but an old shreef would on no account look through it, but ran away as if from a serpent ready to sting him. As to these shreefs, or alleged descendants of the Prophet, some of whom are as black as jet, I wonder what Mahomet, were he to rise from the dead, would say to his sable progeny, not merely black in colour, but with the true Negro features! The phenomenon, however, is less wonderful, when we consider how soon an intermixture, whether black or white, is lost in the course of a few generations, although the lineal descent continue uninterrupted.

We received a plentiful supply of provisions from Hameda. The governor also sent us fish and ficcory. The latter consists of pounded Guinea corn dried in the sun, mixed with water or milk, and seasoned with pepper, but has a sour, disagreeable taste.

Katagum, the capital of a province of the same name, is in 
lat. $12^{\circ} 17^{\prime} 11^{\prime \prime}$ north, and in long. about $11^{\circ}$ east. This province formed the frontier of Bornou before the Felatah conquest. At present it includes the subject provinces of Sansan and Bedeguna. It extends nearly one day's journey to the northward, and five days' journey to the southward, where it is bounded by an independent territory, ealled after the inhabitants Kurry-kurry. On the east it is bounded by the kingdom of Bornou, and on the west by the neighbouring province of Kano. From the best information I could obtain, the whole province can send into the field about 4,000 horse and 20,000 foot, armed with bows, swords, and spears. The principal productions are grain and bullocks, which, with slaves brought from the adjoining territories of the Kafirs, are the staple articles of trade. Here we found, for the first time, kowrie shells in circulation as money ; for hitherto native cloth, or some other commodity of standard price, had been the common medium of exchange. This city was the strongest we had seen since we left Tripoli. It is in the form of a square, the sides facing the cardinal points of the compass, with four corresponding gates, which are regularly opened and shut at sunrise and sunset. It is defended by two parallel walls of red clay, and three dry ditches, one without, one within, and the third between the two walls, which are about twenty feet high and ten feet broad at the base, gradually decreasing upwards to a breadth just sufficient for a narrow footpath. This is protected by a low parapet, and is ascended by flights of steps at convenient distances. Both walls are of the same height, without loopholes or towers, and, instead of being crenelated, terminate in a waving line. The gates are defended by a platform inside over the entrance, where a body of townsmen take their station to repel assailants. The three ditches are of equal dimensions, each about fifteen feet deep and twenty feet wide. There is only one mosque, and this almost in ruins. The governor's residence is in the centre of the city, and occupies a space of about 500 yards square. The governor and principal

e 2 
inhabitants have houses made entirely of clay, besides the coozees already described. They are flat-roofed, in the Turkish style, and sometimes of two stories, with square or semicircular openings for windows. The city may contain from 7,000 to 8,000 inhabitants; including all merchants and tradesmen, together with the servants or slaves of the governor.

Not far to the southward of Katagum is the country of Yacoba, of which I shall mention a few particulars, collected from natives who were here in slavery, as well as from Hameda. It is called by the Mahometan nations Boushy, or country of infidels. It is extremely hilly : the hills, consisting of limestone, are said to yield antimony and silver. The inhabitants have received the name of Yemyems, or cannibals; but with what justice I know not. Most probably the imputation is an idle Arab tale, and undoubtedly the more suspicious, from the well known Moslem abhorrence of Kafirs. On interrogating the Arabs more strictly, they allowed they had never witnessed the fact; but affirmed they had seen human heads and limbs hung up in the dwellings of the inhabitants. At Mourzuk, when we first arrived, a similar report was circulated to our defamation; whether in jest or earnest, I could not ascertain; but the prejudice soon wore off when we were better known.

The river Yow, which is within a quarter of a mile of Katagum, is said to take its rise to the southward among the hills of Boushy, between Adamowa and Jacoba, and after passing Katagum, to turn abruptly to the eastward; it finally empties itself into the Tshad. Its waters were dull and sluggish, as far as we observed; and during the middle of the dry season the naked channel and a few pools of water, sometimes far apart, are all that remain of the river. The breadth of the channel, at the place where we last crossed, was, as above mentioned, about 150 yards; and this may be taken as a fair average breadth from that spot downwards as far as the lake, 
where, however, the depth seemed considerably increased. There is a prevalent opinion among the inhabitants and Arab merchants that, during the rainy season, the waters of this river rise and fall alternately every seven days; which notion, perhaps, originates in a kind of vicissitude in the fall of rain that $I$ have remarked myself during my residence in Bornou.

Jan. 5.-Dr. Oudney thought himself a little better, but the diarrhøa still continued. The kafila left us this morning for Kano. We had a visit from the governor; I happened to be from home, and was sent for. On my return the governor was gone, and had left a message for me to follow him with the compass, spy-glass, \&c. as he wished me to show them to some men of rank: I followed, and found him seated in the company of two or three Felatahs, to whom I had to explain the use of the instruments over again; but a good deal of trouble was taken off my hands by the governor himself, and his Fezzanee servants. I was then taken to visit his favourite wife, who pretended, of course, to be much frightened at the sight of a Christian; she was a jolly, good looking, black wench. The governor had a great number of other women besides, whose dwellings were all very clean and neat. I was next conducted through other quarters of the residence; and, on reaching the stables, we all sat down in an open court, where the cadi and another learned Felatah joined us. The same explanations had again to be repeated. The cadi, who had made the pilgrimage of Mecca, and was acquainted with Arabie learning, appeared to be a man of sense and discernment, and explained the use of the watch to his countrymen with much perspicuity; he was a Felatah, about fifty years of age,-his complexion coal black, - with a hook nose, large eyes, and a full bushy beard. The office of cadi or judge, I may remark, is frequently hereditary, and there is one in every town to administer justice: his sole qualification is a competent knowledge of the Koran, although 
his decisions can be reversed only by the governor of the province, or the sultan of the country.

The governor resides in a large square, surrounded by a wall of red clay, at least thirty feet high, and divided by lower walls into four principal quarters : besides several flat-roofed houses of clay, it contained a number of coozees, for the most part ranged in a single row, just within the great walls. These are principally for the slaves and guards attached to the governor's establishment; it was here we were lodged, the entrance being guarded night and day. Near the eastern gate there was a sort of council or audience hall, from which a passage led to the women's apartments, on the north side of the square. The stables occupied one quarter, each horse having a hut to itself. The pillars that supported a room over the western gate were superior to any $I$ had seen in central Africa; they were formed of the trunks of the palm tree, fashioned into columns, with rude pedestals and capitals of no inelegant appearance, all incrusted with clay.

Jan. 6.-Dr. Oudney was much better to-day. In the afternoon we had a visit from the governor: I had again to show him the sextant and other instruments. He was particularly inquisitive about the rockets we had given to the sheikh of Bornou; he persisted we had still some of them remaining, and when convinced of the contrary, seemed exceedingly desirous I should make him a few. I assured him, with regret, of my inability; while I professed it to be an express duty imposed on me by the king my master, to instruct him and his countrymen in every thing useful and curious. Among many other questions, he asked me if I ever prayed; I said, I should not be a good man if I did not pray, but that we usually prayed alone: at which answer he was highly amused.

Hadje Ali Boo Khaloom (the brother of the late commander of our escort from Mourzuk) arrived here to-day, with a kafila from 
Kouka : they left that place seven days after us. I heartily wished never to see the face of this arrant rogue.

Jan. 7.-The governor paid us an early visit this morning; he came at once into my tent, while I was writing, and I was again obliged to show him my instruments. On opening my chest, there was a small box of powder I had brought from England, still untouched; I was very loth to tell him what it was, but it attracted his attention, and I was compelled to yield to his solicitations for a small supply. To humour him further, I attended him to fire at a mark; I fired twice with my rifle, and happened to hit the mark both times, at a distance of sixty or seventy yards, when he called out "Ouda billa min Sheateen a rajeem," - "The Lord preserve me from devils !" yet, in token of his approbation, he threw over my shoulders, with his own hands, a very handsome tobe.

Jan. 8.-I was indisposed all day, having caught cold.

Jan. 9.-This morning Hadje Ali Boo Khaloom left us for Kano. He tried all in his power to induce us to accompany him, but we knew him too well of old : he even asked the governor to send one of his people with him, but was only laughed at for his assurance.

Our servants caught a female rat, or bandicoot, as it is called in the East Indies, which measured two feet seven inches from the nose to the tip of the tail. The colour of the body was light grey, the tail black, and covered with long hairs, and the head much rounder than that of the common rat.

The diarrhoea of Dr. Oudney had ceased, but the cough was no better, and he was otherwise extremely ill : he had himself cupped on the left side of the chest by one of the natives. This operation is dexterously performed by them; they make the scarifications with a razor, and afterwards apply a perforated horn, from which they first extract the air by suction, and then stop the aperture with the thumb. 
We had a visit from the wife of the cadi, a sister of Duncowa. I gave her a brass ring, a pair of scissors, and some beads.

In the afternoon, I was not a little astonished at a message from the governor, brought us by $\mathrm{El}$ Wordee, acquainting us that Hadje Ali had told him we were spies and bad people, and wishing to know from us if it was true. I did not think proper to disturb Dr. Oudney by relating to him this calumny, and merely desired El Wordee to say to the governor, that as we were in his power he could do with us as he pleased; at the same time referring him particularly to the letter of the sheikh of Bornou. El Wordee came back almost immediately, and assured me the governor was satisfied.

Jan. 10.-To-day we left Katagum; the governor having furnished us with a guide. We had a bassoor, or frame of wood, put on a camel, and spread Dr. Oudney's bed upon it, as he was now too weak to ride on horseback; I also felt myself unwell. The governor accompanied us four miles out of town. At half past three o'clock in the afternoon we were obliged to halt, on account of Dr. Oudney's weakness; he was quite worn out, and could proceed no further; the road, too, being crooked and entangled, and lying along a large swamp to the south. We passed a number of villages.

Jan. 11.-At eight o'clock in the morning we proceeded on our journey; but, at noon, were obliged to stop at the town of Murmur, on account of the alarming situation of Dr. Oudney, who had now become so feeble and exhausted, that I scarcely expected him to survive another day. He had been wasting away in a slow consumption, ever since we left the hills of Obarree, in Fezzan; where he was seized with inflammation of the chest, in consequence of sitting down in a current of cold air after being overheated.

Jan. 12.-Dr. Oudney drank a cup of coffee at day-break, and, by his desire, I ordered the camels to be loaded. I then assisted him to dress, and, with the support of his servant, he came out of the 
tent; but, before he could be lifted on the camel, I observed the ghastliness of death in his countenance, and had him immediately replaced in the tent. I sat down by his side, and, with unspeakable grief, witnessed his last breath, which was without a struggle or a groan. I now sent to the governor of the town to request his permission to bury the deceased, which he readily granted; and I had a grave made about five yards to the north of an old mimosa tree, a little beyond the southern gate of the town. The body being first washed, after the custom of the country, was dressed by my directions, in clothes made of turban shawls, which we were carrying with us as presents. The corpse was borne to the grave by our servants, and I read over it the funeral service of the church of England, before it was consigned to the earth; I afterwards caused the grave to be enclosed with a wall of clay, to keep off beasts of prey, and had two sheep killed and distributed among the poor.

Thus died, at the age of 32 years, Walter Oudney, M. D., a man of unassuming deportment, pleasing manners, stedfast perseverance, and undaunted enterprise; while his mind was fraught at once with knowledge, virtue, and religion. At any time, and in any place, to be bereaved of such a friend, had proved a severe trial; but to me, his friend and fellow traveller, labouring also under disease, and now left alone amid a strange people, and proceeding through a country which had hitherto never been trod by European foot, the loss was severe and afflicting in the extreme. 
Aт day-break, on the following morning, I resumed my journey, trusting to the salutary effects of change of air and abstinence, as the best remedies both for mind and body. The road was swampy, and we crossed a narrow stream called Shashum, that falls into the Yow, near the town. There were numerous villages on all sides.

Jan. 14. - Thermometer $52^{\circ}$. Our road lay through a well cultivated country ; at nine o'clock, A. M., we came to the town of Digoo, having an indifferent double wall, and a triple ditch nearly filled up. The town contained very few houses, but date trees were in great abundance; outside the walls, however, there were several villages, or rather detached clusters of houses. The country afterwards began to rise into ridges, running nearly east and west; our road lying along one of them, gave me an excellent view of beautiful villages all around, and herds of cattle graxing in the open country. In the evening we halted under the walls of a town called Boogawa; this is the last town in the province of Katagum: I did not enter it.

Jan. 15. - The road to-day was through a thickly wooded country. Before mid-day, we again crossed the Shashum, which here runs nearly due north. The camel-drivers brought me a quantity of wild figs, which they found on the trees by the road side, near the river. We next entered an open, well cultivated country, and in the evening halted at a town called Katungwa, which is surrounded by a wall, and has a number of fine date trees. This was the first town I entered in the kingdom of Haussa Proper. I was visited by a 
Felatah, who had been at Bagdad, Constantinople, Jerusalem, and Mecea, and belonged to the order of Dervishes. He was a chattering little fellow, and told me he had seen the Wahabees at Mecca, who, he said, were the same people and spoke the same language as the Felatahs. I made him a present of a pair of scissors and a snuff-box, of which he seemed very proud, and sent me a bowl of bazeen in the evening. I here saw a range of low rocky hills, stretching nearly south-west. They are called, in the language of Haussa, Dooshee, or The Rocks, from which a large town on one of the roads leading from Katagum to Kano takes its name. Since we left the Wells of Bellkashiffra, on the southern borders of the great desert, we had not met with rocks, or even pebbles, till now, the very channels of the rivers being destitute of stones, and the whole country consisting of soft alluvial clay. The camels were missing, and I sent all the servants after them; they were not brought back before midnight, being found on their return to Bornou.

Jan. 16.-The country still open and well cultivated, and the villages numerous. We met crowds of people coming from Kano with goods. Some carried them on their heads, others had asses or bullocks, according to their wealth. All were armed with bows and arrows, and several with swords; the Bornouese are known by carrying spears.

El Wordee and I having advanced before the cavalcade were waiting for it under a tree, near a town called Zangeia, when a man from Katagum went, of his own accord, and told the governor of Zangeia that a friend of the governor of Katagum was close at hand. The governor of Zangeia sent the man to tell us he would come and meet us on horseback, and show us a proper place to pitch our tents. We mounted our horses, and, led by the Katagumite who was so anxious for the honour of the friend of his master, we met 
the governor, about a quarter of a mile from the tree under which we had reposed ourselves. He was mounted on a very fine white horse, gaily caparisoned, and had seven attendants behind him, also on horseback, besides being accompanied by several men on foot, armed with bows and arrows. He advanced to us at full gallop, and, after many courteous welcomes, placed himself at our head, and rode before us into the town. On reaching his own house, he desired us to pitch our tents before his door, observing, "Here is a place of great safety." The camels arriving with the baggage, I presented him with a razor, a knife, a pair of scissors, and some spices. He sent me, in return, some milk and bazeen, with grass and gussub for the horses. Although a governor, I found out he was only a eunuch, belonging to the governor of Kano. He was in person fat, coarse, and ugly, with a shrill squeaking voice, and kept me awake half the night, laughing and talking among his people.

Zangeia is situate near the extremity of the Dooshee range of hills, and must have been once a very large town, from the extensive walls which still remain. The inhabitants were slaughtered or sold by the Felatahs, and plantations of cotton, tobacco, and indigo now occupy the place where houses formerly stood. Indeed the town may be said to consist of a number of thinly scattered villages. Within the walls there is a ridge of loose blocks of stone, connected with the range of hills in the neighbourhood. These masses of rock may be about two hundred feet high, and give a romantic appearance to the neat huts clustering round the base, and to the fine plantations of cotton, tobacco, and indigo, which are separated from one another by rows of date trees, and are shaded by other large umbrageous trees, of whose names I am ignorant. The prospect to the south was bounded by high blue mountains. It was market day; plenty of beef, yams, sweet potatoes, \&c. for sale. 


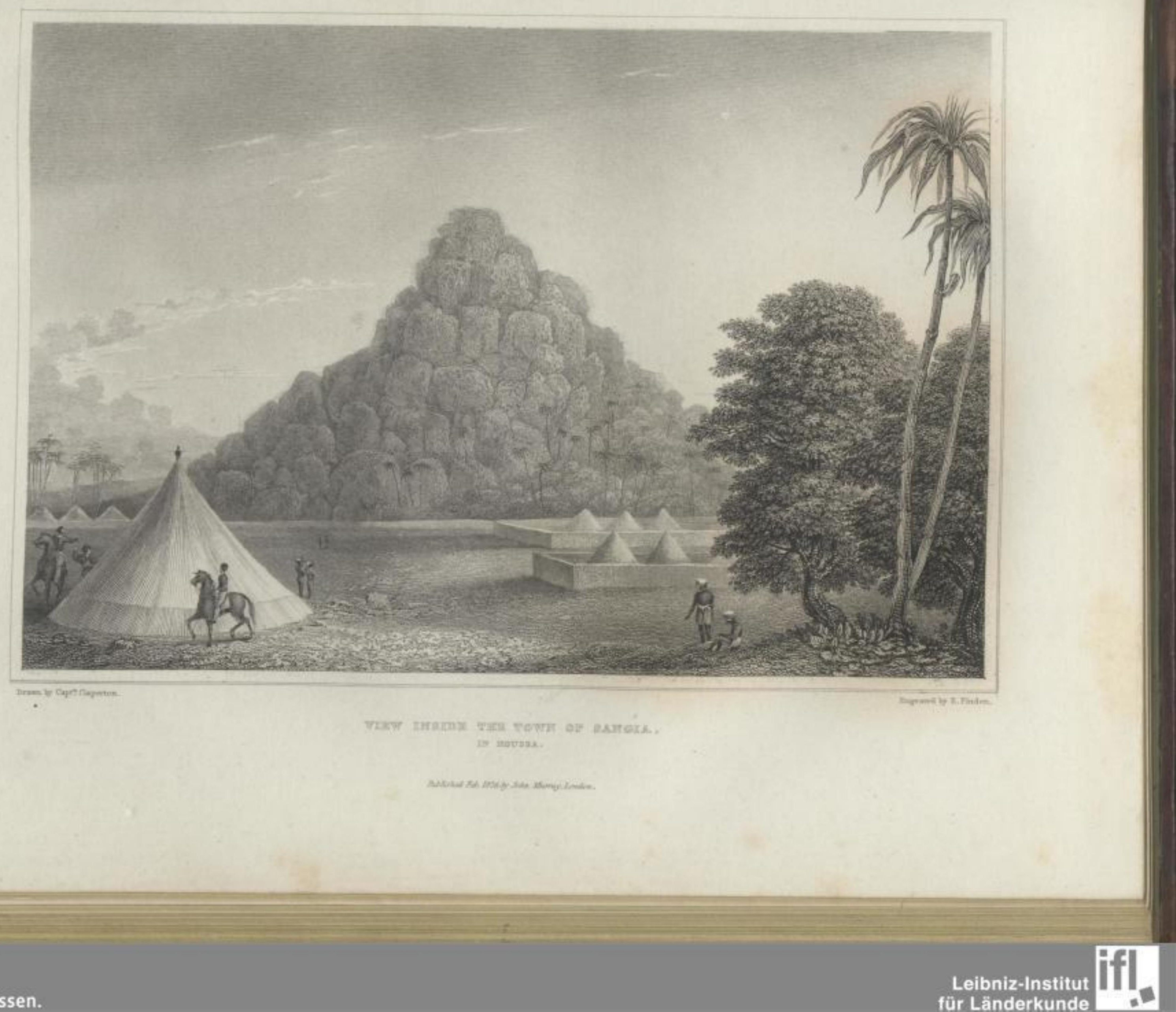


Jan. 17.-The country still highly cultivated, and now diversified by hill and dale. We passed a remarkable range of little hillocks of grey granite; they were naked rocks, flattened or rounded at top, and appeared like detached masses of stone rising singly out of the earth. We also passed several walled towns quite deserted, the inhabitants having been sold by their conquerors, the Felatahs. Women sat spinning cotton by the road side, offering for sale, to the passing caravans, gussub water, roast meat, sweet potatoes, cashew nuts, \&c. In the afternoon, we halted in a hollow, to the west of a town, or rather a collection of villages, called Nansarina, where it was also market day. The governor, when he heard of my arrival, sent me milk and bazeen. I sent him, in return, a pair of scissors and a snuff-box.

Jan. 18.-When I ascended the high ground this morning, I saw a range of hills to the south-west, which, I was told, were called Dul, from a large town at their base. They appeared to be 600 or 700 feet high, not peaked, but oval topped, and running in a direction nearly north and south. I could not learn how far southward they extended. We crossed a little stream, flowing to the north. The country continued beautiful, with numerous plantations, as neatly fenced as in England. The road was thronged with travellers, and the shady trees by the road side served, as yesterday, to shelter female hucksters. The women not engaged in the retail of their wares were busy spinning cotton, and from time to time surveyed themselves, with whimsical complacency, in a little pocket mirror. The soil is a strong red clay, large blocks of granite frequently appearing above the surface.

At eleven in the morning we halted at a walled town called Girkwa, through which I rode with $\mathrm{El}$ Wordee. The houses were in groups, with large intervening vacancies, the former inhabitants having also been sold; the walls are in good repair, and are sur- 
rounded by a dry ditch. It was market day, and we found a much finer market here than at Tripoli. I had an attack of ague, - the disease that chiefly prevails in these parts, - and was obliged to rest all day under the shade of a tree, A pretty Felatah girl, going to market with milk and butter, neat and spruce in her attire as a Cheshire dairy-maid, here accosted me with infinite archness and grace. She said I was of her own nation ; and, after much amusing small talk, I pressed her, in jest, to accompany me on my journey, while she parried my solicitations with roguish glee, by referring me to her father and mother. I don't know how it happened, but her presence seemed to dispel the effects of the ague. To this trifling and innocent memorial of a face and form, seen that day for the first and last time, but which I shall not readily forget, I may add the more interesting information to the good housewives of my own country, that the making of butter such as ours is confined to the nation of the Felatahs, and that it is both clean and excellent. So much is this domestic art cultivated, that from a useful prejudice or superstition, it is deemed unlucky to sell new milk; it may, however, be bestowed as a gift. Butter is also made in other parts of central Africa, but sold in an oily fluid state something like honey.

A native of Mourzuk who resides here sent me some kouskousoo and fowls. I received a visit from a black shreef, who informed me he had seen the sea, and that a river I should cross on the morrow communicated between the Kowara and the Yow. By the Kowara, I understood him to mean the river that passes Timbuctoo, and which, of late years, has been so much talked of in Europe, under the name of Niger. This was a piece of gratuitous information, for on cross-questioning him he could furnish no authority for his opinion. But I soon discovered the whole trick, by El Wordee strongly recommending me to give my informant a present. The country to the south and south-west was very hilly. 
Jan. 19.-We crossed a water-course called Girkwa, from the name of the town in its immediate vicinity. It is the channel of the same river the black shreef alluded to, but did not now contain a drop of water. Indeed the channel itself is extremely shallow, and only about sixty or seventy yards across. The guide furnished me by the governor of Katagum told me, that the river took its rise in the mountains of Dul, and falling into another river, which we should soon come to, and which rose among the mountains of Nora, their united waters flowed into the Yow, to the north of Katagum.

The country was much the same as yesterday; clear of wood, well cultivated, and divided into plantations. At noon we crossed the river Sockwa, alluded to above, and forming a junction with the Girkwa. The water was not above ankle deep in the middle of the stream, which did not now fill one twentieth part of the channel, and both rivers, I have no doubt, are at all times fordable, even during the rainy season. About a mile from the banks of the river, we passed the town of Sockwa, which is defended by a high clay wall. Being very unwell, I did not enter the town, but rode on through a clear, open country, to the town of Duakee, where I halted under a tree until the camels came up. This town is also walled, but contains few inhabitants, although the walls, made of clay like all the others, are of great extent, and in good repair. Before four o'clock the camels arrived, and we pitched our tents. under the tree where I had lain down. The road was still crowded, from sunrise to sunset, with people going to or coming from Kano.

Jan. 20.-By El Wordee's advice, I prepared myself this morning for entering Kano, which was now at hand. Arrayed in naval uniform, I made myself as smart as circumstances would permit. For three miles to the north of Duakee, the country was open and well cultivated. It then became thickly covered with underwood, 
until we ascended a rising ground, whence we had a view of two ' little mounts within the walls of Kano. The soil here is a tough clay mixed with gravel, the stones of which appear to be clay ironstone. The country was now clear of wood, except here and there a few large shady trees, resorted to as usual by the women of the country selling refreshments. The villages were numerous, and the road was thronged with people of all deseriptions.

At eleven o'clock we entered Kano, the great emporium of the kingdom of Haussa; but I had no sooner passed the gates, than I felt grievously disappointed; for from the flourishing description of it given by the Arabs, I expected to see a city of surprising grandeur: I found, on the contrary, the houses nearly a quarter of a mile from the walls, and in many parts scattered into detached groups, between large stagnant pools of water. I might have spared all the pains I had taken with my toilet; for not an individual turned his head round to gaze at me, but all, intent on their own business, allowed me to pass by without notice or remark.

I went with El Wordee directly to the house of Hadje Hat Salah, to whom I had a letter of recommendation from the sheikh of Bornou. We found Hat Salah sitting under a rude porch in front of his house amid a party of Arabs, Tuaricks, and people of the town. When El Wordee presented me, and told him of the sheikh's letter of recommendation, he bade me welcome, and desired me to sit down by his side. After exchanging many compliments, I-inquired for the house he had hired for me, as El Wordee had sent a messenger on horseback the day before, to inform him of my approach, and to request him to have a house ready for my reception. Hat Salah now sent one of his slaves to conduct us to the house.

We had to retrace our steps more than half a mile through the market-place, which is bordered to the east and west by an extensive swamp covered with reeds and water, and frequented by wild ducks, cranes, and a filthy kind of vulture. The last is ex- 
tremely useful, and by picking up offal serves as a sort of town scavenger. The house provided for me was situated at the south end of the morass, the pestilential exhalations of which, and of the pools of standing water, were increased by the sewers of the houses all opening into the street. I was fatigued and sick, and lay down on a mat that the owner of the house spread for me. I was immediately visited by all the Arab merchants who had been my fellow travellers from Kouka, and were not prevented by sickness from coming to see me. They were more like ghosts than men, as almost all strangers were at this time, suffering from intermittent fever. My house had six chambers above, extremely dark, and five rooms below, with a dismal looking entrance or lobby, a back court, drawwell, and other conveniences. Little holes or windows admitted a glimmering light into the apartments. Nevertheless this was here thought a handsome mansion. I paid at first a rent of three dollars a month; but it was afterwards reduced to two dollars. El Wordee was my next door neighbour.

In the evening Hat Salah sent me a sheep, some honey, and a dinner ready cooked. I received a similar present from Michah Eben Taleb, the brother of an Arab merchant of Sockna, residing at Kouka, to whom $I$ had a letter of introduction, with an order for the payment of a hundred dollars.

Jan. 21. - The weather cool and clear. This afternoon I delivered to Hadje Hat Salah the sheikh's letter, and accompanied it with a present of two turban shawls, made of wool and cotton, one white, the other red, both of French manufacture, a scarlet Turkish jacket, lined with silk and trimmed with gold lace, that had belonged

- to the late Dr. Oudney, two clasp knives, two razors, two pair of scissors, two paper snuff-boxes, and one of tin, about a pound of spices, and a parcel of thin brass ornaments for children's caps. These are of the size of a sixpence, stamped with fancy heads, and made at Trieste for the Barbary market. He was much pleased with 
my present, and promised to present me to the governor in two days. In the evening provisions were sent me as before, both by Hat Salah and Michah Eben Taleb.

Jan. 22.--I had a visit from Hat Salah to-day, when I presented him with half a pound of French gunpowder and a few flints. Being very unwell, I remained at home all day.

Jan. 23.-I was still confined to the house by indisposition. In the evening I overheard a conversation concerning the river Quarra, between my servant and the man the governor of Katagum sent with me. The latter described it as running into the sea at Raka, and added the following particulars. The country is called Yowriba by the natives. The ships of Christians visit the town, which is only twenty-four days' journey from Nyffee at a quick rate of travelling, or thirty-two days at a leisurely pace. The river is there as wide as from Kano to Katagum, and the waters salt. Although I think proper to notice this incident, I must at the same time observe, that I place little dependence on such accounts. Next morning I put several questions to him, but he told me quite a different story; for it is commonly believed among them that strangers would come and take their country from them, if they knew the course of the Quarra. Nyffee, as I afterwards learned, is distant from Kano about twelve days' journey.

Jan. 24.-At seven in the morning I set out, accompanied by El Wordee and Hat Salah, to visit the governor, who was at the sansan, or camp, five miles east of Kano. I took with me the sheikh's letter and a present $I$ had prepared the day before, consisting of a sword, a tea-tray, a spy-glass, twenty yards of yellow silk, a white turban, a French shawl, three snuff-boxes, two razors, four clasp knives, two pair * of scissors, a few brass trinkets for children's caps, as already described, and two pounds of spices, besides a broken thermometer, which I understood would be very acceptable. Of course, I could not spare either of the only two thermometers which had hitherto escaped accidents. 
A thermometer is descriptively named by the natives "a watch of heat," and was every where regarded as a great curiosity. I also took a present for the wan-bey, or governor's chief minister, of a French shawl, a large Egyptian shawl, a pound of cloves and cinnamon, a razor, a clasp knife, a pair of scissors, and two snuff-boxes. The sansan, where the governor now was, is a rendezvous for the army. The governor then intended to march against Dantanqua, a former governor of Kano who was deposed, and who, having rebelled, had seized upon a large town and territory called Doura, only distant one day's journey, or about twenty-two English miles, according to the common allowance for a day's journey. I was not a little surprised to find this sansan a walled town of considerable extent. El Wordee and Hat Salah informed me it had been built these five years, the governor of Kano having made for that period a yearly excursion against the rebels, without ever bringing them to a decisive engagement.

We proceeded immediately to the governor's house, which is about 500 or 600 yards from the gate. At the outer guard house, I found all the Arab merchants in attendance, with the horses they had for sale. The governor is always entitled to the first choice; but if he declines them at the price affixed, any other person may become the purchaser. We were shown into the house of the wanbey, until the governor was ready to receive us. In a short time he sent for me: I was accompanied by El Wordee and Hat Salah; but as he does not usually admit Arab merchants into his presence, El Wordee was in this instance specially favoured on my account. When introduced, we had to pass through three coozees or guard houses, the walls of which were covered with shields, and the doors guarded by black eunuchs. These coozees were connected by screens of matting covered over head. The governor was seated at the entrance of an inner coozee. After shaking hands with him, he desired us to sit down: I then produced the presents, explaining to 
him particularly the use of the spy-glass, and commending the sword, by acquainting him that such were worn by the great nobles of England, when they attended on the king. He seemed highly pleased, and bade me a thousand welcomes to the country. I next delivered the sheikh El Kanemy's letter. He read it, and told me he expected to return to Kano in fifteen days, and would then send me to his master Bello, who, he knew, would be very glad to see me. We shook hands again at parting. The governor is a Felatah, of a dark copper colour and stout make, and has the character of being very devout and learned. Except $\mathrm{El}$ Wordee and Hat Salah, the wan bey was the only person present, at this interview, whom we next accompanied to his house, where I gave him his present without any ceremony. He was a thin, slender man, of a pretty fair complexion, with only one eye, and was clad in a rather dirty tobe. He was said to be the father of fifty sons-a circumstance which is here regarded as a matter of much respect and honour. I returned immediately to Kano; but Hat Salah and El Wordee remained behind to sell some horses. Hat Salah had two horses belonging to the late Dr. Oudney to dispose of; one of which was given to him by the sheikh of Bornou, and the other was palmed upon us at Kouka by Hadje Ali Bookhaloom for eighty dollars. The governor of Kano frequently gives from 100 to 120 dollars for a good horse. Mares are seldom for sale, and are highly prized, both for breeding, and because they do not neigh on approaching other horses-a quality that especially fits them for predatory inroads. Geldings are unknown.

Jan. 25 and 26.-I was solicited by some merchants of Ghadamis, settled here, to take supplies of goods or money to any amount, for my bill on our Tripolitan consul; but, having no occasion for advances, I declined this unexpected offer of accommodation, which was frequently and urgently tendered. Ghadamis-the ancient Bydamus $\rightarrow$ is an inland town in the state of Tripoli, and its merchants are 
famed over all central Africa for fair dealing and the extent of their commercial transactions.

Jan. 27 and 28.-The governor sent me a present of a sheep; an immense gourd, upwards of two feet in diameter, filled with wheat; and two other gourds of the same dimensions, filled with rice. A kafila from Bornou arrived to-day. It brought a letter from the sheikh to Hat Salah, warning him not to purchase any slaves, as they would not be allowed to pass through Bornou, on account of the detention of the sheikh's children in Fezzan, who had been sent there for protection during a recent invasion by the people of Begharmi.

Jan. 29.-A courier to-day, from Major Denham at Kouka, brought me letters and newspapers from England; also gunpowder, coffee, tea, and sugar, Peruvian bark, and three bottles of Port wine ; three silver watches, and some articles of dress, such as red caps of Tunis, red Turkish trowsers, and Bornouses, or woollen cloaks, with hoods from Tripoli. Mr. Warrington, our consul at Tripoli, also forwarded a teskara, or order from the bashaw, which Major Denham took care to have enforced by a letter from the sheikh of Bornou, both addressed to Hadje Ali, requiring him to pay the money due by his deceased brother. The sheikh likewise wrote to Hat Salah, requesting him to exert all his influence to overeome the scruples of Hadje Ali; for Hadje Bos Zaid, the other executor, never once hesitated about the matter. The newspapers first apprised me of Belzoni's attempt to penetrate to Timbuctoo by the way of Fez.

Jan. 30.-IIl with ague.

Jan. 31.-A little better.

Feb. 1. 1824.-After breakfast I accompanied Hat Salah, the sheikh's agent, to the sansan, which, since it became a town, is also called Fanisoe, and presented the governor with one of the watches. He was highly pleased with it, and requested me to teach Hat Salah the use of it, that he might give lessons to the wan-bey, who would 
in turn instruct him. I also showed him the sheikh's letter to his master Bello. He read it, and told me I should be sent forward to Sackatoo without delay in a kafila which was then assembling.

On my return I met two governors with troops repairing to the sansan. They had each about five hundred horse and foot. The foot were armed with bows and arrows. The quiver is slung over the left shoulder, together with a small, highly ornamented leathern pouch for little necessaries, and a canteen of dried grass, so compactly plaited, that it is used for holding water. The bow unstrung is sometimes carried in the hand as a walking stick. Many carried on the head a little triangular bag, filled with bruised Guinea corn. Others wore a little conical grass cap, with a tuft of feathers. The rest of their dress consists solely of a tanned skin, strung with coarse shells, or fringed with tassels, girt round the loins, and a pair of sandals of very simple workmanship.

The cavalry were armed with shields, swords, and spears, and otherwise more sumptuously accoutred. The spear is about six feet long, the wooden shaft slender, and the point of iron. The swords are broad, straight, and long, but require no particular description, as, by a vicissitude somewhat singular, they are in fact the very blades formerly wielded by the knights of Malta. These swords are sent from Malta to Bengazee, in the state of Tripoli, where they are exchanged for bullocks. They are afterwards carried across the desert to Bornou, thence to Haussa, and at last remounted at Kano, for the use of the inhabitants of almost all central Africa. The shields, covered with the hides of tame or wild animals, are generally plain and round. There is, however, a remarkable variety, not uncommon, of an oval shape, somewhat broader below than above, with an edging of blue cloth, forming six little lappets, one above, one below, and two on each side. In the centre of the shield there is a stripe of scarlet eloth fastened by the same studs that clinch the iron handle, and around it is scored a perfect Maltese 
cross. This kind of shield is borne by horsemen only; but it is found of the same shape and figure, equally among Tibboes, 'Tuaricks, Felatahs, and Bornouese. A cross of the same form, moulded in a sort of low relief, is not an unfrequent ornament on the clay plaster of their huts. Crosses of other forms also are sometimes cut in the doors of their houses. Several camels, loaded with quilted cotton armour, both for men and horses, were in attendance. One of the governor's slaves wore a quilted helmet of red cloth, very unwieldy, not unlike a bucket in shape, only scooped out in front for the face, and terminating on the crown in a large tin funnel, full of ostrich feathers. He was also clad in a red quilted corslet of the same cumbrous materials. The other articles of this armour are trunk hose for the rider, and a head piece, poitrel, and hausing, all quilted and arrow proof, for the horse. Armour, however, is hardly ever worn, except in actual combat, and then it must very much impede the quickness of their military evolutions. The saddles have high peaks before and behind. The stirrup irons are in the shape of a fire-shovel, turned up at the sides, and so sharp as to render spurs superfluous. This body of heavy horse protects the advance and retreat of the army, the bowmen being drawn up in the rear, and shooting from between the horsemen as occasion offers.

Feb. 2.-This morning I was visited by a nephew of sultan Bello, who arrived yesterday from Sackatoo. He was a lad of a dark copper colour, and of a thin active make, like all the Felatahs. I ordered tea to be presented to him; but he would not taste it, till the brother of El Wordee set him the example, when he ventured to drink a cup, and soon became very fond of it. Before this visit he considered a Christian little better than a monster, as he confessed to me, though, perhaps, with some degree of flattery. I showed him all my instruments, and the presents intended for his uncle, the sultan.

Feb. 3.-I had a visit from another nephew of the sultan, one 
of the finest and most intelligent young men I had seen in this country. He read and spoke Arabic with ease and fluency, and was very anxious to see every thing, and to hear all about my country. He assured me the sultan would be delighted to see me, and said he had a large collection of books, which he made him read aloud. He told me there was a camel road from Sackatoo to Timbuctoo, which, however, was rendered dangerous by the Kafirs of Cobee, a country lying between the two towns.

Feb. 4.-The governor sent back the two horses he had on trial ; but this was to be expected, one of them having galled withers, and the other being nothing but skin and bone. He returned, at the same time, a number of the horses belonging to the Arab merchants, who came to me with loud clamours against this alleged act of injustice. I warily answered, in one of their own hypocritical exaggerations, "Whatever the sultan does is beautiful;" for I knew they only wanted to entrap me into an unguarded expression, which would be repeated to the governor, either to my disadvantage, or to induce him to take all the horses at the price first demanded. Accordingly I was no more troubled with their complaints on this subject.

Feb. 5 and 6.-I had a conversation with Abdelgader, a relation of sultan Bello, at the house of a Ghadamis merchant. Abdelgader was particularly inquisitive about our religious observances, prayers, the worship of images, and the eating of pork. I told him we were commanded by our religion to pray without ceasing; but as no people on earth does as it ought, we generally prayed at stated times. The worship of images, with which I was repeatedly charged, I indignantly abjured. Of course I represented the eating of pork as a mere matter of policy. My Mahomedan catechist next inquired, with some degree of ridicule, as to the doctrine of the Trinity; and turning to his countrymen who were present, without waiting for my reply, exclaimed, in allusion to the three persons of the God- 
head :- " Father, Son, and Uncle." In this way Mahometans are wont to turn to scorn the pure morals inculcated by Christianity, both in precept and in practice. Abdelgader next expressed great curiosity to have my Jew servant, Jacob, s ent for. I declined; explaining to him that it was utterly inconsistent with the toleration to which I had ever been accustomed, to have any man interrogated by constraint respecting his religious opinions; but that, with his own consent, he might be asked any questions A bdelgader pleased. I left the party soon after, and Jacob was prevailed upon to undergo a similar examination; but his holy zeal was quickly fired, for he soon returned home in a storm of passion. To put a stop to such acrimonious and dangerous discussions, I afterw ards hinted to the Ghadamis merchant that a repetition of such conduct, in regard to my servants, would oblige me to complain to the bashaw of Tripoli.

Feb. 7.-Rather sick to-day.

Feb. 8.-The governor returned to the sansan with his army; and the current report was, that they had entered the capital of the enemy; and, supposing Duntungua to have fled to the forest, they began to enjoy themselves in banquets and carousals, when Duntungua suddenly fell upon them with his army, and killed fifteen thousand men, the rest flying in the greatest confusion to Fanisoe.

Feb. 9.-Again unwell.

Feb. 10.-Kano is the capital of a province of the same name, and one of the principal towns of the kingdom of Soudan, and is situate in $12^{\circ} 0^{\prime} 19^{\prime \prime}$ north latitude by observation, and $9^{\circ} 20^{\prime}$ east longitude by dead reckoning, carried on from a lunar observation at Kouka, in Bornou.

Kano may contain from 30,000 to 40,000 resident inhabitants, of whom more than one half are slaves. This estimate of the population is of course conjectural, and must be received with due allowance, although $I$ have studiously under-rated my rough calculations on the subject. This number is exclusive of strangers who come 
here in crowds during the dry months from all parts of Africa, from the Mediterranean and the Mountains of the Moon, and from Sennar and Ashantee.

The eity is rendered very unhealthy by a large morass, which almost divides it into two parts, besides many pools of stagnant water, made by digging clay for building houses. The house gutters also open into the street, and frequently occasion an abominable stench. On the north side of the city are two remarkable mounts, each about 200 feet in height, lying nearly east and west from one another, and a trifling distance apart. They are formed of argillaceous iron-stone, mixed with pebbles, and a rather soft kind of marl. The city is of an irregular oval shape, about fifteen miles in circumference, and surrounded by a clay wall thirty feet high, with a dry ditch along the inside, and another on the outside. There are fifteen gates, including one lately built up. The gates are of wood, covered with sheet iron, and are regularly opened and shut at sunrise and sunset. A platform inside, with two guardhouses below it, serves to defend each entrance. Not more than one fourth of the ground within the walls is occupied by houses: the vacant space is laid out in fields and gardens. The large morass, nearly intersecting the city from east to west, and crossed by a small neck of land, on which the market is held, is overflowed in the rainy season. The water of the city being considered unwholesome, women are constantly employed hawking water about the streets, from the favourite springs in the neighbourhood. The houses are built of clay, and are mostly of a square form, in the Moorish fashion, with a central room, the roof of which is supported by the trunks of palm trees, where visitors and strangers are received. The apartments of the ground floor open into this hall of audience, and are generally used as store-rooms. A staircase leads to an open gallery overlooking the hall, and serving as a passage to the chambers of the second story, which are lighted with small windows. In a 
back courtyard there is a well and other conveniences. Within the enclosure in which the house stands, there are also a few round huts of clay, roofed with the stalks of Indian corn, and thatched with long grass. These are usually very neat and clean, and of a much larger size than those of Bornou. The governor's residence covers a large space, and resembles a walled village. It even contains a mosque, and several towers three or four stories high, with windows in the European style, but without glass or frame-work. It is necessary to pass through two of these towers in order to gain the suite of inner apartments occupied by the governor.

The soug, or market, is well supplied with every necessary and luxury in request among the people of the interior. It is held, as I have mentioned, on a neck of land between two swamps; and as this site is covered with water during the rainy season, the holding it here is consequently limited to the dry months, when it is numerously frequented as well by strangers as inhabitants : indeed, there is no market in Africa so well regulated. The sheikh of the soug lets the stalls at so much a month, and the rent forms a part of the revenues of the governor. The sheikh of the soug also fixes the prices of all wares, for which he is entitled to a small commission, at the rate of fifty whydah or cowries, on every sale amounting to four dollars or 8,000 cowries, according to the standard exchange between silver money and this shell currency. There is another custom regulated with equal certainty and in universal practice : the seller returns to the buyer a stated part of the price, by way of blessing, as they term it, or of luck-penny, according to our less devout phraseology. This is a discount of two per cent. on the purchase money; but, if the bargain is made in a hired house, it is the landlord who receives the luck-penny. I may here notice the great convenience of the cowrie, which no forgery can imitate; and which, by the dexterity of the natives in reckoning the largest sums, forms a ready medium of exchange in all transactions, from the lowest to the $h 2$ 
highest. Particular quarters are appropriated to distinct articles; the smaller wares being set out in booths in the middle, and cattle and bulky commodities being exposed to sale in the outskirts of the market-place : wood, dried grass, bean straw for provender, beans, Guinea corn, Indian corn, wheat, \&c. are in one quarter; goats, sheep, asses, bullocks, horses, and camels, in another; earthenware and indigo in a third; vegetables and fruit of all descriptions, such as yams, sweet potatoes, water and musk melons, pappaw fruit, limes, cashew nuts, plums, mangoes, shaddocks, dates, \&c. in a fourth, and so on. Wheaten flour is baked into bread of three different kinds; one like muffins, another like our twists, and the third a light puffy cake, with honey and melted butter poured over it. Rice is also made into little cakes. Beef and mutton are killed daily. Camel flesh is occasionally to be had, but is often meagre; the animal being commonly killed, as an Irish grazier might say, to save its life : it is esteemed a great delicacy, however, by the Arabs, when the carcass is fat. The native butchers are fully as knowing as our own, for they make a few slashes to show the fat, blow up meat, and sometimes even stick a little sheep's wool on a leg of goat's flesh, to make it pass with the ignorant for mutton. When a fat bull is brought to market to be killed, its horns are dyed red with henna; drummers attend, a mob soon collects, the news of the animal's size and fatness spreads, and all run to buy. The colouring of the horns is effected by applying the green leaves of the henna tree, bruised into a kind of poultice. Near the shambles there is a number of cook-shops in the open air ; each consisting merely of a wood fire, stuck round with wooden skewers, on which small bits of fat and lean meat, alternately mixed, and searcely larger than a pennypiece each, are roasting. Every thing looks very clean and comfortable; and a woman does the honours of the table, with a mat dish-cover placed on her knees, from which she serves her guests, who are squatted around her. Ground gussub water is retailed at hand, to those who can afford this beverage 


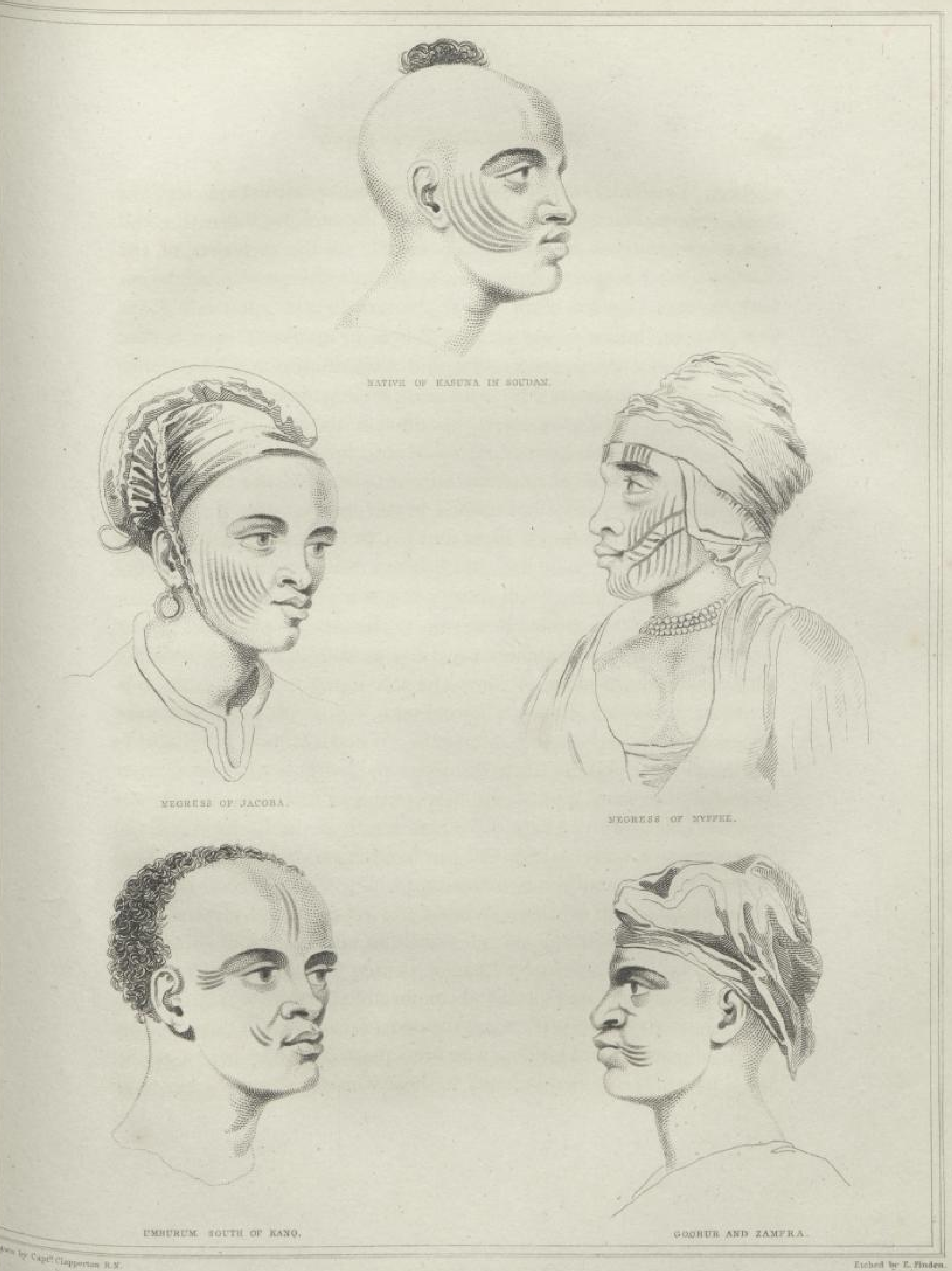

\section{SLUB}


at their repast : the price, at most, does not exceed twenty cowries, or about two farthings and $\frac{4}{10}$ of a farthing, English money, estimating the dollar at five shillings. Those who have houses eat at home; women never resort to cook-shops, and even at home eat apart from men.

The interior of the market is filled with stalls of bamboo, laid out in regular streets; where the more costly wares are sold, and articles of dress, and other little matters of use or ornament made and repaired. Bands of musicians parade up and down to attract purchasers to particular booths. Here are displayed coarse writing paper, of French manufacture, brought from Barbary ; scissors and knives, of native workmanship; crude antimony and tin, both the produce of the country ; unwrought silk of a red colour, which they make into belts and slings, or weave in stripes into the finest cotton tobes; armlets and bracelets of brass; beads of glass, coral, and amber; finger rings of pewter, and a few silver trinkets, but none of gold; tobes, turkadees, and turban shawls ; coarse woollen cloths of all colours ; coarse calico ; Moorish dresses ; the cast off gaudy garbs of the Mamelukes of Barbary; pieces of Egyptian linen, checked or striped with gold; sword blades from Malta, \&c. \&c. The market is crowded from sunrise to sunset every day, not excepting their Sab. bath, which is kept on Friday. The merchants understand the benefits of monopoly as well as any people in the world; they take good care never to overstock the market, and if any thing falls in price, it is immediately withdrawn for a few days.-The market is regulated with the greatest fairness, and the regulations are strictly and impartially enforced. If a tobe or turkadee, purchased here, is carried to Bornou or any other distant place, without being opened, and is there discovered to be of inferior quality, it is immediately sent back, as a matter of course,- the name of the dylala, or broker, being written inside every parcel. In this case the dylala must find out the seller, who, by the laws of Kano, is forthwith obliged to refund the purchase money. 
The slave market is held in two long sheds, one for males, the other for females, where they are seated in rows, and carefully decked out for the exhibition ; the owner, or one of his trusty slaves, sitting near them. Young or old, plump or withered, beautiful or ugly, are sold without distinction; but, in other respects, the buyer inspects them with the utmost attention, and somewhat in the same manner as a volunteer seaman is examined by a surgeon on entering the navy: he looks at the tongue, teeth, eyes, and limbs, and endeavours to detect rupture by a forced cough. If they are afterwards found to be faulty or unsound, or even without any specific objection, they may be returned within three days. When taken home, they are stripped of their finery, which is sent back to their former owner. Slavery is here so common, or the mind of slaves is so constituted, that they always appeared much happier than their masters; the women, especially, singing with the greatest glee all the time they are at work. People become slaves by birth or by capture in war. The Felatahs frequently manumit slaves at the death of their master, or on the occasion of some religious festival. The letter of manumission must be signed before the cadi, and attested by two witnesses; and the mark of a cross is used by the illiterate among them, just as with us. The male slaves are employed in the various trades of building, working in iron, weaving, making shoes or clothes, and in traffic ; the female slaves in spinning, baking, and selling water in the streets. Of the various people who frequent Kano, the $N$ uffuans are most celebrated for their industry; as soon as they arrive, they go to market and buy cotton for their women to spin, who, if not employed in this way, make billam for sale, which is a kind of flummery made of flour and tamarinds. The very slaves of this people are in great request, being invariably excellent tradesmen; and when once obtained, are never sold again out of the country.

I bought, for three Spanish dollars, an English green cotton umbrella, an article I little expected to meet with, yet by no means un- 
common : my Moorish servants, in their figurative language, were wont to give it the name of "the cloud." I found, on inquiry, that these umbrellas are brought from the shores of the Mediterranean, by the way of Ghadamis.

A large kafila of Tuaricks, loaded solely with salt, arrived here from Billma. The Arabs told me it consisted of 3,000 camels ; at all events, the kafila was extremely numerous.

Feb. 11.-A Felatah of respectability having arrived from the sultan, with offers of every accommodation on my journey, I visited the governor to compliment him on his return, and to inquire about my departure for Sackatoo. He received me with much civility, and, addressing me like an old acquaintance by my travelling name, Abdallah, he assured me I should set out in six days.

Feb. 12.-The weather was cold, and we had a fire all day. Indeed it is the invariable practice here to have fires all the year round, both in the wet and dry season, although generally I did not find one necessary.

Feb. 13 and 14.- I had a visit from the governor's eldest son, a stupid fellow, who was afraid to taste a cup of tea with which I presented him. He bluntly told me, I possessed the power of changing people into rats, cats, dogs, and monkeys. I made a servant drink the tea he had refused, and then remarked, "Thank God, neither I, nor any one else, was able to work such wonders, otherwise both of us probably had been long ago metamorphosed into asses, and compelled to bear burdens on our backs." He affected to blame the people of the town for these reports, and told me they were further persuaded, that, by reading in my book, I could at any time turn a handful of earth into gold. I easily refuted this absurdity, by asking him why I applied to Hadje Hat Salah for money if I knew such a secret. He now became somewhat tranquillized, and sipped a little of the tea, but with fear and trembling. He afterwards begged for a black-lead pencil, which I did not choose to 
give him. A son of Sultan Bello, named Abdelgader, also paid me a visit. He returns, early to-morrow morning, to Sackatoo.

Feb. 15.-This afternoon I ascended the eastern mount (one of the two already described) to take an eye sketch of the plan of the town, which, as nearly as I could guess it, may be represented as under. By way of precaution, I was accompanied by Hat Salah's

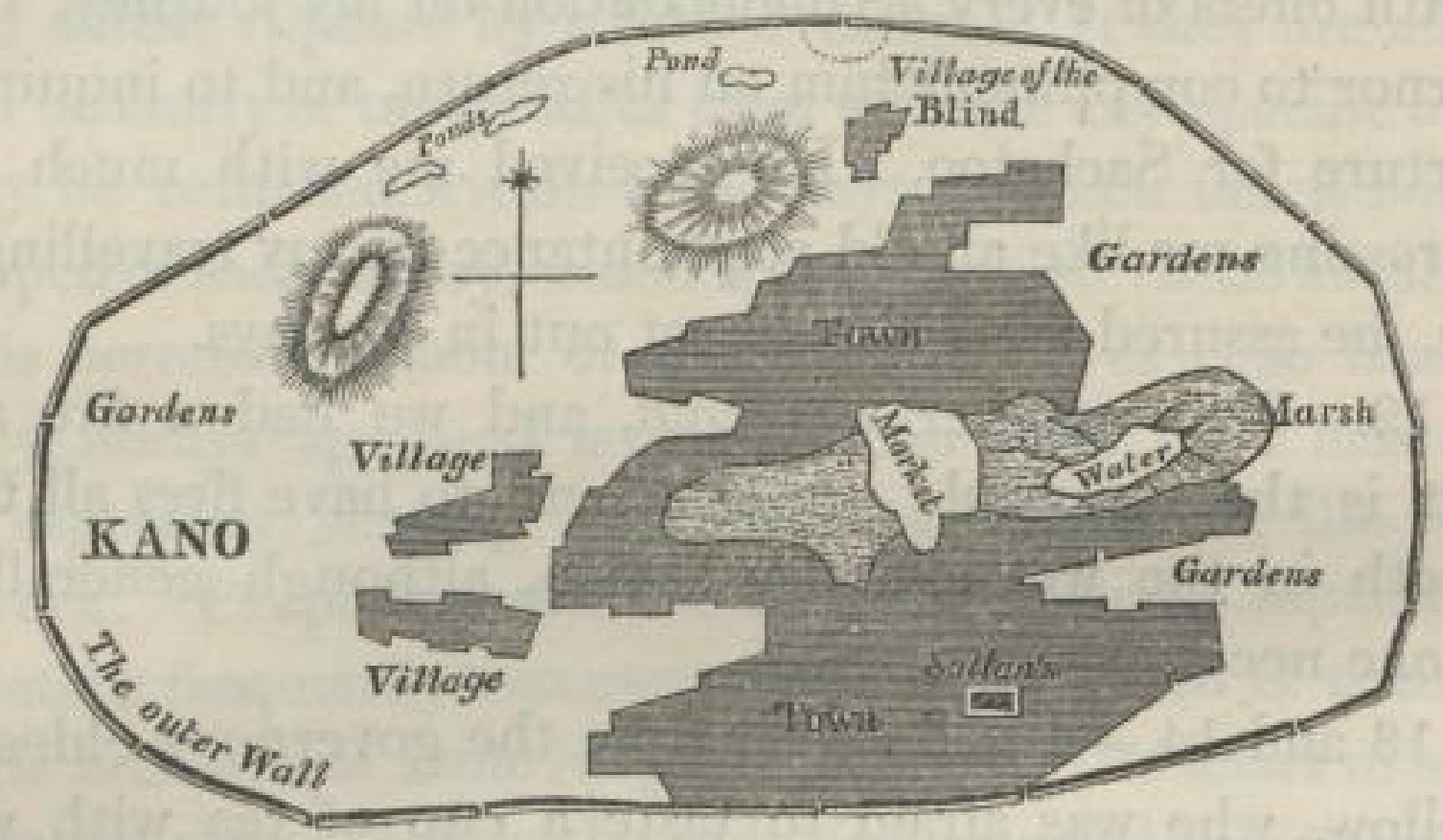

eldest son, to prevent the people fancying I was going to perform some magical feat. On the eastern side of the mount, the young man gravely pointed out to me the print of the foot of the she-camel on which the Prophet rode to heaven. It was certainly very like the print of a camel's foot, only much larger, and seemed to be a hole where two stones had been picked out. I asked my companion, if the prophet's naga, or she-camel, had only one leg. " Oh !" said he, "it had four." Where are the other three? "Oh ?" he replied, "God has done it:" an unanswerable argument, which with them settles all points of religious controversy. He added, "All the faithful of Soudan believe in the truth of this story." The mount I found 
to consist of strata of clay iron-stone, and conglomerate, lying on a bed of soft light clay, apparently mixed with vegetable remains.

Feb. 16.-Early this morning two massi dubu, or jugglers, came to my door. Two snakes were let out of a bag, when one of the jugglers began to beat a little drum. The snakes immediately reared themselves on their tail, and made a kind of sham dance. The juggler afterwards played various tricks with them, sometimes wreathing them round his neck, coiling them in his bosom, or throwing them among the people. On pointing his finger at their mouth, they immediately raised themselves up in an attitude to spring forward; but after having exasperated them to the utmost, he had only to spit in their face to make them retreat quite crestfallen. I measured one of them: it was six feet three inches long; the head large, flat, and blunted, and, along the neck, a kind of gills fully two inches in breadth, and five inches in length, which they elevated when angry. The back and belly were of a dull white, and the sides of a dark lead colour. Between the gills there were five red stripes across the throat, decreasing in size from the mouth downwards. The venomous fangs had been extracted; but still, to guard against all possible injury, the fellow who played tricks with them had a large roll of cloth wound round the right arm. Their bite is said to be mortal, and to prove fatal to a horse or a cow in half an hour.

Having heard a great deal of the boxers of Haussa, I was anxious to witness their performance. Accordingly I sent one of my servants last night to offer 2000 whydah for a pugilistic exhibition in the morning. As the death of one of the combatants is almost certain before a battle is over, I expressly prohibited all fighting in earnest ; for it would have been disgraceful, both to myself and my country, to hire men to kill one another for the gratification of idle curiosity. About half an hour after the massi dubu were gone, the boxers arrived, attended by two drums, and the whole body of butchers, who 
here compose " the fancy." A ring was soon formed, by the master of the ceremonies throwing dust on the spectators to make them stand back. The drummers entered the ring, and began to drum lustily. One of the boxers followed, quite naked, except a skin round the middle. He placed himself in an attitude as if to oppose an antagonist, and wrought his muscles into action, seemingly to find out that every sinew was in full force for the approaching combat; then coming from time to time to the side of the ring, and presenting his right arm to the bystanders, he said, "I am a hyena;" "I am a lion ;" "I am able to kill all that oppose me." The spectators, to whom he presented himself, laid their hands on his shoulder, repeating, "The blessing of God be upon thee;" "Thou art a hyena ;" "Thou art a lion." He then abandoned the ring to another, who showed off in the same manner. The right hand and arm of the pugilists were now bound with narrow country cloth, beginning with a fold round the middle finger, when, the hand being first clinched with the thumb between the fore and mid fingers, the cloth was passed in many turns round the fist, the wrist, and the fore arm. After about twenty had separately gone through their attitudes of defiance, and appeals to the bystanders, they were next brought forward by pairs. If they happened to be friends, they laid their left breasts together twice, and exclaimed, "We are lions;" "We are friends." One then left the ring, and another was brought forward. If the two did not recognise one another as friends, the setto immediately commenced. On taking their stations, the two pugilists first stood at some distance, parrying with the left hand open, and, whenever opportunity offered, striking with the right. They generally aimed at the pit of the stomach, and under the ribs. Whenever they closed, one seized the other's head under his arm, and beat it with his fist, at the same time striking with his knee between his antagonist's thighs. In this position, with the head in chancery, they are said sometimes to attempt to gouge or scoop out 
one of the eyes. When they break loose, they never fail to give a swinging blow with the heel under the ribs, or sometimes under the left ear. It is these blows which are so often fatal. The combatants were repeatedly separated by my orders, as they were beginning to lose their temper. When this spectacle was heard of, girls left their pitchers at the wells, the market people threw down their baskets, and all ran to see the fight. The whole square before my house was crowded to excess. After six pairs had gone through several rounds, I ordered them, to their great satisfaction, the promised reward, and the multitude quietly dispersed.

Both Hat Salah and Benderachmani, another Fezzan merchant residing here, had been with the late $\mathrm{Mr}$. Hornemann at the time of his death. They travelled with him from Mourzuk to Nyffee, where he died of dysentery, after an illness of six days. He passed himself off as an English merchant, professing the Mahometan faith, and had sold two fine horses here. At my instance, Benderachmani sent a courier to Nyffee, to endeavour to recover Mr. Hornemann's manuscripts, for which I offered him a reward of a hundred dollars; but, on my return from Sackatoo, I found the messenger come back with the information, that Jussuf Felatah, a learned man of the country, with whom Mr. Hornemann lodged, had been burned in his own house, together with all Mr. Hornemann's papers, by the negro rabble, from a superstitious dread of his holding intercourse with evil spirits.

All the date trees, of which there is a great number, as well as the fig and pappaw trees, \&c. together with the waste ground, and fields of wheat, onions, \&c. bordering on the morass, belong to the governor. The date trees bear twice a year, before and after the annual rains, which fall between the middle of May and the end of August.

Cotton, after it is gathered from the shrub, is prepared by the careful housewife, or a steady female slave, by laying a quantity of 
it on a stone, or a piece of board, along which she twirls two slender iron rods about a foot in length, and thus dexterously separates the seeds from the cotton wool. The cotton is afterwards teazed or opened out with a small bone, something like an instrument used by us in the manufacture of hat felt. Women then spin it out of a basket upon a slender spindle. The basket always contains a little pocket mirror, used at least once every five minutes, for adjusting or eontemplating their charms. It is now sold in yarn, or made into cloth. The common cloth of the country is, as formerly stated, only three or four inches broad. The weaver's loom is very simple, having a fly and treadles like ours, but no beam; and the warp, fastened to a stone, is drawn along the ground as wanted. The shuttle is passed by the hand. When close at work, they are said to weave from twenty to thirty fathoms of cloth a day. Kano is famed over all central Africa for the dyeing of cloth; for which process there are numerous establishments. Indigo is here prepared in rather a different manner from that of India and America. When the plant is ripe, the fresh green tops are cut off, and put into a wooden trough about a foot and a half across, and one foot deep, in which, when pounded, they are left to ferment. When dry, this indigo looks like earth mixed with decayed grass, retains the shape of the trough, and three or four lumps being tied together with Indian corn-stalks, it is carried in this state to market. The apparatus for dyeing is a large pot of clay, about nine feet deep, and three feet broad, sunk in the earth. The indigo is thrown in, mixed with the ashes of the residuum of a former dyeing. These are prepared from the lees of the dye-pot, kneaded up and dried in the sun, after which they are burned. In the process of dyeing cold water alone is used. The articles to be dyed remain in the pot three or four days, and are frequently stirred up with a pole ; besides which, they are well wrung out every night, and hung up to dry till morning, during which time the dye-pot is covered with a straw mat. After 
the tobes, turkadees, \&c. are dyed, they are sent to the cloth-glazer, who places them between mats, laid over a large block of wood, and two men, with wooden mallets in each hand, continue to beat the cloth, sprinkling a little water from time to time upon the mats, until it acquires a japan-like gloss. The block for beating the tobes is part of the trunk of a large tree, and when brought to the gates of the city, the proprietor musters three or four drummers, at whose summons the mob never fails to assemble, and the block is gratuitously rolled to the workshop. The price of dyeing a good tobe of the darkest blue colour is 3000 cowries, or a dollar and a half; and for glazing it, 700 cowries. The total price of a tobe is 5000 cowries, and of a turkadee, from 2000 to 3000 cowries.

The women of this country, and of Bornou, dye their hair blue as well as their hands, feet, legs, and eyebrows. They prefer the paint called shunee, made in the following manner:-They have an old tobe slit up, and dyed a second time. They make a pit in the ground, moistening it with water, in which they put the old tobe, first imbedded in sheep's dung, and well drenched with water, and then fill up the pit with wet earth. In winter the fire for domestic purposes is made close to the spot, and the pit remains unopened for ten days. In summer no fire is required; and after seven or eight days the remnants of the old tobe, so decayed in texture as barely to hang together, are taken out and dried in the sun for use. This paint sells at 400 cowries the gubga, or fathom ; for this measure of length commonly gives name to the cloth itself. A little of the paint being mixed with water in a shell, with a feather in one hand, and a looking-glass in the other, the lady carefully embellishes her sable charms. The arms and legs, when painted, look as if covered with dark blue gloves and boots.

They show some ingenuity in the manufacture of leathern jars, fashioning them upon a clay mould out of the raw hide, previously 
well soaked in water: these jars serve to contain fat, melted butter, honey, and bees' wax.

They are also acquainted with the art of tanning; in which they make use of the milky juice of a plant called in Arabic brumbugh, and in the Bornouese tongue kyo. It is an annual plant, and grows in dry sandy situations to the height of five or six feet, with a stem about an inch in diameter. It has broad thick leaves, and bears a small flower, in colour and shape not unlike a pink. The fruit is green, and larger than our garden turnip. It contains a fine white silky texture, intermixed with seeds like those of the melon, and becomes ripe some time before the rains commence, during which the plant itself withers. The juice is collected in a horn or gourd, from incisions made in the stem. It is poured over the inner surface of the skin to be tanned, which is then put in some vessel or other; when, in the course of a day or two, the smell becomes extremely offensive, and the hair rubs off with great ease. They afterwards take the beans or seeds of a species of mimosa, called in Arabic gurud. These, when pounded in a wooden mortar, form a coarse black powder, which is thrown into warm water, wherein the skin is steeped for one day; being frequently well pressed and hard wrung, to make it imbibe the liquor. It is then spread out in the sun, or hung up in the wind, and when half dry, is again well rubbed between the hands, to render it soft and pliant for use. To colour it red, they daub it over with a composition, made of trona and the outer leaves of red Indian corn, first beaten into a powder and mixed up with water.

The negroes here are excessively polite and ceremonious, especially to those advanced in years. They salute one another, by laying the hand on the breast, making a bow, and inquiring, "Kona lafia? Ki ka kykee. Fo fo da rana ?" "How do you do? I hope you are well. How have you passed the heat of the day?". The 
last question corresponds in their climate to the circumstantiality with which our honest countryfolks inquire about a good night's rest.

The unmarried girls, whether slaves or free, and likewise the young unmarried men, wear a long apron of blue and white check, with a notched edging of red woollen cloth. It is tied with two broad bands, ornamented in the same way, and hanging down behind to the very ancles. This is peculiar to Soudan, and forms the only distinction in dress from the people of Bornou.

Both men and women colour their teeth and lips with the flowers of the goorjee tree, and of the tobacco plant. The former I only saw once or twice; the latter is carried every day to market, beautifully arranged in large baskets. The flowers of both these plants, rubbed on the lips and teeth, give them a blood red appearance, which is here thought a great beauty. This practice is comparatively rare in Bornou.

Chewing the goora nut, already described, or snuff mixed with trona, is a favourite habit. This use of snuff is not confined to men in Haussa, as is the case in Bornou, where the indulgence is not permitted to women. Snuff is very seldom taken up the nostrils, according to our custom. Smoking tobacco is a universal practice, both of negroes and Moors. Women, however, are debarred this fashionable gratification.

The practitioners of the healing art in this country, as formerly in Europe, officiate likewise as barbers, and are very dexterous in the latter capacity, at least.

Blindness is a prevalent disease. Within the walls of the city, there is a separate district or village for people afflicted with this infirmity, who have certain allowances from the governor, but who also beg in the streets and market-place. Their little town is extremely neat, and the coozees well built. With the exception of the slaves, none but the blind are permitted to live here, unless on 
rare occasions a one-eyed man is received into their community. I was informed the lame had a similar establishment; but I did not see it.

When a bride is first conducted to the house of the bridegroom, she is attended by a great number of friends and slaves, bearing presents of melted fat, honey, wheat, turkadees, and tobes, as her dower. She whines all the way-" Wey kina! wey kina! wey Io." " Oh! my head! my head! oh! dear me." Notwithstanding this lamentation, the husband has commonly known his wife some time before marriage. Preparatory to the ceremony of reading the "Fatha," both bridegroom and bride remain shut up for some days, and have their hands and feet dyed, for three days successively, with henna. The bride herself visits the bridegroom, and applies the henna plasters with her own hand.

Every one is buried under the floor of his own house, without monument or memorial; and among the commonalty the house continues occupied as usual ; but among the great there is more refinement, and it is ever after abandoned. The corpse being washed, the first chapter of the Koran is read over it, and the interment takes place the same day. The bodies of slaves are dragged out of town, and left a prey to vultures and wild beasts. In Kano they do not even take the trouble to convey them beyond the walls, but throw the corpse into the morass or nearest pool of water.

Feb. 22.-At seven in the morning I waited on the governor. He informed me that the sultan had sent a messenger express, with orders to have me conducted to his capital, and to supply me with every thing necessary for my journey. He now begged me to state what I stood in need of. I assured him that the King of England, my master, had liberally provided for all my wants; but that I felt profoundly grateful for the kind offers of the sultan, and had only to erave from him the favour of being attended by one of his people as a guide. He instantly called a fair-complexioned Felatah, and 
asked me if I liked him. I accepted him with thanks, and took leave. I afterwards went by invitation to visit the governor of Hadyja, who was here on his return from Sackatoo, and lived in the house of the wan-bey. I found this governor of Hadyja a black man, about fifty years of age, sitting among his own people at the upper end of the room, which is usually a little raised, and is reserved in this country for the master of the house or visitors of high rank. He was well acquainted with my travelling name; for the moment I entered, he said laughing, "How do you do, Abdullah? Will you come and see me at Hadyja on your return?" I answered, " God willing," with due Moslem solemnity. "You are a Christian, Abdullah?"- "Yes." "And what are you come to see?"- "The country." "What do you think of it ?"- " It is a fine country, but very sickly." At this he smiled, and again asked, "Would you Christians allow us to come and see your country?" I said, "Certainly."- "Would you force us to become Christians?" "By no means; we never meddle with a man's religion."- "What!" says he, " and do you ever pray ?"-_ Sometimes; our religion commands us to pray always; but we pray in secret, and not in public, except on Sundays." One of his people abruptly asked what a Christian was? "Why a Kafir," rejoined the governor. "Where is your Jew servant?" again asked the governor; " you ought to let me see him." " Excuse me, he is averse to it ; and I never allow my servants to be molested for religious opinions." "Well, Abdullah, thou art a man of understanding, and must come and see me at Hadyja." I then retired, and the Arabs afterwards told me he was a perfect savage, and sometimes put a merchant to death for the sake of his goods; but this account, if true, is less to be wondered at, from the notorious villany of some of them. In the afternoon I went to Hadje Hat Salah's, and made an arrangement with him to act as my agent, both in recovering the money due by Hadje Ali Boo Khaloom, and in answering any drafts upon him. In the 
event of my death, I also agreed with him to have my Jew servant Jacob, who was to remain here with my books and papers, sent with them to the sheikh of Bornou, and so to the English consul at Tripoli. I left Jacob here, partly on account of his irritable temper, which, presuming on my countenance and support, was apt to lead him into altercations and squabbles, as well as to take care of my effects. I made this arrangement at Hat Salah's particular recommendation, who strongly impressed upon me the dangers of the journey I had undertaken. According to a eustom which the late Dr. Oudney had always followed at every principal town where we made a short stay, I had two bullocks slaughtered and given to the poor. 


\section{SECTION III. \\ FROM KANO TO SACKATOO, AND RESIDENCE THERE.}

Feb. 23.-Ax day-break all the Arab merchants of my acquaintance waited upon me to wish me a prosperous journey. Hadje Hat Salah and Hadje Ben Hamed accompanied me four miles beyond the gate Kooffe. Before they left me I had a return of fever, and lay down under the shade of a tree to wait for Mohammed Jollie, as my conductor was named. My two camels being evidently overladen, and my servant Abraham unable to walk from sickness, I requested, Hat Salah to buy another camel and send it after me.

At one in the afternoon, Mohammed Jollie, with two loaded camels and a handsome led horse of Tuarick breed, sent as the weekly present or tribute from Kano to the sultan, joined me. He also brought with him a beautiful Felatah girl for his travelling chere amie, who was placed astride on a light dromedary, according to the custom of the country. My fever having abated, we proceeded on our journey, and by sunset reached the village of Yaromba; where I was provided with a house for myself and another for my servants, and with food and provender in abundance. The country had much the same appearance as on the other side of Kano, but was not quite so well cultivated.

Feb. 24.- We traversed a woody country, and crossed the dry beds of several small streams, the course of each being to the eastward. In the afternoon we passed a walled town called Toffa, when the country became still more thickly wooded. There were many villages in 
ruins which had been destroyed by the rebel Duntungua, and the inhabitants sold as slaves. A little after mid-day, we halted at the town of Roma or Soup; where we found the inhabitants very civil, and were furnished with houses and provisions. I was here joined by a she-camel, which Hat Salah had sent by a native of Kano, of the name of Nouzama, whom I also engaged as a servant.

Feb. 25.-The country very woody, the road zigzag, and crossed sometimes by dikes, or ridges of white quartz, running north and south, sometimes by ravines and the dry channels of rivers. We saw many Felatah villages, and numerous herds of horned cattle, and flocks of sheep and goats. The cattle are remarkably fine, and of a white or whitish grey colour; the horns are not disproportionately large in size, in which circumstance they differ from the cattle of Bornou : they have also a hump on the shoulders. The bull is very fierce, and, as in England, the king of the herd; while in Bornou he is tamer, and generally weaker than the cow. The shepherd with his crook usually goes before the flock, and leads them to fresh pasture, by merely calling with a loud but slow voice, "Hot, hot;" while the sheep keep nibbling as they follow. I was well supplied with milk, but only got it fresh from the cow when they understood I was a stranger going to visit the sultan; for, as I have already mentioned, they hold it unlucky to drink or sell milk before it has been churned.

We stopped at the town of Gadania or Kadania, which is surrounded by a wall and dry ditch. The governor was out warring with Duntungua, who had committed dreadful havoc in this neighbourhood. I was accommodated with an excellent house; so were also El Wordee and a shreef named Hassan, a native of Houn in the regency of Tripoli, who had joined my party, and was going a begging to the sultan. This is a very common custom with the shreefs, who sometimes realize a little fortune by visiting all the governors and sultans within their reach. Hassan was blind, but a 
great rogue, and gifted with a ready wit. He frequently amused us on the road with stories of his younger days, when he had his eyesight. I had another attack of fever to-day, and could not walk three paces without assistance.

Feb. 26.-I was detained to-day on account of the disappearance of El Wordee and Shreef Hassan's camels : we did not know whether they had been stolen, or had only strayed during the night. I availed myself of this opportunity of taking a large dose of calomel, and administered another to my servant.

Feb. 27.-The camels were still missing; and had it been otherwise, I could not have continued my journey, for I found myself excessively weak. In the evening El Wordee offered a reward of two dollars to a Tuarick to bring back the camels, to which I added two dollars more. Kadania is very thinly peopled, the inhabitants, as in most other captured towns, having been sold by the Felatahs. The houses are scattered up and down; but there is a good daily market, supplied by the people of the adjoining country. The soil around is a strong red clay. The trees were higher here than ik Bornou; and the fields of Indian corn, gussub, cotton, and indigo, were neatly enclosed with fences, and kept free of weeds.

Feb. 18.-No news of the lost camels. I determined to proceed, and had my camels loaded with the baggage of $\mathrm{El} \mathrm{Wordee} \mathrm{and} \mathrm{the}$ shreef; the former remaining behind, to await the return of the Tuarick. The country was still thickly wooded, with a few cultivated patches of land. The soil was a red and white clay, mixed with gravel, and traversed by ridges of schistus. We crossed the dry beds of several rainy-season streams, whose banks were lined with rocks, and covered with majestic trees. In the little glens and nooks, there were small plots of onions and tobacco; which the inhabitants water from holes dug in the dry channel of the river, by means of a bucket and long bar or lever. At noon we halted at the walled town of Faniroce or "White Water," the walls of which are 
extensive, but the houses few and mean. I was shown into one of the best of them; but my servants had much ado to render it habitable. Soon after El Wordee arrived, but without the camels. In the evening I was visited by the governor, a very good-natured fellow, who, when he saw that I was ill, went and brought some fine trona, of which he recommended me to take a little every evening. On inquiring about the course of the streams whose dry channels I had passed, he informed me that all between this place and Kano run eastward; but that to-morrow I should cross the first that runs to the west, and divides the provinces of Kano and Kashna. At eight in the evening, the Tuarick brought back the camels of El Wordee and the shreef.

Feb. 29.-The governor and some of his friends accompanied us a short distance out of the town. The country was still very woody, and the road extremely crooked. At eleven in the forenoon we crossed the bed of the stream that separates Kano from Kashna, the channel being here about twenty feet broad, and perfectly dry; and at noon we halted at the town of Duncamee. The stream near this town assumes the same name, and, after passing Zirmie, the capital of Zamfra, it bends northward, and traverses the province of Goobeer; then, turning again to the west, it washes the city of Sackatoo, and, at the distance of four days' journey, is said to enter the Quarra at Kubby.

March 1.-At six in the morning we left Duncamee, and travelled through a thickly wooded country; and at noon we passed a walled town, of considerable size, called Geoza, after which we came to ridges of granite, running in a north-easterly direction. At three in the afternoon we halted at the town of Ratah, whose site is very remarkable. It is built amidst large blocks of granite, which rise out of the earth like towers, and form its only defence on the northern side, some of the houses being perched like bird-cages on the top of the rocks. The south side is enclosed by a wall about 
twenty feet high, but in bad repair. The inhabitants are numerous, and the women are the tallest and fattest I ever saw.

March 2.-We rode through a beautiful and well cultivated country, rendered extremely romantic by ledges of rocks, and clumps of large shady trees. We passed a number of villages, the inhabitants of which are mostly Felatahs, who, when they knew I was going to visit the sultan, presented me with new milk. At noon we halted at the town of Bershee, which is situate amongst large blocks of granite, and is the first town with suburbs I had seen in Haussa, although, from the ruinous state of the walls, this was no very important distinction. The governor of Ongooroo was here, on his way from Sackatoo to his province; but, through the care of my guide, Mohammed Jollie, this circumstance did not prevent me from obtaining the best house in the town, and abundance of provisions for myself and servants.

March 3.- The weather clear and fine: we rode to-day through little valleys, delightfully green, lying between high ridges of granite; and, to add to the beauty of the scenery, there were many clear springs issuing out of the rocks, where young women were employed drawing water. I asked several times for a gourd of water, by way of excuse to enter into conversation with them. Bending gracefully on one knee, and displaying at the same time teeth of pearly whiteness, and eyes of the blackest lustre, they presented it to me on horseback, and appeared highly delighted when I thanked them for their civility : remarking to one another, " Did you hear the white man thank me?" After leaving this beautiful spot, the land rose gently into hill and dale, and we had to cross the dry bed of the same rainy-season stream no less than four times in the course of three hours. The country also became more wooded, and worse cultivated; and the soil in most places was of a strong red and blue clay. There were numerous herds of cattle. At two in the afternoon we halted at the village of Kagaria, situate on the brow of a 
sloping hill, and inhabited by Felatahs. Here, for the first time, I found some difficulty in procuring lodgings. The chief of the village, an old venerable-looking Felatah, told my guide, that when they went to Kano, the governor turned up his nose at them, and, if ever he came there, they were determined not to receive him. Then, addressing me, he said, "You are a stranger, from a far distant country; you and your servants shall have a house, but none of the others." I was accordingly conducted to a very excellent house, but took my fellow travellers with me; and, in due time, provisions were sent, with the usual attention.

March 4.-At six in the morning left Kagaria, but not without giving the old Felatah a present of a turkadee, of which he was very proud. Our road lay through a beautiful country, highly cultivated. At nine o'clock we passed through many villages, romantically situate amongst ridges of granite. From the fertility and beauty of the country, it appeared like an ornamental park in England, shaded with luxuriant trees. We now entered a forest, where the road became both difficult and dreary. Here our guide enjoined my servants not to stray from the caravan, as the woods were infested with banditti, who murdered every one they seized too old for the slave market. The soil was composed of clay and gravel: in the hollows I frequently saw rocks of granite, and mica slate. The trees upon the high grounds were low and stunted, amongst which I remarked several wild mangoes. We halted at the Felatah village of Bobaginn, where the country is again open. The inhabitants were kind and attentive in procuring me a house and provisions.

Mar. 5.-The country was now highly cultivated. The road was crowded with passengers and loaded bullocks, going to the market of Zirmie; which town we passed a little to the southward, about noon, when the country became more woody. At two in the afternoon we entered an opening in a range of low hills; this proved to be the dry bed of the river we had crossed at Duncamee, which is 
here joined by another watercourse from the southward. The land rises into hills on each side, and, as our road lay at some distance to the west, we had a beautiful view along the red sandy bed of the river, which formed a striking contrast with the green hills on each side. The banks were planted with onions, melons, cotton, indigo, and some wheat; and watered, by means of a basket and lever, out of holes dug about two feet deep in the bed of the river, in which water is always found in abundance. On the eastern bank there is a town called Kutri, apparently large and populous, with a number of dye-pots in its outskirts. At four in the afternoon we crossed the bed of another small river, coming from the southwest, and falling into the forementioned river, a mile and a half to the east of a town, on its northern bank, called Quari, or Quoli, where we halted. I waited on the governor, who was an aged Felatah: after the usual compliments, he anxiously inquired for Dr. Oudney, and was much disappointed when I informed him of his death. He complained of being grievously afflicted with rheumatic pains; and said he had already outlived most of the people of this country, having attained the age of seventy-two years. We remained with him until houses were prepared for us; and he told me that the river, which flows to the eastward (mentioned before as dividing the provinces of Kano and Kashna), after the junction of some other streams, takes the name of Quarrama.

March 6 and 7.-The weather clear and warm. This morning I exchanged a turkadee, worth about two dollars and a quarter, for a sheep, and gave a feast to $\mathrm{El}$ Wordee and the shreef, along with all our servants. About a hundred Tuaricks came to see me, having learned I had visited Ghraat, and was acquainted with their countrymen. The women and children of the town every where peeped at me through the matting of their houses, with eager curiosity : although some of the Tuaricks were nearly as white as myself. The Tuaricks here have a beautiful breed of horses, full of fire; but they do not 
stand so high as the barbs of Tripoli. In the evening I despatehed a courier with a letter to Sultan Bello, as I had been recommended by the governor of Kano to remain here until a guard was sent from Sackatoo to conduct me through the provinces of Goober and Zamfra, which were in a state of insurrection. I found by observation the town of Quarro to be in lat. $13^{\circ} 7^{\prime} 14^{\prime \prime}$ north.

I was unluckily taken for a fighi, or teacher, and was pestered, at all hours of the day, to write out prayers by the people. My servants hit upon a scheme to get rid of their importunities, by acquainting them if I did such things, they must be paid the perquisites usually given to the servants of other fighis. To-day my washerwoman positively insisted on being paid with a charm, in writing, that would entice people to buy earthen-ware of her; and no persuasions of mine could either induce her to accept of money for her service, or make her believe that the request was beyond human power. In the cool of the afternoon, I was visited by three of the governor's wives, who, after examining my skin with much attention, remarked, compassionately, it was a thousand pities I was not black, for I had then been tolerably good-looking. I asked one of them, a buxom young girl of fifteen, if she would accept of me for a husband, provided I could obtain the permission of her master the governor. She immediately began to whimper; and on urging her to explain the cause, she frankly avowed she did not know how to dispose of my white legs. I gave each of them a snuff-box, with a string of white beads in addition, to the coy maiden. They were attended by an old woman, and two little female slaves, and during their stay made very merry, but I fear their gaiety soon fled on returning to the close custody of their old gaoler.

Mar. 8 and 9.-Thermometer in the shade $91^{\circ}$. To-day I was visited by several females, who evinced much discernment in their curious manipulation of my person. One of them, from Zirmee, the capital of Zamfra, was with difficulty prevailed on to leave me. 
Mar. 10.-We had a shower of rain during the night. Two messengers arrived from Sackatoo, going their rounds with orders for all Felatahs to repair to the capital, as the sultan was going on an expedition, but where they did not know.-Both myself and servants have had a return of the same fever we had at Koka. This was almost always the case whenever we remained two or three days together in any town. In vain I tried every thing in my power to induce my guide to proceed without waiting for the escort; but El Wordee and the shreef, who were the most pusillanimous rascals I ever met with, effectually dissuaded him from it.

I was much amused with a conversation I overheard between the blind shreef and his servant, respecting myself and my intended journey. "That Abdullah," says the servant, " is a very bad man; he has no more sense than an ass, and is now going to lead us all to the devil, if we will accompany him : I hope, master, you are not such a fool." "Yes!" ejaculates the shreef, " it was a black day when I joined that Kafir, but if I don't go with him I shall never see the sultan, and when I return to Kano without any thing, the people will laugh at me for my pains." Says the servant, "Why do you not talk to him about the dangers of the road?" "Damn his father !" replies the shreef, "I have talked to him, but these infidels have no prudence." I now called out,- " A thousand thanks to you, my lord shreef." "May the blessing of God be upon you!" he exclaimed. "Oh! Rais Abdullah, you are a beautiful man; I will go with you wherever you go. I was only speaking in jest to this dog." " My lord shreef, I was aware of it from the first; it is of no importance, but if the escort does not arrive to-morrow, I may merely mention to you I shall certainly proceed, without further delay, to Kashna." This I said by way of alarming the shreef, who liked his present quarters too well, from the number of pious females who sought edification from the lips of a true descendant of the 
Prophet: besides the chance such visits afforded of transmitting to their offspring the honour of so holy a descent.

- March 11.-Small-pox is at present very prevalent. The patient is treated in the following manner:-When the disease makes its appearance, they anoint the whole body with honey, and the patient lies down on the floor, previously strewed with warm sand, some of which is also sprinkled upon him. If the patient is very ill, he is bathed in cold water early every morning, and is afterwards anointed with honey, and replaced on the warm sand. This is their only mode of treatment; but numbers died every day of this loathsome disease, which had now been raging for the last six months.

I had my baggage packed up for my journey to Kashna; to the great terror of $\mathrm{El}$ Wordee, the shreef, and all my servants, who earnestly begged me to remain only one day longer.-A party of horse and foot arrived from Zirmee last night. It was the retinue of a Felatah captain, who was bringing back a young wife from her father's, where she had made her escape. The fair fugitive bestrode a very handsome palfrey, amid a group of female attendants on foot. I was introduced to her this morning, when she politely joined her husband in requesting me to delay my journey another day, in which case they kindly proposed we should travel together. Of course it was impossible to refuse so agreeable an invitation, to which I seemed to yield with all possible courtesy; indeed I had no serious intention of setting out that day. The figure of the lady was small, but finely formed, and her complexion of a clear copper colour; while, unlike most beautiful women, she was mild and unobtrusive in her manners. Her husband, too, whom she had deserted, was one of the finest-looking men I ever saw, and had also the reputation of being one of the bravest of his nation.

A hump-backed lad, in the service of the gadado, or vizier, of Bello, who, on his way from Sackatoo, had his hand dreadfully wounded by the people of Goober, was in the habit of coming every 
evening to my servants to have the wound dressed. Last night he told me he had formerly been on an expedition under Abdecachman, a Felatah chief. They started from the town of Labojee in Nyffee, and crossing the Quarra, travelled south fourteen days along the banks of the river, until they were within four days' journey of the sea, where, according to his literal expression, " the river was one, and the sea was one ;" but at what precise point the river actually entered the sea he had no distinct notion.

March 12.-The weather clear and warm. The Felatah chief again waited upon me to-day, and handsomely offered to conduct me himself to Sackatoo, if my escort did not arrive in time. The town of Quarra is surrounded by a clay wall about twenty feet high, and may contain from 5000 to 6000 inhabitants, who are principally Felatahs. It lies in a valley environed by low hills, the river Quarrama flowing a little to the south of the town, and two or three miles lower down joining the river before-mentioned that passes Kutri. During the dry season, a number of Tuaricks, who come with salt from Bilma, lodge in huts outside the walls.

March 13.-At half-past six o'clock I commenced my journey, in company with the Felatah chief. El Wordee and the shreef were evidently in much trepidation, as they did not consider our present party sufficiently strong in case of attack. Our road lay through a level country, clear of wood, with large fields of indigo, cotton, and grain. At nine in the morning, we were agreeably surprised by meeting the escort I expected. It consisted of 150 horsemen, with drums and trumpets. Their leader, with his attendants, advanced to me at full gallop, and bade me welcome to the country in the name of his master, the sultan; who, he said, was rejoiced to hear I was so near, and had sent him to conduct me to his capital. Nothing could now equal the joy of El Wordee and the shreef, who had both been cursing my temerity the whole morning. During the time we halted with the escort, a party of boxers from 
a neighbouring village passed us, on their way to challenge " the fancy" of Quarra. They were fine looking men, carrying muffles for the hands over their shoulders, and were attended by drummers and a large posse of women. They offered to exhibit before me, but I declined, and we proceeded to a village called Burdarawa, where the commander of the escort begged me to halt for one day, as both his men and horses were much fatigued by their journey from Sackatoo. I was provided with the best house in the village, and supplied with every thing the place afforded. El Wordee, the shreef, and my people, fared equally well. There is a ridge of low hills to the north-east.

March. 14.-At six in the morning left Burderawa, and traversing a thickly wooded country we arrived at the bed of the river Fulche, which in many places was quite dry. The channel was only thirty or forty yards wide where we crossed. We halted on the opposite bank, and sent the camels out to graze. The servants here filled our water-skins. This river joins the river of Zirmee, half a day's journey to the north. Several people were very busy fishing in the pools left by the river; while assistants, floating on a stick buoyed up at each end with gourds, were splashing in the water with spears to drive fish into the nets. I treated the chief of the escort and his friends with tea, of which they had heard many exaggerated reports from people that had been at Kano.

At two in the afternoon we left the banks of the river Fulche, at the quickest pace it was possible to make the camels travel. We were previously joined by an immense number of people, some bearing burdens on their heads, others with loaded asses and bullocks. Our road, for two or three miles, lay through an open country; we then entered a thick wood, by a narrow winding path, where the shreef, and others who rode on camels, suffered severely from the overhanging branches. Bullocks, asses, and camels; men, women, and children, were now all struggling to be foremost ; every person 
exclaiming, "Wo to the wretch who falls behind; he is sure to meet an unhappy end at the hands of the Gooberites." Had it not been for the care of my escort, I must have run great risk of being thrown down, and trampled to death, by the bullocks which frequently rushed furiously past me on the narrow path. The horsemen, however, rode on each side of me, to protect my person. We were now on the confines of the provinces of Goober and Zamfra; and a place better adapted for land pirates, as the Arabs name robbers, is scarcely to be conceived. Till sunset we continued to thread a thick wood, the road being overrun with long grass, and apparently covered with water during the rainy season. The soil now became more gravelly, the trees stunted, and the country altogether more open. The pebbles were of clay ironstone, which in some places was seen in large masses. There were numerous tracks of elephants, and other wild animals. From the great care the escort took of me, I was often almost suffocated with dust in riding over dry clay grounds, for I had horsemen continually on each side of me; while from time to time a reconnoitring party would pass at full speed, then halt, and say prayers, and so skirr past me again and again. During the day a drum was beat every ten minutes, in the rear of our line of march, and at night this was repeated every two or three minutes, and also answered by the trumpets in front.

At half-past two in the morning we stopped at the lake Gondamee, to water our horses and beasts of burden, and to give the foot passengers and slaves time to fill their gourds and water-skins. The place is reckoned the most dangerous in the whole road, as it is only one day's journey to the north of Kalawawa, the capital of the province of Goober, which has been for some time in a state of open rebellion.

The appearance of the country was much the same as before. At four in the morning we came to a large lawn in the woods, where we again halted for an hour. I felt quite refreshed by this 
short rest. The country to the westward of the lake of Gondamee rises into ridges, running north-north-east, with loose gravelly stones and clay on the surface. We continued to travel with the utmost speed, but the people soon began to fag; and the lady of the Felatah chief, who rode not far distant from me, began to complain of fatigue. At noon we halted at the side of a hollow, said to be the haunt of lions, where water is generally found, but this year it was dry. Tracks of elephants were every where visible, but I perceived no marks of lions. We stopped here only half an hour, and set off again, through a country rising into low hills, composed of red clay and loose stones, the descent of some of which proved both difficult and dangerous to the loaded camels. At eight in the evening we halted at the wells of Kamoon, all extremely fatigued. I ordered a little kouskousoo for supper, but fell asleep before it was ready. When $I$ awoke at midnight, $I$ found it by my side; never in my whole life did I make a more delicious repast.

March 16.-At day-break I discovered our camels had strayed in quest of food, nor could I be angry with their keepers, feeling so tired myself from our rapid journey. Indeed my ankles were considerably swelled and inflamed. Here again I experienced the civility of the escort, as all the horsemen were immediately despatched after the camels, with which they returned about eight o'clock. 1 gave the man who found them a Spanish dollar, and to the commander of the escort, and his two principal officers, I made each a present of a cotton kaftan, or loose gown, a knife, looking-glass, snuff-box, razor, and some spices.

I now left the wells of Kamoon, followed by my escort and a numerous retinue, amid a loud flourish of horns and trumpets. Of course this extraordinary respect was paid to me as the servant of the king of England, as I was styled in the sheikh of Bornou's letter. To impress them further with my official importance, I arrayed myself in my lieutenant's coat, trimmed with gold lace, white 
trowsers, and silk stockings, and, to complete my finery, I wore Turkish slippers and a turban. Although my limbs pained me extremely, in consequence of our recent forced march, I constrained myself to assume the utmost serenity of countenance, in order to meet with befitting dignity the honours they lavished on me, the humble representative of my country.

Near Kamoon the country is hilly, but seemed to yield much grain. The soil is red clay, mixed with gravel, the stones of which looked as if covered with iron rust. We passed some beautiful springs on the sloping declivities of the hills, which in general are low, and run in broken ridges in a north-east direction. The valleys between the hills became wider as we approached Sackatoo, which capital we at length saw from the top of the second hill after we left Kamoon. A messenger from the sultan met us here, to bid me welcome, and to acquaint us that his master was at a neighbouring town, on his return from a ghrazie, or expedition, but intended to be in Sackatoo in the evening. Crowds of people were thronging to market with wood, straw, onions, indigo, \&c. At noon we arrived at Sackatoo, where a great multitude of people was assembled to look at me, and I entered the city amid the hearty welcomes of young and old. I was conducted to the house of the gadado, or vizier, where apartments were provided for me and my servants. After being supplied with plenty of milk, I was left to repose myself. The gadado, an elderly man named Simnou Bona Lima, arrived near midnight, and came instantly to see me. He was excessively polite, but would on no account drink tea with me, as he said I was a stranger in their land, and had not yet eaten of his bread. He told me the sultan wished to see me in the morning, and repeatedly assured me of experiencing the most cordial reception. He spoke Arabic extremely well, which he said he learned solely from the Koran. 
March 17.-After breakfast the sultan sent for me; his residence was at no great distance. In front of it there is a large quadrangle, into which several of the principal streets of the city lead. We passed through three coozees, as guardhouses, without the least detention, and were immediately ushered into the presence of Bello, the second sultan of the Felatahs. He was seated on a small carpet, between two pillars supporting the roof of a thatched house, not unlike one of our cottages. The walls and pillars were painted blue and white, in the Moorish taste; and on the back wall was sketched a fire-screen, ornamented with a coarse painting of a flower-pot. An arm-chair, with an iron lamp standing on it, was placed on each side of the screen. The sultan bade me many hearty welcomes, and asked me if I was not much tired with my journey from Burderawa. I told him it was the most severe travelling I had experienced between Tripoli and Sackatoo, and thanked him for the guard, the conduct of which I did not fail to commend in the strongest terms.

He asked me a great many questions about Europe, and our religious distinctions. He was acquainted with the names of some of the more ancient sects, and asked whether we were Nestorians or Socinians. To extricate myself from the embarrassment occasioned by this question, I bluntly replied we were called Protestants. "What are Protestants?" says he. I attempted to explain to him, as well as I was able, that having protested, more than two centuries and a half ago, against the superstition, absurdities, and abuses practised in those days, we had ever since professed to follow simply what was written " in the book of our Lord Jesus," as they call the New Testament, and thence received the name of Protestants. He continued to ask several other theological questions, until I was obliged to confess myself not sufficiently versed in religious subtleties to resolve these knotty points, having always left that task to others 
more learned than myself. He now ordered some books to be produced which belonged to Major Denham, and began to speak with great bitterness of the late Boo Khaloom, for making a predatory inroad into his territories; adding, in his own words, " I am sure the bashaw of Tripoli never meant to strike me with one hand, while he offers a present with the other : at least it is a strange way for friends to act. But what was your friend doing there?" he asked abruptly. I assured the sultan, that Major Denham had no other object than to make a short excursion into the country. The books being brought in, proved to be the Nautical Almanack, two Reviews, Lord Bacon's Essays, and Major Denham's Journal ; all which the sultan returned to me in the most handsome manner. Before taking leave, however, I had to explain the contents of each, and was set to read them, in order to give him an opportunity of hearing the sound of our language, which he thought very beautiful. The sultan is a noble-looking man, forty-four years of age, although much younger in appearance, five feet ten inches high, portly in person, with a short curling black beard, a small mouth, a fine forehead, a Grecian nose, and large black eyes. He was dressed in a light blue cotton tobe, with a white muslin turban, the shawl of which he wore over the nose and mouth in the Tuarick fashion.

In the afternoon I repeated my visit, accompanied by the gadado, Mahomed El Wordee, and Mahomed Gumsoo, the principal Arab of the city, to whom I had a letter of introduction from Hat Salah at Kano. The sultan was sitting in the same apartment in which he received me in the morning. I now laid before him a present, in the name of His Majesty the King of England, consisting of two new blunderbusses highly ornamented with silver, the doublebarrelled pistols, pocket-compass, and embroidered jacket of the late Dr. Oudney; a scarlet bornouse trimmed with silver lace, a pair of scarlet breeches, thirty yards of red silk, two white, two red, and two Egyptian turban shawls, the latter trimmed with gold; four

$m 2$ 
pounds each of cloves and cinnamon; three cases of gunpowder, with shot and balls; three razors, three clasp-knives, three lookingglasses; six snuff-boxes, three of paper, and three of tin ; a spy-glass, and a large English tea-tray, on which the smaller articles were arranged. He took them up one by one. The compass and spyglass excited great interest; and he seemed much gratified when I pointed out that by means of the former, he could at any time find out the east to address himself in his daily prayers. He said, "Every thing is wonderful ; but you are the greatest curiosity of all !" and then added, "What can I give that is most acceptable to the King of England ?" I replied, "The most acceptable service you can render to the King of England, is to co-operate with His Majesty in putting a stop to the slave trade on the coast: as the King of England sends every year large ships to cruise there, for the sole purpose of seizing all vessels engaged in this trade, whose crews are thrown into prison; and of liberating the unfortunate slaves, on whom lands and houses are conferred, at one of our settlements in Africa. "What!" said he, " have you no slaves in England?" "No. Whenever a slave sets his foot in England, he is from that moment free."- "What do you then do for servants ?" "We hire them for a stated period, and give them regular wages : nor is any person in England allowed to strike another; and the very soldiers are fed, clothed, and paid by Government." " God is great !" he exclaimed ; "You are a beautiful people." I next presented the sheikh of Bornou's letter. On perusing it, he assured me I should see all that was to be seen within his dominions, as well as in Youri and Nyffee, both of which, I informed him, I was anxious to visit. He expressed great regret at the death of Dr. Oudney, as he wished particularly to see an English physician, who might instruct his people in the healing art. In the evening I made a present to the gadado of a scarlet bornouse, a pair of scarlet breeches, a red Turkish jacket, two white, and one red turban shawls, three razors, 
three knives, three paper snuff-boxes, and three of tin, three lookingglasses, two pounds of cloves, and two pounds of cinnamon. The gadado is an excellent man, and has unbounded influence with the sultan, to whose sister he is married.

March 18.- Weather clear and warm. Although I was very ill all day, the courtyard of my house was crowded with people, from sunrise to sunset; all of whom I had to see with the greatest patience, and to answer their numberless questions, such as, "Have you rain in your country ?" " Have you wheat?" " Have you goats, sheep, and horses?" But the obvious and favourite interrogatory was, "What are you come for?" This I always attempted to explain to their satisfaction; telling them, "I came to see the country, its rivers, mountains, and inhabitants, its flowers, fruits, minerals, and animals, and to ascertain wherein they differed from those in other parts of the world. When their friends travelled among strange nations, did they not on their return ask them what they had seen? The people of England could all read and write, and were acquainted with most other regions of the earth; but of this country alone they hitherto knew'scarcely any thing, and erroneously regarded the inhabitants as naked savages, devoid of religion, and not far removed from the condition of wild beasts: whereas I found them, from my personal observation, to be civilized, learned, humane, and pious."

March 19.-I was sent for by the sultan, and desired to bring with me the "looking-glass of the sun," the name they gave to my sextant. I was conducted farther into the interior of his residence than on my two former visits. This part consisted of coozees, pretty far apart from each other. I first exhibited a planisphere of the heavenly bodies. The sultan knew all the signs of the Zodiac, some of the constellations, and many of the stars, by their Arabic names. The "looking-glass of the sun" was then brought forward, and occasioned much surprise. I had to explain all its appendages. The 
inverting telescope was an object of intense astonishment; and I had to stand at some little distance, to let the sultan look at me through it; for his people were all afraid of placing themselves within its magical influence. I had next to show him how to take an observation of the sun. The case of the artificial horizon, of which I had lost the key, was sometimes very difficult to open, as happened on this occasion : I asked one of the people near me for a knife to press up the lid. He handed me one much too small, and I quite inadvertently asked for a dagger for the same purpose. The sultan was instantly thrown into a fright: he seized his sword, and half drawing it from the scabbard, placed it before him, trembling all the time like an aspen leaf. I did not deem it prudent to take the least notice of his alarm, although it was I who had in reality most cause of fear; and on receiving the dagger, I calmly opened the case, and returned the weapon to its owner with apparent unconcern. When the artificial horizon was arranged, the sultan and all his attendants had a peep at the sun; and my breach of etiquette seemed entirely forgotten. After the curiosity of all was satisfied, I returned to my house. I had now a severe headach, and was seized with violent vomiting. In the evening the sultan sent me two sheep, a camel-load of wheat and rice, some plantains, and some of the finest figs I had ever tasted in Africa.

March 20.-I returned the visit of Mahomed Gomsoo, the chief of the Arabs; taking him a present of a scarlet bornouse, jacket and breeches, two white turbans, two razors, two knives, two snuffboxes of paper, and two of tin, a pound of cinnamon, and two cases of gunpowder, with some balls and flints. I was warned at Kano of his excessive greediness; but at the same time recommended to make him a handsome present, and to endeavour by all means to keep him in good humour, on account of his great influence. On receiving the presents, Gomsoo promised to give me a letter to the sultan of Youri, who was his particular friend, and with whom he 
had lived many years. He also said he was there when the English came down in a boat from Timbuctoo, and were lost ; which circumstance he related in the following manner:-They had arrived off a town called Boosa, and having sent a gun and some other articles as presents to the sultan of Youri, they sent to purchase a supply of onions in the market. The sultan apprised them of his intention to pay them a visit, and offered to send people to guide them through the ledges of rock which run quite across the channel of the river a little below the town, where the banks rise into high hills on both sides. Instead of waiting for the sultan, however, they set off at night, and by day-break next morning, a horseman arrived at Youri, to inform the sultan that the boat had struck on the rocks. The people on both sides of the river then began to assail them with arrows, upon which they threw overboard all their effects ; and two white men arm in arm jumped into the water, two slaves only remaining in the boat, with some books and papers and several guns: one of the books was covered with wax-cloth, and still remained in the hands of the sultan of Youri. He also told me, and his account was confirmed by others, that the sultan of Youri was a native of Sockna in the regency of Tripoli, and prided himself extremely on his birth; but that he was such a drunkard, whenever any person of consequence came to visit him, that nothing proved so acceptable a present as a bottle of rum.

1 learned, besides, from Gomsoo, that he had been detained a prisoner three years, in a country called Yoriba, on the west side of the Quarra ; which, he said, entered the sea at Fundah, a little below the town of Rakah. The latter is opposite to Nyffee ; is a place of great trade between the interior and the coast, and all kinds of European goods, such as beads, woollen and cotton cloth, pewter and copper dishes, gunpowder, rum, \&c., are to be had there in exchange for slaves. The inhabitants of Yoriba he represented to be extremely ill disposed. I may here mention, that during my stay 
in Sackatoo, provisions were regularly sent me from the sultan's table on pewter dishes, with the London stamp; and one day I even had a piece of meat served up in a white wash-hand basin, of English manufacture.

On my return home from Gomsoo's, I found a message had been left for me to wait on the sultan, with which I complied immediately after breakfast. He received me in an inner apartment, attended only by a few slaves: after asking me how I did, and several other chit-chat questions, I was not a little surprised when he observed, without a single question being put by me on the subject, that if I wished to go to Nyffee, there were two roads leading to it-the one direct, but beset by enemies; the other safer, but more circuitous : that by either route I should be detained, during the rains, in a country at present in a state of open rebellion, and therefore that I ought to think seriously of these difficulties. I assured him I had already taken the matter into consideration, and that I was neither afraid of the dangers of the road nor of the rains. "Think of it with prudence," he replied, and we parted. From the tone and manner with which this was spoken, I felt a foreboding that my intended visit to Youri and Nyffee was at an end. I could not help suspecting the intrigues of the Arabs to be the cause; as, they know well, if the native Africans were once acquainted with English commerce by the way of the sea, their own lucrative inland trade would from that moment cease. I was much perplexed the whole day how to act, and went after sunset to consult Mohamed Gomsoo : I met him at the door of his house on his way to the sultan, and stopped him, to mention what had passed, and how unaccountably strange it appeared to me that the sultan, after having repeatedly assured me of being at liberty to visit every part of his dominions, should now, for the first time, seem inclined to withdraw that permission; adding, that before I came to Sackatoo, I never heard of a king making a promise one day, and breaking it the next. All this, I knew, 
would find its way to the sultan. Gomsoo told me I was quite mistaken; for the sultan, the gadado, and all the principal people, entertained the highest opinion of me, and wished for nothing so much as to cultivate the friendship of the English nation. "But it is necessary for me to visit those places," I remarked, on leaving him; "or how else can the English get here?" As I anticipated, he repeated to the sultan every word I had said; for I was no sooner at home than I was sent for by the sultan, whom I found seated with Mahomed Gomsoo, and two others. He received me with great kindness, and Mahomed Gomsoo said he had made the sultan acquainted with our conversation. I thanked him, and expressed my earnest hope I had neither said nor done any thing to offend him. The sultan assured me that my conduct had always met with his approbation, and that, although he was freely disposed to show me all the country, still he wished to do so with safety to myself. An army, he added, was at this moment ravaging the country through which I had to pass, and, until he heard from it, it would be unsafe to go; but he expected farther information in three or four days. He drew on the sand the course of the river Quarra, which he also informed me entered the sea at Fundah. By his account the river ran parallel to the sea coast for several days' journey, being in some places only a few hours', in others a day's journey, distant from it. Two or three years ago the sea, he said, closed up the mouth of the river, and its mouth was at present a day or two farther south; but, during the rains, when the river was high, it still ran into the sea by the old channel. He asked me if the King of England would send him a consul and a physician, to reside in Soudan, and merchants to trade with his people; and what I had seen among them, which I thought the English would buy? Here again I enforced the discontinuance of the slave trade on the coast, as the only effectual method of inducing the King of England to establish a consul and a physician at Sackatoo; and that, as the 
sultan could easily prevent all slaves from the eastward passing through Haussa and Nyffee, it would be the consul's duty to see that engagement faithfully fulfilled. With respect to what English merchants were disposed to buy, I particularized senna, gum-arabic, bees' wax, untanned hides, indigo, and ivory. I also endeavoured to impress on his mind that Soudan was the country best situate in all Central Africa for such a trade, which would not only be the means of enriching himself, but, likewise, all his subjects; and that all the merchandise from the east and from the west would be conveyed through his territories to the sea. "I will give the King of England," says he, " a place on the coast to build a town : only I wish a road to be cut to Rakah, if vessels should not be able to navigate the river." I asked him if the country he promised to give belonged to him? "Yes :" said he, "God has given me all the land of the infidels." This was an answer that admitted of no contradiction.

He then spoke of Mungo Park, and said, that had he come in the rainy season, he would have passed the rocks; but that the river fell so low in the dry season, boats could only pass at a certain point. He told me, that some timbers of the boat, fastened together with nails, remained a long time on the rocks; and that a double-barrelled gun, taken in the boat, was once in his possession; but it had lately burst. His cousin, Abderachman, however, had a small printed book taken out of the boat; but he was now absent on an expedition to Nyffee. The other books were in the hands of the sultan of Youri, who was tributary to him. I told the sultan, if he could procure these articles for the King of England, they would prove a most acceptable present, and he promised to make every exertion in his power.

March 21. - Confined to my bed all day with headach and bilious vomiting. In the afternoon I was visited by Mahomed Gomsoo, who was going on a journey to Kano. He casually mentioned, that 
it was a fortunate circumstance we did not accompany Hadje Ali Boo Khaloom, when he brought the bashaw's present last year; as the rogue had opened the bashaw's letter before presenting it to Bello, and erased out of the list several of the presents named in it, which he embezzled, and substituted for them some of inferior quality. The news of his brother's wanton inroad into the sultan's territories, with the bashaw's forces arriving at the same time, Bello sent Hadje Ali back without any present, and would not even admit him into his presence. His conduct, he assured me, had exasperated the sultan against all the Arabs in the bashaw's dominions. Both Bello and his father have, it seems, been much cheated by the Arabs in all their dealings, twenty sometimes coming at a time on a begging excursion, with the story of being poor shreefs ; and, if not presented with thirty or forty slaves, besides food and camels, they were sure to bully the Felatahs, telling them they were not Mussulmans, and would never see paradise, on account of the number of the faithful they had put to death in the conquest of Soudan.

March 22.-Clear and warm. My fever a little abated. In the afternoon the sultan sent for me again, to discuss the advantages and best method of establishing a permanent intercourse with England. I expressed myself exactly in the same terms I had done before, carefully avoiding the mention of any thing which might awaken the jealousy of the Arabs.

The direct road to Youri is only five days' journey; but, on account of the rebellious state of the country, it was necessary to take a circuitous route of twelve days. Numbers of the principal people of Sackatoo came to me, to advise me to give up the idea of going; all alleging that the rains had already commenced at Youri, and that the road was in the hands of their enemies. They repeated the same tales to the servants who were to accompany me, and threw them all into a panic at the prospect of so dangerous a journey.

March 23.-Very ill all day. I discovered that the Arabs were 
also tampering with my servants. One of them, named Absalom, was accosted to-day in the market by one of the merchants of that nation, who told him, if ever he arrived at Youri, without meeting with disasters by the way, the sultan there would assuredly sell him, and that he would never be allowed to return.

March 24.-I felt much better. The sultan sent for me this forenoon about the guide who was to accompany me to Youri. One man had already refused, and I had to tempt another with a promise of 40,000 cowries, unknown to the sultan; who kindly took much pains to impress upon me the necessity of my return within twentysix days, on account of the capricious character of the people of that place. From every person here dissuading me from the attempt, I had too good reason to fear that a regular plan was laid to obstruet my further progress. Even El Wordee went so far as to say, that it was contrary to the wishes of the sheikh that we should either go to Youri or Nyffee, and complained sadly of being afflicted with a dysentery, which very opportunely made its attack the instant I expressed a wish to visit Youri ; and, although I protested against his accompanying me, $I$ have no doubt he both practised on my servants, and used his influence with the gadado to oppose my departure. At last El Wordee, and Mahomed Sidi sheikh, a native of Tuat, and fighee to the sultan, came to tell me, that no person would venture to accompany me, from the road to Youri being infested with Kafirs, and that it was impossible to travel in safety without an army. I remained silent; for had I once begun to give vent to my feelings, I might have committed myself. I thank God I had never once lost my temper amid all these crosses and vexations, and in spite even of this deathblow to all my hopes of reaching Youri. The whole tissue of dangers, however, I believed to be a mere fabrication; for the Arabs, having learned what the sultan said with respect to the English opening a trade with his people by the way of the sea, and well knowing how fatal this scheme would prove 
to their traffic in the interior, probably now attempted to persuade both the sultan and the gadado that the English would come and take the country from them: by which insinuations they induced the sultan to embrace this disingenuous expedient to disengage himself from his promise.

March 25.-Clear and warm. Early this morning I was sent for by the sultan, and, although suffering from fever, I went immediately. He was seated in an inner coozee, with only one eunuch in attendance. The conversation again commenced concerning the projected trade with England, when I repeated the same arguments. $\mathrm{He}$ inquired if the King of England would give him a couple of guns, with ammunition and some rockets? I assured him of His Majesty's compliance with his wishes, if he would consent to put down the slave trade on the coast. I further pointed out to him that Sackatoo was the best situate town in all Northern Africa for commerce, without which a nation was nothing; that rich merchants make rich kings ; and that it was in the power of the King of England to make him one of the greatest princes in Africa, when all the trade from the east and west of that continent would centre in his dominions : at the same time advising him strongly to have a port on the sea coast, where he might have ships, and where his people would be taught by the English the art of ship-building, unless he preferred to send some of them to our settlements on the coast to learn to work as carpenters or blacksmiths, where their religion would be respected, and, after learning these trades from us, they would be enabled to instruct their countrymen. By weighing these important considerations in his mind, he would see that it was both his own interest, and the interest of his people, to form a strict friendship with the English; for when once he had ships, his people might trade to every part of the world, and could even make the pilgrimage to Mecea by a much safer route than at present by land, being able 
to go there and return in six months; and, at the same time, bring with them all the produce of the East.

March 26. - I was much better. Being Friday, the Mahommedan Sabbath, a crowd of people from the country came to see me, after being at the mosque, and the square in front of my house was completely filled. I was sitting in the shade, on a mat spread on the ground, and Mahomed El Wordee with me : both he and my servants were in great fright at the increasing numbers of country people, and El Wordee begged of me either to have my guns loaded, or to threaten to fire among the multitude, if they did not go away; or else to send a message to the gadado to have them dispersed. By way of aggravating his alarm, I said to him, with provoking indifference, "Let them look at me, and welcome; they are like all other country people, and will do me no harm." A number of boys squeezing through the crowd, whenever they caught a glimpse of me, called out to their companions, "Wishod en ila hullah ila hullah wahod Mohamoud wa rhasoul illah, hada el Kaffir ;" or more briefly, " ila el ullah Mohamoud wa rhasoul illah, hada el Kaffir," - " I bear witness there is no God but one God, and Mahomet is his prophet; there is the Infidel,' and immediately took to their heels. At last one of my servants stole through the crowd and informed the gadado, who sent and dispersed the people, to the great satisfaction of El Wordee; when I was allowed to enjoy the remainder of the day undisturbed.

March 27.-Clear and warm. In the morning I was very ill with ague, and at eleven the sultan sent for $\mathrm{El}$ Wordee and me, with a request to bring my English saddle along with me. We were conducted farther into the interior of his residence than $I$ had ever been before: the sultan was sitting reading in one corner of a square tower: on showing him my English saddle, he examined it very minutely, and said it was exactly like the ancient Arab saddle, de- 
scribed in one of his books. It was a second-hand saddle which we bought at Malta, and having often also served myself and my servant for a pillow, I had it re-stuffed at Kano: on seeing the maker's eard, "Laurie, Oxford-Street, London," under the saddle lap, the sultan, surmising perhaps that it was a charm, requested me to explain its meaning; upon which I told him, that in England a tradesman generally attached his name to the articles made by him, which, if of superior quality, brought him into notice.

He again renewed the subject of the establishment of an English consul and physician at Sackatoo, as well as of the likelihood of receiving guns and rockets from England, which he now recommended to be sent by the way of Tripoli and Bornou, under the escort of El Wordee. To the latter part of this proposal I gave a direct negative: I assured him, that unless he undertook to convey them to Rakah at his own expense, they would not be sent at all, as the expense and delay by the other route were obstacles of too serious a nature to be repeated; besides, should the bashaw of Tripoli even allow the guns to pass, the sheikh of Bornou, who was famed for prudence and foresight, would forfeit all claim to that character, if he did not seize them on reaching his territory. "Oh! no," said the sultan, " he will never do that ; he is my friend." I again expatiated on the futility of this mistaken confidence, so opposite to sound policy. At this discourse El Wordee seemed to be quite crest-fallen; and it plainly appeared that this was his own device, in order that he might be sent by the bashaw along with another English mission; and after fleecing them throughout the route, have another opportunity here of playing the same game over again. All my former suspicions were now confirmed; and I attribute, in a great measure, to his machinations the necessity of abandoning my journey to Youri. I once more assured the sultan, that it was only by the sea-coast he must expect to maintain an intercourse with England. He then promised, that if I would wait till 
after the rains, he would send me to the governor of Zeg Zeg, with orders to convey me to the coast.

Having heard of our newspapers, he desired me to send for them, calling them the "Huber el dineah," or "News of the world." Being set to read extracts from them, I happened to mention that thousands of them were printed daily, when he exclaimed, "God is great; You are a wonderful people." He asked me about the Greeks, and inquired if they were joined by any other Christians; the discussion of which subject I contrived to evade. He then remarked, "You were at war with Algiers, and killed a number of the Algerines." I assured him that they were a ferocious race, never at peace amongst themselves (having even killed three of their own deys in one month), and persisting in the practice of making slaves of Europeans, until forcibly compelled by us to relinquish it.

In this conversation, he repeated "You are a strange people, the strongest of all Christian nations : you have subjugated all India." I said, we merely afforded it our protection, and gave it good laws. I mentioned, particularly, that many Mahometan states had put themselves under our protection, knowing we were a people that never interfered with the rights of others, whether civil or religious, but caused the laws to be impartially administered among all sects and persuasions. The King of England, I often told him, had, in fact, as many Mahometan subjects as the Grand Signor; and I took care to enlarge upon the favourite topic of several ships conveying the inhabitants of India annually to Mecca.

The sultan again drew on the sand the course of the Quarra, with the outline of the adjoining countries. I now requested him to order one of his learned men to make me a chart of the river, on paper, which he promised to have done. The sultan re-stated that Fundah is the name of the place where the Quarra enters the sea, during the rainy season; and that Tagra, a town on the sea-coast, where many Felatahs reside, is governed by one of his subjects, a 
native of Kashna, named Mohamed Mishnee. In the evening I saw him again, when he told me that he was going on an expedition against some of his enemies, but would not be away more than five days, desiring me not to be uneasy during his absence, and assuring me that I should want for nothing.

To announce to the people any public measure, such as the present expedition, the city crier is sent round, who first proclaims, "This is the will of the sultan;" the people replying "Whatever the sultan does, is good; we will do it:" the crier stops in like manner at the end of every sentence, when the people renew the same assurances of submission. The crier always commences at the sultan's gate, from which he proceeds to the market-place. It was proclaimed on this occasion, that all those who were to accompany the expedition must provide themselves with eight days' provisions. At eight in the evening, the sultan left the capital with his army.

March 28.-This forenoon I had a visit from a famous Marauboot, or holy man : he was accompanied by a great retinue, and repeated the Fatha at his entrance, for the first time this ceremony had been performed before me in Haussa. He began by asking me, abruptly, to become a Moslem : I said, "God willing, I might; but I require much previous instruction in religious matters before I can think of changing my faith." At this answer the bystanders began to laugh immoderately, to the evident discomposure of the holy man's gravity : for my part, I could not discover any wit in what I said, although it had the effect of relieving me from further impertinent questions on religious subjects; and he soon left me, rather disconcerted at his want of success. After sunset I had a visit from Ateeko, the brother of the sultan, to whom I had sent a present of a scarlet jacket, breeches, and bornouse : when he was seated, and the usual compliments were over, I apologized on the score of ill health, and the remoteness of his abode, for not having already paid him a visit. He now told me he had a few things which belonged to the 
Englishman who was at Musfia, with the late Boo Khaloom, but as no person knew what they were, he would gladly sell them to me, ordering his servant at the same time to produce a bundle he held under his arm. The servant took from the bundle a shirt, two pair of trowsers, and two pieces of parchment, used for sketching by Major Denham. The only other articles, Ateeko said, were a trunk, a broken sextant, and a watch; but the watch had been destroyed, as he alleged, in their ignorant eagerness to examine its structure. He then invited me to visit him the following morning, when we might fix the price of what I wished to buy, to which I assented; and he bade me good night ; but, on re-considering the matter, I thought it prudent first to consult the gadado, particularly as the sultan was absent. I began to fear lest a bad construction might be put upon my visit to this mean prince, who, on the death of his father, Bello the first, had aspired to the throne, and had even had himself proclaimed sultan in Sackatoo ; from the mere circumstance of his brother Bello, the present sultan, having expressed the intention, during his father's lifetime, of resigning the splendour of sovereignty for the tranquillity of a learned and holy life. Ateeko even had the audacity to enter his brother's house, preceded by drums and trumpets; and when Bello inquired the cause of the tumult, he received the first intimation of his brother's perfidy, in the answer " The sultan Ateeko is come." Bello, nowise disconcerted, immediately ordered the usurper into his presence, when Ateeko pleaded, in vindication of his conduct, his brother's proposed disinclination to reign ; to which the sultan only deigned to reply, "Go and take off these trappings, or I will take off your head:" Ateeko, with characteristic abjectness of spirit, began to wring his hands, as if washing them in water, and called God and the Prophet to witness that his motives were innocent and upright; since which time, he has remained in the utmost obscurity.

March 29.-I visited the gadado very early, and informed him of 
what had taken place last night. He told me by no means to go while the sultan was absent, as my visit at this juncture might be regarded with a very jealous eye by the people; who would not hesitate to charge 'me with a plot to place prince Ateeko on the throne, by the assistance of England. The gadado undisguisedly expressed his contempt of Ateeko's conduct, and assured me that it was entirely without the sanction of the sultan.-In the afternoon I was again seized with bilious vomiting.

March 30.-Cloudy and warm. El Wordee came to-day in the name of the gadado, to ask me to sell him a silk tobe and some other articles, although it was well known to him I had nothing of the kind in my possession; and had it been otherwise, he was also aware I would not sell them. I suspected that he was manœuvring in some way for himself; and as soon as he was gone, I went to the gadado, and asked him if he had sent any message to me, when it turned out as I conjectured. The good old gadado said he felt quite ashamed that any thing should have been asked in his name; and shaking his head, he said he feared El Wordee was__ then checking himself, he earnestly requested me to take no further notice of it.

March 31.-I was confined to the house all day with ague. During the time I had been in Sackatoo, I had, at the recommendation of both the sultan and gadado, ridden out every morning for the benefit of my health; but instead of choosing the high grounds, I had generally taken my rides by the banks of the river, where there were many stagnant pools of water, and the land was low and swampy. To this I attributed my ague. The Arabs are likewise much afflicted with it at this season of the year. With the gadado's advice, I took my morning rides in future on the high grounds.

April 1.-Morning cool and clear. I discovered that one of my bags of cowries had been cut open; and having good reason to suspect my servant Absalom of the theft, as he was known to have o 2 
made a number of extravagant presents to one of the gadado's female slaves, of whom he was passionately enamoured, I was obliged to dismiss him my service, although both a smart and a brave fellow, uniting at once in his person the important functions of barber and butler.

April 4.-Cool and clear. My ague had left me. In the evening the sultan returned to town.

April 5.-This morning Hadje Ali Boo Khaloom arrived from Kano. Although he left the town of Quarra with a large kafila, consisting of a thousand people, and protected by an escort of fifty horsemen, yet they were attacked between the lake of Gondamee and the wells of Kamoon, by the people of Goober and Zanfra, who after killing one shreef, two Arabs of Tripoli, and seventeen Felatahs, and taking the negroes prisoners, captured all the baggage except that of Hadje Ali. He fortunately escaped with his camels, though less by his own bravery than through the address of one of his slaves, who kept cheering up his master's spirits, and urging the camels to their utmost speed, until they completely outstripped their pursuers. The shreef who was killed left two young children, to whom I sent ten dollars, by way of encouraging others to contribute to their relief.-In the afternoon I paid my respects to the sultan, on his return from the army. Hadje Ali Boo Khaloom accompanied me; but the sultan did not deign to look towards the place where he sat, although he was extremely kind to me, inquiring how I did, and if any thing had happened in his absence.

A slave belonging to Mahomed Moode, the gadado's brother, whose duty it was to run with his spears by his horse's side, had feigned lameness, to be excused attending his master. For this offence his legs were heavily shackled, in which miserable plight he often contrived to crawl to the square before my door, and at length begged me to intercede with his master for his release. In the evening, when his master came as usual to see me, I asked him to 
pardon the slave, who was immediately sent for, and his fetters taken off. It is but justice to say, his master appeared as grateful to me for affording him the opportunity of liberating his slave, as if I had done him a personal favour. The mode of punishing slaves in Sackatoo is by putting them in irons, and throwing them into a dungeon under the common prison of the city. The dungeon is reported to be extremely filthy and abominable. Here they remain without any food, but what is gratuitously supplied by their fellow slaves, until their master releases them. This punishment is much dreaded, and its duration depends entirely on the caprice of the master.

April 6.-Clear and cool.

April 7.-Having obtained the permission of the gadado to purchase from Ateeko the sorry remains of Major Denham's baggage, I went early this morning with El Wordee to the prince's house, which is situate at the west end of the town. After waiting some time in the porch of a square tower, we were introduced into an inner coozee hung round with blue and yellow silk, in sharp pointed festoons, not unlike gothic arches. Ateeko soon made his appearance, and after a few compliments, we proceeded to business. He brought out a damaged leathern trunk, with two or three shirts and other articles of dress, much the worse for wear, and the sextant and parchment already mentioned. The sextant was completely demolished, the whole of the glasses being taken out, or where they could not unscrew them, broken off the frame, which remained a mere skeleton. He seemed to fancy that the sextant was gold, in which I soon undeceived him; and selecting it with the parchment and one or two flannel waistcoats and towels, likely to be useful to Major Denham, I offered him 5000 cowries, at which he appeared much surprised and mortified. El Wordee whispered in my ear,- " Remember he is a prince, and not a merchant." I said, loud enough for his highness to hear, " Remember 
that when a prince turns merchant, he must expect no more than another man; and as that is the value of the articles, it is a matter of indifference to me whether I buy them or not." Ateeko frequently repeated his belief of the sextant being gold; but at length the bargain seemed to be concluded, and I requested him to send a slave to my house with the articles I had picked out, to whom I would pay the money. The slave, however, was recalled before he got half way, and his suspicious master took back the sextant frame, in dread of being overreached by me in its value, which I did not fail to deduct from the price agreed on.

The prince's residence, like those of other great men in this country, is within a large quadrangular enclosure, surrounded by a high clay wall, with a high tower at the entrance, in which some of the slaves or body-guard lounge during the day, and sleep at night. The enclosure is occupied by coozees, some of them in a very ruinous condition. He told me that he possessed a great number of slaves; and I saw many females about his person, most of them very beautiful. He also stated, that he kept two hundred civet cats, two of which he showed me. These animals were extremely savage, and were confined in separate wooden cages. They were about four feet long, from the nose to the tip of the tail; and with the exception of a greater length of body and a longer tail, they very much resembled diminutive hyenas. They are fed with pounded Guinea corn, and dried fish made into balls. The civet is scraped off with a kind of muscle shell every other morning, the animal being forced into a corner of the cage, and its head held down with a stick during the operation. The prince offered to sell any number of them I might wish to have ; but they did not appear to be desirable travelling companions. Ateeko is a little spare man, with a full face, of monkey-like expression. He speaks in a slow and subdued tone of voice; and the Felatahs acknowledge him to be extremely brave, but at the same time avaricious and 
cruel. "Were he sultan," say they, " heads would fly about in Soudan."

After taking leave of the prince, we rode by appointment to view a new mosque, which was building at the expense of the gadado, not far distant from Ateeko's house. Like all mosques, it was of a quadrangular form, the sides facing the four cardinal points, and about 800 feet in length. On the eastern side there were two doors. The western entrance had a small square apartment on the right hand in entering, where the people perform their ablutions before prayers. The roof of the mosque was perfectly flat, and formed of joists laid from wall to wall, the interstices being filled up with slender spars placed obliquely from joist to joist, and the whole covered outside with a thick stratum of indurated clay. The roof rested on arches, which were supported by seven rows of pillars, seven in each row. The pillars were of wood, plastered over with clay, and highly ornamented. On the south side of the body of the building there was a small recess appropriated solely to the sultan's use. Some workmen were employed in ornamenting the pillars, others in completing the roof; and all appeared particularly busy, from the circumstance of the gadado himself being here to receive me. The gadado was very inquisitive to know my opinion, every two or three minutes asking me what $I$ thought of the building. The master builder, a shrewd looking little man, continually laughing, was seated in a position whence he could conveniently overlook all the workmen. He informed me he was a native of Zeg Zeg, and that his father having been in Egypt, had there acquired a smattering of Moorish architecture, and had left him at his death all his papers, from which he derived his only arehitectural knowledge. He was particularly solicitous to possess a Gunter's scale, which I afterwards sent to the sultan.

April 8.-Clear and cool. I was confined to the house all day with ague. Hadje Ali Boo Khaloom, who has paid me two or three 
visits, which I never return, sent me half a sheep, and accompanied the present with great offers of his services, of which I took no notice, but ordered the present to be given to the poor. I always treated this man with civility ; but took good care never to follow any of his suggestions, or to allow myself the smallest freedom of conversation before him.

A number of poor children came to ask alms every morning, to whom I was in the habit of giving two or three cowries a piece. Their cry was, "Allah attik jinne," or " God give you paradise ;" a style of begging that a kafir like me could not withstand; and when almost all Africa doomed me to eternal perdition, I considered it obtaining their suffrages at a cheap rate. Amongst the older beggars, there was one, a native of Bornou, who had once been governor of a town called Sockwa near Katagum, and had come to Sackatoo in consequence of having made certain complaints against Duncowa, which being on investigation found to be untrue, he had been degraded. He was said to be rich; but in order to save his wealth, now feigned madness. Every night after sunset, he used to sing extempore before the gadado's door; and I was frequently the subject of his songs, particularly if I had given him any thing in the course of the day. He generally set the people around him in a roar of laughter.

April 9.-This morning I paid the gadado a visit, and found him alone, reading an Arabic book, one of a small collection he possessed. "Abdullah," said he, "I had a dream last night, and am perusing this book to find out what it meant. Do you believe in such things ?" "No, my lord gadado; I consider books of dreams to be full of idle conceits. God gives a man wisdom to guide his conduct, while dreams are occasioned by the accidental circumstances of sleeping with the head low, excess of food, or uneasiness of mind." "Abdullah," he replied, smiling, " this book tells me differently." $\mathrm{He}$ then mentioned, that in a few days the sultan was going on 
another expedition, and wished him to join it, but that he preferred remaining, in order to have the mosque finished before the Rhamadan, lest the workmen should idle away their time in his absence.

To-day Mahomed Moode, the gadado's brother, lost an adopted son, who died of the small-pox. I paid him a visit of condolence, which seemed to gratify him exceedingly. The Felatahs here, and indeed almost all the principal people of Soudan, bury their dead in the house where they die, as before-mentioned. Poor Moode's grief was inconsolable; after the burial was over, he came and sat down alone in the shade before my door, and spreading his tobe over his knees as if he was reading a book, repeated in a low broken tone of voice several verses of the Koran, his eyes all the time streaming with tears. In this woful state of dejection he remained at least two hours. I could not help admiring the affectionate warmth of his feelings, so indicative of a good heart, and I sincerely sympathized in his sorrow. The child was the son of his brother the gadado. The practice of adopting children is very prevalent among the Felatahs, and though they have sons and daughters of their own, the adopted child generally becomes heir to the whole of the property.

April 10.-At three in the afternoon I waited on the sultan, to wish him success on the present expedition, and a happy return. We conversed on different subjects, but ended, as usual, about the trade with England; when I again endeavoured to impress on his mind, that we should be able to supply his subjects with all kinds of goods at a very cheap rate,-that his dominions were better situated for the gum trade than any other country in Africa,-and that many other valuable articles would be brought here from Timbuctóo, Bornou, and Wadey, and easily carried by the Felatahs to the sea-coast, to be disposed of to the English. He dwelt much on receiving in return cloth, muskets, and gunpowder; and asked 
me if I would not come back, and if the King of England would be induced to send out a consul and a physician, should he address a letter to His Majesty on the subject. He now asked in what time they would come: I told him they could be upon the coast in two months after his wishes were known in England. He resumed,"Let me know the precise time, and my messengers shall be down at any part of the coast you may appoint, to forward letters to me from the mission, on receipt of which I will send an escort to conduct it to Soudan." He also assured me he was able to put an effectual stop to the slave trade, and that the chart I asked for was nearly ready. At the close of this interview, the sultan kindly requested me not to be uneasy in his absence. At five in the afternoon, the sultan and gadado joined the army at the Sansan.

April 11, 12, and 13.-A refreshing breeze for the last two or three days. I received a present of two large baskets of wheat, which the sultan had ordered me before his departure. I was sitting in the shade before my door, with Sidi Sheikh, the sultan's fighi, when an ill-looking wretch, with a fiend-like grin on his countenance, came and placed himself directly before me. I asked Sidi Sheikh who he was? He answered, with great composure, "The executioner." I instantly ordered my servants to turn him out. "Be patient," said Sidi Sheikh, laying his hand upon mine: " he visits the first people in Sackatoo, and they never allow him to go away without giving him a few Goora nuts, or money to buy them." In compliance with this hint, I requested forty cowries to be given to the fellow, with strict orders never again to cross my threshold. Sidi Sheikh now related to me a professional anecdote of my uninvited visitor. Being brother of the executioner of Yacoba, of which place he was a native, he applied to the governor for his brother's situation, boasting of superior adroitness in the family vocation. The governor coolly remarked, "We will try ; go, fetch your brother's head !" He instantly went in quest of his 
brother, and finding him seated at the door of his house, without noise or warning he struck off his head with a sword, at one blow ; then carrying the bleeding head to the governor, and claiming the reward of such transcendent atrocity, he was appointed to the vacant office. The sultan being afterwards in want of an expert headsman, sent for him to Sackatoo, where a short time after his arrival he had to officiate at the execution of 2000 Tuaricks, who, in conjunction with the rebels of Goober, had attempted to plunder the country, but were all made prisoners; this event happening about four years ago. I may here add, that the capital punishments inflicted in Soudan are beheading, impaling, and crucifixion; the first being reserved for Mahometans, and the other two practised on Pagans. I was told, as a matter of curiosity, that wretches on the cross generally linger three days, before death puts an end to their sufferings.

April 14.-Clear and warm. The gadado's harem having paid me repeated visits, I was much struck with the beauty of some of the female slaves. To-day an Arab belonging to a kafila that left Quarra on the 10th instant made his escape here, all his fellow travellers having been taken by the people of Goober and Zamfra, who fell upon the kafila near the lake Gondamee.

April 15.-Notwithstanding that I had an attack of fever to-day, I received a visit from the females of the gadado's household, who during their stay seemed to evince much sympathy, but as soon as they reached the outer square, their unrestrained gaiety and noisy mirth soon convinced me that they only frequented my house as a place where they could with security amuse themselves.

April 16.-I took an emetic of ipecacuanha, with immediate relief of my bilious symptoms.

April 17.-At day-break the sultan returned with the army, having made a large capture of sheep, bullocks, asses, \&c. in the neighbourhood of the new capital of Zamfra. 
April 18.-This morning I went to congratulate the sultan and the gadado on their safe return. In the evening we had rain, thunder, and lightning.

April 19.-The gadado's favourite son, by Bello's sister, died to-day of small-pox, after being considered convalescent, in consequence of riding out too early to visit his grandfather. This lad was buried in the house, as usual, a few hours after death, amid the loud lamentations of the female slaves of the family.

April 20.-I went this morning to condole with the gadado on the death of his son. He was sitting in an inner apartment, and smiling mournfully at my entrance, he said : "This is very kind of you, Abdullah; I have met with a great misfortune, but it is the will of God." I endeavoured to reconcile him to this severe dispensation of Providence, and expressed my hope that he might yet have another son in room of him he had lost. He shook his head, and said, "God willing, but I am an old man :" then covering his face with his hands, we sat together nearly an hour in silence, when, unable to alleviate his grief, I took him by the hand; he pressed mine in return; and I left this disconsolate father with heaviness of heart.

April 21.-News arrived this morning, that the Tuaricks of the tribe of Kilgris had taken and plundered the town of Adia, six days' journey to the northward of Sackatoo ; in consequence of which a proclamation was issued, that all the Tuaricks belonging to that tribe should depart from Bello's dominions in three days, under the penalty of death. The gadado informed me to-day, that he should not be able to accompany me to Kano before the rains, as he once intended, in consequence of all the horses being worn out from want of water during the last expedition. In the afternoon I had a severe attack of ague, with bilious vomiting.

April 22,-Thunder and lightning all night.

April 23. - We heard that another kafila had been seized by the 



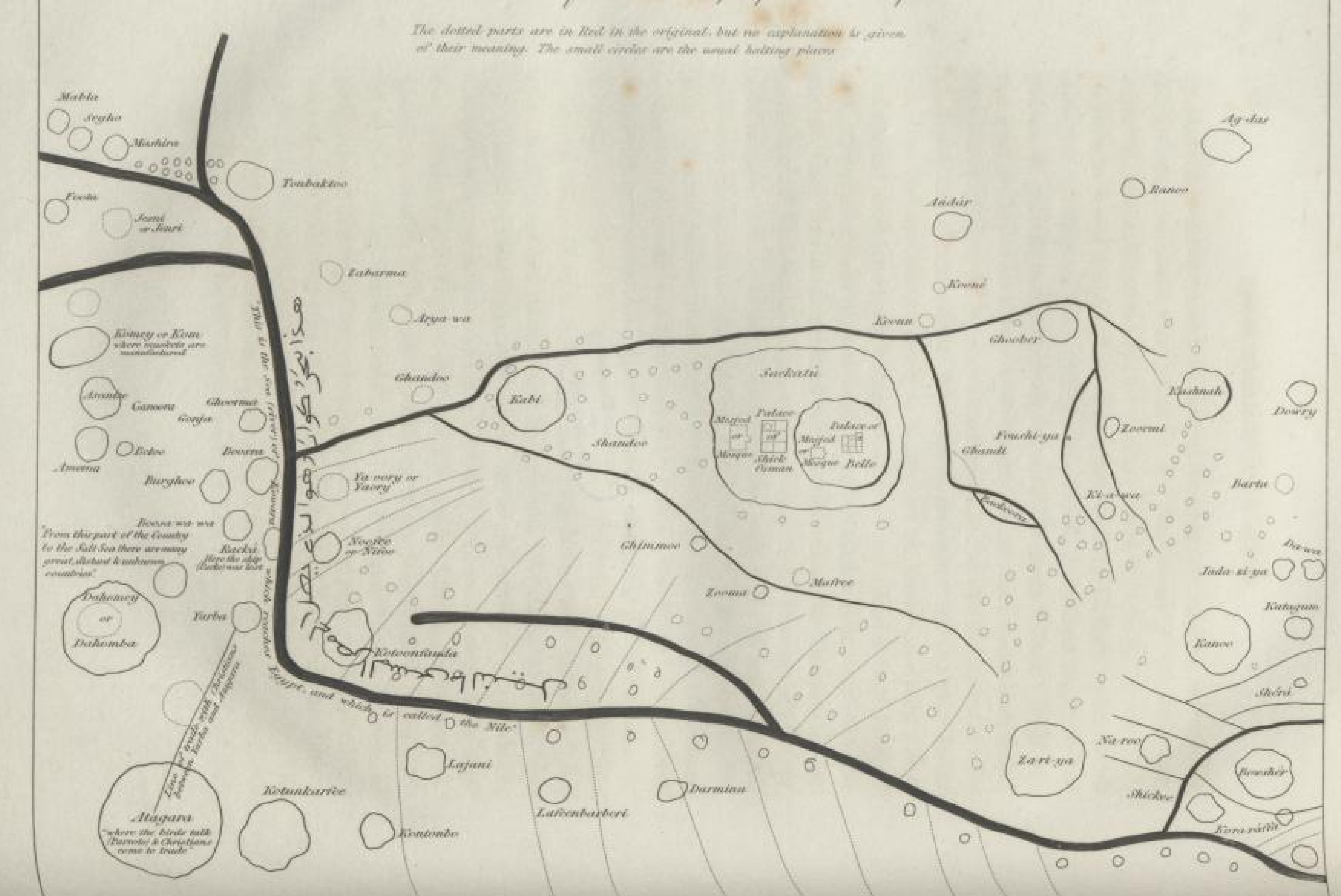


Gooberites, and six Felatah women taken amongst the spoil, besides 300 slaves.

April 27.-To-day a party which had gone on a marauding expedition to Kulee sent word that they had made a large capture of bullocks and slaves.

April 30.-Ill all day. The sultan sent for me in the afternoon. I was taken to a part of his residence I had never before seen : it was a handsome apartment, within a square tower, the ceiling of which was a dome, supported by eight ornamental arches, with a bright plate of brass in its centre. Between the arches and the outer wall of the tower, the dome was encircled by a neat balustrade in front of a gallery, which led into an upper suite of rooms. We had a long conversation about Europe: he spoke of the ancient Moorish kingdom in Spain, and appeared well pleased when I told him that we were in possession of Gibraltar. He asked me to send him, from England, some Arabic books and a map of the world: and, in recompense, promised his protection to as many of our learned men as chose to visit his dominions. He also spoke of the gold and silver to be obtained in the hills of Jacoba and Adamowa ; but I assured him that we were less anxious about gold mines than the establishment of commerce, and the extension of science. He now gave me a map of the country, and after explaining it to me, he resumed the old theme of applying by letter to the King of England, for the residence of a consul and a physician at Sackatoo ; and again expressed his hope that $I$ would revisit his dominions. He next inquired to what place on the coast the English would come, that he might send an escort for the guns; when I promised to write to his Highness on that subject from Kouka. He proposed to have two messengers waiting at the place I should select, at whose return he would send down an escort to the sea-coast.

May 1.- I began to make preparations for my return to Bornou, 
for various reasons which it is unnecessary to detail. The Rhamadan commenced to-day, and the Felatahs keep the fast with extreme rigour. The chief people never leave their houses, except in the evening, to prayer, and the women frequently pour cold water over their backs and necks, under the idea that the greater-thirst they appear to endure, the better entitled they become to Paradise ; although $I$ am inclined to believe that they make a parade of these privations, in a great measure, to obtain the reputation of extraordinary sanctity.

May 2.-Ill all day. I sent for the steward of the gadado's household, and all the female slaves, who had daily performed the duty of bringing me provisions from the time of my arrival: these provisions were, about a gallon of new milk every morning, in a large bowl, for myself, and two gallons of sour milk and ticcory for my servants, at noon; in return for each of which I always gave fifty cowries : at three o'clock, three roast fowls, with doura or nutta sauce, for which I sent fifty cowries; again, after sunset, two bowls of bazeen were brought by two female slaves, to whom I gave one hundred cowries, and about two quarts of new milk afterwards, for which I gave fifty cowries more. As an acknowledgment for their attention during my residence in Sackatoo, I now presented the steward of the household with 10,000 cowries, and the slaves with 2,000 each. The poor creatures were extremely grateful for my bounty, and many of them even shed tears. In the afternoon, I waited upon the sultan, who told me that he had appointed the same escort which I had before, under the command of the gadado's brother, to conduct me through the provinces of Goober and Zamfra, and that an officer of the gadado's, after the escort left me, should accompany me to Zirmee, Kashna, Kano, and Katagum; the governor of which would receive orders to furnish me with a strong escort through the Bedite territory, and to deliver me safely into the hands 
of the sheikh of Bornou. He also mentioned, that the letter for the King of England would be ready next day.

May 3.-At daylight, the camels were brought in from their pasturage, and were sent off in the afternoon to the neighbourhood of the wells of Kamoon. To-day I was visited by all the principal people of Sackatoo, to bid me farewell; and at seven o'clock, in the evening, I went to take leave of the sultan: he was at the mosque, and I had to wait about two hours till he came out. I followed him, at a little distance, to the door of his residence, where an old female slave took me by the hand and led me through a number of dark passages, in which, at the bidding of my conductress, I had often to stoop, or at times to tread with great caution as we approached flights of steps, while a faint glimmering light twinkled from a distant room. I could not imagine where the old woman was conducting me, who, on her part, was highly diverted at my importunate inquiries. After much turning and winding, I was at last brought into the presence of Bello, who was sitting alone, and immediately delivered into my hands a letter for the King of England, with assurances of his friendly sentiments towards the English nation. He had previously sent to me to know what was His Majesty's name, style, and title. He again expressed, with much earnestness of manner, his anxiety to enter into permanent relations of trade and friendship with England; and reminded me to apprise him, by letter, at what time the English mission would be upon the coast. After repeating the Fatha, and praying for my safe arrival in England, and speedy return to Sackatoo, he affectionately bade me farewell. I went next to take leave of my good old friend the gadado, for whom I felt the same regard as if he had been one of my oldest friends in England, and $I$ am sure it was equally sincere on his side: the poor old man prayed very devoutly for my safety, and gave strict charge to his brother, who was to accompany me, to take special care of me in our journey through the disturbed prokinces. The gadado looked very ill, 
owing, as I suppose, to his strict observance of the fast, and the distress which he had recently suffered by the loss of his son.

I shall here add a short description of the city of Sackatoo. It is in lat. $13^{\circ} 4^{\prime} 52^{\prime \prime} \mathrm{N}$. and long. $6^{\circ} 12^{\prime} \mathrm{E}$. and is situate near the junction of an inconsiderable stream with the same river which flows past Zirme, and which, taking its rise between Kashna and Kano, is said to fall into the Quarra four days' journey to the west. The name in their language signifies "a halting place ;" the city being built by the Felatahs after the conquest of Goober and Zamfra, as near as I could learn, about the year 1805. It occupies a long ridge which slopes gently towards the north, and appeared to me the most populous town I had visited in the interior of Africa; for, unlike most other towns in Haussa, where the houses are thinly scattered, it is laid out in regular well built streets. The houses approach close to the walls, which were built by the present sultan in 1818, after the death of his father; the old walls being too confined for the increasing population. This wall is between twenty and thirty feet high, and has twelve gates, which are regularly closed at sunset. There are two large mosques, including the new one at present building by the gadado, besides several other places for prayer. There is a spacious market-place in the centre of the city, and another large square in front of the sultan's residence. The dwellings of the principal people are surrounded by high walls, which enclose numerous coozees and flat-roofed houses, built in the Moorish style; whose large water-spouts of baked clay, projecting from the eaves, resemble at first sight a tier of guns. The inhabitants are principally Felatahs, possessing numerous slaves. Such of the latter as are not employed in domestic duties reside in houses by themselves, where they follow various trades; the master, of course, reaping the profit. Their usual employments are weaving, house-building, shoemaking, and iron work : many bring fire-wood to the market for sale. Those employed in raising grain and tending cattle, of which the 
Felatahs have immense herds, reside in villages without the city. It is customary for private individuals to free a number of slaves every year, according to their means, during the great feast after the Rhamadan. The enfranchised seldom return to their native country, but continue to reside near their old masters, still acknowledging them as their superiors, and presenting them yearly with a portion of their earnings. The trade of Sackatoo is at present inconsiderable, owing to the disturbed state of the surrounding country. The necessaries of life are very cheap: butchers' meat is in great plenty, and very good. The exports are principally civet and blue check tobes, called sharie, which are manufactured by the slaves from Nyffee, of whom the men are considered the most expert weavers in Soudan, and the women the best spinners. The common imports are Goora nuts, brought from the borders of Ashantee; and coarse calico and woollen cloth, in small quantities, with brass and pewter dishes, and some few spices from Nyffee. The Arabs, from Tripoli and Ghadamis, bring unwrought silk, otto of roses, spices, and beads : slaves are both exported and imported. A great quantity of Guinea corn is taken every year by the Tuaricks, in exchange for salt. The market is extremely well supplied, and is held daily from sunrise to sunset. On the north side of Sackatoo there is a low marsh, with some stagnant pools of water, between the city and the river: this, perhaps, may be the cause of the great prevalence of ague, as the city stands in a fine airy situation.

May 4.-I left Sackatoo, accompanied by one of the gadado's officers, named Dumbojee; and we travelled almost all night before we came up with our servants, who had pitched our tents near Kamoon. At daylight we moved on to the wells at Kamoon, where we halted to fill our water skins; and at two in the afternoon, the escort arriving, we proceeded on our journey, being also joined by four merchants and their slaves. We took a new road, where no water is to be had, to avoid the Tooias, as the rebels of Goobeer 
and Zamfra are called; "tooia, tooia," or " war, war," being the national cry of this people on entering into battle.

May 5.-We now pursued a footpath, through thick woods full of briars, which tore our clothes; and, as I had neglected to put on my boots, my legs were much lacerated. At midnight we passed near to a kafila of the rebels, who were travelling between Zamfra and Goobeer. This induced Moodie, the commander of our escort, to continue our journey all night, in spite of my wishes to halt till morning. "No, no; the tooias are near;" was his only reply to my remonstrances; and, in fact, we often heard the sound of their voices. When day dawned we discovered that we had mistaken the road all night, and were actually within a short distance of Calawawa, the capital of Goobeer, no one knowing the safest way to return. I had observed, to my surprise, during the night, that we travelled in a northerly direction; but never dreamed of interfering. Moodie now consulted me on what was to be done, and I recommended our travelling south-east. We accordingly set out as fast as the camels could be driven through a thick underwood, by which my trowsers were all torn, and my legs almost excoriated from the knees to the ancles.

In the afternoon the people on foot began to lag, and one or two were allowed to ride on the camels; but this was soon given up, as the applicants became too numerous to grant this indulgence indiscriminately. A number of the poor natives on foot, who had taken advantage of the escort to pass through this part of the country, overcome with fatigue and thirst, sat down never to rise more. One of my servants, a native of Kano, dropped down apparently dead, after taking a draught of water, of which the negroes drink an immense quantity. Indeed, I may safely say, they drink six times the quantity that Europeans do. I had him lashed on a camel, the motion of which brought him again to life; and, in half an hour's time, after vomiting a great quantity of bile, he was able 
to walk, and soon appeared as fresh as ever. Before sunset we saw the high lands over the lake Gondamee, and then bent our course to the eastward. At sunset a female slave, belonging to Hadje Ali Boo Khaloom, calling out that she saw two tooias, Moodie came up to me at full gallop, and recommended me to exchange the camel on which I was riding for my horse, and to have my firearms in readiness. Although scarcely able to support myself from severe pain in my limbs, I placed myself, however, at the head of the escort; but, fortunately for me, we could see no enemies, otherwise my sorry plight would have left me a very poor chance of success. At length, having reached a beaten path leading eastward, we waited for the camels to come up. The water skins being now all empty, and no one knowing exactly where we were, but each travelling as fast as thirst and weariness would permit him, I kept my people and camels together, and El Wordee, with two of the Arab merchants, considered it safest for themselves not to leave me. A fine Arab horse, belonging to Hadje Ali Boo Khaloom, died of fatigue.

May 6.-Thursday, at four in the morning, El Wordee falling ill, and declaring he could travel no farther, I ordered a halt on his account, but left the loads on the camels. Being separated from the whole of the caravan, except one Arab merchant, I lay down by the side of my horse, and my servants gave me a few small yellow plums they had picked up, which relieved both my hunger and thirst. I now slept soundly on the ground until daybreak, when we continued our journey to the eastward, without following any regular track, and soon came up with several stragglers from the caravan and escort, who, overcome with fatigue, had lain down in the night, and were now pursuing their way, most of them almost unable to speak from excessive thirst. The horsemen were dismounted,- their horses having either died, or being too weak to bear their riders, who were driving them before them. At ten

$q 2$ 
o'clock we fell in with the road to Gondamee, and at noon halted on the south bank of the river Futche. We found that very few had arrived there before us, and, reposing ourselves under the shade of some trees, we despatched some country people with water to our fellow travellers in the rear, who continued to drop in one after another till sunset. At first we ate and drank rather sparingly ourselves, and were also particularly careful to prevent our cattle from injuring themselves by drinking too much water at a time. Notwithstanding our distressed condition, the Felatahs keep the fast of the Rhamadan so strictly, they would not taste water till after sunset.

May 7.-On mustering the kafila at daylight, we found that nine men and six horses had perished on the road. Of these, two were Felatahs going to Mecca, who had come from Ginee, to the westward of Timbuctoo ; and a third was the husband of a woman now left destitute, to whom I promised my protection as far as Kano. At noon I took leave of Moodie and the escort, who wished to conduct me to Zirmee; but as all danger was passed, I declined their friendly offer, and, making them a present of a sheep and 40,000 cowries, we separated. At one in the afternoon I arrived at Quari, and encamped outside the town, but went and paid my respects to the governor, who complained grievously of the privations which he suffered by keeping the Rhamadan, although this was only the seventh day.

May 8.-At daylight I left Quari, and crossed a country intersected by deep ravines. I halted under a large shady tree, during the heat of the day, and, towards sunset, arrived at Zirmee, where I was provided with good accommodation for myself and servants. The governor had gone to reside in one of the small towns in his province during the Rhamadan; but I was visited by his brother and the Imam, who sent me a sheep and provisions, as well as by all the principal people of the place. 
May 9.-Warm and sultry. To-day I received a number of visitors of both sexes.

May 10.-Zirmee, the capital of the province of Zamfra, occupies a peninsula formed by the river, which has here very high and steep banks, covered with mimosas and prickly bushes, through which a narrow winding path leads to the gates of the town. It is surrounded by a wall and dry ditch : the wall is of clay, from twenty to thirty feet high. The governor, named Turnee, is considered a brave man, but bears also the character of a perfect freebooter; and the inhabitants altogether are reputed to be the greatest rogues in Haussa. My servants were cautioned by Dumbojee not to quit the house after sunset, as every black without a beard (to use their expression for a young man) was liable to be seized, gagged, and carried off to some of the neighbouring villages for sale. Runaway slaves, from all parts of Haussa, fly to Zirmee as an asylum, where they are always welcome; and the inhabitants in general have a remarkably reckless, independent look. Three female slaves, belonging to Hadje Ali Boo Khaloom, absconded here; preferring, naturally enough, liberty and a husband, to slavery and a bad master.

May 11.-At sunrise we left Zirmee, and travelled over a well cultivated country. During the heat of the day we again halted under the shade of a tree, and encamped, towards evening, at a village called Yakua, where Dumbojee wished me to lodge in one of the houses, alleging the risk of being robbed, or even murdered, out of doors; but as a number of other people halted outside the village, I merely pointed to them in ridicule of his timid suggestions.

May 12.-At daybreak we left Yakua without having experienced the smallest molestation. Our road, in the early part of the day, lay through a forest of low stunted trees, among which I remarked a great number of wild mangoes. The soil was clay, mixed with large round pebbles of yellow quartz, and in the ravines there 
was mica slate. After travelling for some time on gravelly heights, I halted at Roma, where the soil is a black mould over strong clay, large blocks of siennite running in high ridges from north-northeast to south-south-west. There was abundance of limpid water, and on all sides were seen fruit trees, well cultivated fields, and numerous hamlets and towns. Being market day, the road was crowded with people: some of whom were driving before them as fine bullocks as I have ever seen in any country. One man usually went in front, leading the animal with a rope round its horns, which were dyed with henna, and two or three others followed behind with a rope fastened to the legs. Near the channel of one of the little streams winding among the crags of siennite, I saw five or six plantain trees growing wild. These were the first I had seen in the country; and, on inquiry, the inhabitants told me, that this plant did not bear fruit nearer than Zeg Zeg. The plantains I had from the sultan at Sackatoo were brought from Nyffee. In the afternoon we resumed our journey. The country was open and well cultivated; but the road still winding, and choked up with thorns. At sunset we halted at a large village called Yanduka, the governor of which, having heard I had come from Bello, would not allow me to take up my quarters outside the village, but insisted that I should occupy a house he had provided for me, where I was liberally supplied with provisions.

May 13.-At sunrise we left Yanduka, about two miles beyond which the country became very woody, and rested at noon under the shade of a large tamarind tree, on the banks of a rainy-season stream, which we had already crossed four times since morning. The kuka tree, towering over all the other trees of the forest, grew out of the interstices of the naked rocks, among which the river slowly wound in beautiful meanders. The water procured from pits made in the bed of the river was of a blackish colour, and had a disagreeable smell, seemingly as if strongly impregnated with trona. 
In the afternoon we continued our route, and on ascending a rising ground we descried the minarets of the mosque of Kashna : the country was still very partially cleared of wood. Having sent El Wordee and Dumbojee before me to prepare lodgings, I did not arrive at Kashna till after sunset, when the gates were shut; but on hailing the sentinel, and telling him who I was, he requested me to go round to a little wicket, which I found open. I went immediately to Hadje Ahmet Ben Massoud, who took me to the house provided for me, where I was well supplied with provisions; but the house itself was in wretched repair, full of ants and rats, and, I verily believe, had not been inhabited since the Felatah conquest.

May 14.-After a sleepless night I sent for Dumbojee, desired one of my servants to show him the house, and asked him if this was the gadado's. He informed me it was intended I should be lodged in the house of Voikin Serkis, a friend of the sultan, but El Wordee had told him I preferred staying with the Arabs. I desired him to go immediately to the house of Voikin Serkis, and tell him I was coming. When Hadje Ahmet and El Wordee heard of this message, they came to me in great fright, and entreated I would go with them and choose whatever house I pleased. Not wishing to be troublesome, I accompanied them after breakfast. I was shown through several houses, and fixed on one conveniently situate for astronomical observations: the adjoining court-yard was occupied by the freed female slaves of old Hadje Ahmet. I was ill all day, although this did not prevent me from being tormented with the visits of almost all the principal inhabitants. Fortunately the governor was out of town, but he was polite enough to send me an invitation to his country-house, where he secludes himself during the Rhamadan. Among the Arabs he has the character of being very avaricious, and as I was rather at a loss for a present to offer him, I thought it better to decline the visit, notwithstanding the 
importunity of Hadje Ahmet with me to see him. Hadje Ahmet, the chief of all the Arabs, had resided there for the last thirty years; and although it was the Rhamadan, he ran about with great alacrity, in the heat of the sun, to procure me salt and tar for the camels, and other little necessaries for my own use. But his liberality was unbounded : he even permitted me to visit his seraglio, and told me to pick and choose for myself among, at least, fifty black girls. I took notice that his countrymen would find fault with him for giving up a Mahometan female to a Kafir: "No, no ; you must have one." "Well, as I am sick, and want a nurse, I will take this woman," pointing to an elderly slave. "You have done right," said the Hadje; "she is an experienced woman, and a good cook ; she has seen the world; she has been in Fezzan." This was the first offer of the kind I had ever received from a Moslem; and along with the old woman, two young females were sent to assist her. During my sickness, I never before had the benefit of female nurses, and by their care and attention I soon recovered my health and strength.

May 15.-Cool and cloudy. I was waited upon, a little after daylight, by Hadje Ahmet, who told me, with an air of mysterious confidence, that he had a stone of very great value to show me, and wished my opinion respecting it. "Well, father pilgrim, show it to me, and I will tell you its value." His servant now brought in a leathern bag, from which his master took a bundle of rags; and unrolling them carefully, one after the other, he began to make the most ludicrous faces of mock ecstasy. At last the gem appeared, which he held up with a cry of rapture :- " Look there! what will you give for it ?" It was a piece of rock crystal, about two inches in length, and three-fourths of an inch in diameter. Assuming a countenance of corresponding gravity, $\mathrm{I}$ affected to muse for a short time in silent astonishment, and then drawled out, "A dollar." The mortified Hadje would not satisfy my curiosity about where it came 
from, but in hazarding a conjecture that it was obtained in Yacoba, I fancied he betrayed by his manner that I had hit upon the spot. Although I wished to have the crystal, I was afraid to make another offer, lest, supposing it to be of inestimable price, he might suspect I wished to take an unfair advantage of him; and he again wrapped it up, with like care and solemnity.

May 16. - Clear and warm. In the afternoon we had much rain, with thunder and lightning.

Kashna is in lat. $12^{\circ} 59^{\prime} \mathrm{N}$. by merid. alt. of Antares. According to Hadje Ahmet, it was called Sangras about a century ago, and afterwards Geshna, from the small underwood of that name growing on the ridge whereon the town is built, and which is one of many long ridges that run from north-east to southwest. The walls are of clay, and very extensive; but, as at Kano, the houses do not occupy above one-tenth of the space within them: the rest is laid out in fields, or covered with wood. The governor's residence resembles a large village, and is about half a mile to the east of all the other buildings. On account of the Rhamadan, I was exempted from the ceremony of paying him a visit : his name is Omar Delogie. The fruits here are figs, melons, pomegranates, and limes. Grapes are said to have been plentiful in former times, but at the Felatah conquest the vines were cut down. The houses are mostly in ruins, the principal commerce of the country being carried on at Kano since the Felatah conquest; nevertheless, there is still a considerable trade. There are two daily markets, in different parts of the town, one to the south, the other to the north. The southern market is chiefly attended by merchants of Ghadamis and Tuat; that to the north by Tuaricks. The Ghadamis and Tuat merchants bring unwrought silk, cotton and woollen cloths, beads, and a little cochineal, which they sell for cowries. These are sent to their agents at Kano, to purchase blue 
tobes and turkadees, which are conveyed across the country to supply the fair of Ghraat; and whatever they do not dispose of there to the Tuaricks, they send to Timbuctoo in exchange for civet, gold and slaves. The manufactures of Kashna are chiefly of leather; such as water-skins, red or yellow cushions, and bridles of goat skin, \&c. Tanned bullocks' hides, also, are frequently carried to Fezzan and Tripoli. They prepare very good dried beef, with which the Arab merchants usually provide themselves before crossing the desert. Kashna is a favourite resort of the Tuaricks who frequent Soudan during the dry months. The merchants of Ghadamis and Tuat never keep camels of their own, but hire them from this singular people, who carry their goods across the desert to Kashna, at the rate of ten dollars a load, and likewise convey slaves at twentyfive dollars a head, finding them in every thing. With this revenue, and the produce of the salt they bring with them, the Tuaricks buy grain and other necessaries here to serve them during their sojourn in the desert.

May 17.-At sunrise I left Kashna by the gate Koura, on the south side of the town. I was accompanied so great a distance by Hadje Ahmet, that I was obliged to entreat him to return; reminding him it was the Rhamadan, and that riding in the heat of the sun, without being permitted to quench his thirst, was too severe a trial of any one's faith. In the immediate neighbourhood of Kashna, the country is covered with brushwood and low stunted trees; but we soon entered a well cultivated district. The road too was good. We rested during the heat of the day under a tree, at a cluster of villages called Miwa, near the bed of a rainy-season stream. We afterwards passed the ruins of a number of towns and villages, which had been destroyed by the rebel Duntungua. At sunset we encamped for the night near some villages called Eatowa, where a little girl came to me and told me to look well after my baggage, 
as there were eight thieves in a house which she pointed out, who, she said, plundered all around them.

May 18.-At sunrise we left Eatowa, without sustaining any loss. The country appeared well cultivated, and the soil rich; and in the course of an hour, we passed the walled town of Sabon Gree, the walls of which were in bad repair, and the inhabitants few in number. At noon we halted under a tree near to a village called Burderowa. We were here joined by a merchant of Sockna, who left Kashna the day after us. El Wordee having lost some civet and gold, to the value of thirty-one dollars, suspected his servant of the theft, who, in eonsequence of a guinea-worm in his foot, was allowed to ride on his master's camel; but he strenuously denied all knowledge of the matter, and called on God and the Prophet to judge between him and his master. El Wordee had searched all his baggage at Kashna, without discovering the slightest traces of the stolen property, and was now deploring his loss to the merchant who joined us, whose Arab servant overhearing him, asked him if he had examined the saddle of his camel. El Wordee replied in the negative, when the Arab swore by the Prophet, that the stolen goods were there, for his servant had without orders repaired the saddle at Kashna; which being immediately ripped open, the civet was found. Seated at a little distance under the shade of a tree, I had an excellent opportunity of watching the countenance of the accused, who gazed eagerly at the novel search. The moment the first box was found, he tumed round with his back to the party, and throwing himself on the ground, concealed his face in the earth. All the civet was recovered, but none of the gold, the thief continuing to exclaim to his master: "God judge between you and me, I am innocent." I called out to El Wordee to compel him at once to produce the gold; for he could no longer travel in my kafila, as, not content with exculpating himself, he had basely accused one of $r 2$ 
my own servants of the theft. El Wordee appeared very reluctant to criminate his servant, until I insisted on it. He then proposed the following mode of detection, which is commonly practised among Arabs. The names of each person belonging to the kafila are written on separate pieces of paper, and put into an empty waterskin. Each person in turn is then required to blow until he inflates the skin, which they feign every one but the thief can readily do. When all was prepared with much imposing formality, the culprit called to his master, to say he need not proceed farther, and instantly delivered up the gold, which was secreted about his person. I asked El Wordee what he intended to do with him? He said he would discharge him at Kano. "Do you not intend to punish him ?" "No; although he deserves it. It will not do : the man may do me a mischief;" and he spoke and behaved to him afterwards just as if nothing had happened. This is the uniform custom of all Arabs: however great a vagabond a man may be, he is treated with the same civility as if there was nothing to impeach his character. From this indiscriminate complaisance I must exeept the servants of the bashaw of Tripoli, who are in the habit of using notorious scoundrels with very little ceremony.

After we had finished this affair, we left Burderawa, and travelled through a fine well cultivated country. To-day we passed a great many kafilas of Tuaricks and merchants of Ghadamis, who were leaving Soudan before the rains. At five in the afternoon, we encamped among high ledges of rock, near a little town called Kaffondingee, There was a number of other towns close to it, with fine shady trees in the valleys, among which I saw several trees described in Mungo Park's Travels, under the name of Nutta, but here called Doura by the natives. This tree grows to a greater height than our appletree, is proportionably longer in the trunk, but does not spread its branches so widely: at present it was the season for gathering the 
fruit. The beans of the nutta are roasted as we roast coffee, then bruised, and allowed to ferment in water. When they begin to become putrid, they are washed particularly clean, and pounded into powder, which is made into cakes somewhat in the fashion of our chocolate. These, notwithstanding they retain a disagreeable smell, form an excellent sauce for all kinds of food. The farinaceous matter in which the bean is imbedded is also made into a very pleasant drink; but they say if drunk often, it causes indigestion and enlargement of the spleen. They also make it into a sweetmeat, resembling what is called by the children in England "lollypops." The nutta tree, as well as the micadania or butter tree, is always allowed to remain on clearing the ground. The micadania was not ripe when I saw it; but the fruit was exactly like a peach in shape, only a little more pointed at the end. When ripe, the outer pulpy part is eaten, and the kernels, previously well bruised, are boiled in water, when the fat rising to the surface, is skimmed off. It is not used in food, but only to burn in lamps, and has the appearance of dirty lard.

May 19.-The merchant, who joined us yesterday, was quite outrageous this morning about a basket of glass armlets which a Tuarick had stolen from under his head while he slept. I certainly gave the thief credit for his adroitness, and could not help being somewhat amused at the merchant's distress. He entreated me to stop for a day, to give him time to overtake the kafila of Tuaricks which had gone northward; but this was out of the question. At six in the morning we left Kaffondingee, the merchant remaining in our company, as he was afraid to leave me. We travelled through a country that had formerly been cleared, but was now again overgrown with large trees, the soil being a strong black vegetable mould. We passed the ruins of several walled towns, and halted, during the heat of the day, under some shady trees growing amongst the ruins of 
one of them, called Sofa. The country afterwards became woody, and was said to be much infested by Duntungua's rebel followers. We afterwards arrived at Duncamee; but from the lateness of the hour I did not enter the town, remaining all night in the open air, without pitching my tent.

May 20.-At sunrise I found I had caught a severe cold, from last night's exposure to a strong north-east wind. The road was winding and woody, and I halted during the heat of the day outside the walled town of Faniroa. My old friend the governor being absent on an expedition, I rested under the shade of a tamarind-tree, on account of its coolness and the fine air around me. We afterwards passed the night at Gadania.

May 21.-To-day we had much thunder and lightning, and took up our quarters for the night outside the town of Taffo.

Hay 22.-I sent a horseman off at daylight, for the purpose of acquainting Hadje Hat Salah and the governor of Kano of my return, as I anxiously expected news from Bornou and Tripoli. Meanwhile I rested under the shade of a tree, until a messenger met me with two letters,-one from Major Denham, sealed with black wax, apprising me of the melancholy fate of young Toole, who dauntlessly crossed the desert, with only a guide, to join Major Denham at Kouka. Near sunset I entered Kano, and immediately proceeded to the house of Hadje Hat Salah my agent, who appeared as glad to see me as if $I$ had been his own son. Although it was the Rhamadan, he had a sheep killed to give me a feast; and pressed me to sit down to table the moment I came in. It was indeed a severe punishment for him to be a mere spectator on this occasion, but he turned it off jocularly, calling out, "Abdullah, eat; for you are a hungry Kafir." I found that, during my absence, only one kafila had arrived from $\mid$ Bornou,-the same which had brought me the letters, along with three bottles of port wine, and some gunpowder, 
from Major Denham. Hat Salah, among other news, mentioned that old Jacob, my servant, had been in great distress for my safety during my absence ; and that a female slave of El Wordee's, who was much attached to him, had lost her reason on hearing we were gone to Youri, and in this unhappy state, having thrown herself into a well, she had broken one of her arms.

May 23.-Cool and cloudy. I was visited by all the principal Arabs who were in Kano; amongst the rest old Hadje Boo Zaied, who has ever been our stanch friend, and was a very worthy man. He begged, with great earnestness, that I would not acquaint the sheikh of Bornou or the bashaw of Tripoli of Bello's behaviour to Hadje Ali at Sackatoo. For Boo Zaied's sake, I promised to sereen him, unless questions were expressly put to me concerning his conduct, when I must speak the truth; for he had behaved to me both like a fool and a knave.

May 25.-To-day I paid up my servants' wages, at the rate of four dollars a month, but reduced them in future one half ; notwithstanding which, they were all glad to remain in my service.

May 26.-I waited on the governor, who received me with marked kindness, and inquired particularly after the health of the sultan and of the gadado, and how I had fared in crossing the Gondamee, the river between Futche and Sackatoo.

May 30.-Clear and sultry. I was earnestly solicited by the people to refer to my books, and to ascertain if the new moon would be seen to-day; which much longed-for event, I assured them, would take place after sunset, if the evening was clear. This anxiety was occasioned by the fast of the Rhamadan, then terminating, and the Aid, or great feast, immediately commencing. The evening turning out cloudy, all were in low spirits; but at midnight a horseman arrived express to acquaint the governor that the new moon had been visible.

May 31.-After the arrival of the horseman, nothing was heard 
but the firing of musketry and shouts of rejoicing.-Paying and receiving visits now became a serious occupation. In the morning, accompanied by Hat Salah, I went on horseback to pay my respects to the governor. I accepted his invitation to ride out with him, according to their annual custom; and we proceeded to an open space within the city walls, amid skirmishing and firing of muskets, attended by his people on horseback, and the Arabs and principal townsfolk dressed in their gayest raiments,-all who could possibly muster a horse for the occasion being mounted. The most conspicuous person in the whole procession was a man on horseback in quilted armour, who rode before the governor bearing a two-handed sword. Or reaching the plain, the governor made a speech to the people, declaring his intention to attack Duntungua, when he expected every man to exert his utmost prowess. Their sons too should not, as in times past, be left behind, but would accompany them to the war, and learn to fight the battles of their country under the eyes of their parents. Afterwards we rode home in the same order. All work was laid aside for three days. Men, women, and children, in their finest clothes, paraded through the town; a number of slaves were also set free, according to the custom of Mahometans at this holy season. The owner of my house freed fifteen.

June 1.-I visited the governor, to take leave. He was very kind, and after inquiring if I should ever return, begged me to remember him to his friend the sheikh El Kanemy, and expressed his hope I would give a favourable account of the people I had visited. I assured him, as to the last particular, I could not do otherwise, as I had every where experienced the greatest civility. He then repeated the Fatha, and I bade him farewell.

June 3.-At ten in the morning I left Kano, and was accompanied some miles by Hadje Hat Salah and all my friends on horseback. Before Hat Salah left me, he called all my servants before 
him, and told them he trusted they would behave well and faithfully; for, as they had seen, I was the servant of a great king, the friend of the bashaw of Tripoli, and had been passed from one sultan to another ; consequently any misbehaviour of theirs, on a complaint from me, would be severely punished. We only travelled a short way before halting, for the heat of the day, under a shady tree. In the afternoon we again set forward, and at sunset encamped outside the town of Duakee.

June 4.-This morning we passed through the walled town of Sockwa, which is now reduced to a few huts inhabited by slaves; and halting for the heat of the day under a tamarind tree, we pitched our tents at sunset under the walls of Girk wa, not far from the banks of the river. The people were dancing in honour of the Aid. The dance was performed by men armed with sticks, who springing alternately from one foot to the other, while dancing round in a ring, frequently flourished their sticks in the air, or clashed them together with a loud noise. Sometimes a dancer jumped out of the circle, and spinning round on his heel for several minutes, made his stick whirl above his head at the same time with equal rapidity; he would then rejoin the dance. In the centre of the ring there were two drummers, the drums standing on the ground. They were made of a hollow block of wood about three feet high, with a skin drawn tensely over the top by means of braces. A great concourse of natives were assembled to witness the exhibition.

June 5.-Morning cloudy. At six in the morning we left Girkwa, and reposing ourselves during the heat of the day under some tamarind trees among the villages of Nansarina, we encamped at sunset in the woods. The inhabitants were now very busy in the fields planting grain. Their mode of planting it is very simple. A man with a hoe scrapes up a little mould at regular intervals, and is followed by a woman carrying the seed, of which she throws a few 
grains into each hole, and treads down the mould over them with her feet.

June 6. At noon we halted in the town of Sangeia, the governor of which was at Kano; so I fortunately eseaped the pain of hearing his squeaking voice. We encamped for the night in the woods.

June 7.-At one in the afternoon we halted outside the town of Katungwa. At sunset two horsemen arrived at full gallop, with the news of the governor of Kano having taken a town, at a very short distance to the north, from the rebel Duntungua.

June 8.-Every where the inhabitants were busily employed clearing the ground, and burning the weeds and stubble, preparatory to sowing grain. We sheltered ourselves from the mid-day heat under the shade of a tamarind tree, in the province of Sherra, and halted for the night outside the town of Boosuea. A son of the governor of Sherra was here, attended by a number of horsemen, and a band of music. He drank coffee with me, and I was in turn regaled with music the greater part of the night. The instruments were chiefly flutes and long wooden pipes, called by the natives frum-frum.

June 9.-At sunset we arrived at the town of Dugwa.

June 10. - At daybreak we left Dugwa, and travelled through a thickly wooded country. It rained all day, and we also had some thunder and lightning. At seven in the evening we arrived at Murmur. I heard, at Kano, that a kafila of Arabs, belonging to Augela, had destroyed the clay wall around Dr. Oudney's grave, and made a fire over it, telling the inhabitants he was a Kafir. This report, to my great regret, I found to be true.

June 11.-At sunrise I sent for the governor, to inquire who had committed the outrage, when he protested it was the Arabs, and not the people of the town. I felt so indignant at this wanton act of barbarity, I could not refrain from applying my horsewhip 
across the governor's shoulders, and threatened to report him to his superior, the governor of Katagum, and also to despatch a letter on the subject to the sultan, unless the wall was immediately rebuilt: which, with slavish submission, he promised faithfully to see done without delay. During my halt at noon, near Katagum, I sent Dumbojee forward to inform Duncawa, the governor, of my return. In the afternoon I heard that he was on his way to meet me; and I had scarcely left my resting-place before he made his appearance, attended by about thirty horsemen, who, when they saw me, came up at full gallop, brandishing their spears. I presented the governor with a hundred Goora nuts, every one of which he distributed amongst his people. He gave me many very hearty welcomes, and made numerous inquiries about Bello, and his behaviour to me. $\mathrm{He}$ and his people now galloped into the town, yelling and skirmishing; and although the governor had been sick for some time past, he appeared as lively and cheerful as any of them. On entering Katagum I was lodged in my old quarters, and was immediately visited by my old friend Hameda, the Tripoline merchant, who was still here. I invited him to accompany me to Tripoli, as the late Dr. Oudney had advised him; but he excused himself, on the plea of being unable to collect his outstanding debts from his numerous creditors, who were scattered all over the country.

June 12.-Warm and sultry. Duncawa remained with me all day, and informed me, that he had the sultan's orders to conduct me to Kouka, in Bornou. This mark of respect I positively declined, both on account of his recent illness, and also lest his presence might give umbrage to the sheikh; but agreed to accept from him an escort through the Bede territory. I assured him, when once in Bornou, that I felt myself as safe as in his house. If he insisted, however, on somebody accompanying me, he might, if he pleased, send one of his principal people. I made a formal complaint of the insult committed to Dr. Oudney's grave,-enforcing, in the strongest terms, 
the disgrace of disturbing the ashes of the dead, whose immortal part was now beyond the power of malignant man. He frankly acknowledged the enormity of the act, and faithfully promised to have the wall rebuilt,--even offering to send for the governor of Murmur, and have him punished; but, at the same time, begging me not to acquaint the sultan of the occurrence. I expressed my reliance on his assurances, but apprised him I must inform the gadado of the affair. I afterwards spent the evening with Hameda.

June 13. - There was a fresh breeze in the morning; but it afterwards began to rain. Duncawa being laid up from lameness, $I$ had a day's rest, and again spent the evening with Hameda. The conversation turning on the trustworthiness of slaves, he mentioned to me, that his servants never knew in what apartment of his house he slept; and that he even lay with a dagger, and loaded pistols, under his pillow, lest he should be murdered by his female slaves. He also acquainted me, that almost all the Arabs did the same; for it was chiefly females whom they had reason to fear, the master being often strangled at night by the women of his household.

June 14,-Duncawa visited me again, and made me a present of two tobes, two sheep, and a large quantity of Guinea corn, and gave a tobe to each of my servants. I presented him with six hundred Goora nuts, having brought a large supply of them from Kano.

June 15.-I had every thing prepared for continuing my journey, but Duncawa pressed me to spend another day with him, and I availed myself of the delay to write to Bello and the gadado. I returned my humble thanks to the former for his protection and favour while I sojourned in his territories; and, in acknowledging the uniform kindness of the latter, I did not fail to acquaint him of the outrage committed on Dr. Oudney's grave. I delivered these letters to the charge of Dumbojee, who, having fulfilled his orders, took leave of me here, having first made him a present of a couple of tobes and forty dollars. My guide, Mahomed Dumbojee, had 
now become rich and gay, having a numerous train of attendants; for at every town where we halted, the governor was bound in courtesy to make him a present, in token of respect for the sultan.

Having sent my camels forward, I went to bid farewell to Duncawa, who was still confined to his house by illness. He made me breakfast with him. Our brcakfast consisted of a sheep's head, singed in the same manner as is practised in Scotland-a sheep's fry - and bread and milk. I was accompanied across the Yeou by my friend Hameda, and Duncawa's horsemen, who all wished to be allowed to attend me to Sansan; but I excused myself from this guard of honour, at once troublesome and expensive, by pretending it was unlucky to go beyond the banks of a river with a friend. Attended only by one of Duncawa's principal men, I passed the thick woods on the bank of the river, and, halting under a tamarind tree during the heat of the day, I encamped towards evening at a village called Mica. The inhabitants were all very busy in the fields sowing gussub. They brought me, however, an abundant supply of milk, and repeated inquiries were made after Bello's health; for although they recently belonged to Bornou, of which country they are natives, they entertain, nevertheless, a great respect for their new sultan.

June 17.-I started at daylight, and, as the weather was cloudy and rather windy, I did not halt before reaching Sansan. I was here provided with very indifferent accommodation; but, on threatening I would encamp outside the town, the governor received me into his own house, aceording to Duncawa's orders, and also made me a present of a sheep. At night there was a violent storm, with thunder and lightning. The poor lad Joseph, who had been hired at Kouka by the late Dr. Oudney to tend the camels, was out all night with them. Being a native of Fezzan, and half an idiot, he was here considered a holy man, and I still retained him in my 
service out of charity. It was he who gave me an account of the people of Bede, as he had been a slave among them; and related his story with such artless simplicity, that I implicitly rely on its correctness.

June 18.- Cool and cloudy. I heard to-day of a courier being delayed on his route, by his eamel's being knocked up; and as Duncawa was also preparing a present for the sheikh El Kanemy, I postponed my departure yet another day.

June 19.-At eleven in the forenoon the courier arrived, bringing a sabre as a present for the sultan Bello, and letters from Major Denham, the consul at Tripoli, and the secretary of state. Accordingly at mid-day I set off on my return to Katagum, in order to have the sword forwarded to Bello by Duncawa.

At ten in the morning I entered Katagum, and immediately waited on Duncawa to aequaint him with the cause of my return. I showed him the sword, and explaining to him the manner of attaching the belt, he expressed himself in terms of the highest admiration of both sheath and sabre; and looking again and again at the ornaments, he frequently asked, "Is not this all gold ?" He sent instantly for the cadi, who wrote a letter in my name to Bello, and a courier was despatched with it and the sword. In the evening, another thunder-storm, with much rain.

June 21.-At one in the afternoon I arrived again at Sansan.

June 22.-Clear and sultry. I was further detained on account of the present for the sheikh not being ready.

June 23.-Morning cloudy. At seven in the morning I left Sansan, attended by part of the escort which was to conduct me through the Bede territory, and was obliged to stop about noon at the village of Girkwa, by a violent attack of ague and bilious vomiting. Previous to starting, I was joined by two merchants of Tripoli, who had been at Kano, and begged to be allowed to place them- 
selves under my protection during this perilous part of the journey. In the afternoon Hadje Fudor, the governor of Sansan, arrived with the remainder of the escort, and also brought me a sheep, more in the expectation, I think, of receiving some Goora nuts in return, than from any regard for me. At midnight more rain, thunder, and lightning.

June 24.- Cool and cloudy. At ten in the morning halted at the village of Boorum, to fill our water-skins, and afterwards travelled through a thick wood, where we saw a number of karigums and elephants : the karigum is a species of antelope, of the largest size, as high as a full grown mule. At sunset we pitched our tents in the woods. The night was extremely boisterous, with rain, thunder and lightning, and violent squalls of wind ; and my tent being blown down, the baggage was drenched with water.

June 25.-Next morning we continued our route through a thick wood, and halted at Joba during the heat of the day, when I had my baggage dried in the sun. We still travelled through a thick wood, and at seven in the evening encamped at a village called Gorbua. Rain, thunder, and lightning, all night.

June 26.-Cloudy, with rain. At ten in the morning I left Gorbua, or " the strong town," as it is ironically ealled in the Bornouese language, from being enclosed with matting. Our road, still winding and woody, led through the Bede territory; and at sunset we reached Guba, a small town on the south bank of the Yeou, within the dominions of Bornou.

June 27.-The forenoon was rainy, which obliged us to remain at Guba till one in the afternoon ; when the weather clearing up, we loaded the camels, and crossing to the north bank of the channel of the river, which was now dry, we travelled east by south to the town of Muznee, where we halted for the night.

June 28.-Cloudy, with rain. We travelled eastward along a 
crooked path, full of holes, and overgrown with brushwood, and took up our abode for the night at the town of Redwa. An officer of the sultan of Bornou was here, collecting his master's dues, and sent me milk, onions, and six fowls; and I presented him, in return, with fifteen Goora nuts.

June 29.-After travelling east by north, we halted at noon at Kukabonee, or "wood and fish," a large town on the south bank of the Yeou. We next passed Magawin, and a number of other villages and towns on the banks of the river, which we had not visited before, when we accompanied the sheikh last year.

June 30.-Cool and cloudy. We halted at ten in the morning at Dungamee, in consequence of heavy rain with thunder and lightning, which continued without intermission all day.

July 1.-Clear. The weather was hot and sultry. At sunset we arrived at Mugabee. I shot at a hippopotamus which was swimming in a lake, of which there are many in this part of the country; I seemed to hit it, but it quickly disappeared.

July 2.-Stopped for the day to allow the camels to have food and rest.

July 3.-Between Gateramaran and Mugabee we met Malam Fanamee, the governor of Munga, who had been to Kouka on a visit to the sheikh. He was a dirty looking old man, preceded by a drummer beating a drum, and attended by a parcel of ragged followers, armed with bows and spears. We encamped at night in a wood.

July 4.-At mid-day we halted on the banks of the Yeou : in the afternoon there was thunder, lightning, and rain. A dealer in fish, who had joined our party, solicited me in vain to pursue a route through a town named Sucko, where he was going, promising me a sheep, with plenty of milk, as an inducement. We passed another night in the woods.

July 5.-Clear and cool. At ten in the morning we halted and 
filled our water-skins, and I here shot a hare and two Guinea-fowls. About an hour after starting we had heavy squalls of wind, with thunder and rain: the storm was so violent that the camels lay down with their burdens, and my horse would neither move forward, nor face the storm in spite of all I could do. It was an hour before we were able to resume our journey, and at eight in the evening we encamped in the woods. The dangers of the road being past, my two fellow travellers, the merchants before mentioned, left me at midnight on account of the want of water.

July 6.-To-day I shot a fine male mohur, or beautiful red and white antelope ; a female only of which species I had once shot at Woodie. At noon we took shelter under the walls of Borgee from heavy squalls of wind and sand, but without rain. At sunset we encamped near a well where there had been a great fall of rain, and all the hollows were filled with water. To roast our mohur a large fire was kindled in a hole made in the sand, on which it was placed, and then covered over with hot embers; but, in the morning, to our great disappointment, nothing remained of our prize but the naked skeleton.

July 7.-At noon we halted at the wells of Barta, and encamped at night at the wells and town of Calawawa.

July 8.-At eight in the morning I returned to Kouka : Major Denham was absent on a journey round the east side of the Tchad. Hillman, the naval carpenter, was busily employed in finishing a covered cart, to be used as a carriage or conveyance for the sheikh's wives: the workmanship, considering his materials, reflected the greatest credit on his ingenuity ; the wheels were hooped with iron, and it was extremely strong, though neither light nor handsome.

July 9.- In the afternoon I waited on the sheikh, who was very kind in his inquiries after my health, and expressed much regret at Dr. Oudney's death. 
July 10.-To-day the sheikh sent me three pairs of slippers, two loaves of sugar, and a supply of coffee; and two days afterwards a sheep, two bags of wheat, and a jar of honey. 



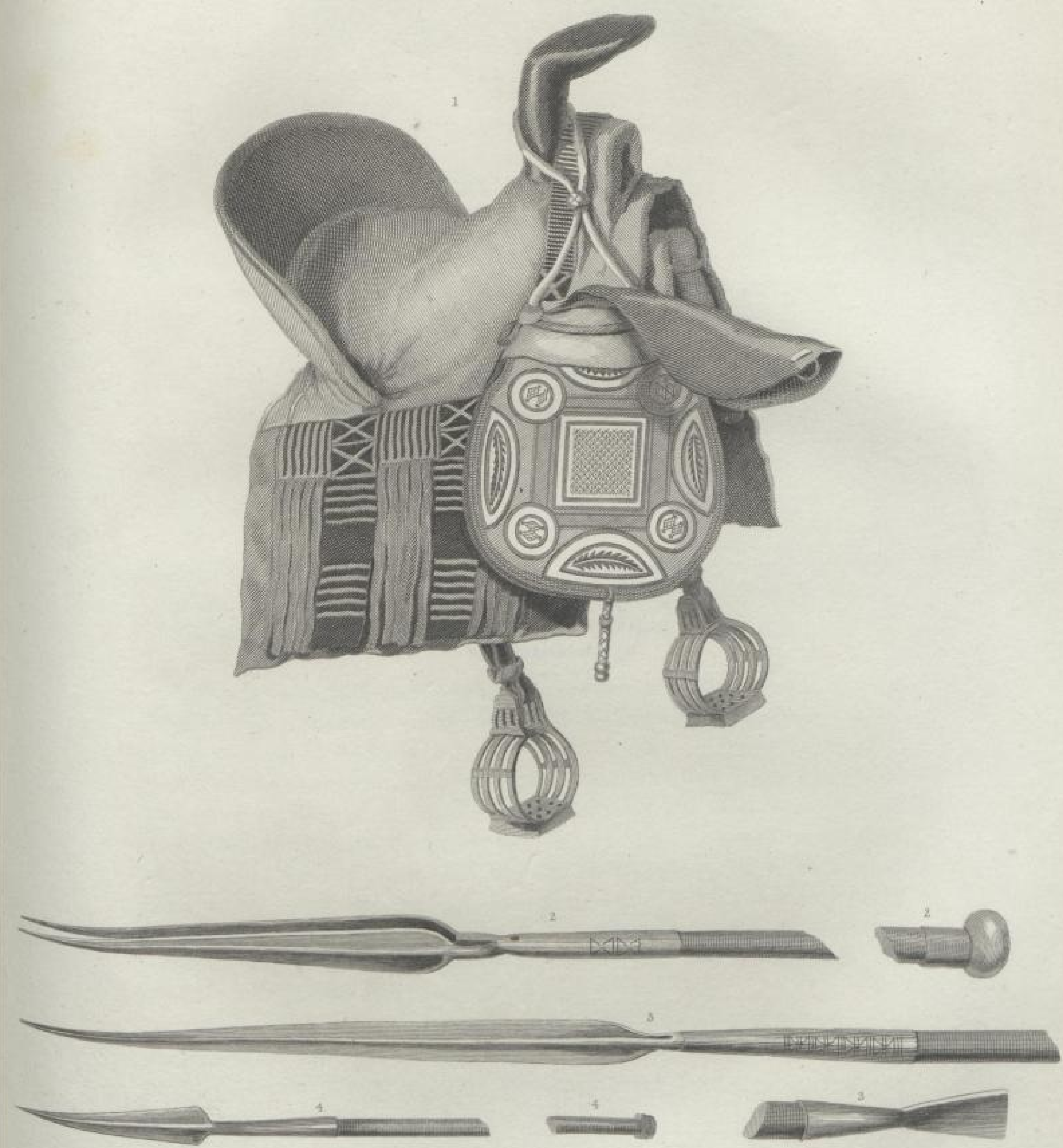

\section{ㄱ SLUB}

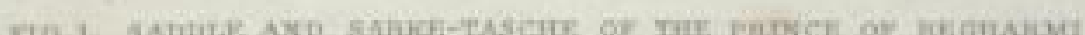

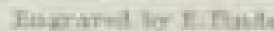

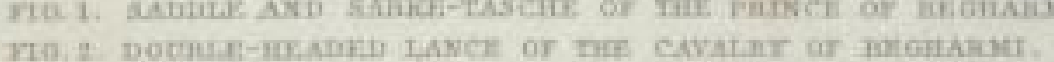

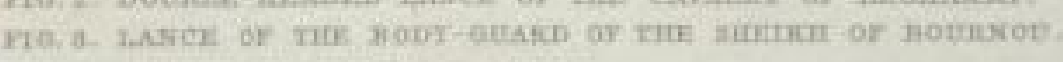

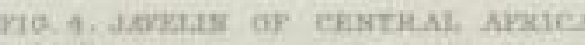




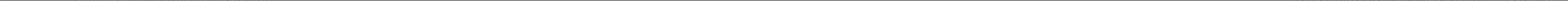




\title{
APPENDIX.
}

\author{
TRANSLATIONS FROM THE ARABIC, OF VARIOUS LETTERS AND \\ DOCUMENTS, BROUGHT FROM BORNOU AND SOUDAN BY \\ MAJOR DENHAM AND CAPTAIN CLAPPERTON.
}

BY A. SALAME, ESQUIRE.

No. I.

Translation of a Letter from the Sheikh Mohammed El Kanemy, Chieftain of Bornou, in the Interior of Africa, to his Most Excellent Majesty King George the Fourth. Brought by Major Denham.

"Praise be to God, and blessings and peace be unto the Apostle of God (Mohammed). From the servant of the High God, Mohammed El Ameen ben Mohammed El Kanemy,

"To the pre-eminent above his equals, and the respected among his inferiors, the great King of the English, salutation be to him from us :

"Whereas your messengers, the travellers through the earth, for the purpose, as they state, of seeing and knowing its marvellous things, have come to us, we welcomed them, and paid attention to their arrival, in consequence of what we heard of your intercourse with the Mùslemeen, and the establishment of your friendly relations between you and their kings, since the time of your and their fathers and grandfathers (ancestors).

"We have thus regarded that friendship, and behaved to them according to its merits, as much as God the Omnipotent enabled us. They communicated your compliments to us, and that which you stated in your letter, that you 
would not object, if we should be in want of any thing from your country, was made known to us; and we felt thankful to you for this (offer) on your part.

"They are now returning to you, after having accomplished their wishes; but one of them, whose period of life was ended, died. This was the physician; and an excellent and wise man he was.

"The Rayes Khaleel (travelling name of Major Denham) desired of us permission, that merchants seeking for elephant-teeth, ostrich feathers, and other such things, that are not to be found in the country of the English, might come among us. We told him that our country, as he himself has known and seen its state, does not suit any heavy (rich) traveller, who may possess great wealth. But if a few light persons (small capitalists), as four or five only, with little merchandize, would come, there will be no harm. This is the utmost that we can give him permission for ; and more than this number must not come. If you should wish to send any one from your part to this country again, it would be best to send Rayes Khaleel; for he knows the people and the country, and became as one of the inhabitants.

"The few things that we are in want of are noted down in a separate paper, which we forward to you.

"Write to the consul at Tripoli, and to that at Cairo, desiring them, if any of our servants or people should go to them for any affair, either on land or at sea, to assist them, and do for them according to their desire. And peace be with you.

"Dated on the evening of Saturday, the middle of the month Fledja, 1239 of Hejra (corresponding to August 1824).

" Sealed. The will of God be done, and in God hath his faith, his slave Mohammed $\mathrm{El}$ Ameen ben Mohammed El Kanemy."

\section{No. II.}

Translation of a Letter from an African Chieftain (Bello) of Soudan, to his Majesty King George the Fourth. Brought by Mr. Clapperton.

" In the name of God, the merciful and the clement. May God bless our favourite Prophet Mohammed, and those who follow his sound doctrine. 
" To the head of the Christian nation, the honoured and the beloved among the English people, George the Fourth, King of Great Britain;

"Praise be to God, who inspires, and peace be unto those who follow, the right path :

“ Your Majesty's servant, Ra-yes-Abd-Allah, (Mr. Clapperton's travelling name,) came to us, and we found him a very intelligent and wise man; representing in every respect your greatness, wisdom, dignity, clemency, and penetration.

"When the time of his departure came, he requested us to form a friendly relation, and correspond with you, and to prohibit the exportation of slaves by our merchants to Ata-gher, Dahomi, and Ashantee. We agreed with him upon this, on account of the good which will result from it, both to you and to us; and that a vessel of yours is to come to the harbour of Racka with two cannons, and the quantities of powder, shot, \&c. which they require; as also, a number of muskets. We will then send our officer to arrange and settle every thing with your consul, and fix a certain period for the arrival of your merchant ships; and when they come, they may traffic and deal with our merchants.

" Then after their return, the consul may reside in that harbour (viz. Racka), as protector, in company with our agent there, if God be pleased.'

"Dated 1st of Rhamadan, 1239 of Hejra." 18th April, 1824.

\section{No. III.}

\section{A Letter from Yousuf, Pasha of Tripoli, to the Sheilk of Bornou.}

“ Praise be to God, and prayers be unto him who was the last of the Prophets (Mohammed).

" To the learned and accomplished, the virtuous Iman, the jealous and zealous defender of the Mohammedan faith, our true friend the Sheikh Mohammed El Kanemy, Lord of the country of Barnooh*, and its dependencies, whom may God protect and dignify, and prolong his life long in happiness and felicity. Peace be unto you, and the mercy and blessings of God be upon you, as long as the inhabitants of the world shall exist.

* Note. This is the proper name of Bornou. A. S. 
"It follows, my Lord, subsequent to the due inquiry we make after your health, which may God preserve, that your esteemed letter has reached us, and we became acquainted with its contents. You informed us that our beloved son, Aba Bak'r Ben Khalloom, arrived in your presence, in company with some persons of the English nation, our friends; and that you received them with extreme kindness, and showed them all the marvellous things that your country contains, and made them see all the extraordinary rivers and lakes that surround it; and that you behaved to them as becoming your high station, and indicating your esteem and regard towards us. May God reward you for all this kindness, and protect you from all evils. This kind treatment was our sanguine expectation, and indeed we were already sure of it, from what we knew of the true friendship and amity established between us.

"What we have now to acquaint you with, is to request that you will continue your protection and assistance to the said English travellers (though we doubt not you do not need this additional recommendation), and cause them to proceed to the country of Soudan, to behold its marvellous things, and traverse the seas (lakes or rivers), and deserts therein. This being the proper desire of the great King of the English himself, we beg of you to use your utmost endeavours, as far as lies in your power, in their safe arrival at the country of Soudan, accompanied either by letters of recommendation, or by troops and guards, in order that they may obtain the accomplishment of their wishes, and return to us safe and unhurt; and whatever kindness you may do to them, it is done to us. Resolve therefore, and exert yourself, as we are confident of your goodness, and let them see all the places which they wish to visit.

" At the end there will be a splendid present, befitting your high rank, sent to you through us, consisting of various rare and elegant articles of value; for the delivery of which, unto your hands, we pledge ourselves.

- "This is all that we have to say at present, and if any affair should occur to you in this country, let us know. And peace be unto you.

" Your friend,

$$
\text { (Signed) "yousur pasha." }
$$

(Dated) " 28 th of Sha-wal, 1238 of Hejra ;" corresponding to August, 1823. 
No. IV.

\section{A Letter from the before named Pasha of Tripoli to Aba Bal'r ben Khal- loom, at Bornou.}

"We received your letter, and comprehended all that you stated to us. We were glad to hear that you, and our friends, the English travellers, with whom we sent you as guide and conductor, had arrived at Barnooh in safety; and that you were kindly received by our friend, my Lord, the Sheikh Mohammed El Kanemy, who immediately allowed the travellers to inspect all the deserts, and seas, lakes and rivers, that are in his country. May God reward him for this act of kindness. We have written to thank him for his laudable behaviour; and we pray to God to enable us to show him equal kindness in return.

"With regard to the persons of the different tribes, who were obstinate and disobedient to you on the road, they have been apprehended, and taken and punished one by one.

“ As long as the English travellers remain at Barnooh, you have to attend, and be with them wherever they go, till they shall have obtained their wishes, and accomplished their object; and when they desire to return, you may accompany and come with them as you went. If this letter should reach you before you leave Barnooh, you must stay with them, as above stated; if it reach you while you are on the road homewards, you must return to Barnooh immediately, and only send us the slave you have with you ; and if you should arrive at Fezzan before this letter reaches you, you may then send your brother to Barnooh, to stay with them instead of you; for we only sent you on their account, for the purpose of facilitating their proceeding, and all their affairs. It is, therefore, impossible that you should leave or part with them, but in this manner; and we are sure that, to a person like you, there is no need to add any stronger words, especially as you know that they are in our honour, and under our protection, both in their going and returning in safety; which is the accomplishment of our wishes. And may you live in happiness and peace.

$$
\text { (Dated) " } 2 \mathrm{~d} \text { of Ze-el-ka'da, } 1238 \text {;" }
$$$$
\text { (Signed) " "yousuf PAsHa,", }
$$

corresponding to August, 1823. 


\section{A Letter from the Sheikh of Bornou to the Sultan of Kanou.}

"Praise be to God, and prayers and peace be unto the Apostle of God (Mohammed).

" From the slave of the high God, Mohammed El-ameen ben Mohammed El-kanemy, to the head of his land and the leader of his people, the learned Mohammed Daboo, lord and master of Kanou : Perfect peace, and the mercy and blessings of God, be unto you.

"Hence, the bearer, who is going to you, is our friend Mohammed Elwardy, in whose company he has some Englishmen; who came to the land of Soodan for the purpose of seeing and delighting themselves with the wonders it contains, and to examine and see the lakes and rivers, and forests, and deserts therein. They have been sent by their king for this purpose.

"Between their nation and the Mooslemeen, there have existed, since the times of their fathers and great grandfathers (ancestors), treaties of religious amity and friendship, special to themselves out of all the other nations that have erred, and are at variance with the doctrine of Aboo Hanifa*. There never was between them and the Mooslemeen any dispute; and whenever war is declared by the other Christians against the Mooslemeen, they are always ready to help us, as it has happened in the great assistance they gave to our nation when they delivered Egypt from the hands of the French. They have, therefore, continually penetrated into the countries of the Mooslemeen, and travelled whereever they pleased with confidence and trust, and without being either molested or hurt. They are, as it is stated, descendants of the ancient Greek emperor Heraclius, who received and esteemed the letter sent to him from the Apostle of God (Mohammed), whom may God bless, by Dahi-yah El-kalbee, containing his exhortation to him to embrace the Moosleman faith; and who, on receiving that sacred epistle, preserved it in a gold case,-though it is stated, in the books of history, that he did not become a Mooslem.

* Aboo Hanifa, or Imam Kanafee, was one of the four great imams or high priests, founders of the four orthodox rites of Mohammedanism; and whose doctrine, it seems, is followed by these people. A. S. 
"Thus, if God permit them to reach you in safety, be attentive to them, and send guards to conduct them to the country of Kashna, safe and unhurt; for they are at the mercy of God, and at the honour of his Apostle; and you are well aware of the Alcoraanic sayings upon the subject of the observance of honour. And peace be with you."

Dated "Wednesday, the 6th day of Rabee-ul-thani, 1239,"

(Corresponding to January, 1824.)

No. VI.

\section{A Letter from the Sheilh of Bornou to Mohammed Bello, Sultan of Hoossa.}

" Praise be to God, and prayers and peace be unto the Apostle of God, (Mohammed).

"To the honoured and accomplished, the virtuous and munificent, the pattern of goodness and the standard of benevolence, head of the Soodanic kingdom, and ruler of the country of Hoossa, our friend, the learned Mohammed Bello, son of the intelligent sheikh Ossman, whose soul may God shelter with the clouds of mercy and peace.

"Our kind salutation, accompanied with affection as strong as the odour of musk, and as perpetual as the movement of the globe, and with the mercy and blessings of God, be unto you.

"Hence, the cause of writing this letter and the purpose of its lines, is to acquaint you that the bearers are English travellers ; whose nation, out of all the other Christians, has maintained with the Mooslemeen uninterrupted treaties of religious amity and friendship, established since ancient periods, which they inberited from their forefathers and ancestors; and, on this account, they penetrate into the Mooslemeen countries whenever they please, and traverse all provinces and lands, in confidence and trust, without fear. They came to our country, sent to us by our virtuous and accomplished friend, the Lord Yousuf Pashá, master of Tripoli, to see and delight themselves with the wonders of the land of Soodan, and to become acquainted with its rarities, as lakes, rivers, and forests (or gardens); equal to which are seldom seen in any other countries. 
"After having accomplished their wishes, in seeing all the things that the land of Barnooh and its environs contained, they felt anxious to visit your country from what they heard of the innumerable wonders therein. I have, therefore, permitted them to proceed on their journey, accompanying them with letters which explain their object.

"You are well aware of what is stated in the Alcoraanic sayings upon the subject of the observance of honour, dietated by our Lord, the Apostle of God; and that the true Mooslemeen have always avoided shedding the blood of Christians, and assisted and protected them with their own honour. Be then attentive to these travellers, and cast them not into the corners of neglect; let no one hurt them, either by words or deeds, nor interrupt them with any injurious behaviour : but let them return to us, safe, content, and satisfied, as they went from us to you; and may the high God bestow upon you the best reward for your treatment to them, and insure to us and to you the path of the righteous for our conduct in this life.

"Our salutation may be given to all who are about you, and to those who are related to you in general. And peace be unto you.

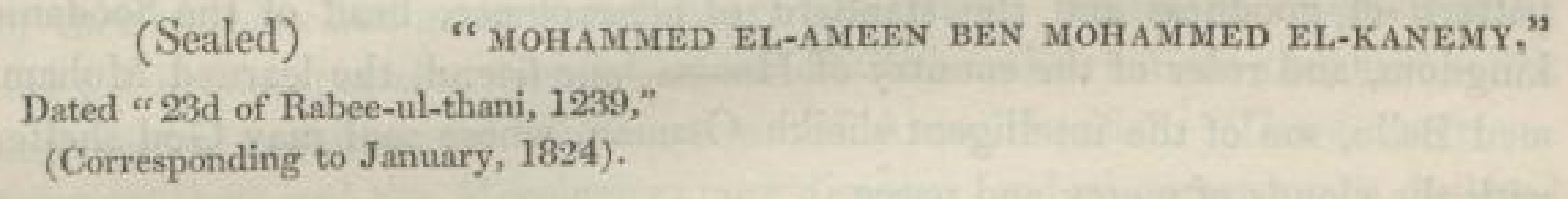
No. VII.
A Letter from the Chieftain Mohammed Gamsoo, at Sackatoo, to the Prince of Ya-oory.

"In the name of God, the merciful and the clement; and prayers and peace be unto our Lord, Mohammed.

"From the slave of God, Mohammed, son of the Hadgi Omar Gamzoo, to our friend, the dearest we have, the Prince of Ya-oory.

"Salutation without end or termination be unto you and all your friends and relations. If you inquire after our health, and that of the Prince of the Mooslemeen, and our friends, we are all sound and vigorous. Our slave has 
reached us with the letter from you, which I showed and read to the prince, and he was delighted with it; and we are prevented from sending you a messenger with an answer, only by the prince having ordered us to proceed to the eastern parts of the country to attend to some of his affairs there. But, if God be pleased to cause us to return in safety, you shall receive an express messenger from me.

"The prince now sends you the English Rayes Abdallah (Captain Clapperton's assumed name), who is anxious to see your country and visit you. He has been honoured and esteemed by the sheikh (of Bornou), and by the prince of Kanoo, as also by the prince of the Mooslemeen; and as you rank among the generous, receive him and honour him generously. When he returns, send us a letter, and express all your wishes in it.

"Give our salutation to our brother and all the friends, and we exhort you to attend to the contents of this epistle for the sake of the friendship which was established between you and our ancestors, and is now between me and you ; especially as you never behaved towards us but very laudably. And may God bestow upon you more good sense, in addition to that which you possess."

\section{No. VIII.}

\section{A Document relating to the Death of Mungo Park.}

"Hence, be it known that some Christians came to the town of Youri, in the kingdom of Yaoor, and landed and purchased provisions, as onions and other things; and they sent a present to the King of Yaoor. The said king desired them to wait until he should send them a messenger, but they were frightened, and went away by the sea (river). They arrived at the town called Bossa, or Boossa, and their ship then rubbed (struck) upon a rock, and all of them perished in the river.

"This fact is within our knowledge, and peace be the end.

"It is genuine from Mohammed ben Dehmann."

[In addition to the above, there is a kind of postscript appended to the document by a different hand; which, being both ungrammatical and scarcely $u \mathcal{2}$ 
legible, I had some difficulty in translating and giving it a proper meaning. The words, however, are, I think, as follows; though most of them have been made out by conjecture.]

"And they agreed, or arranged among themselves, and swam in the sea (river), while the men, who were with (pursuing) them, appeared on the coast of the sea (bank of the river), and fell upon them till they went down (sunk) in it."

\section{No. IX.}

\section{A Letter from the Sheikh of Bornou to Captain Clapperton.}

"Praise be to God, and prayers and peace be unto the Apostle of God.

"From the slave of the high God, Mohammed El-ameen ben Mohammed El-kanemy, to the Ra-yes Abd-allah, the Englishman. Peace be unto him who follows the light of instruction.

"Hence, we received your letter, and comprehended its contents; as also what you acquainted us with relative to the kindness and friendship which the people showed you. May God bless them; and we never doubted this behaviour on their part.

"With regard to what you stated upon the subject of the calumny uttered by some of the Arabs against you, you need not turn your mind to, nor think of it; as nothing shall befal you, while you are in this land, but what God Almighty may inflict upon you, without the instigation of any of his creatures.

"The physician your friend is dead. This is the state of the world; and may God increase your life. Before his death, he promised to give his pistols to us as a present; and on this condition he kept them for his own use, as being borrowed from us, until his return to his own country : but now, as he is dead, you may deliver them to our friend Hadgi Saleh, to send them to us. And may God conduct you (to your own country) in health and safety.

(Sealed) "MOHAMMED EL-AMEEN BEN MOHAMMED EL-KANEMY." 
No. X.

\section{A Document made at the Court of Justice of Bornou.}

"Praise be to God alone. May God bless our Lord Mohammed, and all his relations and friends.

"Whereas, at the court of (here the titles of the sheikh and his pedigree follow,) the Lord Sheikh Mohammed El-Kanemy, Hadgi Alij, son of Hadgi Moosa ben Khalloom, and the English physician, with his two friends, Rayes Abdallah, and Rayes Khaleel, appeared; the physician demanded of the said Hadgi Alij the restitution of two thousand hard silver dollars, which he and his said friends had lent to his late brother Abu Bakr ben Khalloom, through the English consul at Tripoli, on condition of repaying them after their arrival at Barnooh, according to his own acknowledgment and a bond in the said physician's possession ; and that they demanded this debt from Hadgi Alij, because he took possession of all his deceased brother's property. Hadgi Alij replied, that he knew nothing of their claim upon his late brother : but, if they possessed a bond, they might produce it to prove their claim. They produced a paper, not written in Arabic, bearing the seal of the said deceased Abu Bakr; and, as no one could read what that paper contained, the judge told them that, notwithstanding it bore the seal of the said deceased, it could not be valid, nor of any use to them. They then produced one of the friends of the deceased Abu Bakr, as witness, who attested that, while at Tripoli, he was sent by him to the consul's house, where he received the two thousand dollars and delivered them to him (the deceased), knowing that they were to be repaid at Barnooh, according to the present claim. His testimony, however, was not approved of by the judge.

"They appeared a second time at the said court of justice, and alleged that Hadgi Alij, after their first appearance, acknowledged, and pledged himself to pay them the two thousand dollars which they claimed from his late brother; that he paid them a part of the said sum in cotton clothes to the value of six hundred dollars in Barnooh money, and that the remaining fourteen hundred were to be repaid to them by him at the city of Kanoo in Soodan; and they, therefore, wished to legalize this before the judge. 
"Hadgi Alij, however, said, that he gave them the six hundred dollars, merely as an act of kindness on his part, and as a loan from him to them, which they were to return to him at Kanoo; and that he never acknowledged, nor promised to pay his brother's debt; but that, he told them, if they should be in want of more money at Kanoo, he would advance them as much as he could afford. They then requested the judge to restrict him from selling, or sending his brother's property to Kanoo (lest it should be lost on the road), until they had proved their claim by better evidence. Hadgi Alij, at last, agreed, either himself or through his agent, to pay them five hundred dollars more, in addition to the six hundred, two months after their arrival at Kanoo; and fixed a period of one year, from the date of this document between them and him, for the proof of the justice of their claim; and that, if they fail to prove their demand upon his deceased brother before the lapse of the said period, they were to repay him the eleven hundred dollars, and forego all their claims. But if, on the contrary, they should be able to substantiate their demand within the stipulated period, he would then repay to them the nine hundred dollars, balance of the two thousand.

"Upon these conditions, both parties agreed and declared themselves content and satisfied, while they were in a perfect state of health and mind as to deserve reliance and dependence upon.

" Issued from the Court of Justice of the honoured and learned sheikh Mohammed El-ameen ben Mohammed El-kanemy, at Barnooh, on the 27th day of Rabee-ul-a-wal, one thousand two hundred and thirty-nine of the Prophetical Hejra, (corresponding to Deeember, 1823); in presence of Mohammed Zain-ul-Abedeen ben Akhmed ben Mohammed; of Mohammed ben Akhmed ben Aba Bakr; and of Mohammed ben Hadgi Meelad ben Taleb. And may the high God be witness upon all." 


\section{No. XI. \\ Translation of Letters and Documents received from the Sheilth of Bornou concerning $M r$. Tyrwhil's Death.}

1.-A Letter from the above-mentioned Sheikh to the British Consul at Tripoli.

" Praise be to God, and blessings and peace be unto the Apostle of God, (Mohammed).

"From the slave of the High God, Mohammed El Ameen ben Moham. med El Kanemy, to the head of his people, the respected and honoured by the children of his nation, the English Consul resident at Tripoli. After the due salutation, and our inquiry after your health, we have to inform you that we are, by the grace of God, enjoying perfect health and prosperity. Your letter which you sent to Fezzan has reached us, and we comprehended its contents; but the letter you sent by our messengers Abraham and Abdullah has not come to our hand yet, though we hope their arrival will be soon.

"You are well aware, that the omnipotent God hath ordained to every man a certain age, which can neither be increased nor decreased, and hath destined to him a grave, in which he can neither enter before his time, nor from which he can fly when his time comes. Thus, when you know this, it may be an alleviation to your sorrow and grief, when you hear of the death of your friends and relations: so that we have now to acquaint you, that your son Tair (Tyrwhit) ended his life, and his days and hours terminated by his death, on Monday the end of Saffar $1240^{*}$, while we were absent in a war with our enemies. After his death and interment, the elders and priests of our metropolis entered his house, to ascertain and note down the effects he left, in order, and from fear, that in the course of time, there may be no suspicion of distrust thrown upon the trustees. They found the property he left was not considerable : they made a list of it, which herewith you will receive, and left the whole in the hands of his trustees, Eben Saada of Tripoli,

* About the $22 \mathrm{~d}$ or $23 \mathrm{~d}$ of October 1824. 
and the Hadje Aly El-ma-yel, who were his servants. But God knows whether this was the whole of his property, or some of it was fraudulently concealed by those who were in the house at his death.

" With regard to the desire which you expressed to us, to know the source of the inundation of the river that divides our country, we have to inform you that this sea (river) of ours is a great and extensive lake, the circumference of which is about twenty days' journey, and into which various rivers empty themselves from the part of the land of Soodan, and from the right and east of our country, which joins the uninhabited mountains and the land of the Pagans, to whom no one goes. And God only knows what is to be found on the other side of these places.

"Send our salutation to the great King of the English, and to every one who inquires after us amicably.

(Dated) "Sunday, the eve of the end of the month of

$$
\text { (Sealed) MoHammed el Kanemy." }
$$

Rajab, 1240." (About the 20th of March, 1825.)

2.-A Document containing the List of the Property left by Mr. Tyrwhit, as alluded to in the foregoing Letter, and a Certificate of his Death, and the Things that were found after the Return of the Sheikh from his Expedition.

\section{The List.}

"Whereas the Elders and Priests of the metropolis of the Arabs (Barnoo), having assembled and repaired to the house of the deceased English traveller, named Fair (Tyrwhit), who died on Monday the last day of Saffar, 1240, to ascertain and note down what he left; it proved, in their presence, that all his property was as follows :

" First, two swords and a sash, a musket, a pair of pistols, another pair ditto, three . . . . a sash, six silver spoons, a fork, a razor, fifteen bottles of . . . . . . eleven . . . . . ., four coffee cups, three cupping glasses, a sun scale (quadrant), a . . . . ., three squares of soap, a box containing some . . . . , four . . . . , two pair of boots or slippers, a skull cotton cap, a woollen ditto, an Indian looking-glass, twenty pieces of wearing apparel, as shirts, drawers, \&c. of his country, six towels, a paper containing some cinnamon, a black napkin handkerchief for his neck, four 
hand napkins, two . . . . ., a pillow of Soodan manufacture, a silk sash, a silk cord, a . . . . . a jacket embroidered with silver, a yard of red cloth, a canvas bag, three gun covers, a cord for trowsers, some boxes containing part of these things, a pair of Constantinople slippers, a pair of Barbary ditto, or shoes, two serapers of pig's hair (tooth-brushes), a looking-glass, ten pounds of gunpowder, twenty-three bundles of . . . . ., three lookingglasses for the nose (spectacles), a . . . . ., another hand napkin, three empty . . . . ., a broken glass, three squares of soap again, a . . . . three watch rings, a pair of fine razors, a pound of antimony, a pound of coral, fifty-three beads of amber, a pair of Soodanie boots, three pair ditto of his country, a red cloth bornouse or cloak, a . . . . ., fifty hard dollars, fifty-two books, a coffee waiter, two tin cans, three burning glasses, a telescope, a waistcoat, a white bornouse of Barbary, a towel, another bornouse, a writing desk, an umbrella, two loaves of sugar, a . . . . ., two time pieces for the road (compasses), a nose looking-glass (spectacles), a razor, two corkscrews, or ramrod screws, a . . . . . , five . . . . ., three pair of trowsers, four tiger skins, two mats of Noofee, two beds, or small Turkish carpets, a pillow of Soodan, five sacks, fifteen water skins, or leather bags, a cooking pot, a saucepan, an ewer, two large jars, a pan, two coffee pots, two ... . two hooks, four empty . . . . ., a chisel, a hammer, a camel, a female ditto, a horse, a mule, two saddles of Barnoo, one ditto of his country, three wax cloth covers, a . . . . ., two sun glasses, fifty medicine bottles, a woollen bed or carpet, a . . . . . ; and Hamdo Et-tafteef has by him a network shirt or dress, a bird called Jamaj-mak ; and he confessed that he borrowed fifty dollars from the deceased.

"Besides the above property, it was found that he has to receive twenty dollars from one of the inhabitants of Barnoo, and thirty from another; as likewise twenty-four dollars from the servant of the sharif Barakat, sixty dollars from the Mamluk Bey Mohammed, and 165 from the Mamluk Mohammed, son of Hadje Mahmood.

"His debts to various persons are as follows : fourteen and a half dollars to Hamdo Et-tafteef for . . . . . . ., eight dollars to the same, for a bed and six pounds of . . . . . ., four feathers to ..... . and the wages of his two servants; as likewise, three dollars to the burying people, and two dollars to the man who watched his tomb at night, to prevent the body from being devoured by the hyena. 
" His servant Ben Saada stated that this account of the debts owing by, and due to the deceased, were contracted through him for his master.

" This is the whole of the property left by the deceased; and whatever has been noted down in this document, whether of great or little value, has been deposited in the hands of his abovenamed servant Ben Saada of Tripoli, and his fellow-servants."

\section{THE CERTIFICATE.}

"Whereas our Master and Lord, defender of the Moosleman faith, the Sheikh Mohammed El Kanemy, having, after his return from subduing his enemies, assembled the elders and priests of the inhabitants of his metropolis, and gave them a special audience, ordered that the foregoing list, which was written during his absence, be read in their presence; and, after every one heard and understood it, commanded a revisal of the property left by the deceased Englishman to be made, to ascertain its amount afresh. Accordingly, we the undersigned repaired to the house of the deceased, and found all the beforementioned articles extant except the following, which have been used or lost by his servant, Mohammed ben Saada of Tripoli, who had the things under his care. A pair of boots, four bottles out of the fifteen, a napkin or handkerchief for the neck, three pair of trowsers, three . . . ., three squares of soap, a canvas bag, and two . . . . . But a few more articles, which had not been inserted in the list, were found. They are as follows : a piece of Egyptian mat, two pieces of sealing-wax, a bullet mould, four charts or maps, two travelling bags (one of which contains some of the articles, and is deposited with his other servant Hadje Aly El-ma-yel), a cannon ramrod screw, a pound of ... . . , two ... . . ., two bridles, a . . . ." two covers, three horse-shoes, five tin canisters for meat, a wooden bowl, a wax cloth cover, a large tin canister, a writing box containing eight pens, two blank books, nine . . . . ., and a bottle containing some oil.

" His horse, which is mentioned in the list, has been sold to Mohammed Sal-ha for 172 dollars.

" His servant, Mohammed ben Saada, declared before the assembly, that his master, the said deceased Englishman, named Tair (Tyrwhit), on finding his life was hopeless, bequeathed the following articles to his Excellency the 
Sheikh. A mule, a red bornouse, a looking-glass, or telescope, a pair of pistols, ten canisters of gunpowder, of which, however, eight only were found, a pair of Egyptian shoes or slippers, a sword, though it was rusty, a . . . . . a dining waiter or table-cloth, and a ... . . .

" After this, the assembly agreed, by the order of our Lord the Sheikh, to allow to each of the three servants of the deceased (who are intrusted with the things he left), three dollars per month.

"Done on the evening of Monday, the last day of Rajab 1240, in the presence of the noble Sheikh and his assembly, of which we the undersigned are members, and do hereby bear witness before the Almighty God.

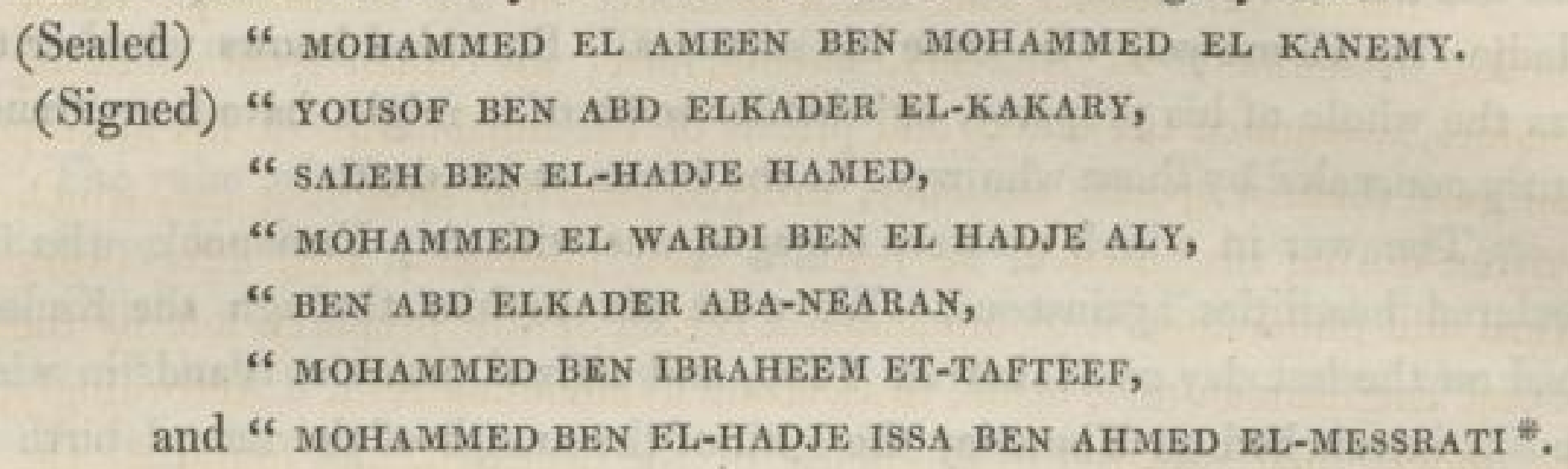

3. A Letter from the Sheikh to Ra-yes-Khaleel, or Major Denham.

" Praise be to God, and blessings and peace be unto the Apostle of God.

"From the slave of the High God, Mohammed El Ameen ben Mohammed El Kanemy, to the honoured by the children of his nation, Ra-yes Khaleel, the Englishman. After our salutation and inquiry after your health, we have to inform you that we are, by the grace of God, enjoying perfect health and prosperity. Your letter has reached us, and we comprehended its contents.

"You are well aware, that the Omnipotent God hath ordained to every man a certain age, which can neither be increased nor decreased; and hath destined to him a grave, in which he can neither enter before his time, nor from which he can fly when his time comes. Thus, when you know this, it

* Explanation. The blanks in this list are those of the names of some articles which I could not make out; they being mostly English in the Moorish character, or described according to the idea those people have of their use. A. S. 
may be an alleviation to your sorrow and grief, when you hear of the death of your friends and relations: so that we have now to acquaint you that your brother Tair (Tyrwhit) ended his life, and his days and hours terminated by his death, on Monday, the end of Saffar, 1240, while we were absent in a war with our enemies. After his death and interment, the elders and priests of our metropolis entered his house, to ascertain and note down the effects he left, in order, and from fear that, in the course of time, there might be no suspicion of distrust thrown upon the trustees. They found the property he left was not considerable : they made a list of it, which herewith you will receive, and left the whole in the hands of his trustees, Eben Saada of Tripoli, and the Hadje Aly El-ma-yel, who were his servants. But God knows whether this was the whole of his property, or whether some of it might have been fraudulently concealed by those who were in the house at his death.

"The war in which we were engaged was with Aly Yamanook, who first declared hostilities against us. We went out to him through the Kanoom road on the last day of Moharram 1240, and arrived near the islands in which he was intrenched on Thursday the 19th of the month of the sacred birth of our Prophet*.

" He entered the islands, and left between him and us seven streams; two of which could not be crossed but in boats, two were as deep as to cover a man to the neck, and the other three had their water as high as the navel only, or perhaps lower.

"We besieged him till he was in great distress, suffered much famine, and most of his animals perished; and when we had collected canoes for the landing of our troops on the islands, he submitted, and begged forgiveness. We at first refused; but when he repeated his applications and solicitations, we consented, binding him by many severe and heavy conditions, which he accepted, and restored to us, according to our demands, all that he had taken from our people. He then came out of the islands, humble like a camel led by his driver, and submissive like a tender twig to the hand that roots it out.

- From this it seems, that the journey was made in forty-nine days, viz. the last day of Moharram, which is the first month of the year, the twenty-nine days of the following month Saffar, and nineteen days of the month in which Mohammed was born, which is the third in the year. Being unacquainted with the distance and the spot, I cannot, of course, pretend to give any farther illustration. A. S. 
" Thus we withdrew our army, after a siege of three months and ten days, and after having likewise subdued all the disobedient and disorderly Arabs, and returned to our home on Sunday the middle of Rajab *.

" Nothing new has happened since you left us, but every good and happiness, and the increase of tranquillity and cheapness. We, however, have lost our illustrious and noble friend Hassan Et-Teflati, who died in this town; as likewise Mohammed Ben Dehman of Katacoom, and Yakoob El-Owjal of Ankarno, to whom may God show mercy and forgiveness.

"The news from the interior is, that the ruler of Wa-da-i made an expedition against the eastern part of the country towards Tamak; but that he was repulsed and returned routed. The truth of this, however, we could not ascertain, because it came from indirect channels.

"The ruler of Foor, also, sent an army against the Turkst, who are in Kordafal or Kordofal ; and it is reported that they had a battle at a place called Kajah, which ended with the defeat of the army of Foor, and the death of three of their grandees, besides what fell of the troops; but that the said chieftain is gathering a larger army, and means to send it against them. God only, however, knows what will be the result.

"The ruler of Bakermy, who last year fled to the land of the Pagans, has not returned; and a brother of his from Wa-da-i has collected what troops he could, and proceeded against him. But God knows what will happen between them.

" Give our salutation to your sister, and all your family and friends; and peace be with you."

Dated and sealed as the foregoing, viz. Letter No. I.

* The middle of Rajab is the 164th or 165th day from his first departure; and according to this, it appears that the sheikh, on returning home, made the journey in fifteen or sixteen days only; whereas, on going, it took him forty-nine days. This difference may perhaps be accounted for, on account of the incumbrances and slow movement of the army. A. S.

†The Sheikh says " he went" through the Kanoom (or Kanem) road, which is by the north side of the lake; and the difference of time occupied in the journey out and home may therefore be easily accounted for, by supposing him to have returned across the Shary by the southern end of the lake, this road being much the shortest, as will appear on referring to the map. Indeed, I see no other way of accounting for the difference. D. D. 


\section{No. XII.}

Translation of an Arabic MS. brought by Captain Clapperton from the Interior of Africa, containing a geographical and historical Account of the Kingdom of Tak-roor, now under the Control of Sultan Mohammed Bello of Hoossa, extracted from a larger Work composed by the said Sultan.

"In the name of God, the merciful and the clement, \&c. \&c.

"This is an extract taken from the work entitled, " Enfak El-may-soor, fee tareekh belad Et-tak-roor," (viz. The Dissolver of Difficulties, in the History of the Country of Tak-roor), composed by the ornament of his time, and the unequalled among his contemporaries, the Prince of the faithful, and defender of the faith, Mohammed Belo, son of the prodigy of his age, the noble Sheikh Ossman," \&c.

\section{PART I.}

\section{THE GEOGRAPHICAL ACCOUNT.}

\section{SECTION I.}

" The first province of this dominion (Tak-roor), on the east side, is, as it is supposed, Foor (Darfoor); and, next to it, on the west side, are those of Wa-da-i, and Baghar-mee. Foor is an extensive country, containing woods, and rivers, and fields fit for cultivation. Its inhabitants are partly composed of itinerants who became settlers, and partly of Arabs who still wander about; and it contains a great number of herdsmen, or graziers of cattle. The food of these inhabitants is the dokhn dura (millet), and the daj'r, or peas. Mooslemanism spread itself very much in this province, and most of its inhabitants perform the pilgrimage; and, it is said, have great respect for the pilgrims, and interrupt them not on their way.

"The inhabitants of Wa-da-i and Baghar-mee are nearly of the same description. Baghar-mee, however, is now desolated. The cause of its ruin was, as they say, the misconduct of her king, who, having increased in levity 
and licentiousness to such a frightful degree, as even to marry his own daughter, God Almighty caused Saboon, the Prince of Wa-da-i, to march against him, and destroy him, laying waste, at the same time, all his country, and leaving the houses uninhabited, as a signal chastisement for his impiety.

"These provinces are bounded on the north by deserts and dry sands, which, in the spring only, are frequented by herdsmen; and on the south by a great many countries, inhabited by various tribes of Soodan, each of whom speak a different language, and among whom Mooslemanism is not much spread.

" Adjoining this country, Baghar-mee, on the west side, is the province of Barnoo, which contains rivers, and forests, and extensive sands. It has always been well peopled, even before the last mentioned country, and its extent and wealth are unequalled by any part of this tract of the earth. Its inhabitants are the Barbar, the Felateen, the before-mentioned Arabs, and a great many of the slaves of the Barbar. These Barbars are of the remnants of those who first inhabited the country between Zanj and Abyssinia, and who were expelled from Yemen by Hemeera*, subsequent to their establishment in that country by Africus. The cause of their being brought to Yemen was, as it is related, as follows :-While Africus reigned over Yemen, and the Barbars in Syria, the inhabitants of the latter country, being oppressed by the iniquities and impiety of their rulers, applied to Africus to deliver them from their hands, and, at the same time, they proclaimed and acknowledged him as their legal sovereign. He marched against the Barbars, fought and destroyed them, except the children, whom he kept in Yemen as slaves and soldiers. After his death, and the elapse of a long period, they rebelled against Hemeera, who then ruled Yemen. He fought and turned them out of that country; whence they emigrated to a spot near Abyssinia (the coast of the Red Sea facing Mokha), where they took refuge. They then went to

* On referring to the History of Yemen, by Mass-oodi, to ascertain the period at which these two sovereigns reigned, I find that the author of this pamphlet has made a mistake in asserting that Africus reigned anterior to Hemeera; whereas Hemeera ruled Yemen many hundred years previously to Africus, and that "Africus was the sovereign wbo removed the Barbars from Syria, Palestine, and Egypt, to their present countries."

From the above-mentioned history (if it can be relied upon) it appears, that the reign of Hemeera was after the demise of the Prophet Heber, and that Africus reigned soon after the death of Alexander the Great. A. S. 
Kanoom, and settled there, as strangers, under the government of the Tawarék, who were a tribe related to them, and called Amakeetan. But they soon rebelled against them, and usurped the country. Fortune having assisted them, their government flourished for some time, and their dominion extended to the very extremity of this tract of the earth; and Wa-da-i and Baghar-mee, as well as the country of Hoosa, with those parts of the province of Bow-sher which belong to it, were in their possession. In the course of time, however, their government became weakened, and their power destroyed.

\section{SECTION II.}

" Adjoining this province (Barnou), on the south side, is that of Aáheer, which is spacious, and contains extensive plains. It is inhabited by the Tawarék, and by some remnants of the Sonhajá, and the Soodan. This province was formerly in the hands of the Soodan inhabitants of Ghoober; but five tribes of the Tawarék, called Amakeetan, Tamkak, Sendal, Agdálar, and Ajdaraneen, came out of Aowjal, and took it from them ; and, after having settled themselves, they agreed to nominate a prince to rule over them, in order to render justice to the weak against the powerful. They appointed a person of the family of Ansatfén; but they soon quarrelled among themselves, and dismissed him. They then nominated another, and continued upon this system, viz. whenever a prince displeased them, they dethroned him, and appointed a different one. These Tawaréks were of the remnants of the Barbar, who spread themselves over Africa at the time of its conquest.

"The Barbars are a nation, descendants of Abraham;-though it is stated that they descended from Yafet (Japhet); and others say, from Gog and Magog, whom " the two horned" Alexander (the great) immured"; but

* The Eastern, and all Mohammedan people, considering Alexander the Great as the only monarch who conquered the globe from east to west, give him the title of " the two horned," in allusion to his said conquests. They likewise believe that Gog and Magog were two great nations, but that, in consequence of their wickedand mischievous disposition, Alexander gathered, and immured them within two immensely high mountains, in the darkest and northernmost parts of Europe, by a most surprising and insuperable wall, made of iron and copper, of great thickness and height; and that, to the present time, they are confined there: that, notwithstanding they are a dwarfish race-viz. from two to three feet in height only-they will one day come out and desolate the world! -A.S. 
that, at the time, a tribe of them, happening to be at Ghair-oon, remained there, and intermarried with the Turks and Tattars.

" It is likewise stated that they (the Barbars) originated from the children of the Jan, or Jinn (Demon), under the following circumstances :-A company of them having gone to Jerusalem, and slept during the night in a plain there, their women became pregnant by the Jinn of that spot. They are, therefore, naturally inclined to blood-shedding, plundering, and fighting. It is also said, that they were the people who slew the prophets Zachariah and Eliah; and that, after leaving Palestine, they proceeded westwards till they arrived at Wa-leeba and Morakéba,-two towns in the interior, west of Egypt, where the Nile does not reach, but the inhabitants drink the rain water*,-where they fixed their residence for some time. They then divided themselves into different tribes, and proceeded westwards in Africa. The tribes of Zedata and Magh-yala first entered the Gharb, and inhabited the mountains. These were followed by that of Láwata, who inhabited the country of Enttablos (Tripoli), which is Barka. They afterwards spread themselves over the interior of the Gharb, till they reached the country of Soossa, where the tribe of Hawazna took possession of the city of Lebda, and the tribe of Nafoosa entered the city of Ssabra, and expelled the Room (Greeks or Romans) who then ruled there.

"It is again stated that they descended from Farek, son of Yonssar, son of Ham ; and that, when Yonssar conquered Africa, they spread themselves over the Gharb, and first inhabited Tunis. Thence they proceeded in tribes towards the southern parts of the Gharb, which communicates with the country of Soodan, where they settled at Aowjal, Fazaran, Ghadamess, and Ghata.

"Thus they came in five tribes from Aowjal, as before mentioned, and conquered this province (Aáheer), as before stated.

\section{SECTION III.}

" Next to the above-mentioned province, on the right hand side, and west of Barnoo, the country of Howssa lies. It consists of seven provinces, to each of which a prince is appointed to superintend its affairs, and the inhabitants of 
the whole speak one language. The central province of this kingdom is Kashnah, the most extensive is Zag-Zag, the most warlike is Ghoobér, and the most fertile is Kanoo.

"It contains rivers, woods, sands, mountains, valleys, and thickets inhabited by the Soodans (who originated from the slaves of the Barbars, and from the people of Barnoo), the Falateen, and the Tawarek. It is presumed that the first father of the Soodans of this country was a slave, named Ba-oo, belonging to one of the former kings of Barnoo; and, on this account we said above, their origin was from the slaves of the Barbars, and the people of Barnoo.

" My friend, the prince of the faithful, Mohammed El-bákery, son of Sultan Mohammed El-ad-dal, informed me that the inhabitants of Kashnah, Kanoo, Zag-Zag, Dor, or Dowry, Ranoo, and Yareem, originated from the children of the above-named slave, Ba-oo, but that the people of Ghoober are free born; because their origin was from the Copts of Egypt, who had emigrated into the interior of the Gharb, or western countries. This tradition he found in the records which they possess.

"These seven provinces (of Howssa) contain a great many wonderful and rare things; and the first who ruled over them was, as it is stated, 'Amenáh, daughter of the Prince of Zag-Zag. She conquered them by the force of her sword, and subjected them, including Kashnah and Kanoo, to be her tributaries. She fought, and took possession of the country of Bow-sher, till she reached the coast of the ocean on the right hand and west side. She died at Atágára, or Ataghér.

"In consequence of these conquests, the province of Zag-Zag is the most extensive in the kingdom of Howssa, including in it the country of Bow-sher; which consists of various provinces inhabited by tribes of Soodan.

"Amoug the provinces of Bow-sher, the following are the most considerable :-First is Ghoo-wary, which contains seven divisions, inhabited by seven tribes of Soodan, who speak one language, and who have not embraced Mooslimanism. Second is Ghoondar. Third is Reer-wa, or Rear-wee, which contains a lead mine. Fourth, fifth, sixth, and seventh, are Yass, Kodoor, Kotoo, and Aádám. Eighth is another Kotoo, which contains a copper mine, and one of alum. And ninth is Kornorfa, which embraces about twenty divisions, ruled by one king, who often sallied forth upon Kanoo and Barnoo, and caused 
much desolation. A gold mine is found in it, as likewise one of salt, and another of antimony. Near to this province there is an anchorage or harbour for the ships of the Christians, who are sent by two sovereigns to traffic or trade with the people of Soodan.

"The province of Atagára, or Ataghér, is likewise one of the most extensive in the territory of Zag-Zag; and near it there is also an anchorage or harbour for the ships of the said Christians. Both these places are on the coast of the ocean.

"In all the above-mentioned provinces of Bow-sher and Zag-Zag, Mohammedanism was not known before our conquest.

\section{SECTION IV.}

"West of Kashnah and Ghoobér there are seven different provinces, extending into the territory of Howssa, which are-Zanfarah, Kabi, Ya-ory, Noofee, Yarba, Barghoo, and Ghoorma. To each of these there is a prince appointed as governor.

"With regard to Zanfarah, it is presumed that the first father of its inhabitants was from Kashnah, and their mother from Ghoober. They had the government of the province in their own hands, and their authority increased after the decline of the power of the people of Kabi. They had once a very ambitious sultan, named Yá-koob (Jacob) ben Bub, who, on coming into power, marched against Kabí, and conquered and ruined most of its towns and villages. He likewise went to Kashnah, and conquered the greatest part of it. Their power, however, was destroyed by one of the sultans of Ghoobér, whose name was Bá-bari, and who, after taking possession of their country (Zanfarah), entailed it upon his generation for a period of fifty years, till they were conquered by us.

" Kabi is an extensive province, containing rivers, forests, and sands. Its inhabitants, it is supposed, had their first father from Sanghee, and their mother from Kashnah. They ruled their own country, and their government flourished very much during the reign of Sultan Kantá, who, it is said, was a slave of the Falateen. He governed with equity, conquered the country, and established peace in its very extremities and remotest places. His conquests,

$$
y 2
$$


it is stated, extended to Kashnah, Kanoo, Ghoobér, Zag-Zag, and the country of Aáheer; but having oppressed the inhabitants of some of these places, Sultan Aly-Alij marched from Barnoo against him, through the road leading to Simbaki, and passed north of Dowra, or Dowry, and Kashnah, and west of Ghoober, till he entered the country of Kabi, and reached the fort of Soorami. The Sultan of Kabí met him on the morning of the feast. They fought together for an hour; at the end of which the former fled westwards, and the Sultan of Barnoo remained there to reduce the fort. But it being very strong, he was obliged to retire, taking the right hand road, till he arrived at Ghandoo, from which place he returned to his own country.

"Sultan Kanta, however, soon prepared an expedition, and followed him through the same road, till he reached Onghoor, where they met, and fought together, and Kanta gained the battle. After making much booty, he returned to a place called Doghool, in the province of Kashnah, where he attempted to subdue a tribe of the Soodan who were disobedient to him. He had a very severe battle with them, during which he received an arrow, which wounded him mortally. On arriving at Jir he died, whence his body was carried by his troops to his palace at Soorami, and there interred. He had three favourite capitals, where he had residences; the most ancient of which was Ghonghoo, then Soorami, and, the last, Leek. His dynasty continued reigning for about one hundred years after his death, notwithstanding the desolation of most of their territories. There were no greater than them in these countries, and their tradition has no equal. Their power was only destroyed when Sultan Mohammed Ebn Shárooma of Ghoobér, Agabba Ebn Mohammed El-mobárék, Sultan of Aáheer, and the Prince of Zanfarah, allied together, and marched against them, taking possession of their dominions, and destroying the three above-named capitals.

"The province of Ya-ory contains mountains and valleys, and is situated on the coast of the river called the Nile. It is inhabited by some tribes of the Soodan, who are mostly weakminded*.

"Noofee is a province that has, on the right and left sides, rivers, forests,

- This expression means nothing less than that the people of Ya-ory are chiefly light-headed; for the author, in this part of the MS., is very clear and intelligible,-A. S. 
sands, and mountains ; and its inhabitants are tribes of the Soodan of Kashnah; but their true origin is a mixture from Kashnah, Zag-Zag, Kanoo, and other places. Their language is different from that of the people of Howssa. They possess much knowledge in the fine and rare arts; and from their country many elegant and marvellous things are still exported.

"Yarba is, an extensive province, containing rivers, forests, sands, and mountains, as also a great many wonderful and extraordinary things. In it the talking green bird, called babaga (parrot), is found.

" By the side of this province there is an anchorage or harbour for the ships of the Christians, who used to go there and purchase slaves. These slaves were exported from our country, and sold to the people of Yarba, who resold them to the Christians.

" The inhabitants of this province (Yarba), it is supposed, originated from the remnants of the children of Canaan, who were of the tribe of Nimrod. The cause of their establishment in the west of Africa was, as it is stated, in consequence of their being driven by Yaa-rooba, son of Kahtan *, out of Arabia, to the western coast between Egypt and Abyssinia. From that spot they advanced into the interior of Africa, till they reached Yarba, where they fixed their residence. On their way they left, in every place they stopped at, a tribe of their own people. Thus it is supposed that all the tribes of Soodan, who inhabit the mountains, are originated from them; as also are the inhabitants of Ya-ory.

" Upon the whole, the people of Yarba are nearly of the same description as those of Noofee.

"The province of Barghoo contains forests and sandst, and is inhabited by tribes of the Soodan, whose origin, it is supposed, was from the slaves of the Falateen. They are insubordinate and stubborn, as also very powerful in magic.

* This was a great sovereign of Arabia, to whom the people of that country gave the title of "Father of Arabia;" and, according to Mass-oodi, he was the first who ruled over Yemen, and wrote the Arabic language. His reign was, as the said historian says, during the lifetime of the Prophet Heber.-A. S.

+ This province seems to contain no rivers ; because the word " rivers" was inserted in the MS., but afterwards struck out by the writer.-A. S. 
"And Ghoorma is an extensive country, larger than Barghoo, and contains rivers, woods, sands, and mountains. Its inhabitants are almost like those of Barghoo, and chiefly robbers and depraved.

\section{SECTION $v$.}

" Near the last-mentioned province, there is an extensive country called Moo-shér, which contains rivers, trees, and a gold mine. It is inhabited by tribes of the Soodan.

"Adjoining to it, on the north side, the province of Sanghee lies. It is extensive, very fertile, and well peopled. Its inhabitants are remnants of the Sonhaja, the wandering Arabs, and the Falateen. They profess the Mohammedan faith, and their princes ruled them always with equity and justice. A great number of learned and pious persons have distinguished themselves from among them.

"Next to Sanghee, on the west side, and north of Barghoo, the country of Malee is situated. It is a very extensive province, and inhabited by the Soodan, who, it is said, originated from the remnants of the Copts of Egypt. Among its inhabitants, some of the Tow-rooth, the Falateen, the Arabs, the Jews, and the Christians, are found. It is likewise supposed that their origin was from Sarankaly, or the Persians. It contains a gold mine, and has an anchorage or harbour for ships sent by two Christian sovereigns, since former periods. This country has always been in a flourishing state from times immemorial. It embraces the province of Banbara, which is very extensive, and contains rivers, forests, and a gold mine. The Soodan who inhabit it are very powerful, and to this time still infidels.

"Near to Banbara there is the province of the Tow-rooth, and that of Footá; which are extensive, and inhabited by their own people, and by those of Sarankaly, or Persians. The Tow-rooth nation, it is said, originated from the Jews, others say from the Christians, and others make them to be descendants of the Soodan of Banbara.

"Beyond the last mentioned countries there is only the province of Dámlá, or Damloo, which lies on the coast of the ocean. In it Mooslimanism is not known; and its inhabitants presume to hear the sound of the sun on 
reaching the meridian at noon. This country contains many wonderful, rare, and extraordinary things, which we are prevented from detailing by the pressure of time.

"Thus we now conclude what we intended to insert in this extract, for the purpose of giving an outline of the geography of the kingdom of Tak-roor."

\section{END OF PART FIRST.}

N. B. The next, or Second Part, contains only the details of the actions and battles that took place when Bello's father conquered these countries.

Onsenvation.-It is proper bere to explain, that the only deviation I made from the original is in dividing the Pamphlet into two parts, and separating the geographical from the military account.-A. S.

No. XIII.

NOTE BY THE TRANBLATOR.-In my translation of the first part of this pamphlet, I stated that the second part embraced only the details of the battles and actions that took place when Sultan Bello's father conquered his present dominions; which details are those of the battles of Kashnah, Dowra, Kanoo, Kabi, and of three actions in the province of Kadawee. These being of no general interest, I considered it superfluous to translate the whole; but, in order to give an idea of the military tactics of the Africans, and the manner of their warfare, I have selected the account of the first battle of Kadawee, which is the longest, and somewhat interesting.

\section{A Narrative of the first Battle of Kadawee.}

"When we assembled and consulted together, respecting the conquest of Kadawee, and our opinions agreed upon its execution, we encamped out, with our troops, commanded by general Aly Jedo. After leaving Manee, or Moona, we marched till we arrived at the west suburbs of the capital, where we found 
the infidels prepared and intrenched within some thickets. We fought them; and God Almighty gave us the victory. We then proceeded till we reached Boori, about half a day's journey from Kadawee, where our friends, the tribes of the Falateen, who had fought the infidels at the right side suburbs, sent and announced to us that they (the infidels) had embraced Mooslemanism; and that a great number, of both settlers and wanderers, who had been beaten by our other troops, had also followed their example. The fight continued on that day till our soldiers reached Jerwa; which place is very near the capital. At sunset, I and my guards retired from the western suburbs, but our people besieged the southern; and the next morning when our brother, the pious Namooda, arrived with his troops, they advanced upon the eastern suburbs. We then held a council and agreed to attack the city, notwithstanding the immense number of the enemy's troops (whose amount God only knows) that was collected in it. This being known, every one of our party, who were besieged in it, and made their escape, came to us. After encamping at Manee, and most of our friends and people had joined us, we marched, commanded by the great vizier Abdullah, till we arrived at Boori, where we stayed till the rest of our followers reached us. We now marched towards Ghazik, and early in the morning came near the capital, which was very strongly fortified, and well protected by being situated between trees and thickets. Our general hastened and advanced till he reached the vanguard of the enemy, where he found that they had prepared, on each side of the town, a company to defend it. They sallied forth, and bore upon our left; we resisted and fought them for an hour, while their people, from the fortifications of the city, were shooting upon our troops volleys of arrows : so that we were attacked on one side by their troops, who came out to us, and on the other by their archers from the town. During this engagement my uncle was wounded in the foot. God Almighty, however, helped us against them, and we routed their troops; and, when we obtained this advantage of their backs, the battle became very hot and sanguinary. I pursued them with a portion of our troops (while the rest, on the right wing of the army, remained fighting against the city), till I drove them towards the place where I was encamped. I then sent to the right wing to join me; and, while we were thus engaged, the enemy came out with a fresh body of horsemen and followed us. On seeing this movement, I hid 
myself, with a number of my cavalry, till they passed and got near our troops, whereupon I started and bore upon them from behind; by which surprise God dispersed and made them fly. We then returned to our troops, and encamped till the next morning, when the enemy sent out against us an immense number of horsemen, at whose head we thought was their prince himself. Our cavalry started and met them; and after a severe battle, routed them. We pursued them till we reached Zoghrob, on the right side of the capital, where we rested three nights, and then marched to re-attack it. On Sunday morning we fought the enemy most terribly, till it appeared as if the city was on the point of being opened to us. In this battle a great number of our people fell martyrs, and we killed as many of the enemy. At sunset we retired to the camp.

"Here the Tawarek conducted themselves with treachery and deceit : they came to us and declared their submission; but, afterwards, they went to the infidel Soodan, and united with them against us. They, likewise, on seeing our success in the first action, swore and agreed among themselves, to seize upon and capture our family. But our friend and brother, the most virtuous among them, Ahmed ben Heeda, having written to us a detail of their design, and cautioned us, we immediately despatched a part of our troops, headed by the vizier, to protect our family. I remained with the rest of the army, contending with the enemy, till the vizier returned and brought the family safe to us.

"During his absence, however, I sent a body of soldiers to seize upon Ackoowee; which they pillaged, and returned safely, bringing with them an immense booty.

" In the mean time the noble shaikh, my father, moved with a multitude of troops, and arrived at Boori ; where, on hearing of his march, I repaired to meet him.

"The Tawarek again deceived us, by writing letters, in which they pledged themselves to meet and unite with us. But when they assembled and joined us, and we encamped at Thunthoo, and our people were scattered in search of provisions, while only the nobles and leaders remained in the camp, we were surprised by the appearance of the enemy near us. The nobles then started to encounter them with what they could collect of our troops, while I and my company were intrenched behind our baggage and animals. At this moment, our friend, the pious brother of the shaikh Saado, came to our assistance, with 
the royal standard in his hand, and desired that we should advance against the enemy immediately. I told him, he had better wait till they approached us nearer. He refused, and advanced by himself and people. I, being very ill, was obliged to remain behind. They reached the enemy, prepared, and darted upon them. After a severe action of an hour, the enemy fled, but not without a great number of our people having fallen martyrs. By this time, our uncle, the vizier, came to our succour, followed by the noble shaikh, our father, and his party.

"They pursued the enemy, and God gave them the victory, and enabled them to plunge their weapons into their bodies, and disperse them in shreds (small parties). In thisengagement we lost about 2,000 martyrs, most of whom were of our best soldiers, and of the most pious and virtuous of our men : as the chief justice Mohammed Thanboo, the noble Saado, Mahmood Ghordam, Mohammed Jamm, the learned and intelligent poet and reciter Zaid, Aboo-bakr Bingoo, the true diviner Es-sudani, and several others. After burying as many as we could of them, we retired and encamped till the next morning, when we buried the rest. This battle took place about two miles from Kadawee."

The manuscript ends thus :

"Ended, by the grace and assistance of God, the writing of this extract, by the hand of its writer, on Wednesday about noon, the 29th of Rajab, 1239 of Hejra, for Rayes Abdallah, the English Christian, in the city of Sackatoo, of the country of Houssa, residence of the prince of the believers, Mohammed Bello; whom may God cause to be ever victorious! Amen." 


\section{No. XIV.}

\section{The Song of Mohammed-Alameen ben Mohammed El-Kanemy, Sheilh of the Koran, Lawgiver to Bornou, and Governor of Kanem, on his return from the Begharmi Country in 1821. Translated by Major Denham.}

"I return to my people, the people of my heart, and the children of my solicitude! At break of day, fasting, coming towards Kouka, with my morning prayer on my lips, in sight of the gate, the gate that saw me depart! The morning wind blew fresh and cool, yet mild as the evening breeze. The battle of spears had been long doubtful; but had ended in glory! had covered my people with honour and victory, God Almighty assisting us! These were our deeds ; they lived in the memory of all. Oh! glorious expedition! But the greatest joy must be told ; the joy, oh, how exquisite! the recovery of my lost love ! a part of myself. Her high and noble forehead, like the new moon, and nose like the rainbow! Her arched eyebrows reaching to her temples, overhanging eyes than which the moon is less bright, as it shines through darkness! large piercing eyes, whose looks never could be mistaken! A single glance at these her all-conquering beauties instantly called her to my mind with all the graces of her disposition; lips sweeter than honey, and colder than the purest water! $\mathrm{Oh}$ ! dearest of my wives! Heaven's own gift! what were my sensations when I removed the veil from thy face! Thou knewest me not in thy alarm; animation had left thee! Thou knewest not what was to follow; and thy large eyes had closed in despair! It seemed that lightning had struck me with its fire! As the light of morning dispels the blackness of night, so did she, reviving, impart to me a gladness overpowering as the blood-red sun, when it breaks forth in its splendour, warming the sons of earth with its re-animating fires. I thought of the day when she was blooming in my presence, when the news of her loss came to me like a blast from the desert. My head was laid low with sorrow! The Spring returned with its freshness; but its showers could not revive my drooping head! Who shall now tell of my joy? From her shoulders to her waist, how fair is her proportion! When she moves, she is like branches waved by a gentle 
breeze! Silks from India are less soft than her skin; and her form, though noble, is timid as the fawn! Let this my joy be proclaimed to all my people ! Let them take my blessing, and give me congratulation! Their chief is alive, returns, and is victorious! All my people, even little children, shall sing these our deeds; all must share in the joy of their chief, as well those whose age prevents their sharing my glories, as those who have yet to learn the path of heroes! God has made us to overcome those who stood against us! They are fallen, and their towns are in ruins! In the open day, by the light of the sun, the children of the prophet trod them under foot! and now we approach our homes! Towards the rising sun, we followed them; they fled! They were destroyed! they bled! and they were bound! On the fifth day of the week, blessed be the day! the standards of the prophet floated in the wind! The lightnings of my spears played around them! The neighings of my horses seemed like thunder to the unbelievers! They fell! The earth claimed them once more, and drank their blood! From the morning until black night we pursued them; and their blood was as food and refreshment to my strongarmed chiefs! Their women, their cattle, and their horses, were amongst our spoils; and he, who was, at the rising of the sun, surrounded by thousands of glittering spears, he, the king, was, on the going down thereof, deprived of all! He was left alone and deserted! David, my captain, my chosen captain, was covered with the blood of his enemies! His garments were of blood colour! He set his foot on the necks of the Kaffirs, as he drew out his never-failing spear, deep as it was in their gory forms! while with his sword he still satisfied his unappeased wrath. Forests of spears pierced our enemies! Cowards on that day were brave! The hitherto boasting but inactive soldier this day proved himself a hero! Who shall sing the deeds of my brave people, and do them justice? With death before their eyes, they embraced danger as a maiden whom they wished to enjoy, smiling, and proud of their strength ; for glory to them was sweeter than new honey or virgin lips. The battle of spears was like a wedding feast, so joyous were my people! Surely their rage is like that of a furious lion in his wrath! which who shall restrain? They are a destroying fire in the eye of their enemies! Stronger than rocks are my followers! Spear them! spear them ! till the sun sees their bones; and let their bodies be food for the birds and hyænas, while they resist the sword of the prophet! But oh! my people, spare the fallen! and those who implore mercy in 
the name of the One and Omnipotent! These were my words. Wading through blood, we arrived at the palace of the sultan. What were all my defeats, when compared to this victory!

"Lend your ears, oh my chiefs! ye who were present ; for they are your deeds I sing ! and ye also who were away; for I sing of your brethren and your children. It was on the first of the month, when we once more came on those, who were enemies to us, and to our faith!

" Tirab, chief in fight, raged alike with the strength of an elephant! and also his wisdom for two days! Four kingdoms towards the declining sun had been destroyed, and one to the south, five in number! Six months I had been from home, and on the seventh I made my return, after humbling my enemies, and binding them as slaves! As food is before the hyæna, so are their enemies before my people. They are devoured! But the prophet's children are saved by God, who watches over true believers! As a thorn pierces whatever disturbs its retirement, so do my spear-hurling hosts dash their pointed javelins into the flesh of those who break our peace and our repose! When I cheer them on, miserable are they that oppose them! But he that submits, and acknowledges the One and Omnipotent, and his Prophet, blessed be God and his angels, shall receive mercy! I govern by the will of the most High, and by God's decree, and administer the law of God, whose servant I am ; and whoever dies under such law, paradise is his."

\section{No. XV.}

\section{Translation of an extempore Arab Song.}

" Oh! she was beauty's self, and shone in matchless symmetry! When shall I hear news of her? how support her absence, and her loss? My hopes are but as the fantastic dreams of night; yet with this hopelessness my love does but increase, even as a star shines the brightest in the blackest night. $\mathrm{O}$ ! Mabrooka! thy head sinks too with sorrow at losing him, whose thoughts are still of thee; but as the desert bird * drops and smooths its wing, but to

$$
\text { * Ostrich. }
$$


display the richness of its plumage, so will thy silent grief but cause thee to appear with increased charms! Vain and cruel delusion! At the moment of the possession of earthly happiness to doom us to melancholy despair, was as if the traveller should draw water to the brink of the well, and then see the wished-for draught snatched from his thirsty lips !

"What she looks upon becomes graceful, enchanted by her loveliness! Oh! she is beauty's self, my polar star* of life."

\section{No. XVI.}

Translation of the Song of the Fexzanneers, on Boo Khaloom's Death.

" Oh! trust not to the gun and the sword! The spear of the unbeliever prevails!

"Boo Khaloom, the good and the brave, has fallen! Who shall be safe? Even as the moon amongst the little stars, so was Boo Khaloom amongst men! Where shall Fezzan now look for her protector? Men hang their heads in sorrow, while women wring their hands, rending the air with their cries! As a shepherd is to his flock, so was Boo Khaloom to Fezzan!

" Give him songs! Give him music! What words can equal his praise? His heart was as large as the desert! His coffers were like the rich overflowings from the udder of the she-camel, comforting and nourishing those around him!

"Even as the flowers without rain perish in the field, so will Fezzaneers droop; for Boo Khaloom returns no more!

" His body lies in the land of the heathen! The poisoned arrow of the unbeliever prevails!

" Oh! trust not to the gun, and the sword! the spear of the heathen conquers. Boo Khaloom, the good and the brave, has fallen! Who shall now be safe ?"

* The word in the original is jiddie, which guides the kafila in traversing the deserts, their track generally lying either north or south. 
No. XVII.

Bornou Vocabulary.

Good for nothing, Fussel

Good,

Bad,

Bread,

Rice,

Come here,

Go away,

Come to-morrow,

Meat,

Water,

Bring water,

I wish to drink,

Stay in the house,

Sit down,

Bed,

Sheep,

Bullock,

Fowls,

Wind,

Sun,

Cold,

Hot to-day,

Woman,

Girl

Fine girl,

Rich girl,

Ugly girl,

Father,

My mother,

Your mother,

My brother,

My sister,

Wife,

Siriah,

Hand,

Leg,

White teeth,

Tongue,

A slave with large eyes, Keir angala shem and handsome,

\section{Great,}

Small,

Old man,

Horse,

Dog,

Sweet milk,

Sour milk,
Angala

Dibbe

Gorassa

Fergami

Arai natin

Lanai daka

Bali arai belte,

Dha

Inki

Inki coutai

Shay aski

A rai fatto nemine

Nemine

Boushe

Anglaro

Feea

Koukee

Karouah

Kangal

Kakou

Kow zow

Kano

Faro

Faro angala

Faro sukala

Faro dibbe

Aba

Yany

Yaanem

Crameny

Yaiany

Neks

Keferous

Musko

Segulni

Teminy bull

Telumny

Kora

Gana

Keeary

Fur or Pur

Krec

Kiam klee

Kyam
I wish to wash,

Musco toliske

I will go to your Fanim laneskin house,

House,

Fatto

God keep you in health, L'affia dagumba

How is your health? Wanumba l'affia? La Are you well? Are lay? Ba lay? you well?

Breeches,

Yangay

A pretty young slave, Keir gana angala

I give you a little phy- Kergun gana gadishe sic: if that does not atte keteen baco, cure you, come to- arai bali morrow,

I am sick,

I am a little better,

Rains coming,

Good day to you,

Good night to you,

Bad boy,

Good boy,

White man,

One,

Two,

Three,

Four,

Five,

Six,

Seven,

Eight,

Nine,

Ten,

Eleven,

Twelve,

Thirteen,

Fourteen,

Fifteen,

Sixteen,

Seventeen,

Eighteen,

Nineteen,

Twenty,

Thirty,

Forty,

Fifty,

Sixty,

Seventy,

Eighty,
Ou donde

Kermunga neske gana Delaky goushe

Dibdony che l'aftia

Booni che l'affia

Tetowa dibbe

Tetowa angala Bull fulk

Telo

Inde

Yasko-

Dago

Ooogoo

Araska

Toolur

Waskoo

Lekar

Meagoo

Meagoo lageree

Indoore

Meagoo yaskun

Meagoo daree

Meagoo ouree

Meagoo araskee

Meagoo toluree

Meagoo waskun

Finde

Fee askar

Fee daga

Fee oogoo

Fee raskee

Fee tolur

Fee tuskoo
Meagoo likareen

- In the southern provinees of Bornou this is pronounced Paro. 
Ninety,

One hundred,

Poor man,

Sick man,

Gussub,

Handsome woman,

Very hot to-day,

Very cold,

Very dirty,

Very clean,

Dead,

I,

You,

Mine,

Yours,

Sandals,

Cap,

You know every thing, Summa nunumba

I know nothing, Afeems noniskeni

I know,

Bring supper,

I wish to eat,

I look for food,

I do not wish,

Have you got a little?

I have nothing,

Honey,

Wood,

At night eat supper,

Morning meal,

I must go home,

Will you, or will you Rakami, rouanimy not?

I will not,

Yes,

No,

Breast,

Quick,

Come, make haste,

Black,

Red,

White,

Grass,

Straw,

Mat,

I have many bullocks,

A great warrior,

I must buy a shirt

Tell me directly,

I have no money,

I have no friend,

You are my friend,

You are not my friend, Nesobi

You are not my friend, Ne sobany gani
I wish to sleep, Manki boniske

I do not sleep in the Kou boniske baco day,
Fee lekar

Koua telleka

Koua laka

angala

Kako ngubboe

Teginy kadafooa

Nema

Kakay

Kakanem

Sono

Noniski

Coutai bree

Maniskin buskin

Manimin boomin

Naguski baco

Afeems baco

Kon̄agun

Kuska

Booni bree boye

Cheny feleski

Oola niske fatto

Waniskee

Geree

Wankee

Gungy

Arai doua

Sellem

remmy

Bull

Kajum

Soogoo

Suggady

Nanin fean' gubbo

Bendugoo gubboo

Konlko manki efeski

Manany doua

Nani gourse baco

Sobany baco

Nema sobany
Where is good water, Indaran inki, angala very good?

lintia

This water is not good, Inki ada angalügĭni

Not good,

Angalăgăny

I will give you nothing, Afeema giski baco

Call him,

Don't beat him,

Strong,

Weak,

Booboonimin

Stron

Wata edkonimy

Kibboo

Kibboo gany

I wish to return to my Bellany lanis country,

Lion,

Bellany laniski

Kourgilly

neumon,

Chorma

How many children Tetous ndago nanimin have you?

Where is your country? Ndara bellanem

You are very handsome, Angala lintia

Come with me,

Go I cannot,

I am tired,

Yeronemin langay

Whip,

Turban,

Sword,

Looking-glass,

Face,

My face,

Your face,

His face,

Their faces,

My foot,

Your foot,

His foot,

Their feet,

All their feet,

Beard,

Foot,

Feet,

Fingers,

Toes,

Who is that ?

What is that ?

What is your name?

Presently,

Wait a little,

White trowsers,

White shirt,

Blue shirt,

Pillow,

Lanem baco

M'bareski

Kourfo

Aliafo

Kazager

Koutrum

Fiska

Fiskany

Fiskanem

Fiskansa

Fiskanday

Sheeny

Sheenum

Sheensay

Sheenday

Sheenday andi summa

N'chitty

Shee

Shee ndiso

Gulandoni

Fergamij

N'dee aty

Aty a fee

Nin dhu

Wakay

Dāgã dāgõ

Yangay bull

Kukoo bull

Kulgoo kagi

Where are you going? Ndara doony min

Where are you come Ndara kadim. from?

From the sheikh's house Fatto shoukobe kaI come,

To-day,

Yesterday,
Kow

Biska 
The day before yester- Biskada day,

Ass,

Mule,

Handkerchief,

Crocodile,

Hippopotamus,

Many mosquitoes,

Hyena,

Elephant,

Calf,

Cow,

Koro

Koro la fuddera

Futtha. Not used

Timsa, karem

Nghroot

Kantano n'gubboo

Dela

Kamāgun

Kena gana

Kena

Where are your shoes ? Sononem daran

Where is your cap ? Geaqua n'daran

A bad man,

You are bad,

Koati dibbe

Do you wish that wo- Kamo ati rakami man?

Not that one? This I Ati waniski too rawish,

Man, guski

Woman,

A strong man,

Kam

Two men,

Two women,

Camel,

Camel's saddle,

Riding camel or ma- Kelgimmo serdebee herhy,

Wear your cap; the Geaqua contai kou sun is strong,

My house,

The house of me,

I will come at night,

It is now night,

Why did you not come Afero biska issamy yesterday?

I could not come,

I am come to-day,

I am angry,

Always,

I go on horseback,

Horse,

I go on foot,

Your house,

His house,

Kamo

Kamqua

Kuandee

Kamundee

Kelgimmo

Kantergue

Fany

Fatto kakai

Ou boone leniske

Kerama boone

bah

Issiskany

Kou issisky

Ou gergan iskana

Zaar

Kela furby linisky

Fur, or Pur

Sheenin linisky

Fanem

Fansa

All their houses are Andi summa fanday one,

Give me this,

A little, not nuch,

Take care,

Now give me.

shut the door,

Not now,

By and by, telo

Ougoaty orashe

Gana

Zebba

Kormashee

Suganay tapah

Kormakany

Oo kanowaì
I will give you a hand- Koulko angala norosome shirt, weskin

I will dress you prettily, Kasamow angala noroweskin

Hear me, I say, $\quad$ Fanimy

God bless you, Allah kabunsho

May you live for ever, Engoubourou dagah

God send you a happy Allah kiaro old age, literally gray hairs,

Bring water to wash Inki coutai muskowy my hands,

toliske

To wash your hands, Muskonem tolei

Like a Bornowy, Kanourin kaleal

Near,

A long way off,

Why are you afraid? Afero ranimin

You come directly ? Kurma ma duaree

The day after to-mor- Wagoro row,

Eat you,

I can read,

Can you read?

I carnot,

I know,

You know,

He knows,

We know,

Ye know,

They know,

Every body knows,

Nobody knows.

Gazelle,

Ducks,

Vulture,

Monkey,

Buffalo,

Nema booy

Rageski karaengen

$\mathrm{Ne}$ karanemin bah

Karaniskin baco

Ooma nongana

Nemn nonems

Shema nosena

Amgaso nony-enna

Ande amgaso

Nony-enna

Amsemma nozana

Ondooma nozana baco

Engry

Enguddoo

Quogoo

Daggel

I will not go,

I will come, Lazusko

Is it necessary for you? Ragumba

It is necessary, Rngiski

Now,

Kurma

Not now, but in a little, Kurmagany, laga too$\sin y$

Why is your cap off : Afero geaquanem goge

It fell off,

My horse,

Your horse,

His horse,

My hut,

Your hut,

His hut,

Onions,

Wheat,

Oogony konusko

Furny

Furnem

Furnsa

Engiminy

Engiminem

Engiminsa

L'bussel

Gomah

Arkum 
Fan of estrich feathers, Kergeaga

Ostrich,

Feathers,

Nham

Riesh

wisha man who knows Ooroo kam angala sidi the road to Waday,

Do you know all the Sidi Waday nony maroad?

All I know,

Waday nosen

Angaso nony ski

In the road, river great Waday den komadagoo is there?

Thereis, but not a great Beetche, gana laga

one,
And a great deal of wa- N'gobboo gany inki ter, there is not, enga

Gussub is there plenty? Argum beetche engubbooba

Rain little, and gussub Inki gana argum ennot much, gubboo, gany

Last year rain plenty, Mindy inki engubboo morethanat thistime, kerma koge

This year,

Last year,

Fish,

Kimmindy

Standard carried before Yerma the Sultan of Bornou,

Firebring, quick,quick, Kano coutai doua, dous

Fire bring, get supper, Kano contai bree deniskin

Mount, we will go,

Neebamin baa lanyée

Now I will come,

Kurma mai issisky

I do not wish, Wanisky, wangy

Wait a little, now he Garany gana kurma will come, machin

Bring water, I will Inki coutai yaskin drink,

I will not come, Isiskin baco

Give grass to the horse Fena kajem furby to eat, zebbo

Nose bag, Engerky

The nose bag for the Engerky furby coutai horse bring,

Fill it with gussub, Fegana argum

Give it him to feed, Yeshery zebbo

Does he feed ? Zebbe ra-watche

He feeds,

A zebbena

Feed he will not, Zebbin baco watche

Take off the nose bag, if Zenney engerky wathe will not, chea

Take him to drink, Yeati inkero

Give him well to drink, Y'eshero angeloro tsas

Bucket none, yesterday Kirfy baco biska broke, creety

Go a bucket good buy, Lanee kerfy angala belinefay
Take care thieves don't Wata kaleny burbo take it,

I wish it, gotzenu

Something I wish,

What do you wish ?

Where are we going

Near now we go ?

Oura kusku

Aqualaka oura kusku

Afferacum Sunset before? Shall Magrubo setteny? we stop?

We shall stop, Zubtsayu bah

At sunset we shall not Mugrubbokelten zubstop, we shall go un- tsay inde leesharo til Ashea; then we letzaya doo go zubtshall stop, nein

Sunset before we shall Mugrubbo setteny doo return, goo lanem

To-day go, to-morrow Kou lanemya bali arai come,

You are very handsome, Neetyangalaengubboo

You than others I like Neety kamo gediro rabest, kuskin ago angalko

Speak true speeches, Mana gereby manariy

It is necessary, I see the Kouroo garoubi ruwell,

This is my town now, Ate bellany kurma

I wish to see, Raguski rusky

Will you buy any thing? Neema eefamy bah

I wish to buy, Raguski effuskin

I do not wish to buy, Wankee effeesky baco

I will not sell,

I wish to sell,

Will you sell?

My feet ache,

Do your feet ache?

My legs,

My knees,

My thighs,

My loins,

My belly,

$\mathrm{My}$ breast,

My neck,

Woman's breast,

My mouth,

My nose,

My tongue,

My teeth,

My cheeks,

The eyes,

The forehead,

Wankee ladisky baco Ragusky ladisky

Ladamin bah

Sheeny zow

Eenim zow bah

Shegul ny

Engurum grum kakai

Dunomy

Duefurgy-ny

Suero-ny

Ingun geny

Dubboony

Tekkum

Cheny

Kinoa-ny

Telam-ny

Teneeny

Gegaty

Shem

Engum

Eyebrows, Engum reshem

Ears,

Summo

Head,

$\mathrm{Kla}$

This woman, her face is Kamo atteta feskansa handsome, angala 
Long gourd with a hole at each end, used by Tibboo and Bornou as a musieal instrument,
Wrapper or petticoat,

Eggs,
Zeneh

Gubbel

\section{No. XVIII.}

Begharmi Vocabulary, taken from the mouth of the late Sultan's son, now a slave of the Sheilih of Bornou.

\begin{tabular}{ll} 
One, & Keddy \\
Two, & Sub \\
Three, & Mattäh \\
Four, & Soh \\
Five, & Mee \\
Six, & Meeka \\
Seven, & Chilly \\
Eight, & Marta \\
Nine, & Doso \\
Ten, & Dokemy \\
Eleven, & Dokemy kar keddy \\
Twelve, & Dokemy kar sub \\
Thirteen, & Dokemy kar muttäh \\
Fourteen, & Dokemy kar soh \\
Twenty, & Doke sub \\
Twenty-one, & Doke sub kar keddy \\
Twenty-two, & Doke sub kar sub \\
Thirty, & Doke muttah \\
Thirty-one, & Doke muttah \\
Forty, & Doke soh \\
Forty-one, & Doke soh kar keddy \\
Fifty, & Doke mee \\
Fifty-one, & Doke mee kar keddy \\
Sixty, & Doke muka \\
Sixty-one, & Doke muka kar keddy \\
Seventy, & Doke killy \\
Seventy-one, & Doke killy kar keddy \\
Eighty, & Doke marta \\
Ninety, & Doke doso \\
One hundred, & Arrou \\
One hundred and one, & Arrou se keddy \\
Two hundred, & Arrou sub \\
One thousand, & Dooboo \\
Two thousand, & Dooboo sub \\
Eyes, & Kammo \\
Leaf of a plant, & Kammo \\
Head, & Geujo \\
Month, & Tara \\
& \\
\hline &
\end{tabular}

Door of a room,

Brenst,

Sun,

Nose,

Belly,

Thighs,

Knees,

Legs,

Feet,

Flesh,

$\mathrm{Ox}$,

Flesh of an ox, . Nja mungho

Sheep,

Goat,

Water,

Flour,

Bread,

Nokinds of fruit known, all plants different.

Onions, (Good, great.) Bussara

Honey, (Quantities eaten.)

Elephant,

Horse,

Mule,

Ass, (plenty),

Dog, (many),

Lion, (plenty),

Lioness,

Leopard,

Gazelle,

Rabbit,

Fowls,

Coek,

Father,

Mother,

Brother,

Sister,
Tara be

Käja

Kăjā

Amo

Ngala

Brinjee

Kejee

Kersha

Njanja

Nja debe

Mungho

Batta

Angha

Mane

Jumo

Tabaka

Tejee,

Keejee

Soudah

El Feddrah

Krow

Besee

Tobio

Tobiony

Nugo

Ngria

Omo

Kenja

Kla

Babma

Konuma

Monnjema

Monnjum 
APPENDIX.

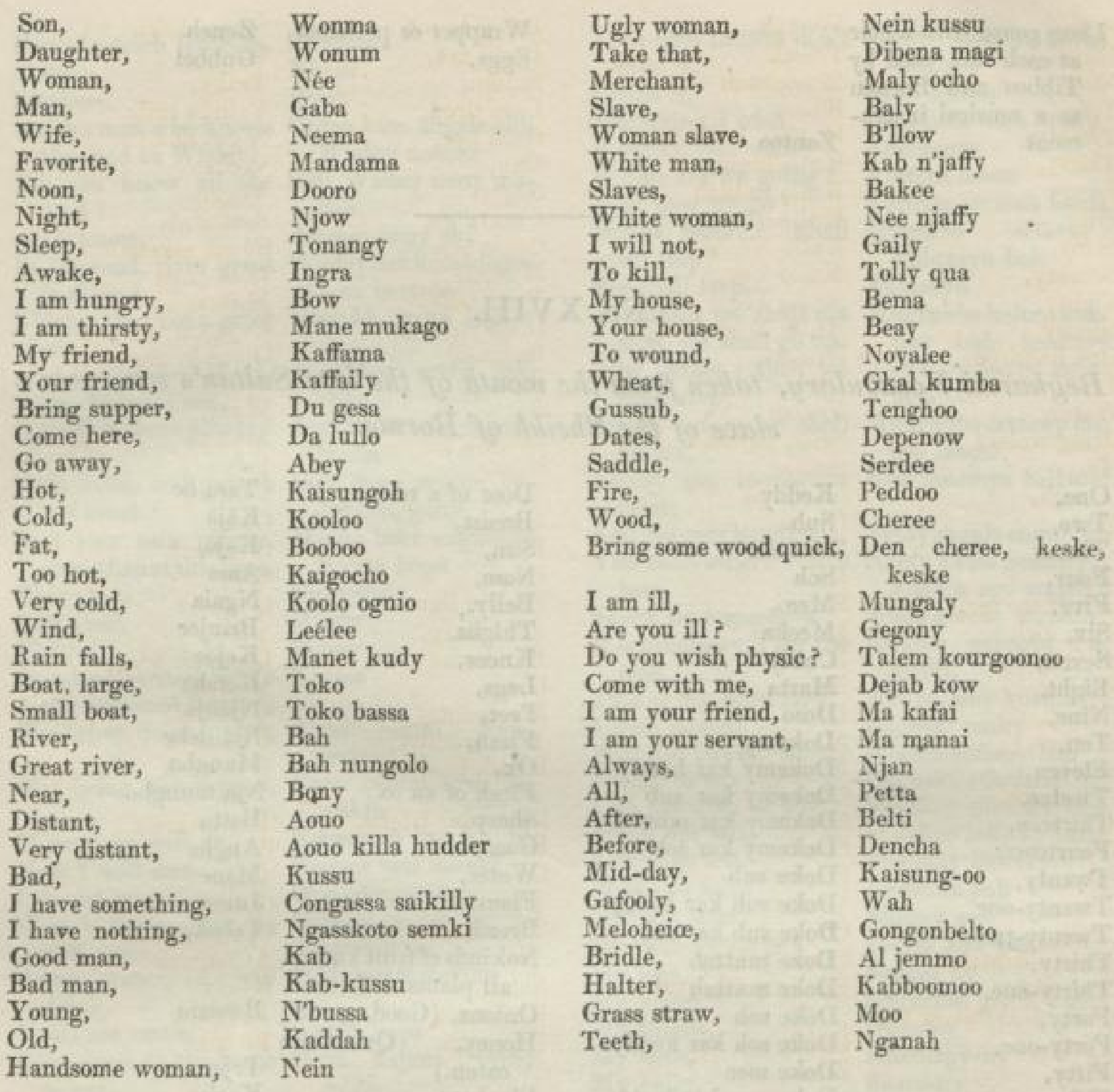

No. XIX.

Mandara Vocabulary, taken from the mouth of Achmet Mandara, a slave of the Sheilic of Bornou.

$\begin{array}{llll}\text { One, } & \text { Mtaque } & \text { Four, } & \text { Fuddah } \\ \text { Two, } & \text { Sardah } & \text { Five, } & \text { Elibah } \\ \text { Three, } & \text { Kighah } & \text { Six, } & \text { N'quaha }\end{array}$




\begin{tabular}{llll} 
Seven, & Vouyah & Bring to eat, & Senga dafah \\
Eight, & Teesah & I will not, & Wyanga \\
Nine, & Musselman & Sultan, & Tsuksa \\
Ten, & Klaou & I am tired, & Yaluffa luffa \\
Twenty, & Kulboa, knlla boa & Good bye, & N'gea dha \\
Thirty, & Kullo kegah & Day, & Vechea \\
Forty, & Kullo fuddah & Night, & Véggea \\
Fifty, & Kullo elibah & I must go, & Amindala \\
Sixty, & Kullo N'quaha & Come here, & Souah sokena \\
Seventy, & Kullo Vouga & My wife, & Muksanga \\
Eighty, & Kullo Teesa & Your wife, & Muksarwa \\
Ninety, & Kullo Musselman & Good road, & Oungala shrugra \\
One hundred, & Drimka & Bad road, & Oungala mangoua \\
Two hundred, & Dibboo & Rice, & Acheiah \\
Water, & Yowah & Butter, & Wyay \\
Bring water, & Sensa yowah & Honey, & Ammah \\
Meat, & Souah & Eyes, & Echey \\
Gussub, & Mudjuga & Nose, & Ukteray \\
Man, & Geela & Mouth, & Okay \\
Woman, & Mug'sa & Ears, & Shimmah \\
Girl, & Gala & Head, & Erey \\
Handsome girl, & Shugra & Female slave, & Quatana \\
Ugly girl, & Mowgwa & Male slave, & Affee \\
Good man, & Zeeriah & Handsome slave, & Quatana mugray \\
Mother, & Mama & Grass, & Massah \\
Father, & Dada & My country, & Uksarwa \\
Brother, & Malay & Your country, & Uksangra \\
Sister, & Koudray & I wish to sleep, & Wenwyah yeksentia \\
Mountains, & Ouvra & & sah \\
River, & Gouah & I am your friend, & Tukkatarwa \\
Well, & Souah & Horse, & Bilsah \\
Spring, & Pooshay & Ox, & Tsah \\
Great, & Yeakay & Tiger-cat, & Oobellah \\
Little, & Chequah & Tiger's skin, & Ogzo oobellah \\
Great mountains, & Ouvre yeakay & Ass, & Anzouwah \\
Little sister, & Koudray Chequah & Sheep, & Keoay \\
Meal, breakfast, or sup- & Rich man, & Tallowah \\
per, & Dafah & Poor man, & Tszuah \\
To eat, & Zuzie & & \\
& & & \\
\hline
\end{tabular}

No. XX.

Timbuctoo Vocabulary.

$\begin{array}{llll}\text { Come, } & \text { Kaa } & \text { Give me to drink, } & \text { Katahary mungence } \\ \text { Go, } & \text { Koey } & \text { I am thirsty, } & \text { Hamai egowei } \\ \text { Quickly, } & \text { Tumba } & \text { I, or me, } & \text { Ei } \\ \text { Give me to eat, } & \text { Kata mung-ha } & \text { You, } & \text { Ee }\end{array}$


Him

They,

Good,

Bad,

Man,

Woman,

Girl,

Boy,

Handsome woman,

Bad man,

Two eyes,

Mouth,

Beard,

Head,

Horse,

Camel,

Ass,

Dog,

Sheep,

An ox,

Oxen,

Meat,

Swreet milk,

Sour milk,

Sultan,

Bread,

River,

Boat,

House,

Slave,

Female slave,

Fire,

Night,

Day,

Wood,

Elephant,

Water,

Blood,

Knife,

Gold,

Silver,

Turban,

Tobe,
Wo

Oo

Aboore e

Affootoo

Harree

Weey

Izowy

Ezahary

Weey tienta

Harree footoo

Moh inka

Mey

$\mathrm{Kabi}$

Bong-0

Barree

Yeo

Furka

Hanshe

Fagee

Hou foh

Hou bobo

Hum

Wah gana

Wah coutoo

Gabee coin

Takoola

Issa

$\mathrm{Hee}$

Hoo

Bunneea

Kong-0

Jarree

Keegee

Noony

Togoolee

Turcondu

Hary

Koorie

Hoorie

Oorah

N'zurfa

Tabbai

Tilleby-kai
Breeches,

Sandals,

Cap,

Clouds,

Earth,

Mountain,

Well,

A ghrazzie,

Spear,

Mat,

The truth,

That man lies,

Eat,

Foot,

Hand,

One,

Two,

Three,

Four,

Five,

Six,

Seven,

Eight,

Nine,

Ten,

Eleven,

Twelve,

Thirteen,

Fourteen,

Fifteen,

Sixteen,

Seventeen,

Eighteen,

Nineteen,

Twenty,

Twenty-one,

Thirty,

Thirty-one,

Forty,

Forty-one,

Fifty,

Fifty-one,
Seeby

Tarne

Foolah

Beenee

Gunda

Foudee

Bungo

Wongo

Yagy

Tangaree

Keemy

Wahareeagoothangany

Ngha

Kay

Kambah

Affoo

Nahinka

Nahinza

Attakee

Aggoo

Ea

Yaha

Yugga

Auwy

Auwy kindofoo

Auwy kindoohinka

Auwy kindohinza

Auwy kindotakee

Auwy kindaggoo

Auwy kindo iddoo

Auwy kindoea

Auwy kindo yaha

Auwy kindoyugga

Warunka

Warunka kindofoo

Warunza

Warunza kindofoo

Waytakkee

Waytakkee kindofoo

Wayaggoo

Wayaggoo kindofoc 


\section{그 SLUB}

Leibniz-Institut für Länderkunde 



\section{ZOOLOGY.}

\section{No. XXI.}

Having been requested by the authors of the preceding narrative to describe the Zoological subjects collected during their journey, we think it right, in the first place, to notice the difficulties attending their acquisition and preservation. The European traveller, who is transported with equal comfort over the rugged heights of Mont Cenis, or along the level plains of Holland, can have little conception of the privations and distresses which attend the wanderer in the desert. The most feeble and timid may encounter the first task without fatigue or fear; but the robur et as triplex of a strong constitution, persevering patience, and undaunted courage, must fortify his resolution who directs his daring course through the sands of the Sahara.

Having arrived at the farthest point of their route, our travellers were occupied no less than five months in their return to Tripoli, pursuing their " weary way" almost wholly through deserts, and suffering severely by sickness and all sorts of privations. Their means, too, of skinning and preserving the animals they procured were of the slightest kind; the only cutting instrument they possessed being a penknife belonging to Major Denham, and a little arsenical soap, left from the stores of the late Mr. Ritchie, their sole antidote to protect the skins from moth and corruption. Such, however, was their ardour in the pursuit of Zoological subjects, that in spite of all the difficulties and drawbacks that beset them, they succeeded in collecting and bringing home upwards of a hundred specimens, and some of them in exceedingly good condition and of peculiar interest; though we regret to say, that less than a third of that number is all that have come into our hands, many of the subjects having fallen into utter decay. 


$\begin{array}{lll}\text { Classis. } & \text { Mammalia. } & \text { Auct. } \\ \text { Ordo. } & \text { Carnassiers. } & \text { Cuv. } \\ \text { Tribus. } & \text { Carnivores. } & \text { Cuv. } \\ \text { Stirps. } & \text { Digitigrades. } & \text { Cuv. } \\ \text { Genus. } & \text { Fennecus. } & \text { Lacep. }\end{array}$

Species 1.-Fennecus Cerdo.

Fennec. Bruce, vii. 281. (8vo). pl. 28.

Animal Anonyme. Buff. Supp. iii. 128. pl. 19. (1776).

Zerda. Penn. Quad.pag. 248. pl. 28.

Canis Cerdo. Gmel. Linn.

Fennecus Brucii. Desm. Mamm. pl. 108. f. 4.

Canis Megalotis. Griff. An. King.

This beautiful and extraordinary animal, or at least one of this genus, was first made known to European naturalists by Bruce, who received it from his drogoman, whilst consul general at Algiers. It was brought from Biscara by a Turkish soldier, from whom the janizary bought it, and who said it was not uncommon at that place, but was more frequently met with in the date territories of Beni Mezzab and Werglah, where these animals are hunted for their skins, which are afterwards sold at Mecca, and thence exported to India. Bruce kept his animal alive for several months, and took a drawing of it in water colours, of the natural size; a copy of which, on transparent paper, was clandestinely made by his servant. On leaving Algiers, Bruce gave the animal to Captain Cleveland, of the Royal Navy, who made a present of it to Mr. Brander, the Swedish consul. Mr. Brander, according to Sparman, as quoted by Bruce, gave an account of the animal in "some Swedish Transactions," but refused to let the figure be published, the drawing having been unfairly obtained. Bruce asserts that this animal is described in many Arabian books, under the name of El Fennec, by which, he adds, that it is known all over Africa; he conceives the appellation to be derived from the Greek word фoiv 
After Bruce left Algiers, he met with two other, Fennecs, one of which had been brought by the caravan of Fezzan to the Island of Gerba, from whence it was carried to Tunis, where Bruce saw it; the other he bought at Sennaar, but where it came from he knew not; though it seems probable that it was a native of the date villages in the desert of Selima. These animals exactly resembled the one first seen at Algiers, and were known by the name of Fennec, and by no other.

The favourite food of Bruce's Fennec was dates, or any sweet fruit; but it was also very fond of eggs : when hungry it would eat bread, especially with honey or sugar. His attention was immediately attracted if a bird flew near him, and he would watch it with an eagerness that could hardly be diverted from its object ; but he was dreadfully afraid of a cat, and endeavoured to hide himself the moment he saw an animal of that species, though he showed no symptoms of preparing for any defence. Bruce never heard that he had any voice. During the day he was inclined to sleep, but became restless and exceedingly unquiet as night came on.

Bruce describes his Fennec as about ten inches long; the tail, five inches and a quarter, near an inch of it on the tip, black; from the point of the fore-shoulder to that of the fore-toe, two inches and seven-eighths; from the occiput to the point of the nose, two inches and a half. The ears were erect, and three inches and three-eighths long, with a plait or fold at the bottom on the outside; the interior borders of the ears were thickly covered with soft white hair, but the middle part was bare, and of a pink or rose colour ; the breadth of the ears was one inch and one eighth, and the interior cavity very large. The pupil of the eye was large and black; the iris, deep blue. It had thick and strong whiskers; the nose was sharp at the tip, black and polished. The upper jaw was projecting; the number of cutting teeth in each jaw, six, those in the under jaw the smallest; canine teeth, two in each jaw, long, large, and exceedingly pointed; the number of molar teeth, four on each side, above and below. The legs were small; feet very broad, with four toes, armed with crooked, black, and sharp claws on each; those on the fore-feet more crooked and sharp than those behind. The colour of the body was dirty white, bordering on cream-colour; the hair on the belly rather whiter, softer and longer than on the rest of the body. 
His look was sly and wily. Bruce adds that the Fennec builds his nest on trees, and does not burrow in the earth.

Illiger, in his generic description of Megalotis, states the number of molar teeth on each side of the upper jaw to be six, but gives no account of those in the lower; nor does it appear on what authority he describes the teeth at all, or where he inspected his type. In other respects, his description agrees pretty closely with that given by Bruce.

Sparman * took the Fennec to be of the species he has called Zerda, a little animal found in the sands of Cambeda, near the Cape of Good Hope ; and Pennant and Gmelin have called Bruce's animal, after Sparman, Canis cerdo ; Brander considered it as a species of fox ; Blumenbach rather as belonging to the Viverræ. Illiger quotes Lacépède as having made a distinct genus of it, Fennecust, and has himself placed it as one, under the name of Megalotis, in the order Falculata, in the same family with, and immediately preceding the genera Canis and Hyena.

M. Geoffroy Saint Hilaire, assuming Bruce's account to be imperfect and inaccurate, supposes that the Fennec is neither more nor less than a Galago ; but M. Desmarest differs from him in opinion, and places it in a situation analogous to that assigned it by Illiger, at the end of the Digitigrades, in the order Carnassiers. Cuvier merely takes the following short notice of this animal in a note, "Le Fennec de Bruce que Gmelin a nommé Canis cerdo, et Illiger Megalotis, est trop peu connu pour pouvoir être classé. C'est un petit animal d'Afrique, dont les oreilles égalent presque le corps en grandeur, et qui grimpe aux arbres, mais on n'en a descrit ni les dents ni les doigts." (Reg. Anim. I. 151. note). This eminent zoologist appears from the above to hold our countryman's veracity, or at least his accuracy of observation, and fidelity of description, in the same low estimation as M. Geoffroy Saint Hilaire; or he would hardly have talked of the ears of the Fennec being nearly as large as its body $\neq$, or have asserted that

* Voyage, ii. 20.

+ Desmarest states, (Ency. Meth. note), that he cannot find any work of Lacépède in which the genus Fennecus is proposed.

† Perhaps M. Cuvier was led into this mistake by an error of the pen or press, in M. Desmarest's translation of Bruce's description of the animal. Bruce says, "from the snout to the 
neither the teeth nor toes have been described. But the illustrious foreigners of whom we have, in no offensive tone we hope, just spoken, are not the only persons who have hesitated to place implicit confidence in all that Bruce has given to the world: his own countrymen have shown at least an equal disposition to set him down as a dealer in the marvellous. Time, however, and better experience, are gradually doing the Abyssinian traveller that justice which his cotemporaries were but too ready to deny him.

M. Desmarest considers all the characters which Bruce has given of the Fennec as correct, " not conceiving it possible, that he could have assumed the far too severe tone he adopted in speaking of Sparman and Brander, if he had not been perfectly sure of his facts."

Mr. Griffith has given the figures of two animals, both, as he conceives, belonging to this genus; one of them came from the Cape of Good Hope, and is now in the Museum at Paris; it is named by Cuvier Canis megalotis, and is described by Desmarest in his Mammalogie, (Ency. Meth. Supp. p. 538): Major Smith has called it Megalotis Lalandii, to distinguish it from Bruce's Fennec. The other animal is from the interior of Nubia, and is preserved in the Museum at Frankfort. Both the figures are from the accurate and spirited pencil of Major Hamilton Smith. The first animal is as large as the common fox, and decidedly different from Bruce's Fennec ; the second, Major Smith considers to be Bruce's animal.

In the fifth volume of the Bulletin des Sciences, sect. 2. p. 262., is an extract from a memoir of M. Leuckart, (Isis, 2 Cahier, 1825), on the Canis cerdo, or Zerda of naturalists, in which it is stated that M. M. Temminck and Leuckart saw the animal in the Frankfort Museum, which had been previously drawn by Major Smith, and recognized it for the true Zerda ; and the former gentleman, in the prospectus of his Monographies de Mammalogie, announced it as belonging to the genus Canis, and not to that of Galago. M. Leuckart coincides in opinion with M. Temminck, and conceives that the genus Megalotis, or Fennecus, must be suppressed, "the animal very obviously belonging to the genus Canis, and even to the sub-

anus, he was about ten inches long;" the translation, "Ce Fennec avoit six pouces de longueur, depuis le bout du nez jusqu' d̀ l'origine de la queue." The same mistake occurs in M. Geoffroy Saint Hilaire's quotation of Bruce; but this cannot be a misprint, for the length is not expressed by the word six, but by the Arabic cypher 6 .

\section{$b b_{2} 2$}


genus Vulpes." He adds, " that it most resembles the C. corsac ; the number of teeth and their form are precisely the same as those of the fox, which it also greatly resembles in its feet, number of toes, and form of tail. The principal difference between the fox and the Zerda consists in the great length of the ears of the latter and its very small size."

The singular controversy, not even yet decided, that has arisen respecting this little animal, has induced us to preface our description of the individual before us, by this sketch of its history.

Fennecus. Dentium formula.-Dentes primores $\frac{6}{6}=\frac{6}{6}$, laniarii $\frac{1}{1}=\frac{1}{1}$, molares $\frac{6}{7}-\frac{6}{7}$ ?

F. supra rufescenti-albus, subtus pallidior; macula suboculari rufä; caudae maculà sub-basali nigrescenti-brunneâ, apice nigro.

Dimensions. Inches.

Length of the head from the extremity of the nose to the occiput, $3 \frac{3}{3}$

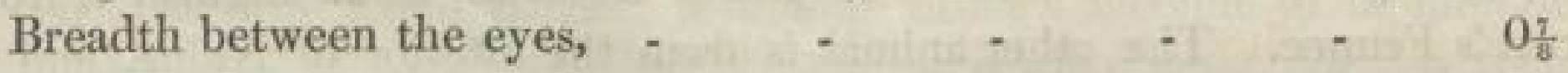

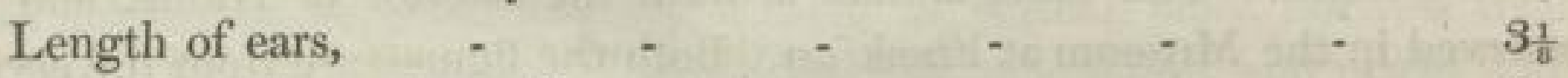

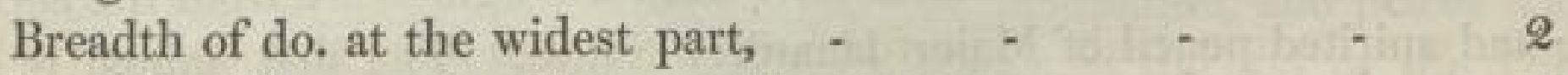

Breadth of the cranium between the ears, - - - $1 \frac{5}{8}$

Length from the occiput to the insertion of the tail, $\quad 9 \frac{1}{2}$

Tail, - - - - - - - - -

*Height before, from the ground to the top of the back, above the

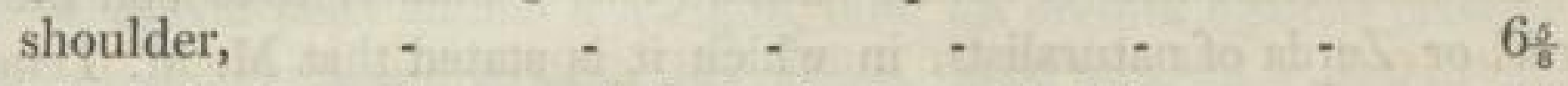

* Height behind, to the top of the back above the loins, - $7 \frac{1}{2}$

Breadth of the extremity of the nose, - - . - . $0.5 \frac{5}{16}$

Length of the middle claws of the fore feet, - . . $\quad 0 \frac{7}{16}$

Exterior do. do. - $\quad$ - $\quad 0 \frac{1}{2}$

Middle and exterior claws of the hind feet, $\quad-\quad-\frac{1}{2}$

The general colour is white, slightly inclining to straw-yellow; above, from the occiput to the insertion of the tail it is light rufous brown, delicately pencilled with fine black lines, from thinly scattered hairs tipped with black; the exterior of the thighs is lighter rufous brown; the chin, throat,

* Taken as the stuffed specimen stands. 
belly, and interior of the thighs and legs are white, or cream colour. The nose is pointed, and black at the extremity ; above, it is covered with very short, whitish hair inclining to rufous, with a small irregular rufous spot on each side beneath the eyes; the whiskers are black, rather short and scanty; the back of the head is pale rufous brown. The ears are very large, erect, and pointed, and covered externally with short, pale, rufous-brown hair; internally, they are thickly fringed on the margins with long greyish-white hairs, especially in front; the rest of the ears, internally, is bare; externally, they are folded or plaited at the base. The tail is very full, cylindrical, of a rufous-brown colour, and pencilled with fine black lines like the back; its colour is rather deeper above than on the under part, and there is a small dark brown spot, at about an inch below its insertion on the upper side; the ends of the hairs at the extremity of the tail are black, forming a black tip about three quarters of an inch long. The anterior feet are pentadactylous, the posterior tetradactylous, and both are covered to the claws with moderately long whitish hairs, slightly inclining to straw-yellow; the claws are of a yellowish-white, or light horn-colour, moderately hooked, very much compressed, and very sharp; those on the hinder toes are most compressed, longest, and least arched. The fur is very soft and fine; that on the back, from the forehead to the insertion of the tail, as well as that on the upper part of the shoulder before, and nearly the whole of the hinder thigh, is formed of tri-coloured hairs, the base of which is of a dark lead colour, the middle white, and the extremity light rufous brown.

The teeth of our animal are much worn, apparently by age; the incisors in the upper jaw are nearly even, the second pair rather broader than the rest; of those in the lower jaw, the outer pair are considerably the largest.

The imperfect state of the teeth, and the difficulty of examining them accurately without having the skull detached, forbids us to be confident as to the number of grinders in either jaw. From the most careful inspection, however, that we could make in the actual state of the specimen, we are inclined to believe that the system of dentition closely, if not exactly, resembles that of the dog. In the present state of uncertainty, whilst opinions of the highest authority are so discordant as to the genus to which this animal should be referred, we do not feel ourselves at liberty to disturb the arrangement adopted by Lacépède, Illiger, and Desmarest, but leave the ultimate 
decision of the question to future naturalists, who may possess more unequivocal data for its solution. One thing, indeed, is pretty obvious, namely, that if Major Denham's animal be not the identical species described by Bruce, it certainly belongs to the same genus; for as it does not appear that Bruce himself ever possessed a detached skull of the Fennec, it is very easy to imagine that he could not accurately ascertain the number of molar teeth in the head of a living animal of such vivacity and quickness, and which was so impatient of being handled, that he could not obtain a correct measurement of its ears, or even count the number of paps on its belly. With such an animal it is not unlikely, moreover, that the two last tubercular grinders should escape the notice of any one attempting to examine the mouth under circumstances so disadvantageous, those teeth being in some measure concealed by the large projecting carnivorous tooth immediately before them. That it cannot be a Galago, as M. Geoffroy Saint Hilaire imagines, is sufficiently evident ; and M. Desmarest has given no less than six distinct, and, we think, conclusive reasons against that opinion, through which, however, we must not follow him at present. The subject has already grown under our hands to a far greater bulk than we intended, and we conclude it by taking leave to question the validity of M. Geoffroy Saint Hilaire's argument respecting the general veracity of $\mathrm{Mr}$. Bruce, and consequently to enter our protest against his Fennec being classed with the Quadrumana.

We retain, provisionally, the generic name of Fennecus, first proposed by Lacépède, and the specific one of Cerdo, adopted by Gmelin; but should the animal ultimately prove to be a different species from Canis cerdo, M. Desmarest's specific appellation of Brucii may with propriety be assigned to it.

Genus. Ryzena. IIl.

Species 2.-Ryzana tetradactyla.

Viverra tetradactyla. Gmel. I. 85.

Suricate. Buff. xiii. t. 8.

This animal was found on the banks of the rivers in the neighbourhood of Lake Tchad. 
Tribus. Plantigrades. Cuv.

Genus. Gulo. Storr.

Species 3.-Gulo capensis.

Gulo Capensis. Desm. Mamm. p. 176.

Viverra mellivora. Gmel. I. 91.

Ratel. Sparman.

Ratel weesel. Penn. Quad. II. 66.

The natives, from whom Major Denham had all the following particulars, informed him, that during the rutting season the Ratel is very fierce, not hesitating to attack a man. Each male has two or three females, whom he scarcely suffers to be a moment out of his sight; if either of them escape his jealous vigilance, and leave him for a short time, she is sure to receive severe chastisement at her return. This animal is very easily killed; a single blow on the nose, which seems peculiarly sensible of the slightest injury, instantly despatches him.

Ordo. Quadrumanes. Cuv.

Genus. Cercoprthecus. Briss.

Species 4.-Cercopithecus ruber.

Cercopithecus ruber. Geoff. Ann. du Mus. xix. 96.

Simia rubra. Gmel. I. 34.

Le Patas. Buff. xiv. pl. 25 and 26.

Red Monkey. Penn. Quad. I. 208.

Ordo. Ruminans. Cuv.

Genus. Camelopardalis. Gmel.

Species 5.-Cameiopardalis Giraffa.

Camelopardalis Giraffa. Gmel. I. 181.

Cervus Camelopardalis. Linn. I. 92.

Giraffe. Buff. XIII. p. 1.

Camelopard. Penn. Quad. I. 65. 
The Giraffes were found on the south-eastern side of Lake Tchad, generally in parties of from two to five or six. They are tolerably numerous, but not very common. The motion of these animals is not elegant; their pace is a short canter, in which they seem to drag their hind legs after them, in an awkward fashion : their speed, however, is such as to keep a horse at a pretty smart gallop. The skin brought home by Major Denham is that of a young animal, not above a year and a half or two years old; the colours are very much lighter than on the skin of an adult animal. In its wild state, the Giraffe carries its head remarkably erect; a character which, Major Denham remarks, is not faithfully preserved in any figure he has seen of this animal.

\section{Genus. Axtilope. Pall.}

Species 6.-Antilope Senegalensis.

Antilope Senegalensis. Desm. Mamm. p. 457.

Le Koba. Buff. xii. pl. 32, f. 2.

Senegal Antelope. Penn. Quad. I. 103.

Only the head and horns of this animal were brought home by Major Denham; it was found on the plains of central Africa. The natives call this species Korrigum.

\section{Species 7.-Antilope bezoartica.}

Antilope gazella. Gmel. I. 190.

Capra bezoartica. Linn. I. 96.

Algazelle. Buff. xii. pl. 3s. f. 1, 2.

Algazel Antelope. Penn. Quad. I. 77.

Linnæus's description of Capra bezoartica speaks of the horns as being " entirely annulated;" but Brisson, to whom Linnæus refers, says they are annulated nearly to the end. In our specimens, a considerable extent from the apex is without the rings. This difference may probably arise from age. In other respects, the horns before us perfectly answer the description of those of Linnæus's Capra bezoartica. M. Gmelin seems to have made some confusion between the Capra Gazella and C. bezoartica of 
Linnæus. He has changed the specific name of Gazella into that of oryx, and he has made Linnæus's bezoartica the Gazella of himself.

Only two horns of this species, and those apparently not fellows, were sent home. This animal was found on the south side of the River Shary, in central Africa.

\section{Species 8.-Antilope cervicapra.}

Antilope cervicapra. Pall.

Capra cervicapra. Linn. I. 96.

Antilope. Buff. xii. pl. 85 and 36.

Common Antelope. Penn. Quad. I. 89.

We have only the horns of this animal. Its African name is El Buger Abiad, or the White Cow.

Genus. Bos. Linn.

Species 9.-Bos taurus.

Bos taurus. Linn. t. I. 98.

Major Denham brought home a pair of horns of enormous size, belonging evidently, from their form, texture, and mode of insertion, to a variety of the common Ox, of which he states that two kinds exist in central Africa, one with a hump before, and very small horns; the other altogether of a larger size, also with a hump, and immense horns.

The circumference of one of the horns before us, at the largest part near the base, is twenty-three inches and a quarter; its length, following the line of curvature, three feet, six inches and a half. It has two curves; and weighs six pounds and seven ounces. Internally it is extremely cellular, or rather cavernous.

\section{Species 10.-Bos bubalis.}

Bos bubalis. Linn. I. 99.

Le Buffle. Buff. xi. pl. 25.

Buffalo. Penn. Quad. I. 28.

We possess the head, with the horns. The name by which the native Africans call this animal is Zamouse. 
Ordo. Pachydermes. Cuv.

Genus. RHINoceros. Linn.

Species 11.-Rhinoceros bicornis.

Rhinoceros bicornis. Gmel. I. 57.

Rhinoceros unicornis, var. $\beta$. bicornis. Linn. I. 104.

Rhinoceros Africanus. Cuv.

Rhinoceros d'Afrique. Buff. Supp. vi. pl. 6.

Two-horned Rhinoceros. Penn. Quad. i. 150. pl. 29.

Here again we have the horns only. The local name of this animal is Gargatan.

Ordo. Rongeurs. Cuv.

Genus. Scıurus. Linn.

Species 12.-Sciurus Dschinschicus.

Sciurus Dschinschicus. Gmel. I. 151.

Sciurus albovittatus. Desm. Mamm. p. 338.

Our species agrees exactly with M. Desmarest's account of his $S$. alboviltalus, except that the tail is rather more decidedly distich than that of the individual he describes; but the dried state of the skin before us prevents our ascertaining its form very minutely. M. Desmarest refers to pl. 89 of Sonnerat's Voyage, vol. ii. for a figure of his Ecurieul de Gingi, which he quiotes as a variety of this species; on looking into Sonnerat, we do not find any figure at all of this animal referred to by that author. Plate 89 is a figure of the Maquis d Bourres.

\section{Genus. Hystrix. Linn.}

Species 13.-Hystrix cristata.

Hystrix cristata. Linn. I. 74.

Porc-épic. Buff. xii. pl. $\$ 1$.

Crested Porcupine. Penn. Quad. 


$\begin{array}{lll} & & \\ \text { Classis. } & \text { Aves. } & \text { Auct. } \\ \text { Ordo. } & \text { Raptores. } & \text { Ill. } \\ \text { Fam. } & \text { Vulturmes. } & \text { Vigors. in Linn. Trans. } \\ \text { Genus. } & \text { Vultur. } & \text { Auct. }\end{array}$

Species 1,-Vultur fulvus.

Vultur fulvus, Briss. I. 462, sp. 7.

Gyps vulgaris. Sav, Ois. d'Egypte.

Le Percnoptere. $P l$. Enl. 426.

Vautour Griffon. Temm. Manuel d'Orn. p. 5.

Alpine Vulture. Var. B. Lath. Gen. Hist. I. p. 17.

This species was observed by Major Denham in the neighbourhood of all the large towns through which he passed. It was attracted by the offal, and refuse of every description, which the inhabitants were accustomed to throw out for its use. For the services which these birds thus performed, they met with protection in return from the natives, who did not permit them to be destroyed.

$\begin{array}{lll}\text { Fam. } & \text { Falconids, } & \text { Leach. } \\ \text { Subfam. Accipitrina. } & \text { V. in Limn. Trans. } \\ \text { Genus. } & \text { Astur. } & \text { Auct. }\end{array}$

Species 2.-Astur musicus.

Falco musicus. Daud. Orn. II. 116, sp. Ixxxviii.

Le Faucon chanteur. Le Vaill. Ois. d'Afr. L. 117, pl. 27.

Chanting Falcon. Lath. Gen. Hist. I. p. 178.

This beautiful Hawk was met with occasionally in most parts of central Africa, but not in any abundance. It was the only species of the family which the officers of the expedition were enabled to preserve and bring home.

$$
\text { c c } 2
$$


Ordo. Insessones. $\quad V$. in Linn. Trans.

Tribus. Fissinostres. Cuv.

Fam. Todide. V. in Linn. Trans

Genus. Eurystomus. Vieill.

\section{Species 3.-Eurystomus Madagascariensis.}

Coracias Madagascariensis. Gmel. I. 379.

Le Rolle de Madagascar. Pl. Enl. 501.

Madagascar Roller. Lath. Gen. Hist. III. p. 79.

Fam. Halcyonide. V. in Linn. Trans.

Genus. Halcyon. Swains.

\section{Species 4.-Halcyon erythrogaster.}

Alcedo erythrogaster. Temm.

Alcedo Senegalensis, var. $\gamma$. Lath. Ind. Orn. 24.9.

Martin Pecheur du Senegal. Pl. Enl. 356, fig. inf.

The birds of this species were met with in abundance in those situations near rivers which form the usual resort of the species of this family. They were more particularly observed in the tamarind trees.

$\begin{array}{lll}\text { Tribus. } & \text { Conirostres. } & \text { Cuv } \\ \text { Fam. } & \text { Convide. } & \text { Leach. } \\ \text { Genus. } & \text { Coracias. } & \text { Linn. }\end{array}$

Species 5.-Coracias Senegalensis.

Coracias Senegalensis. Gmel. I. 379.

Rollier du Senegal. $\quad$ Pl. Enl. 326.

Swallow-tailed Indian Roller. Edw. t. 327.

Senegal Roller. Lath. Gen. Hist. III. p. 75.

These splendid Rollers were very abundant in the thick underwoods throughout central Africa. 
$\begin{array}{lll}\text { Tribus. } & \text { Scansones. } & \text { Auct. } \\ \text { Fam. } & \text { Psittacidas. } & \text { Leach. } \\ \text { Genus. } & \text { Psitracus. } & \text { Auct. }\end{array}$

Species 6.-Psittacus erythacus.

Psittacus erythacus. Linn. i. 144.

Perroquet cendrée de Guinée. $\quad P l$. Enl. 311.

Ash-coloured Parrot. Alb. i. t. 12.

Several specimens of this species were brought over alive to this country, which are now honoured with a place in His Majesty's collection.

\section{Genus. Palzornis. V. in Zool. Journ.}

Species 7.-Palceornis torquatus.

Palæornis torquatus. V. in Zool. Journ. vol. II. p. 50.

Psittaca torquata. Briss. IV. 323.

La perruche à collier. $\mathrm{Pl}$. Enl. 551 .

Perruche à collier rose. Le Vaill. Hist. des Perr. pl. 22, 23.

This species, whose chief habitat is said to be in India, which is the main resort of the group to which it belongs, appears to have a very wide geographical distribution. It has been found on the coast of Senegal, as well as by the officers of the present expedition in central Africa. The specimen before us is very much mutilated, but enough of the bird remains to enable us to identify the species.

Ordo. Rasones. Ill.

Fam. Tetraonide. Leach.

Genus. Prerocles. Temm.

Species 8.-Pterocles exustus.

Pterocles exustus. Temm. Pl. Col. \$ 354. \& $\$ 60$. 
These birds were found in great numbers in the neighbourhood of Bornou. They frequented the low sand hills which were scantily covered with shrubs. Like most of the family, they were found to be excellent eating.

Genus. Francolinus. Steph.

\section{Species 9.-Francolinus Clappertoni.}

Franc. supra brunneus fulvo-variegatus; subtus fulvo-albidus, maculis longitudinalibus brunneis aspersus; strigá- superciliari subocularique, gulâ, genisque albis, his brunneo-lineatis.

Pileus brunneus, ad frontem nigrescens. Striga nigra interrupta extendit a rictu ad genas. Genarim plumæ, anteriores lineis gracilibus, posteriores maculis ovalibus brunneis in medio notatæ. Colli, pectoris, abdominisque plumæ in medio brunneæ marginibus fulvo-albidis, rhachibus pallidis. Dorsi superioris, scapularium, tectrictmque plumæ pallido-fulvo marginatæ partimque fasciatæ. Dorsi inferioris uropyğiique plumæ pallidè brunneæ in medio fusco-brunneo leviter notatæ. Remiges exteriores pogonio externo ad basin fulvo-fasciato, pogonio interno ad basin brunneo, versus apicem rufo-fulvo; interiores utrinque fulvo-fasciatæ. Ptila inferiora in medio brunnea, fulvo ad margines notata. Pleromata inferiora in medio fusca, marginibus fulvis. Femorum plumæ fulvæ in medio brunnex. Rectrices brumeæ fasciis plarimis fulvis undulatæ. Rostrum superné nigrum, infra ad basin rubro tinctum. Pedes, ad frontem nigri, poné rubescentes : tarsis bicalcaratis, calcare superiore obtuso, inferiore acuto. Longitudo corporis, 14. unc.; ala a carpo ad remigem $5^{\text {tam }}, 7 \frac{1}{3}$; cauda, $3 \frac{4}{5}$; rostri, $1 \frac{1}{2}$; tarsi, $2 \frac{3}{10}$.

This species of Francolin, which appears to us to be hitherto undescribed, was met with in tolerable abundance. It frequented sand hills, covered with low shrubs; and was very difficult to be procured in consequence of the great speed with which it ran. We have named the species after Captain Clapperton, R. N. the intrepid and intelligent companion of Major Denham. 


\section{Fam. Struthonide. V. in Linn. Trans.}

Genus. Struthio. Auct.

Species 10.-Struthio camelus.

Struthio camelus. Linn. I. 265.

L'Autruche. $P l$. Enl. 457. ?

The Black Ostrich. Brown's Illust. of Zool. pl. 16.

Major Denham succeeded in bringing alive to this country four of these noble birds, which are at present in His Majesty's menagerie at Windsor.

\section{Genus, OTIs. Linn.}

\section{Species 11.-Otis Denhami.}

O. fusco-brunneo et pallido-fulvo undulatim punctulata, capite brunnescenti-nigro, superciliis genis gulâque albidis, collo rufo, pectore cinereo; pteromatibus remigibus rectricibusque nigris, istis albo-maculatis, his albo-fasciatis ; corpore subtus rufescenti-albo.

Capitis pileus parsque superior nuche brunnescenti-nigri. Regionis auricularis plumæ elongatæ, decompositæ, cinerascenti-albæ. Colli inferioris plumæ frontales elongatæ. Dorsi, uropygii, scapularium, plilorumque plumæ fusco-brunneæ, pallido-fusco undulatim punctulatæ. Pteromata nigra maculis albis grândibus irregulariter notata. Tectrices inferiores albæ ad marginem alarum fusce-variegatæ. Rectrices nigræ; duæ exteriores pogonio interno fasciis duabus albis, externo tribus, notatæ; cæteræ tribus fasciis ejusdem coloris utrinque notatæ, fasciâ sub-apicali nigro sparsâ : duæ mediæ ad apicem fusco-brunneæ, pallido-fusco undulatim punctulatæe. Irides flavæ. Rostrum corneum. Pedes nigri. Longitudo corporis, 3 ped. 9 unc.; cauda, 1 pes, 4 unc.; rostri, ad frontem, $3 \frac{3}{4}$ unc., ad rictum, $4 \frac{1}{2}$ unc.; tarsi, 7 unc.; digiti medii, ungue incluso, $2 \frac{3}{4}$ unc.; exterioris, $1 \frac{7}{0}$ unc.

\section{African Bustard? Lath. Gen. Hist. Vol. VIII. p. 361.}

We have hitherto seen no description that exactly accords with the bird before us. The African Bustard described by Dr. Latham, in the second edition of his "Synopsis," lately published under the title of " A General 
History of Birds," appears to be the most allied to it. But the head of that bird is described as being bare; and such a marked difference prevents us from referring our bird to that species, with which it generally agrees in other points, without some note of doubt. Our specimen is unfortunately very defective : in the quill feathers, and fore parts of the neck, more particularly. These latter are described by Major Denham as singularly beautiful, being elongated and swelling out into a kind of ruff. We are happy to have the opportunity of distinguishing this bird by the name of the enterprising traveller to whose zeal we are indebted for the species itself, and many other valuable acquisitions to science.

This species was met with, in the rainy season, near the larger towns, but not in any great abundance. It frequented moist places, where the herbage was pure and fresh. In such places it was taken in snares by the natives, who used it for food. It was almost invariably met with singly, Major Denham never having observed a pair together more than once. It is singular, also, that it was always found in company with Gazelles : whenever a Bustard was observed, it was certain that the Gazelles were not far distant. Major Denham describes the eye of this bird as large and brilliant. In like manner as is recorded of the Gazelle, with which this bird seems to have so close a sympathy, the Arabs are accustomed to compare the eyes of their most beautiful women to those of the Oubara*.

\section{Ordo. Grallatores. Ill. \\ Fam. Gruide. V. in Linn. Trans. \\ Genus. Balearica. Briss.}

Species 12. Balearica pavonina.

Ardea pavonina. Linn. I. 233.

Balearica. Briss. v. 511.

Oiseau royal. \& Id. $I b$. pl. 41.

L'oiseau royal. \& $\mathrm{Pl}$. Enl. 265.

Crowned African Crane. Edw. t. 192.

Crowned Heron. Lath. Gen. Hist. IX. p. 26.

* Oubara seems to be a general name for the Bustards in Africa. A smaller species than the present, of that country, has received this name as a specific title from M. Gmelin. 
These birds were found in the neighbourhood of the smaller lakes. They were generally observed in flocks of six or eight. A single pair was sometimes met with, but a single bird scarcely ever.

\section{Genus. Platalea. Limn.}

Species 13.-Platalea leucorodia.

Platalea leucorodia. Linn. I. 231.

La Spatule. Pl. Enl. 405.

Spatule blanche. Temm. Manuel d'Orn. p. 595.

White Spoonbill. Penn. Brit. Zool. App. t. 9.

These birds were found in the smaller lakes, and in grounds which were overflowed. They were met with in tolerable plenty.

\section{Fam. ARDEIDs. Leach.}

Genus. Ardea. Auct.

\section{Species 14.-Ardea Coromandelensis.}

Ardea Coromandelensis. Steph. in Shaw's Gen. Zool. XI. p. 577.

Ardea russata. Temm. Manuel d'Orn. p. 506.

Ardea affinis? Horsf. Linn. Trans. Vol. XIII. p. 189.

Ardea comata. var. $\beta$. Lath. Ind. Orn. 687.

Crabier de la côté de Coromandel. Pl. Enl. 910.

This bird was shot in the neighbourhood of Alph, a town situated in the middle of a swamp, described at page 233 of these travels. They were seen in some abundance in that neighbourhood, and were noticed by Major Denham as remarkable for their beauty and gracefulness.

\section{Species 15.-Ardea melanocephala.}

Ard. cinerea; capite cristato, colli parte posteriore lateribusque, regione interhumerali, remigibus, rectricibusque nigris, gula collique parte anteriore albis.

Colli inferioris plumæ elongatæ cinerascentes. Dorsi pars anterior inter humeros nigra, posterior saturatè cinerea. Ptila pallidè cinerea. Tectrices inferiores albæ. Rostrum nigrum, mandibulâ inferiore flavesceute, apicem 
versus nigro marginatâ. Pedes nigri. Longitudo corporis, 2 ped. 9 unc.; ala, 15 unc.; rostri, 4 ; tarsi, 6.

We feel much hesitation in characterizing the bird before us as a distinct species. In a family like the present, where there is so much variation both in age and sex in the same species, it is almost impossible to decide upon the identity or distinction of species, unless by actual observation of the birds themselves in their native haunts, and in their different ages and states of plumage. On the whole, however, it is perhaps the most eligible plan to keep those species separate which show evident marks of distinction; leaving it to more accurate observation to ascertain whether they may be identical with described species, and differing merely by age, sex, or the variations of plumage according to the different seasons of the year.

The bird before us might, at first sight, be supposed to be the common Ardea cinerea, Linn. But that bird, as far as we have observed, never possesses the entirely black head which distinguishes the specimen before us; nor has it the black on the hind part of the neck, nor on the back between the shoulders. The younger bird of our common species has those parts cinereous which are black in the adult : and the crest and lower feathers of the neck are never so much elongated as in the old bird. The strength of the black markings in Major Denham's species, moreover, and the developement of the crest, neck, and scapular feathers, prevent us from concluding it to be an immature bird. If we allow it to be adult, it is decidedly distinct from the adult of $A$. cinerea. We know no other allied species to which we might consider it referable.

These birds were found in great abundance in all the lakes and marshes throughout the route of our travellers. They were met with in company with numberless other species of the family, specimens of which our officers were prevented from preserving, or bringing home, in consequence of the difficulties attending the expedition, to which we have before alluded.

Genus. Scopus. Briss.

Species 16.-Scopus umbretta.

Scopus umbretta. Gmel. I. 618.

L'Ombrette du Senegal. $\quad P l$. Enl. 796. 
The Umbre. Brown's Illust. of Zool. pl. 35.

Tufted Umbre. Lath. Gen. Hist. Vol. IX. p. 23.

Major Denham informs us, that this bird was very rarely seen. The few he observed were met with in the Mimosa trees.

\section{Genus. Inis. Lacep.}

Species 17.--Ibis Athiopicus.

Tantalus Athiopicus. Lath. Ind. Orn. 706.

Ibis religiosa. Cuv. Regne Anim. I. 483.

Abou Hannez. Bruce's Trav. Append. pl. p. 172.

This bird, which is of exceeding interest as being one of the two species of Ibis which were the objects of sacred worship among the Egyptians, was met with by Major Denham on the west borders of the Lake Tchad. He observed them in flocks, and in considerable numbers. Hitherto they have been sparingly seen by travellers, and few specimens have reached our collections.

\section{Genus. Ciconia. Briss.}

\section{Species 18.-Ciconia Marabou.}

Ciconia Argala. Temm. Pl. Col. 301.

This bird was met with rather plentifully in the neighbourhood of large towns, in company with the Vultures, to the manners of which we have already referred, page 195. Like them, they were protected by the natives, in consideration of the services they performed in clearing away all the offensive substances which were thrown out to them from the towns. In India, we find that the corresponding species, Ardea Argala, Lath., is held in equal estimation for similar services. Major Denham mentions his having frequently been a witness of their voracious and omnivorous habits.

M. Temminck first figured and characterized this African species as distinct from that of India. He has given it the name of Argala, while for the Indian bird, which had already received that name from Dr. Latham, he proposes the name of Marabou. We have ventured to reverse the order 
of these names; and while we retain for the Indian species the original name conferred on it by Dr. Latham, which, it is to be recollected, is an Indian word, we have assigned the African species the title of Marabou, which, it is equally to be observed, is a word peculiar to Africa.

The specimen brought home by the present expedition appears to be a young bird, and answers to the description given of the young of this species by M. Temminck. The colours are nearly black in the bird before us, which are grey in the adult bird figured by that gentleman. Major Denham mentions his having noticed some birds nearly allied to this species, which were larger, and different in colour, and which he conceived to be distinct. They probably were the adult birds of this species.

$\begin{array}{lll}\text { Ordo. } & \text { Natatores. } & \text { Ill. } \\ \text { Fam. } & \text { Anatma. } & \text { Leach. } \\ \text { Subfam. } & \text { Anserina. } & \text { V. in Zool. Journ. } \\ \text { Genus. } & \text { Plectropterus. } & \text { Leach. }\end{array}$

Species 19.-Plectropterus Gambensis.

Plectropterus Gambensis. Steph. in Shaw's Zool. XII, Part 2. p. 7. pl. 36.

Anas Gambensis. Linn. I. 195.

Spur-winged Goose. Lath. Gen. Hist. X. 241.

This bird was found in flocks of great numbers on all the lakes. The flesh was very coarse, and of a fishy taste, and afforded very bad eating.

\section{Species 20.-Plectropterus melanonotus.}

Plectropterus melanotos. Steph. in Shaw's Zool. XII. Part 2. p. 8.

Anser melanonotus. Forst. Zool. Ind. p. 21. t. 11.

Anas melanonotus. Lath. Ind. Orn. 839.

Oye de la côté de Coromandel. $\mathrm{Pl}$. Enl. 937.

Black-backed Goose. Penn. Ind. Zool. p. 12. t. 11.

This species, of which fine specimens of the male and female are preserved in the collection, was met with on the lake Tchad. It was not seen in any abundance, and was found in company with other species of the family. The protuberance on the bill of the male is much more enlarged and prominent than is represented in the "Planches Enluminées." 


\section{Subfam. Anatina. $V$. in Zool. Journ. \\ Genus. ANas. Auct.}

Species 21.-Anas viduata.

Anas viduata. Linn. I. 205.

Canard du Maragnan. Pl. Enl. 808.

Spanish Duck. Penn. Gen. of Birds, p. 65. t. 13.

This species was very common, both on Lake Tchad and on all the smaller lakes. It was excellent eating. Mr. Pennant has described the species as an inhabitant of America and Africa. Linnæus says only, that it is found in the lakes of Carthagena; those, it is supposed, of New Spain. Our bird accords very accurately with his description of the species, and also with the figure quoted above from the "Planches Enluminées." We have every reason to conclude with Mr. Pennant, that the species inhabits both the Old and New Continent. The bend of the wing exhibits the rudiments of a spur.

Fam. Pelecanide. Leach

Genus. Onocrotalus. Briss.

Species 22.-Onocrotalus Brissonii.

Pelicanus Onocrotalus. Linn. I. 215.

Le Pelican. Pl. Enl. 87.

White Pelican. Edw. t. 92.

This well known species has been described to us by Major Denham as very abundant on the borders of Lake Tchad. The genus Onocrotalus was first instituted by M. Brisson; but, according to his custom, he left the present species without any specific name. M. Cuvier, in his " Regne Animal," acknowledges the genus ; but neither has he specifically distinguished the bird. We feel much pleasure in now assigning it a name, in memory of the first characterizer of the group; an ornithologist, whose works cannot be studied without the highest advantage, but whose labours have never as yet been sufficiently appreciated. 


\section{Genus. Phalacrocorax. Briss.}

\section{Species 23.-Phalacrocorax pygmaus.}

Pelecanus pygmæus. Pall. Reise. II. 712. t. G.

Dwarf Shag. Lath. Gen. Hist. X. 431.

Cormoran pygmée, jun. Temm. Man. d'Orn. p. 901.

This bird, which agrees very accurately with M. Temminck's description of the young of his Cormoran pygmée, was met with by Major Denham on one of the smaller lakes in central Africa. He describes the species as very rarely occurring.

Genus. Plotus. Linn.

Species 24.-Plotus melanogaster.

Plotus melanogaster. Gmel. I. 580.

Anhinga melanogaster. Forst. Zool. Ind. p. 22. t. 12.

Anhinga de Cayenne. Pl. Enl. 959.

Black-bellied Anhinga. Penn. Ind. Zool. p. 13. t. 12.

Black-bellied Darter. Lath. Gen. Hist. X. 451.

This bird was seen but once or twice during the course of the expedition. It was met with on one of the smaller lakes. It seems to have a very extensive geographical distribution, being found in the New World, in the islands of Java and Ceylon, and now in the interior of Africa.

There are remnants of several other species of birds in the collection, consisting chiefly of bills, legs, and wings. Among them we can trace the apparent remains of the Ciconia alba, Briss.; Ardea garzetta, Linn.; different species of the genus Lamprotornis, Temm.; with various others, of which we regret that we cannot venture to give any description. The foregoing twenty-four species are all that we can undertake to determine upon with accuracy. 
Classis. Reptilia. Auct.

Ordo. Sauriens. Cuv.

Tribus. Lacertiens. Cuv.

Genus. Monitor. Cuv.

Species 1.-Monitor Niloticus.

Lacerta Nilotica. Linn. I. 360.

Varanus Dracæena. Merr. Syst. Amph. p. 59.

Tupinambis Niloticus. Daud. Rept. III. 51.

Monitor du Nile, ou Ouaran. Cuv. Reg. Anim. II. 25.

Tribus. Cameleoniens. Cuv.

Genus. Сhamæleo. Lacép.

Species 2.-Chamaleo vulgaris.

Chamæleo vulgaris. Daud. Rept. IV. 181.

Chamæleo carinatus. Merr. Syst. Amph. p. 162.

Lacerta chamæleon. Linn. I. 364. 
No. XXII.

\section{BOTANICAL APPENDIX.}

BY ROBERT BROWN, ESQ. F.R.SS. L. \& E., F. L.S.

The Herbarium formed during the expedition, chiefly by the late Dr. Oudney, contains specimens, more or less perfect, of about three hundred species. Of these one hundred belong to the vicinity of Tripoli ; fifty were collected in the route from Tripoli to Mourzuk, thirty-two in Fezzan, thirty-three on the journey from Mourzuk to Kouka, seventy-seven in Bornou, and sixteen in Haussa or Soudan.

These materials are too inconsiderable to enable us to judge correctly of the vegetable productions of any of the countries visited by the mission, and especially of the more interesting regions, Bornou and Soudan.

For the limited extent of the herbarium, the imperfect state of many of the specimens, and the very scanty information to be found respecting them, either in the herbarium itself, or in the Journal of the collector, it is unfortunately not difficult to account.

Dr. Oudney was sufficiently versed in Botany, to have formed collections much more extensive and instructive, had the advancement of natural history been the principal purpose of his mission. His time and attention, however, were chiefly occupied by the more important objects of the expedition : as a botanist he had no assistant; and the state of his health during his residence in Bornou must, in a great degree, have rendered him unable to collect or observe the natural productions of that country.

For the few specimens belonging to Soudan, we are indebted to Captain Clapperton, who, after the death of Dr. Oudney, endeavoured to preserve the more striking and useful plants which he met with. His collection was originally more considerable; but before it reached England, many of the specimens were entirely destroyed. It still includes several of the medicinal plants of the natives; but these being without either flowers or fruit, cannot be determined. 
In the whole herbarium, the number of undescribed species hardly equals twenty; and among these not one new genus is found.

The plants belonging to the vicinity of Tripoli were sent to me by Dr. Oudney, before his departure for Fezzan. This part of the collection, amounting to one hundred species, was merely divided into those of the immediate neighbourhood of 'Tripoli, and those from the mountains of Tarhona and Imsalata.

It exceeds in extent the herbarium formed by Mr. Ritchie near Tripoli, and on the Gharian hills, which, however, though containing only fifty-nine species, includes twenty-seven not in Dr. Oudney's herbarium.

The specimens in Mr. Ritchie's collection are carefully preserved, the particular places of growth in most cases given, and observations added on the structure of a few; sufficient at least to prove, that much information on the vegetation of the countries he visited might have been expected from that ill-fated traveller.

In these two collections united, hardly more than five species are contained not already published in the works that have appeared on the botany of North Africa ; particularly in the Flora Atlantica of M. Desfontaines, in the Flore d'Egypte of M. Delile, and in the Floræ Libycæ Specimen of Professor Viviani, formed from the herbarium of the traveller Della Cella.

The plants collected in the Great Desert and its oases, between Tripoli and the northern confines of Bornou, and which somewhat exceed a hundred, are, with about eight or ten exceptions, also to be found in the works now mentioned. And among those of Bornou and Soudan, which fall short of one hundred, very few species occur not afready known as natives of other parts of Equinoctial Africa.

A complete catalogue of the herbarium, such as I have now described it, even if the number and condition of the specimens admitted of its being satisfactorily given, would be of but little importance, with reference to the geography of plants. Catalogues of such collections, if drawn up hastily, and from imperfect materials, as must here have been the case, are indeed calculated rather to injure than advance this department of the science, which is still in its infancy, and whose progress entirely depends on the scrupulous accuracy of its statements. To produce confidence in these statements, and in the deductions founded on them, it should in every case distinctly appear, that in establishing 
the identity of the species enumerated, due attention has been paid to the original authorities on which they depend, and, wherever it is possible, a comparison actually made with authentic specimens.

In the account which I am now to give of the present collection, I shall confine myself to a slight notice of the remarkable known plants it contains, to characters or short descriptions of the more interesting new species, and to some observations on such of the plants as, though already published, have either been referred to genera to which they appear to me not to belong, or whose characters require essential alteration.

In proceeding on this plan, I shall adopt the order followed in the botanical appendix to Captain Tuckey's Expedition to the River Congo. And as there will seldom be room for remarks on the geographical distribution of the species I have to notice, I shall chiefly endeavour to make my observations respecting them of some interest to systematic botanists.

Crucrfers. Fifteen species belonging to this family exist in the collection, one of which only appears to be undescribed, and of this the specimens are so imperfect, that its genus cannot with certainty be determined. Of those already published, however, the generic characters of several require material alterations, some of which suggest observations relative to the structure and arrangement of the natural order.

Savignya AEgyptiaca, (De Cand. Syst. 2. p. 283,) is the first of these. It was observed near Bonjem, by Dr. Oudney, whose specimens slightly differ from those which I have received from M. Delile, by whom this plant was discovered near the pyramid of Saqqârah, and who has well figured and described it in his Flore d'Egypte, under the name of Lunaria parviflora. By this name it is also published by M. Desvaux. Professor Viviani, in giving an account of his Lunaria libyca, a plant which I shall presently have occasion to notice more particularly, has remarked *, that Savignya of De Candolle possesses no characters sufficient to distinguish it as a genus from Lunaria ; and still more recently, Professor Sprengel has referred our plant to Farsetiat. The genus Savignya, however, will no doubt be ultimately established, though not on the grounds on which it was originally constituted; for the umbilical cords certainly adhere to the partition, the silicule, which is never absolutely ses- 
sile, is distinctly pedicellated in Dr. Oudney's specimens, the valves are not flat, and the cotyledons are decidedly conduplicate. In describing the cotyledons of his plant as accumbent, M. De Candolle has probably relied on the external characters of the seed, chiefly on its great compression, its broad margin or wing, and on the whole of the radicle being visible through the integuments. It would appear, therefore, that the true character of the cotyledons of Savignya has been overlooked, chiefly from its existing in the greatest possible degree. To include this degree of folding, in which the margins are closely approximated, and the radicle consequently entirely exposed, a definition of conduplicate cotyledons somewhat different from that proposed in the "Systema Naturale" becomes necessary. I may here also observe, that the terms Pleurorhizæ and Notorhizæ, employed by M. De Candolle, to express the two principal modifications of cotyledons in Cruciferæ, appear to me so far objectionable, as they may seem to imply that in the embryo of this family, the position of the radicle is variable, and that of the cotyledons fixed. It is at least deserving of notice, that the reverse of this is the fact; though it is certainly not necessary to change these terms, which are now generally received.

On the subject of Savignya, two questions naturally present themselves. In the first place: Is this genus, solely on account of its conduplicate cotyledons, to be removed from Alyssinea, where it has hitherto been placed, to Vellex, its affinity with which has never been suspected, and to whose genera it bears very little external resemblance? Secondly : In dividing Cruciferæ into natural sections, are we, with M. De Candolle, to expect in each of these subdivisions an absolute uniformity in the state of the cotyledons? As far as relates to the accumbent and flatly incumbent states, at least, $I$ have no hesitation in answering the latter question in the negative; and 1 believe that in one case, namely Hutchinsia, these modifications are not even of generic importance; for it will hardly be proposed to separate $\mathrm{H}$. alpina from petræa, solely on that ground. I carried this opinion farther than $I$ am at present disposed to do, in the second edition of Mr. Aiton's Hortus Kewensis, where I united in the genus Cakile plants which I then knew to differ from each other, in having accumbent and conduplicate cotyledons; and I included Capsella bursa pastoris in the genus Thlaspi, although I was aware, both from my own observations, and from Schkuhr's excellent figure *, that its cotyledons were incumbent. I am at

$$
\text { * Handb. tab. } 180 .
$$

e e 2 
present, however, inclined to adopt the subdivision of both these genera, as proposed by several authors, and received by M: De Candolle; but to this subdivision the author of the Systema Naturale must have been determined on other grounds than those referred to ; for in these four genera, in which the three principal modifications of cotyledons occur, he has taken their uniformity for granted.

As to the place of Savignya in the natural family, I believe, on considering the whole of its structure and habit, that it ought to be removed from Alyssinex to a subdivision of the order that may be called Brassicea, but which is much more extensive than the tribe so named by M. De Candolle; including all the genera at present known with conduplicate cotyledons, as well as some others, in which these parts are differently modified.

There are two points in the structure of Savignya, that deserve particular notice. I have described the rstivation of the calyx as valvular; a mode not before remarked in this family, though existing also in Ricotia. In the latter genus, however, the apices of the sepals are perhaps slightly imbricate, which I cannot perceive them to be in Savignya.

The radicle is described by $\mathrm{M}$. De Candolle as superior, with relation to the cotyledons. I am not sure that this is the best manner of expressing the fact of its being horizontal, or exactly centrifugal, the cotyledons having the same direction. This position of the seed is acquired only after fecundation; for at an earlier period the foramen of the testa, the point infallibly indicating the place of the future radicle, is ascendant. From the horizontal position of the radicle in this and some other genera, especially Farsetia, we may readily pass to its direction in Biscutella, where I have termed it descendant ; a character which I introduced to distinguish that genus from Cremolobus. But in Biscutella the embryo, with reference to its usual direction in the family, is not really inverted, the radicle being still placed above the umbilicus. On the contrary, in Cremolobea, a natural tribe belonging to South America, and consisting of Cremolobus and Menonvillea, though the embryo at first sight seems to agree in direction with the order generally, both radicle and cotyledons being ascendant, it is, in the same sense, not only inverted, but the seed must also be considered as resupinate: for the radicle is seated below the umbilicus, and also occupies the inner side of the seed, or that next the placenta,-peculiarities which, taken together, constitute the character of the tribe here proposed. It 
appears to me singular that M. De Candolle, while he describes the embryo of these two genera as having the usual structure of the order, should consider that of Iberis, in which I can find no peculiarity, as deviating from that structure *.

Lunaria libyca of Viviani $\uparrow$ is the second plant of Crucifere, on which I have some observations to offer. This species was described and figured, by the author here quoted, in 1824, from specimens collected in 1817 by Della Cella. The specimens in the herbarium were found near Tripoli, where the plant had also been observed in 1819 by Mr. Ritchie, who referred it to Lunaria, and remarked that the calyx was persistent. Professor Sprengel, in his Systema Vegetabilium, considers it a species of Farsetia.

That this plant ought not to be associated either with the original species of Lunaria, or with Savignya, as now constituted, is sufficiently evident. And if it is to be included in Farsetia, it ean only be on the grounds of its having a sessile silicule, with compressed valves, an indefinite number of seeds in each cell, and accumbent cotyledons. But in these respects it accords equally with Meniocus, a genus proposed by M. Desvaux, and with some hesitation received by M. De Candolle, and with Schivereckia of Andrzejowski, which he has also adopted. It does not, however, agree with either of those genera in habit, and it is easily distinguished from both by its simple filaments and other

\section{* SAVIGNYA.}

Savignya. De Cand. Syst. 2. p. 283. Lunaria sp. Delile. Desvaux. Viniani.

Char. Gen. Calyx basi equalis; astivatione valvata. Silicula oblonga, septo conformi, valvis convexiusculis. Semina biseriata imbricata marginata. Cotyledones conduplicata.

Herba annua, glabra (quandoque pube rara simplici). Folis crassiuscula, inferiora obovata in petiolum attenuata grosse dentata, media sape incisa, superiora linearia. Racemi oppositifolii, ebracteati. Flores parvi erecti, petalis violaceis venis saturatioribus. Silicula racemosa, divaricata, inferiores sapius deflexa.

Caly $x$ erectus, sstivatione valvata, ipsis apicibus vix imbricatis. Pelala unguiculata, laminis obovatis sub estivatione mutuo imbricatis. Slamina distincta, edentula, singulum par longiorum glandula subquadrata extus stipatum; breviora, quantum e speciminibus observare licuit, eglandulosa. Ovarium brevissime pedicellatum, ovulis adscendentibus nec horizontalibus. Stylus brevis. Stigma capitatum vix bilobum. Silicula breviter manifeste tamen stipitata, oblonga nume oblongo-elliptica. Valvule uninervie reticulato-venosse. Dissepimentum e lamellis duabus separabilibus uninerviis venis anastomozantibus obsoletis : areolis subtransversim angustato-linearibus, parietibus (tubulis) rectis subpanallelis. Funiculi horizontales, dimidio inferiore septo arcte adnato superiore libero.

+Flor. Lib. Specim. p. 34. tab. 16.f.1. 
characters, which I shall notice hereafter. Is this plant, then, sui generis ? ought it to be united with Alyssum, the character of that genus being modified to receive it? or does not Alyssum require subdivision, and may not our plant be referred to one of the genera so formed? A brief result of the examination of these questions, so far as they are connected with the subject under consideration, will be found annexed to the character which is given of the genus formed by the union of Lunaria libyca with Alyssum maritimum, a plant also in the collection, from the neighbourhood of Tripoli.

Alyssum maritimum, which is described both as an Alyssum and as a Clypeola by Linnæus, is the Konig of Adanson, who founded his generie distinction on the monospermous cells and supposed want of glands of the receptaele; and M. Desvaux, admitting Adanson's genus, has named it Lobularia. In the second edition of Hortus Kewensis I included this plant in Alyssum, which M. De Candolle has also done in his great work.

For the genus here proposed I shall adopt Adanson's name, altering only the termination, and wishing it to be considered as commemorating the important services rendered to botany by my friend Mr. Konig, of the British Museum*.

\section{* KONIGA.}

Konig. Adans. fam. 2. p. 420. Lobularia. Desvaux in Journ, de Botan. appl. 3. p. 172. Alyssi sp. Hort. Kew. ed. 2. vol. 4. p. 95. De Cand. Syst. Nat. 2. p. 318. Lunariæ sp. Viv. Libyc. p. 34. Farsetia sp. Spreng. Syst. Veg. 2. p. 871.

Char. Grn. Calyx patens. Petala integerrima. Glandula hypogyna 8 ! Filamenta omnia edentula. Silicula subovata, valvis planiusculis, loculis 1-polyspermis, funiculis basi septo (venoso, nervo deliquescenti,) adnatis. Semina (sæpissime) marginata. Cotyledones accumbentes.

Herbæ (annuce v. perennes) pube bipartita appressa incana.' Folia integerrima sublinearia. Racemi terminales, nunc basi foliati. Flores albi.

Calyx basi subequalis. Petalorum lamine dilatate. Anther a ovats. Glandularem quatuor per paria filamenta longiora lateraliter adstantes ; reliquæ quatuor abbreviatæ geminatim filamenta breviora stipantes. Dissepimentum, prater areolas ultimas (lamina duplicis) transversim lineares parietibus (tubulis) rectis subparallelis, venis crebre anastomozantibus a nervo descendenti e duobus arcte approximatis formato supra basin evanescenti in monospermis obsoleto ortis descendentibus. Funiculi in dispermis polyspermisque in diversis loculis alterni.

Ons. Koniga ad Alyssinearum tribum De Cand. pertinens, hinc Alysso auctorum inde Farsetix accedit. Sed Alyssum, uti in Hort. Kew. et De Cand. Syst. Nat. constitutum sit, certe divisionem eget.

AuYssum nob. facile distinguendum sequentibus notis. Silicula subrotunda, disco convexo, limbo compresso, apice retuso, loculis dispermis, funiculis basi septo adnatis et post lapsum seminum 
In comparing these two species of Koniga, their agreement is very striking in habit, in leaves, in the closely pressed bipartite pubescence, in the calyx, petals, stamina, and stigma. They eorrespond also in some other points, less obvious but equally important, which I shall separately notice. The first of these is in having eight glands on the receptacle ; a character peculiar, I believe, to these plants, and which first suggested the generic name Octadenia. The glands in Alyssum maritimum were entirely overlooked by Adanson, are not noticed by M. Desvaux, and M. De Candolle has described only the four that subtend the longer stamina. These certainly are much more conspicuous than the remaining four, which, however, occupy the place of the only glands existing in several of the most nearly related genera.

The number and position of the glands in this genus give some support, perhaps, to the hypothesis which I have formerly advanced, of the divisions of an hypogynous disk being in most cases formed of abortive filaments; an opinion more strikingly confirmed, however, in this family of plants, by their form and texture in Alyssum calycinum, and minimum.

The second point in which the two species of Koniga agree is in the structure of the septum. On this, which I consider as a new souree of eharacter in Cruciferæ, I shall offer some remarks in speaking of Farsetia.

The third point of agreement is the adhesion of the funiculi umbilicales to the septum. This adhesion, though really existing, is not very obvious in the monospermous cells of Koniga maritima; but in the supposed variety of this species from Teneriffe, in which the cells are occasionally dispermous, it is manifest, and is very remarkable in all states of Koniga libyca.

I first introduced this adhesion of the funiculi to the septum, as a generie character, in distinguishing Petrocallis from Draba. It has since been advantageously employed in the character of Lunaria by M. de Candolle, who, however, supposes this structure of much rarer occurrence in Cruciferæ than it really

persistentibus, supra liberis et cum iisdem deciduis, in diversis loculis oppositis, in eodem a styli basi equidistantibus: Petalis emarginatis : Filamentis omnibus nonnullisve appendiculatis in speciebus omnibus præter A. calycinum in quo filamenta filiformia simplicia sunt et glandularum loco setule quatuor filamenta nana smulantes exstant.

Ad Alyssum sic constitutum et herbas plerumque annuas pube stellari foliisque integerrimis complectens pertinent A. campestre et calycinum Linn, strigosum Russell.minimum Willd. et strictum cjusd. a quo densiflorum Desfont. vix differt ; fulvescens $S$ mith, umbellatum $D$ esv. ros tratum Stev. micropetalum Fisch. hirsutum Bieb. aliasque species ineditas. 
is. According to my observations, it is neither unfrequent, nor always of generic importance. Thus, I find it to exist in some species only of Arabis, namely A. Turrita, pendula, and canadensis, and hence I did not introduce it into my generic character of Parrya, though I have noticed it in my description of the species.

The principal difference existing between these two species of Koniga is that the cells of the ovarium and silicula of $K$. maritima are monospermous, while those of libyca are polyspermous, the number being variable, apparently indefinite, but not exceeding six. There are, however, other instances in this family, in which the mere difference between definite and indefinite number of seeds is of specific importance only, as in Draba and Meniocus, in each of which a species exists with dispermous cells; and the objection arising from the apparently still greater difference between unity and indefinite number in the two species of Koniga is removed by a supposed third species or variety of K. maritima, in which two seeds are occasionally produced in each cell. It may even be observed, that from unity to the indefinite number in this case, where the ovula in the different cells are alternate, the transition is perhaps more easy than from the binary to the indefinite, in cases where, as in Alyssum properly so called, the ovula are placed opposite in the different cells, and are in the same cell equidistant from its apex ; this symmetry, probably, admitting of addition only by fours.

The next genus of Cruciferæ to be noticed is FARsETI , a fragment of the original species of which is in the collection. There are also several specimens of a plant, found in the desert, supposed to be new, and which, though without flowers, and considerably different in the form of its stigma, I am inclined, from the resemblance in habit, in pubescence, in silicula, in seeds, and especially from the exact similarity in the structure of the septum, to refer to the same genus*.

\section{* FARSETIA.}

Farsetia. Turra Farsetia, p. 5. Farsetia sp. Hort. Kew. ed. 2. vol. 4. p. 69. De Cand. Syst. 2. p. 286.

Char. Grav. Calyx clausus, basi vix bisaccatus. Filamenta omnia edentula, Antherce lineares. Silicula ovalis v, oblonga, sessilis, valvis planiusculis, loculis polyspermis (raro 1-2spermis), funiculis liberis. Dissepimentum uninerve, venosum. Semina marginata. Cotyledones accumbentes.

Herbe suffruticos $\Subset$ ramosa, pube bipartila appressa incanc. Folia integerrima. Racemi subspicati. 
As the introduction of the structure of the dissepiment into the generic characters of Cruciferæ is now proposed for the first time, and as I believe that its texture and appearance should always be attended to in constituting genera in this family of plants, I shall here offer a few remarks respecting it.

According to the particular view which I briefly but distinctly published in 1818, and which M. de Candolle first adopted in 1821, of the composition of the pistillum in Cruciferæ*, the dissepiment in this family is necessarily

Ons. Dissepimentum in omnibus exemplaribus utriusque speciei a nobis visis completum, sed in F. rgyptiaca quandoque basi fenestratum, fide D. Desfontaines. (Flor. Atlant. 2, tab. 160.)

F. agyptiaca species unica certa est, nam F. stylosa, cujus flores ignoti, ob stigmatis lobos patentes non absque hresitatione ad hoc genus retuli.

FARsetia? stylosa, ramosissima, siliculis oblongis polyspermis passimque brevè ovalibus 1-2-spermis, stylo diametrum transversum silicula subæquante, stigmatis lobis patentibus.

Obs. Exemplaria omnia foliis destituta, sed illorum eicatrices ni fallor obvie.

* In a work published in 1810 , the following passage, which has some relation to this subject, occurs. "Capsulas omnes pluriloculares e totidem thecis conferruminatas esse, diversas solum modis gradibusque variis cohasionis et solubilitatis partium judico."-(Prodr. Flor. Nov. Holl. 1 . p. 558.) This opinion, however, respecting the formation of multilocular ovaria, might be held, without necessarily leading to the theory in question of the composition of the fruit in Cruciferæ, which I first distinctly stated in an Essay on Compositie, read before the Linnean Society in February 1816, and printed in the 12th volume of their Transactions, published in 1818. In this volume (p. 89), I observe that "I consider the pistillum of all phanogamous plants to be formed on the same plan, of which a polyspermous legumen, or follieulus, whose seeds are disposed in a double series, may be taken as the type. A circular series of these pistilla disposed round an imaginary axis, and whose number corresponds with that of the calyx or corolla, enters into my notion of a flower complete in all its parts. But from this type, and number of pistilla, many deviations take place, arising either from the abstraction of part of the complete series of organs, from their confluence, or from both these causes united, with consequent abortions and obliterations of parts in almost every degree. According to this hypothesis, the ovarium of a syngenesious plant is composed of two confluent ovaria, a structure in some degree indicated externally by the division of the style, and internally by the two cords (previously described), which I consider as oceupying the place of two parietal placente, each of these being made up of two confluent chordule, belonging to different parts of the compound organ."

In endeavouring to support this hypothesis by referring to certain natural families, in which degradations, as I have termed them, are found, from the assumed perfect pistillum to a structure equally simple with that of Composite, and after noticing those occurring in Goodenovix, I add, "The natural order Crucifere exhibits also obliterations more obviously analogous to those assumed as taking place in syngenesious plants; namely, from a bilocular ovarium with two

$$
f f
$$


formed of two lamellæ, derived from the parietes of the fruit. These lamellæ are in many cases easily separable, and where their union is more intimate, their existence is still evident from the want of correspondence, and consequent decussation, of their areolæ. The lamellæ, which are usually very thin and transparent, have their surface divided into areolæ, in different genera of very different forms, some of which may, with sufficient clearness, be described. In many cases no other appearance exists; in some, however, the axis of the septum resembles either a single nerve, or two distinct parallel nerves; and from this axis, whether formed of one or two nerves, tubes having the appearance and ramification of the veins of a leaf, and which generally terminate within the margin, not unfrequently proceed. This is remarkably the case in Farsetia, as I here propose to limit that genus; the central vessels in both its species being closely approximated, so as to form a single cord, extending from the apex to the base of the septum, and the veins being numerous and uncommonly distinct. Approaches more or less manifest to this structure of Farsetia exist in several other genera, as in Parrya, Savignya, and Koniga. But

polyspermous parietal placentre, which is the usual structure of the order, to that of Isatis, where a single ovulum is pendulous from the apex of the unilocular ovarium; and, lastly, in the genus Bocconia, in the original species of which (B. frutescens), the insertion of the single erect ovulum has the same relation to its parietal placentie, as that of Compositæe has to its filiform cords, a second species (B. cordata) exists, in which these placenta are polyspermous."

From this quotation it is, I think, evident, that in $1818 \mathrm{I}$ had published, in my Essay on Compositis, the same opinion, relative to the structure of the pistillum of Cruciferæ, which has since been proposed, but without reference to that essay, by M. de Candolle, in the second volume of his "Systema Naturale ;" and I am not aware that when the essay referred to appeared, a similar opinion had been advanced by M. de Candolle himself, or by any other author; either directly stated of this family in particular, or deducible from any general theory of the type or formation of the pistillum. I am persuaded, however, that neither M. de Candolle, when he published his Systema, nor M. Mirbel, who has very recently adverted to this subject, could have been acquainted with the passage above quoted. This, indeed, admits of a kind of proof; for if they had been aware of the concluding part of the quotation, the former author would probably not have supposed that all the species referred to Bocconia were monospermous, (Syst. Nat. 2. p. 89); nor the latter that they were all polyspermous. (Mirbel in Ann. des Scien. Nat. 6. p. 267). Respecting Bocconia cordata, though it is so closely allied to Bocconia as to afford an excellent argument in favour of the hypothesis in question, it is still sufficiently different, especially in its polyspermous ovarium, to constitute a distinct genus, to which $I$ have given the name (MacLeay a cordata) of my much valued friend, Alexander Macleay, Esq. Secretary to the Colony of New South Wales, whose merits as a general naturalist, a profound entomologist, and a practical botanist, are well known. 
in this last mentioned genus the nerve, which originates, as in all cases, at the apex, hardly extends, even in the polyspermous species, beyond the middle of the septum, and the veins, which are much less distinct, are descendent.

As far as my observations on this subject at present extend, I expect, with great confidence, uniformity in the structure of the septum of strictly natural genera, and in many cases, though certainly not in all, I have found a resemblance in this respect in more extensive groups. Thus Draba, Arabis, and Aubrietia, agree in having amorphous areolæ, bounded by flexuose tubes or lines ; while Alyssum, Berteroa, and Fibigia, have narrow linear areola, bounded by parallel or slightly arched lines. Capsella bursa differs from Thlaspi and Ethionema, as Draba from Alyssum, and agrees with Lepidium procumbens, Linn. improperly referred to Hutchinsia, and which equally has incumbent cotyledons. Cochlearia differs in like manner from Kernera. And numerous other examples of the same agreement in nearly related plants, and of differences where the usual sources of distinction are less available, might be noticed.

Hesperis nItens of Viviani is sparingly in the herbarium, both in flower and fruit. The seeds, though not ripe, are sufficiently advanced to show that the direction of the cotyledons is in this stage accumbent; and, as I have found in Cruciferæ generally that the ultimate agrees with the early state of cotyledons, I conclude they are likewise accumbent in the ripe seed. The plant is also abundantly different from Hesperis in other respects, and does not appear to be referrible to any genus yet published. This new genus * I have dedicated to the memory of Dr. Oudney, who found the present species in many of the wadeys between Tripoli and Mourzuk, and remarks that camels and mules eat it.

\section{* OUDNEYA.}

Char. Grn. Calyx clausus, basi bisaceatus. Filamenta distineta, edentula. Stigmata connata apicibus distinctis. Siliqua sessilis linearis rostrata, valvis planis uninerviis, funiculis adnatis, septo avenio areolarum parietibus subparallelis. Semina uniseriata. Cotyledones accumbentes.

Suffrutex (O. Africana nob. Hesperis nitens, Viv.lib. p. 38. tab. 5. f. 3.) glaberrimus, ramosus. Folia integerrima sessilia avcnia, inferiora obovata, superiora sublinearia. Racemi terminales, ebracteati. Flores mediocris magnitudinis, petalorum laminis obovatis venosis.

Obs. Ondneya ab Arabidi differt stigmatis forma, siliqua rostro, et dissepimenti areolarum figura. Parrya ad quam genus nostrum accedit diversa est dissepimento binervi venoso! calyce haud clauso, siliqua forma, et seminibus biseriatis testa corrugata.

$$
f f 2
$$


Hesperis ramosissima, which is also in the herbarium, was found in Fezzan. This plant differs in aspect from most of the other species of Hesperis, approaching in some points to Malcomia, in others to Mathiola; and as its cotyledons are very obliquely incumbent, it may form a section or subgenus, with a name, Hesperis (Plagiloba) ramosissima, indicating that character.

Capparides, of which eight species occur in the collection, is the family next to be noticed. I consider this order as belonging to the same natural class with Cruciferæ; and that this class includes also Resedaceæ, Papaveracex, and Fumariacex.

M. de Candolle, in defining Capparideæ, appears to regard the ovarium as having in all cases only two placentæ, and therefore formed of two pistilla or carpella. But to this, which is certainly the more usual number, there are many exceptions. These exceptions occur chiefly in the genus Capparis, which, as it is at present constituted, includes species differing from each other in having an ovarium with from two to eight placentæ, and, consequently, composed of an equal number of pistilla. Capparis spinosa is the most decided instance of the increased number of placentæ, and this, as well as some other nearly related species, are also remarkable in having septa subdividing the placentæ, and uniting in the centre of the compound ovarium.

In the herbarium there are three species of the genus Cleome. Two of these, C. pentaphylla and arabica, are in many respects well known plants; the third I believe to be an undescribed species, but nearly related to monophylla.

If the very natural group, formed by the Linnæan genus Cleome, is not to be preserved entire, its subdivision must be carried much farther, and established on other grounds, than has been done by M. de Candolle, whose genera and sections appear to me to have been equally founded on partial considerations. Thus, his Polanisia, uniting all the Cleomes whose stamina exceed six, contains in its first section, in addition to the species from which the genus was formed, at least two sets of plants, having very little affinity either with each other, or with the original species, whose only congener is placed in a second section.

Gynandropsis also consists of two groups not very intimately connected : the first is composed of species belonging to South America, and having the usual astivation of the family : the second, of which $C$. pentaphylla may be taken* as the type, is chiefly African, and is readily distinguished by its very different astivation, - the great peculiarity of which consists in the petals not covering 
the stamina at any period. To this mode of æstivation of petals, which has never before been noticed, though it equally exists in Crateva and in Resedaceæ, I shall apply the term aperta. It is constantly conjoined, and, perhaps, necessarily connected with the early opening of the calyx, whose segments are originally connivent and slightly imbricate : for it may here be remarked, that in all the modifications of what I have termed imbricate æstivation of petals, they are, I believe, in the very early stage in like manner erect, and the sexual organs equally exposed.

If the expediency of preserving the genus Cleome entire were admitted, a question which I do not pretend at present to decide, it would still be of the greatest importance to arrange its numerous species according to their affinities, and carefully to distinguish the subordinate groups that compose it. To such inferior groups, whether termed subgenera or sections, names, in fact, have been of late years very generally assigned, both by zoologists and botanists.

It has not yet been proposed, however, that these subgeneric names should form an essential part of the name of the species; although, by employing them in this manner, while the principal groups would be kept in view, their subdivision would be carried to the same extent, and the subordinate groups as well expressed as if they had been actually separated into distinet genera.

The adoption of this method, which would not materially disturb names already existing, would probably lead to a greater consistency in the formation of genera, with reference to the natural orders of which they are subdivisions. In this way also the co-operation of two classes of naturalists, at present opposed to each other on the question of the construction of genera, might to a certain extent be expected, and greater uniformity in nomenclature consequently secured.

These advantages appear to me so important, that some expedient for obtaining them will, I am persuaded, at no distant period, be generally adopted.

In favour of the present plan it may be remarked, that it is analogous to the method followed by the Romans in the construction of the names of persons, by which not only the original family, but the particular branch of that family to which the individual belonged was expressed. Thus the generic name corresponds with the nomen (Cornelius), the name of the section with the cognomen (Scipio), and that of the species with the prænomen (Publius).

Without attempting at present to obviate the objections to which the proposed innovation is no doubt liable, I shall proceed to apply it to Cleome 
pentaphylla. According to my view the genus Cleome would include Gynandropsis, a name which, as that of a section, may be continued to those species of M. de Candolle's genus belonging to equinoctial America, and having the common æstivation of the family : while Gymnogonia, derived from its remarkable æstivation, may be employed for the section that includes C. pentaphylla, of which the name might be given in the following manner :-

Cleome (Gymnogonia) pentaphylla. This plant, the earliest known species of Cleome, and that on which the genus was chiefly constituted, was found in Bornou. The species is regarded by M. de Candolle as a native of the West India islands, and he doubts whether it may not also belong to Egypt and India. On the other hand I consider it a native of Africa and India, and am not satisfied with the evidence of its being also indigenous to the American islands, where, though now very common, it has probably been introduced by the negroes, who use it both as a potherb and in medicine. It is not unlikely that M. de Candolle, in forming his opinion of the original country of this plant, has been in part determined by finding several species of his Gynandropsis decidedly and exclusively natives of the new continent. But if I am correct in separating these species from the section to which Cleome (Gymnogonia) pentaphylla belongs, this argument, which I have formerly applied to analogous cases *, would be clearly in favour of the opinion I have here advanced; those species of the section with which $I$ am acquainted being undoubtedly natives of Africa or of India.

Cleome (Siliquaria) Arabica, (Linn. sp. pl. ed. 2. p. 999. De. Cand. prodr. 1. p. 240), a supposed variety of which was found both in the neighbourhood of Tripoli and in Soudan, belongs to another subdivision of the genus, equally natural, and readily distinguishable. The species of this subdivision are included in M. De Candolle's second section of Cleome, but are there associated with many other plants, to which they have very little affinity.

All the species of Cleome Siliquaria are indigenous to North Africa and Middle Asia, except violacea, which is a native of Portugal. Cleome deflexa of M. De Candolle (prodr. 1. p. 240.), founded on specimens in Mr. Lambert's herbarium, which were sent by Don Joseph Pavon as belonging to Peru, seems to present a remarkable exception to this geographical distribution of the section. But on examining these specimens I find them absolutely iden-

* Tuckey's Congo, p. 469. 
tical with some states of violacea. I think it probable, therefore, either that they are erroneously stated to have come from Peru, or that this species may have been there introduced from European seeds.

Cadaba farinosa (Forsk. Arab. p. 68. De Cand. prodr. 1.p. 244) is in the herbarium from Bornou. The specimen is pentandrous, and in other respects agrees with all those which I have seen from Senegal, and with Stromia farinosa of my catalogue of Abyssinian plants, collected by Mr. Salt, and published in his travels. M. De Candolle, who had an opportunity of examining this Abyssinian plant, refers it to his $C$. dubia, a species established on specimens found in Senegal, and said to differ from farinosa, slightly in the form of the leaves, and in being tetrandrous. Of the plant from Abyssinia I have seen only two expanded flowers, one of which is decidedly pentandrous, the other apparently tetrandrous. Mr. Salt, however, from an examination of recent specimens, states it to be pentandrous. It is probably, therefore, not different from C. farinosa of Forskal, whose specimens M. De Candolle has not seen. And as the form of leaves is variable in the specimens from Senegal, and not elliptical, but between oval and oblong, in those of Abyssinia, C. dubia is probably identical with, or a variety merely of farinosa, as M. De Candolle himself seems to suspect.

Crateva Adansoni (De Cand. prodr. 1. p. 243) is in the collection from Bornou. This species is established by M. De Candolle upon a specimen in M. de Jussieu's herbarium, found in Senegal by Adanson, and is supposed to differ from all the other species in having its foliola equal at the base. I have examined the specimen in M. de Jussieu's herbarium, in which, however, the leaves not being fully developed, I was unable to satisfy myself respecting their form. But in a specimen, also from Senegal, which I received from M. Desfontaines, the lateral foliola, though having manifestly unequal sides, are but slightly unequal at the base, and the inequality consists in a somewhat greater decurrence of the lamina on the anterior or inner margin of the footstalk. As well as can be determined, in very young leaves, this is also the case in the specimen from Bornou; and it is manifestly so in my specimen of C. lata, which appears to belong to the same species.

Crateva lata was founded by M. De Candolle on a plant from Senegal, communicated by M. Gay, from whom I also received a specimen in 1824, with the remark, that it was not different from C. Adansonii. In that 
specimen the flowers are male with an imperfect pistillum; in the plant from Bornou they are hermaphrodite, with elongated filaments; and in the specimen received from M. Desfontaines they are also hermaphrodite, but the stamina, though apparently perfect, are fewer in number and shorter than the stipes of the ovarium. I have observed, however, the flowers to be in like manner polygamous in some other species of Crateva, belonging both to India and America, a fact which materially lessens the dependence to be placed on characters taken from the number and length of the stamina in this genus.

Crateva Adansonii, it would appear, then, is the only known species of the African continent, for C. fragrans does not belong to the genus. And it will be difficult to distinguish this African Crateva from a plant which seems to be the most general species of India ; except that in the latter, as in all the other species of the genus, the inequality of the lateral foliola, which is also more marked, consists in the greater decurrence of the lamina being on the outer or posterior margin of the footstalk. This Indian species, which may be named C. Roxburghii, is the Capparis trifoliata of Dr. Roxburgh's manuscripts, but not Niirvala of Hortus Malabaricus (vol. 3. p. 49. t. 42), as he considers it. I have little doubt of its being also the plant described as C. Tapia, by Vahl, (symb.3.p.61.) his specific character well according with it, and not applying, as far as relates to the petals, to any known species of America. But as this character is adopted by Sir James Smith (in Rees's Cyclop.), it may likewise be C. Tapia of the Linnæan herbarium; a conjecture the more probable as Linnæus has distinguished his Tapia by its ovate petals from gynandra, in which they are said to be lanceolate (Sp. pl. ed. 2. p. 637). This celebrated herbarium, however, is here of no authority, for Linnæus was never in possession of sufficient materials to enable him to understand either the structure and limits of the genus Crateva, or the distinctions of its species; and the specific name in question, under which he originally included all the species of the genus, ought surely to be applied to an Ameriean plant, at least, and if possible to that of Piso, with whom it originated. It is hardly to be supposed that the plant intended by Piso can now with certainty be determined; the only species from Brazil, however, with which I am acquainted, well accords with his figure and short description. This Brazilian species is readily distinguishable both from C. Adansonii and Roxburghii, by the form of its petals, which, as in all the other American species, are narrow- 
oblong or lanceolate; and from C. gynandra by the shortness of its stipes genitalium, or torus.

Crateva Tapia so constituted, is, on the authority of a fragment communicated by Professor Schrader, the Cleome arborea of that author, (in Gatt. Anzeig. 1821, p. 70\%. De Cand. Prodr. 1. p. 242.); nor is there any thing in the character of C. acuminata of De Candolle (Prodr. 1. p. 243) which does not well apply to our plant.

C. Tapia, as given by M. De Candolle (op. cit.), is characterized chiefly on the authority of Plumier's figure, in the accuracy of which, either as to the number or length of stamina, it is difficult to believe, especially when we find it also representing the petals inserted by pairs on the two upper sinuses of the calyx.

The genus Crateva agrees, as I have already stated, in the remarkable æstivation of its flower with Cleome Gymnogonia, by which character, along with that of its fruit, it is readily distinguished from every other genus of the order. Although this character of its æstivation has never before been remarked, yet all the species, referred to Crateva by M. De Candolle, really belong to it, except $C$. fragrans, which, with some other plants from the same continent, forms a very distinct genus, that I shall name R RTchIEA, in memory of the African traveller, whose botanical merits have been already noticed.

Capparis sodada nob. Sodada decidua, Forsk. Arab. p. 81. Delile, Flore d'Egypte, p. 74. tab. 26. De Cand. Prodr, 1. p. 24.5.

The specimen in the herbarium is marked by Dr. Oudney as belonging to a tree common on the boundaries of Bornou. It is probably the Suag, mentioned in his journal, observed first at Aghedem, and said to be " a tetrandrous plant having a small drupa, which is in great request in Bornou and Soudan, for removing sterility in females: it is sweetish and hot to the taste, approaching to Sisymbrium Nasturtium;" and that " in passing the plant a heavy narcotic smell is always perceived."

I have here united Sodada with Capparis, not being able to find differences sufficient to authorise its separation even from the first section of that genus, as given by De Candolle.

Forskal describes his plant as octandrous, and M. De Candolle has adopted this number in his generic character. M. Delile (op. cit.), however, admits that the stamina vary from eight to fifteen; and, in the specimen which I

\section{$g g$}


received from M. Jomard, I have found from fourteen to sixteen. But were the number of stamina even constantly eight, this alone would not justify its separation from Capparis, several octandrous species of which, belonging to the same section, are already known.

Another species of Capparis, also from Bornou, exists in the herbarium. It appears to be undescribed, and to belong to M. De Candolle's first section of the genus; but the specimen is too imperfect to be satisfactorily determined.

Both these species have aculei stipulares, and it may here be remarked that all the plants belonging either to Capparis, or to any of the genera of the order whose fruit is a berry, in which these aculei are found, are indigenous either to Asia, Africa, or Europe ; while all the aculeated Cleomes, with the exception of perhaps a single African species, are natives of equinoxial America.

Mmrua rigida. This plant, of which flowering specimens were collected at Aghedem, certainly belongs to Forskal's genus Mærua, adopted by Vahl and De Candolle; and I believe it to be a species distinct from the three already published. It is very nearly related, however, to a fourth species (M. Senegalensis nob.), of which I received a specimen from M. Desfontaines. M. De Candolle has placed the genus Mærua at the end of Capparideæ, between which and Passiflorea he considers it intermediate. This view of its relation to these two orders I cannot adopt. To me it appears truly a Capparidea, having very little affinity with Passiflorex, to which it seems to approach in one point only, namely, the corona of the calyx. But of a similar corona rudiments exist in several other African Capparidex, and from some of these the genus Mærua is with difficulty distinguished *.

* MÆRUA.

Marna. Forsk. Arab. p. 104. Vahl symb. 1. p. 36. De Cand. Prodr. 1. p. 254.

Char. Gen. Calyx tubulosus: limbo 4-partito, estivatione simplici serie valvata: corona faucis petaloidea. Petala nulla. Stipes genitalium elongatus. Stamina numerosa. Pericarpium (siliquiforme?) baccatum.

Frutices inermes, pube, dum adsit, simplici. Folia simplicia coriacea : petiolo cum denticulo rami articulato : stipulis minutissimis setaceis.

Manua rigida, corymbis terminalibus paucifloris, foliis obovatis crassis rigidis aveniis nervo obsoleto, corona lacero-multipartita.

Desc. Frutex ? Rami stricti teretes tenuissime pubescentes. Folia sparsa, obovata cum mucronulo brevissimo, plana semiunguicularia, utrinque pube tenuissima brevissima simplici, nervo 
RESEDACE. The herbarium contains two species of Reseda. The specimens of one of these are too imperfect to be determined. The other is probably undescribed, though very nearly related to $R$. suffruticulosa, and undata of Linnæus. This supposed new species (Reseda propinqua) was found near Tripoli by Mr. Ritchie, and between Tripoli and Mourzuk by Dr. Oudney. It is remarkable in having the ungues of all the petals simple; that is, neither dilated, thickened, nor having any process or appendage at the point of union with the trifid lamina, into which they gradually pass. We have here therefore a species of Reseda with petals not different in any respect from those of many other families of plants; and, although this is an exception to their usual structure in the genus, I shall endeavour to show that all the deviations existing, however complex in appearance, are reducible to this more simple state of the organ.

RESEDACEx, consisting of Reseda, divisible into sections or subgenera, and Ochradenus, which may perhaps be regarded as only one of these subdivisions, I consider very nearly related to Capparideæ, and as forming part of the same natural class. It differs, in the variable number of the parts of its

obsoleto, venis fere inconspicuis. Petioli lineam circiter longi. Stipula laterales, setacea, petioli dimidio breviores, ramulo appressæ, post lapsum folii persistentes. Ramuli floriferi sæpius laterales abbreviati, e foliis confertis floribusque corymboso-fasciculatis (3-6.), quorum exteriores folio subtensi ; quandoque corymbus ramum terminat. Pedunculi teretes, tenuissime pubescentes, ebracteati excepto foliolo florali dum adsit ejusque stipulis vix conspicuis. Calyx infundibuliformis, extus tenuissime pubescens: tubus subcylindraceus, 8-striatus striis elevatis squalibus, intus lineis dnabus prominulis subcarnosis, cum limbi laciniis alternantibus, altera crassiore : limbus tubo paulo longior, 4-partitus laciniis equalibus, ovatis acutiusculis, obsolete venosis, 5 -nerviis, nervis extimis margini approximatis, e fureatione costarum quatuor tubi cum laciniis alternantium ortis ; æstivatione simplici serie valvata marginibus tamen paulo inflexis. Corona faucis monophylla, laciniis limbi multoties brevior, lacero-multipartita lacinnlis subulatis inæqualibus, Stipes genitalium liber, cylindraceus, glaber, altitudine tubi. Stamina: Filamenta indeterminatim numerosa, viginti circiter, filiformia glabra, rstivatione contortuplicata. Antherc incumbentes, ovali-oblongæ obtusæ, basi semibifidæ, loculis parallelo-approximatis, intus longitudinaliter dehiscentibus, astivatione erectæ. Ovarium e centro filamentorum stipitatum, cylindraceum, glabrum, uniloculare placentis duabus parietalibus polyspermis. Stylus nullus. Stigma depresso-capitatum.

Ons. Species hacce proxime accedit Maruæ senegalensi nob. quæ vix pubescens et foliis venosis distincta; in multis quoque convenit, fide descriptionis Forskalii, cum Mrerua uniflora $V a h l$, a nobis non visa. Msrua angolensis, De Cand. (in Museo Parisiensi visa) cui flores pariter corymbosi et corona lacero-multipartita, satis diversa est foliis ovalibus.

$g g 2$ 
floral envelopes, from the other orders of the class, in which the quaternary or binary division is without exception; and it is especially remarkable in having the ovarium open even in its earliest state. From Cruciferæ and Capparideæ, the two families of the class to which they most nearly approach, Resedaceæ also differ in the apparent relation of the stigmata to the placentæ. The stigmata in this order terminate the lobes of the pistillum, and as these lobes are open sterile portions of the modified leaves, from the union of which in the undivided part I suppose the compound ovarium to originate, they necessarily alternate with the placentæ. I have generally found, however, the upper part of each placenta covered by a fleshy or fungous process, which is connected with the margins of the lobes, and therefore with the stigmata, and is probably essential to the fecundation of the ovula. The singular apparent transposition of the placentæ in Sesamoides of Tournefort, so well described by M. Tristan in his ingenious Memoir on the Affinities of Reseda ", appears to me necessarily connected with the extreme shortness of the undivided base of the ovarium; for in supposing this base to be elongated, the placentæ would become parietal, and the ovula, which are actually resupinate, would assume the direction usual in the order.

M. De Jussieu, in his Genera Plantarum, has included Reseda in Capparideæ, and to this determination I believe he still adheres. M. Tristan, in the memoir referred to, is inclined to separate it as a family intermediate between Passifloreæ and Cistineæ, but more nearly approaching to the latter. M. De Candolle, who first distinguished Reseda as an order under the name here adopted, in $1819+$ placed it between Polygaleæ and Droseraceæ, and consequently at no great distance from Capparidex. He must, since, however, have materially altered his opinion respecting it ; for the order Resedaceæ is not included in the first or second part of his Prodromus, and I can find no observation respecting it in these two volumes. It is probable, therefore, that he may either intend to place it near Passifloreæ, as suggested by M. Tristan, or, which is more likely, that he has adopted the hypothesis lately advanced, and ingeniously supported, by Mr. Lindley, respecting its structure and affinities $\ddagger$.

According to this hypothesis, in Reseda the calyx of authors is an involu-

* Annal. du Mus. d'Hist. Nat. 18. p. 392. †.Théor. Elem. ed. 2. p. 244.

† Collect. Bot.tab. 22. 
crum, its petals neutral flowers, and the disk or nectary becomes the calyx of a fertile floret in the centre: and, as a deduction from this view of its structure, the genus has been placed near Euphorbiaceæ.

The points in the structure of Reseda, which appear to have led Mr. Lindley to this hypothesis, are the presence and appearance of the hypogynous disk, the anomalous structure of the petals, and the singular æstivation of the flower; but it is no slight confirmation of the correctness of M. de Jussieu's opinion, that all these anomalies occur in a greater or less degree in Capparideæ, and have been found united in no other family of plants. The remarkable æstivation of Reseda equally exists in Crateva, and in more than one subdivision of the genus Cleome; the hypogynous disk is developed in as great a degree in several Capparideæ; and an approximation to the same kind of irregularity in the petals occurs in two sections of Cleome.

The analogical argument alone then might, perhaps, be regarded as conclusive against the hypothesis. But the question, as far as relates to the petals, and consequently to the supposed composition of the flower, may be decided still more satisfactorily on other grounds. Both M.M. Tristan and Lindley regard the upper divided membranaceous part of the petal as an appendage to the lower, which is generally fleshy. On the other hand, I consider the anomaly to consist in the thickening, dilatation, and inner process of the lower portion, and that all these deviations from ordinary structure are changes which take place after the original formation of the petal. To establish these points, and consequently to prove that the parts in question are simple petals, and neither made up of two cohering envelopes, as M. Tristan supposes, nor of a calyx and abortive stamina, according to M. Lindley's hypothesis, I shall describe their gradual development, as I have observed it in the common Mignonette; a plant in which all the anomalies that have led to this hypothesis exist in a very great degree.

The flower-bud of Reseda odorata, when it first becomes visible, has the divisions of its calyx slightly imbricate and entirely enclosing the other parts. In this stage the unguis of each of the two upper petals is extremely short, not broader than the base of the lamina, and is perfectly simple; there being no rudiment of the inner process so remarkable in the fully expanded flower. The lamina at the same period may be termed palmato-pinnatifid, its divisions are all in the same plane, the terminating or middle segment is whitish or opake, and several times longer than the lateral segments, which are semitransparent. 
Of the remaining four petals, the two middle are dimidiato-pinnatifid, their lateral segments existing only on the upper side; and the two lower are undivided, being reduced to the middle segment or simple lamina. All the petals are erect, and do not cover the stamina in the slightest degree, either in this or in any other stage. The disk is hardly visible. The Antheræ are longer than their filaments, of a pale-green colour; those on the upper or posterior side of the flower being manifestly larger, and slightly tinged with brown. The Pistillum is very minute and open at the top. In the next stage, the calyx is no longer imbricate, but open : the petals have their segments in nearly the same relative proportions; the interior margin of the unguis is just visible; but the transition from unguis to lamina is still imperceptible; the apex of the former not being broader than the base of the latter. It is unnecessary to follow the development through the more advanced stages of the flower, the facts already stated being, in my opinion, absolutely conclusive as to the real nature of the parts in question: and I may remark, that similar observations on certain genera of Caryophyllex, especially Dianthus, Lychnis and Silene, clearly establish the analogy between their petals and those of Reseda.

I am aware that it has lately been proposed to include Dutisca in Resedacea, to which it is nearly similar in the structure of its ovarium, as M. de Jussieu has long since remarked. But this is the only point of resemblance between them; for the calyx of Datisca is certainly adherent, and in most of its other characters it differs widely both from Reseda, and from every other genus yet published. Among the numerous discoveries made by Dr. Horsfield in Java, there is a genus, (Tetrameles nob.) however, manifestly related to Datisca, and remarkable in the regular quaternary division of every part of its diøcious flowers. These two genera form an order very different from every other yet established, and which may be named Datiscex.

Caryophyllex. Five species only of this family were collected near Tripoli, none of which are new.

Of ZYGophyLLEe, six species exist in Dr. Oudney's herbarium, namely, Tribulus terrestris, found in Bornou ; Fagonia cretica, from Tripoli to Benioleed; Fagonia arabica, at Aghedem; Fagonia Oudneyi nob. with Zygophyllum simplex in Fezzan; and Zygophyllum album every where in the desert.

This family, so distinct in habit from Diosmeæ or Rutaceæ, with which it was formerly united, is not easily characterized by any very obvious or constant peculiarities in its parts of fructification.

The distinguishing characters in its vegetation or habit are the leaves being 
constantly opposite with lateral or intermediate stipulæ, being generally compound, and always destitute of the pellucid glands, which universall exist in true Diosmex, though not in all Rutaceæ properly so called.

M. Adrien de Jussieu, in his late very excellent Memoir on the great order or class Rutaceæ, in distinguishing Zygophylleæ from the other subdivisions of that class in which he has included it, depends chiefly on the endocarp, or inner lamina of the pericarp, not separating from the outer lamina or united epicarp and sarcocarp, and on the texture of the albumen. His first section of Zygophylleæ, however, is characterised by the want of albumen; and in his second section I find exceptions to the remaining character, especially in Fagonia Mysorensis, in which the two laminæe of the ripe capsule separate as completely as in Diosmex. Another plant, in my opinion referrible to the same order, and which, in memory of a very meritorious African traveller, I have named Seetzenia africana, has in its ripe capsule the epicarp, or united epicarp and sarcocarp, confined to the dorsal carina of each cell, the endocarp being the only membrane existing on the sides, which are exposed long before the bursting of the fruit. The plant in question has indeed many other peculiarities, some of which may, perhaps, be considered sufficient to authorise its separation from the order to which I have referred it ; for the astivation of its calyx is valvular, it has no petals, its five styles are distinct to the base, and the cells of its ovarium appear to me to be monospermous. It completely retains, however, the characters of vegetation on which I chiefly depend in distinguishing Zygophyllea; and I have no doubt of its being Zygophyllum lanatum of Willdenow *, by whom it is stated to be a native of Sierra Leone; I suppose, however, on insufficient authority, for the specimens in the Banksian Herbarium, from which I have made my observations, were found in South Africa, near Olifant's River, by Francis Masson.

In all the species of Fagonia, and in the two species of Zygophyllum in Dr. Oudney's collection, a character in the fructification still remains, which is not found in Diosmeæ or Rutacex, and which, were it general in Zygophyllex, would satisfactorily distinguish this order from all the families it has usually been compared with. This character consists in the direction of the embryo with relation to the insertion of the funiculus, its radicle being seated at the opposite extremity of the seed, or to express, in the unimpregnated ovarium,

$$
\text { * Sp. plant. 9. p. } 564 \text {. }
$$


the infallible indication of this position, the direction of the inner membrane and nucleus of the ovulum corresponds with that of its testa.

But this character, in general very uniform in natural families, and which, equally existing in Cistineæ, so well defines the limits of that order, as I have long since remarked *, would seem to be of less importance in Zygophylleæ.

M. Adrien de Jussieu, who, in his memoir already cited, admits its existence in Fagonia, and in both our species of Zygophyllum, considers it as an exception to the general structure of the latter genus, in the definition of which he retains the character of " radicula hilo proxima." I believe, however, that in all the species of Zygophyllum, except Fabago, which possesses, also, other distinguishing characters, this opposition of the radicle to the external hilum will be found ; for in addition to the two species contained in the herbarium, in both of which it is very manifest, I have observed it in Z coccineum, and in all the species of South Africa that I have had an opportunity of examining. In some of these species, indeed, it is much less obvious, partly from the greater breadth of the funiculus, and also from its being closely applied, or even slightly adhering, to the testa of the seed. But hence it is possible to reconcile the structure of these species with that of Fabago itself, in which the raphe seems to me to be external : and if this be really the case, Fabago differs from those Zygophylla of South Africa alluded to, merely in the more intimate union of the funiculus with the surface of the testa. Whether this observation might be extended to the other genera of the order, I have not yet attempted to ascertain.

Balanites Agrptiaca, though not belonging to Zygophylleæ, may be here mentioned. The specimen is from Bornou, but like all the other plants of that country, has no particular place of growth indicated, nor is there any observation respecting it. For a very full and interesting history of this plant, I may refer to M. Delile's Flore d'Egypte ( $p .77 . t a b .28$ ).

Of Cistinex, three species were observed between Tripoli and Mourzuk.

The Geraniacex of the collection consist of four species of Erodium, all of which were found on the same journey.

Of Malvaces, considered as a class, there are twelve species in the herbarium. Only two of these are particularly deserving of notice. The first, Adansonia digitata, found in Soudan, where the tree is called Kouka, is described by Captain Clapperton; the second, Melhania Denhamii, a new and

* In Hooker's Flora Scotica, p. 284. 
remarkable species of the genus, differing from all the others in having its bracteæ regularly verticillated, and, at the same time, longer and much broader than the divisions of the calyx.

A single species of Viris is in the collection, from Bornou.

Neurada prostrata, generally referred to Rosacex, was found in Wady Ghrurbi.

Tamariscinex. A species of Tamarix, apparently not different from T. gallica, is the Attil, common in Fezzan, where, according to Dr. Oudney, it is the only shady tree.

Loranthex. A species of Loranthus, parasitical on the Acacia nilotica, was observed very commonly from Fezzan to Bornou.

Leguminosi. Of this class the herbarium contains thirty-three species, among which there are hardly more than two undescribed, and these belonging to a well-established genus.

Of the order or tribe Mrmosex only three species occur, namely, Acacia nilotica, Mimosa Habbas, and Inga biglobosa, ora species very nearly related to it. Of this last named plant, I judge merely from ripe fruits adhering to the singular club-shaped receptacle, or axis of the spike. The specimens were collected in Soudan, and belong to a tree of considerable importance to the inhabitants of that country, by whom it is called Doura. According to Captain Clapperton, "The seeds are roasted as we roast coffee, then bruised, and allowed to ferment in water; when they begin to become putrid, they are well washed and pounded; the powder made into cakes, somewhat in the fashion of our chocolate; they form an excellent sauce for all kinds of food. The farinaceous matter surrounding the seeds is made into a pleasant drink, and they also make it into a sweetmeat." The Doura of Captain Clapperton is probably not specifically different from the Nitta mentioned by Park, in his First Journey; nor from Inga biglobosa of the Flore d'Oware of M. de Beauvois, according to whom it is the Nety of Senegal ; and he also well remarks, that Inga biglobosa, described by Jacquin as a native of Martinico, has probably been introduced into that island by the Negroes, as he himself found it to have been in St. Domingo.

Inga Senegalensis of M. De Candolle (Prodr. 2. p. 442) may also belong to the same species.

It is possible, however, that some of the plants here mentioned, though very nearly related to each other, and having all the same remarkable clubshaped spike, may be specifically distinct; for it appears from specimens col$h h$ 
lected at Sierra Leone by Professor Afzelius, that two plants having this form of spike are known in that colony; and two species, with similar inflorescence, probably distinct from those of Africa, are described in the manuscript Flora Indica of Dr. Roxburgh. All these plants possess characters fully sufficient to distinguish them from Inga, to which they have hitherto been referred. The new genus which they form, one of the most striking and beautiful in equinoxial Africa, I have named PARKIA*, as a tribute of respect to the memory of the celebrated traveller, by whom the fruit of this genus was observed in his first journey, and who, among other services rendered to botany, ascertained that the plant producing Gum Kino is a species of Pterocarpus $†$. I have formerly endeavoured to distinguish Mimoseæ from Cæsalpineæ, by the valvular æstivation of both its floral envelopes, and by the hypogynous insertion of its stamina. Instances of perigynous insertion of stamina have since been noticed by MM. Kunth and Auguste de St. Hilaire; but no exception has been yet pointed out to the valvular astivation of their calyx and corolla.

$$
\text { * PARKIA. }
$$

ORD. NAT. Leguminosa-Mimasea : Cæesalpineis proximum genus.

Char. Gen. Calyx tubulosus ore bilabiato $\left(\frac{2}{7}\right)$; xstivatione imbricata! Petala 5. subæqualia, supremo (paulo) latiore; sestivatione conniventi-imbricata. Stamina decem, hypogyna, monadelpha. Legumen polyspermum : epicarpio bivalvi; endocarpio in loculos monospermos sarcocarpio farinaceo tectos solubili.

Arbores (Africano et India orientalis) inermes. Folia bipinnata, pinnis foliolisque multijugis; stipulis minutis. Spica axillares, pedunculatex, clavata floribus inferioribus (dimidii cylindracei racheos) sape musculis.

Parkı Africana, pinnis sub-20-jugis, pinnulis sub-30-jugis obtusis intervalla aquantibus, cicatricibus distinctis parallelis, glandula ad basin petioli, rachi communi eglandulosa, partialium jugis (2-3) summis glandula umbilicata.

Inga biglobosa, Palis de Beauv. Flore d'Ouare, 2. p. 53. tab. 90. Sabine in Hortic. Soc. Transact. 5. p. 444. De Cand. Prodr. 2. p. 442.

Inga Senegalensis. De Cand. Prodr. 2. p. 442.

Mimosa taxifolia. Pers. Syn. 2. p. 266. n. 110.

Nitta. Park's First Journey, p. 336-337.

+ Park's Second Journey, p. exxiv. where it is stated to be an undescribed species of that genus. Soon after that Narrative appeared, on camparing Mr. Park's specimen, which is in fruit only, with the figure published by Lamarck in his Illustrations (tab.602.f. 4.), and with M. Poiret's description (Encyc. Meth. Botan. 5. p. 728.), I referred it to that author's P. erinacca, a name which is, I believe, adopted in the last edition of the Pharmacopoia of the London College. Dr. Hooker has since published a drawing of the same plant by the late Mr. Kummer, and considering it a new species, has called it Pterocarpus Senegalensis. (Gray's Trav. in Western Africa, p. 395, tab. D.) 
Parkia, however, differs from other Mimoseæ not only in its æstivation, which is imbricate, but in the very manifest irregularity of its calyx, and in the inequality of its petals, which, though less obvious, is still observable.

Erythrophleum, another genus indigenous to equinoxial Africa, which I have elsewhere* had occasion to notice, and then referred to Cæalpineæ, more properly belongs to Mimoseæ, although its stamina are perigynous. In this genus, both calyx and corolla are perfectly regular, and their æstivation, if not strictly valvular, is at least not manifestly imbricate, though the flower-buds are neither acute nor angular. In Erythrophleum and Parkia, therefore, exceptions to all the assumed characters of Mimosex are found, and there is some approach in both genera to the habit of Cæsalpinex. It is still possible, however, to distinguish, and it will certainly be expedient to preserve, these two tribes or orders. Abandoning divisions strictly natural, and so extensive as the tribes in question, merely because we may not be able to define them with precision, while it would imply, what is far from being the case, that our analysis of their structure is complete, would, at the same time, be fatal to many natural families of plants at present admitted, and among others to the universally received class to which these tribes belong. No clear character, at least, is pointed out in the late elaborate work of M. De Candolle + , by which Leguminesæ may be distinguished from Terebintaceæ and Rosaceæ, the orders supposed to be the most nearly related to it. It is possible, however, that such characters, though hitherto overlooked, may really exist; and I shall endeavour to show that Leguminosæ, independent of the important but minute differences in the original structure and developement of its ovulum, may still be distinguished at least from Rosacea.

In the character of Polygalex, which I published in 1814 $\neq$, I marked the relation of the parts of the floral envelopes to the axis of the spike, or to the subtending bractea. I introduced this circumstance chiefly to contrast Polygalex with Leguminose, and to prove, as I conceived, that Securidaca, which had generally been referred to the latter family, really belonged to the former.

M. de Jussieu, who soon after published a character of Polygaleæ, entirely omitted this consideration, and continued to refer Securidaca to Leguminosæ. M. De Candolle, however, in the first volume of his Prodromus, has adopted

\footnotetext{
* Tuckey's Congo, p. $430 . \quad+$ Memoires sur la Famille des Legumineuses.

$\ddagger$ Flinders's Voy. to Terra Austr. 2. p. 542.
}

$h h 2$ 
both the character and limits of Polygalex, which I had proposed, though apparently not altogether satisfied with the description he himself has given of the divisions of the calyx and corolla.

The disposition of the parts of the floral envelopes, with reference to the axis of the spike, in Polygalex, namely, the fifth segment of the calyx being posterior or superior and the fifth petal anterior or inferior, is the usual relation in families the division of whose flower is quinary. This relation is in some cases inverted; one example of which I have formerly pointed out in Lobeliacex*, as I proposed to limit it, and a similar inversion exists in Leguminosæ. But this class also deviates from the more general arrangement of the parts of the flower with regard to each other. That arrangement consists, as I have long since remarked $t$, in the regular alternation of the divisions of the proximate organs of the complete flower. To this arrangement, indeed, many exceptions are well known; and M. De Candolle has given a table of all the possible deviations, but without stating how many of these have actually been observed ¥.

In Leguminosæ the deviation from the assumed regular arrangement consists in the single pistillum being placed opposite to the lower or anterior segment of the calyx.

In these two characters, namely, the relation of the calyx and corolla both to the simple pistillum and to the axis of the spike or to the bractea, Leguminosæ differ from Rosaceæ, in which the more usual arrangements are found.

But in those Rosaceæ, in which the pistillum is solitary and placed within the anterior petal, its relation to the axis of the spike is the same as that of Leguminosæ, in which it is within the anterior division of the calyx. And in all families, whether dicotyledonous or monocotyledonous, this, I believe, is uniformly the position of the simple solitary pistillum with regard to the spike or bractea.

The frequent reduction of Pistilla, in plants having the other parts of the flower complete in number, must have been generally remarked. But the order in which these abstractions of pistilla take place, or the relations of the reduced series to the other parts of the flower, have, as far as I know, never yet been particularly attended to. It will probably appear singular, that the observation of these relations in the reduced series of pistilla should have suggested the

* Flinders's Austr. 2, p. 559.

+ Prodr. Flor. Now. Holl, 1, p. 558.

‡ Theor. elem. ed. 2. p. 183. 
opinion, that in a complete flower, whose parts are definite, the number of stamina and also of pistilla is equal to that of the divisions of the calyx and corolla united in Dicotyledones, and of both series of the perianthium in Monocotyledones.

This assumed complete number of stamina is actually the prevailing number in Monocotyledones ; and though in Dicotyledones less frequent than what may be termed the symmetrical number, or that in which all the series are equal, is still found in decandrous and octandrous genera, and in the greater part of Leguminosæ. The tendency to the production of the complete number, where the symmetrical really exists, is manifested in genera belonging or related to those pentandrous families in which the stamina are opposite to the divisions of the corolla, as by Samolus related to Primulaceæ, and by Bæobotrys, having an analogous relation to Myrsineæ; for in both these genera, five additional imperfect stamina are found alternating with the fertile, and consequently occupying the place of the only stamina existing in most pentandrous families. Indieations of this number may also be said to exist in the divisions of the hypogynous disk of many pentandrous orders.

With respect to the Pistilla, the complete number is equally rare in both the primary divisions of phænogamous plants. In Monocotyledones, the symmetrical number is very general, while it is much less frequent in Dicotyledones, in which there is commonly a still farther reduction.

Where the number of Pistilla in Dicotyledones is reduced to two, in a flower in which both calyx and corolla are present and their division quinary, one of these pistilla is placed within a division of the calyx, the other opposite to a petal or segment of the corolla. In other words, the addition to the solitary pistillum, (which is constantly anterior or exterior), is posterior or interior. This is the general position of the component parts of a bilocular ovarium, or an ovarium having two parietal placentæ; and in flowers whose division is quinary, I can recollect no other exceptions to it, than in some genera of Dilleniacer.

It is particularly deserving of notice, that the common position of the cells of the bilocular pericarpium with relation to the axis of the spike was well known to. Casalpinus, who expressly distinguished Cruciferce from all other bilocular families by their peculiarity in this respect, the loculi in that family being placed right and left, instead of being anterior and posterior*.

* Cesalp. de Plantis, p. 327. cap. xv. et p. 351, cap. liit. 
On the subject of the position of the Pistilla in the other degrees of reduction from the symmetrical number, I shall not at present enter. But in reference to Leguminosæ, I may remark, that it would be of importance to ascertain the position of the Pistilla in the pentagynous Mimosea, stated to have been found in Brazil by M. Auguste de St. Hilaire*. Are these Pistilla placed opposite to the divisions of the calyx, as might probably be inferred from the position of the solitary Legumen in this class? Or are we to expect to find them opposite to the petals, which is the more usual relation, and their actual place in Cnestis, though the single ovarium of Connarus, a genus belonging to the same family, is seated within the anterior division of the calyx ?

In the very few Leguminosæ in which the division of the flower is quaternary, namely, in certain species of Mimosa, the ovarium is still placed within one of the divisions of the calyx.

As to Moringa, which was originally referred to this class from a mistaken notion of its absolutely belonging to Guilandina, it is surely sufficiently different from all Leguminosæ, not only in its compound unilocular ovarium with three parietal placentæ, but also in its simple unilocular antheræ; and it appears to me to be an insulated genus, or family (Moringece), whose place in the natural series has not yet been determined.

Cesalpinez. Of this tribe, four species only occur in the collection. One of these is Bauhinia rufescens of Lamarck (Illustr. 329, f. 2.); another is Cassia (Senna) obovata, which, according to Dr. Oudney, grows wild in small quantities in Wady Ghrurbi.

Papilionaces. Twenty-six species of this tribe are contained in the herbarium, none of which form new genera, and the only two species that appear to be unpublished belong to Indigofera.

Alhagi Maurorum, or Agoul, is abundant in Fezzan, where it forms excellent food for camels.

Composux $x$. Of this class, thirty-six species exist in the collection. The far greater part of these were found in the vicinity of Tripoli and in the Desert. All of them appear to belong to established genera, and very few species are undescribed.

Rubiacex. The herbarium contains only six species of this family, five

* De Cand. Legum. p. 52. 
of which, belonging to Spermacoce and Hedyotis, were found in Bornou and Soudan; the sixth, a species of Galium, near Tripoli.

Of Asclepiades only three plants occur. One of these is a new species of Oxystelma, exactly resembling in its flowers O. esculentum of India, from which it differs in the form of its leaves, and in that of its fruit*. A species of Dœmia was found in the Desert; but the specimens are too imperfect to be ascertained.

Of Apocinea, strictly so called, there is no plant whatever in the collection; and of Gentianex, a single species only of Erythræa.

Sesamex. An imperfect specimen of Sesamum pterospermum, of the catalogue of Mr. Salt's Abyssinian plants $\uparrow$, is in the collection from Bornou.

SAPотеж. The only plant of this family in the herbarium is the Micadania, or Butter Tree of Soudan, particularly noticed by Captain Clapperton. The specimen, however, is very imperfect, consisting of detached leaves, an incomplete fruit, and a single ripe seed. On comparing these leaves with the specimen of Park's Shea Tree + , in the Banksian Herbarium, I have little doubt that they both belong to one and the same species. Whether this plant is really a Bassia, is not equally certain ; and the seed at least agrees better with Vitellaria paradoxa of the younger Gærtner, (Carpol. tab. 205.) than with that of Bassia, figured by his father, (de Fruct. et Sem. Pl. tab. 104.)

That the woody shell in the nuts of all Sapotea is really formed of the testa or outer membrane of the seed, as I have elsewhere stated \$, and not of a portion of the substance of the pericarpium, according to the late M. Richard and the younger Gærtner, is proved not only by the aperture or micropyle being still visible on its surface, as M. Turpin has already shown in one case, ( $A n n$. $d u$ Mus. d'Hist. Nat. 7, tab.11, f. 3 .); but also by the course and termination of the raphe, as exhibited in the younger Gærtner's figures of Calvaria and Sideroxylum, (Carpol. tabb.200, 201, et 202.) and by the origin and ramification of the internal vessels.

* Oxystelma Bornouense, floribus racemosis, corolle laciniis semiovatis, folliculis inflatis, foliis lanceolatis basi cordatis.

Obs.-Inflorescentia et corolla omnino O. esculenti, a quo differt folliculis inflatis, et foliis omniluus basi cordatis.

† Salt's Voy. to Abyss. append. p. 1xiii.

\$ Park's First Journey, p. 202 and 352.

$\S$ Prod. Flor. Nov. Holl. 1, p. 528. 
Scrophularine. Only six species of this family occur, none of which are unpublished.

Orobanche compacta of Viviani was observed between Fezzan and Bornou.

Of Convolvulacex there are five species, four of which belong to Bornou; the fifth is an aquatic Ipomøea, found creeping on the borders of a small lake near Tintuma. Possibly this plant may be Ipomœa aquatica of Forskal, and consequently Convolvulus repens of Vahl, (symb. 1, p. 17.) It is not, however, the plant so called by Linnæus, which proves, as I have elsewhere stated, (Prodr. Fl. Nov. Holl. 1, p. 483.) to be Calystegia sepium; nor does it belong to either of his synonymes. Our plant differs also from Vahl's description of his Convolvulus repens, in having constantly single-flowered peduncles, and leaves whose posterior lobes are rather acute than obtuse, and are quite entire. It is probably, therefore, distinct; and I have named it Ipomœa Clappertoni*.

Among the few Labiate, there is a species of Lavandula, possibly distinct from but very nearly related to L. multifida. It was found on the mountains of Tarhona.

Of Boraginex, the herbarium includes eleven species, the greater part of which were collected near Tripoli, and all of them belong to well established genera.

Primulacex. Of this family two species of Anagallis occur in the collection, and of these A. cærulea was observed both near Tripoli and in Bornou.

Samolus Valerandi was also found near Tripoli, in Wady Sardalis in Fezzan, and in Bornou.

Of Dicotyledonous, or even of all phænogamous plants, $S$. valerandi is perhaps the most widely diffused. It is a very general plant in Europe, has been found in several parts of North Afriea, in Dr. Oudney's herbarium it is from Bornou, I have myself observed it at the Cape of Good Hope and in New South Wales, and it is also indigenous to North America.

The geographical distribution of the genus Samolus is equally remarkable. At present eight species are known, of which S. Valerandi is the only one in-

* Irosrasa Clappertoni, glaberrima repens, foliis sagittatis: lobis posticis acutiusculis integerrimis, pedunculis unifloris. 
digenous to Europe, or which, indeed, has been found in the northern hemisphere, except the nearly related $S$. ebracteatus of Cuba. All the other species belong to the southern hemisphere, where $S$. Valerandi has also a very extensive range.

Of Plumbagines, there are three species of Statice Taxanthema; for the latter name may be preserved as belonging to a section, though hardly as that of a genus, so far at least as depends on inflorescence, which in both subdivisions of Statice is essentially similar; that of Statice Armeria being only more condensed. Of the three species in the herbarium, one appears to be unpublished.

Among the plants of the Apetalous orders in the collection, there are very few remarkable, and hardly any new species.

Gymnocarpus decandrum was observed by Dr. Oudney very commonly in gravelly deserts, on the route from Tripoli to Fezzan; and Cornulaca monacantha of M. Delile is said to be widely extended from Tripoli to Bornou, and to be excellent food for camels.

MonocotYLEDones. The number of species belonging to this primary division contained in the herbarium is altogether seventy. But Graminex and Cyperaceæ being excluded, thirteen only remain, namely, three species of Juncus, a single Commelina, three Melanthaceæ, three Asphodelex, one speeies of Iris, and two Aroideæ, of which Pistia Stratiotes is one.

Of these thirteen plants, two appear to be unpublished, both of them belonging to Melanthacea. The first, a congener of Melanthium punctatum, which is also in the collection, was found in Fezzan.

The second is a species of Colchicum, very different from any hitherto described; and which yet, by Mr. Ritchie, who first observed it, is said to be common in the desert near Tripoli, where it was also found by Dr. Oudney.

This species, which I have named Colchicum Ritchï, is easily distinguished from all its congeners by having two cristæ or membranous processes which are generally fimbriated, at the base of each segment of the perianthium, parallel to eaeh other, and to the intermediate filament. But this character, though excellent as a specific difference, is neither of generic importance, nor sufficient to authorise the formation of a separate section *

* Colchicum (Hermodactylus) Ritchï, limbi laciniis basi intus bicristatis! fasciculo $2-$ multifloro, foliis linearibus. 
Bulbocodium and Merendera, however, which, following Mr. Ker*, I consider as belonging to Colchicum, appear to me decidedly to form subgenera or sections ; and in this opinion I am confirmed by having found a fourth section of the same genus. This fourth subgenus is established on Hrpoxis Fascicularis, a plant which has been seen by very few botanists, and which Linnæus introduced into his Species Plantarum, and referred to Hypoxis, solely on the authority of the figure published in Dr. Russell's History of Aleppo. In the Banksian Herbarium I have examined part of the original specimen of this species, found by Dr. Alexander Russell, and figured by Ehret in the work referred to, as well as more perfect specimens collected by Dr. Patrick Russell ; and am satisfied that its ovarium is not in any degree adherent to the tube of the perianthium. I find, also, that Hypoxis fascicularis differs from Colchicum merely in having a simple unilocular ovarium with a single parietal placenta and an undivided style, instead of the compound trilocular ovarium with distinct or partially united styles, common to all the other sections of that genus.

A reduction, as in this case, to the solitary simple pistillum $\dagger$, though existing in all Graminex and in certain genera of several other families of Monocotyledones, is yet comparatively rare in that primary division of phænogamous plants, and in the great class Liliaceæ, the present species of Colchicum offers, I

Obs.-Spathe 2-8-floræ; limbi laciniæe vel lanceolate acutiusculæe vel oblongæe obtuse ; criste laciniarum omnium sape fimbriato-ineisæ, exteriorum nune integerrimæ. Ovula in singulis ovarii loculis biseriata, placentarum marginibus approximata ; nec ut in C. autumnali quadriseriata.

* Botan. Magaz. 1028.

+ The late celebrated M. Richard, in his excellent "Analyse du Fruit," in pointing out the distinctions between a simple and compound pericarpium, produces that of Melanthacex as an example of the compound, in opposition to that of Commelinea or of Juncex, which, though equally multilocular, he considers as simple. A knowledge of the structure of Colchicum Monoearyum would, no doubt, have confirmed him in his opinion respecting Melanthacex.

It has always appeared to me surprising, that a carpologist so profound as M. Richard, and whose notions of the composition of true dissepiments, and even of the analogy in placentation between multilocular and unilocular pericarpia, were, in a great degree, equally correct and original, should never have arrived at the knowledge of the common type of the organ or simple pistillum, to which all fruits, whether unilocular or multilocular, were reducible; and that he should, in the instance now cited, have attempted to distinguish into simple and compound two modifications of the latter so manifestly analogous, and which differ from each other only in the degree of coalescence of their component parts. 
believe, the only known example. Yet this remarkable character is here so little influential, if I may so speak, that Hypoxis fascicularis very closely resembles some states of Colchicum Ritchii, and in the Banksian herbarium has actually been confounded with another species of the first or trigynous section of the genus.

To the first section, which includes Colchicum Ritchii, the subgeneric name Hermodactylum may, perhaps, be applied; while that established on Hypoxis fascicularis may be called Monocaryum.

The position of the pistillum in Colchicum (Monocaryum) fasciculare is not easily determined. I believe it to be placed within the anterior segment of the outer series of the perianthium, but, from the great length of the tube, it is difficult to ascertain such a point in dried specimens. This, however, is the position in which 1 should expect it, both in reference to the usual relation of the solitary simple pistillum to the axis of the spike, or to the subtending bractea in all phænogamous plants; and also with regard to the constant relation of the parts of the compound pistillum to the divisions of the perianthium in Monocotyledones : for it is worthy of remark, that a difference in this relation may be said to exist in the two primary divisions of phænogamous plants-the pistilla when distinct, or their component parts when united, being in Dicotyledones usually placed opposite to the petals, when these are of equal number; while in Monocotyledones the cells of the trilocular ovarium are, I believe, uniformly opposite to the divisions of the outer series of the perianthium.

Cyperaces. Of twelve species of this family existing in the herbarium, six are referrible to Cyperus, three to Fimbristylis, and three to Scirpus. - Among these there is no remarkable, nor, I believe, any undescribed species. Of C. Papyrus, which, according to Captain Clapperton, grows in the Shary, there is no specimen in the collection.

Graminex. Of this extensive family, with which Dr. Oudney was more conversant than with any other, and to which, therefore, during the expedition, he probably paid greater attention, the herbarium contains forty-five species : and in dividing the order into two great tribes, as I have formerly proposed *, thirty

* Flinders's Voy. to Terra Austr. 2. p. 582.

$$
\text { i i } 2
$$


of these species belong to Poacea, and fifteen to Panicea. This relative proportion of these two tribes is considerably different from what might have been expected, in the climates in which the collection was formed : it seems, however, to be connected with the nature of the surface, for in the Great Desert the reduction of Paniceæ is still more remarkable; this tribe being to Poacex, in that region, in the proportion of only five to eighteen.

Dr. Oudney remarks with respect to the grasses of the desert, that he observed no species with creeping roots; for a species of Arundo related to Phragmites, which he notices as the only exception, is not properly a desert plant.

Among the very few Gramineæ deserving particular notice, the first is Avena Forskanir of Vahl. The specimens in the herbarium which were collected in the desert of Tintuma in some respects differ from all the others that $I$ have seen of this variable species. In the Banksian herbarium there is an authentic specimen from Forskal; I have received from M. Delile specimens both of his A. Forskalii and arundinacea, described and figured in his Flore d'Egypte; and am also in possession of others in somewhat different states, collected in Egypt by M. Nectoux and Dr. Sieber. From a comparison of all these specimens, I am led to believe, that A. Forskalii and arundinacea are not specifically distinct ; and it is at least evident, that arundinacea more nearly approaches to the plant of Forskal than that to which M. Delile has applied the name Forstalii.

This grass, which does not belong to Arena, is referrible to Danthonia, from the structure of the outer valve of its perianthium. But Danthonia requires subdivision into several sections, of which, perhaps, our plant may be considered as forming one.

The character of the section established on Danthonia Forskalii would chiefly consist in the very remarkable obliquity of the joints of the locusta, which is, indeed, so great, that after their separation each flower seems to have at the base an almost vertically descendent spur; and as the inferior extremity of the upper joint is produced beyond the lower, a short calcar actually exists before separation, and this calcar is equally manifest in the terminal rudiment of the locusta. The present, therefore, is a case of more remarkably oblique articulation in grasses than even that existing in Holcus acicularis (Andropogon 
acicularis, Retz), which led to the formation of Centrophorum; a genus still admitted by Professor Sprengel *, and respecting the structure of which a very singular explanation has been lately offered by $\mathrm{M}$. Raspail $\uparrow$. In one respect, the two cases differ. In Danthonia (Centropodia) Forskalii, the articulations being in the axis of the locusta or spicula, each flower appears to have this spur-like process; while in Holcus (Rhaphis) acicularis, the joint being in the peduncle or branch of the racemus, the spur is common to three locustæ.

Dr. Fischer, in whose herbarium the specimen was observed which led to the formation of Centrophorum, will probably recollect the communication made to him on the subject of that plant, of which Dr. Trinius himself has since corrected the characters. He retains it, however, as a distinct genus, for which he has adopted the name Rhaphis, given to it by Loureiro, by whom it was originally proposed, on other, but not more satisfactory grounds.

Triraphis Pummio is the second plant of this family to be noticed. It is undescribed, and belongs to a genus of which the only two published species were found in the intratropical part of New Holland $\ddagger$. In several points of structure the African plant is very different from $T$. pungens, the first of these species; in some respects it approaches to mollis, the second species, especially in the inequality of its setæ or aristæ, but it differs from both in habit, and in having only one perfect flower in each locusta $\S$.

Of Pennisetum рiснотомum, (Delile, Flore d'Egypte, p. 15, tab. 8, f. 1.), which, in several different states, is in the collection, it is remarked by Dr. Oudney, that " it is a great annoyance to man and beast, from the prickly calyx (involucrum);" and by Major Denham, that from Aghedem to Woodie " it covered the surface of the country, and annoyed the travellers to misery ;" he observes, also, that the seed is called Kasheia, and is eaten.

* Syst. Veg. 1. p. 132.

+ Annal, des Scien. Nat, 4. p. 425.

$\ddagger$ Prodr. Flor. Nov. Holl. 1. p. 185.

\$ Triraphis Pumilio, panicula coarctata abbreviata, locusta glumam vix superante 3-4flora : flosculo infimo hermaphrodito; reliquis neutris univalvibus. 
Panicum turgidum, (Forsl. Arab. p. 18 ; Delile, Flore d'Egypte, p. 19, tab. 19, f. 2.), is also one of the most common grasses from Tripoli to Bornou.

Of Acotyledones, the only plant in the collection is Acrostichum velleum, found on the Tarhona mountains. Mr. Ritchie's herbarium contains, also, a single plant of the same family, namely Grammitis Ceterach.

The foregoing observations have extended much beyond the limits which the number and importance of the plants they relate to may seem to require. I still regret, however, that I cannot add a few remarks on such species as, although not in the herbarium, were observed, either indigenons or cultivated, in the countries visited by the mission, and for information respecting which I am indebted to Major Denham and Captain Clapperton. But it being determined no longer to delay the publication of the very interesting Narrative, to which the observations already made will form an Appendix, I am unable at present to enter on this part of my subject. 
No. XXIII.

Letter to Major Denham, on the Rock Specimens brought from Africa. By Charles Konig, Esq. F.R.S.

British Museum, Feb. 25th, 1826.

My dear Sir,

I have great pleasure in transmitting to you, for whatever use you may think proper to make of it in the Appendix to your fortheoming work, the little I have to advance on the geological and a few other objects, that were collected by you, the late Dr. Oudney, and Captain Clapperton, on your journey through the great African desert, and are now deposited in the British Museum. It chiefly consists of the descriptive catalogue of a small series of rock specimens, originally drawn up by me without particular regard to their geognostic occurrence; to which I now prefix a few desultory remarks that occurred to me, when, with a view to its publication, I subjected that list to a second perusal. My materials are, indeed, very scanty; but their description may, nevertheless, (in conjunction with the observations dispersed in the body of the work, of which I have not been able to avail myself) lead some of your geological readers to more or less important results relative to the structure of the tract of country in which they were collected.

There are among the specimens I have examined none that might be referred to the primitive formations, except those gathered south and west of Kouka. The principal specimen of granite (No. 1.) brought by you from the Mandara mountains strongly resembles some of the fresh large-grained varieties of the same from the Fetish rocks in Congo. Those from Soudan, with feldspar, in its progress to kaolin, (No. 5.) betray the principal cause of the striking appearance of the granite mountains in that part of central Africa. The effects of atmospheric influence on that component, spreading chiefly in the direction of the natural rifts of the rock, are, in the Soudan mountains as well as in those of the Hartz, the Riesengebirge, and other European granitic districts, manifested partly by the immense and numberless blocks, wholly or partially detached, and confusedly piled up on the sides of the mountains, or 
strewed over the plains in fantastic groups; and partly by the almost total disintegration of the masses into gravel at the foot of the ridges. The former of these effects is illustrated by the sketch of a granite mountain in Soudan, which you were so good as to show me. There are a few other specimens of granite from Soudan; but they present no characters from which any useful information is likely to be derived; the less so, as they appear to be casual fragments, not found in situ. The mica slate (No. 9.), as Captain Clapperton informed me, occurs at the upper part of the ridges between Quarra and Zurma; and a ticket, accompanying a micaceous rock specimen, (No. 11.) from the same locality, as I suppose, states it to be " used for glazing earthen ware."

These are all the specimens of primitive rocks. As to those of secondary and tertiary formations, which have been brought home, it will appear from the subjoined catalogue, (as, indeed, with regard to part of the kingdoms of Tripoli and Fezzan, has already been pointed out by Dr. Buckland), that they may be referred to three formations, viz. 1. to the fletz-trap or basaltic formation; 2. to a formation analogous to the Paris limestone, (calcaire grossier, grob-kalk); and 3. to some members of the secondary formation from the chalk to the alpine limestone inclusively.

The few specimens of the first mentioned of these formations are specified under Nos. 14 to 18. To the second I would refer the sandstone No. 26 . with fragments of small univalve shells, not unlike a species of Paludina, and the plastic clay of Cano, of which, I suppose, are made the light pipe bowls, brought from thence; together with some other specimens of clay, and also some fragments of shells, apparently from the tertiary limestone, but the localities of which are not mentioned.

But by far the greater proportion of the specimens brought home by you belongs to that series of the secondary formations of which the variegated sandstone is the principal member. Subordinate to this is the ferruginous sandstone, (Nos. $47,8 c$.) with its beds of brown hydrous oxide, into which, as also into ochrey ironstone, (Nos. $84-90$.) it appears to pass by gradual transition. The white sandstone, called quader-sandstein by most German geologists, and sandstone of Konigstein by Baron Humboldt, is not specified as such in the list ; I am, however, inclined to think it is not entirely wanting in several parts of the tract you have traversed, especially to the southward of the boun- 
dary of Fezzan. I conclude it, from what you have mentioned to me of the picturesque and ruin-like appearance of many of the mountain ranges in those parts, which is peculiar to that sandstone; from the external character of some of the specimens, which, however, have no localities affixed to them; as also from the impressions of small bivalves on one or two of them. No stress is perhaps to be laid on the occurrence of fibrous limestone, which substance is known to be among the mineral contents of quader-sandstone at the foot of the Hartz, where this link of the fletz sandstone formation rests on the red marle sandstone, without the intervention of shell limestone, of which latter I have seen no specimens among those from North Africa.

More characteristic are the specimens of the variegated sandstone, properly speaking. The varieties, which, by their patches, stripes, and flamed delineations, are more particularly entitled to that denomination, are Nos. 31 -36. The friable sandstone of Traghen (No. 23.) probably owes its green colour to oxide of nickel : the colouring matter seems chiefly to reside in the clay by which the grains are held together.

Particularly remarkable are those varieties of sandstone in which the cement is quartz, both with and without ferruginous admixture (Nos. $37-46$ ). They are all (with the exception of a few of more loose texture, which belong to a tertiary formation) referable to the variegated sandstone series. In some of these the cement of various colours, yellowish, red, brown, bluish, is so completely conferruminated with the grains, that, upon breaking a specimen, the fracturing plane invariably passes through them, producing a uniformly smooth and frequently conchoidal surface. Sometimes both cement and grains are united into one homogeneous quartzy mass, in which, especially when thoroughly impregnated with oxide of iron, scarcely the slightest vestiges of former granulation remain perceptible. Such an extraordinary transformation of the cementing mass, observable not only in this but likewise in the quadersandstone, the iron sand, and the variety of the newest sandstone called molasse, presupposes a state of liquefaction, and is but imperfectly accounted for by those who ascribe it to infiltration.

The result of another, equally enigmatical, liquefaction of siliceous matter, (which is, however, generally, though gratuitously, attributed to the agency of lightning) we see in the tubular concretions that have been found near Drigg in 
Cumberland, on the Senner heath in Westphalia, at Pillau in the vicinity of Konigsberg, at Halle upon the Saale, and, lastly, on the plains near Dibla in the Tibbou country. The African sand tubes differ from those of Drigg, as the sands themselves differ from each other in the two localities; the texture of the former is more homogeneous and pure, some being translucent and almost colourless ; and, when cylindrical, not unlike some tubular varieties of stalactic carbonate of lime. Others are internally of a light-grey colour, here and there marked with white specks from semi-fused grains of sand: their outer surface is either approaching to smooth, or studded with snow-white opaque grains of sand, sunk in the vitrified substance ; but they are not coated by the agglutinated sand which, in the English tubes, forms a rough crust, gradually passing into the vitreous substance of the sides. The stem, to judge from the short fragments I have seen, is very irregular in its circumference, and (except in the small cylindrical tubes, whose surface is even) polymorphously jagged, compressed, and contorted. Their interior lustre is superior to that observable in the European Fulgurite, Astraphyalite, Ceraunian Sinter, Blitzröhren,-names under which these tubular concretions have been introduced into our systems of mineralogy.

In most of the specimens of the variegated series described in the catalogue, the presence of common salt is obvious to the eye or the taste, or at least discoverable on the application of chemical re-agents. The tickets placed with No. 35, and some others, are inscribed "Aluminous slate ;" but these specimens belong to the micaceous variety into which the red marle sandstone so frequently passes, and which sometimes forms distinct beds in it, overlaid by variegated and white marle slate; neither is the salt with which they are impregnated any other than muriate of soda.

The gypsum, of which some varieties are among the specimens found in the red marle, both at the most northern and the most southern points where Dr. Oudney collected, is of course referable to the newer, and some even to the newest, formation : it is mostly foliated-fibrous, and, in several specimens, intermixed with red clay.

I have little to say on the specimens of limestone enumerated in the list : most of them agree perfectly well with our new magnesian limestone; but external as well as chemical characters in detached fragments, not observed in 
situ, are but uncertain guides to the determination of the various modifications of Werner's older fletz limestone, to which, I suppose, those specimens must all be referred.

There are only two specimens of common salt brought home, neither of which exhibit any thing peculiar in their appearance: but were they ever so numerous or remarkable in their exterior, they would not contribute greatly towards illustrating the history of the saline deposites and saliferous formations of the regions from which they come. The excessive abundance of salt in the variegated sand all over the central part of northern Africa, indicates either the existence of an extensive deposition of that substance beneath the prevailing rock formation, or the uninterrupted operation of causes by which those superficial saline masses, crusts, and efflorescences (the last of these observable in most specimens of sandstone brought from thence), are produced independently of briny waters emanating from such deposits of rocksalt. Mr. Keferstein, who has collected a multitude of instances of the occurrence of salt springs in situations which would seem to preclude the possibility of an immediate connexion between them and extensive beds of rock salt, has by ingenious reasoning and a number of interesting facts endeavoured to prove, that, in contact with waters circulating in the earth, the members of the saliferous formation (especially the clay to which, as an inseparable concomitant of salt, the name of salzthon has been given) are endowed with the power of generating salt by means of a chemical process, of which the rationale (as that of many others) remains among the desiderata of the science.

Those who are of opinion that brine springs are, under all circumstances, derived from great salt formations, and that their rise and presence, in any given situation, may be satisfactorily accounted for, by hydrostatic pressure alone, will probably find nothing extraordinary in the peculiar occurrence of that substance in the clay of the extensive salt fields of Mafen, Hamera, \&c.; they will consider the various forms under which it presents itself in those tracts merely as the result of aggregation of saline particles conveyed from the great depot to the crevices of the clay, gypsum, and sandstone, and left there by the simple process of evaporation. I shall not attempt examining which of the two theories derives most support from the different phenomena relative to the production of salt observed by you on your journey, or to the occurrence of fresh water springs in the centre of salt hills, dwelt upon by Herodotus, and

$$
k k 2
$$


other circumstances belonging to halurgic geology ; but refer you, for materials necessary for this inquiry, to the important facts detailed by the abovementioned author in the second volume of his periodical work (Teutschland, geognostisch-geologisch dargestellt, Weimar, 1823), as also to those opposed to them by no less an authority than Mr. V. Langsdorff in his last work (Anleitung zur Salzwerkskunde, Heidelberg, 1824).

The specimens of trona (carbonate of soda), collected on the expedition, exhibit this salt in various degrees of purity. In some, it is mechanically mixed with muriate and sulphate of soda ; in others, it appears, when divested of the casually adhering substances, to be perfectly pure. Of the latter, we have two very distinct varieties, as far, at least, as external characters are concerned. The one consists of layers, or crusts, of about one-third of an inch in thickness, opaque, and of a white colour, generally with an almost imperceptibly slight tinge of red; and yellowish stains are sometimes observable. These layers, when broken, display distinct concretions between lamellar and granular ; the lower surface is rough, and more or less impure, the small interstices being partly filled up with reddish earthy matter; the distinct concretions terminate at the upper surface, in small, slightly cuneiform, apparently four-sided compressed prisms, acuminated by two planes which meet under an angle of about $95^{\circ}$; but both the lateral and terminal edges are constantly rounded off; and the planes uneven and striated. These crystals, not much inferior in hardness to carbonate of lime, are internally splendent, externally dull, and generally covered by a fine efflorescence, and also often studded with small limpid cubical crystals of muriate of soda. This variety is formed in the lakes of Ghraat, apparently in the same manner as the carbonate of soda (urao) of the Lagunilla lake of Venezuela, or that of the S. Macarius lake in Egypt, but appears to be less contaminated with other salts than either of these.

The other variety of carbonate of soda (the locality of which is doubtful, two tickets having been found accompanying the specimen, the one with " Kanem," the other with " hills of Traghen,") occurs in pieces which appear to have been part of a vein or layer. They are composed of groups of divergingly radiated acicular crystals, closely grown together, intermixed with indeterminable capillary crystals, confusedly aggregated. Some of these crystals appeared as very compressed four-sided prisms, indistinctly acuminated by two planes set on the acute lateral edges. Its fracture is lamellar-fibrous, passing 
into splintery ; fragments wedge-shaped. Its colour is a dingy greenish, or yellowish-white, appearing brownish in the more compact parts of the pieces. The internal lustre is splendent; the external surface covered by a yellowish white powder. In the crystalline state, both these varieties of trona appear to be perfectly pure; it is, however, possible that they may differ from each other in the proportion of the water and carbonic acid with which the soda is combined in them. If, as Berthollet thinks, the origin of native carbonate of soda is to be looked for in the decomposition of common salt by carbonate of lime, we may farther conjecture, from the traces of bituminous matter found with the trona, that the rock instrumental to it is fetid limestone, beds of which are frequent concomitants of saliferous formations.

The following is the catalogue of the specimens of which I have been able to determine the localities.

1. Large grained granite; the deep-flesh-coloured feldspar in greater proportion than the greyish quartz, and the black, small-scaly mica. "From the Mandara mountains."

2. The same; with feldspar of dirty-yellowish colour. From the Mandara range, and two similar varieties from the " hills of Dutchie Zangia, Soudan."

3. Similarly coloured variety, but of smaller grain. From the same places.

4. Large grained variety of the same; the feldspar of a yellowish colour, and in a state of incipient decomposition, with little black mica. Mandara.

5. Variety similar to the preceding; in a state of disintegration: the feldspar decomposing into a reddish earth. From Quarra and Zurmee, Soudan.

6. Granite, both fine and coarse-grained, almost entirely composed of flesh-red feldspar, with indeterminable particles of a black substance, apparently mica. "From the high ridges of Zurma."

7. The same, small-grained, rather slaty, approaching to gneiss, composed of greyish-white feldspar and quartz, with predominant black small-scaly mica. From Nansarena, Soudan.

8. Portion of a boulder, chiefly composed of fine-grained dirty-grey semicompact feldspar and some quartz ; with disseminated particles of magnetic iron ore (a syenitic rock). "Found near Agutefa."

9. Greenish-grey mica slate, with little admixed quartz and feldspar. "It forms the upper part of the ridges between Quarra and Zurma, Soudan.” 
10. Yellowish-grey, soft, and friable mica slate. "From between Duakee and Sackwa, Soudan."

11. A hard slaty mass, composed of brilliant silvery small scales of mica, penetrated by, or mixed with, brown and yellow hydrous oxide of iron. From the same.

12. White, massive, and irregularly crystallized fat quartz, stained by oxide of iron. "From a vein in the rocks of Quarra and Zurmee."

13. The same, out of the granite of the Mandara mountains.

18. a. Yellowish and bluish-white quartz in large grains, as gravel. "From the bed of the river Yaou, seven days on the road to Soudan*."

- Three very interesting bivalve shells, distinct, it appears, from the other species of the genera to which they respectively belong, have been discovered in the above-mentioned river by Major Denham. The first, a species of Ætreria, I distinguish as

FTHeria Denhami : testa irregulariter rotundato-oblonga, ad cardinem gibbosa, utriusque valvæ callo cardinali basim versus oblique truneato.

Hab. in Africe interioris fluvio Gammaroo.

The form of the cardinal callosity to which the semi-internal ligament is attached affords a distinction sufficiently characteristic of the species; its oblique truncating plane, which extends towards the rather indistinct umbo, is, in the closed state of the shell, in partinl contact with that of the corresponding and similarly formed callus of the other valve. The general form of the shell is oblong or rounded, but appears to be subject to considerable variation : one of the specimens before me exhibits the exterior of Lamarck's A. transversa, which latter is no doubt a casual variety only of the other species described and figured by that naturalist.

These shells are externally furnished with a blackish-brown epidermis; beneath thís a white film is deposited, on the removal of which a beautiful pearly naker appears, similar to that of the internal surface of the valves. The blistered appearance of the interior of both the valves is constant in all specimens, and may, as intimately connected with the structure of the shell, be considered of sufficient importance to be admitted into the distinetive character of the genus.

Lamarck, imagining that these shells live at the bottom of the sea, named the genus, as he says, after one of the daughters of Oceanus. Though the Ætherix are now well known to be fluviatile shells, the emendators of zoological nomenclature may still be exonerated from framing s new name for this genus, since the old one is derivable from the original locality of its species ; a part of central Africa having, according to Pliny, been anciently known by the appellation of Ttheria.

The second shell, a new species of IripiNa, may be thus characterized:

IsidiNa Oudnci : testa transversa ovato-lanceolata tumidiuscula, cardine stricto sub-edentulo, basis margine sinuato.

Hab. cum priore.

This species is very distinct from E. elongata in form and in the hinge line being without 
14. Greyish-black close-grained basalt. "From the hills in the Sebha district."

15. The same; with rarely disseminated grains of decomposing olivine. From the same.

16. The same; vesicular (basaltic amygdaloid), cells empty. Benioleed.

17. The same as the preceding, with disseminated granular particles, and minute acicular crystals of specular iron, which also mostly invest the irregularly shaped cells. " Benioleed; used for grindstones."

crenulation; and from E. nilotica, which it resembles in the latter of those characters, it differs by its form, inferior thickness, and iridescence. The length of the specimen before me is $4 \mathrm{~g}$, its greatest breadth at the umbe nearly two inches. Placed on the basal edge, which is eoncave, the anterior side presents a considerable slope from the umbo to the exterior margin, which gives the valves a tapering or ovate-lanceolate form. The external epidermis, of a greenish-brown colour, exhibits slightly undulating stria of growth. The interior surface is slightly uneven-undulated, white, with delicate opalescent colours, green and faint pink; the former chiefly disposed in spots. The muscular impressions are more slightly marked than in the other species.

For the third shell, which I considered as a new species of Avopos, I propose the name of

Anopos Clappertoni : testa transversim oblonga, antice in extremo cardine acute excisa.

Hab. cum antecedentibus.

The notch at the anterior extremity of the hinge being always acute, never obtusangular or rounded, I have confined myself to it in the distinctive character of this species, which differs in several other respects from Axopon purpureus and rugosus of Swainson, to both of which it is, however, nearly related. The size of the shell, in the several specimens before me, varies from $1 \frac{1}{2}$ by $\frac{s}{4}$ of an inch to 3 inches by nearly $1 \frac{1}{2}$. Its form is transverse-oval, with a slight slope at the anterior end. The hinge margin is straight. Epidermis olive-green, appearing of a reddishbrown colour, owing to the pink colour of the surface underneath, which latter in one specimen passes into bluish-green at the umbones. Muscular impressions three; one of them, at the anterior end, oval, and continued in a faint tapering form towards the hollow of the umbo; of the two other impressions, which are both stronger marked, the one nearest to the edge of the valve is oval, with a small rounded sinus at the inner border, and close to it a smaller irregularly oval mark with notched margin: the two principal marks are connected by the edge of the impression of the mantle, the smaller mark being placed within the line. The tinge of the internal surface is pink, imperfectly painted over as it were with white. The several specimens, in different stages of growth, exhibit all these characters; there is, however, among them a single valve of rather larger dimensions and more rounded than the rest, with a fine bronze-coloured internal surface like that of Irrdina nilotica. Whether this is to be considered as a distinct species, or only as a variety indicative of the full grown state of the shell, I must leave to the decision of conchologists more experienced in discriminating the ambiguous species of this genus. 
18. The same, of a greyish-brown colour; cells elliptic, and partly filled with carbonate of lime. "Black mountains near Sockna."

19. Greenish and yellowish grey, fine-grained crumbling sandstone. "Found with the gypsum of the hills to the northward of Om-el-Abeed."

20. The same, brownish-yellow ; " occurring in beds near Om-el-Abeed." In. The same, reddish and yellowish, fine-grained, rather friable. Wady Kawan.

22. Similar, reddish-brown variety of sandstone, but more friable than the preceding. Tadrart ridge.

23. The same, of a colour between grass and leek-green, fine-grained, very crumbling. "Traghen, under a gypsum crust; often in beds of from ten to twelve feet. It has the appearance of some of the soft sandstone in the mountain range near Tripoli.”

24. Yellowish-white friable sandstone, and fine sand, strongly impregnated with salt. "Under a calcareous crust, Fezzan."

25. Similar sand of a very fine rounded grain. "From the Wady, in which is the Trona lake."

26. Yellowish clayey sandstone, filled with small rounded quartz grains and minute white particles of small univalve shells, (Paludina?) " Gaaf."

27. Fine and close-grained yellowish-white sandstone, of a thin stratified structure, which is distinctly seen at the disintegrated parts of the fragment. "Wady Katefa, under the basalt ; forming fine precipitous walls in the middle of the range."

28. Brownish-red friable sandstone; the rounded grains of various sizes, loosely united by clay. "Sandstone of the hills of Wady Ghrarbi. There is a finer and tender species, and also a stratiform one; but my specimens are lost."

29. The same, of a similar colour, intermixed with yellowish, less crumbling, and containing pebbles. "From the hills to the westward of Hamera, on which the town is built."

So. Sandstone of yellowish colour and fine-grained, faintly variegated with purple. Aghadem.

31. The same, fine-grained, white, with linear purplish streaks, being the edges of horizontal filmy depositions of iron ochre of that colour. Wady Kawan. 
32. A similar variety, exhibiting purplish-yellow and red variegations, thoroughly impregnated with salt, which is also seen efflorescent on the surface. " Hills of Wady Ghrarbi."

33. Similarly coloured sandstone, in laminar fragments, passing, by decomposition, into soft clay variegated with the same colours. Wady Kawar.

34. Tabular fragment of very close-grained nearly compact variegated sandstone; colours, purplish and two shades of yellow, in irregular stripes. "Sebha district."

35. Purplish-brown slaty sandstone, micaceous on the planes of separation, passing into cream yellow and white clay-stone of the same structure. "Aluminous slate (sic) in different states, forming a considerable part of the mountain range, Tadrart, Tuarick country."

36. A tabular fragment, like the preceding; micaceous on the rifts, of reddish-brown colour, being thoroughly penetrated by oxide of iron. Aghadem.

37. Yellowish sandstone, composed of round grains of quartz, with white clayey cement, which, towards the surface of the rolled piece, becomes quartzy. From ditto.

38. A similar large-grained variety, of reddish-yellow colour with brown streaks, in which the cementing clay, become quartzy, is scarcely distinguishable from the grains. "Forming the eastern boundary of the hills near Traghen."

39. A large fragment of the same quartzy sandstone, of yellow colour, with red streaks and brown nucleus, nearly compact, so as to exhibit on its conchoidal fractural surfaces the traces only of a granular structure. "Strewed over the plain between Ghudwa and Mourzuk."

40. The same, brownish-red, in the shape of a rolled amorphous fragment, having acquired a uniform glossy surface like red jasper. From ditto.

41. Yellowish variety of the same, the granular passing into compact structure. "Thick exposed beds from Om el Abeed to Sebha."

42. Yellowish-grey variety of the same, as perfectly compact tabular fragments, having their surfaces studded with small polymorphous bodies imitating the appearance of parts of secondary fossils. From ditto.

43. The same as the preceding, having its surface marked by small bivalve shells, converted into the mass of the sandstone. From ditto.

44. Sharp-edged fragments, of a variety like No. 39., of a deep chocolatebrown colour and flat conchoidal fracture. "Between Sebha and Timinhint; rocks about 250 feet high." 
4.5. The same, in which the quartz grains are very firmly cemented by darkred or brown siliceous iron-stone, sometimes enclosing larger rounded grains and small pebbles; the whole forming a very hard compact conglomerate with conchoidal shining fractural surface. "From between Om el Abeed to Sebha, and near Zuela."

46. Fragment of a mass of quartzy sandstone and compact brown ironstone, externally stalactic reed-like, with black glossy surface. "From the hills of Wady Ghrarby."

47. Brown ferruginous sandstone, nearly compact, and with drused cavities, enclosing yellowish nodules of magnesian limestone. "Forms the upper part of numerous low hills, and the surface of exposed parts on the road from Hamera to Zuela."

48. A mass of yellow and brown ferruginous sandstone with amorphous botryoidal surface, unequally penetrated by siliceous brown oxide of iron, which produces the appearance of a mixture of brown ochrey clay-ironstone. "Near Timinhint, forming the summit of hills."

49. Wood-hornstone; dark brown, with lighter coloured centre, being part of a cylindrical stem or branch of a dicotyledonous tree. "From between Mestoota and Gatrone."

50. Flint composed of conchoidal distinct concretions, some of them forming nuclei ; the layers of alternating brown and white colours, irregularly curved. "Quantities strewed over the plain from Temasta to Bonjem."

51. Yellowish-grey flint passing into hornstone, in irregularly angular pieces, with brown glossy corroded surface. " La Saila; hills of silex and opal."

52. White hornstone; a boulder with corroded glossy surface. "Strewed in large quantities between Wady el Beny and Wilkna, and on the summit of gypsum hills."

53. Yellowish-white substance intermediate between hornstone and calcedony, in angular pieces, with cream-coloured cacholong on the surface. "On the way from Gatrone to Tegerhy."

54. Brownish-red carnelian; a fragment, with irregularly botryoidal yellowish decomposed surface. From ditto.

55. Several fragments of variously shaped rough sand tubes; internal surface highly glazed. "From the sands near Dibla."

56. Lithomarge, reddish-brown, here and there variegated with bluish-green 
and greyish, in fragments with rather tuberculated surface. " Aghadem, beds in the sandstone."

57. The same, but penetrated by iron ochre, and much harder; with small imbedded pyriform concretions. From ditto.

58. Brownish-red and yellowish-grey variegated slaty clay, very soft and unctuous to the touch. From ditto.

59. Small-foliated amorphous gypsum, confusedly crystallized, with adhering red marl. "From the curiously formed gypsum hills of Bonjem to Hormut and Takui, with large quantities of opal on the top."

60 . Some specimens of white, granular, and foliated gypsum; one of the varieties composed of wedge-shaped laminæ. Bonjem.

61. Large-foliated white selenite. "Close to the Tchad, Kanem."

62. Compact limestone, of bluish-grey colour, divisible into tabular fragments. " Benioleed, under the basalt."

63. Light cream-coloured nearly compact limestone, in tabular fragments; fracture even, fractural surface slightly glimmering. Benioleed.

64. Fragment of a similar variety of limestone, with conchoidal fracture. "Benioleed, lowest observable stratum except one."

65. Compact limestone, of a reddish and cream yellow colour, variegated with pale brown, of very close texture, and small-conchoidal fracture. "Hills to the north of Benioleed."

66. Fragment of a greenish-grey tabular magnesian limestone, splendent on the fractural surfaces, the lustre produced by a curved-lamellar, though (in one direction) apparently compact structure. "On the ridges between Meshroo and Tegerhy."

67. Yellowish-red, close-grained, nearly compact limestone, here and there with minute scales; external exposed surface uneven, glossy. " Temedetan, forming thick strata."

68. Rolled fragment, of a reddish-yellow variety of magnesian limestone, with glossy surface, and of earthy fracture, including some dark-coloured grains, (oxide of manganese?) " Found in the deserts, sometimes finely dendritic."

69. Light cream-coloured hard (magnesian) limestone, with earthy uneven fracture; the exposed surface shining, partly corroded, partly smooth. "Hills of Gaaf."

70. A similar variety. "From the Assoud, Wady el Malagi."

71. A rolled fragment of yellowish-grey compact limestone (magnesian), of $l l_{2}$ 
even and dull fracture ; the surface shining, wrinkled by decomposition. "To the north and south of the Wells of Mafrass."

72. The same variety as the preceding, in the shape of a large conical lump, with uneven and corroded glossy surface, enclosing rounded pieces of the same limestone. From ditto.

73. A similar variety of magnesian limestone, forming a botryoidal group of more or less globular concretions, from upwards of half an inch to half a line in diameter, and intimately grown together with each other. "Meshroo and El Wahr."

74. Yellowish limestone, of curved-lamellar structure. "Forming veins in the basaltic rocks in Agutefa."

75. Brownish-yellow limestone, in stalagmitical irregular layers. "On the desert, between Mushroo and El Wahr."

76. Another fragment, apparently part of a large stalagmitic nodule, in layers on a yellow granular mass of earbonate of lime. From ditto.

77. Greyish-brown and hair-brown fibrous limestone, in tabular pieces; the fibres perpendicular, or in an oblique direction to the horizontal planes, straight or slightly curved. In some specimens, the hair-brown layer is sardonyx and onyx-like, succeeded by a red and a white stratum, the former generally in the form of a crust, with superficial small acute rhombohedrons of carbonate of lime; in others, the hair-brown layer is traversed by white veins. " Boundaries of Fezzan and Tuarick country."

78. Sulphate of barytes; a group of bluish and brownish prismatic crystals, (var. rétrécie of Haüy), covered by red marle.

79. Common salt, in white, opaque, granular aggregations, externally stained by ferruginous clay. " Road between Hamara and Zuela."

80. A saline incrustation, of yellowish-white colour, partly solid, in thin tables, partly in powder, composed of carbonate, muriate, and sulphate of soda. “ Near Germa."

81. Carbonate of soda (trona), thick-fibrous foliated, in crusts of the thickness of one-fourth to one-third of an inch, indistinctly crystallized on the upper surface. "From the trona lakes in Wady Trona."

82. The same, studded on the upper surface with small limpid cubical crystals of muriate of soda. From ditto.

83. Carbonate of soda, of yellowish and greenish-grey colour, in masses with diverging radiated fracture. Kanem? 
84. A rolled piece of nearly compact brown ironstone. "Upper strata from Aghadem to the southward of El Wahr."

85. Compact brown ironstone, of dark brown colour ; an irregularly tubercular nodule, with surface, particularly that of the old fractural planes, glossy, the recent fracture exhibiting a dull earthy surface. "From plains to the southward of Bonjem."

86. Compact brown ironstone, of deep chesnut-brown colour, in rounded oblong pieces of from one-half to upwards of an inch in diameter, the whole glossy as if varnished; fracture even, earthy. From ditto?

87. Fragment of compact brown ironstone, mixed with much quartzy matter. Wady Kawar and Aghadem.

88. Massive and granular brown ironstone, mixed with much yellow iron ochre and sand. "In loose masses or crusts, on the top of the ridges between Sockatoo and Kashna, and on the low hills around Sockatoo."

89. Fragments of clayey brown ironstone with ochrey nodules. "Wady Shiati hills."

90. A mass, mixed, of brown ironstone and red and yellow iron ochre. " From the soil of Wady Sandalion, Tuarick country."

91. Cubic fragments of common galena, (sulphuret of lead). Kanem, Soudan.

92. Pure tin, cast in moulds, in the form of thick wire. Brought from Soudan.

I conclude this long letter with mentioning a specimen of Roman cement, taken from the ruins of Ghirza, which, in parts where the admixture of small stony fragments is not observable, has very much the appearance of, and might easily be mistaken for, a granular-crystalline variety of tertiary limestone. It has unquestionably undergone a transformation : a circumstance which may, in some measure, serve to justify the remark of Lepère- " C'est le temps seul et non l'art qui manque à la pétrification absolue de nos mortiers et cimens; nos neveux diront de nos constructions ce que nous disons de celles des anciens."

I have the honour to be, my dear Sir,

$$
\text { Yours very faithfully, }
$$

Charles Konic.

To Major Denham, \&ce. 
No. XXIV.

Thermometrical Journal kept at Kouka in Bornou.

\begin{tabular}{|c|c|c|c|c|c|c|c|c|c|}
\hline \multirow{2}{*}{ Date. } & \multirow{2}{*}{ Winds. } & \multicolumn{3}{|c|}{ Fah. Thermometer. } & \multirow{2}{*}{ Date. } & \multirow{2}{*}{ Winds. } & \multicolumn{3}{|c|}{ Fah. Thermometer. } \\
\hline & & $5 \mathrm{~mm}$ & Noon. & 3 p.m. & & & 6 a.m. & Noon. & $3 \mathrm{p} \cdot \mathrm{m}$. \\
\hline March 1823. & & & & & April 1823. & & & & \\
\hline 15 & E.N.E. & 70 & 98 & 103 & 25 & E.N.E. & 85 & 103 & 102 \\
\hline Sunday, 16 & S.S.E. & 75 & 95 & 102 & 26 & N.E. & 85 & 103 & 103 \\
\hline & S.S.E. & 78 & 99 & 104 & Sunday, 27 & N.E. & 86 & 102 & 102 \\
\hline 18 & E.N.E. & 77 & & 104 & 28 & N.E. & 83 & 101 & 103 \\
\hline & S.E. & & & 98 & 29 & E.N.E. & 81 & 103 & 103 \\
\hline & E.N.E. & 78 & 95 & 101 & 30 & E.N.E. & 82 & 103 & 103 \\
\hline 21 & N.E. & 82 & 100 & 105 & May. & & & & \\
\hline 22 & E.N.E. & 80 & 97 & 100 & 1 & E.N.E. & 85 & 106 & 106 \\
\hline Sunday, 23 & N.E. & 78 & 90 & 94 & 2 & N.E. & 85 & 103 & 105 \\
\hline 24 & N.E. & 79 & 94 & 97 & 3 & N.E. & 83 & 105 & 98 \\
\hline 25 & E.N.E. & 79 & 97 & 101 & Sunday, 4 & E.N.E. & 81 & 99 & 99 \\
\hline 26 & E.N.E. & 79 & 100 & 103 & 5 & E.N.E. & 82 & 95 & 96 \\
\hline 27 & E.N.E. & 79 & 101 & 103 & 6 & E.N.E. & 81 & 102 & 102 \\
\hline 28 & E.N.E. & 82 & 97 & 98 & 7 & N. & 86 & 104 & 103 \\
\hline 29 & E.N.E. & 80 & 97 & 100 & 8 & N.E. & 71 & 99 & 96 \\
\hline Sunday, 30 & N.E. & 80 & 94 & 97 & 9 & N.E. & 81 & 99 & 96 \\
\hline 31 & E.N.E. & 80 & 94 & 96 & 10 & N.E. & 85 & 95 & 94 \\
\hline 1 & N.E. & 77 & 98 & 101 & Sunday, 11 & N.E. & 86 & 101 & 95 \\
\hline & N.E. & 80 & 95 & 100 & 12 & Calm. & 81 & 99 & 95 \\
\hline 3 & S.E. & 80 & 99 & 101 & 13 & W.S.W. & 75 & 98 & 98 \\
\hline 7 & N.E. & 80 & 99 & 102 & 14 & W.S.W. & 75 & 95 & 98 \\
\hline 8 & N.E. & 80 & 99 & 103 & 15 & W.S.W. & 74 & 97 & 97 \\
\hline 9 & E.N.E. & 78 & 98 & 102 & 16 & W.S.W. & 72 & 92 & 95 \\
\hline 10 & E.N.E. & 77 & 97 & 99 & 17 & S.W. & 74 & 97 & 98 \\
\hline 11 & N.E. & 72 & 100 & 100 & Sunday, 18 & W.S.W. & 74 & 96 & 99 \\
\hline 12 & N.E. & 78 & 104 & 107 & 19 & W.S.W. & 73 & 96 & 99 \\
\hline Sunday, 13 & N.E. & 84 & 100 & 105 & 20 & W.S.W. & 76 & 95 & 99 \\
\hline 14 & E.N.E. & 82 & 100 & 105 & 21 & W.S.W. & 74 & 102 & 100 \\
\hline 15 & N.E. & 87 & 103 & 105 & 22 & W.S.W. & 73 & 100 & 100 \\
\hline 16 & E.N.E. & 86 & 95 & 105 & 23 & W.S.W. & 84 & 104 & 101 \\
\hline 17 & E.N.E. & 87 & 99 & 106 & 24 & S.W. & 76 & 96 & 96 \\
\hline 18 & E.N.E. & 86 & 103 & 109 & Sunday, 25 & S.W. & 73 & 96 & 96 \\
\hline 19 & N.E. & 88 & 102 & 106 & 26 & S.W. & 81 & 98 & 100 \\
\hline Sunday, 20 & E.N.E. & 87 & 102 & 107 & 27 & S.W. & 76 & 99 & 100 \\
\hline 21 & E.N.E. & 85 & 100 & 100 & 28 & S.W. & 80 & 98 & 99 \\
\hline 22 & E.N.E. & 86 & 102 & 103 & 29 & W.S.W. & 81 & 97 & 102 \\
\hline 23 & E.N.E. & 85 & 102 & 103 & 30 & W.S.W. & 82 & 100 & 102 \\
\hline 24 & N.E. & 83 & 101 & 103 & 31 & W.S.W. & 80 & 100 & 102 \\
\hline
\end{tabular}




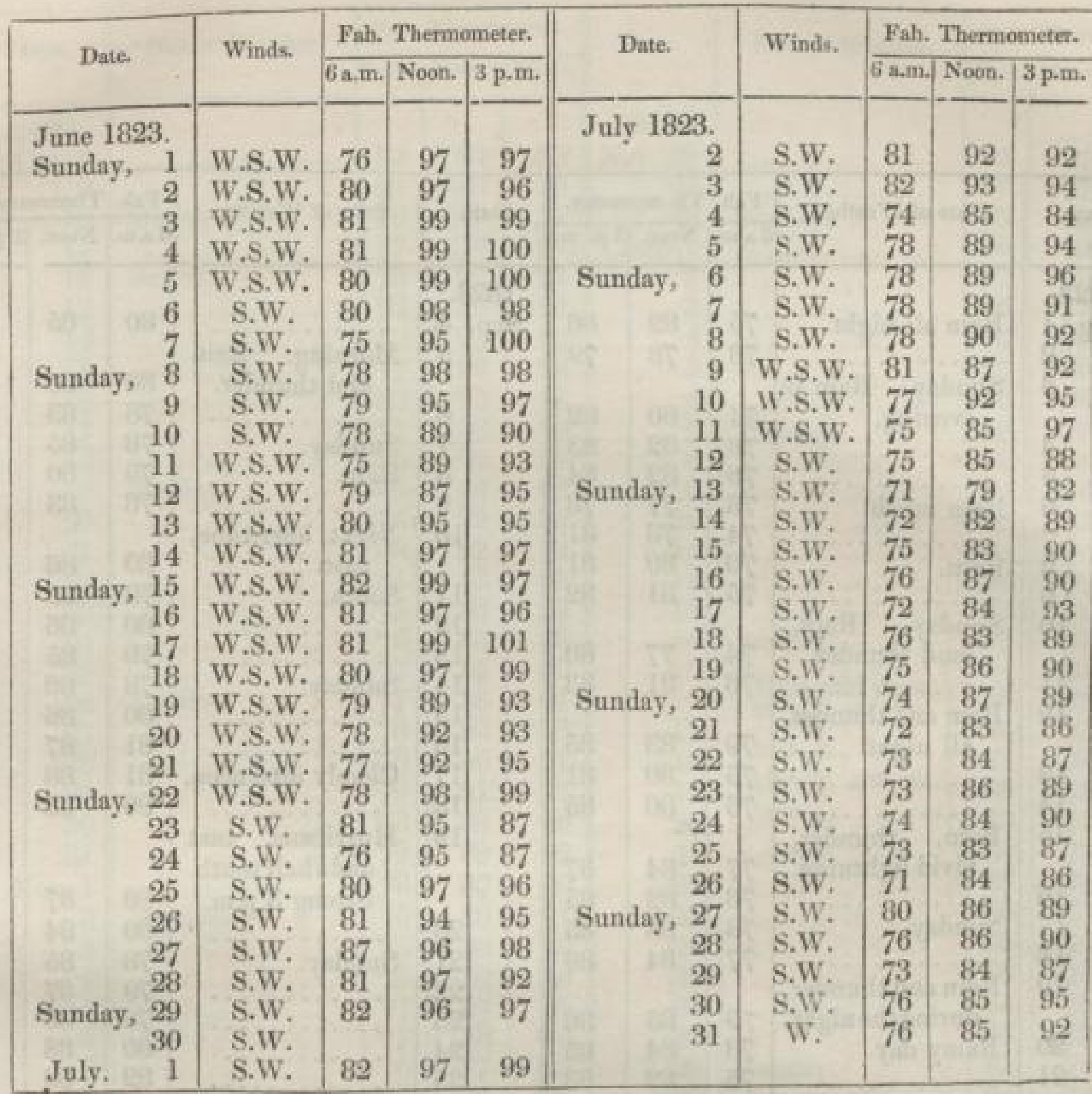




\begin{tabular}{|c|c|c|c|c|c|c|c|c|c|}
\hline \multirow{2}{*}{ Date. } & \multirow{2}{*}{ State of Weather. } & Fah. & \multicolumn{2}{|c|}{ Thermometer. } & \multirow{2}{*}{ Date. } & \multirow{2}{*}{ State of Weather. } & \multicolumn{3}{|c|}{ Fah. Thermometer. } \\
\hline & & 6 a.m. & Noon. $\left.\right|^{3}$ & $3 \mathrm{p} . \mathrm{m}$. & & & $6 \mathrm{am}$ & Noon. f & 3 p. m. \\
\hline 1823. & & & & & 1823. & & & & \\
\hline Aug. ${ }_{2}^{1}$ & $\begin{array}{l}\text { Rain all night. } \\
\ldots \ldots \ldots \ldots \ldots\end{array}$ & $\begin{array}{l}75 \\
73\end{array}$ & $\begin{array}{l}82 \\
78\end{array}$ & $\begin{array}{l}86 \\
79\end{array}$ & Sep. $\frac{4}{5}$ & Morning. Rain & 80 & 85 & 88 \\
\hline 3 & Sunday. Rain in & & & & & and thunder. & 80 & 80 & 81 \\
\hline 4 & evening. & $\begin{array}{l}74 \\
78\end{array}$ & $\begin{array}{l}80 \\
82\end{array}$ & 82 & 6 & Sunday & 78 & 83 & $\begin{array}{l}84 \\
86\end{array}$ \\
\hline 5 & & 76 & $\begin{array}{l}82 \\
82\end{array}$ & $\begin{array}{l}83 \\
84\end{array}$ & $\begin{array}{l}7 \\
8\end{array}$ & $\begin{array}{l}\text { Sunday } \\
\text { Rain. }\end{array}$ & $\begin{array}{l}78 \\
79\end{array}$ & $\begin{array}{l}85 \\
80\end{array}$ & $\begin{array}{l}86 \\
81\end{array}$ \\
\hline 6 & Rain much. & 73 & 77 & 78 & 9 & & 78 & 83 & $\begin{array}{l}81 \\
85\end{array}$ \\
\hline 7 & & 74 & 78 & 81 & 10 & Night, hurrieane, & & & \\
\hline 8 & Rain. & 76 & 80 & 81 & & east & 80 & 86 & 88 \\
\hline $\begin{array}{r}9 \\
10\end{array}$ & & 75 & 81 & 82 & 11 & South. & 78 & 85 & 87 \\
\hline 10 & $\begin{array}{l}\text { Sunday. Rain, } \\
\text { loud thunder. }\end{array}$ & 74 & 77 & 80 & $\begin{array}{l}12 \\
13\end{array}$ & $\cdots$ & $\begin{array}{l}80 \\
79\end{array}$ & $\begin{array}{l}86 \\
85\end{array}$ & $\begin{array}{l}88 \\
87\end{array}$ \\
\hline 11 & ........... & 76 & 81 & 83 & 14 & Sunday. & 78 & 86 & 89 \\
\hline 12 & Rain and thunder & & & & 15 & n....... & 80 & 86 & 89 \\
\hline & a & 79 & 83 & 85 & 16 & & 81 & 87 & 89 \\
\hline $\begin{array}{l}13 \\
14\end{array}$ & n......... & 75 & 80 & 81 & 17 & Cloudy afternoon. & 81 & 88 & 89 \\
\hline $\begin{array}{l}14 \\
15\end{array}$ & $\dot{\mathbf{R}_{\Omega}}$ & 76 & 80 & 85 & $\begin{array}{l}18 \\
10\end{array}$ & $\cdots$ & 80 & 85 & 87 \\
\hline 15 & vivid lightning. & 77 & 84 & 87 & 19 & $\begin{array}{l}\text { Hurricane, east } \\
\text { andahalf south. }\end{array}$ & & & \\
\hline 16 & Cin & 76 & 82 & 85 & & 3 p.m. & 80 & 87 & 85 \\
\hline 17 & Sunday. & 78 & 83 & 85 & 20 & $\cdots \cdots \cdots \cdots$ & $\begin{array}{c}80 \\
-\infty\end{array}$ & 84 & 87 \\
\hline 18 & & 77 & 84 & 86 & 21 & Sunday. & $\begin{array}{l}78 \\
70\end{array}$ & 85 & 87 \\
\hline 19 & $\begin{array}{l}\text { Rain and thunder } \\
\text { during thenight. }\end{array}$ & 79 & 85 & 86 & $\begin{array}{l}22 \\
23\end{array}$ & $\cdots \cdots \cdots$ & 79 & $\begin{array}{l}87 \\
86\end{array}$ & $\begin{array}{l}89 \\
88\end{array}$ \\
\hline 20 & Rainy day. & 78 & 84 & 85 & 24 & & 80 & 88 & $\begin{array}{l}86 \\
90\end{array}$ \\
\hline 21 & & 75 & 82 & 83 & 25 & .. & 82 & 89 & 92 \\
\hline 22 & Mt & 74 & 79 & 83 & 26 & Violent storm, & & & \\
\hline 23 & Morning cloudy. & 74 & 80 & 84 & & noon wind $\mathrm{N}$. & & & \\
\hline 24 & Sunday. & & & & & hail and rain. & 80 & 89 & 90 \\
\hline & & 76 & 83 & 85 & 27 & $8 n$ & 76 & 86 & 89 \\
\hline 25 & Night violent. & 75 & 77 & 79 & 28 & Sunday. & 80 & 86 & 88 \\
\hline 26 & Nigl & 75 & 78 & 79 & 29 & …… & 81 & 87 & 91 \\
\hline 27 & All night. & 74 & 78 & 79 & 30 & & 80 & 86 & 91 \\
\hline 28 & $\begin{array}{l}\text { Day and might, } \\
\text { showers. }\end{array}$ & 73 & 77 & 79 & Oet. 1 & $\begin{array}{l}\text { Kain and wind in } \\
\text { night. }\end{array}$ & 80 & 87 & 91 \\
\hline 29 & Rain. & 74 & 78 & 80 & 2 & . $\ldots \ldots \ldots \ldots$ & 78 & 84 & 85 \\
\hline 30 & & 75 & 80 & 82 & 3 & & 80 & 85 & 88 \\
\hline 31 & Sunday. Rain, & & & & 4 & Wind, thunder. & 81 & 87 & 90 \\
\hline Sep. 1 & $\ldots$ & 74 & 78 & $\begin{array}{l}80 \\
81\end{array}$ & 与 & $\begin{array}{l}\text { Sunday, raun and } \\
\text { wind. }\end{array}$ & 80 & 86 & 88 \\
\hline 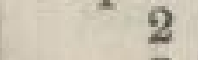 & $\ldots \ldots$ & 76 & 84 & 86 & 6 & n........ & 79 & 8 & 89 \\
\hline & & 79 & 85 & 89 & 7 & ......... & 80 & 88 & 90 \\
\hline
\end{tabular}




\begin{tabular}{|c|c|c|c|c|c|c|c|c|c|}
\hline \multirow{2}{*}{ Date. } & \multirow{2}{*}{ State of $W$ eather. } & \multicolumn{3}{|c|}{ Fah. Thermometer. } & \multirow{2}{*}{ Date. } & \multirow{2}{*}{ State of Weather. } & \multicolumn{3}{|c|}{ Fah. Thermometer. } \\
\hline & & $6 \mathrm{am}$. & Noon. & $3 \mathrm{p} \cdot \mathrm{m}$. & & & $6 \mathrm{~s} \cdot \mathrm{m}$. & Noon. & 3 p.m. \\
\hline $\begin{array}{l}1823 . \\
\text { Oct. } 8\end{array}$ & & 80 & 89 & & $\begin{array}{l}1823 . \\
\text { lov, } 28\end{array}$ & & & & \\
\hline & 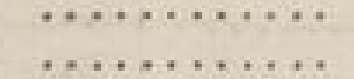 & 79 & $\begin{array}{l}89 \\
89\end{array}$ & 92 & 29 & 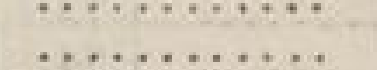 & 66 & 77 & 79 \\
\hline 10 & Breeze N.W. & 78 & 89 & 91 & 30 & Sunday, & 67 & 79 & 80 \\
\hline 11 & $\ldots \ldots \ldots$ & 77 & 90 & 92 & Dec. 1 & $\ldots \ldots \ldots \ldots$ & 66 & 79 & 81 \\
\hline 12 & Sunday, & 79 & 92 & 94 & 2 & $\ldots \ldots \ldots \ldots$ & 67 & 78 & 80 \\
\hline 13 & $\ldots \ldots \ldots \cdots \cdots$ & 78 & 92 & 94 & 3 & $\ldots \ldots \ldots \ldots \ldots$ & 66 & 79 & 81 \\
\hline 14 & n........ & 79 & 91 & 93 & 4 & …… & 65 & 78 & 80 \\
\hline 15 & n........ & 77 & 92 & 93 & 5 & $\ldots \ldots \ldots \ldots$ & 67 & 80 & 82 \\
\hline 16 & 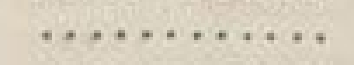 & 83 & 92 & 94 & 6 & $\ldots \cdots \cdots$ & 68 & 80 & 82 \\
\hline 17 & $\ldots \ldots \ldots \ldots \ldots$ & 81 & 92 & 94 & 7 & Sunday, & 68 & 78 & 80 \\
\hline 18 & $\ldots \ldots \ldots \ldots \ldots$ & 80 & 90 & 93 & 8 & ........ & 63 & 76 & 78 \\
\hline 19 & Sunday, & 81 & 92 & 94 & 9 & $\ldots \ldots \ldots \ldots$ & 64 & 76 & 78 \\
\hline 20 & $\ldots \ldots \ldots \ldots$ & 79 & 92 & 94 & 10 & n......... & 63 & 75 & 77 \\
\hline 21 & $\ldots \ldots \ldots \ldots$ & 80 & 92 & 94 & 11 & $\ldots \ldots \ldots \ldots$, & 64 & 76 & 78 \\
\hline 22 & n.m.n. & 81 & 93 & 95 & 12 & $\ldots \ldots \ldots \ldots \ldots$ & 64 & 77 & 78 \\
\hline 23 & $\ldots \ldots \ldots \ldots \ldots$ & 75 & 90 & 92 & 13 & . & 64 & 78 & 78 \\
\hline 24 & n........ & 76 & 85 & 88 & 14 & Sunday, & 63 & 75 & 77 \\
\hline 25 & $\ldots \cdots \cdots \cdots$ & 77 & 87 & 90 & 15 & (Dull cold days.) & 64 & 74 & 76 \\
\hline 26 & Sunday, & 77 & 88 & 91 & 16 & Wind N.N.E. & 63 & 75 & 77 \\
\hline 27 & nn. & 78 & 90 & 92 & 17 & & 64 & 75 & 76 \\
\hline 28 & $\ldots \ldots \ldots \ldots \cdots$ & 78 & 90 & 91 & 18 & elondy sun at & 63 & 74 & 76 \\
\hline 29 & $\ldots \ldots \ldots \ldots$ & 79 & 91 & 93 & 19 & cloudy sun at & 63 & 72 & 74 \\
\hline 30 & $\ldots \ldots \ldots \ldots$ & 78 & 88 & 90 & 20 & 11001 & 63 & 71 & 72 \\
\hline 31 & ........... & 79 & 89 & 92 & 21 & Sunday, & 64 & 73 & 75 \\
\hline Nov. 1 & $\ldots \ldots \ldots \ldots$ & 78 & 87 & 90 & 22 & ............ & 65 & 74 & 75 \\
\hline 2 & Sunday, & 76 & 89 & 91 & 23 & $\ldots \ldots \ldots \ldots+$ & 66 & 73 & 75 \\
\hline 3 & $\cdots \cdots \cdots \cdots \cdots$ & 75 & 88 & 89 & 24 & $\ldots \ldots \ldots \ldots$ & 65 & 74 & 76 \\
\hline 4 & $\ldots \ldots \ldots \cdots$ & 76 & 88 & 90 & 25 & $\ldots \ldots \ldots \ldots \ldots$ & 66 & 74 & 77 \\
\hline 5 & $\ldots \ldots \ldots \ldots$ & 77 & 87 & 89 & 26 & n..., $\ldots, \ldots$ & 64 & 75 & 76 \\
\hline 6 & $\ldots \ldots \ldots \ldots \ldots$ & 77 & 88 & 90 & 27 & . & 64 & 72 & 74 \\
\hline 7 & $\ldots \ldots \ldots \ldots \ldots$ & 76 & 87 & 90 & 28 & Sunday, & 65 & 73 & 75 \\
\hline 8 & & 75 & 86 & 88 & 29 & & 64 & 74 & 76 \\
\hline 9 & Sunday, & 76 & 88 & 90 & 30 & N.E. cold. & 61 & 63 & 65 \\
\hline 10 & $\ldots \ldots \ldots \ldots \ldots$ & 77 & 86 & 89 & 31 & $\ldots \ldots \ldots \ldots \ldots$ & 58 & 66 & 73 \\
\hline 11 & $\ldots \ldots \ldots \ldots \ldots$ & 79 & 87 & 88 & & & & & \\
\hline 12 & $\ldots \ldots \ldots \ldots \ldots$ & 76 & 88 & 90 & 1824. & & & & \\
\hline 13 & $\ldots \ldots \ldots \ldots \ldots$ & 74 & 87 & 89 & Jan. 1 & $\ldots \ldots \ldots \ldots \ldots$ & 61 & 74 & 76 \\
\hline 14 & $\ldots \ldots \ldots \ldots \ldots$ & 74 & 86 & 88 & 2 & $\ldots \ldots \ldots \ldots \ldots$ & 60 & 71 & 72 \\
\hline 15 & $\ldots \ldots \ldots \ldots \ldots$ & 73 & 87 & 89 & 3 & . & 61 & 72 & 73 \\
\hline 16 & Sunday, & 74 & 88 & 89 & 4 & Sunday, & 60 & 70 & 74 \\
\hline 17 & $\ldots \ldots \ldots \cdots \cdots$ & 74 & 83 & 86 & 5 & $\ldots \ldots \ldots \ldots \ldots$ & 61 & 73 & 75 \\
\hline 18 & $\ldots \ldots \ldots \ldots \ldots$ & 75 & 85 & 87 & 6 & $\ldots \ldots \ldots \ldots$ & 63 & 75 & 77 \\
\hline 19 & $\ldots \ldots \ldots \ldots$ & 75 & 86 & 88 & 7 & n.......... & 65 & 77 & 79 \\
\hline 20 & $\ldots \ldots \ldots \ldots \ldots$ & 75 & 85 & 87 & 8 & $\ldots \ldots \ldots \ldots \ldots$ & 65 & 82 & 84 \\
\hline 21 & $\ldots \ldots \ldots \ldots \ldots$ & 75 & 86 & 88 & 9 & $\ldots \ldots \ldots \ldots$ & 66 & 84 & 86 \\
\hline 22 & $\ldots \ldots \ldots$ & 69 & 78 & 81 & 10 & & 65 & 83 & 85 \\
\hline 23 & Sunday, & 71 & 79 & 81 & 11 & Sunday, & 64 & 82 & 84 \\
\hline 24 & $\ldots \ldots \ldots \ldots \ldots$ & 69 & 77 & 79 & 12 & $\ldots \ldots \ldots \ldots \ldots$ & 65 & 83 & 85 \\
\hline 25 & $\ldots \ldots \ldots \ldots \ldots$ & 68 & 78 & 80 & 13 & $\ldots \ldots \ldots \ldots \ldots$ & 66 & 84 & 86 \\
\hline 26 & $\cdots \cdots \cdots$ & 67 & 79 & 81 & 14 & & 66 & 85 & 86 \\
\hline 27 & …...... & 66 & 78 & 80 & 15 & Elephant, & 70 & 851 & 87 \\
\hline
\end{tabular}




\begin{tabular}{|c|c|c|c|c|c|c|c|c|c|}
\hline \multirow{2}{*}{ Date. } & \multirow{2}{*}{ State of Weather. } & \multicolumn{3}{|c|}{ Fuh. Thermometer. } & \multirow{2}{*}{ Date. } & \multirow{2}{*}{ State of Weather. } & \multicolumn{3}{|c|}{ Fah. Therr } \\
\hline & & $6 \mathrm{am}$ & Noon. & 3 p.m. & & & a a.m. & Noon. & 3 p.m. \\
\hline \begin{tabular}{|r|} 
Jan. 1624 \\
17 \\
18 \\
19 \\
20 \\
21 \\
22
\end{tabular} & 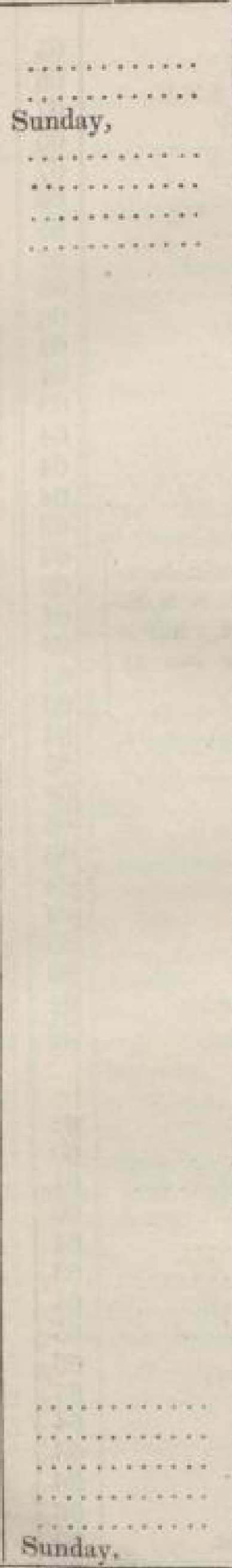 & $\begin{array}{l}75 \\
74 \\
75 \\
75 \\
74 \\
75 \\
74\end{array}$ & $\begin{array}{l}86 \\
85 \\
87 \\
90 \\
87 \\
88 \\
86\end{array}$ & $\begin{array}{l}87 \\
86 \\
89 \\
91 \\
89 \\
90 \\
87\end{array}$ & $\begin{array}{r}1824 . \\
\text { Mar. } \\
9 \\
10 \\
11 \\
12 \\
13 \\
14 \\
15 \\
16 \\
17 \\
18 \\
19 \\
20 \\
21 \\
22 \\
23 \\
24 \\
25 \\
26 \\
27 \\
28 \\
29 \\
30 \\
31 \\
\text { Apr. } \\
2 \\
3 \\
4 \\
5 \\
6 \\
77 \\
8 \\
9 \\
9 \\
10 \\
11 \\
12 \\
13 \\
14 \\
15 \\
16 \\
17 \\
18 \\
19 \\
20 \\
21 \\
22 \\
23\end{array}$ & 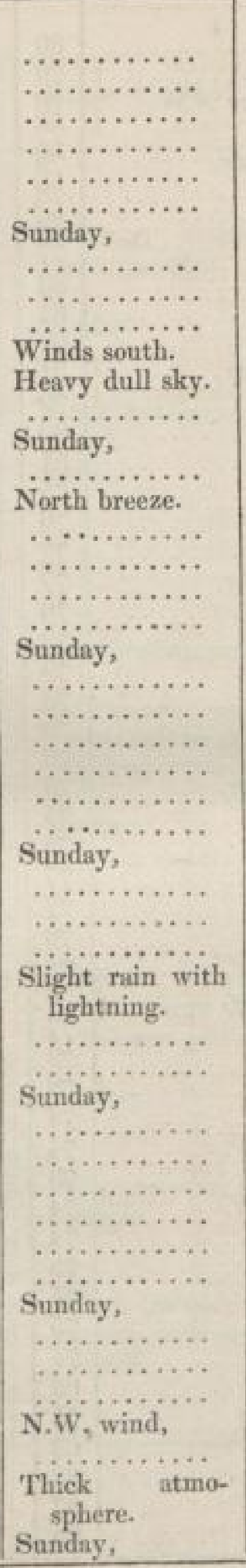 & $\begin{array}{l}80 \\
79 \\
79 \\
78 \\
79 \\
78 \\
80 \\
82 \\
80 \\
79 \\
79 \\
78 \\
79 \\
79 \\
78 \\
75 \\
76 \\
77 \\
78 \\
80 \\
83 \\
85 \\
84 \\
85 \\
86 \\
85 \\
84 \\
79 \\
84 \\
86 \\
87 \\
86 \\
90 \\
87 \\
88 \\
86 \\
87 \\
86 \\
87 \\
86 \\
85 \\
86 \\
84 \\
85 \\
86 \\
86 \\
85\end{array}$ & $\begin{array}{c}95 \\
91 \\
92 \\
93 \\
92 \\
94 \\
95 \\
95 \\
94 \\
93 \\
92 \\
91 \\
93 \\
94 \\
93 \\
90 \\
89 \\
90 \\
94 \\
95 \\
99 \\
99 \\
98 \\
99 \\
97 \\
94 \\
95 \\
93 \\
96 \\
99 \\
98 \\
100 \\
101 \\
99 \\
100 \\
102 \\
103 \\
101 \\
101 \\
100 \\
100 \\
101 \\
101 \\
100 \\
100 \\
100 \\
100\end{array}$ & \begin{tabular}{|c|}
96 \\
93 \\
94 \\
95 \\
94 \\
96 \\
97 \\
98 \\
96 \\
95 \\
94 \\
93 \\
95 \\
96 \\
95 \\
92 \\
91 \\
91 \\
97 \\
99 \\
101 \\
102 \\
100 \\
100 \\
99 \\
96 \\
96 \\
95 \\
100 \\
101 \\
100 \\
104 \\
104 \\
102 \\
103 \\
105 \\
105 \\
103 \\
102 \\
103 \\
104 \\
105 \\
103 \\
105 \\
106 \\
100 \\
102 \\
103 \\
102 \\
\end{tabular} \\
\hline
\end{tabular}




\begin{tabular}{|c|c|c|c|c|c|c|c|c|c|}
\hline \multirow{2}{*}{ Date. } & \multirow{2}{*}{ State of Weather. } & \multicolumn{3}{|c|}{ Fah. Thermometer. } & \multirow{2}{*}{ Date. } & \multirow{2}{*}{ State of Weather. } & \multicolumn{3}{|c|}{ Fah. Thermometer. } \\
\hline & & $6 \mathrm{a} . \mathrm{m} \cdot$ & Noon. & 3 p.m. & & & $6 \mathrm{stm}$. & Noon. & 3 p.m. \\
\hline 1824. & & & & & 1824. & & & & \\
\hline Apr. $\begin{array}{l}26 \\
27\end{array}$ & $\begin{array}{l}\text { volent } \\
\text { N.W. }\end{array}$ & $\begin{array}{l}86 \\
86\end{array}$ & $\begin{array}{l}103 \\
102\end{array}$ & $\begin{array}{l}103 \\
102\end{array}$ & $\begin{array}{r}\text { June } 11 \\
12\end{array}$ & Wind S.S.E. & $\begin{array}{l}87 \\
89\end{array}$ & $\begin{array}{l}97 \\
99\end{array}$ & 100 \\
\hline 28 & winds. & 83 & 102 & 103 & 13 & Sunday, & 88 & 100 & $\begin{array}{l}102 \\
104\end{array}$ \\
\hline 29 & $\ldots \ldots \ldots \ldots$ & 80 & 102 & 103 & 14 & .......... & 89 & 100 & 104 \\
\hline 30 & $\ldots \ldots \ldots \ldots \cdots$ & 82 & 103 & 103 & 15 & , $\ldots \ldots \ldots \ldots$ & 90 & 101 & 103 \\
\hline May ${ }_{2}^{1}$ & Sunda........ & 86 & 104 & 106 & & & & & \\
\hline & $\begin{array}{l}\text { and thick, with } \\
\text { wind. }\end{array}$ & 83 & 100 & 104 & & & & & \\
\hline $\begin{array}{l}3 \\
4\end{array}$ & Rain, & 83 & 100 & 100 & & & & & \\
\hline 5 & Thunder. \{ & 81 & 100 & 100 & & & & & \\
\hline $\begin{array}{l}6 \\
7\end{array}$ & $\ldots \ldots \ldots \ldots$ & 86 & 98 & 100 & & & & & \\
\hline 8 & .......... & 85 & 99 & 101 & & & & & \\
\hline 9 & Sunday, & 87 & 99 & 102 & & & & & \\
\hline 10 & $\ldots \ldots \ldots \ldots$ & 88 & 99 & 101 & & & & & \\
\hline 11 & $\ldots \ldots \ldots \ldots$ & 87 & 97 & 99 & & & & & \\
\hline 12 & n.w. & 89 & 99 & 101 & & & & & \\
\hline 13 & $\begin{array}{l}\text { First day of } \\
\text { summer. }\end{array}$ & 88 & 99 & 106 & & & & & \\
\hline 14 & n......... & 80 & 99 & 104 & & & & & \\
\hline 15 & $\ldots \ldots \ldots \ldots \ldots$ & 81 & 100 & 104 & & & & & \\
\hline 16 & Sunday, & 86 & 100 & 104 & & & & & \\
\hline 17 & $\ldots \ldots \ldots \ldots$ & 84 & 99 & 100 & & & & & \\
\hline 18 & n........ & 86 & 100 & 102 & & & & & \\
\hline 19 & $\ldots \ldots \ldots \ldots \ldots$ & 87 & 101 & 103 & & & & & \\
\hline $\begin{array}{l}20 \\
21\end{array}$ & $\ldots \ldots \ldots \ldots$ & $\begin{array}{l}88 \\
86\end{array}$ & $\begin{array}{l}102 \\
100\end{array}$ & $\begin{array}{l}104 \\
104\end{array}$ & & & & & \\
\hline 22 & ……. & 85 & $\begin{array}{r}100 \\
99\end{array}$ & 104 & & & & & \\
\hline 23 & Sunday, & 86 & 98 & 104 & & & & & \\
\hline 24 & Sun rises at 5 . & 88 & 101 & 102 & & & & & \\
\hline 25 & 10. and the & 87 & 100 & 103 & & & & & \\
\hline 26 & day is $13 \mathrm{~h} . ?$ & 88 & 100 & 104 & & & & & \\
\hline 27 & $10 \mathrm{~m}$. sets 6. & 87 & 101 & 103 & & & & & \\
\hline 28 & 10 & 88 & 102 & 103 & & & & & \\
\hline 29 & $\begin{array}{l}\text { Morning thick } \\
\text { hot vapours. }\end{array}$ & 89 & 101 & 102 & & & & & \\
\hline 30 & Sunday. Night & & & & July 19 & v & 80 & 87 & 90 \\
\hline & stormy, norain. & 91 & 100 & 101 & 20 & & 78 & 87 & 89 \\
\hline 31 & $\ldots \ldots \ldots \ldots$ & 88 & 98 & 100 & 21 & Much rain. & 79 & 88 & 90 \\
\hline June 1 & $\ldots \ldots \ldots \ldots$ & 90 & 101 & 102 & 22 & Dull. & 80 & 86 & 86 \\
\hline 2 & $\ldots \ldots \ldots \ldots \ldots$ & 89 & 99 & 102 & 23 & $\ldots \ldots \ldots \ldots$ & 80 & 90 & 95 \\
\hline 3 & $\ldots \ldots \ldots \ldots$ & 90 & 103 & 105 & 24 & ... & 79 & 89 & 91 \\
\hline 4 & $\ldots \ldots \ldots \ldots$ & 90 & 102 & 104 & 25 & Sunday, & 80 & 91 & 92 \\
\hline 5 & Dull. & 89 & 103 & 104 & 26 & $\ldots \ldots \ldots \ldots \ldots$ & 80 & 90 & 92 \\
\hline 6 & Sunday, & 88 & 102 & 103 & 27 & $\ldots \ldots \ldots \cdots \cdots$ & 78 & 88 & 90 \\
\hline 7 & ……. & 87 & 101 & 102 & 28 & $\ldots \ldots \ldots \ldots$ & 79 & 87 & 91 \\
\hline 8 & $\ldots \ldots \ldots \ldots$ & 88 & 99 & 100 & 29 & $\ldots \ldots \ldots \ldots$ & 78 & 88 & 92 \\
\hline 9 & $\ldots \ldots \ldots \ldots \ldots$ & 89 & 100 & 102 & 30 & $\ldots \ldots \ldots \ldots \ldots$ & 80 & 89 & 91 \\
\hline 10 & $\ldots \ldots \ldots \ldots \ldots$ & 87 & 98 & 99 & 31 & $\ldots \ldots \ldots \ldots$ & 80 & 89 & 90 \\
\hline
\end{tabular}

$m m 2$ 


\begin{tabular}{|c|c|c|c|c|c|c|c|c|c|}
\hline \multirow{2}{*}{ Date, } & \multirow{2}{*}{ State of Weather. } & \multicolumn{3}{|c|}{ | Fah. Thermomoter. } & \multirow{2}{*}{ Date. } & \multirow{2}{*}{ State of Weather. } & \multicolumn{3}{|c|}{ Fah. Thermometer. } \\
\hline & & $6 \mathrm{a} \cdot \mathrm{m}$. & Noon. & 3 p.m. & & & $6 \mathrm{am}$. & Noon. & 3 p.m. \\
\hline 1824. & & & & & 18 & & & & \\
\hline Aug. 1 & Sunday, & 81 & 92 & 96 & Aug. 8 & Sunday, & 78 & 84 & 87 \\
\hline & $\cdots$ & 81 & 93 & 95 & 9 & . & 79 & 88 & 90 \\
\hline & $\ldots \ldots \ldots \ldots$ & 80 & 90 & 91 & 10 & ... & 80 & 89 & 90 \\
\hline 4 & $\ldots \ldots \ldots \ldots$ & 78 & 87 & 90 & 11 & & 79 & 88 & 90 \\
\hline 5 & $\ldots$ & 79 & 89 & 92 & 12 & Mueh rain. & 80 & 89 & 90 \\
\hline & Sultry. Aide & 80 & 94 & 95 & 13 & $\ldots \ldots \ldots \ldots$ & $\underset{78}{78}$ & 80 & 82 \\
\hline & Night, rain. & 81 & 91 & 93 & 15 & Sunday, & 76 & $\begin{array}{l}81 \\
82\end{array}$ & 81 \\
\hline
\end{tabular}

Thermometrical Journal kept at Kano.

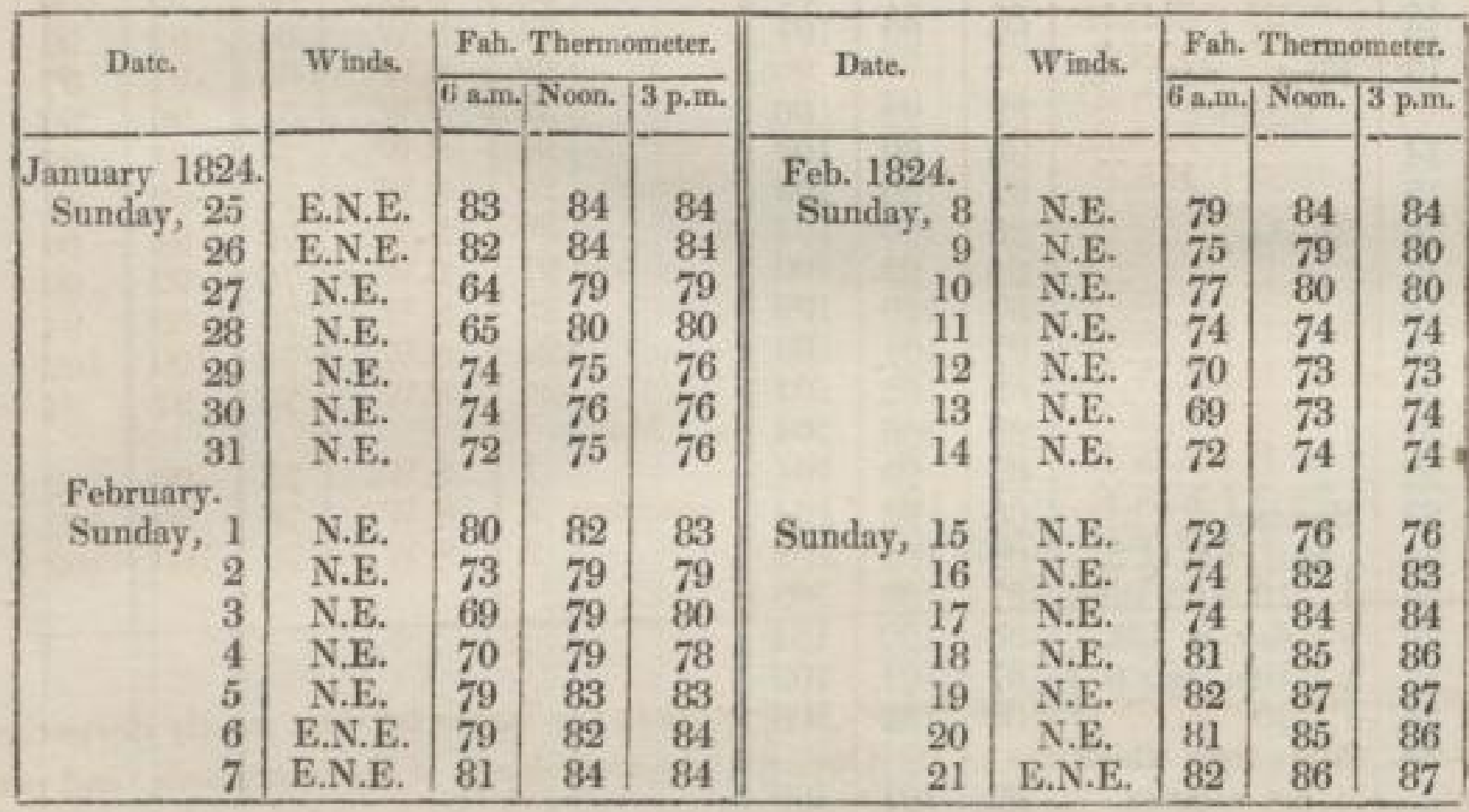


Thermometrical Journal kept at Sackatoo.

\begin{tabular}{|c|c|c|c|c|c|c|c|c|c|}
\hline \multirow[t]{2}{*}{ Date. } & \multirow{2}{*}{ Winds. } & \multicolumn{3}{|c|}{ Fah. Thermometer. } & \multirow{2}{*}{ Date. } & \multirow{2}{*}{ Winds. } & \multicolumn{3}{|c|}{ Fah. Thermometer. } \\
\hline & & $6 \mathrm{a} . \mathrm{m} \cdot$ & Noon. & 3 p.m. & & & $6 \mathrm{am} . \mathrm{m}$ & Noon. & $3 \mathrm{p} \cdot \mathrm{m}$ \\
\hline March 1824. & & & & & April 1824. & & & & \\
\hline 16 & E.N.E. & 84 & 93 & 95 & $\begin{array}{l}10 \\
\times\end{array}$ & E.N.E. & 84 & 100 & 104 \\
\hline 17 & E.N.E. & 82 & 94 & 96 & Sunday, 11 & S.W. & 84 & 95 & 98 \\
\hline 18 & E.N.E. & 84 & 91 & 95 & 12 & S.W. & 84 & 100 & 104 \\
\hline 19 & E.N.E. & 86 & 94 & 96 & 13 & S.W. & 84 & 99 & 103 \\
\hline 20 & E.N.E. & 82 & 93 & 95 & 14 & S.W. & 84 & 104 & 108 \\
\hline Sunday, 21 & E.N.E. & 83 & 94 & 96 & 15 & S.W. & 86 & 103 & 106 \\
\hline 22 & E.N.E. & 84 & 94 & 95 & It & S.I & 87 & 102 & 106 \\
\hline 23 & E.N.E. & 82 & 93 & 96 & 17 & S.V & 89 & 100 & 102 \\
\hline 24 & E.N.E. & 84 & 95 & 98 & Sunday, 18 & S.W. & 87 & 97 & 102 \\
\hline 25 & E.N.E. & 83 & 96 & 97 & 19 & S. 1 & 87 & 100 & 104 \\
\hline 26 & E.N.E. & 82 & 94 & 96 & 20 & S.I & 88 & 99 & 100 \\
\hline $\begin{array}{r}27 \\
\end{array}$ & E.S.E. & 82 & 94 & 99 & & S.W & 84 & 92 & 95 \\
\hline Sunday, 28 & E.S.E. & 86 & 96 & 98 & 22 & S.W. & 85 & 91 & 97 \\
\hline 29 & E.S.E. & 84 & 94 & 96 & 23 & S. & 81 & 96 & 98 \\
\hline 30 & E.S.E. & 84 & 96 & 100 & 24 & S.W. & 78 & 81 & 82 \\
\hline 31 & E.S.E. & 81 & 96 & 99 & Sunday, 25 & S.W. & 74 & 92 & 91 \\
\hline 1 & E.S.E. & 79 & 94 & 98 & 26 & & 79 & 94 & 96 \\
\hline 2 & E S.E. & 78 & 94 & 98 & 27 & S.W. & 76 & 92 & 98 \\
\hline 3 & E.S.E. & 84 & 98 & 98 & $\begin{array}{l}28 \\
29\end{array}$ & $\begin{array}{l}\text { S.W. } \\
\text { S.W. }\end{array}$ & $\begin{array}{l}79 \\
74\end{array}$ & $\begin{array}{r}89 \\
100\end{array}$ & $\begin{array}{r}94 \\
102\end{array}$ \\
\hline lay, 4 & E.N.E. & 74 & 95 & 98 & 30 & S.W. & $\begin{array}{l}74 \\
76\end{array}$ & $\begin{array}{r}100 \\
91\end{array}$ & $\begin{array}{r}102 \\
94\end{array}$ \\
\hline 5 & E.N.E. & 83 & 92 & 96 & May. & & & & \\
\hline 6 & E.N E. & 76 & 98 & 101 & 1 & S.W. & 76 & 98 & 102 \\
\hline 7 & E.N.E. & 77 & 100 & 102 & Sunday, 2 & S.W. & 76 & 99 & 102 \\
\hline $\begin{array}{l}8 \\
9\end{array}$ & $\begin{array}{l}\text { E.N.E. } \\
\text { E.N.E. }\end{array}$ & $\begin{array}{l}78 \\
85\end{array}$ & $\begin{array}{r}100 \\
98\end{array}$ & $\begin{array}{r}104 \\
99\end{array}$ & & S.W. & 78 & 100 & 102 \\
\hline
\end{tabular}

Nors.-The observations of the height of mercury in the barometer were mostly discontinued at Kouka, partly from the illness of Dr. Oudney, who took charge of the instrument, and partly from the uncertainty of its accuracy. At Tripoli it was regularly registered three times a day for about three months, the mean height during that period being 30,39 inches. About the middle of the desert, and indeed most of the way from Mourzuk to the Yeou, it generally stood abont 28,50 , and at Kouka from 28,72 to 29 inches.

THE END. 
LONDON :

TRINTED BY THOMAS DAVISON, WHITEFRIARS.

\section{$\neg$ SLUB}




\section{I T O F P L A TE S.}

No.

1. Alameen ben Mohammed El Kanemy, Sheikh of Bornou, Frontispiece

2. Part of the Stony Desert,

3. Castle at Mourzuk, from Mr. Ritchie's Grave

to face page xvi

4. Woman of Sockna

5. Vignette, Arabs Meeting

6. View of the Bahr Mandia

7. Castle, and Salt Lake Tegishy . . . . . . . 5

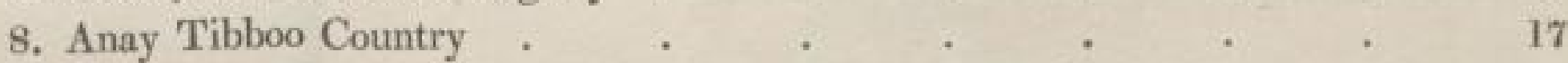

9. Kanemboo Marketwoman,-Unmarried Woman of Soudan . . 46

10. Body Guard of the Sheikh of Bornou . . . . . . 64

11. Reception of the Mission by the Sultan of Bornou $\quad$. $\quad$. $\quad$. $\quad 79$

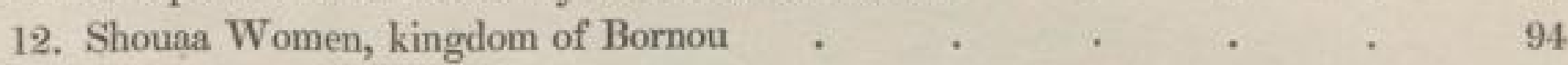

13. Arrival at Mora, the capital of Mandara . . . . 111

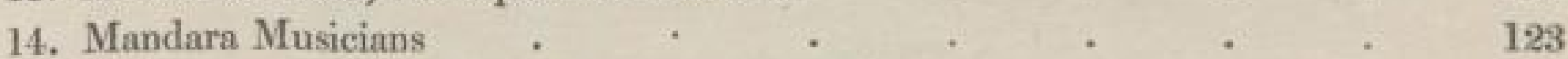

15. Plan of the Pass of Hairy, Mandara mountains _ . . 127

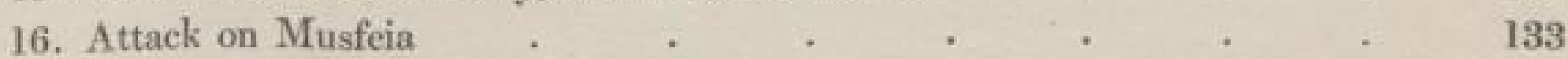

17. Vignette, Manner of Roasting Fish . . . . . . 148

18. The River Gambarou, or Yeou, near Lada _ . . . 152

19. Favourite of the Seraglio, accompanying a Military Expedition . 163

20. Kanemboo Spearman,-Munga Bowman, in the service of the Sheikh of Bornou . . . . . . . 166

21. Abdel Gassam, a Felatah from Timbuctoo-A Bornouese on a Journey 177

22. Vignette, Kanemboo Night Watch . . . . . . 180

23. Hut, and Carpenter's Shop . . . . . . 201

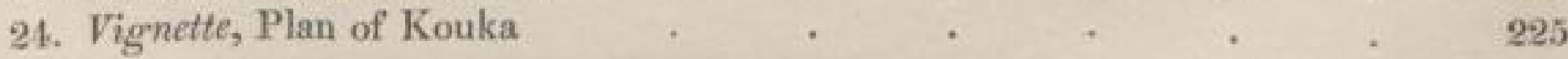




\section{LIST OF PLATES.}

No.

25. Fishing Boats on the River Shary

26. River Shary, from the Walls of Kussery

27. Vignette, Negresses Pounding Corn

Page

28. A Loggun Lady-Funha of Maffatai-Abdelahi of Mandara 259

29. Hager Teous, or the Footstool of Noah _ _ _ _ _ . . 261

30. Sketch of the Lake Tehad . . . . . 266

31. Lancers of the Sultan of Begharmi . . . . . $\quad 279$

32. Manner of Fishing on the River Yeou . $\quad$. $\quad . \quad$. . $\quad 284$

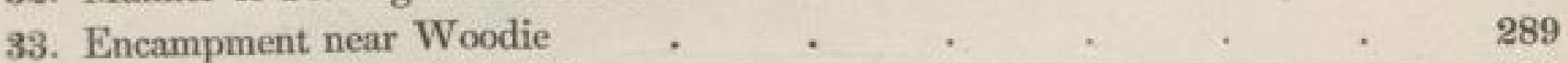

34. Ghirza, south face of Building . . . . . 305

35. Frieze on do. . . . . . . . . . . . $\quad$. $\quad$.

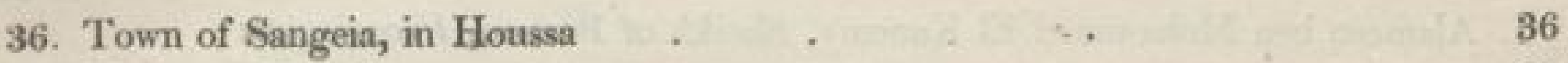

37. Natives of Soudan _ . $\quad$. $\quad . \quad$. $\quad . \quad 54$

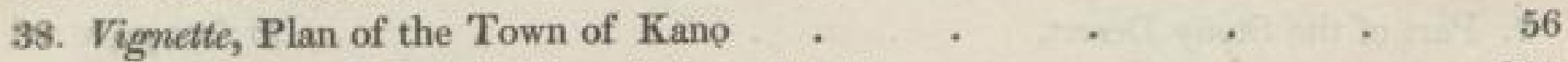

39. A Reduction of Bello's Map of Central Africa . . . 109

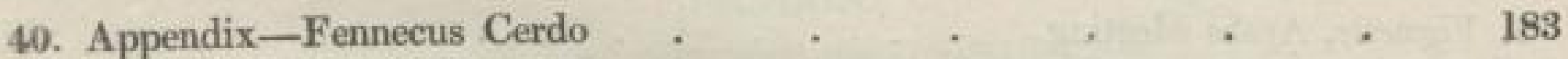
41-42-43. Arms and Armour of Central Africa, brought home by Major Denham,-Three Plates.

44. General Map of the Routes of the Travellers. 


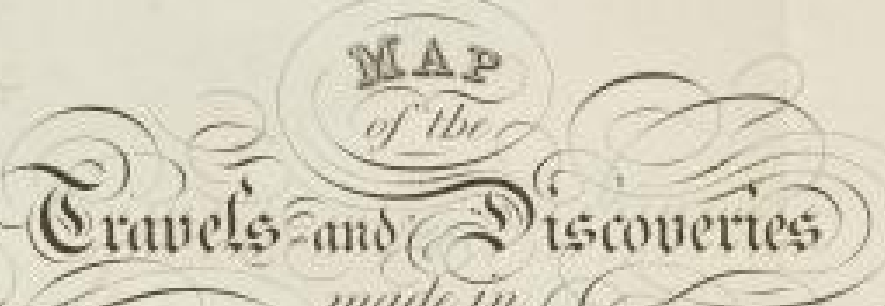

(NORTHERN \& CENTRAL AFRICA.)

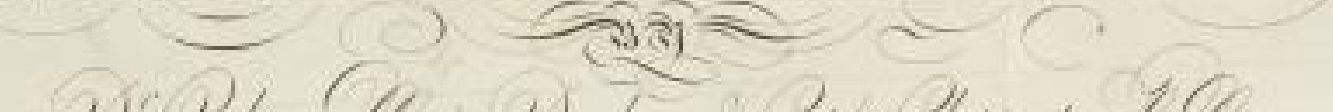

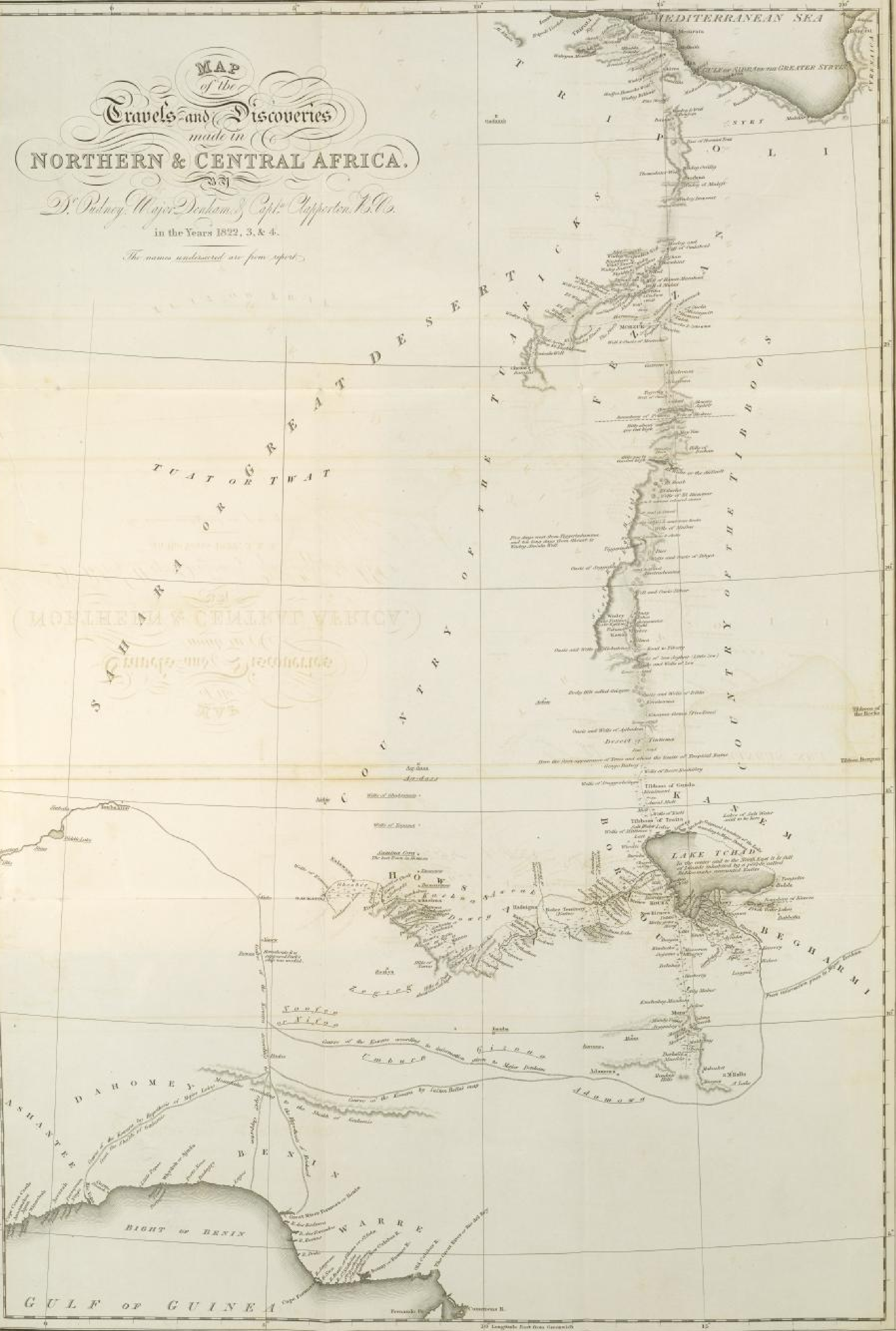

\section{SLUB}




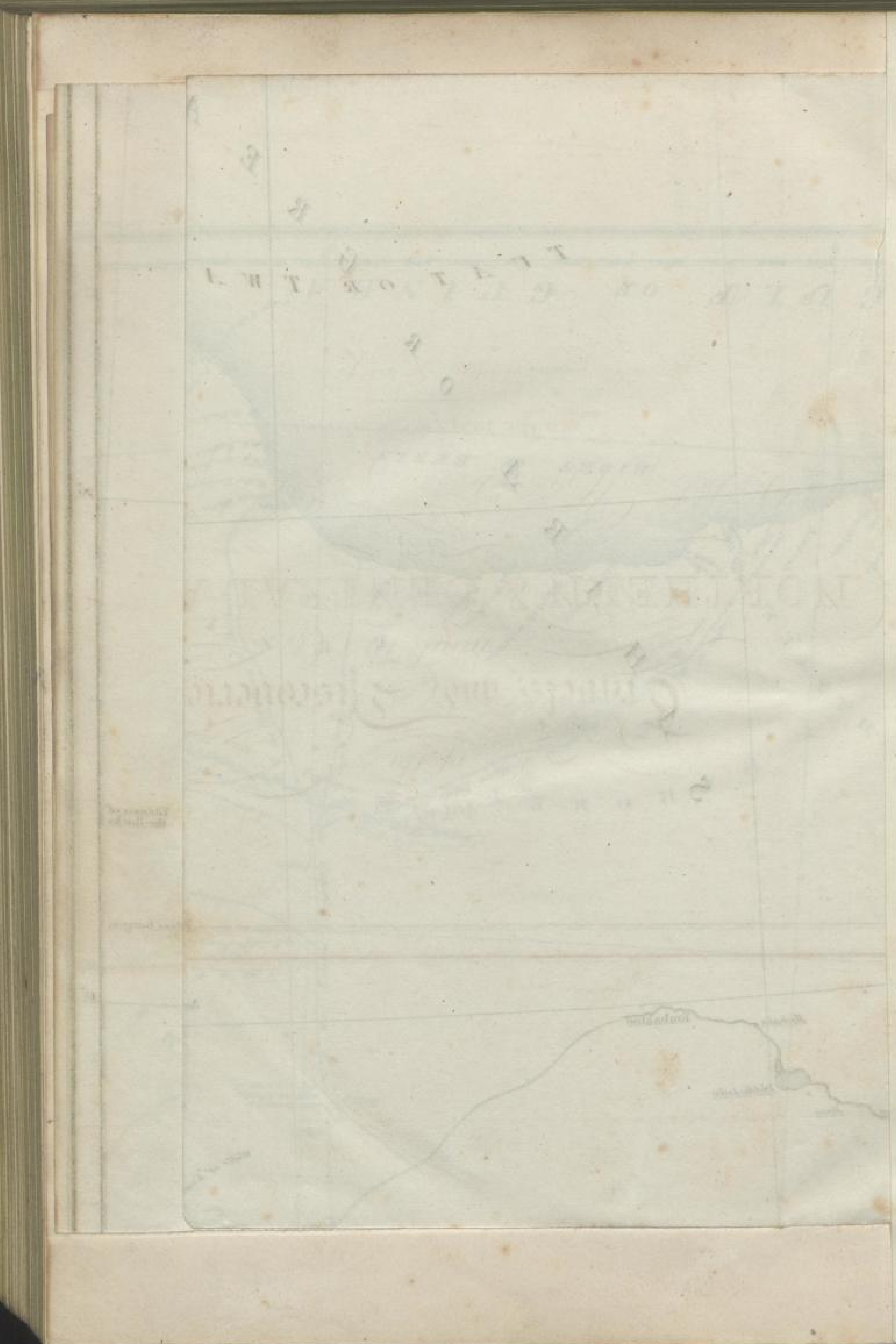

\section{$\neg$ SLUB}




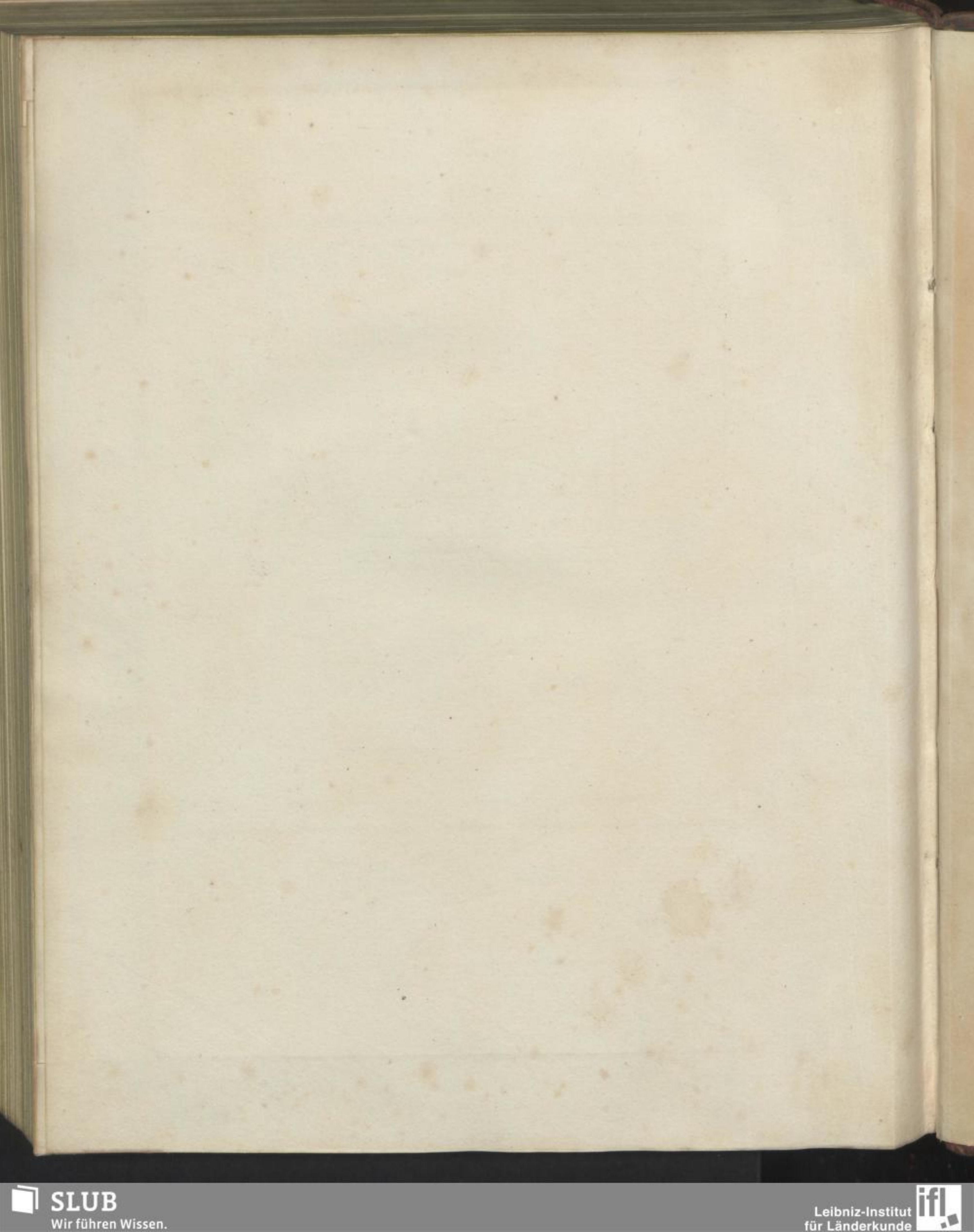





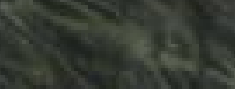
.
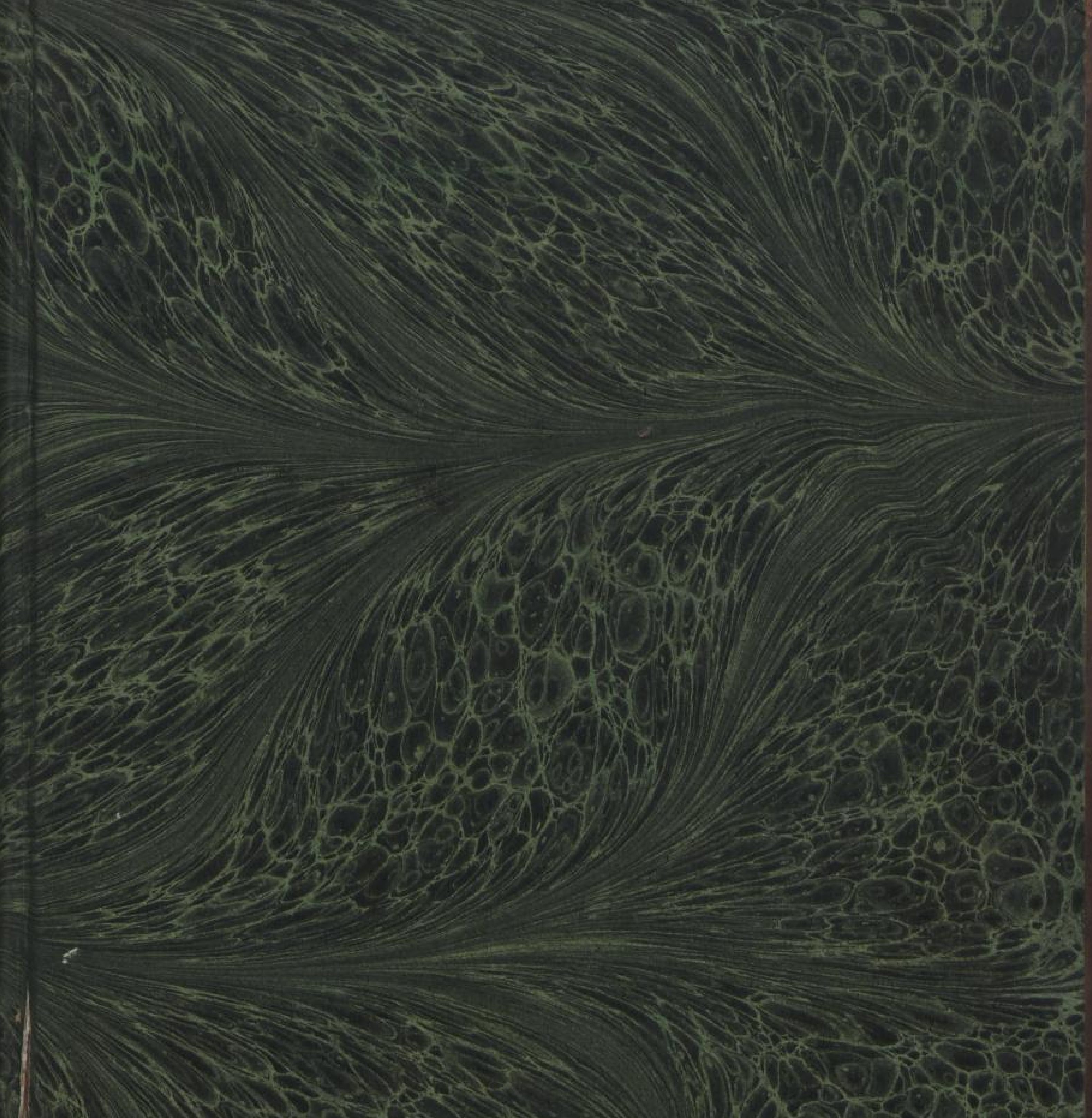

(3.)

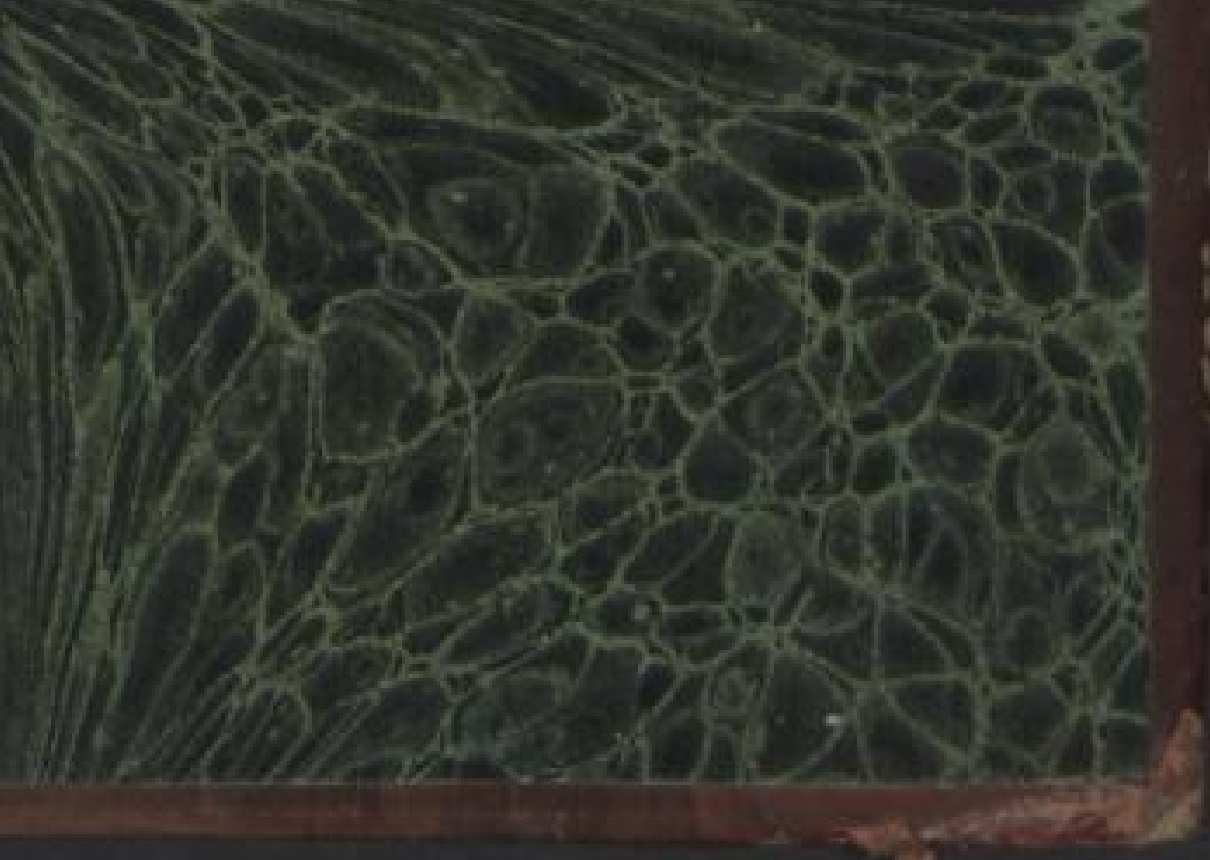




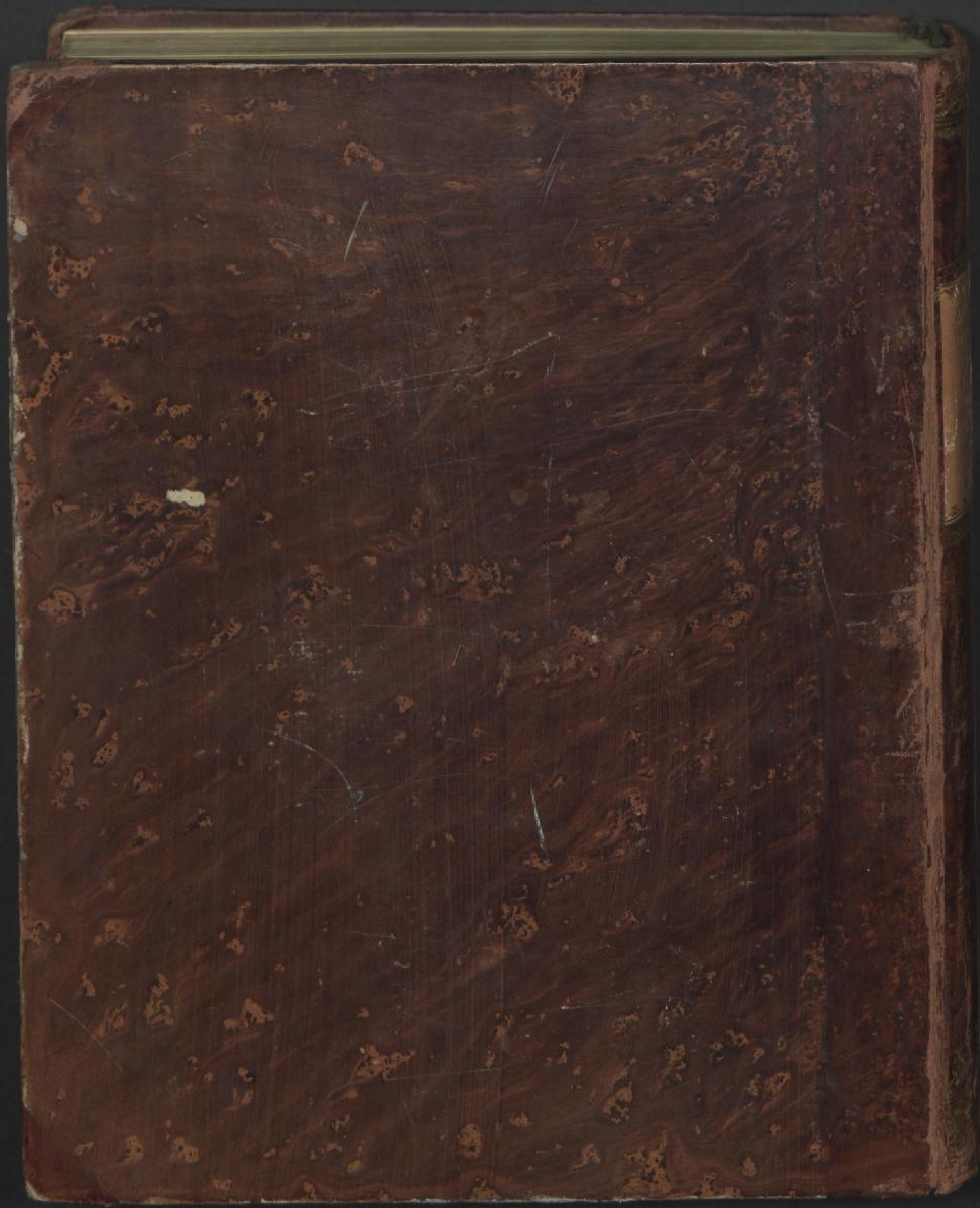

